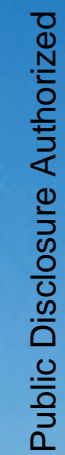

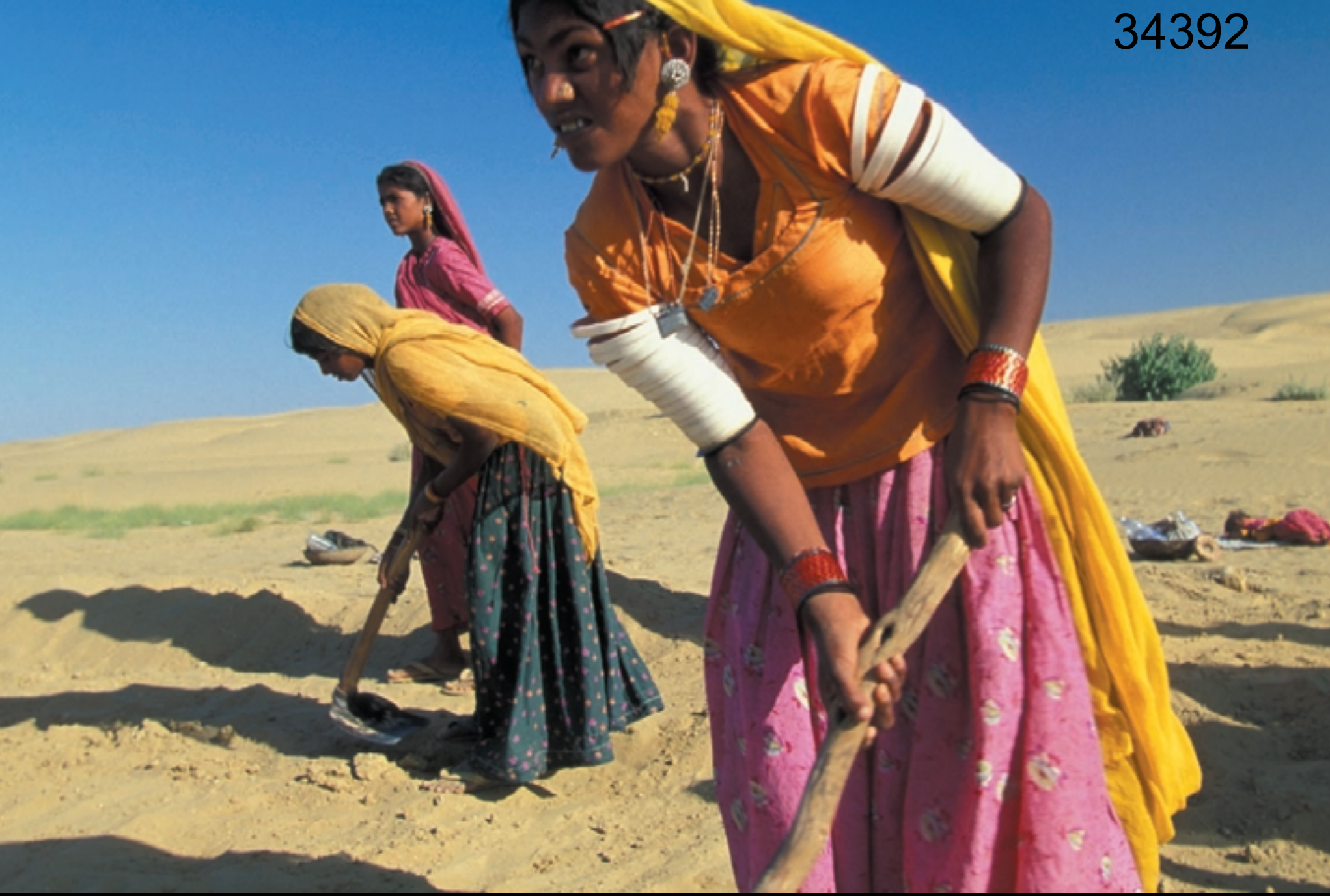

\title{
Agriculture Investment Sourcebook
}

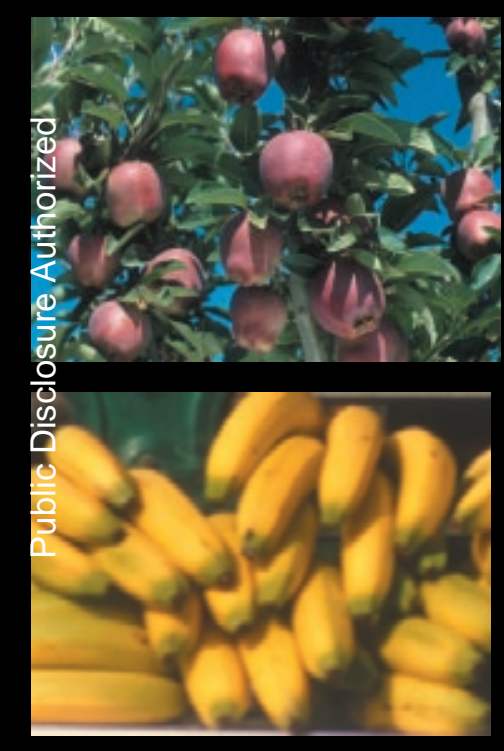

(4)
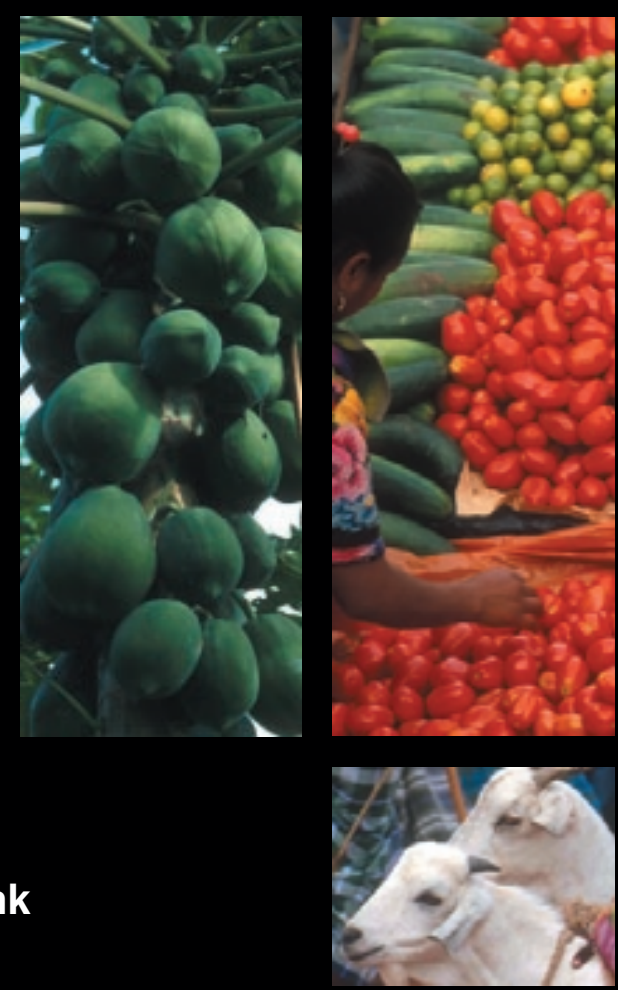

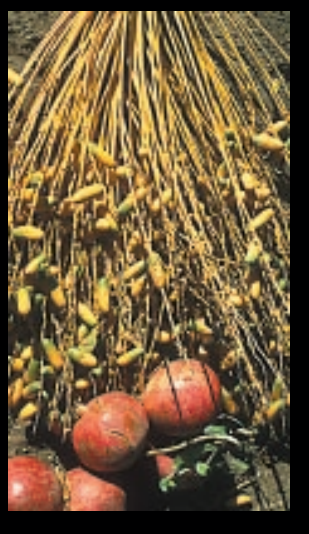

The World Bank
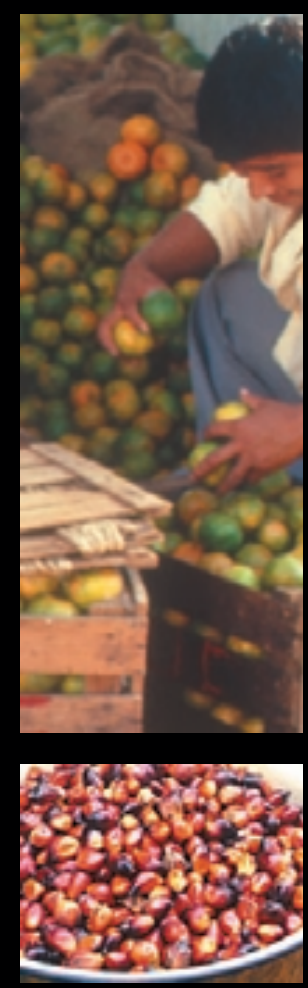

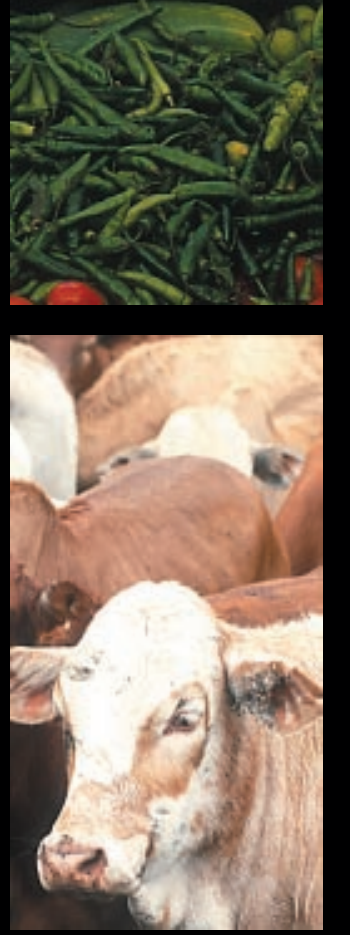


This Sourcebook is also available online at www.worldbank.org/agsourcebook, where the content will be updated on a biannual basis. 
The World Bank

\section{Agriculture Investment Sourcebook}

Agriculture and Rural Development

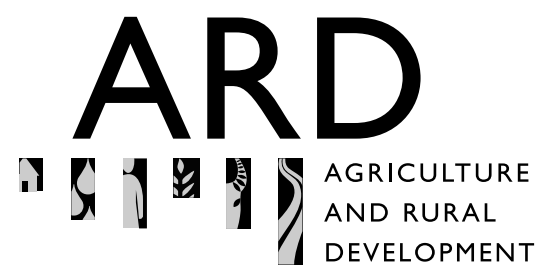


(C) 2005 The International Bank for Reconstruction and Development / The World Bank

1818 H Street NW

Washington DC 20433

Telephone: 202-473-1000

Internet: www.worldbank.org

E-mail: feedback@worldbank.org

All rights reserved

\section{234070605}

The findings, interpretations, and conclusions expressed herein are those of the author(s) and do not necessarily reflect the views of the Executive Directors of the International Bank for Reconstruction and Development / The World Bank or the governments they represent.

The World Bank does not guarantee the accuracy of the data included in this work. The boundaries, colors, denominations, and other information shown on any map in this work do not imply any judgement on the part of The World Bank concerning the legal status of any territory or the endorsement or acceptance of such boundaries.

This report has been prepared by the staff of the Agriculture and Rural Development Family of the World Bank. It is available at www.worldbank.org/agsourcebook, which will be updated on a biannual basis. Some of the numbers quoted are estimates or approximations. Please direct questions or comments to ard@worldbank.org.

\section{Rights and Permissions}

The material in this publication is copyrighted. Copying and/or transmitting portions or all of this work without permission may be a violation of applicable law. The International Bank for Reconstruction and Development / The World Bank encourages dissemination of its work and will normally grant permission to reproduce portions of the work promptly.

For permission to photocopy or reprint any part of this work, please send a request with complete information to the Copyright Clearance Center Inc., 222 Rosewood Drive, Danvers, MA 01923, USA; telephone: 978-750-8400; fax: 978-750-4470; Internet: www.copyright.com.

All other queries on rights and licenses, including subsidiary rights, should be addressed to the Office of the Publisher, The World Bank, I8I 8 H Street NW,Washington, DC 20433, USA; fax: 202-5222422; e-mail:pubrights@worldbank.org.

Library of Congress Cataloging-in-Publication data has been applied for.

ISBN 13: 978-0-82 I3-6085-X

ISBN 10: 0-8213-6085-X 


\section{CONTENTS}

Foreword vii

Preface ix

Acknowledgements xii

Acronyms and Abbreviations xiv

Introduction $\quad$ xvii

Module 1: Building Agricultural Policy and Institutional Capacity 1

Agriculture Investment Notes 12

Preparing a National Agricultural Development Strategy $\quad 12$

Developing Capacity for Agricultural Sector Policy Formulation $\quad 17$

Reform of Agriculture Subsidy and Protection Policy 22

$\begin{array}{ll}\text { Facilitating Efficient Adjustment to Liberalized Trade } & 27\end{array}$

Adjustment Lending for Agriculture Policy Reform 32

Improving Animal Health Services Through Public/Private Partnerships 37

Strengthening Farmer Organizational Capacity to Influence Agriculture Policy $\quad 42$

$\begin{array}{ll}\text { Innovative Activity Profiles } & 47\end{array}$

Bulgaria: Adjustment Lending in a Transitional Economy $\quad 47$

Ecuador: Commodity Chain Consultative Councils for Policy Formulation 49

Turkey: Hybrid Adjustment/Investment Lending 51

Guinea: Livestock Sector Partnership-Public Sector Herder Organization and the Private Sector 53

Module 2: Investments in Agricultural Science and Technology 55

Agriculture Investment Notes 68

$\begin{array}{ll}\text { Competitive Research Funds } & 68\end{array}$

Strengthening Public Research Institutes $\quad 73$

Enhancing University Participation in National Agricultural Research Systems $\quad 78$

Local Agricultural Research Committees 83

Biotechnology, Biosafety, and Agricultural Development 88

Innovative Activity Profiles 93

Brazil: Spill-ins from Foreign Research and Development Laboratories 93

Colombia: Decentralized, Demand-Driven, Competitive Technology Generation 95

Ecuador: Strategic International Alliances for Capacity Building and Research $\quad 97$

India: Focus on Biotechnology 99

India: Revitalizing Institutional Capacity in Forestry Research 101

Senegal: Making Research Demand Driven 103

Module 3: Investments in Agricultural Extension and Information Systems 105

$\begin{array}{ll}\text { Agriculture Investment Notes } & 118\end{array}$

$\begin{array}{ll}\text { Contracting Extension Services } & 118\end{array}$

Decentralizing Agricultural Extension and Information Services 124

Client Groups as Key Intermediaries in Extension 129

Mass Media and Communications Technologies in Extension 135

Estonia: Transition to Private Extension Advisory Services $\quad 140$

Innovative Activity Profiles $\quad 142$

India: Participatory and Decentralized Agricultural Technology Transfer 142 


\section{CONTENTS CONTINUED}

Russian Federation: Using Information and Communications Technologies for Rural Information Services

Uganda: Extension Decentralization, Privatization, and Reform 146

Venezuela: Contracting Decentralized Extension Services 148

Module 4: Investments in Sustainable Agricultural Intensification $\quad 151$

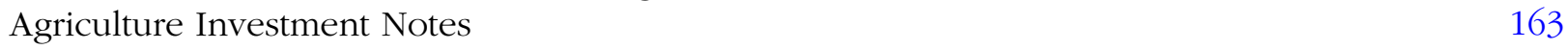

Market-Driven Diversification 163

Smallholder Dairy Production 169

Aquaculture Production Systems $\quad 174$

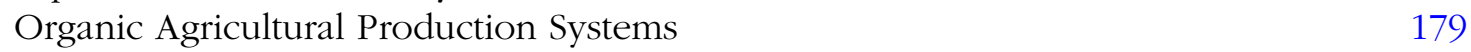

Urban and Periurban Agriculture $\quad 184$

Conservation Tillage 189

Integrated Pest Management $\quad 194$

Integrated Nutrient Management for Sustaining Soil Productivity 199

China: Fruit Promotion in the Mid-Yangtze 204

Innovative Activity Profiles 206

India: Community Organization for Sodic Lands Reclamation 206

India: Income Generation through Aquaculture 208

Module 5: Investment in Sustainable Natural Resource Management for Agriculture 211

Agriculture Investment Notes 223

Community-Based Natural Resources Management 223

Watershed Management for Agricultural Development 228

$\begin{array}{ll}\text { Agroforestry Systems } & 233\end{array}$

Pastoralism on Arid and Semi-Arid Lands 238

Integrated Livestock-Wildlife Management 243

Innovative Activity Profiles $\quad 248$

Brazil: Participatory Microcatchment Strategy for Increased Productivity and Natural $\begin{array}{ll}\text { Resource Conservation } & 248\end{array}$

China: Commercial Plantations to Help Conserve Forests 250

Egypt: Matruh Resource Management to Ensure Sustainable Livelihoods for Remote

Bedouin People 252

Latin America and Caribbean: Payments for Environmental Services in Silvopastoral Systems 254

China: Watershed Management Approach to Optimizing Incomes and Ecology in Poor

Highlands 256

Module 6: Investment in Agribusiness and Market Development 259

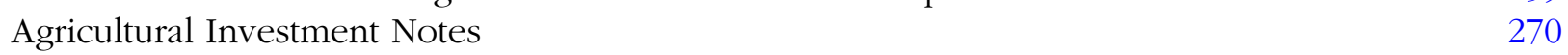

Supporting Market and Supply Chain Development $\quad 270$

Horticultural Exports from Developing Countries $\quad 275$

Private Seed Enterprise
Development

Promoting Private Sector Fertilizer Distribution Systems 285

Getting Markets Right in the Post-Reform Era in Africa 290 


\section{CONTENTS CONTINUED}

Innovative Activity Profiles 295

Bangladesh: Autonomous Organization for Facilitating Market-led Export 295

China: Smallholder Cattle Development for Import Substitution 297

Colombia: Productive Agribusiness/Farmer Partnerships 299

Mali: Building Export Mango Systems 301

Module 7: Investments in Rural Finance for Agriculture 303

Agriculture Investment Notes 314

Microfinance Institutions Moving into Rural Finance for Agriculture 314

Financial Services through State Banks

Production Credit from Input Suppliers, Processors, and Buyers 324

Membership-Based Financial Organizations 329

Innovative Activity Profiles $\quad 334$

Vietnam: Mobile Banking for Rural People $\quad 334$

Zimbabwe: AGENT Program $\quad 336$

India: Piloting of Smart Cards in Rural Areas 338

Madagascar: Microleasing for Agricultural Production $\quad 340$

Ghana: Inventory Credit for Small-Scale Farmers 342

Module 8: Investments in Irrigation and Drainage $\quad 345$

Agriculture Investment Notes $\quad 355$

Investments to Empower Farmers to Manage Irrigation and Drainage Systems 355

Investments in Irrigation for Crop Diversification 360

Investments in Waterlogging and Salinity Control 365

Investments in Shallow Tubewells for Small-Scale Irrigation $\quad 370$

Innovative Activity Profiles $\quad 374$

China: Consumptive Use in Water Resource Management for Productivity, Equity, and

the Ecology $\quad 374$

Egypt: Improving Agricultural Production Through Better Drainage 376

India: Rationalized Public, Private, and Farmer Roles in Groundwater Management 378

Mali: Institutional Reform to Focus Public Role on Essential Public Goods 380

Niger: Tailoring Irrigation Technology to Users' Needs 382

Module 9: Investments in Land Administration, Policy and Markets 385

Agriculture Investment Notes 397

Investments in Systematic Land Titling and Registration 397

Community-Managed Land Reform $\quad 402$

Innovative Activity Profiles $\quad 407$

Armenia: Benefits of Securing and Registering Land for Rural Development $\quad 407$

Brazil: Participatory Negotiations and Market-Assisted Land Reform 409

The Lao People's Democratic Republic: Preserving Women's Rights in Land Titling 411

Module 10: Managing Agricultural Risk, Vulnerability, and Disaster 413

$\begin{array}{ll}\text { Agriculture Investment Notes } & 422\end{array}$

Commodity Price Risk Management $\quad 422$

$\begin{array}{ll}\text { Agricultural Insurance } & 427\end{array}$ 


\section{CONTENTS CONTINUED}

Responding to Disaster with Seed Distribution 432

Innovative Activity Profiles $\quad 437$

Kenya: Community-Based Drought Management 437

Mongolia: Sustaining Livelihoods in Areas with High Natural Disaster Risk 440

Tanzania: Accessing Market-Based Price Risk Management Instruments 442

India: Innovative Rainfall-Indexed Insurance $\quad 444$

Module 11: Scaling Up Agricultural Investments in the Bank's Changing Internal

Environment $\quad 447$

Agriculture Investment Notes 459

Targeting Agricultural Investments to Maximize Poverty Impacts 459

Nine Lessons for Improving Project Design for Better Investment Performance 465

Agriculture Sector Program Lending $\quad 470$

Community-Driven Development for Increased Agricultural Income 475

Monitoring and Evaluation: Measuring and Assessing Agricultural Development $\begin{array}{lr}\text { Programs } & 480\end{array}$

Innovative Activity Profiles $\quad 485$

Mozambique: Harmonized Donor Funding Around Principles 485

Brazil: Empowering Rural Communities for Poverty Reduction 487

Uganda: Cross-Sectional Programmatic Adjustment Lending Focusing on
Poverty Reduction

$\begin{array}{ll}\text { Appendix: Key Websites } & 491\end{array}$

$\begin{array}{ll}\text { Index } & 495\end{array}$ 


\section{FOREWORD}

The World Bank's new rural strategy, Reaching the Rural Poor, commits the Bank to five core areas of rural development:

- fostering an enabling environment for broad-based and sustainable rural growth;

- enhancing agricultural productivity and competitiveness;

- encouraging non-farm economic growth;

- improving social well-being, managing and mitigating risk, and reducing vulnerability; and

- enhancing sustainability of natural resource management.

Underlying all of the goals is support to agricultural growth that benefits the poor, for without a renewed effort to accelerate growth in the agricultural sector, few countries will be able to reach the Millennium Development Goals, especially the goal of halving poverty and hunger by 2015.

While developing the new rural strategy, the need to better articulate good practice in agricultural policies and investments became clear.This is especially so, since the nature of donor supported investments in the 
sector, and the instruments for channeling those investments, has changed drastically over the last decade. This first edition of the Agriculture Investment Sourcebook, responds to that need, by compiling a wide range of emerging good practice and innovative approaches to investing in the agriculture sector. The first edition already provides a rich menu of options for profitably investing in the agricultural sector, but it is a work in progress. There are still important gaps that need to be filled, and good practice is constantly evolving as knowledge and experience accumulate. Our partners in other multilateral and bilateral institutions, national organizations, and civil society organizations possess much of the knowledge on how to get agriculture moving, and that has not been captured in this edition. We, therefore, plan to update of most of the modules in this Sourcebook annually.

Our challenge now is to build on this edition of the Sourcebook by intensifying our efforts to evaluate, learn, and share knowledge in ways that promote the agricultural agenda and the welfare of rural people.

Kevin Cleaver

Director

Agricultural and Rural Development
Sushma Ganguly

Sector Manager

Agricultural and Rural Development 


\section{PREFACE}

nvesting to promote agricultural growth and poverty reduction is a central pillar of the World Bank's current rural strategy, Reaching the Rural Poor, which was released in 2003. One major thrust of the strategy outlines the priorities and the approaches that the public sector, private sector, and civil society can employ to enhance productivity and competitiveness of the agricultural sector in ways that reduce rural poverty and sustain the natural resource base. These actions involve a rich mixture of science, technology, people, communication, management, learning, research, capacity building, institutional development, and grassroots participation.

This Sourcebook has been prepared to help in implementing the rural strategy, by sharing information on investment options and innovative approaches that will aid the design of future lending programs for agriculture. The Sourcebook provides generic good practices and many examples that demonstrate that investment in agriculture can provide rewarding and sustainable returns to development efforts. The contents have been assembled from all regions and thematic groups of the Bank, and from the experiences of many partners. 


\section{Box I. The Sourcebook Modules}

I. Building Agricultural Policy and Institutional Capacity

2. Investments in Agricultural Science and Technology

3. Investments in Agricultural Extension and Information Services

4. Investments in Sustainable Agricultural Intensification

5. Investments in Sustainable Natural Resource Management

6. Investments in Agribusiness and Market Development

7. Investments in Rural Finance for Agriculture

8. Investments in Irrigation and Drainage

9. Investments in Land Administration, Policy, and Markets

10. Managing Agricultural Risk, Vulnerability, and Disaster

I I. Scaling Up Agricultural Investments in the Bank's Changing Internal Environment

Source: Authors.

\section{STRUCTURE OF THE SOURCEBOOK}

The Sourcebook is intended as a ready reference for practitioners (World Bank staff and their partners in borrowing countries) seeking summary information on the state of the art about good practice for agricultural investments, and innovative activities that merit close monitoring for potential scaling up.

The Sourcebook is divided into eleven selfcontained modules (see box 1). Each module contains three different types of subunits, which can also be stand-alone documents:

1.A Module Overview provides a summary of the major issues and investment options for each investment area, and is intended as a broad introduction to the topic.

2.Several Agricultural Investment Notes (AINs) summarize good practice (and sometimes bad practice) in specific investment areas, to provide a brief, but technically sound, overview for the nonspecialist. For each AIN the investments have been evaluated in different settings for effectiveness and sustainability, and can be broadly endorsed by the community of practitioners from within and outside the Bank.

\section{Several Innovative Activity Profiles (IAPs)}

highlight design of successful or innovative investments. These provide a short description of an activity in the Bank's portfolio or that of a partner agency, focusing on potential effectiveness in poverty reduction, empowerment, or sustainability. Activities profiled have often not been sufficiently tested and evaluated in a range of settings to be considered "good practice," but should be closely monitored for potential scaling up.

The Sourcebook thus provides introductions to topics, but not detailed guidelines on "how to" design and implement investments. The standalone nature of each subunit of the Sourcebook allows flexibility and adaptability of the materials, but necessarily results in some replication of the issues covered. Selected readings and Web links ${ }^{1}$ are provided for readers who seek more in-depth information and examples of practical experience. All Sourcebook material is available on the World Bank Web site that links with additional key sources of information, such as other Web sites, readings, and manuals.

\section{PREPARATION OF THE SOURCEBOOK}

The Sourcebook draws on a wide range of experience from donor agencies, governments, institutions, and other groups active in agricultural development. However, in this first edition of the Sourcebook, the initial contributions draw heavily from World Bank experience, especially the "communities of practice" represented by the Bank's various thematic groups. Approximately two-thirds of the AINs and most of the IAPs originate from within the Bank. In the future, it is hoped that these will be complemented by more contributions

I. A list of Websites where many selected readings can be obtained is provided in Appendix I. Since specific Web links are often cumbersome and become quickly outdated, only the generic institutional Web links are provided. 
drawn from the wealth of experience in other international development agencies and in countries, possibly as a major activity of the newly formed Rural Alliance Platform (a multidonor initiative) that is intended to share experiences and coordinate donor actions. Although the Sourcebook seeks to share experience of both successes and failures-providing cautionary guidance on investment strategies to avoid repeating past mistakes - there is a much greater interest in sharing successes than failures, and this is reflected in the content.

\section{WHAT IS NOT COVERED}

Thematic topic coverage is not always comprehensive, as materials were assembled on a pragmatic basis, depending on available materials, and on specialists willing to contribute original notes. The modules generally address the priority issues within a thematic area or areas in which operational guidance is needed, but there are important gaps that should be filled in future editions.

The Sourcebook also focuses on design of agricultural investment programs at the country level, and does not address important regional and global issues for the sector. Likewise, investment programs are the unifying element throughout the Sourcebook, although policy issues specific to those programs are also covered. The contents are also specifically focused on agricultural investments, recognizing that rural development and rural poverty reduction requires a much broader approach, and that even successful agricultural performance requires investments in areas such as rural infrastructure.

The Sourcebook, and the AINs in particular, therefore address public sector investment opportunities for agricultural development and how these might be approached. A companion publication in the World Bank's Directions in Development series, will be oriented to broad policy issues, and the sequencing and integration of different types of investment within a coherent agricultural sector strategy.
THE SOURCEBOOK AS A LIVING DOCUMENT The Sourcebook is expected to expanded and updated, as experience is gained with new investment initiatives. Most module overviews and investment notes should be valid for a number of years. Individual modules can be used as stand-alone documents, and it is expected that several modules will be developed into their own Sourcebook - this is already occurring for the "Irrigation and Drainage" Module. The useful life of an IAP will be less, as most are based on recent experience and have been subjected to limited evaluation. Readers are encouraged to check on current status by contacting the person named in each profile. 


\section{ACKNOWLEDGMENTS}

The preparation of this Sourcebook involved a large number of people from within all units of the World Bank working on agriculture, and a variety of partner organizations. The design, and day-to-day coordination of the Sourcebook, has been carried out by Gary Alex and Sam Kane (ARD consultants), and the overall task has been managed by Derek Byerlee and Eija Pehu (ARD), who collectively assume responsibility for remaining errors and omissions. Agricultural and Rural Development Thematic Groups (TGs) coordinated the preparation of several of the modules, specifically: Sustainable Agricultural Systems and Knowledge Institutions (SASKI) (Modules 2, 3, and 4); the NRM Thematic Group (Module 5); the Private Sector and Agribusiness Thematic Group (Module 6); Land Policies Thematic Group (Module 9); Community-Driven Rural Development (part of Module 11); and the Gender Thematic Group (gender-related input across all modules). Individuals within these teams who merit special recognition include: Marie-Hélene Collion (MNA), Francois Le Gall (AFR), Kees van der Meer (ARD), Wael Zakout (EAP), John Bruce (ARD), Klaus Deininger (DEC), Idah Pswarayi-Riddihough (EAP), Jaime Webbe (AFR), Melissa Williams (ARD) and Daniel Sellen (SAR). A number of individuals played a leading role in other modules, especially Jock Anderson (ARD) and John Nash (ARD) (Module 1); Douglas Pearce (CGAP), Andrew Goodland (EAP), and Kees Van der Meer (ARD) (Module 7); Safwat Abdel-Dayem (ARD), and Ariel Dinar (ARD) (Module 8); Jock Anderson (ARD) and Panayotis Varangis (ARD) (Module 10); and Shawki Barghouti (ARD), and Sushma Ganguly (ARD) (Module 11).

Many individuals made written contributions to module overviews and good practice notes. From within the World Bank, these included: Safwat Abdel-Dayem (ARD), Gary Alex (ARD consultant), Mubarik Ali (ARD), Jock Anderson (ARD consultant), Amitabh Brar (CGAP Consultant), Shawki Barghouti (ARD), John Bruce
(ARD), Derek Byerlee (ARD), Marie-Hélène Collion (MNA), Sanjiva Cooke (ARD), Cristophe Crepin (AFR), Cees de Haan (ARD consultant), Klaus Deininger (DEC), Ariel Dinar (ARD), Nina Doetinchem (AFR), Graham Eele (DEC), Enos Eskuri (ENV), Erick Fernandez (ARD), Andrew Goodland (EAP), Matthias Grueninger (MNA), Sam Kane (ARD consultant), Francois Le Gall (AFR), Annabel Mulder (ARD consultant), John Nash (ARD), Ridley Nelson (OED), Walter Ochs (ARD consultant), Nwanze Okidegbe (ARD), Douglas Olson (EAP), Douglas Pearce (CGAP), Eija Pehu (ARD), Herve Plusquellec (Consultant), Idah PswarayiRiddihough (EAP), Annu Ratta (ARD consultant), Pierre Rondot (ARD), Tijan Sallah (AFR), Kristina Sorby (ARD consultant), Amal Talbi (ARD), Kees van der Meer (ARD), Panayotis Varangis (ARD), Jaime Webbe (AFR), Melissa Williams (ARD), Johannes Woelcke (ARD), Wael Zakout (EAP), and Ronald Zweig (EAP).

Contributors to the module overviews and good practice notes from outside the Bank included; Jacqueline Ashby (Centro Internacional de Agricultura Tropical), Duncan Burnett (National Resources Institute), Pavla Cornejo (Development Alternatives Inc.), Octavio Damiani (IFAD), Timothy Donnay (USAID), Carl Eicher (Michigan State University), Gerd Fleischer (GTZ), Wayne Frank (USAID), Eleni GabreMadhin (formerly International Food Policy Research Institute and now AFR, World Bank), Francesco Goletti (Agrifood Consulting International), John Kerr (Michigan State University), Hamdy Eisa (ARD consultant), Kimberly Lucas (USAID), Jerry Martin (Development Alternatives Inc.), Steve Morin (USAID), Erin Nicholson (USAID), Linda Nicolaides (University of Greenwich), John Orchard (National Resources Institute), Anja Schilling (Swiss Federal Institute for Snow and Avalanche Research), Thomas Thompson (International Fertilizer Development Center), Eduardo Trigo (private consultant, Argentina), Robert Tripp (Overseas Development Institute), Dannielle 
Typinski (USAID), and Don van Atta (Development Alternatives Inc.).

Many Bank staff contributed and/or reviewed profiles of innovative ongoing or completed projects or project components: Paolo Agostini (LAC), Deepak Ahluwalia (SAS), Ousmane Badiane (AFR), Manish Bapna (SAS), Mohamed Benali (EAP), Eustacius Betubiza (ECA), Adel Bichara (MNA), Erin Bryla (ARD consultant), Raimundo Caminha, Arie Chupak (EAP), Luis Coirolo (LAC), Marie-Hélène Collion (MNA), Christine Cornelius (AFR), Cees de Hahn (ARD), Graeme Donovan (consultant), Henry Gordon (ECA), Wahida Huq (SAS), Rapeepun Jaisaard (ECA), Toru Kinishi, Patrick Labaste (AFR), William Lane, Douglas Lister (MNA), Graciela Lituma (LAC consultant), Mark Lundell (ECA), Salifou Mahaman (AFR), Matthew McMahon (LAC), Robin Mearns (EAP), Jessica Mott (ECA), Mohinder Mudahar (SAS), Ohn Myint (SAS), John Nash (ARD), Douglas Olson (EAP), R.S. Pathak (SAS), Eija Pehu (ARD), Jeeva PerumalpillaiEssex (AFR), Anna Roumani (LAC consoultant), G. Russell, Götz Schreiber (ECA), Daniel Sellen (SAS), Ashok Seth (consultant), Paul Sidhu (SAS), Harideep Singh (LAC), Geoffrey Spencer (EAP), Jürgen Voegele (EAP), Pierre Werbrouck (LAC), Wael Zakout (EAP), and Zongmin Li (ECA consultant).

Each module was peer reviewed, usually by two Bank staff and one outside person. We appreciate the review contributions of; Deepak Ahluwalia (SAS), Jock Anderson (ARD consultant), Ousmane Badiane (AFR), Frank Byamugisha (AFR), Marie-Hélène Collion (MNA), Louise Cord (PREM), Carlos Cuevas (OPD), Ijsbrand de Jong (AFR), Maria Fernández (LAC), Henry Gordon (ECA), Matthias Grueninger (MNA), Steven Jaffee (ECA), Jacob Kampen (AFR Consultant), Nadim Khouri (LAC), Hoonae Kim (EAP), Agnes Kiss (AFR), Renate Kloeppinger-Todd (formerly IFC and now ARD), Donald Larson (DEC), Mark Lundell (ECA), Ohn Myint (SAS), Aleksandar Nacev (ECA), David Nielson (AFR), Gunars Platais (LAC), Katrine Saito (PRM), William Steele (AFR), Juergen Voegele (EAP), Josef
Toledano (AFR), and members of the SASKI, NRM, Land Policies, and Community-Driven Rural Development Thematic Groups. We also wish to thank the external reviewers; Suresh Babu (IFPRI), Kathleen Cloud (University of Illinois), Ralph Cummings (USAID), Howard Elliott (ISNAR), Mary Hill Rojas (WIDTECH), Peter Hobbs (Cornell University), Susana Lastarria (University of Wisconsin), John Pender (IFPRI), William Rivera (University of Maryland), David Rohrbach (ICRISAT), Arja VainioMattila (University of Western Ontario). Overall peer review was provided by Julio Berdegue (RIMISP, Chile), Benoit Blarel (ECA), Hamdy Eisa (consultant), Gershon Feder (DEC), and Peter Hazell (IFPRI),

Finally, Kevin Cleaver (ARD) and Sushma Ganguly (ARD) contributed invaluable guidance and support throughout the preparation of the Sourcebook. Many other individuals provided suggestions or support, including Felicity Proctor (ARD), Csaba Csaki (ARD), Mark Lundell (ECA), Mohamed Ben Ali (EAP), Severin Kodderitzsch (ECA), Manish Bapna (SAS), Ernst Lutz (AFR), Dina Umali-Deininger (SAS), Robert Townsend (AFR), and members of the Agricultural and Rural Sector Board. Reginald MacIntyre (ARD consultant), Helen Freeman, and Cynthia Bartel (ARD consultant) provided able editorial support. Sarian AkiboBetts (ARD) assisted with logistics and assembly of the manuscript, and Corazon Solomon (ARD), Felicitas Doroteo-Gomez (ARD) and Rebecca Oh (ARD) were extremely supportive in managing finances and contracts. Melissa Williams (ARD) and Kathryn Carr (ARD) managed the publication production, and Rosemary O'Neill (ARD) oversaw the electronic version. While the above list is comprehensive, it is very likely that we have overlooked important contributors. Our apologies for this oversight, but thanks all the same. 


\section{ACRONYMS AND ABBREVIATIONS}

\begin{tabular}{|c|c|c|c|}
\hline ADC & Agribusiness Development Center & IADB & Inter-American Development Bank \\
\hline ADS & Agricultural Development Strategy & IAP & Innovative Activity Profile \\
\hline AIN & Agricultural Investment Note & ICA & Investment Climate Assessment \\
\hline AKIS & $\begin{array}{l}\text { Agricultural Knowledge and Infor- } \\
\text { mation System }\end{array}$ & ICT & $\begin{array}{l}\text { Information and Communication } \\
\text { Technology }\end{array}$ \\
\hline APL & Adaptable Program Lending & IFAD & International Fund for Agricultural \\
\hline ASAL & Agricultural Sector Adjustment Loan & & Development \\
\hline ASP & Agricultural Sector Program & IFC & International Finance Corporation \\
\hline ATM & Automatic Teller Machine & IFPRI & International Food Policy Research \\
\hline BDS & Business Development Services & & Institute \\
\hline $\mathrm{BP}$ & Bank Procedure & IGA & Income Generating Activity \\
\hline $\mathrm{Bt}$ & Bacillus thuringiensis & ILWM & Integrated Livestock-Wildlife Man- \\
\hline CAS & Country Assistance Strategy & & agement \\
\hline \multirow[t]{2}{*}{ CBNRM } & Community-Based Natural Resource & IMF & International Monetary Fund \\
\hline & Management & IMT & Irrigation Management Transfer \\
\hline $\mathrm{CBO}$ & Community-Based Organization & INM & Integrated Nutrient Management \\
\hline CDD & Community-Driven Development & IPM & Integrated Pest Management \\
\hline $\mathrm{CF}$ & Conservation Farming & IPPM & Integrated Production and Pest \\
\hline \multirow[t]{2}{*}{ CGAP } & The Consultative Group to Assist & & Management \\
\hline & the Poor & IPR & Intellectual Property Rights \\
\hline CGIAR & $\begin{array}{l}\text { Consultative Group on International } \\
\text { Agricultural Research }\end{array}$ & LEISA & $\begin{array}{l}\text { Low External Input and Sustainable } \\
\text { Agriculture }\end{array}$ \\
\hline \multirow[t]{2}{*}{ CIAL } & Comité de investigación agricola & $M \& E$ & Monitoring and Evaluation \\
\hline & $\begin{array}{l}\text { local/local agricultural research } \\
\text { committee }\end{array}$ & $\mathrm{MBFO}$ & $\begin{array}{l}\text { Membership-Based Financial Orga- } \\
\text { nization }\end{array}$ \\
\hline CRGP & Competitive Research Grant Program & MDG & Millennium Development Goal \\
\hline \multirow[t]{2}{*}{ CRMG } & Commodity Risk Management & MENA & Middle East and North Africa \\
\hline & Group & MFI & Microfinance Institution \\
\hline CT & Conservation Tillage & MIS & Management Information System \\
\hline DFID & $\begin{array}{l}\text { Department for International Devel- } \\
\text { opment }\end{array}$ & NARI & $\begin{array}{l}\text { National Agricultural Research } \\
\text { Institute }\end{array}$ \\
\hline DIS & Direct Income Support & NARO & National Agricultural Research \\
\hline \multirow[t]{2}{*}{ ECA } & Eastern Europe and Central Asia & & Organization \\
\hline & Region & $\mathrm{NGO}$ & Nongovernmental Organization \\
\hline ESW & Economic and Sector Work & NOAA & National Oceanic and Atmospheric \\
\hline EU & European Union & & Agency \\
\hline FAO & Food and Agriculture Organization & NRM & Natural Resource Management \\
\hline FFS & Farmer Field School & O\&M & Operations and Maintenance \\
\hline GCD & Groundwater Conservation District & OD & Operational Directive \\
\hline GDP & Gross Domestic Product & OECD & Organization for Economic Coop- \\
\hline GEF & Global Environment Facility & & eration and Development \\
\hline GMO & Genetically Modified Organism & OED & Operations and Evaluation Depart- \\
\hline \multirow[t]{2}{*}{ GTZ } & Deutsche Gesselschaft fur & & \\
\hline & Technische Zusammenarbeit & OED & Operations Evaluation Department \\
\hline НАССР & Hazard Analysis Critical Control Point & $\mathrm{OP}$ & Operational Policy \\
\hline HIV/AIDS & Human Immunodeficiency Virus/ & PAD & Project Appraisal Document \\
\hline
\end{tabular}




\begin{tabular}{|c|c|c|c|}
\hline PDA & Personal Digital Assistant & $\mathrm{T} \& \mathrm{~V}$ & Training-and-Visit \\
\hline PIM & Participatory Irrigation Management & TAP & Technical Assistance Provider \\
\hline $\mathrm{PO}$ & Producer Organization & TG & Thematic Group \\
\hline PRSP & Poverty Reduction Strategy Paper & TRIPS & Trade Related Intellectual Property \\
\hline \multirow[t]{2}{*}{ PSAL } & Programmatic Structural Adjustment & & Rights \\
\hline & Lending & $\mathrm{TT}$ & Task Team \\
\hline PSIA & Poverty and Social Impact Analysis & UNESCO & United Nations Educational, Scien- \\
\hline PVR & Plant Variety Rights & & tific and Cultural Organization \\
\hline QAG & Quality Assurance Group & UPUA & Urban and Periurban Agriculture \\
\hline$R \& D$ & Research and Development & URAA & Uruguay Round Agreement on \\
\hline R\&E & Research and Extension & & Agriculture \\
\hline RPO & Rural Producer Organization & USAID & United States Agency for Interna- \\
\hline S\&T & Science \& Technology & & tional Development \\
\hline SAC & Structural Adjustment Credit & WHO & World Health Organization \\
\hline SAL & Structural Adjustment Loan & WMA & Wildlife Management Area \\
\hline SECAC & Sectoral Adjustment Credit & WTO & World Trade Organization \\
\hline SECAL & Sectoral Adjustment Loan & WUA & Water User Association \\
\hline SME & Small/Medium Sized Enterprise & WUG & Water User Group \\
\hline SPA & Sector Performance Analysis & & \\
\hline
\end{tabular}





\section{INTRODUCTION}

romoting pro-poor agricultural growth is not easy. It is subject to risks from many areas, from uncertain prices to the weather. Many investments, while providing high payoffs, can take years, even decades to fully materialize. And because the population directly affected by rural development is widely dispersed, and often has little political voice, the results are often not visible to influential decision-makers. With the myriad demands on limited development funds, it is not surprising that in recent years agriculture has not received as much attention as it should have.

However, few countries will reduce poverty significantly, nor will the world community achieve the Millennium Development Goals (MDG), if agriculture and rural development are ignored (see box A). The first MDG to "eradicate extreme poverty and hunger" cannot be reached without addressing the livelihood issues of the 70 percent of the world's poor who live in rural areas, and without ensuring access to food of the poorest and most vulnerable. Rural people are also the custodian of much of the world's land and water resources, and biodiversity, and will be central to achieving MDG 6 on environmental 


\section{Box A. Millennium Development Goals: 1990-2015}

I. Eradicate extreme poverty and hunger

- Halve the number of people with less than $\$ 1$ a day

- Halve the share of people who suffer from hunger

2 Achieve universal primary education

- Ensure completion of primary schooling

3. Promote gender equality and empower women

- Eliminate gender disparity at all levels of education

4. Reduce child mortality

- Reduce by two-thirds the under five mortality rate

- Improve maternal health

- Reduce by 75 percent the maternal mortality rate

5. Combat HIVIAIDS, malaria, and other diseases

- Reverse the spread of HIVIAIDS

6. Ensure environmental sustainability

- Reverse loss of environmental resources

7. Halve the share of people without access to potable water

8. Significantly improve the lives of at least 100 million slum dwellers

9. Develop a global partnership for development

- Raise official development assistance

- Expand market access, especially in agriculture

- Encourage debt sustainability

Source: www.developmentgoals.org

sustainability. Other MDGs such as gender equality (many farmers are women), child nutrition (depends on access to nutritious food), and market access (especially international trade in agriculture which remains highly protected) depend directly or indirectly on propoor agricultural growth.

The World Bank current rural strategy, Reaching the Rural Poor, is designed to respond to these challenges within a rapidly changing environment for agricultural and rural development. The strategy seeks to:

- Foster an enabling environment for broadbased and sustainable rural growth.

- Enhance agricultural productivity and competitiveness.

- Encourage rural nonfarm economic growth.
- Improve social well being, manage and mitigate risk, and reduce vulnerability.

- Enhance sustainability of natural resources management.

Pro-poor agricultural growth is therefore highlighted as one of the five strategic areas of the strategy, but it also heavily influences the other four areas, including nonfarm economic growth, which in most countries is closely linked to agricultural growth.

To act on these five major strategic areas, the Bank, other international agencies, and national public and private sectors will have to increase investment in agricultural and rural development. However, this must be done in a way that improves outcomes and impacts. Good practices associated with such investment outcomes must be mainstreamed into the Bank's portfolio.

\section{THE WORLD BANK'S SUPPORT TOTHE SECTOR}

The World Bank is the largest single provider of loans for agricultural development, accounting for over one-half of all lending for agriculture of the international financial institutions. However, financing for agricultural development by the World Bank and other donors has dropped sharply since 1990 (see figure A and figure B). This drop reflects both past successes (increased production and lower food prices) and failures (poor ratings for outcomes, development impacts, and sustainability for agricultural projects). The rural strategy commits the Bank to reverse this trend if countries are to meet the MDG goals of rural poverty reduction and environmental sustainability. In particular, the strategy calls for a coordinated effort to identify good practice and innovative activities that should be scaled up to have wider impactsthe focus of this Sourcebook.

The Strategy also sets high standards for lending quality in terms of outcomes and impacts. The gap between quality of agricultural lending and the average Bank-wide lending has narrowed 
FIGURE A. IBRD/IDA COMMITMENTS TOTHE AGRICULTURE, FISHING AND FORESTRY SECTOR, FYI990-2003

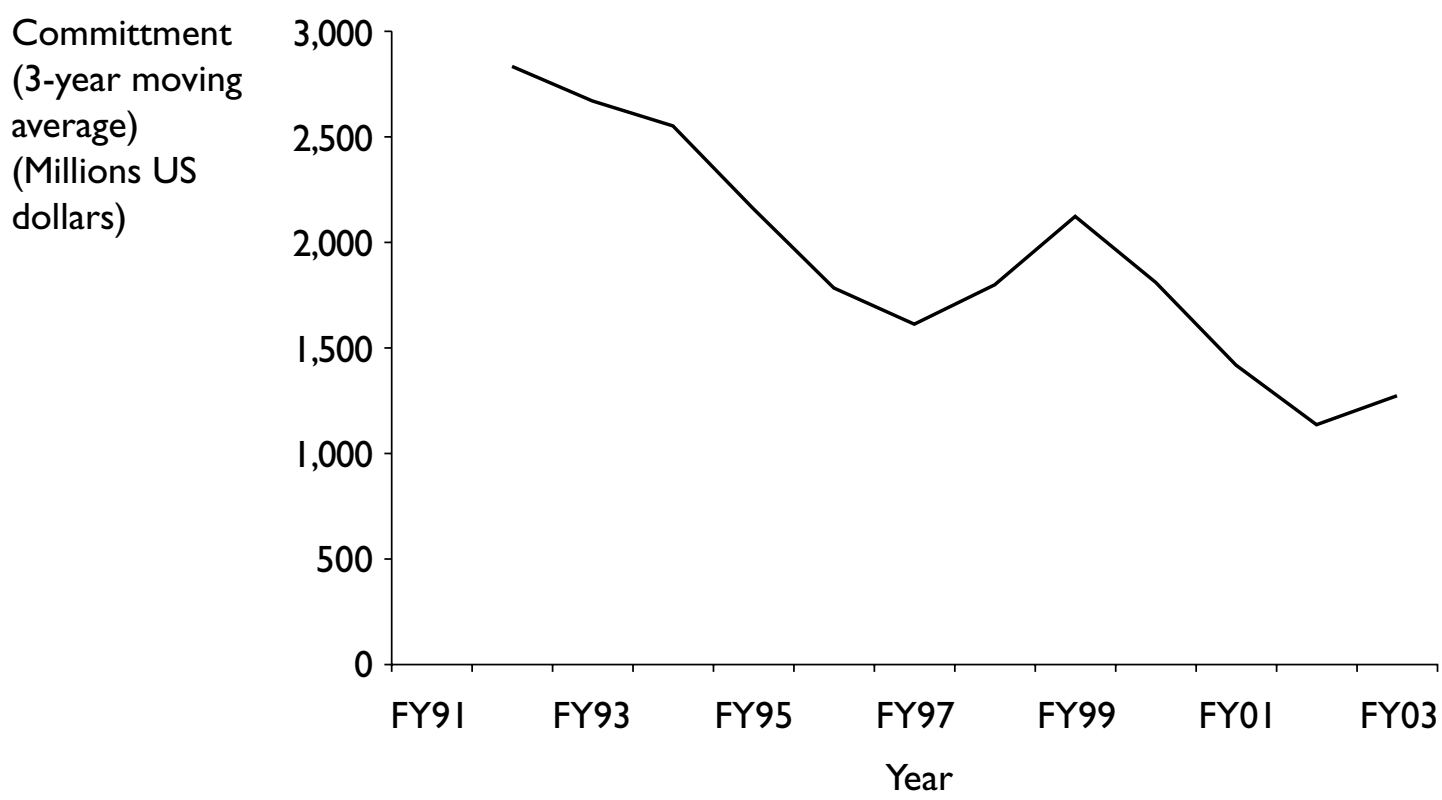

Source:World Bank Internal Documents

FIGURE B. AGRICULTURE, FISHING AND FORESTRY SECTOR: SUB-SECTORAL COMMITMENTS FY 1995-2003

Irrigation and drainage

General agriculture, fishing and forestry

Forestry

Crops

Animal production

Agro-industry

Agriculture market and trade

Agriculture extension and research
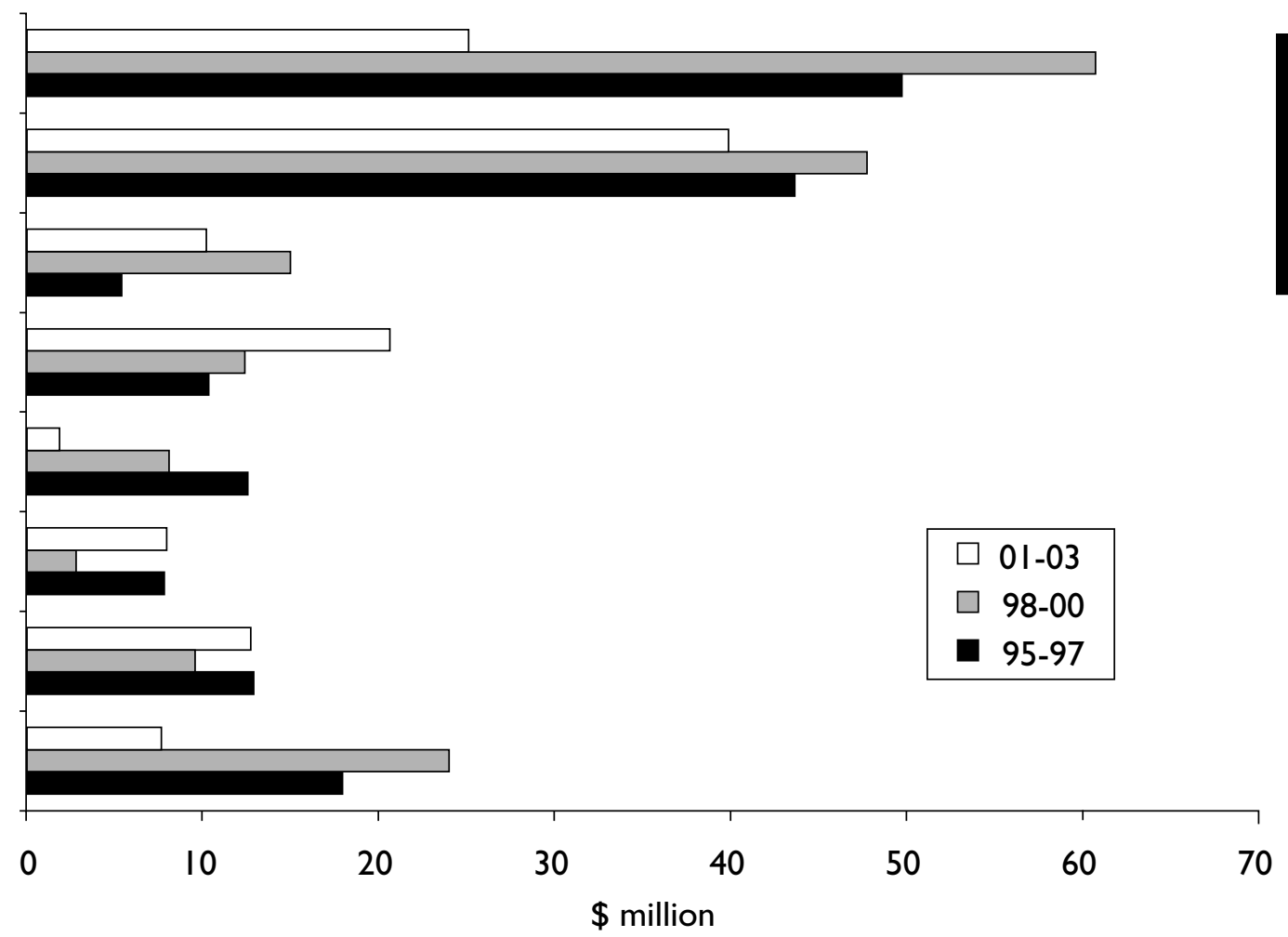
Box B. The changing context for agricultural development

The environment and context for investment in agriculture has changed dramatically over the past 20 years. Instead of investing with a view to increasing production and world food supplies, agricultural sector investments must now seek to increase competitiveness and profitability along the commodity chain from farmer to consumer, enhance sustainability for the environmental and natural resource base, and empower rural people to manage change. The rural strategy identifies a number of critical changes that will influence this process, namely:

- A crisis in commodity prices for traditional agricultural exports (cotton, coffee).

- Rapidly growing demand for higher-value agricultural products due to urbanization and income growth.

- Increased export demand for fruits, vegetables, and a variety of niche products (organic produce), especially within evolving multinational food market chains.

- Aging of the farm population and the impact of HIV/AIDS on farming, especially in Africa.

- Growing scarcity and degradation of land and water resources.

Source:World Bank, 2003.

significantly in recent years. This is despite the special challenges associated with agricultural lending-dependency on weather, vagaries of commodity prices, the dispersed and often remote nature of agricultural production, the high level of poverty in the sector, and an uneven global playing field for developing countries in agricultural trade.

The improvement in lending quality reflects a transition from public-sector oriented lending to "new style" projects and programmatic approaches based on private-sector implementation, market principles, decentralization, and beneficiary participation. This transition has not been easy or straightforward, and in all subsectors the quest for good practice continues. Further improvements in lending ratings require a concerted effort to share good practice for technical aspects of agricultural investments, the processes by which investments are designed, and the structure and sequencing of investment programs both within the sector and across sectors. The challenge is to identify, adapt, and disseminate these good practices to have a wider impact on sector performance and investment-an objective of this Sourcebook.

\section{CROSSCUTTING THEMES}

Future investments in agriculture will need to deliver on some established principles for successful development programs-sound policy frameworks for investment, long-term institutional development, a focus on core public goods (such as research and roads), empowerment of farmers, and a private-sector orientation. Future investment programs, however, have to respond to a rapidly changing environment for agricultural investments (see box B)

The modules in this Sourcebook reflect a new emphasis in the rural strategy in several dimensions (see table A). These in turn highlight a number of crosscutting themes in the Sourcebook.

Policy REForm. Many experiences have shown that investment made in a poor policy environment produces poor results. In most countries, markets are now much more open and trade far freer than in the past. Many, if not most, parastatal corporations involved in agricultural markets have been closed or scaled down. Still, there remains an unfinished agenda for policy reform that cuts across the various thematic areas for investment treated in individual modules. The challenge is now shifting from first generation of policy reforms built around market liberalization, and redefinition of the role of the state, to second generation policies and regulations to enhance competitiveness and growth. These reforms, in turn, require new roles and skills for the public sector.

\section{InSTITUTIONAL CAPACITY. Institutional capacity} development remains the key agenda item for donor investments. Moving from a governmentcontrolled and directed development strategy to a paradigm of market-based growth requires a myriad of institutional changes in how programs operate and are financed, how institutions are organized and interact, and what policies and capacities they need. Getting the institutional framework right is seldom a one-step process, 
and the real test is the ability of institutions to evolve and adapt to a rapidly changing environment for agriculture. In some sectors, especially research, extension, financial services, and market development, long-term institutional development is often required through a series of careful sequenced investments.

Public Versus PRIVATE SECTOR ROLEs. Agriculture is by and large a private sector activity. One of the major reasons for the reduction in agricultural lending has been the redefinition of the role of the state, and the emphasis on the private sector and market development. In nearly all thematic areas of agricultural development addressed in this Sourcebook, there has been a marked shift toward private-sector implementation of programs and market-based allocation of resources. This has naturally led to more emphasis on policies to create the conditions for private sector investment, and a reduction of public sector investment programs. Public funding for agricultural programs is unlikely to increase dramatically, but must be focused on core public goods-science and technology innovations, information and dissemination, infrastructure services, and environmental conservation.

Public-PRIVATE PARTNERSHIPS. It is now recognized that a rigid distinction between public and private sector roles is not possible, and there are many gray areas where public-private partnerships, often in conjunction with civil society and producer and community organizations, are needed. In the least-developed countries, especially in Africa, the withdrawal of the public sector from markets (through the elimination of parastatals) has left a vacuum that has not been adequately filled by the private sector, due to high transactions costs and risks. This means that there is a need for a more active public sector role in coordination activities, joint financing, and building needed capacity to allow the private sector to fill its role, in addition to financing core public goods (especially infrastructure). Many responsibilities are also being devolved to local or state governments for decentralized program implementation, and this provides additional challenges and opportunities. Strategies such as contracting-out to the private sector, providing targeted matching grants to support activities within the public interest, and expanding collaborative action in the context of market supply chain development and trade associations, and various types of consultations and coordination forums with the private sector are all important. There is still much to do in this area to establish good practice.

EMPOWERING FARMERS. A demand-side orientation for investment programs represents a fundamental shift in thinking away from seeing the farmer as a passive entity in his/her own farming situation, to recognition that the farmer is the ultimate decisionmaker guiding change 
in the sector. Empowerment of farmers is the result of decentralized program management, participatory approaches to planning and implementation, building capacity of producer and community organizations, responsiveness and accountability of public agencies to users, and wide access to information about all these developments. Involving local communities early in project design and throughout implementation increases the ability of projects to effectively respond to demand, positively impacts the way projects are implemented, and contributes to the sustainability of the outputs and the outcomes of the project.

Making participatory mechanisms fully effective will take time, as old habits are hard to change. Strengthening and working through partnerships with producer organizations provides a tool for empowering farmers that runs throughout this Sourcebook-influencing policy formulation, carrying out research and extension, implementing land reform programs, expanding financial services and marketing functions, improving management or irrigation systems and natural resources, establishing new production systems, and coping with risk and vulnerability. Few, if any, producer organizations do all of these, but different organizations address different priorities, such that these organizations need to be an integral part of the design of most agricultural investment programs. Finally, investment programs will have to broaden participation to include all stakeholders, not just farmers (and particularly women farmers), as consumers and agribusinesses have important interests that need to be heard in policy and program design.

DiVERSIFICATION TO HIGHER-VALUE COMMODITIES. Markets have also changed with liberalization of trade policies in global markets, and the growing demands for higher-value, higherquality products. This is reflected in the growing "supermarketization" of food outlets in Latin America and other regions, and the global sourcing of food products by multinational food companies. These changes in consumer demand provide a basis for much greater diversification of regional and national agricultural production and marketing systems, and much greater demands on the support systems for agriculture-research, advisory services, irrigation and drainage, market grades and standards, and information services - to provide the enabling environment for farmers to benefit and the private sector to grow and diversify.

INTERNATIONAL AGREEMENTS AND REGULATORY SYSTEMS. International agreements and regulatory systems have become more important with increasing trade and global economic integration, requiring increased emphasis on developing capacity for governments to represent their national interests in negotiations, and for mechanisms for producers and private agribusinesses to influence negotiating positions. Advocacy by developing countries, development bodies, and much of civil society for improved access to markets for agricultural products in industrial countries, and elimination of export subsidies, is a key issue. Most international agreements also require developing new skills and capacities in both public and private sectors for effective implementation.

ReCognition of DifFerent farm types. Adjustmentwhether to export to liberalized global markets or to the competitive domestic market within a country-is forcing many changes on small farmers, including the transition out of agriculture for marginal farms. Most agricultural sectors have a combination of different farm types, with different needs for public services and investments and different abilities to respond to markets. In all adjustments there are winners and losers-at least over the short term. The transition to liberalized markets offers unprecedented opportunities for small farmers to improve their economic circumstances and so lift themselves out of poverty. It may, however, also lead to their greater marginalization if the economic environment does not enable family farms to become more market oriented and if inefficient markets, especially land markets, constrain adjustment. If farmers produce high-value agricultural products, they will need access to the complex 
technology and market information needed to compete in these markets. For other farmers, adjustment programs may be required to ensure their transition to the nonfarm sector, including into agricultural processing industries.

\section{ADAPTING TO THE LOCAL CONTEXT}

The many geographic regions, countries, and agro-ecologies in which the Bank is involved present quite different development problems and opportunities, as seen in the regional rural strategies of the Bank. Sub-Saharan Africa and South Asia, with their high concentrations of rural poor, require particular attention to achieving broad-based growth through small farmers. Middle-income countries of East Asia and the Pacific, Latin America, and the Middle East/North Africa require more attention to programs for marginal areas where poverty is increasingly concentrated. Eastern Europe continues to focus on strengthening of markets and private sector capacities and attention to environmental conservation. The Middle-East-North Africa area is especially concerned with improved management of natural resources (particularly the scarce water resources). Within these very broad differences, design of investments in the agricultural sector must be context specific, introducing reforms suited to the country conditions and sensitive to the path-dependent evolution of rural institutions. Trade-offs are often necessary and design of investments must be based on extensive analysis of past experiences and options for future program and market development.

\section{SCALING UP INVESTMENT PROGRAMS}

The rural strategy commits the Bank to a process of rapidly scaling up good practice in order to achieve greater impact and coverage. (box C) These efforts to increase investment in agriculture must rely heavily on monitoring, feedback, analysis, and evaluation, facilitated through internal and external networking (meetings, workshops and conferences, joint impact assessment, peer-to-peer exchanges, cross-visits). There is also much to be learned from failure as well as success.

\section{Box C. Checklist of readiness for scaling-up}

What is known about impact?

- Level of social, environmental, or economic impact.

- Cost of delivery of benefits.

- Nature of beneficiaries.

- Time scale.

What is known about success factors?

- Organizational process and institutional factors.

- Cultural, environmental, and social factors.

- Policy and sectoral environment.

- Characteristics of beneficiaries.

What is the "state of practice"?

- Innovation - minimal objective evidence.

- Good practice - clear evidence from some settings.

- Policy principle - proven in multiple settings.

What are the scaling options?

- Internal replication; program expansion.

- Catalyzing and supporting others; joint ventures.

- Capacity building; partnerships; replication by others.

- Diffuse concepts and models; policy advocacy.

Source: World Bank 2003a.

Learning and information management and sharing processes are essential, and the recognition of this provides the basis for this Sourcebook and its attempt to:

- Improve monitoring and learning within projects and programs and between programs, projects, sectors, and regions.

- Identify and share widely the knowledge of what works and what does not in agricultural development projects and programs.

- Support the buildup of knowledge to help practitioners address specific needs, situations, and local variability.

Investments with complex and multiple goals make this process more difficult, and this is a fact relevant to the increased focus on poverty reduction and environmental sustainability. Combining impact assessment and ongoing learning processes may help to make monitor- 
ing and evaluation activities more efficient and relevant to program needs. The preparation of this Sourcebook has identified ongoing evaluation and impact monitoring as a serious weakness, that must be corrected to guide successful scaling up of projects.

\section{REFERENCES CITED}

Millennium Development Goals Website: www.developmentgoals.org

World Bank. 2003. Reaching the Rural Poor: A Renewed Strategy for Rural Development. Washington, D.C.: World Bank.

2003a. "Scaling-Up Issues and Options: Supporting the World Bank Rural Development Strategy on Implementation of Good Practice and Innovation." World Bank, Washington, D.C. 


\section{BUILDING AGRICULTURAL POLICY AND INSTITUTIONAL CAPACITY}

eveloping an enabling environment for pro-poor agricultural growth is essential for ensuring

that the various types of public investments described in this Sourcebook are effective.

Governments must provide public goods and establish supporting legal, administrative, and regulatory systems to correct for market failures, facilitate efficient operation of the private sector, and protect the interests of the disadvantaged. The role of the public sector is evolving, driven by trade liberalization and international agreements, and requiring new skills and analytical capacities. Investments should focus on public sector program and institutional reforms, adjustment lending, human resource development, and strengthening capacity of sector institutions, both public and private.

\section{RATIONALE FOR INVESTMENT IN POLICY AND INSTITUTIONAL CAPACITY}

The World Bank's Rural Development Strategy identifies two important elements of successful poverty reductionæcreation of an investment climate conducive to rural growth, and empowerment of the poor to share in the benefits of that growth. Investments in policy and institutional capacity are critical to 
ensuring that the public sector can effectively carry out its functions, which include coordination, participatory development of sector strategies, policy formulation, and allocation and monitoring of public investment in agriculture. These governmental functions seek to promote an environment conducive to private sector activity and competitive markets in socially acceptable ways (see box 1.1).

Public policy is anchored in a set of values defining societal goals and a set of beliefs about the best way of achieving those goals. Institutions are the rules, enforcement mechanisms, and organizations supporting market transactions. Institutions help transmit information, enforce property rights and contracts, and manage competition in markets, thus giving people the opportunity and incentives to engage in fruitful market activity. Together, public policy and institutions create the en-

\section{Box I.I Key policies to promote a competitive agriculture}

- Macroeconomic - ensure undistorted exchange rate policy, removal of implicit taxes and market barriers, nondiscriminatory taxation, macroeconomic stability, and government credibility.

- Trade - facilitate exports, participate in trade negotiations, reduce protection on import-substitute goods with relatively low and uniform tariffs, and remove nontariff barriers (while providing protection from acute price volatility).

- Labor - ensure agricultural employment meets core labor standards especially in regard to child labor, hazardous work, and equal employment opportunities for women.

- Competition - reevaluate the role of marketing boards, promote competition in input markets, establish labeling regulations for grades and standards.

- Environment/natural resource use - establish sustainable management, internalize externalities where possible, and develop markets for pollution and carbon credits.

- Land - develop land markets, security of tenure, titling and recording of land transactions, and land reform for fair distribution of land ownership.

- Technology - maintain public good research activities, and foster private sector participation in research and extension activities.

- Welfare and food security - establish social safety net programs to cope in times of extreme price changes and natural disasters.

Source:World Bank 2003 abling environment in which markets guide the allocation of resources for efficient outcomes. Although specific policies relevant to various subsectors within agriculture (for example, land administration, natural resources management, and agricultural research) are addressed throughout this Sourcebook, the means by which policy is established, and the structure of the institutions devised to do this and to promote overall sector growth, are addressed here.

\section{PAST INVESTMENTS}

Support for policy and institutional development in the agricultural sector has evolved dramatically. In the 1970s and 1980s, much investment went to building state organizations to manage agricultural development programs. Ministries of agriculture, starting often with very limited capacity, expanded their range of agencies and programs, many of which attempted to supply inputs, credit, and services directly to producers, and to purchase and market agricultural products. Some of these public sector investments had high payoffs. However, economic returns to many of these investments (such as large-scale irrigation) are now lower, and some interventions (such as subsidies) are very costly in terms of the distorting effect that they have on domestic markets.

The failure or lack of sustainability of many of these programs led to a rethinking of the role of the state in the agricultural sector. This was responsible for a surge in adjustment lending (that is, lending to support policy and institutional reforms conducive to growth) by the World Bank in the 1980s, when such annual lending averaged over US\$900 million. From 1990 through 2003, Bank agricultural adjustment lending totaled US $\$ 5$ billion.

Although adjustment lending and associated policy and institutional reforms have had significant impact on developing public policies for the agricultural sector, the reform process is not yet complete in many countries. Secondgeneration policy adjustments are needed in many cases, and capacity for effective implementation of many reforms is lacking. In particular, rapid changes in global markets and 
technology demand a renewed focus within the public sector to correct persistent market failures, ${ }^{1}$ efficiently provide core public goods ${ }^{2}$, establish supporting systems that encourage private initiative and investment, and protect the interests of the poor (see box 1.2).

Over the past decade, there has been increasing recognition that "good governance" is key to sustainable development and poverty reduction. Good governance is reflected in a capacity for analyzing policy options and the capacity for implementing the policies and programs with transparency and accountability. However, the speed and impact of improvements in governance has been less in rural areas due to lower levels of education, lower qualification of civil servants, and more deeply ingrained traditions of paternalism. The effectiveness of public sector institutions in promoting pro-poor agricultural growth is also hampered by the fact that there are often many different ministries or agencies operating within the sector (for example, public works, water resources, trade, and environment) each with a high degree of centralization.

\section{KEY ISSUES IN POLICY AND INSTITUTIONAL CAPACITY DEVELOPMENT}

The new generation of investments in policy and institutional reform will likely be more challenging than in the past. Emphasis must be on actually implementing reforms and finetuning these to suit local situations and evolving market conditions. The requirement for high-quality information and analysis to support policy formulation and investment is now greater than before, and there is a critical need to learn from experience, through improved monitoring and evaluation of policy impacts.

Changing role of government. Many public sector institutions are oversized and overly

\section{Box I.2 Payoffs to public investment}

Public investment reduces rural poverty through improved growth in agricultural production, agribusiness development, rural nonfarm employment, lower food prices, and migration. While there are often long time lags between investment and visible impact, investments in agricultural research, education, and rural infrastructure are often the most effective in promoting agricultural growth and poverty reduction (see inset table). Regional analysis within India also suggests that public investment in less-favored areas not only offers the largest poverty reduction per unit of spending, but also leads to the highest economic returns.

\section{Returns of agricultural public investments and impacts on poverty reduction in China and India}

\begin{tabular}{|c|c|c|c|c|}
\hline \multirow[b]{2}{*}{ Sector } & \multicolumn{2}{|c|}{$\begin{array}{l}\text { Economic } \\
\text { returns* }\end{array}$} & \multicolumn{2}{|c|}{$\begin{array}{l}\text { Returns - } \\
\text { poverty** }\end{array}$} \\
\hline & China & India & China & India \\
\hline$R \& D$ & 9.59 & 13.45 & 6.79 & 84.5 \\
\hline Irrigation & 1.88 & 1.36 & 1.33 & 9.7 \\
\hline Roads & 8.83 & 5.31 & 3.22 & 123.8 \\
\hline Education & 8.68 & 1.39 & 8.80 & 41.0 \\
\hline Electricity & 1.26 & 0.26 & 2.27 & 3.8 \\
\hline Poverty loan & n.a. & 1.09 & 1.13 & 17.8 \\
\hline
\end{tabular}

*For China, yuan total rural GDP/ yuan exp., and for India, Rupee per Rupee spending

*** For China, no. poor reduced/ 10,000 yuan exp., and for India, no. poor reduced/million Rupee exp.

Source: Fan, Zhang, and Zhang 2002

centralized. Although they may (arguably) have been effective in the past, they are now inappropriate to their new roles. Many public sector agencies are still involved in areas where the private sector would be more efficient (for example, marketing, and input supply), but lack the capacity and incentives to intervene effectively to promote the private sector. Privatization of noncore public functions and decentralization of remaining programs and governance systems are critical to fostering

I. Market failure relates to high levels of risk and ineffective insurance markets, presence of economies of scale and indivisibilities, positive and negative externalities, and distributional inequalities. Governments must only act to correct such failures where interventions resulting in government failure are not worse than the original market failure.

2. Public goods are defined as those for which private suppliers cannot fully appropriate the benefits of their initiatives - they are nonrival (one person's consumption of a good or service does not reduce availability to others) and nonexcludable (individuals cannot be easily excluded from consumption). Interventions relating to goods that are undersupplied because of positive externalities (for example, agricultural research and roads) will be different to interventions where economies of scale and natural monopolies create a rationale for public investment (for example, irrigation and rural electrification). 
market development and agricultural growth. The role of government has shifted toward being more of a coordinator that develops and enforces the rules by which private sector participants interact within market arenas. This change, however, requires considerable capacity to formulate and implement policies to promote market development and coordination, and create capacity to respond to markets. Although current development strategies provide for increased private sector leadership and a declining role for the public sector, the quality and efficiency of public sector institutions and policy are increasingly important to the emergence of a modernized and competitive agriculture. The major priorities are to:

- Support implementation of unfinished reforms, such as reducing public sector bureaucracies, privatizing state corporations, and devolving programs to lower levels of government for more efficient implementation.

- Formulate coherent national agricultural development strategies and innovative sector development programs.

- Develop mechanisms for producers and the private sector to participate in policy and program formulation and implementation through public-private partnerships.
- Develop capacities and institutions for government to carry out regulatory, information, policy, and negotiation functions to promote efficient markets and respond to international agreements and standards (see box 1.3).

InTER-Ministerial COlLaboration. Development and implementation of policies affecting the agricultural sector increasingly depend on ministries and agencies outside of the agricultural ministry, that deal with public finance, food security, trade negotiations, natural resource management, and science and technology. An effective strategy for pro-poor agricultural development must necessarily seek to strengthen linkages and communication between the range of public agencies with a stake in agricultural development (for example, environment, land, labor, finance, industry, trade ministries). The large number of private sector interests involved across these areas complicates this. Thus the government must adopt a coordinating role whereby it encourages, ideally through incentives rather than regulations, cooperation among ministries, agencies, and the private sector, and a comprehensive approach to cross-sectoral issues. This coordinating role must extend into the regional and international arenas in which agriculturally-related agreements are increasingly made.

Public-PRIVATE PARTNERShips. It is now clear that more efficient outcomes can generally be

\section{Box I.3 Typical regulatory requirements of a modern agricultural and food system}

- Legal and business regulation (with low costs of compliance for doing business), transparency, adjudication of contract disputes, contract enforcement, market regulation.

- Food safety regulations and standards (especially in processing facilities), and testing for contamination (including microbial) and chemical residues.

- Natural/environmental and common property resource (waterways, forests, air, fauna) protection, and land and water use management including tenure administration.

- Biosafety regulation with respect to genetically modified organisms, pest and disease control and appropriate quarantine border measures, and agricultural biodiversity preservation.

- Intellectual property rights (IPR) regulations to provide incentives for innovation, enforcement of IPR laws and patents, balancing security of property rights with technology accessibility for smallholders.

- Verification and certification of seeds and plant propagation materials and registration and regulation of agrochemical use.

- Inspection services and issuance of phytosanitary certificates, and verification and certification of products for satisfying relevant grades and standards.

- Labeling requirements and their enforcement.

Source: Authors 
achieved if the private sector is involved in the provision of public services. Many government functions can be contracted out to specialized private sector firms and nongovernmental organizations (NGOs) under competitive bidding. Governments can also partner with the private sector including producer organizations, NGOs, and trade associations, in areas such as policy formulation, food safety regulation, and the provision of infrastructure. ${ }^{3}$ Other functions that need to be performed by the public sector are often better accomplished if the agencies are organized as financially autonomous entities, capable of securing much of their funding through the recovery of costs from users. This is typically the case with "toll goods" and "natural monopolies" such as land registration and titling bureaus, some phytosanitary services, plant varietal and agrochemical registration, plant varietal protection, and seed certification. The financial viability of these public service entities requires that commercial and social objectives be kept separate and distinct. Where full cost recovery may exclude the poor from a particular service, graduated fees or targeted voucher systems for the needy can be introduced. These approaches will require a transparent definition of eligibility and a system that can be readily implemented.

Multiple GOALs FOR THE SECTOR. Formulation of public policy requires difficult choices (given limited resources) among alternative (and often competing) priorities. A traditional focus of ministries of agriculture has been on food production and self-sufficiency. This focus must be broadened to include poverty reduction and environmental concerns. Food security will remain an objective, but with greater concern for improved access by the poor to a variety of safe and nutritional foods (see box 1.4). Increased employment and income opportunities complemented by better market integration and more effective and targeted social safety nets are needed for poverty reduction. Broad-based growth led by the private sector is often the most effective means to reduce poverty. Public expenditures must support provision of core

\section{Box I.4 Food security, safety, and quality}

Food security depends on there being adequate food availability, access, and utilization. Availability depends on production and market supply, and access to incomes that enable the purchase of food. Food utilization depends on health conditions and food quality that enables it to meet nutritional needs. As such, food quality and safety are essential to food utilization and food security. Potential investment areas for food safety and quality include:

General:

- Policy analyses and food chain diagnostic studies

- Nutritional surveillance studies

- Food fortification or supplementation programs

- Micronutrient-rich foods promotion

\section{Export focused:}

- Developing laboratory capacity for residue testing and biological agents, for example

- Strengthening capacity for food inspection, auditing, and certification

- Training, risk analysis, and systems for product traceability

- Information on export market import standards

Domestic market focused:

- Investments in water and sanitation

- Hygiene training for street food vendors

- Plant and animal quarantine infrastructure

- Vaccination programs against livestock diseases

Source: Authors

public goods to promote private sector investment, but in ways that are focused more sharply on addressing the needs of the poor. Also, environmental considerations are an increasingly important element of agricultural development initiatives, and policies and institutions must provide a basis for valuing natural resources used in agricultural production, internalizing environmental costs and benefits in production systems, and developing markets for environmental services.

Reform of Subsidies. Despite the fact that rich countries continue to maintain trade-distorting subsidies, developing countries must review their agricultural support policies (price supports, border protection, and subsidies) with a view to improving sector efficiency and equity. Subsidies on inputs create disincentives to use scarce resources efficiently (for example, subsi-

3. See Innovative Agricultural Project (IAP): "Guinea: Livestock Sector Partnership_-Public Sector Herder Organizations and the Private Sector." 
dized irrigation water), may have environmental costs (for example, pesticide subsidies), and draw scarce resources away from high payoff public investments, such as agricultural research and infrastructure. Numerous studies have shown that subsidies are disproportionately captured by the largest producers and do not meet the social equity objectives often used for their justification (see box 1.5). Finally, in the longer term, subsidies may undermine competitiveness, since they typically become capitalized into land values, raising producers' production costs. Since subsidies generally create strong vested interests, removal of subsidies is often difficult, and may require interim, transition support so that producers have sufficient time and resources to adjust to changed conditions. Countries that have successfully made this transition have achieved a more dynamic and competitive agricultural sector (see box 1.6).

LACK OF TECHNICAL AND HUMAN CAPITAL. Governments often lack the skilled staff, equipment, and management tools to efficiently implement complex programs. A chronic lack of funds for in-service training and persistent traditional attitudes with regard to training have deprived public servants of knowledge and skills to design and manage interventions for a sector in which the private sector is in the lead. Past institution-building efforts often failed in part because of low government salaries and poor incentive structures. The result was a "revolving door" situation in key ministry units as the besttrained staff left for the private sector or international employment. Critical to future reforms and institutional development will be the ability to build and retain the necessary qualified human resources (with skills in areas such as marketing and management), and the incentive systems to staff institutions that formulate policy. Development of these human resource capabilities must also take into account the future needs of private sector agencies, such as producer groups, agribusiness associations, and commodity chain consultative groups.

BuILDING CAPACITY IN PUBLIC EXPENDITURE MANAGEMENT. In many countries, capacity to manage public expenditures (both budget formulation and execution) is especially weak in ministries of agriculture. Efforts must focus on strengthening capacity for: policy formulation and costing, using results-oriented budgeting, management of budget execution, monitoring and reporting, and mechanisms for stakeholder participation and interfacing with donors. Building capacity for the development of medium-term expenditure frameworks is critical to translating Poverty Reduction Strategy Programs (PRSPs) into public expenditure programs, and ensuring that agricultural sector

\section{Box 1.5 India: inequitable distribution of subsidy benefits}

The Government of India and most Indian states have subsidized agricultural inputs since the Green Revolution. In India, input subsidies to agriculture as a percent of agriculture GDP averaged 9 percent during the 1990s. In the state of Punjab, the largest subsidies are for electricity for pumping groundwater (a state subsidy) and fertilizer (a Government of India subsidy). Large farmers receive a disproportionate share of these subsidies (see inset table). The share of total subsidies that small farmers receive is less than the share of total land area that they farm, and the reverse is true for large farmers. Such subsidies are aggravating serious environmental degradation, especially over-exploitation of groundwater.

Distribution of Punjab input subsidies by farm size, 1995-96

\begin{tabular}{|c|c|c|c|c|c|}
\hline & $<$ I ha & I - 2 ha & 2 - 4 ha & $4-6$ ha & $>6$ ha \\
\hline Farms in size category (\%) & 18.6 & 16.8 & 29.3 & 16.8 & 18.5 \\
\hline Land area in category (\%) & 2.9 & 5.8 & 20.1 & 21.0 & 50.2 \\
\hline$\%$ of fertilizer subsidy & 2.5 & 4.8 & 18.6 & 21.9 & 52.2 \\
\hline$\%$ of electricity subsidy & 1.3 & 4.1 & 17.4 & 22.5 & 54.7 \\
\hline$\%$ of canal water subsidy & $\mathrm{I} .4$ & 3.6 & 16.9 & 23.0 & 55.1 \\
\hline
\end{tabular}


priorities are reflected in implementation of PRSPs, and related programmatic assistance.

\section{FUTURE PRIORITIES FOR INVESTMENT}

Future investments in policy and institutional capacity require sustained efforts over a considerable time to develop stable and competent public sector institutions to support market development and address market failures. The level of financing required for these initiatives will often be quite modest, but continuity of support is critical.

DeVELOPING AND IMPLEMENTING AN AGRICULTURAL STRATEGY. A comprehensive agricultural sector strategy is essential as a basis for investment for pro-poor growth. Such a strategy might form a part of a broader rural development strategy or PRSP, but will usually need to be developed in greater detail as a stand-alone agricultural strategy document. In providing a "vision" for the future role of the sector, strategies should focus the efforts of donor organizations and governments on the most relevant problems and solutions, and should ensure that initiatives are complementary rather than conflicting. Translating strategy priorities into budgetary allocations is often more difficult than formulation of sector strategies. Budgetary allocations must be well planned and based on revenue expectations, as well as realistic estimates of the funding needs for different policy priorities.

Sequencing of funding allocations is also important. Budget allocations are, of course, largely within the responsibility of ministries of finance. However, good analysis and effective information systems within the agricultural sector, backed by competent policy staff with good presentation and negotiating skills, are important for promoting public investment in agriculture and improving investment quality.

Building POLICY AND NEGOTIATING CAPACITY. Developing and maintaining adequate policy formulation, implementation, and analytical capacity has been a recurrent problem in most countries. Retaining well-trained economists is especially important for policy formulation and analysis, since they often find attractive employment opportunities outside of government
Box I.6 New Zealand: benefits of unsubsidized agriculture: an OECD example

Protection and subsidies often constrain growth and competitiveness of the agricultural sector. During the mid 1980s, producer support in New Zealand accounted for about 40 percent of farmer income. The fiscal unsustainability of these subsidies, loss of preferential access to British markets, and spiraling inflation pressured the government to abandon most support payments. Deregulation was rapid (nearly all subsidies were removed in 1984) and substantial (almost 30 different subsidies and export incentives were removed and no industry continued to receive preferential treatment). Around one percent of New Zealand's farmers exited agriculture (with the help of a one-time exit grant valued at approximately one-third of annual income).

Since the late 1980s, agricultural output has grown by more than 40 percent, the rate of productivity growth has increased almost six-fold, the share of farming in GDP has risen from 14.2 to 16.6 percent, and the share of rural population has remained constant. Reform prompted greater competition, lower input costs, adoption of practices that were more environmentally sustainable, and a more diversified and adaptable sector responsive to market needs.

Source:World Bank 2003.

service. Although there is no easy solution to the problem of retaining qualified economists, a common solution is for government to contract out policy research to universities, consulting firms, and research foundations, and to undertake joint analyses of policy implications with relevant stakeholders. However, ministries of agriculture still require a core capacity to tap available policy research, contract with outside institutions to fill research gaps, and analyze research output for use in the policymaking process.

A related need is to develop the capacity to participate in negotiations at regional or global levels (for example, the ongoing Doha Development Agenda negotiations under the auspices of the World Trade Organization (WTO) and effectively represent the needs and concerns of domestic producers and citizens. Such negotiations include trade, the environment, grades and standards for market entry, intellectual property issues, foreign investment, and negotiation with donor agencies (see box 1.7). Donor agencies can provide technical assistance 
and training in these areas so that public officials can evaluate potential negotiating positions and the likely implications of these on various groups, with particular emphasis on the poor and vulnerable.

Reforming agricultural ministries. Ministries of agriculture are often inefficient and very conservative, and may resist devolution of traditional core functions. Past investments in public institutions resulted in substantial bureaucratic structures ("over-dimensioned") requiring large recurrent cost financing. However, reform of a single ministry is often difficult unless carried out within the context of structural reform of the entire civil service system, or at least of the ministries dealing with the agricultural sector (see box 1.8). Reform is likely to be a long-term process and political changes can easily wipe out progress, requiring a new start on reforms. A bottom-up effort that builds a base and constituency for ministry reform among key stakeholders is important.
STRENGTHENING STATISTICAL AND INFORMATION SERVICES. The quality of agricultural data systems is thought to have declined in many countries in recent years, along with declines in ministry of agriculture budgets for these systems. Good information is an essential base for sound policy formulation and for guiding investments by both the public and private sectors. ${ }^{4}$ Agricultural censuses, production and yield surveys, and market information systems can improve decisions of government, producers, and agribusinesses. Market information systems are especially important to efficient operation of the private sector.

Wide dissemination of information is particularly important for maximizing the benefits of data collection and to ensure equitable access to information on production and markets. New information and communications technologies (such as Web portals) can help improve the quality, dissemination, and costeffectiveness of data collection. Although there is a significant public good element in such

\section{Box I.7 International agreements related to agriculture}

The international community through a variety of international agreements has addressed many issues facing the agricultural sector. Countries, signatories to the agreements, are required to implement their provisions. Some key agreements, conventions, treaties, or protocols that affect agriculture include:

- International Plant Protection Convention (1951)

- International Code of Conduct on the Distribution and Use of Pesticides (1985)

- International Code of Conduct for Plant Germplasm Collecting and Transfer (1993)

- World Trade Organization (WTO) Agreement on Agriculture (1995)

- WTO Trade Related Intellectual Property (TRIPS) Agreement (1995)

- Code of Conduct for Responsible Fisheries (1995)

- United Nations Convention to Combat Desertification (1996)

- World Food Summit: Rome Declaration and Plan of Action (1996)

- Cartagena Protocol on Biosafety (2000)

- Stockholm Convention on Persistent Organic Pollutants (POPs) (200I)

- International Treaty on Plant Genetic Resources for Food and Agriculture (200I)

Negotiations continue on a number of outstanding issues involving such areas as subsidies and market access for agricultural trade (WTO), market standards, and biotechnology (in the Food and Agriculture Organization/World Health Organization (FAO/WHO) Codex Alimentarius Committees). Governments, the private sector, and civil society need to understand the implications of agreements on these issues, have the institutional capacity to implement their relevant provisions, and the ability to formulate and present views in future negotiations.

Source:WEHAB Working Group 2002.

4. See the IAP,"Ecuador: Commodity Chain Consultative Councils for Policy Formulation" 
systems, a portion of the costs may be recovered from the private sector.

FACILITATING ADJUSTMENT AND MANAGING RISK. A pressing issue in many countries is to assist producers to adjust to market and trade liberalization-events that affect prices (and so change competitiveness and profitability among industries), and affect risks faced by farmers. This may require government assistance to farmers (especially small farmers) to make the transition to other enterprises in which they have a comparative advantage, or in some cases to exit agriculture altogether. ${ }^{5}$ In some circumstances, income support programs can be helpful but must be "decoupled" (that is, not paid on the basis of current input use, output, or prices) so that these do not distort production. Similarly, market-based risk management systems for commodity prices and modern information and communication technologies have potential to help producers to cope with risk during the transition.

DeCENTRALIZING PROGRAMS AND AUTHORITy. Decentralization is commonly promoted as a means of empowering agricultural producers by enabling local participation in the decision-making process. This is expected to lead to more responsive and locally applicable policy decisions. Although there can be a trade-off between greater local government authority over expenditure and potential misuse of funds, financial responsibility is an important element of effective decentralization. If local governments and private organizations are to carry out decentralized functions effectively, they must have adequate revenues, either raised locally or transferred from the central government, and must have authority to make decisions about expenditures (that is, political decentralization). While local governments have a role in providing "local" public goods, there are also many "national" or "regional" public goods that local government will not have the technical capacity or interest to address.
Box 1.8 Tanzania: reform of the Ministry of Agriculture

Prior to the Agricultural Sector Management Project in Tanzania, the Ministry of Agriculture was overloaded with tasks for which it was ill suited. Reforms helped state agricultural institutions to manage less, but better, in support of a market-based economy. The government role in the agricultural sector was better defined, enabling the ministry to focus on three major tasks - policy formulation and planning, development and provision of services in partnership with the private sector, and regulation and inspection. Reform entailed divestiture of many parastatals, spinning-off services of a commercial nature to the private sector and reducing staff within the ministry. Staff skills were upgraded through on-thejob training and higher education overseas, and agricultural information systems were strengthened to support a marketbased economy. Since reforms had implications beyond agriculture, other ministries were actively involved.

Source:World Bank Internal Documents.

All decentralization reforms need to recognize the limits of local government activity. Public investment will be necessary to develop capacity of local governments and assist them in formulating coherent and effective strategies and programs for decentralization. However, this can be difficult given the large number of (often small) local governments and the frequency with which they change. In addition, provision of many agricultural services (for example, technical advisory services) is in many cases the domain of user groups, farmer organizations, and trade associations. These may have different interests and priorities than local government, and agreements about how these responsibilities are divided, can be highly effective.

Developing participatory systems. Participation enhances stakeholder influence and control over priority setting, policymaking, resource allocations, and access to public goods and services. This in turn improves government accountability and transparency, and increases overall governance and economic efficiency of development activities. Rural producer organizations can be central to a participatory system for agricultural decision-making, but frequently

5. See the IAP, "Turkey: Hybrid Adjustment/Investment Lending" 
must make a transition from having been passive recipients of government assistance to being independent institutions developing their own policies, programs, and strategies and negotiating with the government as equals. At the same time, initiatives to support the development of such groups must do so in a manner that avoids the potential for any one group (or a number of powerful individuals within the group) to pursue narrow agendas at the expense of other groups (or other individuals within the group). Agribusiness trade associations (often participating in commodity chain or marketing chain interest groups) are other key stakeholders with interest and influence in the sector. The public sector should explicitly seek to develop alliances with such groups, and build a strong constituency for agricultural institutions, but in ways that avoid special interest subsidies and protection.

\section{SCALING UP INVESTMENTS}

Improving policy and institutional capacity is critical for designing and implementing sound programs for pro-poor agricultural growth. Some indicators for monitoring the extent of progress in this area include:

- Existence of a sound agricultural sector development and investment strategy.

- Level of private investment in agriculture and agribusiness, and surveys of the investment climate for private investors in the sector.

- Extent and quality of rural producer organization and agribusiness association input into agriculture policy formulation and program design and implementation.

- Availability and quality of statistical information on the agricultural sector, agricultural production, and markets.

- Effective regulatory systems for emerging areas such as food safety, biosafety, intellectual property rights, and phytosanitary standards.
- The extent of liberalizing support and protection policies for agriculture.

Analytical work and policy dialogue is especially important to assessing the needs for policy and institutional capacity building, and for preparing investment proposals prior to scaling up.

\section{SELECTED READINGS}

Asterisk $\left(^{*}\right)$ at the end of a reference indicates that it is available on the Web. See Appendix 1 for a full list of Websites.

World Bank. 2003. Reaching the Rural Poor: A Renewed Strategy for Rural Development. Washington, D.C.: World Bank.

Ellis, F. 1992. Agricultural Policies in Developing Countries. Cambridge and New York: Cambridge University Press.

Monke, E. A., and S. R. Pearson. 1989. The Policy Analysis Matrix for Agricultural Development. Ithaca, N.Y.: Cornell University Press.*

Timmer, C. P., W. P. Falcon, and S. R. Pearson. 1983. Food policy Analysis. Baltimore: Johns Hopkins University Press.*

World Bank. 2002. A Sourcebook for Poverty Reduction Strategies. Washington, D.C.: World Bank.

\section{REFERENCES CITED}

Fan, S., Zhang, L., and X. Zhang. 2002. Growth, Inequality, and Poverty in Rural China: The Role of Public Investments. Research Report 125. Washington, D.C.: IFPRI.

Singh, K. 2003. "Punjab Agricultural Policy Review." Report for the World Bank. New Delhi, May 31. World Bank, Washington, D.C. Processed.

WEHAB Working Group. 2002. "A Framework for Action on Agriculture." World Summit on Sustainable Development Report. WEHAB Working Group, Johannesburg. 
World Bank. 2003. "Agricultural Policies and Trade." In Global Economic Prospects: Realizing the Development Promise of the Doha Agenda. Washington, D.C.: World Bank.

This Overview was prepared by Derek Byerlee, Sam Kane, and Gary Alex, with inputs from Jock Anderson, John Nash, and Pierre Rondot. Peer review comments were provided by Deepak Ahluwalia, Mark Lundell, Jock Anderson, Ralph Cummings (USAID), and Suresh Babu (IFPRI). 
AGRICULTURE INVESTMENT NOTE

\section{PREPARING A NATIONAL AGRICULTURAL DEVELOPMENT STRATEGY}

An effective agricultural development strategy (ADS) is critical for identifying the key issues and opportunities facing the agriculture sector, and developing operationally sound programs to promote pro-poor growth. Strategies must provide a "vision" for the future role of the sector, and set forth a policy framework and the investment priorities needed to achieve this vision. Key areas for support include building the human and institutional capacity for strategic analysis and planning, and establishing a participatory consultative process to articulate an agricultural development strategy that can result in real progress for the sector.

Too many countries continue to invest in agricultural development without a clear overall strategy. Central planning of agricultural production seldom worked in the past and is largely discredited. The role of government in promoting economic growth and development has changed with the increased importance of private-sector investment in agriculture. This does not, however, mean that the government can abdicate its role in promoting agricultural development, and unless this role is clearly defined, the payoffs from investment in the sector are likely to be less than satisfactory.

\section{WHAT IS AN AGRICULTURAL DEVELOPMENT STRATEGY?}

An ADS is a roadmap to assist governments, civil society, and donors in defining interventions to meet key objectives for the agricultural sector-typically including improved productivity and competitiveness, reduced rural poverty, enhanced household food security, increased capital accumulation by poor rural households, and more sustainable management of natural resources. Such articulation of strategy does not imply central planning, but rather an analysis of the options and priorities for government in promoting sustainable agricultural sector growth. An ADS is both product and process. As product, the written document serves to focus and facilitate the process. The strategy combines analysis, process, and required action, and usually has five elements:

- A snapshot of the current status of the agricultural sector, which, depending on the state of existing knowledge, may involve new economic and sector analysis, perhaps involving formal models such as discussed in the final section of this note.

- A national vision of agriculture within the time frame of a generation.

- A diagnosis of the key constraints that prevent the agricultural sector from achieving the vision, and an analysis of the main opportunities, inevitably requiring new analytical studies and likely involving modeling of growth processes.

- Action plans for implementing the vision, including assignment of responsibilities and estimation of costs, and a comprehensive program of monitoring and evaluation to measure costs and benefits and to understand any required revisions.

Developing an understanding of agricultural production and marketing systems and their sources of vulnerability is a complicated task, particularly if it involves considering mechanisms to help some people leave agriculture. Common problems include: insufficient time for broad consultation, gaps in the required knowledge base, particularly concerning reliable data on poverty in agroecological and local government areas, problems with incountry expertise, and lack of political and/or bureaucratic champions.

\section{BENEFITS}

Effective processes for preparation of an ADS rely on intensive fact-finding, diagnostic studies, analyses, and program monitoring, evalua- 
tion, and impact assessments. An ADS will present combinations of policies and programs around which stakeholders can form a consensus and mobilize resources needed (see box 1.9). This process helps to identify political champions for reform, and can promote interchange of experiences among practitioners to learn what works and what does not work in sectoral institutions, programs, and markets. Overall, an ADS can focus efforts such that duplication of projects and conflicts among different initiatives are reduced, and it can enhance collaboration among stakeholders (including donor agencies, governments, the private sector, and farmer and community organizations).

\section{POLICY AND IMPLEMENTATION ISSUES}

Agricultural AND RURAL DEVELOPMENT STRATEGIES. There is now a recognition that rural development is broader than agricultural development, involving substantially more attention to social, off-farm, and infrastructural investments. While an ADS can be developed as a component of a Rural Development Strategy, this involves a trade-off between the benefits of approaching agriculture as part of the larger rural picture, and the potential problems of coordination and dilution of focus in analyses and planning. Development of a stand-alone ADS is often a useful and preferred option.

Agricultural strategy as PROCEss. The process of forging an ADS shapes its design and chances of being implemented, and its likely development impact. Hallmarks of a successful process are:

- Strong political and administrative leadership at central and local levels.

- A strategic document identifying desired outcomes of decentralized agricultural development programs, specifying timetables, budgets, and responsibilities.

- Consensus building and ownership of a vision of agricultural development by policymakers, sector stakeholders, and the development community.

\section{Box 1.9 Uganda: plan for modernization of agriculture}

In order to raise agricultural growth rates, the Ugandan Government developed a Plan for Modernization of Agriculture through a broad-based consultative process. This plan is part of Uganda's broader strategy, which is defined in the Poverty Eradication Action Plan (PEAP). The plan has been used as an important input into its Poverty Reduction Strategy Paper (PRSP) and subsequent Poverty Reduction Support Credit (PRSC) in which agriculture has high priority. A focus point of the plan is the transformation of subsistence agriculture to commercial agriculture to accelerate growth through technical change throughout the sector. Priority areas for action are: research and technology development; agricultural advisory services; rural finance; agro-processing and marketing; agricultural education; sustainable natural resource utilization and management; and supportive physical infrastructure, particularly roads. The plan provides the strategic and operational framework for sustainable agricultural transformation, but does not provide a detailed plan for action. It describes the types of policy interventions required to promote agricultural and rural development, and defines the roles of the public sector, the private sector, and the civil society in this process.

Source: Government of the Republic of Uganda 2000.

- Mobilization of institutions and partnerships at different levels and in different sectors to implement the ADS.

- Broad local participation in regular monitoring, and understanding of the likely impact on those who will benefit and those who will lose.

COUNTRY LEADERSHIP. The country must take the lead in analysis and strategy formulation, but can benefit from donor support, especially through sharing relevant experience from other countries and regions.

Time frame AND macro COnTEXT. Agricultural development is a long-term process, involving institutional change, market development, and technological adaptation. The time horizon for an ADS should be about 5-10 years, with an expectation that it be revised and updated approximately every five years. Elections and changes in government are important factors affecting timing for strategy preparation. As changes are not always predictable, preparation 


\section{Box I.10 Key snapshot data}

Profile of the agricultural population

- Number of farmers by farm size, land use and tenure status.

- Agricultural laborers and wages.

- Agribusinesses by size, type, and profitability.

Public sector investment programs

- Density and state of rural roads, public markets, agricultural extension services.

- Adult literacy rate: overall, male, and female.

- Share of agricultural value invested in research.

Agricultural production systems

- Major agroclimatic zones and soil types (map).

- Irrigated (surface and ground, large-scale and small- andmedium) and rainfed (map).

- Farmers' organizations, NGOs in the sector.

- Agriculture's share of GDP, employment, import and export.

- Major markets (domestic and foreign).

- Indicators of productivity and comparative advantage.

- Details of sectoral protection and taxation.

The natural resource base

- Management systems of natural resource base.

- Trends in resource base change.

- Frequency of natural calamities.

Source:World Bank Internal Documents

of strategies should seek commitments across the political spectrum. Since macroeconomic crises often accompany adjustment lending, practitioners should be made aware of the need and rationale to focus on high-quality fiscal adjustment measures in agricultural spending in order to protect agricultural growth. Monitoring the effects of exchange rates adjustments on agricultural terms of trade can lead to useful identification of policy problems and corresponding recommendations.

Multiple ministries. Many issues within a broad concept of "agriculture" (for example, irrigation, livestock, food, trade, input supply, agroindustry, and agricultural education) are the responsibilities of different ministries. It is critical that inter-sectoral linkages and interactions (for example, macroeconomic policy and agricultural trade policy) are appropriately accommodated. Strong participatory leadership skills and good coordination are necessary to produce a single strategy with support across a range of ministries.

\section{LESSONS LEARNED}

DeVElop Baseline information. A snapshot of the current status of agriculture is critical at the onset of the process, and this should include details and data such as that listed in box 1.10.

IDENTIFY KEY CONSTRAINTS AND OPPORTUNITIES. CONstraints are factors that impede improved sector performance. Opportunities are strengths that can be built upon to improve sector performance. These relate to policies, institutions, governance, public investment programs, and the sociopolitical environment (see box 1.11).

DEVELOP ACTIONS TO OVERCOME CONSTRAINTS AND TAP OPPORTUNITIES. This section of the ADS will usually contain recommended actions in policy reform, institution building, decentralization, and investment in infrastructure and human capital. Proposed actions should be based on worldwide experience of both success and failure.

IMPLEMENTATION AND MONITORING. Implementation requires translating broad strategic directions into institution-, budget-, and region-specific action plans, focusing on the issues raised in an ADS, mobilizing the financing for projects and programs, building institutions, and mainstreaming agricultural development in national plans. Monitoring development impact is an integral component of an ADS, as it enables built-in flexible and effective response in the course of implementation.

\section{RECOMMENDATIONS FOR PRACTITIONERS}

Recommendations for practitioners involved in investments (see box 1.12) related to preparing agricultural strategies include:

- Develop a vision for agriculture shared by as many stakeholders as possible, with input from farmers themselves expressed through farmer and community organizations, local government, NGOs, and 
others. Such a vision expresses what a strategy is designed to achieve, without reverting to overly specific centralized planning targets of the past. The vision should be specific enough to guide public policies and programs and allow monitoring by tracking defined indicators to assess progress.

- Draw from global experiences, but recognize the context-specific characteristics that will shape the relevance of this experience to the local setting. Having strong and committed "champions," both in national governments and in key donor and civilsociety organizations, is critical to reaching early strategic agreement and focus.

- Seek support at all levels as a national ADS involves multisectoral issues, and engagement with a range of stakeholders concerned with agricultural development.

- In countries engaged in PRSP-like processes, link into the PRSP dialogue with government, private sector, and civil society representatives at national and local levels so that there is broad consultation at all stages of formulating strategy.

- Examine the current status of agriculture to establish the facts about rural poverty and the systems of production within which the poor operate. Identify key constraints that impede improved performance and opportunities on which to build and prioritize among actions for implementing the ADS.

- Exploit available models of the economy and the agricultural sector, or contemplate undertaking new modeling to better understand key intersectoral linkages, and to more realistically model growth paths implicit in the vision being addressed. The range of possible analytic models includes computable general equilibrium models, social accounting matrices, simplified growth models, and multi-market models). While some of these resources have been

\section{Box I.I I Illustrative data reflecting constraints and opportunities}

Policy

- Nominal/effective protection coefficients and resourcecost estimates for selected agricultural commodities.

- Subsidies on agricultural resources and inputs.

- Food security and welfare policy.

Institutional

- Price variability and postharvest losses for selected commodities.

- Methods available for managing price risks.

- Land tenure and ownership structure.

- Legal and regulatory environment (for example, contract enforcement).

- Technology generation and transfer systems.

Governance

- Degree of fiscal decentralization.

- Percentage of marketed inputs/outputs managed by public organizations.

Public investment programs

- Investment in basic rural infrastructure.

- Investment in agricultural research and extension.

Sociopolitical (in qualitative terms where applicable)

- Constraints on specific groups.

- Hidden costs of doing business.

Source:World Bank Internal Documents.

\section{Box I.12 Potential investments}

- Technical assistance for review of past experience and analysis of the current situation.

- Systems for gathering, processing, and storing data and information for ADS development.

- Technical assistance for developing approaches to ADS development that encourages and enables all stakeholders to participate.

Source: Authors. around for decades, their guidance and insight are very relevant to the formulation of a sound ADS (Tolley, Thomas, and Wong 1982; Timmer, Falcon, and Pearson 1983; Tsakok 1990; Belli et al. 2001).

- Develop effective mechanisms for monitoring the ADS implementation and development impact. 


\section{SELECTED READINGS}

Asterisk $\left(^{*}\right)$ at the end of a reference indicates that it is available on the Web. See Appendix 1 for a full list of Websites.

Timmer, C. P., W. P. Falcon, and S. R. Pearson. 1983. Food policy Analysis. Baltimore: Johns Hopkins University Press.*

Tolley, G. S., V. Thomas, and C. M. Wong. 1982. Agricultural Price Policies and the Developing Countries. Baltimore: Johns Hopkins University Press.

Tsakok, I. 1990. Agricultural Price Policy: A Practitioner's Guide to Partial-Equilibrium Analysis. Ithaca, N.Y.: Cornell University Press.

\section{REFERENCES CITED}

Belli, P., J. R. Anderson, H. N. Barnum, J. A. Dixon, and J.-P. Tan. 2001. Economic Analysis of Investment Operations: Analytical Tools and Practical Applications. Washington, D.C.: World Bank.

Gittinger, J P. 1982. Economic Analysis of Agricultural Projects. 2nd ed. Baltimore: Johns Hopkins University Press.

Government of the Republic of Uganda. 2000. Plan for Modernisation of Agriculture: Eradicating Poverty in Uganda. MAAIF and MFPED: Entebbe, Kampala.

Timmer, C. P., W. P. Falcon, and S. R. Pearson. 1983. Food policy Analysis. Baltimore: Johns Hopkins University Press.

Tolley, G. S., V. Thomas, and C. M. Wong. 1982. Agricultural Price Policies and the Developing Countries. Baltimore: Johns Hopkins University Press.

Tsakok, I. 1990. Agricultural Price Policy: A Practitioner's Guide to Partial-Equilibrium Analysis. Ithaca, N.Y.: Cornell University Press.
This Note was prepared by Jock Anderson, Sam Kane, and Gary Alex, based on "Reaching the Rural Poor; Annex 5 Guidelines for the Preparation of National Rural Development Strategies,"World Bank, 2003. 


\section{AGRICULTURE INVESTMENT NOTE}

\section{DEVELOPING CAPACITY FOR AGRICULTURAL SECTOR POLICY FORMULATION}

Government policies and investment strategies provide a critical base for agricultural sector development, and all governments need a capacity for such policy formulation. However, many developing countries lack the people and institutions needed for effective agricultural policy formulation. New efforts to build local capacity to promote agricultural development must take a broader view of the policy formulation process. It should involve different stakeholders from the public and private sectors and civil society in collaborative relationships, partnerships, and networks to guide public policy and investment decisions in the agricultural sector.

Addressing objectives of rural poverty reduction, environmental conservation, food insecurity, and economic growth requires a supporting policy environment built on sound analysis, research, and formulation and dissemination of agricultural policies. Many developing countries lack people and institutions able to provide this environment. Past capacity development efforts focused on investment in university-level education and short-term training of policy units. New approaches advocate collaborative projects, partnerships, and networking to address the current situation, which is characterized as follows:

- Institutional capacity to conduct sound agricultural policy analysis, formulation, and dissemination is weak, and even when individual capacity exists in the country, there is a dearth of effective mechanisms to use existing capacity.

- Investments in capacity have not always been successful, especially in improving institutional capacity.
- The need for effective capacity for policy formulation is becoming greater, as global trends increase challenges to the agricultural sector, and more participants (public sector, private sector, and civil society) are involved in developing this capacity.

\section{PUBLIC POLICY FORMULATION AND PLANNING}

Capacity for policy formulation can refer to individuals, organizations, or the country as a whole. For investment purposes, the main focus is likely to be capacity of organizations in the public sector (for example, policy units, public research organizations), private sector (universities, trade and farmer associations, consulting firms), and civil society NGOs, institutes).

Capacity of an organization refers to its ability to successfully apply its skills and resources to the accomplishment of its goals. Capacity development is a process of improving an organization's performance by increasing its potential in terms of its resources (human resources skills, infrastructure, finance, technology) and management (program and process management, strategic leadership, and networking and linkages). Capacity for agricultural policy includes capacity for policy analysis, policy formulation, and policy dissemination.

The balance of resources (infrastructure, technical, financial) and technical and managerial skills needed for policy formulation should be guided by external factors (political, social, legal, cultural context) and internal features (organization culture, incentives, and management style) of the relevant organization. While most projects focus on the capacity of government agencies, the private sector (including producer organizations) and civil society need capacity to participate in policy debates (capacity for policy communication, public awareness, and negotiating skills).

\section{BENEFITS}

Improved policy research can reduce wasteful allocation of resources, increase incomes of farmers and enterprises, better target the disadvantaged, improve farmers access to 
services and infrastructure, accelerate policy reforms, and improve the success of policy reforms (see box 1.13). Further, the improved communication among stakeholders associated with increased capacity improves negotiation and helps enhance transparency and ownership of adopted policies, resulting in more likelihood of success in implementation.

\section{POLICY AND IMPLEMENTATION ISSUES}

SuSTAINABILITY. Various factors explain the lack of sustainability of past investments in capacity development. First, the long-term nature of capacity development requires a multi-year commitment of funds that can be rarely expected from any single donor. Second, incentive and management problems are often a result of the lack of public sector reforms related to salaries, performance incentives, hiring and firing practices, and accountability processes in the public service. Where fundamental public administration reforms are required, objectives of capacity development projects should be revised and made more realistic. Third, narrow

Box I.13 Bangladesh: collaborative research and capacity strengthening

Capacity strengthening in food policy analysis was one of the four main components of the Bangladesh Food Policy Project funded by United States Agency for International Development (USAID) and implemented by International Food Policy Research Institute (IFPRI) in collaboration with the Ministry of Food between 1989 and 1994. The policy analysis during the project estimated the inefficiency and costs of the foodtargeted programs and enabled the government to abolish the food rationing system, reinforce its Food for Work and Vulnerable Group Feeding Programs, and introduce the new Food for Education program. Estimates of the internal rate of return for food policy research investments ranged from 110 to 260 percent. Other impacts included a saving of about US\$60 million per year from abolishing ineffective targeted programs, and increased school attendance of poor children by 27 percent for boys and 31 percent for girls. Studies were completed in a collaborative fashion with local organizations. The project strengthened the technical and analytical capabilities of local institutions, and showed that capacity-strengthening activities, strategically tied to information sharing, increases the acceptance and adoption of research results.

Source: Babu 1999. concepts of capacity (involving mainly analytical skills and the public sector) have often been used. Fourth, the use of long-term technical assistance can in some cases actually weaken capacity development efforts. Finally, lack of sustainability might be the result of linking capacity development to policy reforms.

Participation. Project design and evaluation needs to take into account the participants involved in capacity development, and the type of policy analysis, formulation, and dissemination they are pursuing. The identification of what capacity needs to be developed, for whom, and how, requires the participation of different stakeholders (especially the poor, women, and disadvantaged groups). Participatory methods for improved communication and building consensus are critical to improve policy formulation capacity. A demand-driven approach is most likely to identify the real capacity needs, and enhance the ownership and sustainability of the project and processes (see box 1.14).

InSTITUTIONAL CONSIDERATIONS. An important issue is the flexibility the public sector has to use existing country capacity in the private sector, NGOs, and civil society. Contracting out of certain functions (for example, agricultural policy research) to the private sector builds on existing nation-wide capacity. The use of competitive or matching grants can be an effective way of harnessing existing capacity in other organizations. Coexisting capacity development activities in the country should be coordinated such that efforts are not duplicated. When policy formulation for the agricultural sector depends on the inputs of several line agencies outside of the agricultural ministry, there may be issues as to where capacity development should be located to be most effective. In general, sound policy formulation relies on transparent debate and circulation of ideas, and policy units that have an appropriate level of autonomy from the central government.

ENVIRONMENTAL CONSIDERATIONS. Environmental issues are increasingly important in the design of agricultural programs and policies. Both public 
Box I.14 Ukraine: ownership in capacity building-the Ukraine Agricultural Policy Analysis Unit

In 1998, the World Bank and other donors began supporting the Ukraine Agricultural Policy Analysis Unit (APAU, whose primary role is to advise the Cabinet of Ministers on major issues of reform in agriculture. Collaboration between foreign technical assistance and highly qualified local experts has built strong local capacity for policy analysis. As the APAU arrangement is not under Ministry control, it can provide relatively unbiased recommendations. The unit has developed a reputation throughout the government as a consistent source of high-quality policy advice.

Because of this reputation, the APAU has been able to position itself to strongly influence the reshaping of the agenda of Ukrainian agricultural policy, by improving current policy outputs, facilitating policy coordination, and proposing more marketoriented approaches to current problems. Among the primary functions of the APAU has been provision of technical comments to draft agriculture-related laws as they are being developed. The unit has also published many papers, presenting original analyses of various sector issues, and has delivered, a wide variety of training activities. Currently, donors fund the professional staff and other expenses. It remains to be seen to what extent the unit capacity will be sustainable once foreign assistance is withdrawn.

Source:World Bank Internal Documents.

and private sector capacity is needed to address issues such as environmental impact analysis, trade and environment linkages, biodiversity, and genetically modified organisms.

\section{LESSONS LEARNED}

ConteXt, CONTENT, AND TIME DimENSIONS. Capacity development for policy formulation depends on the context in which the capacity is developed, the content of the capacity being developed, and the time horizon in which the process takes place. Confusion among these might lead to the wrong choice of capacity development activities. Context can relate to policy reform (for example, agricultural input market liberalization), structural change (movement from central planning to market orientation), strategy formulation (10-year strategy for agricultural research), or evaluation of past policies (policy review and impact analysis) and will determine the skills and amount of time needed. Similarly, emphasis will differ with regard to analysis, coordination, dissemination and awareness, negotiation, policy evaluation, and network management, depending on the specific context. Choices made as to the time horizon (short to long) of the capacity development effort will depend on resources available and desired outputs.

TeChnical AND PROCESS assistance. Capacity development projects should use a combination of technical and process assistance. An exclusively technical approach is not appropriate when policy formulation is concerned, because of the need to involve different stakeholders who may not have technical backgrounds. Even for those who do, the process of analyzing, formulating, and disseminating policy is as important as technical skills. A combination of methods and approaches to improve both technical and managerial skills is necessary for effective capacity development.

COllaborative aRRANGEMENTS AND COMMUNICATION. Methods of promoting collaboration and communication include hands-on research, coauthorship of reports and presentations, joint design and implementation of field work, and joint planning of workshops and training activities (see box 1.15). Outsourcing of analytical tasks and dissemination activities can promote collaboration between the public and private sectors. Policy research in particular should be conducted by academic institutions and private consulting firms - the capacity of which must be built in most cases.

Monitoring and eValuation. Monitoring and evaluation (M\&E) of capacity development should clarify "what capacity" is to be monitored and how this is to be measured. Also, the purpose of M\&E and how results will be used should be clear-if M\&E is regarded mainly as a surveillance system rather than as a learning 
Box I.15 Viet Nam: collaboration for increased agricultural policy analysis capacity

Since the late 1980s, Viet Nam has been developing capacity in policy formulation appropriate to the market system. Capacity building approaches in the agricultural sector have included short- and long-term training courses in-country and abroad, curricula development in the university, strategy formulation, policy analysis training, adoption of new research programs, and restructuring of the Ministry of Agricultural and Rural Development. These have been supported by different donors and have involved collaborative arrangements with various universities and research centers under the umbrella of the Consultative Group on International Agricultural Research (CGIAR).

One of the most successful outcomes has been the renewal of the Information Center for Agriculture and Rural Development located in the ministry. The center includes some of the best agricultural policy analysts in Viet Nam, is responsive to the policy formulation needs of decisionmakers, and has established a network including research organizations, universities, international agricultural research centers, and local experts.

Source: Authors.

tool for improvement, it is likely that the overall process of M\&E will fail. The methods, baselines, and indicators used for M\&E should be clearly defined and agreed before starting the process, and agreement should be reached as to who will conduct the M\&E. This will minimize conflicts of interest and improve the reliability of information obtained.

\section{RECOMMENDATIONS FOR PRACTITIONERS}

Capacity building investments should (see box 1.16):

- Understand the context of the capacity development initiative as this will largely determine the appropriate project content and time frame.
- Undertake extensive consultations with stakeholders in the government, private sector, academia, and civil society to develop a sense of what is needed and by whom, what is available, who will support investments, and how these will be monitored.

- Promote participation and ownership through national workshops, close association with project designers, follow-up meetings, and sharing the initial project documents.

- Ensure that investment initiatives have builtin flexibility that allows periodic planning.

- Involve a consortium of consulting service providers, as no single consulting service provider is likely to be able to meet all the requirements for capacity building.

- Provide for contracting-out of research activities and competitive grants during project implementation.

- Ensure that sufficient management oversight is provided for policy-related investments and that adequate resources are available for donor and agency coordination.

- Explore possibility of cofinancing both within the same time period and over time, so as to improve long-term support to capacity development. 


\section{SELECTED READINGS}

Asterisk $(*)$ at the end of a reference indicates that it is available on the Web. See Appendix 1 for a full list of Websites.

Capacity.org. 2003. "Evaluating Capacity Development." Capacity.org newsletter, no. 17

(April). http://www.capacitry.org.

ECDPM. 1998. Approaches and Methods for National Capacity Building: Report of a Workshop. Maastricht: European Center for Development Policy Management.*

IFPRI. 2000. "Best Practices: Strengthening Policy Research Capacity around the World." IFPRI, Washington, D.C.*

Rice, E. 1999. "Capacity Building in the Agricultural Sector in Africa." Operations Evaluation Department Report Precis 180. World Bank, Washington, D.C.*

World Bank. 2001. 'Public Expenditure Management and Accountability: Evolution and Current Status of World Bank Work." World Bank, Washington, D.C.

\section{REFERENCES CITED}

Babu, S. 2000. "Impact of IFPRI's Policy Research on Resource Allocation and Food Security in Bangladesh." Impact Assessment Discussion Paper 13. International Food Policy Research Institute, Washington, D.C.

This note was prepared by Francesco Goletti $(\mathrm{ACl})$ with inputs from Derek Byerlee and Gary Alex. 
AGRICULTURAL INVESTMENT NOTE

\section{REFORM OF AGRICULTURE SUBSIDY AND PROTECTION POLICY}

Past programs for providing support to farmers (for example, input subsidies, guaranteed prices, border protection) have been market distorting and highly inefficient. Such policies are typically costly to consumers, detrimental to the environment, and regressive in terms of domestic income distribution. Impacts on world markets have significant consequences for developing countries where agriculture is of major economic importance. Key elements for policy reform in this area include: reducing input subsidies, decoupling support from production, converting existing tariffs to ad valorem forms, reducing the overall level of support/protection, and restructuring of the classification and commitment system governed by the WTO.

Support to agricultural producers can be provided through (1) border measures such as import tariffs and restrictions that raise domestic prices (thus financed by consumers), (2) export subsidies (generally taxpayer funded), and (3) subsidies to farmers (on both agricultural inputs and output) that are also financed by taxpayers. While these policies are generally intended to support economic development objectives, the impacts of support policies extend across international borders

\section{Box I.I7 OECD Producer Support}

Average producer support equivalents over 2000-02 equated to US\$47 billion (United States), US\$92 billion (European Union), and US\$48 billion (Japan) (total support being considerably higher). These producer supports also vary greatly among commodities: rice $8 \mathrm{I}$ percent, sugar 45 percent, wheat 36 percent, beef and veal 36 percent, and poultry 16 percent. On average, prices received by OECD farmers were 31 percent above world prices and almost one-third of total farm receipts originated from government programs. Of this support, 69 percent is administered via price support and output payments; the most distorting mechanisms.

Source: OECD 2002. and can have major negative implications for producers, consumers, and the environment, both domestically and abroad. Agricultural support policies, especially in Organization for Economic Cooperation and Development (OECD) countries, lower the world price of many commodities and increase world price variability, both of which are damaging to developing countries. Counter-cyclical policies in rich countries tend to increase resource transfers to farmers when world commodity prices decline, leaving producers in developing countries to bear the brunt of fluctuations.

Protection for agricultural producers has remained very high, especially in the large OECD economies (see box 1.17). This support has closed markets that would otherwise have been available to developing country producers, and led to surpluses that have been exported (sometimes using export subsidies) onto world markets, depressing world prices. Average levels of border protection (tariffs and nontariff barriers) are also high in developing countries, where governments have intervened heavily in commodity and input markets, through parastatals and marketing boards, and with price supports and input subsidies.

\section{BENEFITS}

The benefits to a country from reform of its support policy (irrespective of reform in other countries) are substantial and include: a freeing of public resources for other uses; greater overall economic efficiency; and the transition to more dynamic and innovative farming systems that can adapt more easily to changing market signals. Further, reform at the global level will result in even greater benefits - the estimated annual gain to developing countries from liberalization of agriculture and food by highincome countries is more than US\$30 billion and an estimated US\$114 billion from developing countries' own liberalization of agriculture and food trade policy (World Bank 2002).

However, there may be losers in the overall reform process and the effects will differ across countries. Countries that are net importers of 
agricultural products-and consumers in all countries that do not liberalize-will lose as prices rise. These losses will be tempered to the extent that agricultural production and exports of some products expand, and price volatility declines. Also, some producers will face increased production costs as input subsidies are removed. However, overall, unilateral liberalization will usually result in significant net benefits to the country, with important poverty reduction potential, despite some groups being made worse off in the short run.

\section{KEY POLICY AND IMPLEMENTATION ISSUES}

TAX ON DEVELOPMENT. The collective impact of policies of those countries providing large support to domestic producers, has significant impacts for those countries that do not provide comparable support (whether by choice or otherwise). Industrial country agricultural protection blocks growers in developing countries from diversifying out of traditional crops as a way of increasing value and reducing vulnerability to price fluctuations. The escalating tariff structure in industrial countries-with higher tariffs for processed than for primary goods-magnifies the protection of domestic processing industries above the nominal tariff rate. In the European Union (EU) and Japan, fully processed manufactured food products face tariffs twice as large as products in the first stage of processing. These policies amount to a tax on development.

INPUT SUBSIDIES. Governments frequently provide support to farmers through subsidized inputswater, power, credit, fertilizer, seed, and chemicals-that distort production incentives and impose net costs to taxpayers and consumers. WTO rules allow the continuation of some production subsidies that are non or "minimally" trade distorting, such as for general government services (research, disease control, infrastructure), structural adjustment assistance, and regional assistance programs. In general, domestic support should be redirected to the areas where greater public good elements lieinfrastructure and institutions that enable efficient private sector supply of inputs at prices that enable producers to compete in global markets. Sound economic analysis must underlie decisions to continue any input support policy.

POLITICAL NATURE OF SUPPORT AND BURDEN ON TAXPAYERS. Agricultural support poses huge out-ofpocket costs to taxpayers and consumers. During 2000-02, the average annual total support to agriculture in OECD countries reached US\$315 billion. Of that, the EU provided US $\$ 113$ billion, the United States US\$95 billion, and Japan US\$65 billion. In India, input subsidies alone averaged about 9 percent of agriculture GDP during the 1990s (Gulati and Narayanan 2003). Although fiscal transfers are lower in developing countries (due in part to an inability of the public sector to finance these), protection levels in the form of trade barriers (which require less financing) are common. Such trade barriers often place a major burden on poor consumers, especially where such protection is directed at traditional food crops. Although it is often evident that resources used for support and protection would be better allocated elsewhere, there is strong political pressure to maintain support to primary producers. This is in part because the (greater) benefits of liberalization are more diffuse than the concentrated benefits of protection, so the incentives for the beneficiaries to lobby for liberalization are correspondingly less.

LOW TRANSFER EFFICIENCY. In terms of income transfer efficiency (the percentage of consumer and taxpayer transfers that farmers actually receive), no support policy linked to agricultural activity is efficient. On average, only 25 percent of producer support actually finds its way into the producer's pocket. Only 25 percent of production subsidies and 20 percent of input subsidies benefit farmers (OECD 2002).

INEQUITABLE DISTRIBUTION OF BENEFITS. Large farmers and landowners get a much larger proportion of benefits than small-scale farmers. In Europe the largest 4 percent of farmers receive 21 percent of support and have per-capita in- 
comes that are more than double the average EU wage (Podbury 2000). In the US, the largest 5 percent receive over 20 percent of government payments. Similar trends exist in developing countries. This is largely because when support is given through either an artificially high price (for example, from import restrictions, export subsidies, or direct payments per ton of production) or through input subsidies, the biggest beneficiaries are the biggest producers, who are also the biggest users of inputs.

AdVerse environmental impacts. Agricultural subsidies and protection can lead to excessive use of chemicals and fertilizers that can harm the environment. The high price paid to rice farmers in Japan, for example, encouraged overuse of insecticides to protect crops. In 1993, although Japan produced only 3 percent of the world's rice, their share of global expenditure on rice insecticides was 34 percent. Reducing distortions forces farmers to base input and output decisions on real economic costs, thus promoting sound farming practices and sustainable natural resource management.

INTERNATIONAL AGREEMENTS. New multilateral trade negotiations were launched at the Fourth WTO Ministerial Conference held in Doha in 2002, with the objective of significantly reducing all types of barriers to agricultural trade including: barriers to market access, export subsidies, and trade-distorting domestic support. Developing country policy reforms will take place within this context, but will continue to be influenced by unilateral political realities (see box 1.18).

Domestic agricultural support is classified in the WTO Uruguay Round Agreement on Agriculture (URAA) using a system of "boxes" that rank programs according to their effect on trade (see box 1.19). Policies deemed as trade distorting are put in the "amber box" which consists of direct subsidies and price support reflected in the gap between a fixed world reference price and domestic support prices. For industrial (developing) countries, amber box support was subject to a 20 (13) percent reduction by 2000 (2004).

\section{LESSONS LEARNED}

Responding to protectionism in the North. The continued high subsidies to farmers in many industrial countries makes agricultural trade reform in developing countries much more difficult, as reducing their import barriers appears to be "unilateral disarmament." The question of whether this kind of reaction is good development policy is a complex issue. Continued protectionism in a developing country represents a tax on their consumers, and in the case of many food products, this falls disproportionately on the poor. However, if it is likely that industrial country subsidies on a product will be reduced or eliminated in the near term, with a consequent rise in its world price, temporary protection for domestic producers may be justified. Given the slowness in global trade negotiations, in most cases it is economically prudent for countries to adopt policies (and producers to allocate resources) that accept prevailing international prices, distorted though they may be. It must be recognized, however, that this may be politically difficult and require considerable policy dialogue among a range of stakeholders. In any case, policies of the industrial countries cannot be used to rationalize developing country tariffs higher than the percentage by which these policies depress world prices, which (about 5-20 percent for most products). Decoupled income support programs (payments that are not linked to product prices, input use, or outputs) can be important for making the process of tariff reduction more palatable for producers.

BRING AGRICULTURAL PRODUCTS INTO THE GENERAL FRAMEWORK OF AD VALOREM TARIFFS. Reducing tariff peaks on products important to developing countries is critical. Although developed countries boast average ad valorem tariffs of less than 5 percent on manufactured goods, they still have very high tariffs on many agriculture products. Specific tariffs - a tax expressed per unit of quantity - are nontransparent, because their impact on relative prices changes frequently and unpredictably, as world prices change. They also tax lower-value products relatively more, thereby creating a systematic bias against developing country products. 
Tariff quotas (application of one level of tariff to imports within a certain quota, and a higher level of tariff to imports over that volume) result in a system whereby imports within the quota are very profitable, generating a wasteful use of resources geared toward obtaining import quotas. Both specific tariffs and tariff quotas should be converted into ad valorem tariffs-that is, tariffs calculated on some percentage of the border prices. Tariff escalation also needs to be significantly reduced or eliminated by bringing down higher tariffs on processed products (Hewitt 2003).

UNDERTAKE STRONG COMMITMENTS TO REDUCE TRADEDISTORTING DOMESTIC SUPPORT. Effective reform of support policies across industrial and developing countries will require changes to current methods of measurement and classification of support as well as strong commitments to reductions, and would be aided by changes to current methods of measurement and classification of support. Many stakeholders (including donors, governments, and the private sector including trade associations and producer groups) have a role in the policy analysis, advocacy, and negotiations processes related to this. Key investment areas for the public sector are outlined in box 1.20. Potential changes that developing countries, supported by donors, might advocate relate to both industrial countries and the developing countries themselves and include:

- Commitment to reduce support on a policy type and commodity sector basis, rather than based on a single aggregate measurement of support.

- Further reduction of amber box subsidies (for example. to a maximum of 5 percent of the value of production at world prices), with a commitment to extend that ceiling to each individual commodity sector in the future.

- Tighter criteria for policies included in the green box, with a cap on these at 5 percent of the total value of agricultural production, as measured at world prices, or current levels of expenditures on the measures included in the redefined green box, whichever is lower.
Box I.18 What happened at Cancun?

The Cancun World Trade Organization (WTO) Ministerial Meeting in September 2003 was originally planned to be a midterm review of progress in the Doha Round negotiations. Instead, because so little progress had been made in key areas, it became an attempt to break the impasse. Ultimately, it failed to do so. The proximate cause of the failure was disagreement over whether to include in the Doha agenda the "Singapore Issues" of investment, competition policy, transparency in government procurement, and trade facilitation. But there is a widespread feeling that a compromise could have been reached in this area had not the atmosphere been poisoned by the stalemate in agriculture. The EU and US made a joint offer, but developing countries considered it too little, too late, and with too many loopholes that would allow the rich countries to avoid serious reform. For their part, the developing countries were not very forthcoming; they made many demands, but few offers. What is now needed to put the negotiations back on track is a grand bargain in which both developed and developing countries play their part.

Source: Authors.
Box 1.19 Domestic support in agriculture: the World Trade Organization's colored boxes

AMBER BOX -includes all domestic support measures considered to distort production and trade, except those in the blue and green boxes. These include measures to support prices, or subsidies directly related to production. Members are required to reduce that support unless current levels are already low (5 percent of agricultural production for industrial countries, 10 percent for developing countries).

BLUE BOX - is the Amber Box with conditions that reduce distortion. Any support that would normally be in the Amber Box is placed in the Blue Box if the support also requires farmers to limit production. At present there are no limits on spending on Blue Box subsidies.

GREEN BOX - are subsidies that do not distort trade or at most cause minimal distortion, such as research and extension services. These are government funded and do not involve price support, but include direct income support for farmers, which is "decoupled" from current production levels or prices. They also include environmental protection and regional development programs. There are no limits on Green Box subsidies.

Source:WTO. 


\section{Box I.20 Potential investments}

- Analytical studies to identify the instances where subsidized inputs or price support might be appropriate.

- Support for the transition away from protection to market-led production systems.

- Training for policy makers and representatives in international trade regimes and negotiations.

Source: Authors.

\section{SELECTED READINGS}

Asterisk $\left({ }^{*}\right)$ at the end of a reference indicates that it is available on the Web. See Appendix 1 for a full list of Websites.

Barry, P. J. 1999. "Risk Management and Safety Nets for Farmers." Choices 14 (3): 1.

Ingco, M., and D. Nash, eds. In Press. Agriculture and the WTO: Creating a Trading System for Development. Conference Edition. Washington, D.C.: World Bank.

World Bank. 2003. "Agricultural Policies and Trade." In Global Economic Prospects: Realizing the Development Promise of the Doha Agenda. Washington, D.C.: World Bank.*

World Bank. 2003. Market Access: Agricultural Policy Reform and Developing Countries. Trade Note 6. International Trade Department. World Bank. Available at www.worldbank.org/trade.

World Bank. 2003. "Export Subsidies: Agricultural Policy Reform and Developing Countries". World Bank. Available at www.worldbank.org/trade.

World Bank. 2003. "Domestic Support for Agriculture: Agricultural Policy Reform and Developing Countries" World Bank. Available at www.worldbank.org/trade.

\section{REFERENCES CITED}

Gulati, A., and S. Narayanan. 2003. The Subsidy Syndrome in Indian Agriculture. New Delhi: Oxford University Press.
Hewitt, A. 2003. "The Reform of Agricultural Policies in OECD Countries: A Developing Country Perspective." World Bank, Washington, D.C. Processed.

OECD 2002. "Agricultural Policies in OECD Countries: Monitoring and Evaluation 2002." OECD, Paris.

Podbury, T. 2000. "US and EU Agricultural Support: Who Does it Benefit?" ABARE Current Issues. (October): 1-5.

World Bank. 2002. Global Economic Prospects and the Developing Countries 2002. Washington D.C.: World Bank.

WTO. Domestic Support in Agriculture: The Boxes. http://www.wto.org/english/ tratop_e/agric_e/agboxes_e.htm.

This note was prepared by Sam Kane and John Nash with inputs from Derek Byerlee and Gary Alex. 
AGRICULTURE INVESTMENT NOTE

\section{FACILITATING EFFICIENT ADJUSTMENT TO LIBERALIZED TRADE}

Trade liberalization has potential to yield considerable benefits to the poor in developing countries, but often requires adjustments that are difficult or painful to execute effectively. Making the transition away from inefficient protected domestic industries to commercially oriented production based on global market forces presents several challenges, both economic and political. These include improving competitiveness by overcoming existing policy biases within agriculture, participating effectively in global negotiations, managing acute price volatility, providing safety nets for the poor that are adversely affected by liberalization, improving the investment climate to assist emerging profitable industries, and retraining of the workforce.

Rapid growth of the world economy has been driven in part by the even faster rise in international trade resulting both from technological developments and concerted efforts toward trade liberalization. Trade liberalization is the reduction of trade barriers to allow price signals in world markets to guide the allocation of resources. It involves the deregulation of both domestic and international market environments such that price signals are based primarily on economic forces (demand and supply) that foster the development of competitive markets. As a result of trade liberalization, the relative price structures for both agricultural inputs and outputs can change substantially, and this, coupled with the decline in prices for traditional commodities, can have major implications for producers.

While trade liberalization can potentially help the poorest move from extreme poverty, liberalization alone will not necessarily contribute to growth or poverty reduction and may in fact make the poor worse off if not supported by focused transitional policies and appropriate investments for adjustment. Deregulation in isolation of complementary policy and investment initiatives may leave gaps that the private sector is unwilling to fill, and may further marginalize the poor from participation in markets. These challenges provide a rationale for public-sector intervention to assist with the transition and adjustment process. The means by which this adjustment can be facilitated are many and include transitional income support payments, formal market-based mechanisms to manage risks, and general industry assistance for adjusting from one production system to another. Many of these issues are addressed elsewhere in this Sourcebook, and this note will focus on those that are more directly related to trade policy.

\section{BENEFITS}

Outward-oriented countries tend to consistently grow faster than ones that are inward-looking. The increase in aggregate welfare of developing countries from global agricultural trade reform could be some US $\$ 142$ billion annually. Most of these gains would come from trade policy reforms within developing countries themselves (about US\$114 billion). Developing countries stand to gain significantly because their exports face higher barriers, and the agricultural sector is relatively large.

Poor consumers stand to benefit the most through increased availability and variety of food at lower prices. And since poor consumers spend more of their limited incomes on food, they benefit disproportionately, making food market liberalization a very pro-poor policy. Producers benefit from the emergence of profitable new production opportunities that arise when inappropriate subsidies and barriers to trade are reduced. Farm incomes can increase both from higher prices of traditional products, and from diversification to new products that become profitable. Further, input costs can fall and access to new technologies can be improved when input markets are liberalized. Some producers whose govern- 
ments heavily subsidize inputs may lose (via increased production costs), at least in the short run, but stand to benefit in the long run provided they have an underlying competitive advantage in some products. Exit strategies or permanent transfers may be necessary for those that do not.

\section{POLICY AND IMPLEMENTATION ISSUES}

Changing architecture of WORLD trade. While trade barriers in industrial countries are generally low, the remaining barriers are concentrated on agricultural products and labor-intensive manufactures in which developing countries have a comparative advantage. As agriculture has a larger tradable component than most sectors, the trade environment and trade policy strongly affect the agriculture sector. New multilateral trade negotiations were launched at the Fourth WTO Ministerial Conference, held in Doha in 2001, with the objective of significantly reducing all types of barriers to agricultural trade, including trade-distorting domestic support. For developing countries, the capacity to effectively participate in these negotiations must be increased so that they are fairly represented, and their interests and concerns relating to agricultural trade can be presented in global efforts to achieve meaningful progress in global trade policy reform.

Policy biases against agriculture. Despite protecting domestic producers, developing countries have in the past typically taxed their agricultural sectors, to some extent directly (for example, by taxes on exports or controlled food prices), but even more so, indirectly, through trade barriers and macroeconomic policies that overvalued the exchange rate, and turned the internal terms of trade against agriculture. Commodity and input markets have been characterized by heavy government interventions through centralized input procurement measures (government parastatals and marketing boards), input subsidies, quotas, taxes on exports of agricultural commodities, and various regulatory rules. These biases all reflect market and trade regimes that are far from "liberal" in the sense that they are highly regulated, and economic signals are distorted by direct and indirect public sector interventions.

Transitional issues. The resistance to policy changes presented by adversely affected groups in part reflects barriers to their exit from inefficient production systems, as well as barriers to their participation in new opportunities as they emerge. Imperfectly functioning capital and labor markets, inadequate public services, poor infrastructure, and research and extension systems that are biased toward traditional (protected) production systems, all limit the ability to transform farming systems and improve resource liquidity including labor mobility. Poorer farmers may be among the most adversely affected. Older persons, those who are less educated, and those with human capital specific to farming are particularly affected. The public sector must promote the development of supporting institutions and infrastructure, and of retraining programs for adjustment.

INCREASED PRICE VARIABILITY. Variable levies and quotas, as means of stabilizing the domestic price of tradable food commodities shifted domestic instability of prices to world markets. The URAA completed in 1994 had some effect in reducing the trade-distorting effects of such policies, and the Doha Round is expected to result in much more significant reforms. At the national level, there has been increased transmission of global price movements to domestic producers and consumers, which is further complicated by other factors such as exchange rate fluctuations, climatic factors and poor infrastructure. A challenge is to develop effective ways for farmers to manage price risks while at the same time avoiding distorting price signals and production incentives.

Changing PRICE STRuctures. The biggest farm level implication of trade liberalization and the movement toward competitive markets is typically the adjustments of relative prices (both for agricultural inputs and outputs) that result from the removal of commodity-specific support or protection, either at home or 
abroad. Existing production systems that have provided often-stable livelihoods for generations can suddenly become unprofitable, but new opportunities open up to producers for redeploying resources used in the now inefficient industries. The key issue for policymakers is to recognize where and when adjustment is essential, and to provide an environment in which the exit of inefficient farmers and entry to new market opportunities is enabled.

\section{LESSONS LEARNED}

There are several means of addressing issues associated with trade liberalization and with assisting the transition, such that potential benefits for the poor are fully exploited. Informal measures such as growing a variety of crops with different market and climatic risks can assist the transition to a commercially oriented agricultural sector. Contract farming and off-farm employment are also important. Some of the more formal measures include: direct income support, agricultural insurance, and marketbased price risk management. These are touched on here and discussed in greater detail in other chapters of this Sourcebook.

INCOME SUPPORT AND SAFETY NETS. By decoupling support from prices, direct income support programs can provide for transition from pricedistorting subsidies to an efficient and liberalized sector. Payments should be fixed and guaranteed (usually per hectare up to a maximum), and not influenced by ex-post realizations of market conditions. Features that will increase the effectiveness of a decoupling scheme include: make the payment program transitory and for adjustment purposes only; impose no requirements on input use or on outputs; implement credible and time-consistent policies with no changes in the eligibility or payment rules; discontinue all other programs linked to price support; and bind payments and time frame into WTO to prevent reversal or agreements. Public works programs, incentive systems for exit, government distribution of resources in-kind, cash payments, and social funds can all be used to help those who are most likely to be adversely affected through the transition phase.

PRICE BANDS. Price bands and price floors are tools that have been used to manage price risks resulting from moves toward trade liberalization. Price floor schemes aim for the elimination of the worst-case scenarios associated with several concurrent years of especially low world prices. For specific "sensitive" commodities, a minimum world price or threshold level might be defined, below which a government would commit itself to intervention in order to maintain the domestic price received by producers. The threshold price should be based on the minimum-average cost of the least-cost international exporter. This leaves unhindered the development of market-based price risk management activities that programs of "price stabilization" have impeded. Similarly, many countries are interested in price ceilings to protect poor consumers from temporary sharp jumps in prices of food staples. These schemes should be approached with care, as although they are based on solid theoretical underpinnings, experience to date has been mixed.

WTO SAFEGUARDS. When there is either an abrupt and large inflow of imports, or a sudden decline in import prices that threaten a country's import-competing sector, WTO safeguards can be applied as a means of assisting producers in the adjustment process. These measures (see box 1.21) permit the temporary suspension of WTO obligations.

COMPLEMENTARY PUBlic INVESTMENT TO FACILITATE TRANSITION TO EFFICIENT SYSTEMS. TO encourage the necessary overall reallocation of resources that is required to ensure sustainable growth from trade and market liberalization, establishment of a supportive investment environment is critical, as is the means to empower the poor to participate in it. Trade reform must often be combined with public expenditure reform that encourages productivity growth, competitiveness, reduced transaction costs, and market development. Key issues largely relate to overcoming supply side constraints and include: 
Box I.2I WTO safeguard measures for countries adjusting to liberalization

- Anti-dumping measures (based on injury to a domestic industry) to counteract the effects of firms using price discrimination to lower export prices below home market prices.

- Countervailing duties also based on injury to a domestic industry, but apply to the subsidization of the exporting country's government.

- Emergency temporary safeguards that are immediately applicable without formalities in the event of imports threatening serious injury to domestic industries.

- Other measures include those related to balance of payments, "general waivers," and modifications of schedules.

Source: Foster and Valdés, in press.

- Building analytical capacity (in terms of understanding policy reform options and impacts with respect to substitution effects, supply response, exchange rate effects) for agricultural policy development, including the removal of the policy biases (that is, by reducing explicit and implicit taxes on agriculture and reform of public sector marketing arrangements), and developing macroeconomic policy that complements trade policy (for example, maintenance of a stable real exchange rate at a realistic level-avoiding overvaluation).

- Upgrading public sector institutions related to markets and trade-including customs, quality, grades and labeling standards, certification agencies, financial supervision agencies, contract enforcement regulations, and property rights laws.

- Development of private sector institutions critical for markets-namely risk management systems (agricultural insurance, methods for price risk management), agencies for product certification, trade associations and other frameworks for private sector organization and group action, rural finance systems (including inventory credit), and mechanisms for supply chain coordination (for example, contracting and vertical integration).
- Development of physical infrastructure and industries essential to trade and the transition to alternative production systems, such as transport, communications, financial sector, and business services, particularly through introduction of regulatory policies that, where feasible, harness competition. Efficient and integrated input and output markets will only evolve if ineffective parastatals are privatized or abolished. As for institutions, supporting industries and infrastructure may require various forms of public-private cooperation.

- Retraining labor so that displaced workers can develop new skills to productively fill emerging employment opportunities.

Research and extension systems often need reform to become more market-driven in order to provide farmers with technologies relevant to the new production opportunities. Elimination of testing requirements for imported and domestically produced inputs (seeds, fertilizers, and pesticides) not related to environmental or sanitary or phytosanitary threats will also ensure that farmers can readily access a wider range of world-class technologies.

\section{RECOMMENDATIONS FOR PRACTITIONERS}

Investments associated with facilitating adjustment to trade liberalization (see box 1.22) should:

- Ensure that the interests of the agricultural sector and consumers as a whole are represented in trade policy negotiations at global and regional levels.

- Generally, accept the world price structure as a long-term characteristic of the environment, and ensure that resource allocation decisions are based on this, regardless of whether the prices are depressed by the policies of other countries.

- Provide support programs as temporary transitional tools. Industry-specific support 
should only be used where comparative advantage exists, and reductions in global barriers are highly likely in the near future.

- Consider using decoupled income payments as a safety net (for example, support payments based on land area rather than production level) to cushion farmer incomes from precipitous price declines when other forms of support are phased out. Ensure that income payments are transitional and do not become entitlements.

- Promote the development of supporting industries, institutions, and infrastructure.

- Develop training programs to enable poor farmers and agricultural workers to redeploy their skills to new industries. Training should endow workers with skills that are flexible and so can be adapted to various industries over time.

\section{SELECTED READINGS}

Asterisk (*) at the end of a reference indicates that it is available on the Web. See Appendix 1 for a full list of Websites.

Baffes, J., and J. Meerman. 1998. "From Prices to Income: Agricultural Subsidization without Protection?" The World Bank Research Observer 13 (2): 191-211.*

Dollar, D., and K. Aart. 2001. "Trade, Growth, and Poverty." Policy Research Working Paper 2615. World Bank, Washington D.C.*

Ingco, M., and D. Nash, eds. In Press. Agriculture and the WTO: Creating a Trading System for Development. Conference Edition. Washington, D.C.: World Bank.

Sadoulet, E., de Janvry, A., and B. Davis. 2001. "Cash Transfer Programs with Income Multipliers: PROCAMPO in Mexico." FCND Discussion Paper 99. IFPRI, Washington, D.C.

Valdés, A. 1998. "Trade Policy Reform and Agriculture." In J. Nash and W. Takacs, eds.,

\section{Box I.22 Potential investments}

- Capacity building and advocacy to promote a fair liberalization process in international trade negotiations.

- Assistance for governments to develop income support and safety net programs that help groups made worse off by liberalization.

- Technical assistance in the development of risk management mechanisms that protect viable industries from short-term acutely low prices.

- Investments to develop retraining programs and reform research and extension systems.

- Technical assistance and capacity building to improve the investment climate, key administrative services, and critical infrastructural needs.

- Technical assistance to help small-scale farmers in developing countries use market-based risk management instruments.

Source: Authors.

Trade Policy Reform: Lessons and Implications. Washington DC.: World Bank.*

World Bank. 2002. Global Economic Prospects and the Developing Countries 2002. Washington D.C.: World Bank.*

\section{REFERENCES CITED}

Foster and A. Valdés. In Press. "Managing Potential Adverse Inpacts of Agriccultural Trade Liberalization." In M. Ingco and D. Nash, eds., Agriculture and the WTO: Creating a Trading System for Development. Conference Edition. Washington, D.C.: World Bank.

This Note was prepared by Sam Kane and John Nash with inputs from Derek Byerlee. 


\section{AGRICULTURE INVESTMENT NOTE}

\section{ADJUSTMENT LENDING FOR AGRICULTURE POLICY REFORM}

Adjustment lending for agriculture (lending to support policy and institutional change for sustained economic growth) expanded greatly in the late 1980s and 1990s, but included relatively little focus on poverty in project design and analysis. Some programs have tended to overrely on conditionalities and tranching. Challenges for future investment in agricultural adjustment programs include improving analytical capacity, building government ownership and support, improving the design and application of repayment conditions, ensuring that the poor benefit, and improving collaboration with other donors. Within the World Bank, new operational policy guidelines are expected to improve adjustment lending (or "development policy lending") and eliminate some of the past restrictions on these programs.

Box I.23 Poverty and social impact analysis

Poverty and social impact analysis (PSIA) involves the analysis of the distributional impact of policy reforms on the well-being of different stakeholder groups, with a particular focus on the poor and vulnerable. Important elements that PSIA needs to address include:

- Identification of the reforms likely to have the most significant impact

- Identifying stakeholders that influence the adoption and implementation of the policy and which are being influenced.

- Understanding transmission channels by which stakeholders be affected.

- Assessing institutions.

- Gathering data and information.

- Analyzing impacts

- Contemplating enhancement and compensation measures

- Assessing risks

- Monitoring and evaluating impacts

- Fostering policy debate and feeding back into policy choice.

Source: Arulpragasam et al. 2003.
After focusing on major infrastructure investments in the 1960s and 1970s, attention turned to the "software" side of development and the provision of services and the policy environment for development. Policies that distorted private sector investment and activity, especially with regard to the marketing of products and inputs, were an obvious constraint to growth during the 1980s. Strategies evolved for dealing with these distortions through loans conditional on market-liberalizing policy changes. These loans, variously called "structural adjustment loans" (SALs) and "sectoral adjustment loans" (SECALs), were devised largely to encourage the government to retreat from private sector activities and to facilitate a more open economy. Agricultural sector adjustment loans (ASALs) were designed specifically for the agriculture sector.

\section{LENDING FOR AGRICULTURAL SECTOR ADJUSTMENT}

Adjustment loans aim to support policy and institutional changes needed to create an environment conducive to sustained and equitable growth. Adjustment operations generally aim to: promote competitive market structures (legal and regulatory reform); correct distortions in incentive regimes (taxation and trade reform); establish appropriate monitoring and safeguards (financial sector reform); create an environment conducive to private investment (judicial reform, adoption of a modern investment code); encourage private sector activity (privatization and public-private partnerships); promote good governance (civil service reform); and mitigate short-term adverse effects of adjustment policies (establishment of social protection funds) (Jayarajah and Branson 1995). Eligibility for an adjustment loan requires agreement on policy and institutional reform actions and satisfactory macroeconomic management. Funds are disbursed in one or more stages (tranches) into a special deposit account, with tranches released when the borrower complies with stipulated conditions such as the passage of reform legislation, the achievement of certain performance benchmarks, or other evidence of progress toward a satisfactory policy framework. 
Adjustment operations accounted for 17 percent of total Bank lending in the 1980s, and increased to 29 percent of total lending during the 1990s. This is partly attributable to increased lending in the post-Soviet bloc countries, where the need to reduce the role of the state in the economy was great. Agricultural adjustment lending has varied widely, ranging from 5 percent of total agriculture lending in 1998 to 48 percent in 2002.

\section{BENEFITS}

Successful adjustment lending can lead to a more stable macroeconomic environment, a more transparent incentive system, improved efficiency of resource allocation, and strengthened institutions and capacity for policy analysis, all contributing to accelerated economic growth. There can be a positive effect on poverty through the increased income and employment opportunities resulting from adjustment, although in the short term there may be adverse effects on poverty reduction. Since a sound policy environment is essential to sustainable growth, adjustment lending can be an important development tool to facilitate policy and institutional reform and implementation. However, if not well designed and implemented, policy-based lending can be highly ineffective.

\section{POLICY AND IMPLEMENTATION ISSUES}

EFFECTS ON THE POOR AND MONITORING. With adjustment lending, conditionality can lead to major changes in agriculture that have large consequences for various stakeholder groups. The lag-time between adjustment and economic growth is substantial, and the poor can be adversely affected through this transition phase. Poverty and social impact analysis (PSIA) is critical for ensuring that the design of reforms pays particular attention to impacts among different social groups and on the long-term effect on poverty (see box 1.23). Also, supervision and monitoring is critical for effective implementation of ASALs and assists borrowers in identifying problems in time for mid-course corrections (though this cannot compensate for poor design or lack of commitment). Failure to monitor social impacts of adjustment lending in sufficient detail has been a deficiency of earlier operations. In some cases, when supervision ends with release of the final tranche, policy reversals undermine reforms. Even after the final tranche release, progress should continue to be closely monitored, particularly with regard to impacts on the poorer and more vulnerable groups.

OVER-RELIANCE ON CONDITIONS AND TRANCHING. As it is rarely possible to implement the full array of needed policy changes and institution-building activities at the outset of a reform program, conditionalities are typically a necessary part of adjustment lending. For instance, actions relating to upgrading institutions, trade liberalization, and deregulation of licensing systems and financial markets, can take several years, so drastic reform may not be possible over relatively short periods. Past adjustment lending however, has tended to over-rely on conditions and tranching. An even distribution of the priority conditionalities, and making the first tranche release conditional on the more important reform actions can help reduce delays of important reform activities. Conditionalities should be realistic, both economically and politically, and seen to be so by both the lender and the government (Jayarajah and Branson 1995). Future programs should include fewer conditionalities representing well-focused and monitorable policy actions and clear expectations for the borrower. ${ }^{6}$

CONTENT AND COVERAge. The overall conclusion of a recent study is that the analytical underpinnings and relevance of the components of ASALs have been appropriate on most issues (Feder and Anderson 2003). Typically, thematic coverage of agricultural adjustment operations includes domestic market reforms and privatization, external trade reform, land reform

6. See the IAP,"Bulgaria: Adjustment Lending in a Transitional Economy" 
Box I.24 Generating ownership

A 1995 World Bank study found that the most important factors generating program ownership were (I) political stability; (2) support of (or lack of opposition from) various constituencies; and (3) preconceived official attitudes toward reform. Conversely: (I) a specific regime type did not intrinsically exhibit a greater degree of political will; (2) the intensity of external and exogenous shocks neither facilitated nor posed obstacles to achieving a consensus toward reform; (3) the initial conditions in the economy had little relevance in either encouraging or impeding ownership; and (4) the frequency and amount of government-Bank interaction was neither a necessary nor a sufficient guarantee for program ownership in the face of binding constraints.

Source: Jayarajah and Branson 1995.

to allow private ownership/user rights, removal of input subsidies and other price distortions, and rural finance reforms. Domestic market reforms and privatization are still the core of adjustment operations, reflecting the fact that recent ASALs have been funded in regions still dominated by state-controlled domestic markets where most marketing and processing (and in Eastern Europe and Central Asia, agricultural production) was handled by parastatals or state-supported entities. Most ASALs address domestic market and external trade reform components as well.

IMPLEMENTATION PROBLEMS. Implementation has a mixed record, particularly regarding the removal of state control over the domestic economy and the privatization of large parastatals, where vested interests (and their political patrons in and around government) had much at stake. In some cases, subsidies have been removed, then reintroduced in different, less direct, forms. Even officially privatized parastatals are on some occasions still not fully delinked from government control and budget support (and consequently, not likely to operate as efficiently as expected).

The relatively weak actual performance of governments in implementing ASALs reflects an overly optimistic assessment of political commitment, and/or of government capacity, to carry certain measures through a noncooperative parliamentary system or a noncohesive governmental apparatus. Sufficient scrutiny and realism to identify potential political risks and government weaknesses is an important part of agricultural adjustment operations. Donors can support the process by (1) strengthening the institutions involved; (2) assessing the capacity of the borrower and tailoring conditionality accordingly; and (3) providing an appropriate mix and sequence of program and project support to maintain critical expenditures and promote investments for longer-term growth.

SucCess factors. Success of adjustment initiatives is likely to be greater where infrastructure is well developed, educational levels are high, institutions in the public and private sectors are mature, trade regimes are less highly distorted, and there is an ability to withstand or cope with exogenous shocks (such as droughts). Governments implementing policy reforms need to be insulated from adverse impacts on income and savings to protect the reform process and maintain credibility. This may require governments to provide transitional support to ensure both the success of the reforms and to minimize the effects of the reform on the most vulnerable groups. Successful adjustment often results in agricultural production moving from low to higher value-added activities. This requires policies conducive to resource mobilization, development of infrastructure, trade and risk management, and technology transfer.

Many countries that have failed to relax entry and exit barriers for investment, and to sufficiently open their economies to private investment, both domestic and foreign.

\section{LESSONS LEARNED}

ANaLYTICAL Foundations. Sound design of adjustment lending agricultural programs begins with operationally oriented analytical work carried out well before program initiation. Ongoing policy dialogue on major macroeconomic and sectoral issues is an important element in the design process to build consensus for reform both within the government and among varied stakeholder groups. It is important to have 
adequate knowledge of the public enterprise sector before embarking on privatization or public sector reforms. Also important are fiscal adjustment measures in agricultural spending that protect agricultural growth from crisis, and understanding the effects of exchange rate policy on agricultural terms of trade. This reflects the importance of basing phasing and sequencing of reform activities on thorough analytical work that accounts for time lags, substitution effects, and the linkages between agricultural policy reforms and reforms in other sectors.

EstABLISHING OWNERSHIP. Ownership increases the success of adjustment lending (Jayarajah and Branson 1995) (see box 1.24). Despite its importance, borrower ownership remains conceptually elusive and insufficiently explored with regard to policy and practice of adjustment lending. It is seldom clear as to what constitutes adequate ownership or what can be done to increase and sustain commitment to an adjustment program. For ASALs, for instance, having allies outside ministries of agriculture and ministries of finance is helpful because of strong intersectoral linkages.

Public ENTERPRISE REFORM. In many cases, adjustment lending for public enterprise reform must accompany le.ding for agricultural sector policy reform. Public enterprise reforms include those related to divestiture of public enterprises (privatization) and those aimed at enterprises retained in the public sector. Both require constant attention to governance issues such as corruption and transparency. Privatization requires that enterprises appear viable to investors with the primary consideration in negotiations (that need to be transparent) being the quality of the investors and their plans for the enterprise, not the prices they offer.

COOPERATION AMONG DONORS. Donor assistance is often part of a wider international effort; and many groups typically have a significant say in the policy dialogue with borrowers. Close cooperation among donors and NGOs is necessary to avoid duplication of effort and conflicting advice and objectives. World Bank

\section{Box I.25 Potential investments}

- Design of adjustment program reforms and implementation plans, including identification of unambiguous and realistic conditions.

- Situation and problem analysis to identify key thematic issues to be addressed and possible reform options.

- Building ownership and administrative capacity of the borrower through training and education programs.

- Program budget support.

Source: Authors.

adjustment lending needs to ensure consistency between the conditionalities imposed by the Bank and those prescribed by the IMF. In general, a synergy exists between Fund policies on stabilization and Bank support for structural change. Policy Framework Papers for lowincome countries can foster agreement between the two institutions and the borrower.

\section{RECOMMENDATIONS FOR PRACTITIONERS}

As is the case for any lending program, adjustment operations must be built on strong analytical foundations, giving primacy to good prior economic and sector work. Adjustment lending interventions (see box 1.25) should:

- Coordinate the design and implementation of adjustment loans with the International Monetary Fund and other donors, and ensure reforms are consistent with reforms in other sectors and are supported by an appropriate macroeconomic framework.

- Look for highly visible borrower commitment to, and ownership of, a definite reform plan. Conditionalities should be kept to a minimum, be realistic, and clearly indicate the expectations of the borrowing country.

- Identify what should be analyzed at the donors expense and what governments themselves, with technical assistance, should analyze.

- Progress in a logical sequence and disburse funding via appropriate tranching that 
requires that higher priority conditions be met first. Efforts to reduce price and other sector distortions should cover both outputs and inputs.

- Consider appropriate increases in investment lending to complement adjustment lending, and in particular, to overcome infrastructural constraints faced by producers.

\section{SELECTED READINGS}

Asterisk (*) at the end of a reference indicates that it is available on the Web. See Appendix 1 for a full list of Websites.

Arulpragasam, J., S. Beddies, S. Brown, et al. 2003. "A User's Guide to Poverty and Social Impact Analysis." World Bank, Washington D.C.*

Easterly, W. 2001. "The Effect of International Monetary Fund and World Bank Programs on Poverty." Policy Research Working Paper 2517. World Bank, Washington, D.C.*

Jayarajah, C., and W. H. Branson. 1995. Structural and Sectoral Adjustment: World Bank Experience, 1980-92. Operations Evaluation Study. Washington D.C.: World Bank.*

World Bank. 1994. Adjustment in Africa: Reforms, Results, and the Road Abead. New York: Oxford University Press.

World Bank. 2001. "Adjustment Lending Retrospective: Final Report, Operations Policy and Country Services." World Bank, Washington, D.C.

\section{REFERENCES CITED}

Arulpragasam, J., S. Beddies, S. Brown, et al. 2003. "A User's Guide to Poverty and Social Impact Analysis." World Bank, Washington D.C.

Feder, G. and Anderson, J. R. 2003. "Review of Agricultural Adjustment Lending: FY1996 FY2002." ARD, World Bank, Washington, D.C. Processed.
Jayarajah, C., and W. H. Branson. 1995. Structural and Sectoral Adjustment: World Bank Experience, 1980-92. Operations Evaluation Study. Washington D.C.: World Bank.

This Note was prepared by Jock Anderson and Sam Kane with inputs from Gary Alex and Derek Byerlee. 


\section{AGRICULTURE INVESTMENT NOTE}

\section{IMPROVING ANIMAL HEALTH SERVICES THROUGH PUBLICI PRIVATE PARTNERSHIPS}

An efficient animal health service is critical to livestock production. Most such services in developing countries have historically been provided by the public sector but have been set back by quality problems. Over the past 20 years, service efficiency has declined dramatically. A better balance between the public and the private sector and between professional and paraprofessional veterinary staff may offer considerable potential to improve services. Actions needed to ensure an efficient animal health service include refocusing and strengthening public sector activities to undertake public goods, such as policy development, quarantine and disease surveillance, vaccination against major diseases, food safety, and establishing, especially in more marginal areas, networks of community animal health workers. Private services for private good tasks, such as clinical treatments, vaccination, and animal breeding, should also be promoted.

Poor animal health is the main reason for losses in livestock production. Direct and indirect losses of meat, milk, and work output are estimated at about US\$2 billion a year in Sub-Saharan Africa alone. Better animal health service is the production input in highest demand by livestock farmers and is, therefore, a key point of contact between the government and the farmer.

Over the past 20 years, the quality of public veterinary services has declined in many developing countries. Structural adjustment programs reduced funding for university veterinary departments while recruitment of new staff continued. As a result, the ratio of expenditure on salaries to expenditure on recurrent costs increased to $85: 15$ in many African countries, compared to an optimal 60:40 (de Haan and Bekure 1991; Gauthier
Gauthier, Simeon, and de Haan 1999). A similar trend has been observed in South Asia. Lack of operating funds for public sector field veterinary services is partly responsible for major outbreaks of rinderpest in Sub-Saharan Africa and the Middle East in the 1980s and, more recently, of Rift Valley fever in East Africa and foot-and-mouth disease in Zimbabwe, Botswana, and South America.

\section{IMPROVING ANIMAL HEALTH SERVICES}

Animal health services in developing countries are typically based in a public sector agency where veterinarians lacking sufficient resources try to cover all aspects of animal health. To improve animal health services, reform must provide for more efficient distribution of service delivery responsibility at two levels: between public and private service providers, as well as between professional veterinarians and paraprofessionals (lay animal health workers). In defining this responsibility, both public health and food safety issues need to be adequately considered, and lay animal health workers need to be directed by a responsible veterinarian (public official or mandated private veterinarian).

Public/PRIVATE DistRIBUTION OF SERVICE DELIVERY RESPONSIBILITY. The economic characteristics of services should help define the distribution of responsibilities between the public and the private sector. For the public sector, service delivery focuses on "public goods," which involve market failures, externalities, or moral hazards. Government strategy should be to strengthen the public sector to "do less but better" and to create an enabling environment for private sector development. The less but better approach implies that public sector tasks must be supervised but not necessarily implemented, by public agencies (see table 1.1).

ProfessionaL/PARAPROFESSIONAL DISTRIBUTION OF RESPONSIBILITIES. A more efficient distribution of responsibilities between professional and paraprofessional veterinarians and lay animal health care workers can improve the efficiency of delivery of animal health services. Herder- 
Table I.I Economic characteristics and delivery of animal health services

Type of economic good

Service
Clinical diagnosis
Clinical treatment
Vaccine production
Vaccination, major contagious
diseases

Public

Private

Sectoral Delivery

of strong
consumption
externalities

Vaccination against minor diseases

Veterinary surveillance (quarantine, epidemiology)

Control of vet. pharmaceutical sales

Food safety control

(meat inspections)

Veterinary research/extension

Public because
of strong
consumption
externalities

Private but some

consumption

externalities

Pure private

Pure private

Private but some

consumption

externalities

Public because

of strong

consumption

externalities

Public because

of moral hazard

Public because

of moral hazard
Public because of market failure (poverty focused)

Private for commercial purposes
Public

Private
YY

YY

YY

Y

YY (contracted by public sector)

YY

Y

(contracted by public sector)

$Y$
(contracted by
public sector)

Y

"Y" = Yes, acceptable; "YY" = "Yes, strongly recommended"

Source: Umali, Feder, and de Haan 1994.

auxiliaries or low- and mid-level technicians are important in most private animal health systems, especially in traditional livestock production systems. These technicians are familiar with local conditions and are often more readily accepted by the local population than are public veterinarians. Although paraprofessionals generally have extensive knowledge of the local situation (including of gender roles), they need to distinguish tasks undertaken by auxiliaries from those for which official controls are necessary to prevent major disease outbreaks, public health threats, or loss of important markets. Animal health services should ensure effective communication between professional and paraprofessional animal health providers, as well as regulate paraveterinarian use of products that carry public health risk (antibiotics), disease quarantine risk (attenuated vaccines), or drug resistance (antibiotics or trypanocides). 


\section{BENEFITS}

Since the early 1990s, in Sub-Saharan Africa, policy change has resulted in the number of private veterinarians increasing from almost zero to about 2,500 in 2000. Veterinarians in private practices almost unanimously indicate that they are now better off than as public servants. In Eastern Europe, a private service system evolved, almost by default (see box 1.26). Morocco shifted from a public system in 1980 to an entirely private system in 1990 (see box 1.27). Progress has been slower in South and East Asia, where public sector services are still dominant.

A vast network of auxiliary veterinary assistants (estimated at 10,000 or more) is now operating in Sub-Saharan Africa, and paraprofessionals are increasingly common in South and East Asia. Farmers generally view these private systems as better than public systems in delivering timely services, providing services to the poor, and reducing livestock mortality. A "willingness to pay" survey in three Indian states has shown that the landless poor are willing to pay for good quality services. In a variety of settings, animal health service reforms have reduced the incidence of human brucellosis and other diseases transmitted from animals to humans; reduced mortality in cattle by 45 percent to 60 percent and in small stock by 20 to 70 percent; and increased family incomes by US $\$ 48$ to US $\$ 300$ per year.

\section{POLICY AND IMPLEMENTATION ISSUES}

Clarify PUBliC AND PRIVATE SECTOR ROLES. The first step for every policymaker is to define or redefine public and private sector roles, taking into account standards and guidelines from the world body for animal health (OIE). Experience shows that this should be done in a public debate and that the political change to a multiagent setup is critical. Since there are often significant vested interests such as public sector employees working at two or more jobs, this is often a complex and sensitive process.

Prevent unfair competition. Unfair competition (continued subsidization of public services and
Box I.26 Former Soviet Union countries: privatization of veterinary services

Under the former Soviet Union's centralized economy, most veterinarians were employed by collective farms. In the 1990s, these farms were broken up and many workers and veterinarians received farm assets. Veterinarians had few alternatives other than to start private practice, though on a small scale. It took most governments a decade to acknowledge private services and formalize this in their veterinary legislation. In a few countries, viability of private veterinary services was enhanced by the state contracting veterinarians to carry out mandated disease control programs. The change in the state role from executing veterinary services to overseeing quality of services was much slower. A major problem for veterinarians was their limited lack of business management experience.

Source: Schillhorn van Veen, forthcoming.

"moonlighting" by public service veterinarians) is a most serious entry barrier to the privatization of animal health services and can be addressed by introducing full cost recovery by the public sector for curative and noncompulsory interventions. Given the choice between unreliable public services and highquality private services, farmers will pay for services. Decentralizing revenue collection by introducing a revolving account at district level also creates a direct incentive for cost recovery.

\section{Box I.27 Morocco: privatization success}

The Moroccan government (the Moroccan Livestock Service Directorate) privatized its veterinary services in 1983. From only two private veterinarians in that year, the number increased to 76 in 1989 and 318 by 2000 , or about one-half the total number of veterinarians in the country. Private veterinarians now provide care for 70 percent of the country's cattle and 60 percent of its sheep. Factors in this success were:

- The political will of the livestock service to make privatization a success.

- Support from a well-functioning, national association of veterinarians.

- A clear subcontracting policy for compulsory vaccination campaigns. The government pays the veterinarian a fee for each vaccination.

- Suspension of public provision of curative services and noncompulsory vaccinations once a private veterinarian has established a practice in an area.

Source: de Haan 1993. 


\section{Box I.28 Potential investments}

- Policy analyses and technical assistance in policy reform.

- Strengthening animal health training in universities and training centers.

- Public-private partnerships to strengthen paraprofessional skills.

- Financing for contracted private provision of food safety inspections, vaccination for major diseases, and other public goods services.

- Financial services for private animal health workers.

- Public veterinary laboratories.

- Research and extension on animal production and health.

Source: Authors.

Extent of PRIVATIZATION. Many feel that liberalization has gone too far, and that inadequate regulatory control over the quality of veterinary treatment has led to indiscriminate use of dangerous substances. Moreover, the reorganization of ministries of agriculture as part of structural adjustment and decentralization reforms, has left central veterinary departments weak and poorly equipped to carry out their tasks. Privatization has left marginal areas with inadequate veterinary coverage. The need for efficient, official veterinary services operating under a direct chain of command principle must be considered in any decentralization and privatization reforms.

\section{LESSONS LEARNED}

ELIMINATE BARRIERS TO IMPORTS OF VETERINARY INPUTS. Sales of drugs are important to the financial viability of private veterinarians. Veterinarians should not, however, be given a monopoly on all drug sales, in particular the sale of items that pose little or no risk to public health, such as feed additives, anthelminics, and certain acaricides. Government intervention in veterinary drug trade should remain normative and regulatory, establishing lists of drugs that can be imported.

ReCOnsider finAnCial SUPPORT MECHANisms. Although donors have tried to accelerate animal health service restructuring through targeted credit schemes, in some cases the emergence of private animal health workers has occurred spontaneously. This partly resulted from credit from pharmaceutical companies, providing an important source of funds for private animal health workers. Although many prospective private veterinarians argue that they need a car, less expensive means of transport can often serve as well.

\section{RECOMMENDATIONS FOR PRACTITIONERS}

Distribution of responsibilities between public and private sectors is the key policy issue, and once defined they should be confirmed through appropriate regulations. Rather than copying regulations from industrial countries, rules should be adapted to the needs of the prevailing production systems, allowing a broader scope of responsibility for herderauxiliaries and lower-level technicians in areas that cannot profitably maintain a professional veterinarian. Legislation should also allow other activities, such as subcontracting of public sector work or artificial insemination, that are often critical for the economic survival of the private practitioner (see box 1.28).

Professional veterinarian training in most developing countries still focuses on public sector tasks, with little hands-on skill development and often complete neglect of commercial and management skills and herd-health management. Training in those areas is critical to the successful restructuring of animal health services because public sector veterinarians are notoriously poorly equipped in economics and policy areas.

Quality of paraprofessional animal health workers depends on selection of mature personalities, both men and women, from the community with an interest in a part-time occupation (shopkeepers, farmers). Paraprofessionals should undergo training in regular short courses (two to six days because part-time workers can not afford more time) and should also be part of networks of private veterinarians to enhance quality and availability of supplies. 


\section{SELECTED READINGS}

Asterisk $\left(^{*}\right)$ at the end of a reference indicates that it is available on the Web. See Appendix 1 for a full list of Websites.

Catley, A., S. Blakeway, and T. Leyland. 2001. Community-Based Animal Healthcare A Practical Guide to Improving Primary Veterinary Services. London: Intermediate Technology Development Group Publishing.

FAO. 1991. "Guidelines for Strengthening Animal Health Services in Developing Countries." FAO, Rome.*

FAO. 1997. "Principles for Rational Delivery of Public and Private Veterinary Services with Reference to Africa." Rome, FAO.*

OIE. 2003. "Guidelines for the Evaluation of Veterinary Services." In Terrestrial Animal Health Code. 12th ed. Paris: OIE.

\section{REFERENCES CITED}

de Haan, C. 1993. "The Delivery of Livestock Services to Smallholders." In P. W. Daniels, S. Holden, E. Lewin, and S. Dadi, eds., Livestock Services to Smallholders: A Critical Evaluation. Proceedings of a seminar held in Yogyakarta, Indonesia, November 10-15, 1992. Indonesia International Animal Science Research and Development Foundation, Bogor, Indonesia.

de Haan, C., and S. Bekure. 1991. "Animal Health Services in Sub-Saharan Africa: Initial Experiences with Alternative Approaches." Technical Paper 134. World Bank, Washington, D.C.

Gauthier, J., M. Simeon, and C. de Haan. 1999. "The Effect of Structural Adjustment Programs on the Delivery of Veterinary Services in Africa." Proceedings for Regional Conference of Office International des Epizooties for Africa, Dakar, and Senegal, Paris.
Schillhorn van Veen, T. W. Forthcoming. Eastern Europe and the Former Soviet Union: Animal Health Systems in Transition. Office of International Epizootics Scientific and Technical Review 23. Place: Publisher.

Umali, D. L., G. Feder, and C. de Haan. 1994. "Animal Health Services: Finding the Balance Between Public and Private Delivery." World Bank Research Observer 9 (1): 76-9.

This Note was prepared by Cees de Haan with inputs from the Sustainable Agriculture (SASKI) Thematic Team of the World Bank. 
AGRICULTURE INVESTMENT NOTE

\section{STRENGTHENING FARMER ORGANIZATIONAL CAPACITY TO INFLUENCE AGRICULTURE POLICY}

Lack of capacity to use economic opportunities and an inability to access resources and services contribute to poverty-a condition that is also profoundly affected by a lack of empowerment. In the competition for economic and political power, the voices of the poor, particularly the rural poor, are usually not heard. Rural producer organizations (RPOs) help address these problems by empowering rural people, building rural social capital, increasing farmers' voice in public sector decision-making. Building this capacity requires: identifying rural producer organizations, strengthening their internal governance structures and information systems, developing an active policy dialogue with government agencies, and building technical, strategic, and negotiating capacity of RPO leaders.

In most countries, economic liberalization has been accompanied by political liberalization that offers new opportunities for action by economic agents, including rural producer organizations. The withdrawal of the state from some activities has left a vacuum in the institutional and organizational framework for addressing rural needs. This vacuum has only been partially filled by the private sector. There is also a need for improved governance in the regulatory environment and the correction of market failures (public goods, externalities).

Adjusting to new economic and market conditions is made more difficult in rural areas by the imbalance of power between poorly organized agricultural producers and powerful public or private operators. This imbalance is largely related to producers' limited access to information and education, and a relative lack of capacity to formulate objectives and define a strategic vision for development. Their participation in public debates on economic and political liberalization often remains symbolic and, in practice, decisions are made without them. Increasingly governments are aware of the importance of having farmers participate in agricultural policymaking, and therefore support RPO capacity building. This requires institutional frameworks that recognize their potential role, and mechanisms for farmers to voice their concerns at the local, national, and international levels of policy formulation.

\section{RURAL PRODUCER ORGANIZATIONS}

In all rural societies, traditional organizations have an inward-oriented or "bonding" function to facilitate collective actions that mitigate against the uncertainties of agricultural production, and regulate relationships within the group. In contrast, formal producer organizations perform a "bridging" function to organize relationships between the group and the outside world. In the context of developing countries, RPOs typically include elements of both traditional and formal organizations. They are rooted in local customs, but organized on economic principles. Inclusion is characteristic in traditional groupings, where everyone is inherently a member, but formal producer organizations tend to be more exclusive. RPOs are membership organizations created by producers to provide services. They differ from NGOs, which also provide services to producers, but are not necessarily membership based. RPOs can be local and serve only at village and inter-village levels, or can operate at regional and national levels (as unions and federations).

\section{BENEFITS}

Many of the world's poor live in rural areas with agriculture or agriculture-related activities as the mainstay of their livelihood. When poor producers band together, they gain bargaining power and may access the services and resources they need to diversify, improve competitiveness, access markets, increase incomes, and equitably distribute associated benefits.

RPOs play an important role in policy dialogue and in some cases, rural federations are in- 
volved with macroeconomic and political issues. Examples include the Indigenous and Afro-Ecuadorian Peoples Development Project (Ecuador) and the Agricultural Services and Producer Organizations Project (Senegal; see box 1.29). In both countries, RPOs are at the forefront of a larger civil society movement, advocating political and socioeconomic changes. Strengthening the capacity of producer organizations to influence policy in an informed and democratic manner builds social capital that complements investments in other forms of capitalænatural, human, physical, and financial. Effective RPOs can improve policy outcomes and the efficiency of rural service providers. This in turn can have major benefits for poor people if they are able to organize themselves effectively.

\section{POLICY AND IMPLEMENTATION ISSUES}

Multiple Functions of RPOs. Rural producer organizations typically perform multiple functions, generally including: advocacy or policy functions (syndicates or unions), economic and technical functions (cooperatives or associations), and local development functions (especially when decentralization has not yet taken place and local governments do not exist). Most RPOs address all three functions to varying degrees.

EQUTTY. RPOs are not necessarily inclusive. There may be entry barriers for the poorest of the poor, who lack the minimum assets and, in general, do not belong to formal groups that can help them take advantage of what an RPO can offer. The cost of reaching the unorganized can be high, but projects financed by donors may help RPOs improve inclusion to reach the poorest, and make sure that their voices are heard in policy development processes.

Resistance to RPO empowerment. Empowering producer organizations should create forces in a society that can lead to a shift in power relationships. Since existing elite groups may try to counter these forces, wide communication and careful monitoring of ongoing change processes are necessary. Governments and civil servants are likely to resist change because they are afraid of losing control and privileges. Political parties and individuals will try to co-opt the process and use RPOs as vehicles to promote their own agenda. An effective RPO support program should therefore analyze stakeholder interests to identify potential opponents and resistance to reform, and design specific activities that bring about win-win situations.

INCREMENTAL PROCESS OF DEVELOPMENT. Empowerment of RPOs through learning-by-doing will frequently entail some failures and misuse of funds by the emerging organizations. Appropriate controls and audits are necessary and a phased program of institutional development and delegation of responsibilities is frequently

\section{Box I.29 Senegal: strengthening RPO capacity to participate in policymaking}

The National Cooperation and Consultation Committee of Rural People of Senegal (CNCR: Conseil National de Concertation et de Coopération des Ruraux) was created in 1993 by 19 national federations to represent rural producers in agricultural policy formulation and negotiation processes. CNCR goals are to: (i) strengthen the unity of the farmers movement and represent rural producers, (ii) defend farmers' interests in decision-making processes regarding agriculture and rural development, and (iii) contribute to sustainable development of family farming systems.

Since 1994, CNCR has been recognized by the Government of Senegal and the World Bank as a partner in preparation and implementation of a US\$6 million RPO capacity-building component of the Agricultural Services and Producer Organization Project. CNCR also chairs the board of directors of the National Agricultural Research Fund, and is an influential member of the Board of the National Agency for Agricultural and Rural Advisory Services. CNCR (http://www.cncr.org) is systematically associated with any agricultural policy formulation in Senegal, and at a regional level participates in West African Monetary Union policymaking meetings as a member of the West African Network of Rural Producers Organizations http://www.roppa-ao.org).

Source: Bosc et al. 2002. 
beneficial. Capacity building of producer organizations is a slow and uneven process regulated by existing social behavior and cultural norms. Donors may get impatient and force the process artificially, thus engendering unsustainable advances.

\section{LESSONS LEARNED}

IDENTIFYING ORGANIZATIONS TO SUPPORT. EXperience indicates that any membership organization should be eligible for program support as long as members are agricultural producers living in rural areas and providing it meets three criteria:

- It should be recognized as useful (principle of utility) by its members-members must value the ability of the entity to promote beneficial policy.

- It should have an identity (that is, a history and effective operating rules) that, even if not formalized, regulates the relationships among its members and between members and the outside world.

- It should be legally recognized, with governing bodies functioning effectively, in particular holding regular elections and meetings with accountability mechanisms.

Box I.30 Colombia:The Colombia Coffee Growers Federation

The Colombia Coffee Growers Federation represents approximately 250,000 farms with the objective of serving the welfare of the country, and promoting the economic and social wellbeing of Colombian coffee growers. The Federation engages in activities such as transport, coffee storage, agricultural research, and public works programs. The Federation has a democratic hierarchy based on Municipal Committees that are democratically elected. Managers are accountable to the democratically elected Coffee Congress. The large volume of coffee produced means that producers can achieve economies of scale and have effective negotiating power.The Federation has demonstrated considerable political influence. The Coffee Fund, financed from membership fees and a levy on production, is large enough to influence Colombia's macro-economy. As a result, the Federation works in consultation with the government to manage this fund. Some Committees have negotiated with local government to put up 30 percent matching funds for local projects.

Source: Bosc et al. 2002.
Often the best-established producer organizations are commodity-based associations dominated by large farmers. These are legitimate representatives of the sector, but do not necessarily represent the interests of small farmers. Still, such organizations usually open membership to smaller farmers to maintain the association's credibility as a representative of all-farmer interests. Public support should encourage such developments and effective integration of smallfarmer interests in the association agenda. Small-farmer influence and participation is facilitated by having local and regional meetings and activities in addition to national activities, and by carrying out programs targeted to the needs of small producers.

Defining WHAT to STRENGTHEN. Investments need to help RPOs become more effective at providing the services for which they were created. This often requires improvements in:

- Internal governance structures and accountability mechanisms.

- Internal and external information systems.

- Capacity to articulate members needs and negotiate.

- Technical and managerial capacity to implement activities.

- Strategic capacities for policy analysis and defining a vision and strategy to achieve objectives.

ESTABLISHING A POLICY DIALOGUE WITH GOVERNMENT. Investments to strengthen RPO capacity need to promote an enabling environment through projects and policy dialogue with government (see box 1.30). This might entail: obtaining recognition of RPOs from governments and ending mistrust from public services; ensuring that RPOs are seen as full partners in development; and providing up-to-date information to RPOs to facilitate their participation in developing rural development policies and preparing and implementing rural projects. RPOs 
must be given enough time, resources, and information to prepare effectively for participation in these activities.

LEGITIMACy. RPO leaders may be isolated from their base and lack accountability to their members. Although programs to strengthen RPOs are intended to resolve these problems, access to funds and services may still be available only to RPO leadersæoften the local elitexto the detriment of members. To mitigate against such risk, support programs for RPOs should be extensively advertised to ensure that those who have problems accessing the information, often the poorest, are aware of the fund's existence. Close monitoring and systematic evaluation is essential.

Allow self-management of funds. Providing a flexible development fund or demand-driven services linked to a productive investment fund allows RPOs to define activities to be financed and determine the timing and pace of implementation. RPOs manage the funds they have been granted, and typically are able to select service providers from a list of regularly certified vendors. Such a funding mechanism requires that donors, RPOs, and the government agree on procedures and criteria for RPOs to access funds. To ensure compliance with procedures and quality of services, close monitoring is required, as well as systematic, random, and post-activity audit by government and/or donors.

\section{RECOMMENDATIONS FOR PRACTITIONERS}

There is no blueprint for supporting RPO development to improve policy analysis and advocacy capacities, as this must be tailored to country circumstances (especially the political environment), and the characteristics of RPOs in that country. However, one principle applies: support should empower RPOs-not make them instruments of donor or government policy. Key recommendations for investment include (see box 1.31):

- Guarantee equal access to all RPOs that meet funding criteria, and accept the

\section{Box I.3I Potential investments}

- Legal and regulatory reforms to facilitate rural producer organization growth.

- Assistance to national or regional federations to: (a) train leaders and members, and (b) build strategic planning skills and develop operation and management procedures.

- Study tours and exchange visits.

- Assistance in forming local, regional, and national RPO consultative forums.

- Demand-driven funds to finance, on a matching grant basis, RPO services, programs, and productive investment.

Source: Authors.

limitations of RPOs-work with them at their pace in a "learning-by-doing" manner.

- Concentrate on agreed-upon transparent decision-making processes and procedures, and let RPOs decide the nature of the activities they want to finance.

- Target activities that RPOs have chosen and that fit within their working capacity.

- Ensure that supported RPOs are legally registered, with transparent governing rules, procedures, accounting, and reporting systems.

- Guarantee independence from government or donor agencies, yet develop a strong and active policy dialogue with relevant government agencies.

- Promote a conducive legal environment with laws and regulatory systems that promote growth and recognition of RPOs.

- Promote effective decentralization and deconcentration of public services to provide a basis for empowerment of local communities.

- Promote a dialogue among donor agencies to harmonize approaches and procedures in support of RPOs. 


\section{SELECTED READINGS}

Asterisk $(*)$ at the end of a reference indicates that it is available on the Web. See Appendix 1 for a full list of Websites.

Bosc, P., D. Eychenne, K. Hussein, B. Losch, M.-R. Mercoiret, P. Rondot, and S. Mackintosh-Walker. 2002. "The Role of Rural Producer Organizations in the World Bank Rural Development Strategy." Rural Development Strategy Background Paper 8. World Bank, Washington D.C.*

Hussi, P., J. Murphy, O. Lindberg, and L. Brenneman. 1993. The Development of Cooperatives and Other Rural Organizations: The Role of the World Bank. Technical Paper 199. Washington, D.C.: World Bank.

Pratt, D., F. Le Gall, and C. de Haan. 1997. Investing in Pastoralism: Sustainable Natural Resource Use in Arid Africa and the Middle East. Technical Paper 365. Washington, D.C.: World Bank.

Rondot, P., and M.-H. Collion, eds. 2001.

"Agricultural Producer Organizations: Their Contribution to Rural Capacity Building and Poverty Reduction." Report of a Workshop, June 28-30, 1999, Washington, D.C. World Bank, Washington D.C.*

Subramanian, A., V. Jagannathan, and R. Meinzen-Dick, eds. 1997. User Organizations for Sustainable Water Services. Technical Paper 354. Washington, D.C.: World Bank.

\section{REFERENCES CITED}

Bosc, P., D. Eychenne, K. Hussein, B. Losch, M.-R. Mercoiret, P. Rondot, and S. Mackintosh-Walker. 2002. "The Role of Rural Producer Organizations in the World Bank Rural Development Strategy." Rural Development Strategy Background Paper 8. World Bank, Washington D.C.

This Note was prepared by the Sourcebook team based on the Agricultural Technology Note "Investing in Rural Producer Organizations" by Pierre Rondot. 
INNOVATIVE ACTIVITY PROFILE

\section{BULGARIA:ADJUSTMENT LENDING IN A TRANSITIONAL ECONOMY}

Bulgaria has a diversified agriculture, with fertile soils and favorable climatic conditions. By the end of the communist period in 1989, 90 percent of the land was in large cooperatives or agro-industrial complexes averaging 24,000 hectares. Input use was intensive and livestock production was highly subsidized.

What's innovative? Agriculture sector adjustment reform in a transitional economy - privatization, commercialization, land, and financial sector reform.

After 1990, priority was given to dismantling large production complexes and to distributing land and nonland assets, including livestock, to former owners. Most input prices were decontrolled. However, new owners were often illequipped to manage their new assets, and price controls (together with export controls and taxes) were maintained on outputs in order to keep food prices low for the urban population. This led to large illegal exports and shortages, especially in grains. There was great instability in the trade regime, and import tariffs were high on fertilizer, a key input. Fertilizer use declined by 75 percent and agricultural production in 1997 was only 45 percent of the 1989 levels. State intervention in cereal marketing and credit continued. By the mid 1990s, both macroeconomic imbalances and lack of structural reforms caused a financial crisis.

A new government was elected in 1997 with a strong commitment to market reform. The government eliminated export bans and controls on agriculture and food profit margins, eliminated most import quotas and duties on cereals, liberalized markets, and abolished subsidized agricultural credit.

PROJECT OBJECTIVES AND DESCRIPTION The Agriculture Sector Adjustment Loans (ASAL) I \& II sought to promote efficiency in agriculture, contribute to rural employment generation, improve living standards, and provide more consumer choices by:

- Developing an active land market.

- Developing a grain market by privatizing the grain marketing agency and limiting the operations of State Grain Reserves.

- Privatizing agro-industrial and processing firms, including grain mills, seed, and food industries.

- Privatizing irrigation systems by decentralizing operations management and maintenance to water user associations.

- Improving agricultural financing to rural areas by private providers.

- Liberalizing trade, improving market regulations, and increasing competitiveness of tradable commodities.

- Improving forest legislation and increased community-based participation in forest management.

- Supporting Bulgaria's accession process to the EU.

\section{BENEFITS AND IMPACTS}

Both loans were one-tranche operations, supporting a program of about 2 years. The government took all of the designated steps before each of the loans went to the Board. A key feature of the Bulgaria adjustment program was that it had the full support of the elected government and parliament. Another feature was the willingness of the Bank to adjust the state food reserves condition in response to perceived risks of food shortages over the period of the loan by the Bulgarian Government, in light of tensions in Kosovo.

Under ASAL I \& II Bulgaria transformed itself, in a very short period of time, from having one of the worst agricultural trade regimes to one 
of the most open in the region. The loans also had significant institutional development impact through privatization in the areas of grain marketing, input marketing, and farmer services - all key steps toward EU accession. Grain crop production in 2002 was 4 million metric tons (the highest since the start of reforms) and was due in part to increased farmer access to highquality seeds and fertilizer supported by the ASAL. Land market development led to an increase in land transactions of about 190 percent in 2000-01.

Achievements are particularly significant given the politically challenging nature of the needed reforms. Strong borrower ownership, with constructive dialogue between the Bank, borrower, and other stakeholders, and highquality economic sector work contributed significantly to this success and to the likely sustainability of the outcomes.

However, despite agriculture performing better than the economy as a whole, some major problems remain. Rural poverty reduction cannot be determined and privatization of agro-enterprises and institutional changes in irrigation have not yet revitalized these subsectors (irrigation requires an investment program). As well, agricultural exports have been declining given higher quality products from competitors, and neither land markets nor rural finance are yet stimulating the rural economy as desired. These shortcomings notwithstanding, the country has continued to stay on track in its bid for EU accession, fulfilling one of the top policy priorities.

\section{LESSONS LEARNED AND ISSUES FOR WIDER APPLICABILITY}

- Timely and quality sector work is essential. The Bank began analytical work two full years before the ASAL I was approved. Policy Notes effectively engaged the government and other stakeholders, to build support and consensus for difficult broad reforms. Process and substance are equally important.
- Timing of Bank interventions was important. Constructive disengagement in a period of poor policy environment prior to 1997 helped develop credibility with a new government serious about economic reforms.

- The "big bang" approach for transitional economy reform can work under the right conditions, with the caveat that this success followed a long period of slow or no change.

- Single tranche adjustment can work when there is strong commitment and when undertaken within a well-elaborated, medium-term framework. Moreover, singletranche loans are more flexible than multitranche loans since they avoid locking into legal conditions and policy targets that may not be fully supported by the Government.

The project shows the positive impact of the Bank's proactive and constructive engagement with the borrower, ensuring progress on all reform package elements, and preventing backsliding in key areas. However, a major issue is whether greater priority should have been given to targeted poverty reduction in a rural sector with a serious and increasing poverty problem.

\section{COUNTRY PROFILE: BULGARIA}

$\begin{array}{ll}\text { Project Name } & \begin{array}{l}\text { Agricultural Sector Adjustment } \\ \text { Loan (ASAL I and II) }\end{array} \\ \text { Project ID } & \begin{array}{l}\text { ASAL I: P057925, and ASAL II: } \\ \text { P057926 }\end{array} \\ \text { Project Cost } & \text { ASAL I: US\$75.8 million, and ASAL } \\ & \text { II: US\$50.0 million } \\ \text { Dates } & \text { ASAL I: FY 2000 - FY 200I, and } \\ & \text { ASALII: FY 2002 - FY 2003 } \\ \text { Contact Point } & \text { Henry Gordon } \\ & \text { The World Bank, I8I8 H Street } \\ & \text { NW, Washington D.C. 20433 } \\ & \text { Telephone: (202) 473-296I; } \\ & \text { Email: Hgordon@Worldbank.org }\end{array}$


INNOVATIVE ACTIVITY PROFILE

\section{ECUADOR: COMMODITY CHAIN CONSULTATIVE COUNCILS FOR POLICY FORMULATION}

Ecuador's agricultural sector is characterized by a variety of production systemsæboth temperate and tropicalæand a natural resource base with high production potential. There is a very competitive export sectoræbanana, flowers, and shrimpæas well as a large traditional smallholder sector producing rice, potato, coffee, cacao, maize, and livestock. The sector is characterized by low productivity even in the export sector, and most growth over the past 30 years has come from the expansion of agricultural area.

What's innovative? Using new data to bring stakeholders together into market chain consultative councils with the government.

Widespread improvement in agricultural productivity will require the government to provide key public goods, including information on which farmers, traders, processors, and financial institutions can base decisions. Improved information is equally important to the Ecuadorian Government, as it moves away from past broad-based programs to more targeted interventions aimed at helping the poor. Unfortunately the information base for public policy has been weak. The last agricultural census was conducted in 1974, and data sets no longer provide a sound basis for decision-making. An improved database was essential for sound policy formulation and development of business plans.

\section{PROJECT OBJECTIVES AND DESCRIPTION}

The Agricultural Census and Information System Technical Assistance Project aims to improve availability, consistency, validity, and timeliness of agricultural information to facilitate decision-making processes in both the public and private sector. The project includes four components:

- An Agricultural Policy Component to strengthen sector policy analysis capacity, budget analysis, and investment monitoring.

- An Agricultural Information and Dissemination Component to improve crop and livestock information services, market news and price information, agroclimatic impact forecasts, and the computer and information system capacity of the Ministry of Agriculture.

- An Agricultural Sample Census Component to support design and execution of a national sample census, and strengthen data processing capabilities.

- An Agricultural Farm Production Survey Component to improve production survey methodology, speed processing of two surveys per year, and finance one farm expenditure survey.

\section{BENEFITS AND IMPACTS}

The project financed the 2002 Ecuadorian Agricultural Census, which has provided an abundance of data on the agricultural sector and on the various commodity subsectors. As part of the process of analyzing and interpreting these data, the Ministry facilitated the formation of Consultative Councils for eleven subsectors (coffee, banana, potato, dairy, and others). Each Consultative Council comprises producers, traders, input suppliers, exporters or processors, and key ministry officials.

The Councils met originally to review data from the census. The census information was a critical motivating factor in forming the councils, because it filled a void where there had been little hard data on the size and characteristics of the subsectors. Much of the census data were originally controversial, as the data conflicted with prior views and assumptions on the sector. The Councils helped to verify and 
interpret census information and to promote awareness and use of the data. Councils continue to meet to discuss and seek solutions to subsector problems and to represent subsector interests with the government.

The main contribution of the Councils has been to facilitate dialogue between the government and the various actors in the production chain (producers, marketers, processors, exporters, and importers). Use of up-to-date, reliable information has enabled these groups to agree to manage the production chains in a rational and efficient way. There have been agreements reached on milk prices and imports, corn prices, soybean imports, and various other commodities.

The major factor contributing to the success of the 14 Councils has been their ability to discuss policy options based on factual data. The formation of the Councils was not defined in the project design, but was introduced later and seen as an opportunity to make better use of and to confirm the validity of census data.

\section{LESSONS LEARNED AND ISSUES FOR WIDER APPLICABILITY}

The Councils provide a mechanism for intervening to address problems, as all participants in the subsector are represented. This in some cases enables the Council to negotiate or initiate action to address a problem, where the government-with its limited capacityæacting alone would be unable to intervene effectively.

The Councils will continue with the active encouragement of the government, which will consider promoting formation of Consultative Councils for other subsectors as needed. Future modifications of the Consultative Council structure will likely increase the representation of smaller farmers.

Consultative Councils based on commodity market chains and industry clusters would be useful in most countries as a mechanism for consultation between the public and private sectors, and between different private sector stakeholders in a commodity production and marketing chain. Linking such Councils with data from an Agricultural Census or other analytical work on a subsector may be useful to encourage participation and provide coherence for initial Council meetings.

\section{COUNTRY PROFILE: ECUADOR}

$\begin{array}{ll}\text { Project Name } & \begin{array}{l}\text { Agricultural Census and Informa- } \\ \text { tion System Technical Assistance } \\ \text { Project }\end{array} \\ \text { Project ID } & \text { P077949 } \\ \text { Project Cost } & \text { US\$4.8 million } \\ \text { Dates } & \text { FYI999 - FY 2004 } \\ \text { Contact Point } & \text { Matthew McMahon } \\ & \begin{array}{l}\text { The World Bank, I8I8 H Street } \\ \text { NW,Washington D.C. 20433 } \\ \end{array} \\ & \text { Telephone: (202) 473-8586; } \\ & \text { Email: Mmcmahon@worldbank.org }\end{array}$


INNOVATIVE ACTIVITY PROFILE

\section{TURKEY: HYBRID ADJUSTMENT/INVESTMENT LENDING}

In the late 1990s, one of the most critical issues in Turkey's agricultural sector was the inefficient and costly system of agricultural support policies. Subsidies for fertilizer, credit and price supports, mainly for sugar, hazelnut, and tobacco, were distortionary and failed to enhance productivity growth. These agricultural policies favored larger farmers, were a heavy burden on consumers and taxpayers, and contributed to Turkey's macroeconomic problems. Reforming this system was a primary goal of a dialogue initiated with Bank policy notes and workshops in 1998, leading to inclusion of agricultural policy reform elements in the Bank's Economic Reform Loan, effective 2000, and in an IMF macroeconomic stabilization package. The reforms are also important to assist the government in meeting preconditions for EU accession. Recent work in Turkey highlights the latest usage of hybrid lending, moving the reform agenda forward quickly, but requiring "handson" coordination to ensure success.

What's innovative? Agricultural sector reform through a hybrid loan with an adjustment component supported by investment components.

\section{PROJECT OBJECTIVES AND DESCRIPTION}

The Agricultural Reform Implementation Project (ARIP) evolved from the Economic Reform Loan to ensure sustainability of the reforms, including change and formation of sustainable institutions.

Two-thirds of the loan is for an investment program with objectives to:

- Substitute subsidies with an incentiveneutral support system of Direct Income Support (DIS) payments, made on a per hectare basis to partially mitigate adverse impacts on income of removal of distortionary subsidies.

- Facilitate farmers' transition out of tobacco and hazelnut production through per hectare grants for a switch to alternative crops such as maize, soybean, sunflower, beans, vegetables, and medicinal plants, and more efficient production patterns.

- Promote more efficient cooperative marketing channels by assisting the execution of the Law on Agricultural Sales Cooperatives, through restructuring and cooperative development programs and financing labor retrenchments.

- Build public support for politically sensitive reforms.

One-third of the loan is adjustment lending that seeks to enable the government to make up some of the anticipated shortfall in funds needed for the critical first rounds of the DIS payments in 2001-03.

\section{BENEFITS AND IMPACTS}

A recent supervision report noted that the government is on track with key elements of the ARIP supported program. With payments to over 2.18 million farmers, more than 50 percent of all DIS-eligible farmers were paid under the 2001 DIS Program, exceeding by four-fold the target 12.5 percent of all farmers to be paid. In 2002, direct and indirect agricultural subsidies (not including DIS) totaled US\$1.1 billion, compared to US\$7.2 billion in 1999. No new subsidies have been introduced.

Uptake on farmer transition grants has been slow because farmers are uncertain that hazelnut and tobacco support prices are being permanently removed. However, as government credibility on this improves, uptake of this component should increase.

After a slow start, the Agricultural Support Cooperative Union reform program has had 
some success, but progress in two of the largest unions is uneven. Turning the unions into true member-owned cooperatives is still incomplete because this takes time.

\section{LESSONS LEARNED AND ISSUES FOR WIDER APPLICABILITY}

In the political economy of reform, "a spoonful of sugar helps the medicine go down." Combined adjustment and investment lending may provide the appropriate mix - drawing attention of higher-level government officials through adjustment components while also providing needed long-term investment. Typically adjustment lending is negotiated through the Ministry of Finance with implementation of policy (and painful reforms) carried out by line ministries. Adding an investment component makes these often-painful adjustments more palatable to all parties involved, and can prove particularly beneficial for reforms affecting the rural sector. In the past, hybrid lending was tried and discarded due to the mismatch of time frames for these two instruments; however, recent evolution in approaches increases the likelihood that they can prove positive complements for policy reform.

Lessons learned include:

- Laying a base for policy dialogue pays off, even if advice is not adopted right away.

- Conditionality must be clear and straightforward with strong government ownership.

- Given the macroeconomic implications of agricultural subsidies, cooperation with the IMF and integration of other Bank operations is helpful. The Bank took part in all key meetings; the Fund integrated key agricultural policy reforms into its program.

- For policy reform, a hybrid loan has important advantages over pure investment or adjustment loans. Preparing and supervising investment components keeps Bank staff involved in program details, and facilitates early resolution of design and implementation problems. The budgetary support aspect of an adjustment loan allows more Bank engagement in policy dialogue, compared to a pure investment operation.

- The investment portion of a hybrid loan makes it significantly more resource-intensive than a straight adjustment loan, and requires "hands-on" attention by the Bank.

- Giving farmers a range of options, rather than preselecting an alternative crop, was wise. A selection menu encourages adoption of and participation in programs.

- Cooperatives financed and directed by government often degenerate and lose efficiency and member participation. Member ownership and participation and relevance of services are key to sustainable development of such cooperatives.

\section{COUNTRY PROFILE: TURKEY}

\begin{tabular}{|c|c|}
\hline Project Name & $\begin{array}{l}\text { Agricultural Reform Implementa- } \\
\text { tion Project }\end{array}$ \\
\hline Project ID & P070286 \\
\hline Project Costs & US\$662.0 million \\
\hline Dates & FY 2002 - FY 2006 \\
\hline Contact Point & $\begin{array}{l}\text { Mark Lundell } \\
\text { The World Bank, I8I8 H Street } \\
\text { NW,Washington, D.C. } 20433 \\
\text { Telephone: (202) 458-4655; } \\
\text { Email: mlundell@worldbank.org; }\end{array}$ \\
\hline
\end{tabular}


INNOVATIVE ACTIVITY PROFILE

\section{GUINEA: LIVESTOCK SECTOR PARTNERSHIP-PUBLIC SECTOR HERDER ORGANIZATIONS ANDTHE PRIVATE SECTOR}

Guinea has a strong pastoral tradition, with more than 2.2 million cattle and 1.5 million small ruminants kept by 210,000 households. Before 1984, the sector was overwhelmingly dominated by the public sector. The government set cattle prices and imposed a mandatory off-take of 10 percent from each herd. The livestock public sector was overstaffed, highly centralized, poorly trained, and unable to provide adequate services to herders.

What's innovative? Reform of livestock services including developing a community system of paraprofessionals, private sector services, and public sector policy formulation.

From 1987 to 1995 a structural adjustment program for national livestock services rationalized the sector, and prepared for future transfer of productive and commercial functions to herders and the private sector. The public sector terminated 1200 government jobs, retraining dismissed agents as producers or animal health service providers. A line of credit, training plan, and study tours supported this reorientation. The government transferred state-owned clinics to the private sector, where private veterinarians demonstrated greater efficiency with better cost/benefit ratios. Herder organizations were formed to facilitate easier access to basic livestock services.

\section{PROJECT OBJECTIVES AND DESCRIPTION}

The National Agricultural Services Program helped to establish a new animal health services system based on (i) a rationalized, restructured public sector, progressively deconcentrated and refocused on core public functions, (ii) a growing network of private services providers, and (iii) herders organizations structured around socioeconomic objectives. The program established or facilitated:

- A unique mechanism for generating and diffusing technologies at the grassroots level through private agents (paraprofessionals such as auxiliaries or paravets) within herder communities to offer basic animal health services and broader livestock services.

- An environment conducive to national and foreign private firms to supply wholesale inputs and livestock products.

- Private veterinary clinics to assist paraprofessionals in herder groups distribute inputs.

- Coverage of the country's main livestock zones by private veterinary clinics and private input providers to respond to the herders' ever-increasing demands.

- Downstream construction of small commercial animal and meat markets for processing of livestock products and sub-products (hides and skin for exports).

- Strong involvement of producer organizations in production commodity chains.

- Lighter, deconcentrated public management of livestock sector institutions.

With this project the National Directorate for Livestock (NDL) refocused on its public service mission, and completed the transfer to the private sector of animal health care and inputs distribution. The NDL remained responsible for policymaking, support to the development of herder and other professional organizations (including research and extension), and epidemiological surveillance and control.

\section{BENEFITS AND IMPACTS}

The program put in place a nationwide livestock services system (input delivery, technol- 
ogy transfer, advocacy, training) based on private delivery (veterinary clinics, private farms and paraprofessionals). This improved efficiency of services and strengthened social linkages in transhumance zones of conflict (see table 1.2). Strengthened herder organizations and private operators improved demand and quality of services, such that the total numbers of auxiliaries nationwide is expected to reach 21,000 in the near futureæa $1 / 10$ ratio of auxiliaries to herders, compared to a $1 / 20$ ratio today.

Reforms contributed to an annual growth rate of the livestock sector of 5.6 percent, growth in livestock numbers from 2.4 to 3.5 million, and an increase in meat production of 12,750 metric tons. There was better coverage of herders' needs in basic animal health care and creation of additional employment. Annual fiscal revenues from the sector rose and herder organizations have been able to pay for basic services, thus ensuring the sustainability of the investment in the sector. With privatization of two state agencies, the distribution of animal health products is now entirely assumed by the private sector.

About 1,050 groups were provided with support (primarily capacity strengthening) by the DNE. In addition, DNE provided support to more than 200 departmental, provincial, regional, and national coordination committees. A total of 54 conflict management committees were established in transhumance migratory areas to help resolve conflicts between farmers and herders.

Table 1.2 Changes in the Guinea livestock sector, 1987-2000

\begin{tabular}{lrr} 
Sector Stakeholders & Pre-1987 & 2000 \\
\hline Herders' Associations & 0 & 1050 \\
Private Veterinarians & 0 & 42 \\
Auxiliaries Animal Health Workers & 0 & 11,800 \\
Government Livestock Agents & $1800+$ & 691 \\
Government Livestock Staff in Cities & $1080+$ & 55
\end{tabular}

Source:World Bank Internal Documents.

\section{LESSONS LEARNED AND ISSUES FOR WIDER APPLICABILITY}

The Guinea experience can serve as a model for rehabilitation of the livestock sector. Specific strategies and investments will vary depending on local situations, but four conditions are likely to be required for any successful reform initiatives:

- Reform is a long-term process that spans the life of more than one project. It requires the adoption of an agreed approach by all concerned parties to be successful. The case of the livestock reforms is such an example. It has taken over a decade to implement and has broad support of all involved.

- Working through existing national directorates instead of project units, and using civil servants instead of contractual personnel for project implementation, strengthens government's capacity and ownership.

- Political buy-in of the government into a major privatization initiative is an absolute necessity for its successful implementation. This can be achieved by demonstrating upfront that privatization can be a win-win proposition as in the case of the DNE.

- Motivating and equipping staff to leave the public sector is not merely achieved through training. A sound program must also assist concerned staff during the transition.

\section{COUNTRY PROFILE: GUINEA}
Project Name
National Agricultural Services Program (Livestock Health and Animal Health Component)
Project ID P00I08I
Project Component Cost US\$5.9 million
Dates FY $1997-$ FY 200I
Contact Point Francois Le Gall
The World Bank, 1818 H Street NW, Washington D.C. 20433 Telephone: (202) 473-0355; Email: Flegall I@worldbank.org 


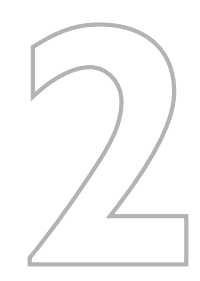

\section{INVESTMENTS IN AGRICULTURAL SCIENCE AND TECHNOLOGY}

igher rates of growth in agricultural productivity are essential to promote broad-based economic growth, reduce rural poverty, and conserve natural resources. Productivity growth, in turn, is based largely on application of science, technology, and information, provided through national agricultural research and development (R\&D) systemsænot just public organizations, but all organizations that generate, share, import, and use agricultural knowledge and information.

\section{RATIONAL FOR INVESTMENT}

Investment in agricultural science and technology (S\&T) has been critically important to past growth performance, and is likely to be even more important for achieving future global development priorities, especially the Millennium Development Goals (MDG) of halving poverty and hunger by 20I5. The challenge in deciding future investments in agricultural R\&D is to maintain past productivity gains, while supporting technological innovation in more diverse agricultural systems that will differentiate products and add value by processing, to enable rural producers to capture a larger share of the gains.Accordingly, 
the World Bank's current rural strategy, Reaching the Rural Poor, places high priority on investments in agricultural S\&T.

Growth AND COMPETITIVENESS. S\&T underpin innovation needed to promote economic growth, and enhance competitiveness. Agriculture is a critical sector in many countries, especially in low-income countries. Although complementary investments in policy reform, markets, and institutions are necessary, investment in S\&T is a key element in enhancing a country's competitive advantage by reducing production costs, improving product quality, and generally increasing efficiency along the commodity chain.

POVERTY REDUCTION. Investment in agricultural research has major impacts on poverty reduction through direct effects on producer incomes, indirect effects on consumer welfare through lower food prices, employment and wage effects, and growth-induced effects throughout the economy (see box 2.1). International Food

\section{Box 2.I Past contributions of science and technology}

The historical focus of research efforts on food crop technologies, with emphasis on genetic improvement, has been undeniably successful. Average crop yields in developing countries have increased by 71 percent since 1961, while average grain yields have doubled (to 2.8 tons per hectare). Yields of many commercial crops and livestock have also grown rapidly (see inset figure below).

Yield growth in developing countries, 196 I-200 I

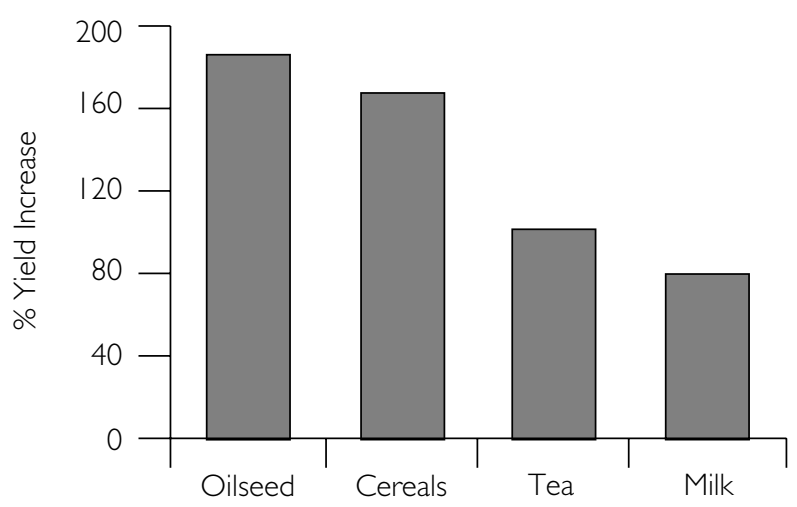

Source: FAOSTAT 2002.
Policy Research Institute (IFPRI) studies on impacts of public investment in India and China show agricultural R\&D to have higher impacts on poverty reduction than do most other public investments, behind only investment in education in China and rural roads in India (Fan, Zhang, and Zhang 2000; Fan, Hazell, and Thorat 1999). Studies show that in low-income countries, a one percent increase in agricultural yields leads to a 0.8 percent reduction in the number of people below the poverty line (Thirtle, Lin, and Piesse 2003).

Over the long term, effects on food prices are especially important, as food is a large share of the expenditures of poor households. Employment and wage effects of labor-intensive production and value-added processing are especially important to poor people, who depend relatively more on wage labor (see box 2.2).

FOOD SECURITY. By 2020, IFPRI projects food needs in developing countries to increase by nearly 600 million tons which is equal to onethird of current world food production. Continued investment to increase productivity and enhanced environmental sustainability of production systems is needed to ensure global food security. Investments in technology must also enhance household food security by increasing productivity of household food production, smoothing seasonal availability, mitigating the effects of drought, and improving nutritional content.

ENVIRONMENT AND NATURAL RESOURCES. Future increases in agricultural productivity must come from intensification, rather than exploitation of additional natural resources. Agricultural systems must use natural resources more efficiently and repair past damage to ecosystems. This depends on application of scientific knowledge, developing farmers' skills, and a policy framework to improve resource use and conservation.

Public GOODS. Many products of agricultural research are public goods that the private sector lacks incentives to produce. Small 
Box 2.2. Agricultural research and development and poor people

Experience indicates that a broad-based approach to promoting agricultural growth can have substantial impacts on poverty reduction, providing agriculture is important to the incomes of rural poor; the agro-ecological base allows significant potential for productivity growth; land distribution is relatively equitable; and the poor consume nontradable food staples. This is illustrated by evidence from India (see inset figure A) and Nigeria (see inset figure B). Without these preconditions, agricultural research may still have strong poverty reduction impacts, but must be carefully targeted at poor producers and consumers.

India: elasticity of poverty reduction with respect to yield growth

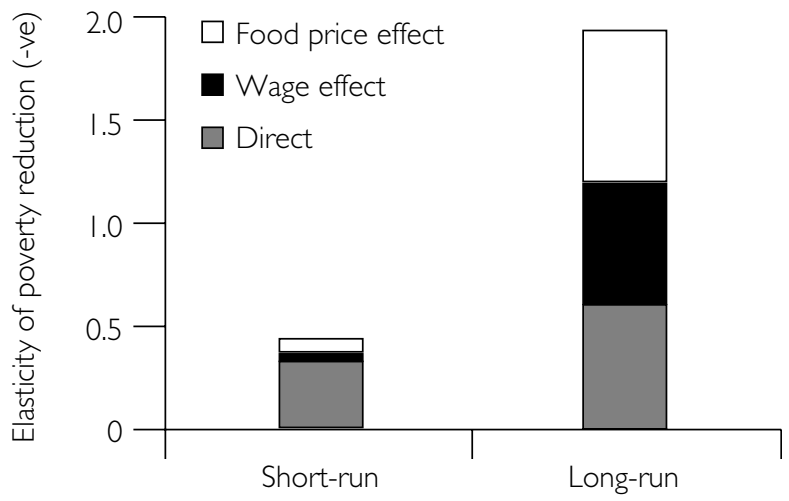

Source: Datt and Ravallion 1998

\section{Nigeria: impact of cassava research and development}

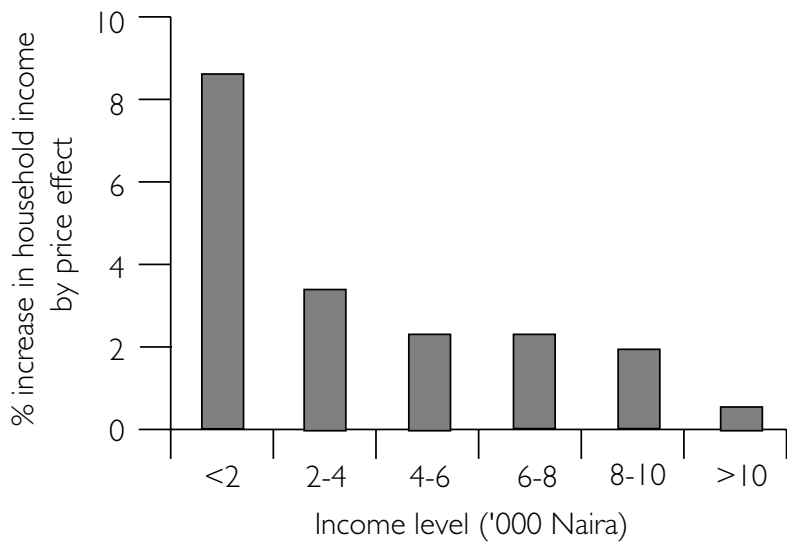

Source: Source: Afolami and Falusi 1999

Source: Datt and Ravallion 1998; Afolami and Falusi 1999

farmers with limited purchasing power are not organized to finance research. Private firms, with limited opportunity to appropriate profits from provision of technologies, will not invest sufficiently in research. Because of these market failures and because of long-term risky payoffs, the public sector funds most agricultural research, especially in developing countries (see figure 2.1). Although private sector funding for agricultural research is expanding rapidly, due in part to the application of stronger intellectual property protection, this private research often relies on knowledge provided by publiclyfunded research.

ECONOMIC RETURNS TO INVESTMENT IN SCIENCE AND TECHNOLOGy. Studies consistently show high returns to investments in agricultural research in developing countries, averaging over 40 percent (see table 2.1). Rates of return tend to be higher for research in industrial countries and for commodities with short production cycles. The paradox is that, despite such evidence off high returns, agricultural R\&D funding is stagnating in many countries.

\section{PAST INVESTMENT ACTIVITY}

In the early 1980s, as the Bank recognized the major contribution of R\&D to increasing agricultural production, lending for agricultural R\&D increased rapidly to become a priority in the agricultural loan portfolio. Since 1980, the Bank has provided over US $\$ 2.5$ billion for agricultural research in about 100 countries (see figure 2.2), accounting for a large share of all external support for agricultural research in developing countries. In addition, the Bank is a leading contributor to the Consultative Group on International

Agricultural Research (CGIAR), granting US $\$ 50$ million annually to the system. However, despite the high priority accorded to agricul- 
FIGURE 2.I PUBLIC AND PRIVATE AGRICULTURAL R\&D INVESTMENT, I 976-95

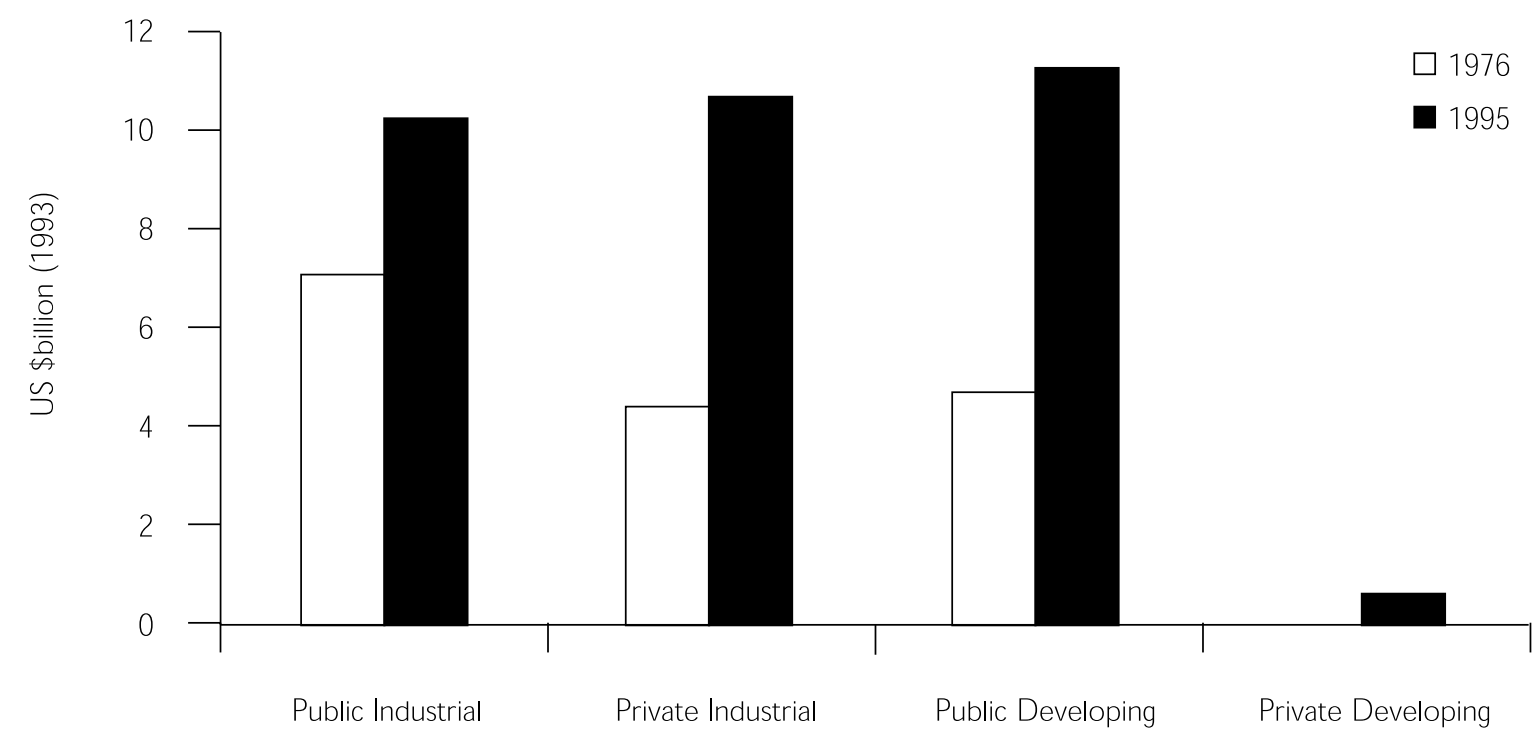

Source: Pardey and Beintema 200I.

tural S\&T in the Bank's rural strategies, lending has fallen sharply since 1998. This is especially so in Africa and South Asia, where past investments often failed because borrowing countries had not committed to a program of sustainable institutional development.

World Bank support to agricultural technology programs has evolved over time. A "bricks and

Table 2.I. Estimated rates of return to investment in agricultural research

\begin{tabular}{lcc} 
Region & $\begin{array}{c}\text { Number } \\
\text { of estimates }\end{array}$ & $\begin{array}{c}\text { Median rate } \\
\text { of return (\%) }\end{array}$ \\
\hline Africa & 188 & 34 \\
Asia & 222 & 50 \\
Latin America & 262 & 43 \\
Middle East/North Africa & II & 36 \\
All developing countries & 683 & 43 \\
All developed countries & 990 & 46 \\
All & I,772 & 44 \\
\hline Note : Information based on studies carried out from 1953 to 1997. \\
Source: Alston et al. I998.
\end{tabular}

mortar" period up to the early 1980s emphasized expanding public sector research through investment in physical infrastructure, equipment, and human resource development, in many cases to create centralized national agricultural research organizations/institutions (NAROs/NARIs). From the late 1980s, emphasis shifted to improving management of existing public sector research organizations through better planning, improved financial management, greater accountability, and increased relevance of programs to clients. In the mid-to-late 1990s the instability and inefficiency evident in many public research organizations (see box 2.3) led to an emphasis on development of institutionally pluralistic agricultural knowledge and information systems (AKISs) with greater client and private sector participation and financing.

A 1997 evaluation of World Bank lending for agricultural research from 1980 through the early 1990s suggested that portfolio performance should be rated as "unacceptable" (Purcell and Anderson 1997). The evaluation recommended that the Bank provide comprehensive assistance for research systems, only when the borrower makes a clear commitment to adequately fund the system and to adopt sound management principles. 
FIGURE 2.2 LENDING FOR AGRICULTURAL RESEARCH, I 98 I-2002

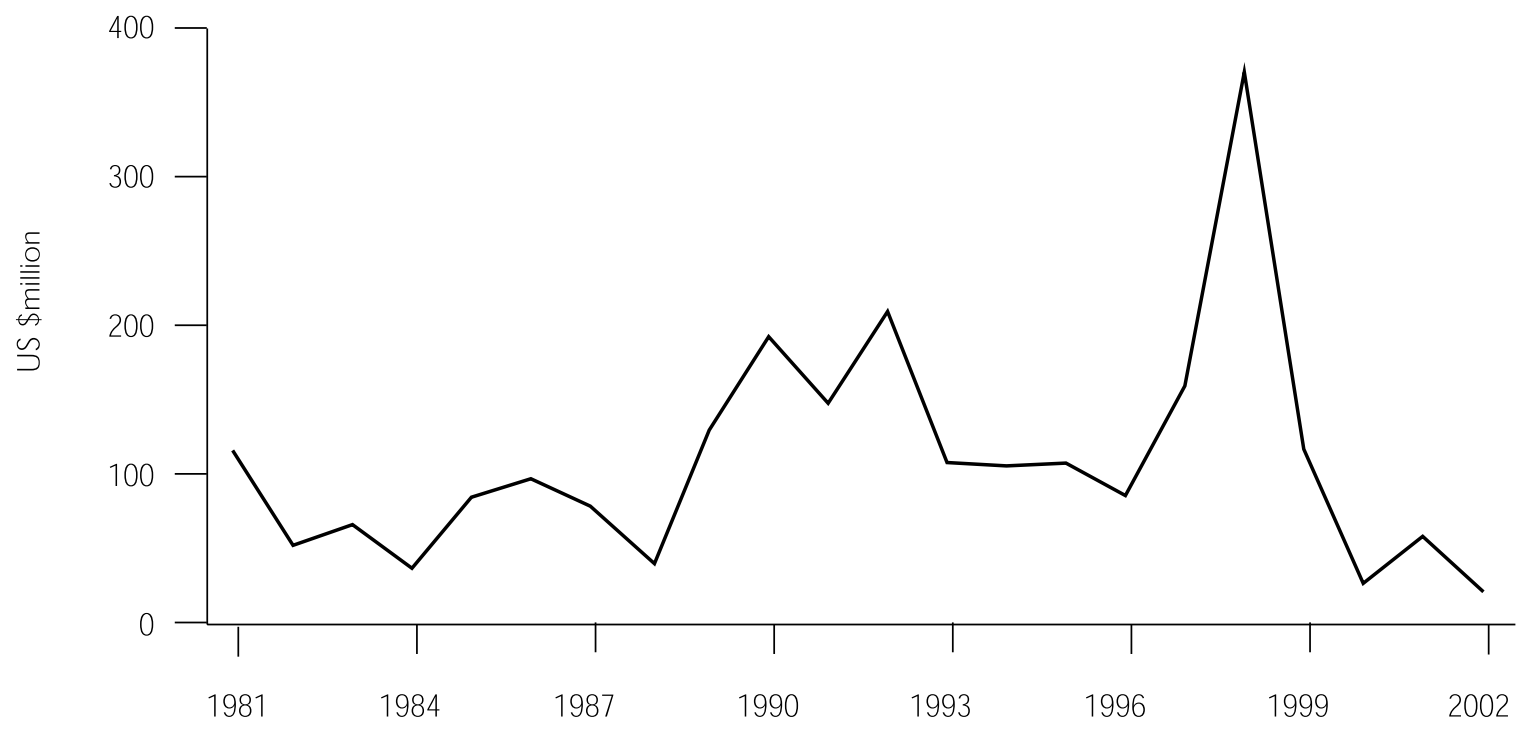

Source:World Bank Internal Documents.

Since 1997, the Bank has supported agricultural R\&D within the framework of the development of effective and efficient AKISs that "link people and institutions to promote mutual learning and generate, share and utilize agriculture-related technology, knowledge and information" (FAO/ World Bank 2000). Such a system integrates farmers, agricultural educators, researchers, and extensionists to harness knowledge and information from various sources for improved livelihoods (see figure 2.3). Farmers are at the heart of this knowledge triangle and, along with other rural people, must be central partners. Investments in this system must be long term, focused on support to increasing rural innovation and competitiveness, and follow a set of guiding principles (see box 2.4).

\section{FUTURE DIRECTIONS FOR LENDING}

Promoting PluRalistic sYsTems. Public research agencies will remain central to providing coherence to many research efforts. ${ }^{1}$ Strategies, however, must enhance, not restrict, participa-

Box 2.3 Common problems in public research organizations

Common problems identified in reviews of World Bank support to agricultural research result from strong path-dependency in institutional development and slow institutional and policy change:

- Lack of a consensus on a strategic vision for public sector research organizations and the evolution of the research system.

- Ineffective leadership for many research organizations, resulting in internal management problems and lack of political support and funding for research.

- Continued emphasis on building centralized national agricultural research organizations/institutes (NAROs/NARIs) at the expense of fostering a public-private system, including universities.

- Difficulties in establishing an appropriate legal and governance framework for research organizations to provide the efficiency and flexibility needed in management of financial, physical, and human resources.

- Loss of highly qualified scientific staff, and difficulties in recruiting the best and the brightest.

- Weak links of NAROs with other research providers, clients, technology transfer agencies and developmental organizations.

- Weak accountability to clients and funders.

Source: Authors

I. See the AIN,"Strengthening Public Research Institutes" 
FIGURE 2.3 ARGRICULTURAL KNOWLEDGE TRIANGLE

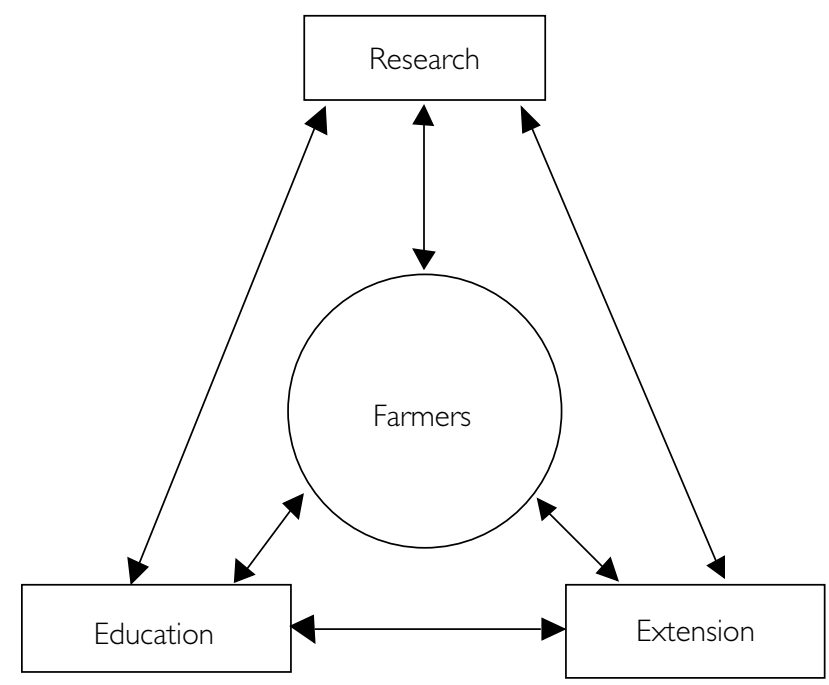

tion by the full range of research providers, including universities, private firms, nongovernmental organizations (NGOs), and farmer organizations. This will require:

- Defining public and private roles. Effective research systems incorporate both public and private organizations, each filling the role for which it has an advantage. Public funding is critical to provide public goods and to establish the rules of the game that encourage an efficient overall research system. Not all countries can afford extensive public systems, but all must have institutional capacity to provide rural people access to benefits from advances in S\&T, whether developed at home or elsewhere. Efforts to promote greater private sector

\section{Box 2.4 Guiding principles for investment in research systems}

The World Bank and FAO developed the following guiding principles for agricultural knowledge and information systems (AKISs) program design:

Defined role for the public sector. Research investments need to target public funding for the provision of public goods so that investments are:

- Made within a sound policy framework.

- Based on clear national strategies that articulate a longterm vision and national policies, plans, and objectives for research.

- Economically efficient with benefits and expected outcomes that justify the investment.

- Equitable with research results available to the poor and minority groups.

Strengthened demand for services. Strengthening demand is critical to improving their efficiency, effectiveness, and sustainability, and requires that investments be:

- Demand-driven responding to farmer needs and interests and involving clients in program governance, priority setting, and evaluation.

- Participatory, empowering local people to solve problems and mobilize resources.

- Based on subsidiarity with responsibilities devolved to the lowest possible level of government consistent with competency, comparative advantage, and efficient use of funds.

Improved quality of services. Management improvements essential to improving research execution require that research programs are:
- Accountable for use of funds and for results, with incentive structures that ensure assignment of qualified staff who are given adequate support and held responsible for results.

- Relevant to the needs and resource constraints of different categories of clients, balancing objectives of profitability, productivity, and sustainability.

- Pluralistic, involving a range of institutions with different comparative advantages undertaking different research activities.

- Well monitored and evaluated to ensure a resultsorientation; account for impacts on human, social, and environmental capital; and demonstrate cost effectiveness.

Based on a sustainable system. Institutional sustainability depends on principles listed above and on financial sustainability and development of institutional capacity through investments that:

- Develop human and social capital necessary for clients and local institutions to be capable of continuous learning and problem solving.

- Are cost-shared by major stakeholders, based on agreed criteria including ability to pay for and use research results.

- Develop political support from stakeholders as a basis for securing future financing.

Source: FAOMorld Bank 2000. 
participation in developing country research systems have mixed results but remain a long-term priority for science policy.

\section{- Improving science and technology policy.} Many countries have invested substantially in technology development, while restricting import of "free" technology available through access from abroad i.e. "spill-ins". Sound policy frameworks for innovation (intellectual property rights (IPRs), biosafety regulations, genetic resources policy, and seed and input market regulations) are prerequisites to efficient functioning of scientific organizations and to enabling developing countries to reap benefits from global advances in S\&T.

- Delinking funding and execution. Decisions on financing of public goods can often be separated from responsibilities for producing them and, even when public financing of services is justified, the private sector (for-profit or not-for-profit) is often more efficient in delivering the product. Initial experiences show that competitively contracting S\&T services divides responsibility between the public and private sectors and improves the quality, accountability, and impact of services.

- Promoting partnerships. An efficient and effective division of labor for S\&T depends on partnerships to integrate the various players into an overall system. Partnerships allow for specialization, exploit institutional comparative advantage, and may reduce costs. Partnerships are often particularly useful in linking institutions with differing competitive advantages for work at different levels of the research continuum, as with international research centers for strategic research, and NGOs and producer organizations for adaptive research.

STRENGTHENING DEMAND FOR RESEARCH PRODUCTS. Past investments in S\&T have mostly focused on supply of research products. Farmers, and especially poor farmers, generally lack ability to participate in funding, priority setting, execu- tion, and evaluation of research programs. To be effective and sustainable, research systems must become more responsive to client demands and interests and become more accountable to clients by:

- Encouraging participation. Empowering farmers as purchasers, providers, and cofinanciers of research helps ensure that research systems respond to their needs. Rapid appraisals and participatory on-farm research draws on farmer knowledge and provides opportunities for them to participate fully in planning, executing, and evaluating research. Farmer and other stakeholder participation on research governing boards and advisory panels can have real influence over research decisions and priorities. Participation of women farmers is particularly important, given their crucial role in rural production systems; the special constraints under which they operate (for example, time constraints); and their range of activities and enterprises, including marketing, agroprocessing, and food storage.

- Decentralizing and deconcentrating research. Decentralization strategies being pursued in many countries lead to complex trade-offs in the case of agricultural research. Deconcentrating research involves establishing research facilities under a central research institute but located in different agro-ecological zones or political units (for example, provinces). Decentralization devolves funding, governance, and administrative responsibilities to regional, state, or local governments. Both approaches can bring scientists closer to clients and better focus research on local problems and opportunities, but they can also result in inefficient and fragmented systems that fail to take advantage of important economies of size and scope in much R\&D. However, where possible, decentralizing adaptive research is desirable, by ultimately allocating funding to users, who then contract needed research services (see figure 2.4). 
FIGURE 2.4 PUBLIC AGRICULTURAL RESEARCH FUNDING

The old arrangement

Funders

Providers

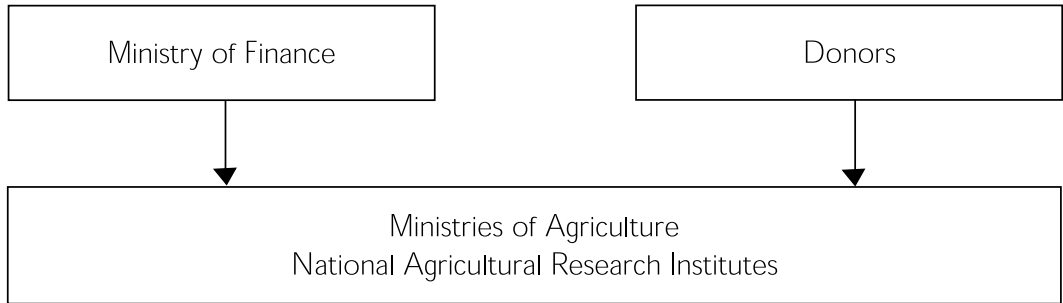

The new arrangement

Funders

Providers

Fund allocation \& coordinating bodies

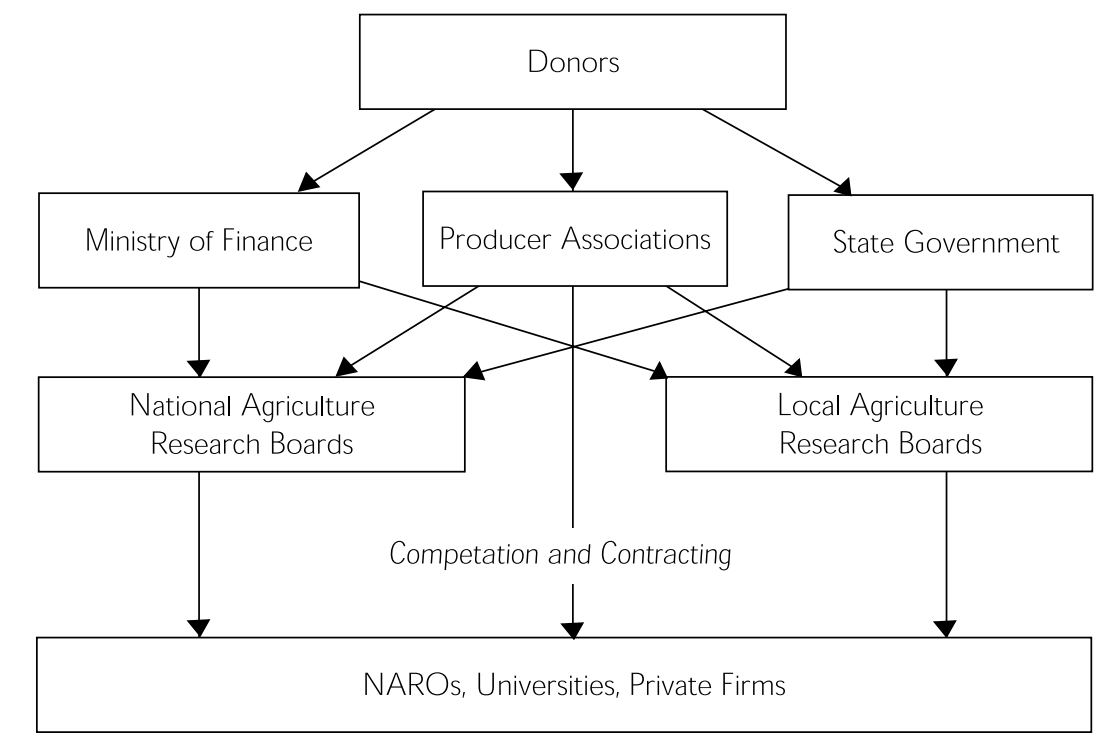

- Responding to consumer demand. Increasing consumer purchasing power and changes in food preferences will promote the market signals to direct private R\&D. Public research programs also must also learn to respond better to market demands.

Sustainability of R\&D inVestments. Many public research organizations have suffered financial crises with declining budgets leading to minimal operating budgets and erosion of salaries and incentives. Financing a recurrent cycle of expansion and decline of public research organizations under consecutive Bank projects is inefficient and requires greater attention to:
- Right-sizing. Sustainability demands that national governments provide adequate budgetary support to agricultural R\&D, and 'right-size' research organizations to the resources available, using funds saved for operating costs and for paying scientists competitive salaries. Without evidence of government commitment to such policies and reforms, external investment directed to public research organizations is inefficient and unsustainable. Agricultural R\&D must receive priority in national budgets.

- Ensuring sustainable financing. Public investment in agricultural research in developing countries must increase sharply 
FIGURE 2.5 AGRICULTURAL RESEARCH INTENSITY BY REGION; PUBLIC SECTOR ONLY

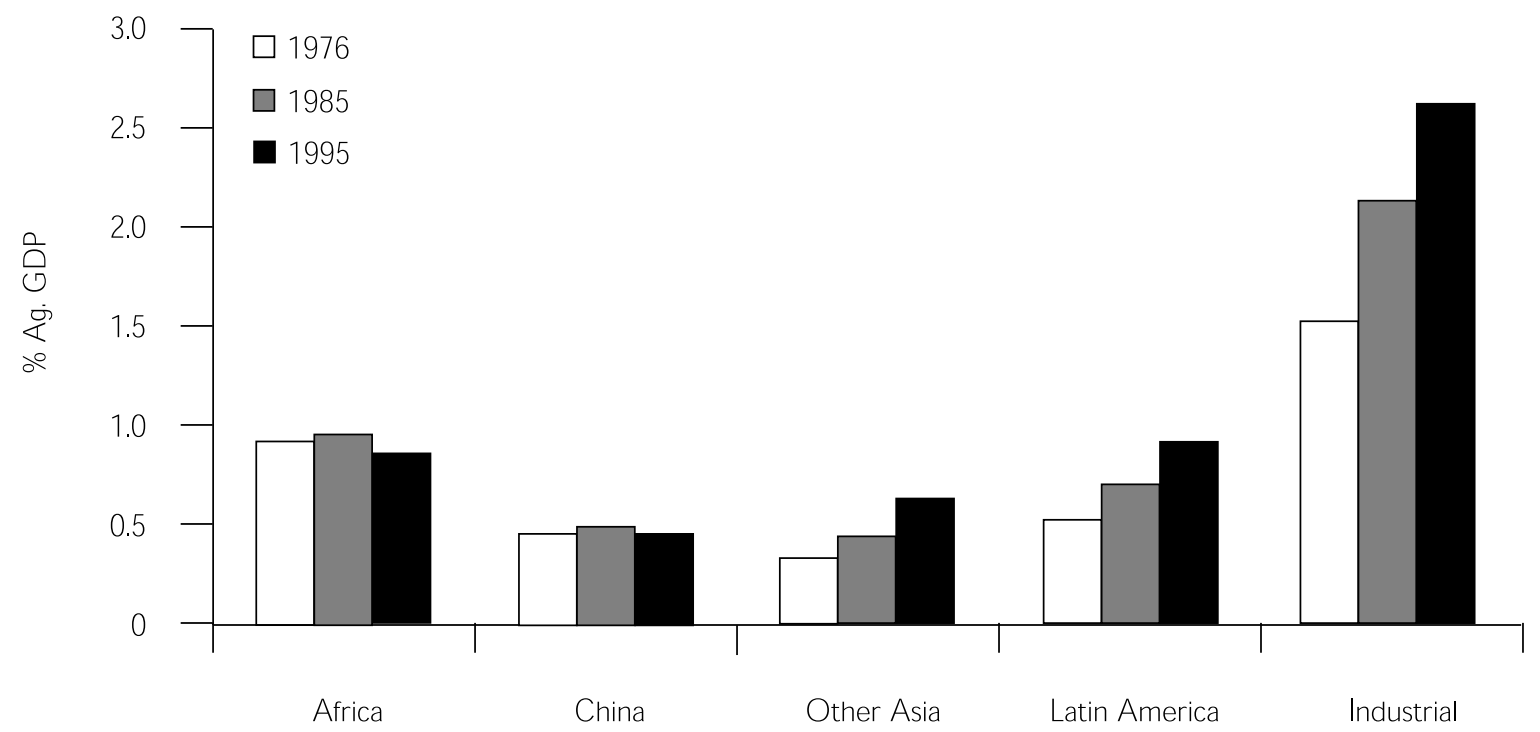

Source: Pardey and Beintema 200I.

in order to promote a dynamic and competitive agricultural sector (see figure 2.5). In almost all cases, government must provide core funding for public research institutions (or universities) that maintain a core scientific capacity to undertake longterm public good research.

- Improving management. Currently, many research organizations are unproductive, suffering from poor leadership, onerous bureaucratic procedures, political interference, low morale, and weak links to clients. Reforms are needed, through long-term support for institutional development to address problems of inadequate operating funds, weak human resource policies, lack of performance incentives, and lack of clear priorities. In many cases, this requires the creation of flexible and efficient autonomous research organizations that are run along private-sector lines, with independent governing boards representing key stakeholders.

- Accountability. Reforms must make research institutions and researchers accountable to clients and funding agencies. Client co-financing of research, participation in governance bodies, and participa- tory evaluation are key to ensuring accountability. Such reforms should help to develop a local political constituency for sustainable organizations, but this will generally require better evaluation of impacts and diffusion efforts to increase public awareness of these impacts.

CHANGING RESEARCH PRIORITIES. Research systems must reconcile national priorities derived from national development strategies and policies, with demand driven and market-oriented priorities arising from clients. However, future investments will often give priority to the following areas:

- Improved poverty targeting. With the private sector increasingly serving the commercial farming sector, public funding must focus more sharply on the poor. Public R\&D organization must carefully set priorities in terms of commodities, regions, and types of technology important to the poor, combined with bottom-up processes of participatory priority setting, executing, and evaluating research. Poverty targeting leads to quite different strategies for different types of farmers (see table 2.2). Gender is relevant also in targeting S\&T investments 
Table 2.2 Strategies for enhancing poverty reduction of agricultural research by farm type

\begin{tabular}{|c|c|c|c|}
\hline Sector & Direct impacts & Indirect impacts & Major R\&D actors \\
\hline Commercial farmers & $\begin{array}{l}\text { - Increase micronutrient } \\
\text { content of food to provide } \\
\text { nutritional benefits }\end{array}$ & $\begin{array}{l}\text { - Increase productivity to } \\
\text { reduce food prices for } \\
\text { non-tradable food staples } \\
\text { - Generate employment in } \\
\text { high-value industries, } \\
\text { processing and handling }\end{array}$ & $\begin{array}{l}\text { - Private agribusiness } \\
\text { - Public regulatory } \\
\text { framework } \\
\text { - Producer/trade } \\
\text { organizations }\end{array}$ \\
\hline $\begin{array}{l}\text { Small, market-oriented } \\
\text { farmers }\end{array}$ & $\begin{array}{l}\text { - Diversify production to } \\
\text { increase value-addition } \\
\text { and high value crop/ } \\
\text { livestock production } \\
\text { - Develop technologies to } \\
\text { reduce production risks } \\
\text { - Strengthen producer } \\
\text { organizations to improve } \\
\text { demand for research and } \\
\text { build human and social } \\
\text { capital }\end{array}$ & $\begin{array}{l}\text { - Increase agricultural } \\
\text { productivity to stimulate } \\
\text { overall economic growth } \\
\text { - Diversify production } \\
\text { systems to generate } \\
\text { employment } \\
\text { - Increase productivity to } \\
\text { reduce food prices } \\
\text { - Increase value-added }\end{array}$ & $\begin{array}{l}\text { - Public research } \\
\text { - Public-private partnerships } \\
\text { - Producer organizations } \\
\text { - NGOs }\end{array}$ \\
\hline $\begin{array}{l}\text { Subsistence-oriented } \\
\text { farmers }\end{array}$ & $\begin{array}{l}\text { - Increase productivity and } \\
\text { reduce production risks } \\
\text { and improve storage and } \\
\text { utilization of food } \\
\text { - Reduce labor require- } \\
\text { ment for tasks performed } \\
\text { by women and the very } \\
\text { poor } \\
\text { - Encourage market access } \\
\text { for higher value crops/ } \\
\text { livestock } \\
\text { - Improve natural resource } \\
\text { management (NRM) }\end{array}$ & $\begin{array}{l}\text { - Build human and social } \\
\text { capital necessary to } \\
\text { address a range of } \\
\text { livelihood opportunities }\end{array}$ & $\begin{array}{l}\text { - Public research } \\
\text { - Producer and community } \\
\text { organizations } \\
\text { - Women's groups } \\
\text { - NGOs }\end{array}$ \\
\hline
\end{tabular}

Source: Byerlee and Alex 2002.

to reduce poverty, as a large share of poor farmers are women in most developing countries and the number of women farmers is increasing as men migrate to off-farm employment.

- Aligning RED to market trends. Improved technology and information, especially at the postharvest stage, is essential to help farmers to orient to market needs, lower costs, im- prove product quality and food safety, meet more demanding grade and standard requirements, and diversify to higher-value and niche products. Nontraditional exports (for example, horticultural exports, cut flowers, organic foods) offer potential for major increases in rural employment and incomes, but frequently require substantial research and an entirely new base of knowledge and skills not generally available in country. 
- Natural resources and environmental conservation. Degradation of natural resources and public concern over environmental issues, are shifting research priorities and funding toward broader issues, many global in nature such as land, water, forests, and biodiversity; pesticide safety, and residue minimization; livestock waste management; water quality preservation; and watershed protection. There are also increasing opportunities for agriculture to provide environmental services through carbon farming and conserving biodiversity. Success in meeting these challenges requires sharply increased skills in research on natural resources management (NRM), social sciences, and environmental issues.

- Social science and policy research. In many research systems, there is a perennial problem of maintaining capacity to carry out socioeconomic research. This will become even more crucial in future, with the need to provide support to public policy formulation, poverty reduction, a more market-oriented agriculture, and natural resource management.

ACCessing NeW KNOWLEDGe. Developing countries will need to make use of the latest advances in S\&T to address intractable problems in agricultural production and exploit new opportunities. Country size and level of technological development will shape different strategies for different countries, as they seek to overcome both scientific and institutional constraints associated with the use of new technologies. Key strategies to tap benefits from new technologies include:

\section{- Investing in advanced science and technol-} ogy. Biotechnology and information and communications technologies provide new tools to address the needs of the rural poor. To a large extent, developing countries are not sharing in the benefits from these advances, thus creating "molecular" and "digital" divides. While strategies to access these new technologies will vary with country science capacity and level of development, all countries will need to strengthen their policy and regulatory frameworks for IPRs, biosafety and food safety, and identity preservation (that is, tracability of products from farm to consumer).

- Strategic alliances and partnerships. All countries can benefit from regulatory frameworks favorable to technology spillins, public-private partnerships, and regional and international alliances. Links to the CGIAR enable many developing countries to tap sources of new knowledge and innovations. However, since many commodities are not covered by the CGIAR (for example, horticulture, tropical fruits, and coffee) research organizations must seek a broader range of partners. Regional research initiatives led by regional or subregional agricultural research organizations are especially important in sharing the cost of research for many small countries.

- Managing IPRs. Proprietary technologies are important in providing incentives for private sector research investments, but the results of such investments often do not benefit the poor. Public research institutions need the capacity to form partnerships or contractual arrangements to obtain use of proprietary scientific knowledge and to patent their own research in ways that will protect the interests of resource-poor farmers.

STRENGTHENING UPTAKE PATHWAYS. Linear systems of research that pass recommendations to extension, which then transfers them to farmers, are largely obsolete. AKISs have become more pluralistic, and farmers now seek out advisory and information services from a variety of sources. R\&D organizations must use a range of potential uptake pathways or institutional mechanisms to provide research results to users.

- Commercializing research products. Public research institutions will increasingly rely on private sector market mechanisms for dissemination of research products. 
Establishing links early in the research process is often critical to ensure that appropriate partnerships are established and that the final research product can be used. Clustering of industries and $R \& D$ organizations into science parks may facilitate commercialization of public sector innovations. The success of the industrial clusters has varied greatly and seems to relate to the level of critical mass in the cluster, the diversification of the companies, the economic incentives provided, and the intensity of interaction between R\&D bodies and business communities.

\section{- Linking to demand-driven extension sys-} tems. Decentralized extension services accountable to local user groups should facilitate client "purchase" of research services and products that respond to their needs. Matching grant programs for farmer and community groups can allow them to test and disseminate new technologies. A number of countries have introduced competitive grant programs to provide such grants to farmer groups.

\section{SCALING UP INVESTMENTS}

Investments in S\&T to support rural development remain a priority for the World Bank Group. Research reforms such as competitive funding, contractual mechanisms, user funds, decentralization, science parks, and regional and international partnerships, have promise. However, for most of these initiatives, experience is still limited, and more in-depth evaluation is required prior to wider scaling up. Biotechnology is also a key investment priority, but monitoring of risks, both actual and perceived, must be an integral part of Bank support. Complementary investments in agricultural education have been neglected, but are essential to ensure a new generation of agricultural scientists and leaders.

Agricultural investments must be tailored to individual country conditions and needs, and sustainability of investments is a continuing challenge. Long-term commitments, through adjustable program lending and sequential operations, are important to building institutional capacity and sustainability of agricultural knowledge and information systems. The level of financing provided might be less per year than in the past, but continued over a longer period.

Increased agricultural S\&T sector analysis and policy dialogue are needed in many countries that have yet to commit to reform of their agricultural research systems. In these cases, policy dialogue will provide options for moving forward with reforms, before Bank support to agricultural S\&T is renewed. Better monitoring and evaluation of research programs at all levels is essential to improve program management and impacts, enhance scientific quality, and demonstrate results to funding agencies.

Finally, important gaps in established good practice that need to be addressed in future work include new approaches to researchextension linkages in decentralized systems, commercialization of research products, decentralizing research, involving producer organizations in financing and executing research, and multicountry research investments.

\section{SELECTED READINGS}

Asterisk (*) at the end of a reference indicates that it is available on the Web. See Appendix 1 for a full list of Websites.

Byerlee, D., and R. G. Echeverria, eds. 2002. Agricultural Research Policy in an Era of Privatization. Wallingford, U.K.: CABI Publishing.

Chema, S., E. Gilbert, and H. Roseboom. In Press. A Critical Review of Key Issues and Recent Experiences in Reforming Agricultural Research in Africa. Research Report 24. The Hague: ISNAR.*

Gijsbers, G., W. Janssen, H. Hambly Odame, and G. Meijerink, eds. 2001. Planning 
Agricultural Research: A Sourcebook. Wallingford, U.K.: CABI Publishing.

ISNAR. International Service for National Agricultural Research. http:// www.isnar.cgiar.org.

Pardey, P., and N. Beintema. 2001. Slow Magic: Agricultural RED a Century after Mendel. Food Policy Report. Washington, D.C.: IFPRI.*

Tabor, S., W. Janssen, and H. Bruneau, eds. 1998. Financing Agricultural Research: A Sourcebook. The Hague: ISNAR.*

World Bank. AKIS Sustainable Agriculture. http://www.worldbank.org/akis.

\section{REFERENCES CITED}

Afolami, C. and A. Falusi. 1999. "Effect of Technology Change and Commercialisation on Income Equity in Nigeria: The Case of Improved Cassava." Paper presented at Assessing the Impact of Agricultural Research on Poverty Alleviation workshop, sponsored by CIAT, San Jose, Costa Rica.

Alston, J. M., M. C. Marra, P. G. Pardey, and T. J. Wyatt. 1998. Research Returns Redux: A Meta-Analysis of the Returns to Agricultural $R E D$. EPTD Discussion Paper No. 38. Washington, D.C.: IFPRI.

Byerlee, D., and G. Alex. 2002. "Designing Investments in Agricultural Research for Enhanced Poverty Impacts." SASKI Good Practice Note. World Bank, Washington, D.C.

Datt, G., and M. Ravallion. 1998. "Farm Productivity and Rural Poverty in India." FCND Discussion Paper 42. IFPRI, Washington, D.C.

Fan, S., L. Zhang, and X. Zhang. 2000. Growth and Poverty in Rural China: The Role of Public Investments. EPTD Discussion Paper 66. Washington, D.C.: IFPRI.

Fan, S., P. Hazell, and S. Thorat. 1999. Linkages between Government Spending, Growth, and Poverty in Rural India. Research Report 110. Washington, D.C.: IFPRI.

FAO/World Bank. 2000. "Agricultural Knowledge and Information Systems for Rural Development: Strategic Vision and Guiding Principles." FAO, Rome; World Bank, Washington, D.C.

FAOSTAT. 2002. FAO Statistical Databases. http://apps.fao.org/default.htm.

Pardey, P., and N. Beintema. 2001. Slow Magic: Agricultural R\&D a Century after Mendel. Food Policy Report. Washington, D.C.: IFPRI.

Purcell, D. L. and J. R. Anderson. 1997. Agricultural Extension and Research: Achievements and Problems in National Systems. Operations Evaluation Study. Washington, D.C.: World Bank.

Thirtle, C., L. Lin, and J. Piesse. 2003. "The Impact Of Research Led Agriculture Productivity Growth On Poverty Reduction In Africa, Asia And Latin America." Contributed paper for the 25th conference of the International Association of Agricultural Economists, Durban.

This Overview was prepared by Derek Byerlee, Gary Alex, and Eija Pehu, with inputs from the Sustainable Agriculture (SASKI) Thematic Team of the Bank. Peer review comments were provided by Marie-Hélène Collion, Howard Elliott, Juergen Voegele, and Jacob Kampen. 


\section{AGRICULTURE INVESTMENT NOTE}

\section{COMPETITIVE RESEARCH FUNDS}

Competitive research funds are being introduced in many countries for financing agricultural research, to mobilize available research capacity, stimulate scientific creativity, and promote efficiencies in the research system. Competitive research funds can be an effective mechanism for allocating resources for agricultural research and can drive reform of the overall research system. High-quality review, administrative efficiency, and transparent processes are essential to program credibility, but most programs have yet to develop sustainability strategies.

Many countries are seeking to reform to national agricultural research systems that have become unproductive due to lack of operating funds, incentives, and flexibility. Competitive research funds are used as financing mechanisms to mobilize available scientists for work on key problems, develop institutional linkages and research capacities across organizations, and to link scientists with users of new technologies.

\section{COMPETITIVE RESEARCH GRANTS PROGRAMS}

(CRGPs) research providers are selected on a competitive basis, using calls for proposals and

scientific peer review to allocate funding. CRGPs are often linked to establishment of an agricultural research fund, open to a variety of potential contributors who may wish to finance specific research on technology transfer activities through the fund. CRGPs complement "core" funding or "block" grant funding, which annually allocate funds to specified public research organizations for their core research programs, infrastructure, and human resources.

\section{BENEFITS}

CRGPs are flexible and can be used to accomplish objectives difficult to achieve through block funding. CRGPs can restrict funding to specific research topics (for example, rice); types of research (for example, adaptive onfarm research); projects requiring collaboration between organizations or with farmers; or research within a specific region or discipline (see box 2.5). Their flexibility makes CRGPs a useful tool in building national agricultural research systems, as they can:

- Mobilize the best available scientists, including those in universities and the private sector, for work on specific highpriority projects.

- Develop a pluralistic research system by providing operating costs to better utilize available human and physical infrastructure from a wide range of institutions.

\section{Box 2.5 Ecuador: competitive grants}

The Program for Modernization of Agricultural Services in Ecuador finances a competitive research grants program (CRGP) that has funded I 12 research projects. The program has supported strategic work on innovations to open new export markets through controlling fruit fly (cherimoya, guava, zapote, and other Andean fruits), decreasing production costs for new export products (snails, tree tomatoes, babaco, mushrooms, and artichokes), and controlling disease and insects in traditional exports crops (banana, cacao, and coffee).

The program introduced a new research culture and brought new organizations into the research system. Research projects are being executed by 45 different public and private organizations, with most projects directly linked to potential users of the technologies. The government contracted program management to a private agency to develop procedures and ensure objectivity in program operations. Research project costs averaged US $\$ 1$ 16,000, of which 54 percent is financed by grants and 46 percent by executing agencies, mostly through in-kind contributions. By leveraging of cofinancing for research projects, the program helped increase national research funding by 92 percent to approximately 0.54 percent of agricultural GDP.

Source:World Bank Internal Documents 
- Promote research partnerships and collaboration between different organizations, disciplines, or countries.

- Make research more demand-driven by involving clients in setting priorities and financing, executing, and evaluating research.

- Increase total research funding by mobilizing funds from farmers, industry, and other sources.

- Improve research quality and innovation by selecting projects based on rigorous technical review of scientific merit, sound work plan, and expected results.

\section{POLICY AND IMPLEMENTATION ISSUES}

Success with competitive funding generally requires realistic expectations, clear priorities, efficient and transparent program management, and involvement of stakeholders in setting priorities. It is important to be especially clear about objectives and desired long-term outcomes, and to design CRGPs accordingly.

BASE FOR COMPETITION. CRGPs require sufficiently large numbers of potential research providers to ensure a competitive environment and adequate expertise for peer review and monitoring activities - a problem in small countries. CRGPs must also enjoy strong support from research organizations and relevant government ministries (see box 2.6). Protection from political interference in resource allocation is crucial to maintaining program credibility.

Limitations. Competitive grants can be an important element of overall research funding, but are inherently unstable and do not provide the continuity required for some types of many programs. CRGPs should therefore be used to complement core funding that provides infrastructure, human resource development, salaries, and support for long-term research programs requiring continuity (such as crop breeding).
Box 2.6 Brazil: EMBRAPA competitive grants scheme

In 1997 EMBRAPA (the Brazilian Agricultural Research Corporation) launched a competitive grants program to diversify funding for research and stimulate efficiencies and change in the national research system. World Bank financing (two-thirds for competitive grants and one-third for capacity building) supported a program targeting small-farm production technology, advanced technologies, natural resource management (NRM), and agribusiness.

By 1999, the program had funded 69 projects (212 subprojects) from 506 proposals submitted in five calls for proposals. Several factors facilitated the fast start-up. Brazil has a large agricultural research establishment with 5,500 full-time researchers distributed equally in EMBRAPA, state research agencies, and universities. The country had extensive experience with competitive research programs, though not in the agricultural sector.The staff of the program secretariat traveled extensively to solicit stakeholder views on the program, and to publicize the program and procedures for grant proposals.

Source: Reifschneider, Byerlee, and de Souza 2000

Priority SetTing. Competitive funding can promote demand-driven research by involving key stakeholders, especially users, in setting priorities, formulating projects, and screening proposals. However, purely demand-driven approaches with individual proposals considered in isolation can lead to a fragmented portfolio of projects that lacks synergies between activities and does not address national priorities. Important technological or market opportunities can be lost because of farmers' lack of information and preference for short-term results.

Program sustainability. Most programs financing CRGPs envision them as permanent features of the agricultural research system. This requires mechanism to ensure institutional and financial sustainability. The institutional structure for a CRGP must be efficient and transparent if it is to win ongoing support from researchers and clients. An independent, influential, and respected governing board can help defend the program and sustain its institutional vitality.

COSTS AND COFINANCING. Introducing CRGPs can involve high upfront costs-although established 
funds in industrial countries have held overhead costs to less than 5 percent. Continuity of program funding is critical, and program design should consider sources for future funding, including:

- Cofinancing from the research provider (a grantee) to increase overall funding and demonstrate commitment to projects being financed.

- Phasing in government funding for the CRGP, with donor financing gradually declining as a percentage of total program funding.

- Building the CRGP into existing research funding so that competitive funding is used to complement the core research program.

- Establishing an agricultural research fund to support the CRGP with funding from a variety of sources, including in some cases, an endowment.

- Creating mechanisms for the private sector (farmers' organizations, NGOs, and agribusiness) to finance grants in areas of special interest to the financier.

\section{LESSONS LEARNED}

Programs must maintain operational efficiency, vitality, and transparency throughout imple- mentation with strict standards for accepting and evaluating proposals.

Proposal preparation. Competitive grants are being introduced where there is no history of competitive funding, where there are poor incentive systems in research organizations, and where producersæespecially smallholdersæare not well organized to express their demands. Proactive support for applicants to develop proposals helps ensure good quality proposals by investing up front in building capacity for onfarm diagnosis, problem definition, socioeconomic evaluation, and writing proposals. This may include workshops, field exercises, and establishment of local networks with farmer organizations and extension. "Affirmative action" might be needed to strengthen capacity of poorer regions or weaker institutions to enable them to compete for grants.

GOVERNANCE AND MANAGEMENT STRUCTURE. A sound governance and management structure is critical to efficient operation and integrity of a CRGP (see table 2.3). Pluralistic governance typically requires an umbrella council, board, or steering committee with strong private and nongovernmental participation. A program secretariat with financial management powers and an appropriate level of technical expertise is necessary for efficient day-to-day program operations.

Table 2.3 Typical governance structure for a CRGP

Governing board

Technical advisory committee

Secretariat

Technical review panel
Responsible for overall policy for program; oversees operations; establishes program priorities and policies; represents program with funding agencies.

Responsible for technical oversight of operations; provides technical input to preparation of calls for proposals; advises on peer reviewer selection; monitors technical quality of research projects. This is sometimes a subcommittee of the governing board or is combined with the technical review panel described below.

Responsible for management of program and daily operations; provides support for governing and technical bodies; facilitates communications regarding program operations.

Responsible for evaluation, scoring, and ranking proposals and making recommendations for funding.

Source: Authors. 
Decentralization. Research-both basic and strategic - usually requires competition and selection at the national or international level, whereas adaptive research CRGPs might be managed entirely at the state or district level. Decentralized management is especially useful in developing regional capabilities for adaptive research and developing linkages with producers. Decentralized CRGPs often benefit from oversight by a national secretariat.

Client participation. Farmer participation at all levels is desirable and is probably best sustained through participation in project preparation and execution, rather than in governing and review bodies. Rural producer organizations (RPOs) should be encouraged to collaborate in, or lead adaptive research projects under competitive grant programs. Rural women need to be fully represented in such organizations.

INSTITUTIONAL REFORM AND CAPACITY BUILDING. COMpetitive funding can be an important tool in the reform process, gradually changing the mentality of tradition-bound research organizations. In Eastern Europe and Central Asia, CRGPs have worked around entrenched institutional structures resistant to change, financing critically needed research and demonstrating mechanisms that better link research to clients

Phased Growth. Programs should start small and build on experience as scientists and administrators become familiar with program operations and until the program's reputation and credibility have been established. New programs require a learning period as scientists come to understand and accept the proposal-writing process, and as the funding body gains experience with proposal solicitation and review.

\section{RECOMMENDATIONS FOR PRACTITIONERS}

Care in each step of the program implementation process is essential for efficient and effective CRGP operations and related investments (see box 2.7). In all programs, transparency and good communications with the scientific

\section{Box 2.7 Potential investments}

- Capacity building for research organizations.

- Analytical studies for program priority setting.

- Administrative secretariat with adequate technical assistance.

- Program promotion and assistance in preparing research proposals.

- Funds for research grants.

- Monitoring and evaluation systems and impact studies.

Source: Authors.

community enhance efficiency and quality of research. Sound programs require:

- Clear program objectives that are established from the outset to determine the size, structure, duration, and type of grants to be madeæwhether for bringing new institutions into the research system, building institutional capacity, promoting partnerships, enhancing quality of research, developing linkage to clients, resolving a high priority problem, or increasing the total level of research funding.

- Specific priorities for funding that conform to national research strategies and objectives to avoid a highly dispersed portfolio.

- Eligibility and screening criteria for proposals and grant recipients as these provide the basis for proposal review and ensure quality proposals. Criteria generally cover: scientific quality, clarity of work plan, timeliness of completion, relevance to priorities, experience of proposer, adequacy of institutional support, adequacy of budget, and compliance with cofinancing arrangements. Review sheets with scoring and ranking systems provide a transparent basis for selection decisions.

- Calls for proposals to provide comprehensive information on program objectives and priorities and clear, detailed guidance for submitting proposals. Eligibility requirements should be as flexible as possible to enhance participation of nontraditional research suppliers. Calls for proposals 
should be advertised widely to ensure that all eligible candidates are aware of the program.

- Technical review of all eligible proposals to evaluate each proposal according to the criteria established. High standards of review from the beginning of a program contribute to quality projects in the long term. Technical advisorypanel members should have clear terms of reference and be selected for their scientific expertise.

- Formal award of grantsgenerally made by the governing board based on recommendations from technical review panels, possibly with consideration of additional criteria, such as regional equity, strategic partnership development, and funding mobilization.

- Monitoring and evaluation based on detailed targets and milestones provided in project proposals, and on semiannual and annual reports from grant recipients. Program evaluations must be planned when the program is launched, and should focus on project outputs, outcomes, and impacts. The monitoring and evaluation system must cover individual grant projects, portfolio management by the CRGP secretariat, and institutional, economic, and social impacts of the CRGP.

\section{SELECTED READINGS}

Asterisk (*) at the end of a reference indicates that it is available on the Web. See Appendix 1 for a full list of Websites.

AKIS Thematic Team. 1999. "Competitive Research Grant Programs: Good Practice for Design and Management." World Bank, Washington, D.C.*

George, Pamela. 1999. "Designing and Managing Competitive Research Grant Programs: Good Practice and Lessons Learned." Draft prepared by AKIS Thematic Team. World Bank, Washington, D.C.
Echeverria, R. G., and H. Elliot. 2002. "Financing Agricultural Research by Competitive Funding." In D. Byerlee and R. G. Echeverria, eds., Agricultural Research Policy in an Era of Privatization. Wallingford, U.K.: CABI Publishing.

\section{REFERENCE CITED}

Reifschneider, F. J., D. R. Byerlee, and F. B. de Souza. 2000. Competitive Grants in the New Millennium: A Global Workshop for Designers and Practitioners. Proceedings of an international workshop sponsored by the Brazilian Ministry of Agriculture and Food, Embrapa, IDB, and the World Bank, May 16-18. Brasília, Brazil: Embrapa.

This Note was prepared by Derek Byerlee and Gary Alex based on the Good Practice Note "Competitive Research Grant Programs Good Practice for Design and Management" with inputs from the Sustainable Agriculture (SASKI)

Thematic Team of the World Bank. 


\section{AGRICULTURE INVESTMENT NOTE}

\section{STRENGTHENING PUBLIC RESEARCH INSTITUTES}

In many countries, institutional reforms are essential to make public research organizations more effective and efficient. A frequentæand often soundæstrategy for reform involves providing public agricultural research organizations with an independent legal status and mixed public-private system of governance. This can provide operational flexibility essential for sound management of research, diversification of funding, and recruitment of productive scientists. The success of these reforms depends on freedom from political interference, a clear vision and strategy, respected leadership, a stable funding base, and close links to stakeholders.

Public agricultural research systems provide a basis for innovation and increased productivity necessary for a sustainable and competitive agricultural sector. National research systems are becoming increasingly pluralistic, with a growing role for the private sector, new mechanisms for research funding, and more global scientific linkages. Despite these changes, public sector NAROs continue to have a central role to undertake basic and long-term research, to provide public goods products, and to support overall development of the research system. However, many public research organizations need to resolve problems of low productivity and relevance if they are to effectively carry out these roles.

\section{AUTONOMOUS NATIONAL AGRICULTURAL RESEARCH ORGANIZATIONS}

Most public research organizations were established in the 1950s and 1960s as research departments under ministries of agriculture. These grew over time with strong donor support, but soon ran into problems due to lack of compatibility between civil service rules and the requirements for efficient research execution. By the 1980s, these problems led many such organizations to seek greater autonomy and sufficient flexibility to efficiently manage financial, physical, and human resources for agricultural research. Autonomy was expected to allow the research institute to get rid of excess staff, and improve management systems and personnel policies. Three major types of national agricultural research organizations have evolved:

- Semiautonomous organizations have a legal status different from the regular civil service but lack a legal corporate identity. Such organizations provide some flexibility in financial and personnel management, but often continue to follow civil service rules. Their power to set their own business rules is often ambiguous, and they lack adequate flexibility to carry out modern scientific research. Most NAROs fall into this category.

- Publicly-owned corporations have a mixed, public-private governing body that, in principle, has the power to set the rules for financial, personnel, and asset management. However, since such organizations remain in the public sector, their flexibility is often constrained by political factors and public funding continues to dominate. Research organizations in Colombia, Uruguay, and Brazil are in this category.

\section{- Private or nongovernmental research} corporations are fully private entities that operate for-profit or not-for-profit. These organizations have full powers and more independence from political processes, though they might still receive considerable financial support from government. The Crown Research Institutes in New Zealand (private for profit) and some research foundations such as FUNDAGRO in Ecuador (private not-for-profit) are examples.

In practice, newly created autonomous or semiautonomous research organizations have generally found themselves still reliant on public funding, and substantially under the control of the ministry of agriculture. Autonomy 
has not solved all problems, but it has generally proven preferable to managing research programs within a government bureaucracy (see box 2.8). Whatever their legal base (public or private), national or subnational organizations will likely continue to form the backbone of national research systems, and will continue to rely on public funding (Eicher 1999). Longterm development of these organizations must be planned in the context of the overall national research system, and with a view to the roles that the research organization will play in that larger system.

\section{BENEFITS}

Major reasons for creating legally independent NAROs include administrative flexibility and increased stakeholder involvement.

\begin{abstract}
Administrative flexibility enables NAROs to obtain competent management, maintain a creative environment, and have dependable operating budgets. Good research depends on respected leaders and highly qualified scientists motivated to perform. This requires a flexible recruitment and promotion system, the ability to reward outstanding performance and dismiss
\end{abstract}

\section{Box 2.8 Uruguay: effective reform}

During the 1980s, it became apparent that the Uruguayan Agricultural Research Center under the Ministry or Agriculture was constrained by civil service regulations and poor linkages to farmers. As a result, in 1989, the National Agricultural Research Institute was created as a publicly owned legal entity, but with full powers to set its own business rules along private-sector lines. The institute is governed by a Board of Directors, with two members from government and two from farmer organizations. Farmers contribute about 40 percent of its budget through a levy ( 0.4 percent) on sale of agricultural products. Government is obliged by law to provide a matching contribution.

Total research funding has increased and the institute has developed a good reputation for its research work. One key to success was strong links to clients through decentralized research stations with regional advisory councils of farmers. Commodity working groups, roundtable consultations, and a technology diffusion unit further strengthen relations with clients.

Source: Allegri 2002. unproductive scientists, and a collegial, nonhierarchical, and nonbureaucratic institutional environment.

Increased political status of an autonomous organization can give the director the same political status as the most senior government official in the sector and can increase the influence of the research establishment in national policy debates, and can be an asset in negotiating agreements with local or international organizations.

Increasing stakeholder involvement includes farmers and their associations, the broader scientific community, and other branches of government in the governance and financing of the research organization (see box 2.9). This helps focus research on the most critical problems facing agriculture, informs users of new technologies being developed, and diversifies the base of funding for research. Participation by the broader scientific community, especially by universities, facilitates research collaboration and enhances scientific rigor in evaluating research programs.

\section{POLICY AND IMPLEMENTATION ISSUES}

Many initiatives to create autonomous NAROs in the 1980s and 1990s failed. Reasons included: fear by government officials that the organization might abuse its autonomy; institutional cultures that were too weak to prevent NARO officials from abusing flexibility; defective design (such as statutes that poorly defined roles for the governing body); flawed implementation (such as government interference with NARO management); and external and internal resistance (such as opposition from staff who feared loss of job security). Overcoming such opposition and establishing new operating procedures requires time and consistent support for management improvements.

Decentralization reforms are being pursued in many countries with a view to improving public services. For research systems, especially in larger countries, these can serve to provide 
By the early 1990s, poor human and financial management, weak staff accountability, and lack of farmer input to program content caused inefficiency within the Cote d'Ivoire public research institute. Agricultural research came under strong pressure to provide technical support to producer organizations (POs) and extension staff and as a result, the National Agricultural Research Center was established as a private company with minority financial participation by the state. Board members are elected by the general assembly, which has a majority of users. After an external selection process, researchers were appointed and given three years to choose between remaining as civil servants with the Ministry of Sciences or becoming Center staff with private status. The researchers agreed to take Center employee status, provided their retirement and health insurance rights were guaranteed.

The Center's structural reforms and decentralization facilitate relationships with the private sector; a new salary and incentives system is enjoyed by researchers; and POs, which have strong representation on the board, support the new structure. Following four years of discussion, POs, the Center, the extension agency, the Ministry of Agriculture, and donors are setting up a National Decentralized Interprofessional Fund for Agricultural Services Financing, which will finance research, extension, training, and PO development. The Fund will be managed by users, with funding from levies on major crops to ensure financial sustainability for core agricultural services. The government and donors may provide additional funding.

Source:World Bank Internal Documents.

administrative flexibility, facilitate closer links to clients, and allow for better focus on problems of a particular province or agro-ecological zone. Both decentralization and deconcentration can realize some of these outcomes, but may sacrifice economies of scale and scope, and lose the critical mass of scientists and facilities that is often necessary for productive research. Still, decentralizing adaptive research is important in almost all cases as a means of improving responsiveness to client needs.

Salary scales for scientists are a recurring problem in public research organizations. Although good scientists generally compete on international or regional markets, many NAROs maintain civil service salary scales for research scientists that are inadequate. While this is indefensible, there is no easy solution without broader civil service reform, as senior civil servants generally resist increasing salaries for scientists above those of other government officials. Ongoing reforms in China are using a rigorous review process to identify about onethird of the scientists who are internationally competitive and who will be put on a special pay status that will quadruple their salaries; other scientists will be assigned to privatized research organizations or retired. Other incentive options include: providing opportunities for consulting or contract research, liberal training and sabbatical policies, and arrangements to commercialize research innovations.

\section{LESSONS LEARNED}

There is no single "right way" to reform research organizations, as the specific country context and maturity of the existing research organization must be considered.

KEY REFORMs. To be truly independent, NAROs must have an independent governing body to prevent undue political interference. A governing body representative of major stakeholders, selected on the basis of professional merit, should have freedom to select the chief executive officer based on merit and to establish policies for open, transparent, merit-based recruitment and promotion, and performance-based evaluation and reward systems. The chair of the governing body should generally be a highly respected individual from outside government.

SEPARATION OF FUNDING AND EXECUTION. Increasingly, the bodies that fund research are separate from those that perform research. Competitive and contractual funding mechanisms favor organizations that can deliver high quality, relevant research (see box 2.10). They need to compete for grants, and the signing of results-oriented contracts often improves performance. 


\section{Box 2.10 Bangladesh: failed reform}

The Bangladesh Agricultural Research Management project (1996-200 I) failed to achieve projected efficiencies through institutional reform relating to the structure and role of the Bangladesh Agricultural Research Council, and associated national agricultural research organizations (NAROs). As a result, despite having financed useful research, the project outcome was considered "moderately unsatisfactory" and sustainability "unlikely."

Problems started early. Although the government passed an act to empower the Council there were requests for "flexibility" in the reform agenda even before appraisal. At appraisal, the government announced that personnel reforms were not possible, and research institutes could not be separated from parent ministries. During implementation, three major problems were not addressedælack of the Council's authority over research institutes, lack of central budget and program coordination, and excess numbers of institutes and stations. Fundamental problems included the lack of a high level champion for reforms, and inability to subordinate individual interests of ministries and institutes to the need to improve overall coordination and efficiency. As a result, research efficiency suffered and the Council is considered "unsustainable."

Source:World Bank Internal Documents.

BROADER PUBLIC SECTOR REFORM. Many countries are attempting to modernize and reorganize the public sector as a whole. In reforming research organizations, consultations with those managing broad public sector reforms are important.

OPERATING RULES. In creating or reforming an autonomous research body, considerable time and resources are required to develop appropriate rules and policies. A governing body and a chief executive officer with requisite skills and experience from outside the public sector facilitates this process. Those with only public sector experience are likely to copy government business rules and policies, defeating major objectives of autonomy. Particular atten-

\section{Box 2.II Potential investments}

- A management change team.

- Technical and legal assistance for developing the legal documentation for establishment.

- Technical assistance and training for establishing operating procedures, manuals, and guidelines.

- Civil works and equipment.

- Training for governing board members, NARO management staff, and key stakeholders.

- Core operational funding for research programs and for capacity development on a declining basis.

- Funding for competitive grants programs.

- Technical assistance in developing diversified sources of funding.

- Partnerships and linkages with international research programs.

Source: Authors. tion should be paid to developing human resource management and incentive systems.

\section{RECOMMENDATIONS FOR PRACTITIONERS}

Past experience provides a number of good practices for the successful NARO reform and related investments (see box 2.11).

- A thorough analysis of current performance is required to lay the foundation for clear mission and vision statements that establish a clear role for the organization, define public sector roles, and link the organization to funding sources, technology transfer agencies, and national policy organizations (see box 2.12).

- Planning should be fully participatory through workshops and consultations that include a full cross section of farmer categories.

- Identifying a leader, or a "change" manager", is important as independent research organizations with poor leadership often fail.

- An effective governing body that is highly professional, representative of key stakeholders, and independent is critical. Terms of reference for the governing body should clearly define its role in formulating policies and priorities for the organization, but avoid interference in its day-to-day management. 
- Institutional and legal reform should be accompanied by strategies to diversify funding usually through: participation in competitive grants schemes, commercialization of research products, tapping of private funding through production levies, contracts with the private sector, and joint ventures.

- The price of flexibility is greater accountability for results. Funding agencies must establish realistic, clearly understood performance measures of evaluating performance. The staff of funding agencies need training in this area.

\section{SELECTED READINGS}

Asterisk (*) at the end of a reference indicates that it is available on the Web. See Appendix 1 for a full list of Websites.

AKIS Thematic Team. 1998. "Reforming Agricultural Research Organizations: Creating Autonomous Bodies and Managing Change." AKIS Good Practice Note 01/99. World Bank, Washington, D.C.*

Byerlee, D., and R. G. Echeverria, eds. 2002. Agricultural Research Policy in an Era of Privatization. Wallingford, U.K.: CABI Publishing.

\section{REFERENCES CITED}

Allegri, M. 2002. "Partnership of Producer and Government Financing to Reform Agricultural Research in Uruguay." In D. Byerlee and R. G. Echeverria, eds., Agricultural Research Policy in an Era of Privatization. Wallingford, U.K.: CABI Publishing.

Eicher, C. K. 1999. "Institutions and the African Farmer." Issues in Agriculture 14. CGIAR, Washington, D.C.

This Note was prepared by Derek Byerlee and Gary Alex based on the Good Practice Note "Reforming Agricultural Research Organizations Creating Autonomous Bodies and Managing Change" with inputs from the Sustainable Agriculture (SASKI) Thematic Team of the World Bank.

\section{Box 2.12 Stakeholders to include in the governing body}

- Producer organizations

- Agribusiness sector

- Ministries of Agriculture, Science and Technology, and Finance

- Technology transfer agencies-public or private, including NGOs

- Distinguished university scientists

Source: Authors. 


\section{AGRICULTURE INVESTMENT NOTE}

\section{ENHANCING UNIVERSITY PARTICIPATION IN NATIONAL AGRICULTURAL RESEARCH SYSTEMS}

Universities, with their functions of educating students and generating and disseminating knowledge, are central to productive AKISs. The number of agricultural faculties has grown rapidly, and since about half of the agricultural scientists in developing countries work in universities, they have considerable potential to carry out research. University faculties devote about 25 percent of their time to research, and the balance to teaching programs, supervising postgraduate students, and consulting. Agricultural universities and faculties of agriculture in universities face challenges of providing relevant and high quality training for future agricultural scientists, mobilizing funding for research, disseminating research findings, and recruiting, promoting and retaining gifted teachers and researchers.

Agricultural universities and faculties of agriculture in universities in developing countries are central to building a comprehensive AKIS. They train future research staff and have the potential to use existing staff and facilities, such as libraries, laboratories, and demonstration farms to carry out research at marginal additional cost. Many universities also provide consulting services to various public, private, and NGOs.

Degree training is the primary function of agricultural universities. From the early 1960s to the mid 1980s, agricultural universities helped to quadruple the number of developing country agricultural researchers. However, results from the early phase of donor investment in university research have been mixed. Some agricultural universities actively participate in AKIS and generate high-quality research, but in others, research capacities have eroded. Many universities have expanded training capacities, but have been unsuccessful in achieving fiscal sustainability and establishing sound research programs. This is changing as CRGPs have increased university participation in agricultural research of national importance in a number of countries, including Ecuador, Brazil, and Chile.

International donors have invested heavily in universities and faculties of agriculture. From 1964 to 1990, World Bank-financed projects provided US $\$ 713$ million for 41 projects supporting universities in 25 countries (both agricultural and general). From the 1950s to 1996, the United States Agency for International Development (USAID) provided US\$456 million for 63 agricultural universities in 40 countries. In the 1990s, donor support to universities declined sharply, but there has been a renewed interest in the important symbiotic relationships between investments in agricultural higher education, research, and extension. Three recent examples illustrate the "new directions" in donor strategies for supporting tertiary (higher) education:

- The World Bank publication Constructing Knowledge Societies (2002) stresses the powerful role that universities play in creating and disseminating knowledge, building professional capacity, and reducing poverty.

- Four United States foundations have committed US\$100 million to assist in reforming universities in six countries in Africa over the 2000-2005 period.

- USAID in 2002 launched a new global training and capacity-building initiative to increase graduate training in food and agriculture in United States universities, and to strengthen agricultural higher education in developing countries.

\section{UNIVERSITY CONTRIBUTIONTO NATIONAL AGRICULTURAL RESEARCH SYSTEMS}

Many universities have the potential to participate in national agricultural research systems (see box 2.13). Competitive grants, contracts, and other mechanisms provide the necessary 
Box 2.13 Uruguay: linking universities to the National Research Institute

In Uruguay, effective linkages have established a research partnership between universities and the National Research Institute.

- Ten percent of the Institutes research budget is set aside for competitive contracting for research with outside agencies. Universities receive almost half of this funding.

- University and Institute staff meet annually to prepare joint research programs.

- Senior Institute staff spend up to 20 percent of their time teaching at universities.

- The Institute facilitates university linkages with international programs (especially the international agricultural research centers.

- University students receive National agricultural research institute fellowships.

Source: Hobbs et al. 1998.

links to do this (see box 2.14). In addition, as private universities are becoming more important in the provision of higher education, these also should have an equal opportunity to compete for government support for technology development programs.

The complementary nature of research, education, and extension indicates a need for close communication and cooperation among the core institutions in pluralistic national technology development systems. Agricultural universities and agricultural faculties can make the following contributions:

- National research. A university can assume full responsibility for public sector agricultural research by establishing a NARI within the university.

- Basic research. A university can focus on basic and strategic research, leaving applied and adaptive research to other institutions.
- Regional research. A university can assume lead responsibility for work on a particular commodity or production system within its region.

- Consultant services. A university can provide consultant services by providing its research findings to NARIs, NGOs, international agencies, and commercial firms.

\section{POLICY AND IMPLEMENTATION ISSUES}

Universities must adapt to a changing global agricultural environment and address new training and research challenges related to NRM, agribusiness, biotechnology, and trade.

Training FutUre ReSEARCH SPECIALISTS. Historical support of donor-funded overseas postgraduate training is declining. World Bank support for such training declined by 34 percent from 1990 to 1997, and the number of USAIDfinanced postgraduate students studying

\section{Box 2.14 Ghana: establishing a university role in national agricultural research programs}

In Ghana, the Bank-supported National Agricultural Research Project, initiated in 1992, helped bring universities into the national research program through two mechanisms:

- The Ghanaian National Commodity/Factor Research Programs, established for 17 strategically important research areas, are led by Program Coordination Committees. Scientists from universities serve on these committees and may serve as program coordinators.

- A research grants scheme was designed to draw universities and other institutions into the research system, and to complement research activities under the national program. The scheme gave priority to basic and strategic research. By mid 1998, it had funded 110 research projects, including 34 that supported postgraduate research at local universities.

Source:World Bank Internal Documents. 
agriculture in the United States fell from 310 in 1990 to 82 in 2000.

Long-term training for most masters' students is now undertaken in developing countries, and doctoral students are educated in both industrial and developing countries. The next challenge is to improve the quality and fiscal sustainability of universities that have developed a regional reputation for high-quality masters' and doctoral training.

UNIVERSITY RESEARCH AND NATIONAL STRATEGIES. Research priorities must balance the university's independence against strategic national research needs, with policies and strategies designed to encourage, not stifle, individual initiative by scientists. Tying national funding to research on high-priority topics will stimulate research in these areas.

FACULTY InCENTIVES. University programs require adequate salaries, innovative policies relating to faculty consulting, and incentives to faculty for development-oriented research and for mentoring and supervising postgraduate students. When university scientists take second jobs or consulting work to supplement

\section{Box 2.15 Chile: financing university research}

In Chile, even though the primary mission of higher education is training, the budget for agricultural research at the nation's 17 universities reached US\$4 million in 1995. Funding came from:

- Government grants to universities, including a research fund used to contract staff.

- National competitive research grant programs (CRGPs), which are a major source of research funding, but provide funding that is unstable, unfocused, and does not cover overhead costs.

- Government research contracts, mostly for applied and adaptive research projects.

- Sale of research goods and services, especially contract research.

- Research grants from private sector and international sources.

- University income and other sources that provided small amounts of research funding.

Source:Venezian 1993. their university salaries, research programs are often disrupted and the time available for research and supervision of postgraduate students is curtailed.

FINANCING UNIVERSITY RESEARCH. Competitive funding mechanisms are becoming increasingly important for financing university research (see box 2.15), but if overhead costs are not covered, there can be a net loss of funds available for the university's own research program. A sustainable agricultural research program requires funding for:

- Infrastructure (building laboratories, establishing electronic communications, procuring equipment, and acquiring land or other facilities) and training research students to the masters and doctoral level.

- Thesis research of postgraduate students possibly funded through a competitive grant program or a research fund dedicated to thesis research.

- Strategic research programs focusing on particular problems, such as biotechnology or natural resources management. These programs require long-term funding and are usually inappropriate for funding through a competitive system.

- Maintaining relevance and effectiveness of research programs by establishing mechanisms to expand interaction with farmers. Universities can gain local agricultural knowledge by recruiting students from farm backgrounds, integrating students into joint university-NARI research projects, and expanding research in the rural social sciences and in rural production systems covering farming systems, ecosystems, and agro-ecological regions.

\section{LESSONS LEARNED}

Strategic plans, institutional structures for research, and project investments can enable universities to execute high-quality research, if 
the universities have an adequate policy framework. (see box 2.16).

CRGPs targeting university scientists are costeffective mechanisms for linking university research capability to national programs. Assistance with grant proposal preparation might be needed to help universities compete for such funding.

Research infrastructure development should conform to university research priorities, with expansion limited to essential facilities that can be maintained over time. Investments should include human resource development through postgraduate training and sabbaticals as well as investment in equipment, buildings, and related facilities.

Postgraduate programs provide universities with a cadre of motivated and low-cost student researchers. Client-oriented postgraduate research contributes to the relevance of university programs, links research to teaching and has the potential to attract funds from the private sector, donor projects, and other sources. Successful postgraduate programs require an experienced faculty, an adequate physical infrastructure, library and Internet resources, and modest operating budgets.

University programs establishing strategic research alliances with other institutions can strengthen national research programs while building postgraduate training capacities in universities. Ecuador's competitive grants program financed strategic alliance grants that enabled universities to establish partnerships with local and foreign institutions to develop postgraduate training programs and expand core research capability. ${ }^{2}$

\section{RECOMMENDATIONS FOR PRACTITIONERS}

Balanced development of efficient and sustainable technology systems suggests that universities must become important contributors to
Box 2.16 Uganda:building an integrated agricultural knowledge and information systems

In Uganda, the five-year Agricultural Research and Training Project, initiated in 1993, built an integrated system for agricultural research and education that includes universities. Support to the university system covered:

- Training to fill critical gaps in the university faculty.

- A Continuing Agricultural Education Center to provide demand-driven training for clients.

- A program for twinning Makerere University with foreign universities to strengthen curricula.

- Capacity building for diploma-level training at agricultural colleges.

- Close coordination with universities in developing an effective national agricultural research institute (NARI).

Source:World Bank Internal Documents.

pluralistic national technology systems. Project investments (see box 2.17) can:

EVALUATE UNIVERSITY CAPACITY TO CONTRIBUTE TO R\&D. Assessments of institutions and their agricultural research capacities and programs should categorize universities as to whether they deserve broad program support and can effectively absorb such support; need reform, but are still appropriate for targeted assistance; or require major reforms before investments can be justified. Major university investments should also be conditioned on commitments to respond to market and client needs.

ESTABLISH MANDATES AND STRUCTURES. At both the national government and university levels, improving the framework for productive university involvement in research generally requires:

Box 2.17 Key investments to develop university research capacities

- Infrastructure (human and physical).

- Postgraduate degree training.

- Strategic alliances.

- Core research support.

- Competitive research grants.

Source: Authors.

2. See the IAP,"Ecuador: Strategic International Alliances for Capacity Building and Research" 
- Providing university research programs legitimacy and visibility, helping align programs with national priorities, and enabling them to attract government funding.

- University support to effectively carry out research. This often requires a policy statement; a strategy outlining priorities and links to users and other programs; incentive systems that reward mentoring and supervision of postgraduate students and client-oriented collaborative research; and a small research management unit to facilitate funding, execution, planning, monitoring, and evaluation.

- NARI-university partnerships, which include joint research projects, joint supervision of postgraduate students, and joint seminars and annual research reviews.

- Links to clients and stakeholders to ensure that programs respond to client needs. Links can be established with POs and rural NGOs that promote equity in development.

- Research publications that disseminate and promote research findings and increase the visibility of university programs. Equal incentives should be provided to locally published, development-oriented research, and to more academic work published internationally.

\section{SELECTED READINGS}

Asterisk (*) at the end of a reference indicates that it is available on the Web. See Appendix 1 for a full list of Websites.

FAO. 1993. "The Role of Universities in $\mathrm{Na}-$ tional Agricultural Research Systems." Report of the FAO Expert Consultation, March 10-22, Rome.

World Bank. 2002. "Constructing Knowledge Societies: New Challenges for Tertiary Education." World Bank, Washington, D.C.*

World Bank. AKIS Sustainable Agriculture. http://www.worldbank.org/akis.

\section{REFERENCES CITED}

Hobbs, H., C. Valverde, E. Indarte, and B. Lanfranco. 1998. "The Agricultural Technology Development Fund for Contract Research: An INIA (Uruguay) Initiative." Briefing Paper 40. ISNAR, The Hague.

Venezian, E. 1993. "A Case of University Participation in National Agricultural Research: the Faculty of Agriculture, Catholic University of Chile." In FAO, The Role of Universities in National Agricultural Research Systems. Report of the FAO Expert Consultation, March 10-22, 1991. FAO, Rome.

This Note was prepared by Carl Eicher and Gary Alex, based on a World Bank Good Practice Note "Integrating Universities into National Agricultural Research and Extension Systems," with inputs from the Sustainable Agriculture (SASKI) Thematic Team of the World Bank. 


\section{INNOVATIVE ACTIVITY PROFILE}

\section{LOCAL AGRICULTURAL RESEARCH COMMITTEES}

Local Agricultural Research Committees (known by their Spanish acronym CIALs) are locallyelected groups of farmers who run volunteer agricultural technology testing services financed by local contributions in cash and kind and supplemented by funds from state or NGOs. CIALs enable farmers to express their technology demands, and participate in the design, testing, and dissemination of appropriate technologies. This adaptive research service is accountable to its clients, increases the outreach of technology services to remote areas, and provides feedback to improve technology design. Training facilitators and committees is a one-off investment that enables a research and extension program to expand its coverage at low cost, or to reduce the overall cost of maintaining contact with farmer groups. The CIAL approach has been adapted successfully in eight Latin American countries and is expanding in Africa and Asia.

Development of technology recommendations is costly and time consuming, and mechanisms to ensure feedback to research and extension (R\&E) providers from poor farmers are essential, but widely lacking. This results in low rates of technology adoption by resource-poor producers. Even where a market for R\&E services exists, the weak capacity of farmers to express demand is a constraint. However, resource-poor farmers in tropical countries have successfully developed profitable and ecologically sustainable agricultural technologies on their own. Collaboration between farmers and researchers at an early stage in the design and testing of technologies has the potential to blend local and nonlocal technical knowledge and lead to successful innovations.

LOCALAGRICULTURAL RESEARCH COMMITTEES Strengthening the capacity of poor farmers to articulate their research needs and to partici- pate in the design, testing, and dissemination of appropriate technologies is the objective of widespread experimentation with farmer participatory research groups in developing countries. CIALs were developed to provide farmers and POs with a research service that is accountable to its client group, increases the ability of R\&E services to reach remote areas, and provides feedback to improve the design of technology.

The CIAL is a farmer-run, volunteer research service that is initiated by and answerable to its client group. Client groups may be informal or formally organized groups of farmers motivated to test agricultural innovations (including the best local practices) when appropriate technologies are lacking or unproven for local conditions. The client group elects a committee of farmers chosen for their interest in experimentation and willingness to serve. The client group can replace committee members who do not put in enough time and elect new ones. Committees, ranging in size from four to more than 20 members, conduct research on local, priority topics. This approach enables farmers to share risk and build on local experience when trying out untested agricultural innovations.

The committee works with its clients to establish priorities for research topics, consults with R\&E providers, raises funds, plans experiments, conducts trials on several farms, and regularly reports results to clients and R\&E providers. Initially, the committee organizes a diagnostic process in which all clients participate in consultations with other farmers. When priorities are being established, attention to gender or ethnic differences is important, and special interest groups may need or demand a committee of their own. A local or regional facilitator encourages client groups to choose a research theme with good chances of success, and with the potential to benefit most of its clients.

When the client group identifies a research topic, the committee searches for information to establish whether there is really a need for research. If the committee finds that locallyproven technologies are available, it asks 
farmers or R\&E providers experienced with the technology, to provide community-wide training. If committee members are unsure of what works locally, the experiment, will generally compare multiple, unproven solutions that may be indigenous or of external origin.

The major costs of establishing a CIAL are incurred during the first year for training and a one-off petty cash or inputs' fund for operations. For example, in Colombia, facilitator training by salaried professionals costs approximately US\$600 and the start-up funds for CIAL operations (the CIAL Fund) range from US $\$ 25$ to $\$ 500$ per CIAL in cash or kind. The facilitator, who may be a professional or a farmer with prior experience in a local committee, assists client groups to establish CIALs, and then progressively hands over responsibility to the committee. One facilitator can support 50 or more CIALs, provided that person can bring some members to regular meetings or has transportation to visit them. Training of facilitators and committees is a one-off investment that enables a research and extension program to expand coverage at a low cost. Training of experienced farmers as facilitators drastically reduces costs.

The CIAL process has been adapted successfully to different situations provided that committees, facilitators, and client groups keep to the basic principles outlined in the Recommendations for Practitioners section. Adaptations by NGOs, universities, local governments, producer organizations, vocational schools, and experiment stations has resulted in a wide variety of committees (see box 2.18). The main difference in committee adaptation depends on

\section{Box 2.18 CIAL development and spread}

The CIAL approach to participatory on-farm research was first used by the International Center for Tropical Agriculture in 1992. By 2003 over 250 ClALs operate in eight Latin American countries. An unknown number of adaptations of the approach exist in East and West Africa and Asia, including China.

Source: ISNAR. whether the committee's priority is research or community development. If it is research, a small group of expert farmers experiment with innovations on behalf of their client group. If the priority is community development, the CIAL process may be included in social projects, such as credit schemes.

Effective links to research organizations is key to all CIAL approaches. When farmers are very poor and there is a high level of cultural dependency or risk-avoidance, adaptations as outlined in box 2.19 are useful first steps in establishing effective CIALs.

\section{BENEFITS}

CIALs have achieved three types of benefits: more rapid technology adoption; human and social capital formation; and welfare benefits. Technology adoption and welfare benefits accrue to the wider client group; human and social capital formation benefits accrue mainly though not exclusively to the members of committees. Farmers and their organizations gain new knowledge and skills plus the capacity to engage R\&E providers in support of local experimentation (see box 2.20).

\section{POLICY AND IMPLEMENTATION ISSUES}

Financial sustainability. CIAL costs depend primarily on the frequency of visits by facilitators and the number of CIALs supported by each facilitator. This in turn depends on the density of CIALs in a region. Typical levels of facilitator-CIAL contact are biweekly for a new CIAL. After the first experimental cycle the frequency of contact is reduced progressively, and costs typically drop by 50 percent. In Colombia, in 1999, the cost of establishing a CIAL averaged US $\$ 670$ for the first year, declining to US\$400 in the second year and US\$200 in the fourth year. The costs of CIAL operations are often partly financed by sponsors who provide experimental inputs and/or petty cash (for example, NGOs, local government, R\&E providers), and will be partially or wholly financed by local farmers' contributions and community-based fundraising by 
- Where short-term food security is a priority, begin by evaluating treatments in researchers' trials, and subsequently share risk in farmer-run experimentation (Ecuador, East Africa).

- Run a collective production plot using proven technologies together with the CIAL's small experimental plots for untried technologies. The collective production helps compensate committee members for their time and adds to the petty cash fund (Honduras, Colombia).

- Test and monitor innovations on farms without establishing formal experiments. This is especially useful with livestock or natural resource management (NRM) practices (East Africa, Southeast Asia)

- Elect a large committee. In Northeast Brazil large committees sustained CIALs through periods of seasonal migration. In Honduras, large committees made the human capital development benefits of membership accessible to a broader crosssection of the client group.

- Create a petty cash fund by providing the CIAL with experimental inputs in kind and then use profits from trials to fund the committee's activities. This enabled CIALs in Bolivia and Colombia to increase their petty cash fund.

- Run the petty cash fund as a revolving credit fund or as a small venture capital fund that makes loans for equipment that is rented out to the client group.

- Form a CIAL to provide R\&D on new products or processes for small agro-enterprises.

Source: Authors.

committees (for example, raffles, dances, collective production plots). Once a petty cash fund has been established, most committees keep their fund going, and some have increased their funds over time. The costs of facilitator salaries and training are most commonly borne by sponsors such as NGOs, universities, local government, or public sector R\&E providers.

\section{LESSONS LEARNED}

InSTITUTIONAL SUPPORT. CIALs provide a local adaptive research service that accelerates innovation when an active relationship is maintained with an NGO or state research or extension provider. Mature CIALs can function successfully with as little as three or four contacts per year with their facilitator, but geographically-isolated CIALs do not realize their full research potential. R\&D providers working with CIALs must commit to regular contact, respect for farmer research, punctuality, accountability, and shared decisionmaking. Support from R\&D decisionmakers and links to local government enhance sustainablity (see box 2.21). In the initial phases, institutions can overburden CIAL members with incessant demands for meetings, but continuing contacts can motivate participation.

\section{Box 2.20 The potential impact of Local Agricultural Research Committees}

- Strengthened farmer experimentation. An impact study of over 300 households in Colombia found that individual farmers influenced by Local Agricultural Research Committees (CIALs) were involved in over 50 different kinds of experiments on their own.

- Improved the quality and relevance of on-farm research. Monitoring shows that 75 percent of CIAL experimental data can be statistically analyzed by scientists, and that other data are meaningful to farmers (CIAT, 1998).

- Developed agro-enterprises. CIALs have introduced profitable new crops, post-harvest processes and/or new varieties.

- Improved food security. An impact study in Colombia found that communities with CIALs had fewer respondents short of food in the "hungry months," compared to those without.

- Increased poor people's access to new technologies. In Colombia, analysis of I 5 technologies found that 63 percent of farmers in the poorest strata were adopting between six and I $5 \mathrm{CIAL}$ technologies, and were as likely to do so as the better-off strata of farmers. The speed of adoption of new technologies was faster in communities with CIALs and their neighboring communities, than in other communities that relied on traditional R\&E.

Source: Authors. 
Box 2.21 Bolivia: organizing Local Agricultural Research Committees in municipalities

Sustainability and accountability can be ensured by establishing channels whereby Local Agricultural Research Committees (CIALs) set priorities for their research and report back to established farmer organizations and local government. In Bolivia, municipalities are required by law to identify and respond to community demands for services, and rural municipalities must involve farmers in preparing municipal development plans and in local boards for economic promotion that coordinate development efforts. Colmi Municipality already has ten CIALs with committee members elected by the farmer organizations or rural syndicates, themselves elected by communities. The CIALs are linked with the municipality through their syndicate's central office, which participates in Colmi's local board for economic promotion and serves as a channel for CIALs to influence municipal priorities, request support, and contribute to municipal projects. This is proving an important source of human and social capital.

Source: Authors.

Organizational Base. CIALs work best when formed inside a client group's informal or formal organization (for example, when a community, farmer association or cooperative, women's group, parent's association, parish council, or small enterprise elects and oversees the committee). Establishment of a CIAL inside an R\&E organization is a second-best option, as this can result in loss of direct accountability to clients.

SOCIAL CONSIDERATIONS. CIALs can catalyze commitment to collective action and to women's participation, but factionalism, conflict, or suspicions within the client group can seriously undermine its support for a committee. Women's participation in CIALs is often difficult and associated with the need to gain acceptance. A CIAL must regularly report on progress to its client group to ensure accountability of the committee, so that research products belong to the community, not to the committee or individuals.

ReAl teChNology deVElopment. CIALs are costeffective when they build local capacity such as helping poor people collectively manage untried innovations. If clients, committees, facilitators, or R\&E providers judge CIALs only on their success in teaching large numbers of farmers to adopt proven technologies, they undervalue the generation of useful knowledge made available to many by CIALs. Restricting CIALs to demonstrating technologies usually means their experimentation is not driven by the client group's demand for innovation, but by the facilitator's perception of what is "safe." CIALs play an important role in participatory learning by generating new information, but they are a complement to assisted learning, not a substitute. In practice, many CIALs engage in both research and assisted learning.

\section{RECOMMENDATIONS FOR PRACTITIONERS}

Many features of the CIAL process (such as type of sponsoring organization, who facilitates, committee size, type of experimentation, size of petty cash fund) and related investments (see box 2.22) can vary greatly, provided that sponsors, trainers, client groups, committee members, and facilitators understand and adhere to the following basic principles:

- Form CIALs by motivating the client group to elect farmers interested in testing agricultural innovations and by building on local experience. Programs need to support farmers in learning how to innovate rather than demonstrating technological "fixes."

- Establish a CIAL research topic priority that is relevant to the majority of farmers in the client group.

- Plan activities that regularly generate and sustain the petty cash fund needed to support CIAL operations.

- Expand and rotate committee membership and ensure that committee members provide regular progress reports on experiments to their clients, so that that research products reach the wider community and not just the committee members or the sponsor.

- Include committee experimentation for very poor, risk-averse client groups in social 
projects with short-term returns to sustain commitment over time and build local capacity.

- Encourage CIALs to exchange visits and sponsor their own regional meetings to exchange results.

- Minimize costs of visiting CIALs by possibly targeting agro-ecological zones that can be reached from an experiment station or municipal extension office.

- Train experienced farmers with prior experience in a CIAL as facilitators to reduce costs of facilitation, especially when moving into large-scale implementation.

- Promote attendance of scientists and key R\&D decisionmakers at CIAL meetings to ensure their support for CIALs.

\section{SELECTED READINGS}

Asterisk (*) at the end of a reference indicates that it is available on the Web. See Appendix 1 for a full list of Websites.

Ashby, J. A., A. R. Braun, T. Garcia, M. del Pilar Guerrero, L. A. Hernandez, C. A. Quiros, and J. I. Roa. 2001. "Investing in Farmers as Researchers: Experience with Local Agricultural Research Committees in Latin

America." CIAT, Cali, Colombia.*

CIAT. Solutions That Cross Frontiers. http:// www.ciat.cgiar.org/ipra/.

\section{REFERENCES CITED}

CIAT. 1998. Background Information on Farmer Participatory Research: Latin America's Farmer-researchers. http:// www.ciat.cgiar.org/newsroom/ release_17.htm.

ISNAR. Case Study: Honduras Participatory Research. Farmer Participation in Conservation and Research Local Agricultural Re-

\section{Box 2.22 Potential investments}

- Training for CIAL facilitators: US\$600 per person for a short course plus one year of follow-up support. One facilitator can support up to 50 mature CIALs.

- Start-up funds for CIAL experiments: a one-time, nonrenewable investment in a CIAL fund can range from US $\$ 25$ to 500 in cash or kind.

- Average running costs per CIAL in Colombia were US\$670 for the first year, US\$400 in the second year, and US\$200 in the fourth year.

Source: Authors.

search Committees, Honduras and Nicaragua. http://www.isnar.cgiar.org/shiip/ Honduras-particip.htm.

This Note was prepared by Jacqueline Ashby of the Centro Internacional de Agricultura Tropical, Cali, Colombia. 


\section{INNOVATIVE ACTIVITY PROFILE}

\section{BIOTECHNOLOGY,BIOSAFETY, AND AGRICULTURAL DEVELOPMENT}

New techniques of biotechnology can stabilize yields and improve rural incomes, reduce negative environmental impacts, provide nutrient-enhanced and better quality food, and deliver vaccines and antibodies to improve health. While most benefits have occurred in industrial countries, the techniques have considerable potential for sustainable small-farm systems in developing countries. However, due to the potential environmental and health effects and socioeconomic implications, some new technologies are controversial. Private sector commercial dominance of biotechnology poses major challenges for access by poor people. Biotechnology strategies must be country-specific, depending on needs and scientific capabilities. All countries, however, will need the capacity for developing technology policies and strategies, a strong regulatory framework, and scientific skills to make use of appropriate technologies.

Agricultural biotechnology is increasingly seen as a valuable tool for addressing production and nutritional constraints in developing countries, particularly in commodities important to poor producers and consumers. This view is supported in the World Banks current rural strategy, Reaching the Rural Poor, which commits the Bank to helping developing countries assess, and safely use new technologies. However, continuing controversy and debate over possible adverse health and environmental impacts, and ethical and legal issues relating to IPRs has slowed adoption in developing countries. To benefit from rapid global advances in the biological sciences, developing countries will have to invest public funds in products that are not of commercial interest to the private sector, but are of high priority to their poor producers and consumers.

\section{WHAT IS BIOTECHNOLOGY?}

Agricultural biotechnology refers to a wide range of technologies and products that can improve productivity or quality of crops, livestock, fisheries, and forests. The first generation of these technologies, including plant tissue culture, micropropagation, molecular diagnostics of crop and livestock diseases, and embryo transfer in livestock, have already been adopted in many developing countries. These are simple to use, often inexpensive, and relatively free of regulatory requirements and public controversy.

The next generation of tools and products, based on molecular biology, is providing revolutionary advances in genetic knowledge and the capacity to change DNA. These molecular technologies can be either a research tool for development of technologies (genetic markers, gene mapping) or a technological innovation for field use, transfering genes within and across species to generate transgenics (genetically modified organisms, commonly known as GMOs). Molecular approaches require advanced skills, research laboratories, and the capacity to manage intellectual property. These requirements may pose a constraint for developing countries. The use of transgenic crops also requires regulatory capacity to manage possible environmental and health risks, which have been the subject of considerable debate.

The application of molecular biotechnology has so far been limited to a small number of input traits, which are mostly of interest to commercial farmers in temperate countries. This research has been carried out in the private sector by large life science companies, which have very little incentive to invest in adapting this technology to the needs of tropical countries. For the full benefits of biotechnology to reach poor farmers and consumers in developing countries, national and international public sector institutions will have to target investments to enable their researchers to gain access to proprietary technologies, resulting from private sector research. Developing country scientists will need to be able to apply these innovations to 
national germ plasm, and develop capacity to do biotechnology research. Some benefits can be achieved by increasing the precision and speed of conventional breeding, whereas others can only be achieved through transgenic crops.

\section{BENEFITS}

Modern biotechnology tools have the potential to significantly raise agricultural productivity in a more environmentally-friendly manner, supply cheaper and more nutritious food, and contribute to poverty alleviation. ${ }^{3}$ Many of the first generation of biotechnologies are relatively easy to apply, but still offer substantial benefits such as higher and more stable yields due to increased tolerance to diseases and pests (see box 2.23). Examples include virus-resistant sweet potatoes in Kenya, insect-resistant maize in East Africa, insectresistant cotton in China, and marker-assisted selection for sleeping sickness in African cattle.

Input costs may also be lower as resistance to insect pest and disease is incorporated into crops and animals, reducing the need for externally applied pesticides. For example, in Mexico, pesticide use on cotton fell by more than 80 percent, from an average of nearly 14 $\mathrm{kg} / \mathrm{ha}$ of active ingredient in the 1980s to about $2 \mathrm{~kg} / \mathrm{ha}$ in 2002, as a result of using the Bacillus thuringiensis $(\mathrm{Bt})$ cotton variety resistant to bollworm (Traxler et al. 2003). The reduction in pesticide use has significant environmental and health benefits, and the introduction of herbicide-resistant crops can be used in minimumtillage systems that reduce soil degradation and erosion (see box 2.24). There is also potential to improve food quality (for example, "golden rice," with high vitamin A content), and to develop healthier animal and plant products (leaner meats, improved fatty acid profiles in oil crops, and less fungal toxins in food crops).

\section{BIOSAFETY FRAMEWORKS}

Application of genetic engineering to crop and livestock improvement is relatively recent. In 1994, the first transgenic variety reached the

3. See the IAP,"India: Focus on Biotechnology"

\section{Box 2.23 Kenya: benefits of biotechnology for small-scale} banana producers

Bananas are an important crop for 20 million resource-poor farmers in East Africa, but pests and diseases cause major production and quality problems. In 1996 the International Service for the Acquisition of Agri-Biotech Applications, the Kenya Agricultural Research Institute, and Genetic Technologies Ltd. initiated a joint effort to produce disease-free planting materials by tissue culture. Initially the tissue culture plantlets were imported from South Africa, but now both the institute and Genetic Technologies have developed their capacity for banana micropropagation and distribution of plantlets. Net income of the participating farmers has increased by 35 percent. The project is scaling up to establish a self-sustaining system of production, distribution, and utilization of tissue culture banana plantlets. More varieties will be offered and the project will be extended to new areas within Kenya and in the East Africa region.

Source:Wambugu and Romano 200 I; Persley and George 1999

market in the United States and, as increased numbers of transgenic products were fieldtested and commercialized, questions were raised about the safety of these products. As the development of molecular biotechnology is relatively recent, there is yet no model for a single best approach to deal with safety issues.

Risks associated with GMOs in agriculture generally are in two categories: food safety and environmental safety. Food safety risks include the potential increase in allergenicity

\section{Box 2.24 China: Bt cotton}

China is the world's largest producer and consumer of cotton. In 200 I, China produced 5.3 million metric tons (25 percent of world production). About 13 million small farmers, usually farming less than 0.5 hectares each, grow cotton. Adoption of Bt cotton progressed quickly from its introduction in 1997 to I.5 million hectares in 2001 (3I percent of total area under cotton) with four to five million farmers benefiting from the new technology. The benefits have come through yield increases of up to 10 percent, reduction by one-half to two-thirds in volume of insecticides used, reduced insecticide poisonings, and gains in income of approximately US\$500/hectare. Farmers adopting new technologies increased incomes despite the fall in cotton prices.

Source: James 2002. 
increase in toxins in these products. Environmental risks include: the possibility of gene flow to other cultivars of the same species or to related weed species, with the risk of developing aggressive weeds that are resistant to diseases, pests, and herbicides that could potentially upset the ecosystem balance; the possible effect on nontarget organisms from crops with resistance traits operating through insecticidal protein expression; and the potential displacement of traditional cultivars by a small number of transgenic cultivars that effectively reduce the biodiversity typically found in small farmers' fields.

Biosafety frameworks are required to assess and manage such risks. They typically include five key elements: national policies; national inventory and evaluation; knowledge, skills and capacity; regulations governing risk assessment and risk management; and systems to monitor, inspect, and implement regulations. Ideally, the evolution of a national biosafety system begins with a national policy that is the basis for legislation and/or regulations, leading to design and implementation of the systems necessary to undertake risk analysis, inspection, monitoring, and enforcement. A national assessment of existing regulatory, scientific, technical, economic, and social capacity is relevant to the policy and implementation processes. Transparency and public participation are essential to build public trust in institutions, and in the risk assessment and risk management procedures in a national biosafety system.

Except for a few countries with an extensive or growing domestic biotechnology sector, development of a comprehensive national capacity for a biosafety system is not likely to be necessary or feasible. Pragmatic, cost-effective solutions to the problem of establishing regulatory systems will often involve combining responsibility for risk assessment and risk management in one agency, and drawing on existing expertise in the private sector and internationally agreed norms. Countries with a small science community can implement effective biosafety systems by capitalizing on external expertise and information and harmonizing risk assessment principles, information requirements, and standards of assessment on a regional basis. This can help prevent conflicts of interest in small countries where developers of technology serve as risk assessors. Harmonizing biosafety standards requires adoption of common values and objectives; shared interests and concerns; the need to overcome differences and to avoid disputes; the need to cooperate with other interests; and the need to simplify procedures. In the absence of some or all of these factors, chances of effective harmonization are limited.

\section{POLICY AND IMPLEMENTATION ISSUES}

ECOLOGICAL AND FOOD SAFETY RISKS. Possible risks from using biotechnology tools and techniques relate to environmental and food safety. The likelihood of risks, and appropriate risk management methods will contribute to risk assessment regulations and guidelines governing biosafety. Risk and risk management strategies are likely to be case-specific, depending on the trait, location, and management of the crop.

COSTS AND CAPACITY. Molecular biotechnology research can require substantial investments for the necessary biosafety framework and laboratories, for training scientists who must remain current in the field, and for the operating costs for research. Consequently, a firm commitment that ensures sustainable financing is needed before investing in biotechnology.

INTELLECTUAL PROPERTY. Intellectual property disputes involve genes from developing countries being used by private sector companies in developed countries. Access by poor people to new technologies protected by patents held by private companies, the major developers of new technology, is another area of controversy. Developing countries need to develop the technical and legal capacity for establishing IPR laws, for negotiating international and commercial IPR agreements, and for patenting, where it is in the interest of the poor, inventions developed in their public research organizations. 
InTERnational TRADE. Public controversy associated with consumer concerns over transgenic crops may produce uncertainty in the markets and difficult policy issues for those countries wanting to build biotechnology capacity while exporting to regions which do not accept GMO food products, such as Europe. Some developing countries may have to decide whether to give up opportunities to reduce food costs through transgenics or give up their ability to export to European markets.

\section{LESSONS LEARNED}

Current biotechnology investments under Bank projects focus on strengthening public sector research organizations to serve smallholder farmers, and are quite modest when compared to large investments by private companies focused on products for commercial agriculture. Key lessons are that:

- While potential benefits from applying new tools to appropriate productivity and quality traits justify strong support for biotechnology, it is important that the public sector remains impartial and ensures that potential risks are considered, understood, and addressed before proceeding with any biotechnology investment.

- Investment in biotechnology needs to be driven by its ability to solve agricultural problems, and priority for such funding should be within the overall national research strategy that assesses tradeoffs with, and complementarities from other areas of research.

- Public dialogue is very important and most countries have underinvested in this prior to undertaking research and testing on GMOs. This lack of dialogue contributes to controversies and slows the release and uptake of valuable technologies.

- No broad generalizations can be made about the risks of GMOs, and evaluation and decision-making must be done on a case-by-case basis reflecting traits and the economic and ecological situation.

- If the benefits of biotechnology in poor countries are to reach farmers and consumers, national and international public sector groups will have to support research, access to proprietary technologies and to the development of appropriate regulatory frameworks for public and private research and technology transfer.

\section{RECOMMENDATIONS FOR PRACTITIONERS}

In many countries, investments in applied and adaptive research on the use and application of noncontroversial biotechnologies will be appropriate, targeting plant tissue culture, micropropagation, molecular diagnostics of crop and livestock diseases, and (possibly) embryo transfer in livestock. Public investment in biotechnology research on and/or evaluation of GMOs may be appropriate where this is clearly targeted to Bank and country objectives, especially poverty reduction (see box 2.25). Such investments should:

- Be based on country assessments to identify opportunities and limitations on biotechnology investments.

\section{Box 2.25 Potential investments}

Investment in facilities, training, and technical assistance is needed to:

- Develop country strategies and priorities through consultations with end-users of technologies.

- Develop capacity for research on application of first generation, noncontroversial biotechnologies.

- Strengthen national biotechnology research capabilities.

- Support strategic alliances, both with the private sector and with advanced research organizations.

- Develop capacity for both food and biosafety risk assessment.

- Establish appropriate biosafety and food safety regulatory frameworks and enforcement mechanisms.

- Address public concerns, through information availability, and public dialogue and consultations.

Source: Authors. 
- Support capacity building for biotechnology research within the framework of a wellarticulated national policy and strategy.

- Target high priority problems that are best solved through biotechnology, rather than conventional research methods.

- Give prior consideration to costs and tradeoffs in generating technologies locally, rather than drawing on regional and international collaboration to develop and/or import appropriate tools and technologies.

- Develop a sound biosafety framework with its regulatory environment and monitoring capacity, prior to undertaking biotechnology research. This framework may be able to draw on regional capacity to evaluate and manage risks and benefits. This capacity needs to also be reviewed before research funding.

\section{SELECTED READINGS}

Asterisk $\left(^{*}\right)$ at the end of a reference indicates that it is available on the Web. See Appendix 1 for a full list of Websites.

Food and Agriculture Organization of the United Nations. http://www.fao.org.

International Food Policy Research Institute. http://www.ifpri.org.

International Service for the Acquisition of Agribiotech Applications. http://www.isaaa.org.

International Service for National Agricultural Research. Agricultural Biotechnology; Research, Policy, Management and Service. http://www.isnar.cgiar.org/ibs.htm.

\section{REFERENCES CITED}

James, Clive. 2001. Global Review of Commercialized Transgenic Crops: 2001. ISAAA Briefs 24: Preview. Ithaca, N.Y.: ISAAA.
Persley, G. J., and Pamela G., eds. 1999. Banana, Breeding, and Biotechnology: Commodity Advances through Banana Improvement Project Research, 1994-1998. Banana Improvement Project Report 2. Washington, D.C.: World Bank.

Traxler, G., S. Godoy-Avila, J. Falck-Zepeda, and J. Espinoza-Arellano. 2003. "Transgenic Cotton in Mexico: Economic and Environmental Impacts." In N. Kalaitzandonakes, ed., Economic and Environmental Impacts of First Generation Biotechnologies. New York: Kluwer Academic.

Wambugu, F. M., and M. K. Romano. 2001. The Benefits of Biotechnology for Small-Scale Banana Producers in Kenya. ISAAA Briefs 22. Ithaca, N.Y.: ISAAA.

This Note was prepared by Eija Pehu with inputs from the Sustainable Agriculture (SASKI) Thematic Team of the World Bank. 


\section{INNOVATIVE ACTIVITY PROFILE}

\section{BRAZIL: SPILL-INS FROM FOREIGN RESEARCH AND DEVELOPMENT LABORATORIES}

Brazil's agricultural sector has been an important source of economic growth. Today the sector faces the multiple challenges of increasing productivity while addressing pressing poverty, unbalanced regional growth, and natural resource constraints. Agricultural research is important for increasing productivity and reducing rural poverty.

What's innovative? Collaborative linkage programs with industrial countries, involving placement of midcareer scientists in foreign research institutions to capitalize on advanced research.

Brazil has a broad agricultural research system. In the mid 1990s, the national research agency Empresa Brasiliera de Pesquisas Agropecuarias (EMBRAPA) had 2,064 researchers and an extensive infrastructure. State (province) research systems had an additional 2,395 researchers, and university teaching and research faculty numbered over 4,000 . However, this capacity was underutilized and lacked adequate operating funding and linkages between institutions. As in many other developing countries, the need to include private sector research, to increase competition, and to make research demand-driven and responsive to farmer needs, was recognized. There was a need for strengthening domestic capacity by capitalizing on research resources outside the public sector, and encouraging technology and scientific spill-ins (or activities) from advanced research institutes.

\section{PROJECT OBJECTIVES AND DESCRIPTION}

In 1997, the Agricultural Technology Development Project led by EMBRAPA was initiated to increase the efficiency and sustainability of resources in the Brazilian agricultural research system. This was to be accomplished in four ways by: stimulating development of a more integrated and diversified National Agricultural Research System, with greater participation of the private sector; increasing the role of clients in defining research and technology transfer priorities; refocusing public sector research on public goods, such as research on family farms, natural resource management, and upstream technology activities not attractive to the private sector; helping EMBRAPA to address issues of decentralization and diversification of the research system; and facilitating increased scientific spill-ins from advanced research institutes.

Nearly two-thirds of project funding allocated to a CRGP acted as a catalyst for the long-term transition of the research system toward a diversified system of agricultural research and technology transfer. A committee, with representatives from various public, civic, and private stakeholders including farmer groups, selects the best research proposals.

A companion institutional capacity-building program aims to increase the capacity of institutions to bid for grants, and includes support for research management improvements, training, special studies, public-private partnerships, and international collaborative research programs. The international collaborative linkages program includes a program for "EMBRAPA's Foreign R\&D Lab," referred to as LABEX.

Under the LABEX program, promising Brazilian senior scientists in mid career are assigned to research programs in advanced research institutions in industrial countries. These scientists observe the latest scientific developments in their field, develop joint programs for future collaboration, and facilitate interaction between research teams in areas relevant to the Brazilian agro-livestock sector. LABEX was initiated as a cooperative program between EMBRAPA and the Agricultural Research Service of the United States Department of Agriculture (USDA). The LABEX program operates in the United States and France, and is under analysis for collaboration in Asia, probably with Japan. 


\section{BENEFITS AND IMPACTS}

The projects competitive grants component resulted in establishing relationships between EMBRAPA and the wider scientific community. About 258 diverse institutions are full participants, and another 400 are collaborating on research projects. EMBRAPA has now adopted the competitive system for all its research subprojects, including the Bank-supported project.

The LABEX program is innovative in facilitating technology spill-ins. LABEX-USA, the first such collaboration in the Americas, established a "virtual laboratory" concept. Focus areas in this partnership are: Natural Resource Management (NRM) in Amazônia; the Cooperative Program in the Animal Genome; International Cooperation and Sustainable Agriculture in the Insect Genome; and Management of Swine Effluents in the State of Santa Catarina. LABEX-USA has already made significant contributions including: sequencing the genome of the bacteria responsible for Pierce disease in California grapevines; experiments in precision-measurement of climatic variations to determine soil electricity conductivity and stresses in nitrogen, phosphorus, and water; and studies in intellectual property and biotechnology designed to establish modalities for more open use of patented/protected processes.

The LABEX-France model involves research partnerships with Agropolis in Montpellier, increasing the capacity of EMBRAPA to find new technologies and opportunities for cooperation with the European public and private sectors in agriculture. Priority areas for LABEXFrance are biotechnology and advanced biology, agroindustrial technology, and sustainable management of natural resources. A Brazilian researcher from each focus area is located in France, developing research activities applicable to Brazilian concerns, and locating new technologies and opportunities for cooperation. The physical infrastructure available in LABEXFrance collaboration provides several advantages over traditional forms of research cooperation as it reduces costs of conducting research; allows activities to be initiated or closed without direct overheads and infrastructure investment; and develops integrated research teams around specific projects.

\section{LESSONS LEARNED AND ISSUES FOR WIDER APPLICABILITY}

Brazil has an extensive and well-developed agricultural research capacity. Rapid advances in science, and limited research funding, even in the best of circumstances, make it essential to avoid duplication of research effort and to access new technologies and scientific knowledge in the most cost-effective way. This requires international exchanges and linkages.

In the past, bilateral grant aid provided support for international training, collaborative research, and institutional development. In most countries, this has declined, leading to a growing isolation of research scientists. EMBRAPA's LABEX program seeks to leverage EMBRAPA resources by developing collaborative research, education, training, and outreach efforts in areas of mutual interest with international research institutions. This strategy is likely to be relevant to many other countries, especially those with more limited research and educational capabilities than Brazil.

\section{PROJECT COUNTRY: BRAZIL \\ Project Name Agricultural Technology Develop- ment Project \\ Project ID P043873 \\ Project Cost US\$120 million \\ Dates $\quad F Y 1997-F Y 2005$ \\ Contact Point Raimundo N. Caminha The World Bank, Edificio SUDENE, Sala I3S-02 I, Cidade Universitaria, 50670-900 Recife, PE, Brazil Email:Rcaminha@worldbank.org}




\section{INNOVATIVE ACTIVITY PROFILE}

\section{COLOMBIA:DECENTRALIZED, DEMAND-DRIVEN, COMPETITIVETECHNOLOGY GENERATION}

By the early 1990s, the institutional model of the traditional public system of agricultural research and extension in many Latin American countries had declined in its effectiveness. While working fairly well in the past in delivering technology for major commodities, the model now faced new challenges to which it was unable to respond. Challenges included the development of sustainable production systems, resource conservation, processing, and markets and exports. In part, problems were due to an overly centralized, highly bureaucratic research system that was not well linked to its clients.

What's innovative? Decentralized decision-making facilitating smallholder participation in a transparent process for priority setting, and the awarding of competitive research grants.

In the early 1990s, the Government of Colombia committed itself to decentralizing technology development and transfer in order to bring applied research and extension (R\&E) closer to the priority problems of target beneficiaries, who would participate in characterizing, prioritizing, and solving their problems.

\section{PROJECT OBJECTIVES AND DESCRIPTION}

In 1995, the National Agricultural Technology Development Project (PRONATTA) was designed with World Bank support to assist this decentralization process, by offering funding for regional research funding and institution building. The project's four key objectives were to: promote a pluralistic technology system; support demand-driven and decentralized approaches; diversify financing through cofinancing by users and research providers; and provide incentives for reforming public R\&D. Two program components involved:
- Creation of a competitive fund in which resources are assigned to proposals responding to needs of small rural producers.

- Institutional development, aimed primarily at building local institutional mechanisms to allow stakeholders, particularly small producers, to participate in addressing problems of agricultural system productivity and competitiveness.

For assigning funds, the competitive fund used four criteria: the use of a systems approach, addressing sustainability, participation of endusers in technology development, and building farmer capacity.

Implementation was decentralized to five regions where local "nodes" were established and linked into regional "networks" to coordinate research activities. The nodes are informal groups open to research institutions, farmer groups, NGOs, private sector, and officials of departmental secretariats of agriculture. A total of 340 organizations have participated in the nodes, and an additional 160 in thematic networks that operate parallel to the nodes. Nodes develop lists of priority research issues and project profiles, and at the network level consolidate these for the region. These priorities are submitted to the PRONATTA Regional Coordination Unit.

Competitive project selection for grants is done largely at the regional level. Calls-for-proposals are distributed widely, and proposals screened for eligibility by the PRONATTA's coordination unit. Regional technical panels, using priorities established by the regional networks, evaluate the proposals, which are ranked by priority and submitted to the PRONATTA central office for funding within the limits of available funds.

The program has maintained high-quality standards for award of grants. For the six callsfor-proposals up to the year 2003, rates of approval of proposals ranged from 13 to 22 percent. Some 616 grants were awarded out of 3,786 proposals submitted. 


\section{BENEFITS AND IMPACTS}

Within two years, the competitive fund expanded rapidly to cover all five regions of Colombia and has funded over 600 projects at an average cost of US\$50,000. The program has been widely-recognized for its transparent approach to the awarding of grants and for having funded high-quality, relevant research. Of all projects funded by PRONATTA, 96 percent are rated satisfactory.

A total of 179 implementing agencies have been involved in project execution. The Colombian Institute for Agricultural Research has received 39 percent of the grants; NGOsæ11 percent; universitiesænine percent; producer associationsæsix percent; other public institutionsæfour percent; other agenciesæfive percent; and alliances between different institutionsæ26 percent.

PRONATTA research projects have demonstrated their impacts with higher productivity, and adoption of sustainable management practices among small producers, especially through reduced use of agricultural chemicals and improved soil management practices. About 153,000 beneficiaries have adopted technologies introduced by PRONATTA. A recent impact evaluation of completed projects found that the vast majority are producing, or are likely to produce, significant short- to medium-term benefits, mostly for small-scale producers. Benefits far exceed the cost of the investments.

\section{LESSONS LEARNED AND ISSUES FOR WIDER APPLICABILITY}

Competitive research grant program design should emphasize transparency in operation of the grant programs; incorporate farmers and other beneficiaries in the process of priority setting, evaluation, and selection of projects; establish sound monitoring and evaluation systems; and develop mechanisms to enhance portfolio coherence. Major lessons learned from the PRONATTA experience are that:

- A competitive fund can draw a wide variety of research and extension service providers into the national research system, thus building a diverse research system with varied sources of funding.

- Decentralized execution of a competitive grants program is key to substantively involving local people in an applied and adaptive research program.

- Local institutional capacity building for client groups, local government, and potential service providers is important for promoting competition. Representative involvement of all sections of farming groups is not a simple task, and depends on community dynamics. Effective involvement requires long-term investment in institutional development and community participation.

Projects similar to the PRONATTA program are being implemented in Peru, Ecuador, Nicaragua, Brazil, Mexico, and some countries in Europe and Central Asia.

\section{PROJECT COUNTRY: COLOMBIA}

\begin{tabular}{ll} 
Project Name & $\begin{array}{l}\text { Agricultural Technology Develop- } \\
\text { ment Project (Components: } \\
\text { Research }\end{array}$ \\
& \multicolumn{1}{c}{ Sub-Projects; Institutional } \\
& Development) \\
Project ID & P006880 \\
Project Component Cost & Research Sub-Projects: \\
& US\$2I.0 million \\
& Institutional Development: \\
& US\$1.I million \\
& FY 1996-FY 2004 \\
Dates & Matthew A. McMahon \\
Contact Point & The World Bank, I8I8 H Street, \\
& NW, Washington D.C. 20433 \\
& Telephone: (202) 473-8586;
\end{tabular}




\section{INNOVATIVE ACTIVITY PROFILE}

\section{ECUADOR: STRATEGIC INTERNATIONAL ALLIANCES FOR CAPACITY BUILDING AND RESEARCH}

By the mid 1990s, Ecuador's agricultural research system, based principally on a public sector research institute, faced interrelated problems of low productivity, a funding crisis, and attrition of scientists. At the same time technological and management innovation was needed to improve productivity and competitiveness of its important agricultural sector. Modernization of production systems and sector institutions were essential if the sector were to compete in regional and global markets. As a result, the government undertook a program of institutional reform, with the objective of strengthening research capacity in a variety of public and private organizations, increasing efficiency of research, and improving linkages to clients.

What's innovative? Competitive financing of grants for strategic alliance with international research organizations to strengthen domestic capacity for research and education.

\section{PROJECT OBJECTIVES AND DESCRIPTION}

The Agricultural Research Project had three major objectives: to introduce a competitive research grants program (CRGP), to develop partnerships with international science institutions, and to strengthen national research institutions. The government contracted a private firm to manage the CRGP within policy guidelines established by the government.

Competitive grants for strategic partnership alliances with international research organizations were financed in parallel with grants for individual research activities. Both followed the same competitive procedures and targeted development of local institutional capacity for research in key thematic areas. Institutions submitting proposals had to demonstrate a commitment to cofinancing a substantial and sustainable program in identified priority areas for research. Strategic Alliance Grants (SAGs) were also authorized to improve higher education (masters level) in agriculture. Strategic alliance grants were larger than research project grants (average US\$321,000 versus US\$62,000). Participating institution cofinancing contributions averaged 45 percent of total program costs.

The SAG Program was designed to facilitate access to relevant technologies and technical expertise available internationally. The technology spill-ins resulting from this program represent a cost-effective means of improving the technology base for Ecuador's agriculture. The competitive selection procedure requires evidence of institutional commitment to longterm work in the program area. This also allowed Ecuadorian institutions to set their own priorities for program development, and to select their own partners for alliances.

\section{BENEFITS AND IMPACTS}

The SAGs financed six alliances for postgraduate program development in agricultural subjects. Six Ecuadorian universities participated as lead institutions and developed alliances with eight foreign universities, six international research centers, four local universities, and four other institutions.

Seven SAGs for agricultural research financed partnership development for three Ecuadorian universities, the public research institute (with two research alliances), an NGO, and a producer group. Research themes included fruit processing, regional agribusiness development, soils, production systems, biotechnology, medicinal plants, and soil salinity management. Alliances involved six foreign universities, four international research centers, three local universities, and ten other institutions, including various client groups.

The strategic alliances have allowed local organizations to draw on resources and technical expertise from international centers of excellence, and encouraged long-term relation- 
ships with partner research and educational institutions and with client groups. This has proven effective in developing local capacity and providing efficient access to spill-ins of scientific knowledge and the latest technologies.

Competitive selection procedures helped to identify institutions with sufficient capacity and an interest and commitment to developing as a center of excellence for a specific thematic issue. Adding education programs to the SAGs provided for longer-term strategic capacity development for the country.

\section{LESSONS LEARNED AND ISSUES FOR WIDER APPLICABILITY}

Financing for development of research capacity is likely to be needed in most countries where CRGPs are being introduced. Such capacity building can be financed through core funding for a research agency, though, as in the case of Ecuador, competitive procedures may be useful in identifying institutions with commitment to a particular field of research and a core capacity on which to build. This latter approach has been shown to be feasible even in a small research community such as Ecuador.

Competitive selection of projects to be financed also allows for participating institutions to provide cofinancing, thus increasing total funding available for research and strengthening the overall system.

\footnotetext{
PROJECT COUNTRY: ECUADOR

Project Name Agricultural Research Project (Competitive Grants Component) 


\section{INNOVATIVE ACTIVITY PROFILE}

\section{INDIA: FOCUS ON BIOTECHNOLOGY}

Despite food grain self-sufficiency, India faces continuing challenges in sustaining agricultural growth rates. Post green revolution developments have brought into sharp focus concerns relating to productivity, sustainability, and environmental protection. Developments in biotechnology offer great scope for improvements in crops, livestock, and aquaculture. Development of transgenic crops with increased yields and improved nutritional qualities, and development of diagnostic kits for plant and animal diseases, are some areas with considerable potential.

What's innovative? Development of domestic competitiveness in biotechnology research through focused training of research staff, organized into "Teams of Excellence" with control over resources through the competitive grant funding process.

Consequently building domestic capacity and advancing research in biotechnology is critical and use of research providers, not part of the national agricultural research system, is considered necessary in order to improve the outcomes of these activities. At the same time, with the rapid pace of international research, links to international researchers is necessary.

\section{PROJECT OBJECTIVES AND DESCRIPTION}

The overall objectives of the National Agricultural Technology Project were to: improve the efficiency of the Indian Council of Agricultural Research (ICAR) organization and management systems; enhance the performance and effectiveness of priority research programs and of scientists in responding to the technological needs of farmers; and develop models that improve the effectiveness and financial sustainability of technology dissemination with greater accountability to, and participation by, the farming communities. The project sought to change the research agenda from being commodity-and-budget driven to one that was disciplinary-and-demand driven. The process used for developing scientific capacity included:

- Establishing teams of excellence.

- Training of scientists.

- Funding research through competitive grants which were open to public, private, and community organizations.

Teams or centers of excellence, consisting of a prominent individual scientist or a group of scientists within existing institutions, are provided with administrative and financial autonomy to facilitate contracting and collaboration with a range of partners. This approach was designed to draw in new ideas and disseminate these, and to pilot new forms of decentralized management of research units/activities. Because of rapid developments in science, strengthening international linkages is important to improve the quality of science and the capabilities of scientists. Funds allocated under this subcomponent promote links with institutions having complementary interests/expertise.

Within the NATP project, biotechnology investments use tools of modern science to improve crop, livestock, and fisheries productivity as the research program seeks to develop transgenic crops with inbuilt biotic and abiotic resistance and to reduce the use of pesticides. The project also aims to develop diagnostic kits for early disease detection in animals and aquaculture; to develop vaccines for better health management in animals; and to use biotechnology tools for processing and adding value to crops by increasing the shelf life of fruits and vegetables.

The project established a Biotechnology Advisory Group (BAG) composed of scientists from public and private agencies to provide additional views in establishing research and training priorities. The BAG group was designed to "brainstorm" various issues related to biotechnology, guide ICAR, and review proposals submitted both through the sponsored and 
competitive route. The project team considered it important to establish such an advisory group, because ICAR institutions are the weakest amongst various agencies involved in biotechnology research, such as the Council for Scientific and Industrial Research, universities, and the private sector. During the period 19982003 the project:

- Established teams of excellence in the area of plant biotechnology, viral biotechnology, and animal biotechnology.

- Trained 200 scientists annually in state-ofthe-art knowledge on crop and animal biotechnology.

- Developed transgenic rice, cotton, mustard, muskmelon, potato, and pigeonpea.

- Used competitive grants to fund highquality research in biotechnology.

- Established management systems to provide for rigorous monitoring and evaluation, including progress on execution of research activities.

\section{BENEFITS AND IMPACTS}

There has been significant progress in developing capabilities for plant transgenic research with major successes with transgenic rice and cotton.

Transgenic rice is already at the fourth generation stage, and field-testing will take place in 2004. Transgenic rice and cotton carry the Bacillus thuringiensis $(\mathrm{Bt})$ gene that mediates resistance against insects. In addition, two genes (Lr 19 and Lr 28) were tagged for the first time using molecular markers, and have been combined in one genotype providing strong resistance to leaf rust disease in wheat. Another major achievement has been the characterization of viral genomes of plant and animal viruses, enabling the development of plants with in-built resistance to insects and viruses, and improved viral detection methods in livestock and aquaculture. Development of diagnostic kits will help detect plant viruses in citrus, potato, and banana, as well as diseases of livestock.

\section{LESSONS LEARNED AND ISSUES FOR WIDER} APPLICABILITY

The progress on biotechnology research and its initial results illustrate that:

- Research programs focused on key problems, and subject to rigorous and transparent monitoring, can yield important dividends.

- Building in-house competence through human resource development and physical infrastructure can result in rapid progress and quality research outputs.

- Competitive research grants, awarded through a transparent selection process and followed up by good monitoring, evaluation, and impact/outcome assessment, are an effective mechanism for financing high-quality research work, undertaken by multidisciplinary teams from a range of institutions.

- Competitive grants can be useful in providing research support to more young scientists and to female scientists.

In view of the major successes under the program, ICAR is developing major biotechnology programs based on a Competitive Research Grants Scheme. Program management emphasizes transparency, quality evaluation, and bottom-up approaches.

\section{PROJECT COUNTRY INDIA}

\begin{tabular}{|c|c|}
\hline Project Name & $\begin{array}{l}\text { National Agricultural Technology } \\
\text { Project }\end{array}$ \\
\hline Project ID & P0I056I \\
\hline Project Cost & US\$249.0 million \\
\hline Dates & FY 1999 - FY 2004 \\
\hline Contact Point & $\begin{array}{l}\text { Paul Singh Sidhu } \\
\text { The World Bank, } 70 \text { Lodi Estate, } \\
\text { New Delhi I I0 003, India } \\
\text { Email: Psidhu@Worldbank.org }\end{array}$ \\
\hline
\end{tabular}




\section{INNOVATIVE ACTIVITY PROFILE}

\section{INDIA: REVITALIZING INSTITUTIONAL CAPACITY IN FORESTRY RESEARCH}

The Indian Council of Forest Research and Extension (ICFRE) has been conducting forestry research in India since the colonial era. ICFRE's research activities lacked the scientific and institutional mechanisms for ensuring scientific rigor, research priorities, for client orientation, and for using research results. Management systems for staff, research activities, finances, reference libraries, and other facilities needed significant upgrading. For research, systems were needed to ensure that research addressed specific technical concerns, provided multidisciplinary perspectives, and reflected national priorities and regional needs.

\footnotetext{
What's innovative? A stand-alone project focused on institutional development of a key forestry research organization by addressing core issues of organizational weaknesses and basic institutional management rather than specific technical tasks.
}

\section{PROJECT OBJECTIVES AND DESCRIPTION}

The main objective of Forestry Research Education and Extension Project (FREEP) was to improve the capacity and quality of forestry research. Other components included biodiversity conservation and government forest policy analysis and development. Specific objectives related to:

- Strengthening the capacity of national, regional and state institutions to conduct priority forestry research, including planting stock improvement programs, through improvements to institutional management and administration programs.

- Improving the system of forestry education in research and academic institutions.

- Improving the dissemination of research findings to users of the information.

FREEP represented a successful departure from past forestry projects in that it did not focus on research as one component within a broader forestry operation, or on forestry research within a broader research operation. FREEP specifically focused on improving institutional capacity to conduct forestry research, education, and extension, and to build this capacity in the national research system.

\section{BENEFITS AND IMPACTS}

The project achieved its targets by improving the capacity of ICFRE to plan, prioritize, and carry out forest research. Specific targets achieved included:

- After extensive consultation with stakeholders to identify priorities, ICFRE developed and is now implementing a National Forest Research Plan.

- Research Advisory Groups, comprising multidisciplinary experts and clients, and chief scientific advisors, review research projects to ensure their scientific quality and their relevance to user needs. Increased computer literacy and improved facilities (library, modern nurseries, research equipment) help modernize research.

- An information management system and human resource development plan facilitate program budgeting and improved staff management.

- Improved planting stock programs (in all states), small grants programs, technology licensing, extension activities and materials, and curricula reforms have dramatically increased ICFRE's client outreach.

- The project has been quite successful in developing the "forestry knowledge and information system" but its intergration into the broader AKIS remains uncertain.

\section{LESSONS LEARNED AND ISSUES FOR WIDER APPLICABILITY}

This successful approach to institutional capacity development in forestry research provides lessons that can be applied beyond the forestry 
sector and agriculture to other institutional revitalization programs as it:

- Focused on specific activities critical to sustainable change (for example, implementation of a sound management information system, arrangements to increase interactions with clients, external peer review mechanisms, and technical oversight).

- Addressed directly core organizational weaknesses within institutions and brought about institutional change within the relatively short time frame of one project.

- Focused on basic institutional management issues, such as finance, staffing, and administration, rather than on specific technical tasks or functions of an institution, for example, specific research.

- Coordinated with broader agricultural research and information programs and institutions to give coherence to technical services for rural areas, and to seek economies of scale in program operations. These policies and institutional mechanisms need to be mutually supportive in order to avoid conflicts and to enhance sustainability of technical services.

\section{PROJECT COUNTRY: INDIA}

Project Name Forestry Research Education and Extension Project (Components: Research Management; Research Program Support)

Project ID POI0448

Project Component Cost US\$48.7 million

Dates FY $1995-$ FY 2002

Contact Point Jessica Mott The World Bank, I8 8 H Street, NW, Washington, D.C. 20433 Telephone: (202) 458-5607; Email: JMott@worldbank.org 


\section{INNOVATIVE ACTIVITY PROFILE}

\section{SENEGAL: MAKING RESEARCH DEMAND DRIVEN}

Evaluation of the Second Agricultural Research Project, completed in 1996, highlighted poor performance of the Senegalese Research Institution - ISRA (Institut Sénégalais de Recherches Agricoles). Despite considerable investment since the mid 1980s, with two successive Bank and two successive USAIDfunded research projects, ISRA was still not responding to farmers' needs. Management reforms, including incentive systems to reward performance and financial management improvements, remained pending. Investments in important subsectors of postharvest technology and agroprocessing had been neglected because they were the responsibility of a different research institute, the Food Technology Research Institute (ITA).

What's innovative? A new funding mechanism that provides for core institutional capacity building in parallel with a competitive research fund with separate funds for farmer-proposed and researcher-proposed projects, so as to develop demand orientation in research.

\section{PROJECT OBJECTIVES AND DESCRIPTION}

The Agricultural Services and Producer Organization Project is a shift in approach from support only for supply of services to support for both supply of and demand for services. Without strong demand from end-users, public research institutions were unlikely to make essential, but difficult, reforms to improve responsiveness of research to clients. The project sought to strengthen producer organization (PO) capacity to become effective research partners, and establish mechanisms to make research institutions accountable to clients. The project design recognized the need for:

- Capacity building for two research institutes (ISRA and ITA).
- An alternative to "institutional" or core funding for research operating costs.

- More effective utilization of scarce human and physical resources for research.

The project established the National Agricultural Research Fund (NARF), a legally independent entity that separates its research funding function from the execution function, and enables qualified entities, both public and private, to access funds for research. Parallel core funding provides ISRA and ITA with funds for infrastructure, training, and management strengthening needs.

NARF finances research proposals submitted through two mechanisms: researcher-developed proposals related to ISRA's or ITA's strategic plans, and responses to calls-forproposals issued by NARF on themes identified by end-users. The two types of proposals undergo the same two-tier screening procedure: first, by a scientific and technical committee of 15 scientific resource persons (six from outside Senegal) that screens proposals for scientific quality; and then by a management committee with a majority of producer organization and private sector representatives. Once a proposal is approved, NARF signs a contract with the lead research institution.

\section{BENEFITS AND IMPACTS}

The two separate funding mechanisms of core funding of research institutes and NARFcontracted research, guarantee that institutional development continues, while funding for operating costs goes directly to research teams working on projects relevant for the users, and for which teams are accountable for results. Projects are screened rigorously. Only 26 of the first 79 research proposals were approved.

Projects promote collaboration between organizations with research capacity ( 85 percent of projects); with international organizations (12 percent); and with development agencies, such as POs, NGOs, or others (58 percent). Overall, 
38 different institutions have received funding under the 26 projects.

Under new funding arrangements, the Ministry of Finance agreed that government funding must cover research institute fixed costs, which can no longer be financed by International Development Assistance funds. This lead the Government to recognize that it could no longer afford to support ISRA's extensive research infrastructure, and that closing redundant facilities was inevitable.

The program's success is qualified by the fact that in its initial stage, no proposals were accepted for research on products likely to be significant for future exports (horticulture and fisheries), for basic food crops (rice), or for future technological breakthroughs (biotechnology). The Fund is therefore considering narrowing the scope for future grants to priority topics as defined by a group of experts from within the national agricultural research system.

\section{LESSONS LEARNED AND ISSUES FOR WIDER APPLICABILITY}

Sustainability of a competitive research fund mechanism depends on a manager's ability to attract funding from other donors. For this reason, one performance indicator for the project is the number of other donors that the Fund attracts.

Research funds should be managed independently of research-implementing organizations, because of the conflicts of interest. Locating funds outside government ministries allows for more flexible management.

Establishing a management committee with a majority of users' representatives, responsible for the program, produces a very different dynamic than when government officials are a majority on the governing body.

Having two channels for researcher-proposed and user-requested research proposals provides flexibility and allows a program to respond both to immediate producer concerns and to opportunities identified by scientists.

The generation of sufficient proposals of good quality and relevance is a function of the research capacity of the country's human resources, hence the importance of core funding for capacity building in parallel with a competitive fund.

Research partnerships with strong international research organizations also enhance quality of research, but governments often object to use of loan funds to finance foreign researchers. Complementary bilateral grant funding can therefore be important to finance collaboration of researchers from advanced research institutions.

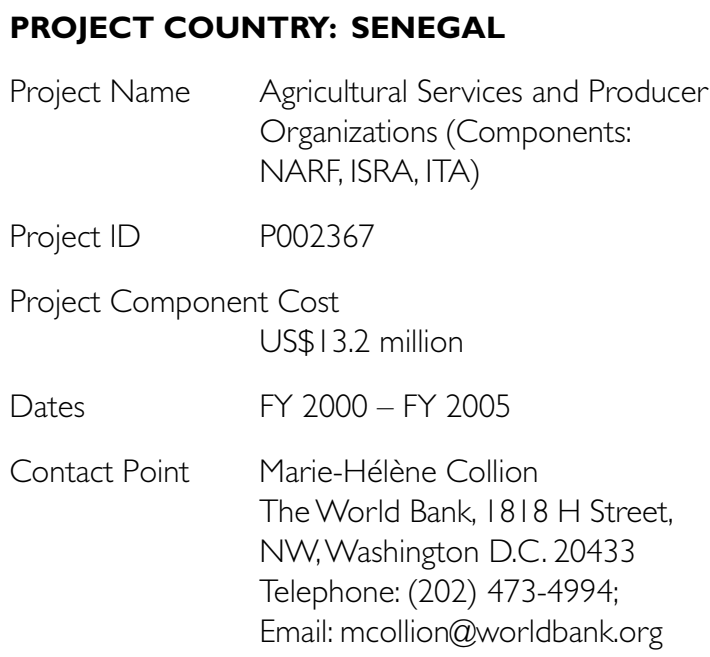




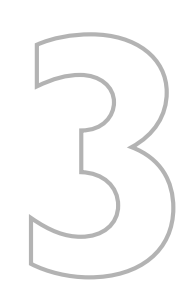

\section{INVESTMENTS IN AGRICULTURAL EXTENSION AND INFORMATION SYSTEMS}

lobally, ministries of agriculture, universities, and the private sector employ more than 600,000

extension agents (Swanson, Farmer, and Bahal 1990). In the past, extension services, largely

public, were equated with the transfer of agricultural production technology in pre-deter-

mined "packages". Extension systems are now understood to be much broader and more diverse, including public and private sector and civil society institutions that provide a broad range of services (advisory, technology transfer, training, promotional, and information) on a wide variety of subjects (agriculture, marketing, social organization, health and education) needed by rural people to better manage their agricultural systems and livelihoods. This module seeks to summarize principles and good practice for investments in building effective and sustainable extension systems.

\section{RATIONALE FOR INVESTMENT}

The success of rural development programs depends largely on decisions by rural people on questions such as what to grow, where to sell, how to maintain soil fertility, and how to manage common grazing 
areas. Most clients of extension are farmers, both women and men, but many other rural people who are not economically active in farming also rely on extension and information services to inform and influence rural household decisions.

Past returns to extension investment have been valuable but often high (see box 3.1). Future increases in agricultural production and rural income must come from intensification, rather than "extensification" of agriculture. Knowledge and related information, skills, technologies, and attitudes will play a key role in the sustainable intensification of agriculture and the success of other rural investments. New technologies and markets offer rural households new opportunities, but they require better access to information. Globalization and the need to trade in a global environment requires farmers and other rural people to become more competitive by acquiring more knowledge to base decisions on and new skills to implement those decisions.

Although agriculture remains critically important for their economic well-being, rural people need other options and expect more information than in the past, including information on health care and nutrition, consumer products, and government and other pro-

Box 3.I Returns to investment in extension and information services

Evaluations have often criticized extension for low efficiency and lack of equity in service provision, but report relatively high cost/ benefit ratios (Perraton et al. 1983). Rates of return on extension investments in developing countries have generally ranged from 5 percent to more than 50 percent (Evenson 1997). A recent metastudy of 289 studies of economic returns to agricultural research and extension found median rates of return of 58 percent for extension investments, 49 percent for research investments, and 36 percent for investments in research and extension combined (Alston et al. 2000). But methodological problems are daunting and rates of return are highly variable for even the same program, such that there is a considerable need for additional evaluation of extension impacts.

Source: Gautam 2000; Feder, Murgai, and Quizon 2003. grams. Many farmers want to stop farming (or because of lack of competitiveness will be forced to) and will seek information, education, and alternative skills to prepare them for new employment.

Extension services make significant contributions to environmental protection and sustainable management of natural resources by promoting conservation of land, water, and forests; conservation of biodiversity; pesticide safety and residue minimization; livestock waste management; and water quality preservation and watershed protection. The client base for environmentally oriented extension goes beyond the smallscale farmer because the varied activities of rural residents, such as hunting, disposal of waste materials, harvest of fuel wood, and other products, affect the environment.

\section{PAST INVESTMENT ACTIVITY}

Public extension expenditures grew rapidly in the 1970s and were estimated at US\$6 billion globally for 1988 (Swanson, Farmer, and Bahal 1990). Since then, structural adjustment programs, public sector retrenchment, and reallocation of expenditures suggest that there may have been a substantial decrease in funding for extension; however, total funding often remains high (up to 2 percent of agricultural GDP). In some countries the extension service is one of the largest agencies in the government.

Since 1981, the World Bank has provided US $\$ 3$ billion in direct support for extension, while mobilizing another US $\$ 2.5$ billion from governments, beneficiaries, and other sources (see figure 3.1). This Bank financing has fostered recognition of the importance of extension and has shaped development of many national extension systems.

In the past, the World Bank was often associated with Training-and-Visit (T\&V) extension, a system popularized in the 1970s and 1980s to address severe management deficiencies in existing extension services. T\&V proved effective in specific circumstances in which standard- 
FIGURE 3.I TRENDS IN WORLD BANK LENDING FOR EXTENSION PROGRAMS, FY83-FY02

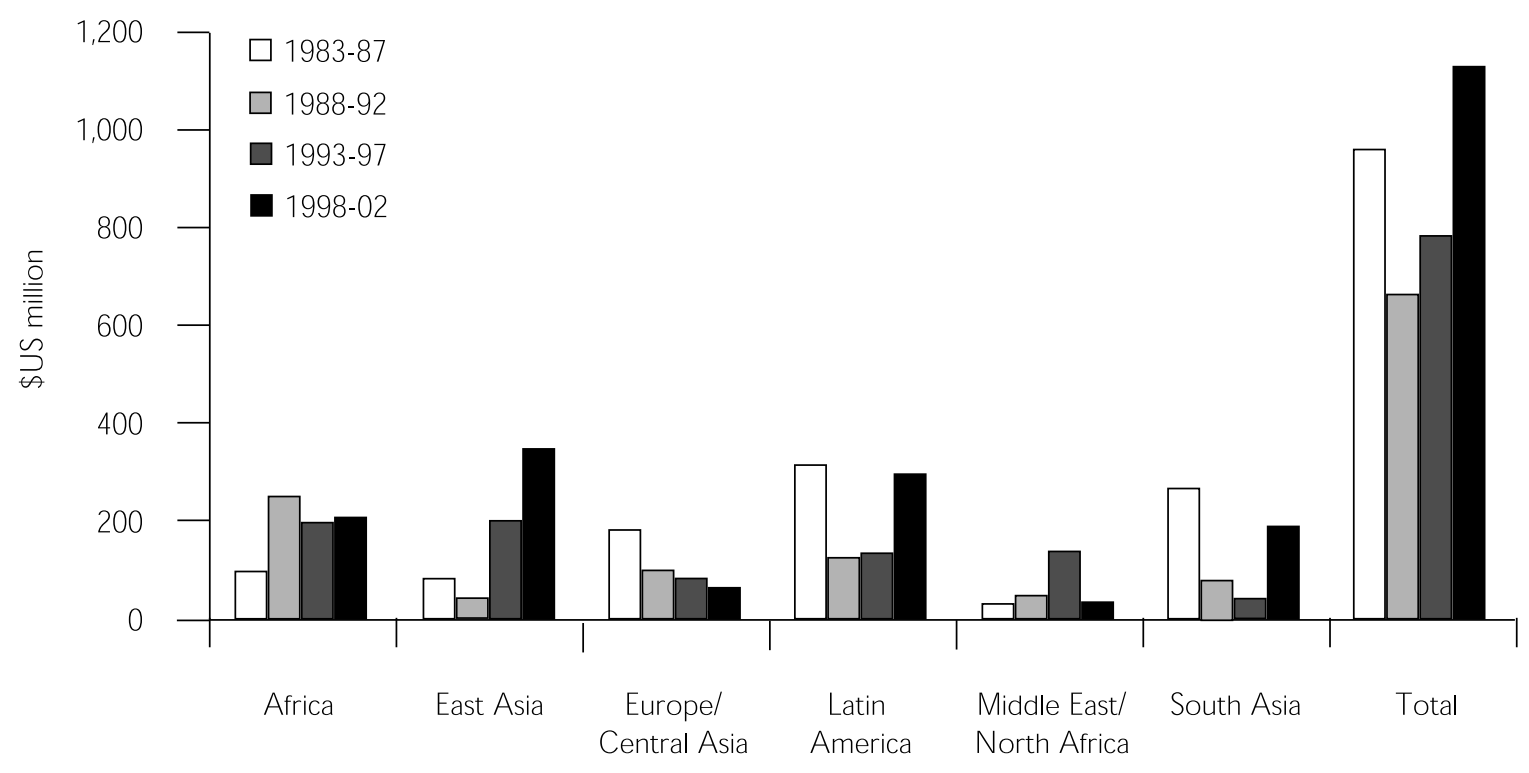

Source:World Bank Internal Documents.

ized technology packages could be introduced over large, relatively homogeneous areas. But $\mathrm{T} \& \mathrm{~V}$ did not resolve problems of sustainability or address the needs of diverse rainfed systems and was widely considered a failure.

The World Bank Operations Evaluation Department (OED) review of Bank support to extension services found that extension projects produced considerable benefits. The results of the OED review also noted concern over sustainability because three out of four projects were rated "uncertain" in terms of likely sustainability (Purcell and Anderson 1997). The OED study emphasized that no single extension model is universally relevant, and situation-specific models need to be developed based on general principles and analyses of specific farming systems and social conditions. The study found widespread problems with inadequate funding for recurrent costs, insufficient technology, poor links to research, limited farmer participation, and a top-down mentality. Extension staff quality was a major constraint and staff training programs were inadequate to correct deficiencies. The OED study suggested that investment in state-run, staff-intensive extension services is inappropriate for many countries and concluded that temporary, targeted programs may provide a better return on investment. It also revealed a limited capacity of most borrowers and of Bank staff to undertake the necessary analysis for the design of extension systems.

By the early 1990s, the World Bank recognized the need for new approaches to extension investments, including a larger role for the private sector, nongovernmental organizations (NGOs), and producer organizations, as well as a more inclusive approach to women, indigenous peoples, and poor people (Cleaver 1993; Ameur 1994; Antholt 1994).

\section{KEY ISSUES FOR INVESTMENT}

Future investments must avoid past mistakes and seek more sustainable institutional arrangements for providing knowledge and information services to rural people. The emerging view is that the farmer is a responsible entrepreneur, managing complex, agricultural and off-farm activities to maximize well-being within many constraints. The farmer is a key source of innovation-a concept reflected in a simple knowledge triangle (see figure 3.2). Key to the concept of the agricultural knowledge 
triangle is the realization that improving rural productivity, social equity, and competitiveness requires effective and efficient agricultural knowledge and information systems (AKISs) that "link people and institutions to promote mutual learning and generate, share, and utilize agriculture-related technology, knowledge, and information" (FAO/World Bank 2000). Such a system integrates farmers, agricultural educators, researchers, and extension workers to harness knowledge and information from various sources for better farming and improved livelihoods.

Providing diverse extension and information services to rural people necessitates a diversity of public and private service providers on both the supply and demand side of the extension services market. How this market functions depends on the institutional and policy environment for innovation and by the quality of services provided. The diversity in extension service suppliers reflects also the diversity in types of information and cost of providing information. Radio and television, input suppliers, agribusinesses, newspapers, neighbors, public extension agents, religious organizations, bankers, NGOs, and other agencies each have their own strengths,

\section{FIGURE 3.2 ARGRICULTURAL KNOWLEDGE TRIANGLE}

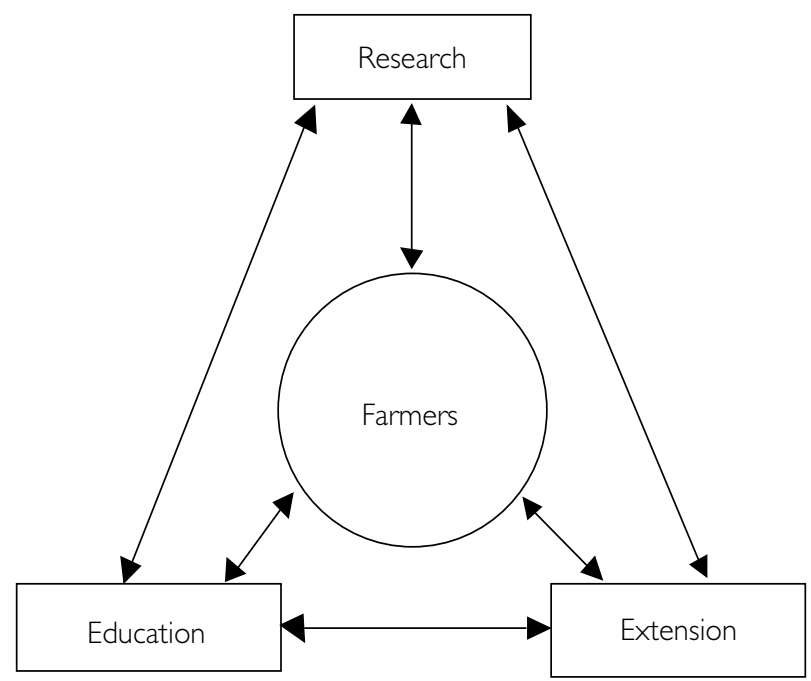

Source: FAO/World Bank 2000. weaknesses, and motivations. This framework underlies the guiding principles for investment in extension and information systems (see box 3.2) (FAO/World Bank 2000).

\section{FUTURE DIRECTIONS FOR LENDING}

Future investments must recognize a diversity of clients and client needs, and varied approaches for technology transfer, advisory services, facilitation, educational, and information services. Making services more responsive to clients will entail focusing more on human and social capital development, as well as on giving the farmer more influence over the extension agenda and the way in which services are delivered. To develop extension systems that are consistent with FAO/World Bank principles for effective AKISs, investments are needed to better define public sector roles, enhance financial sustainability, strengthen ability of clients to express demand for services, support extension system reforms, improve quality of services, address key poverty and environmental issues, and exploit potential of mass media and communications technologies.

Defining Public and private Sector Roles. Private market mechanisms often fail to provide a socially optimum level of extension services for two reasons. First, the demand from small-scale farmers may not be expressed well because of the farmers' failure to recognize benefits from alternative production and marketing options; because farmers have limited purchasing power; or because they are not organized to access services. Second, supply is constrained because there may be few individuals or institutions capable of providing technical services or limited opportunity for private firms to appropriate benefits by charging for provision of information. The characteristics of specific services influence whether these are best supplied by the private, voluntary, or public sectors-different extension service needs are best fulfilled by different agencies. Extension services can be categorized by differences in excludability (the degree to which farmers who do not pay for a service can be excluded from its benefits) and rivalry 
Box 3.2 Guiding principles for public investment in extension systems

Defined role for the public sector:

Made within a sound policy framework that provides a conducive environment for investments to achieve desired impacts.

- Based on clear national strategies that articulate a long-term vision and national policies, plans, and objectives for extension investments.

- Economically efficient with benefits and expected outcomes that justify the investment.

- Equitable with appropriate services available to the poor and minority groups and with a keen recognition that farmers and herders are both male and female.

Strengthened demand for services:

- Demand-driven, responding to farmer needs and interests and involving clients in program governance, priority setting, and evaluation, often by working through and strengthening producer organizations.

- Participatory, drawing on and empowering local people to solve problems and mobilize local resources.

- Based on subsidiarity with responsibilities devolved to the lowest possible level of government and consistent with organizational competency, comparative advantage, and efficient use of funds.

Improved quality of services:

- Accountable for the use of funds and for results with incentive structures that ensure assignment of qualified staff who are given adequate support and held responsible for providing services to clients.

- Relevant to the needs and resource constraints of different categories of clients, balancing objectives of profitability, productivity, and sustainability, and drawing on effective training and links to research and other sources of innovation.

- Pluralistic, involving a range of institutions with different comparative advantages; often separating financing and service delivery to broaden the range of service providers, raise operational efficiency, and make service providers more accountable for performance and results.

- Well-monitored and evaluated to ensure a results orientation, account for impacts on human, social, and environmental capital, and demonstrate cost effectiveness.

Based on a sustainable system:

- Develop human and social capital necessary for clients and local institutions to foster continuous learning and problem solving.

- Cost-shared by major stakeholders.

- Develop political support from stakeholders as a basis for securing future financing.

Source: FAO/World Bank 2000.

(the extent to which one farmer's use of a service reduces its availability to others). While there is frequently a mix of public and private elements in any specific extension service, some common services can be broadly classified, as reflected in examples in table 3.1.

Public and private sector roles frequently overlap, providing justification for publicprivate partnerships. If families or firms benefit from services, they should pay; if communities benefit, community groups or local government should pay; and if the region benefits, the province or state should pay. The public sector should finance extension services that generate important benefits for society as a whole, but which extension clients are unlikely or unable to finance on their own. The most important positive externalities associated with extension and information services are productivity spillovers, positive environmental and health (human, livestock, and crop) impacts of appropriate technology use, and poverty reduction. Public financing is often important for coordination (often indirect) of extension activities, regulation and provision of unbiased technical recommendations, disaster response and poverty-oriented programs, training and development communications programs in which economies of scale/scope exist, and promotion of the rural extension and information system as a whole. In general, the share of public sector in the funding of extension services will decline with the transition to commercial 
Table 3.I Economic characteristics and delivery mechanisms for different extension services

\begin{tabular}{|c|c|c|c|c|c|}
\hline \multirow[b]{2}{*}{ Service } & \multirow{2}{*}{$\begin{array}{l}\text { Main type } \\
\text { of good }\end{array}$} & \multicolumn{2}{|c|}{$\begin{array}{l}\text { Major delivery } \\
\text { mechanisms }\end{array}$} & \multicolumn{2}{|c|}{$\begin{array}{l}\text { Main financing } \\
\text { mechanism }\end{array}$} \\
\hline & & Public & Private $^{a}$ & Public & Private $^{a}$ \\
\hline Farm advisory services (generic) & Public & Yes & $\begin{array}{l}\text { Yes if } \\
\text { contracted }\end{array}$ & Yes & No \\
\hline $\begin{array}{l}\text { Farm advisory services } \\
\text { (farm-specific) }\end{array}$ & Private & Yes & $\begin{array}{l}\text { Yes, } \\
\text { preferred }\end{array}$ & $\begin{array}{l}\text { Yes for } \\
\text { small } \\
\text { farmers } \\
\text { and with } \\
\text { cofinancing }\end{array}$ & $\begin{array}{l}\text { Yes, } \\
\text { preferred }\end{array}$ \\
\hline Farmer training & Toll & Yes & Yes & Yes & Yes \\
\hline Integrated pest management advice & Public & Yes & $\begin{array}{l}\text { Yes, if } \\
\text { contracted }\end{array}$ & Yes & No \\
\hline $\begin{array}{l}\text { Market price info. (individualized } \\
\text { services) }\end{array}$ & Toll & No & Yes & No & Yes \\
\hline $\begin{array}{l}\text { Market price information services } \\
\quad \text { (mass media) }\end{array}$ & Public & Yes & $\begin{array}{l}\text { Yes, } \\
\text { preferred }\end{array}$ & Yes & Yes \\
\hline $\begin{array}{l}\text { Environmental conservation } \\
\text { information services }\end{array}$ & Public & Yes & $\begin{array}{l}\text { Yes, if } \\
\text { contracted }\end{array}$ & Yes & No \\
\hline Irrigation water management advice & Common pool & Yes & $\begin{array}{c}\text { Yes, farmer } \\
\text { organization } \\
\text { preferred }\end{array}$ & Yes & $\begin{array}{c}\text { Yes, if } \\
\text { cofinanced }\end{array}$ \\
\hline $\begin{array}{l}\text { Farmer organization development } \\
\text { assistance }\end{array}$ & Common pool & Yes & Yes & Yes & Yes \\
\hline $\begin{array}{l}\text { Advice on control of major } \\
\text { contagious diseases }\end{array}$ & Public & Yes & No & Yes & No \\
\hline $\begin{array}{l}\text { Product quality certification for } \\
\text { export markets }\end{array}$ & Private & Yes & Yes & No & $\begin{array}{l}\text { Yes, } \\
\text { preferred }\end{array}$ \\
\hline
\end{tabular}

Note:The term "private" includes farmer organizations.

Source: Authors.

agriculture. For low income countries, public funding and other roles of the public sector may continue to be critical for many years.

Promoting PRIVATE SECTOR SERVICES. The private goods element of many extension services has raised interest in privatizing extension services.
In reality, most information services are provided outside of government, and extension systems need to be designed with the understanding that they will be cost effective "only if the public role is defined to complement what the private sector can and will deliver" (Beynon et al. 1998). Public sector programs should 
avoid competing with private extension services and should provide technical support to private providers, develop public-private partnerships for service delivery, share information, coordinate activities with private service providers, establish mechanisms for accreditation of private advisory services, and establish financing mechanisms to cofinance private service delivery. ${ }^{1}$

Contracting FOR EXTENSION SERvices. There is growing recognition that, even in situations in which public financing of extension is justified, private service delivery is often the more efficient way to serve clients. Contracting strategies for extension services take many approaches to the division of responsibilities for financing, procurement, and delivery of services, though most reforms involve public funding for private service delivery (Rivera, Zijp, and Alex 2000). Contracting promotes institutional pluralism, accountability to clients, and efficiency in operations. Contracting directly by farmers introduces fundamental changes in relationships (see figure 3.3). Public financing of contracted extension and information services represents an investment in public goods knowledge for smallholders, as well as support for development of a pluralistic extension system and extension services market. ${ }^{2}$

DeVEloping sustainable financing MeChanisms. Cost recovery is important to expand resources available for extension and to ensure that clients value the services being provided. Key to this are:

- Introducing cost-sharing mechanisms. Various cofinancing arrangements are possible, including financing under a producer-controlled levy on agricultural products, fee-for-service arrangements, cost-sharing for a total program, or cofinancing by a producer organization. Although large producers might be able to fully fund costs of extension services, most commercial farmers will drop out of programs if their share of costs exceeds 50 percent to 65 percent of the total. For small-scale farmers in developing countries, a cost-recovery rate of 10 percent to 20 percent is a reasonable initial target.

\section{FIGURE 3.3 ALTERNATIVE FINANCING MECHANISMA FOR EXTENSION SERVICES}
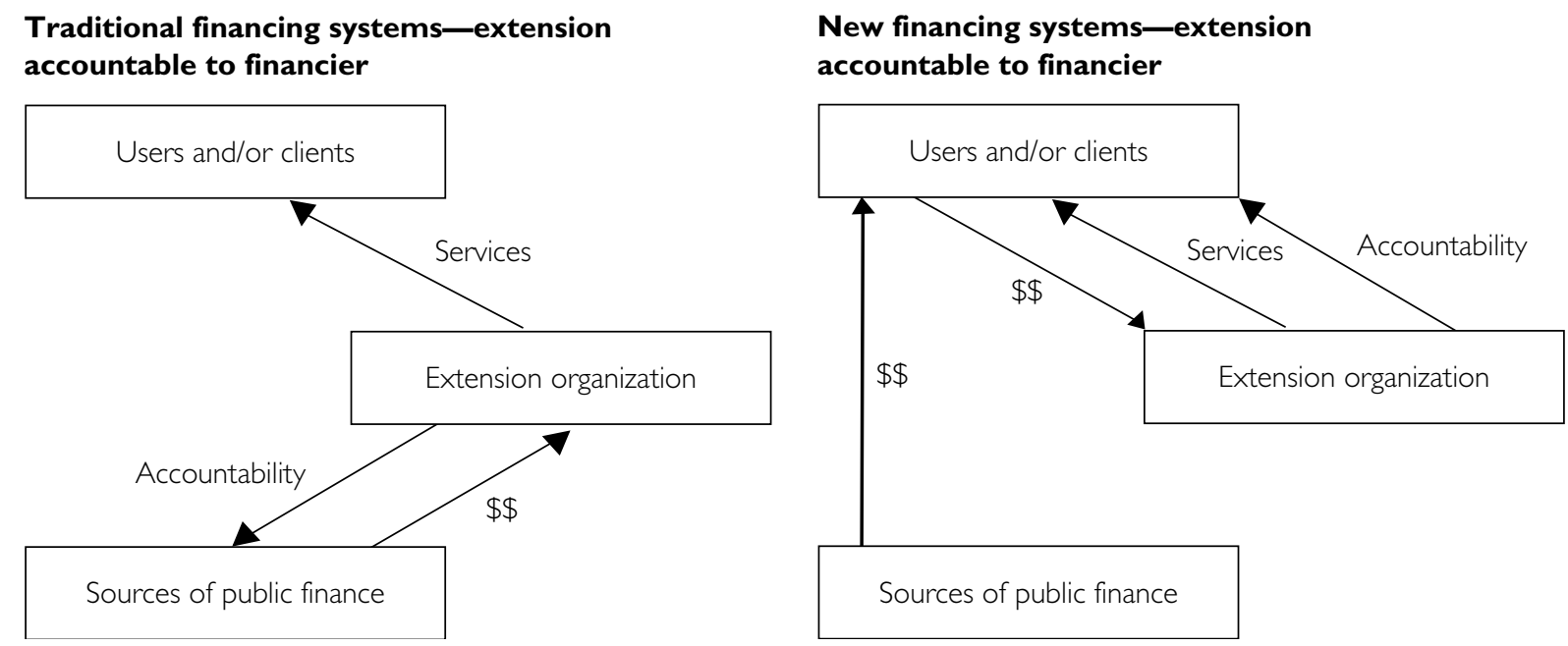

I. See the IAP,"Estonia:Transition to Private Extension Advisory Services"

2. See the AIN, "Contracting Extension Services" 
- "Downsizing" public extension agencies. This is a difficult but an inescapable issue that many public extension agencies will face. Situations in which public funding and operating procedures do not allow existing staff to be used effectively and profitably, it is preferable to reduce the number of government staff. This might involve transfers to decentralized government units (but only if the staff can be used effectively there), early retirements with redundancy payments, or other arrangements, such as secondments to or contracting by NGOs and other development programs. Undertaking new extension initiatives without addressing existing problems of overstaffing undermines the chances for program sustainability.

- Accessing other sources of funding. Diversifying the funding base enhances financial sustainability of public extension programs. Sources might include environmental groups (ministries of environment, NGOs, and environmental services beneficiaries); special interest groups (women's organizations, youth, and expatriate communities); humanitarian NGOs; and others.

StRENGTHENING THE DEMAND FOR SERVICES. Future investments in extension must emphasize development of capacity for clients to express their demand for services, increase their influence over or active participation in programs, and enhance their ability to finance services. Investments can introduce inclusive participatory approaches, accountability mechanisms, and strengthen producer organizations.

- Increasing client participation. Participatory extension intensifies and improves interaction between farmers and extension agents, recognizing that innovation requires decisions by the farmer to change practices. In such programs, extension agents increasingly serve as facilitators, assisting farmers to develop skills in problem analysis, problem solving, and management. Participatory methods are inclusive and foster equal access to extension services and resources for women and ethnic minorities. They merge with participatory technology development, which taps indigenous knowledge especially relevant to sustainable agriculture. ${ }^{3}$

- Increasing accountability to clients. Increasing user influence over extension services is an element of the most recent extension reforms. Placing client representatives on advisory and management boards, involving farmers in setting program priorities, evaluating participation of staff and programs, and giving authority to farmers to approve work plans all help make extension services more responsive to farmers. Through demand-driven funding programs, the greatest accountability comes when farmers are given authority to set the agenda, select service providers, and hire and fire extension staff. These programs typically use mechanisms that enable client groups to propose development activities. Once the activity is approved, financing or other resources are transferred to the client group, which is then responsible for implementing the approved project with extension providers accountable to the client groups.

- Working with client organizations. Client groups of various types make extension services more accessible to small-scale farmers by providing economies of scale in service delivery and a mechanism for producers to express their demands for services. Working with client groups may enable extension programs to reach more farmers and rural households (increasing efficiency), facilitate participation in extension activities (increasing effectiveness), and develop human resources and social capital (increasing equity). The client group

3. See the IAP,"India: Participatory and Decentralized Agricultural Technology Transfer" 
role may entail receiving services for organizational strengthening (client), facilitating delivery of services (partner), providing services to members (executing agency), or financing services (financier). Roles and potential differ markedly between small informal extension contact groups and formal commercial organizations. Producer organizations are a main focus for agricultural extension, but women's and other community groups are also important partners. Investments are needed to strengthen client group capacities and develop mechanisms for their effective involvement in extension and advisory services.

Reforming GOVERNMENT EXTENSION SERVICES. Governments retain a key role in guiding the evolution of the extension system as a whole. Public extension services remain important for extension coordination even when most services are privatized or decentralized. Organizational arrangements will vary by country, and extension will be based in a department within the ministry of agriculture, in an autonomous institute, or combined with a research organization. Support is often needed for reforms to promote a pluralistic system, establish a coherent national strategy, manage for results, and decentralize extension program responsibilities. An important first step for program reform and new investments is the development of a national strategy for extension through broad consultation with stakeholders (see box 3.3). Mechanisms for regular consultations and exchange of information among service providers must take place frequently at both national and local levels and depend on using the convening power of a government agency.

- Decentralizing extension program. Decentralization reforms being implemented in many countries offer opportunities for fundamental changes in the way in which rural extension services are provided. Transferring program governance, administration, and management to the local level facilitates user participation and
Box 3.3 Development of national extension strategies

The 1994 evaluation of World Bank support to extension emphasized the importance of basing extension investments on a sound strategy for a national extension system (Purcell and Anderson 1997). Such a strategy requires, among other things, thorough analysis of:

- Farming systems and production and social conditions.

- Available technologies and management innovations that can increase productivity, including the productivity of research and other programs to provide future innovations.

- Market and economic trends for key commodities.

- Government commitment for funding and human resources for extension.

A national extension strategy should:

- Prioritize target groups and areas and plan differential program approaches appropriate to their needs and opportunities.

- Integrate public and private sector activities and traditional and modern communications technologies.

- Plan activities at a level of sophistication and intensity supportable with available human resources.

- Maximize cost recovery and farmer ownership of extension programs.

- Ensure that technology generation/adaptation and information support services are in place.

- Incorporate plans for staff training in technical, economic, social, and communications skills.

- Accept that extension program formats are not permanent but must change in response to circumstances.

- Incorporate comprehensive monitoring and evaluation (M\&E) systems.

Source: Purcell and Anderson 1997.

cofinancing, enhances the response to local problems and opportunities, increases accountability to clients, and increases program efficiency. But these reforms are not easy. A comprehensive strategy for decentralizing extension services must ensure service quality, develop capacities needed at all levels in the system, and provide clear definition of the respective roles and responsibilities of local and national governments and user groups.

- Managing for results. Public extension agencies need to improve their focus on objectives and manage for results. This 
requires clear objectives and effective systems for monitoring and evaluating individual and program performance. Incentive systems must be aligned with institutional objectives to reward individuals and programs that produce results in terms of overall social objectives.

IMPROVING THE QUALITY OF SERVICES. While all of the above reforms aim to improve the relevance and quality of extension services, additional investment is essential to improve the capacity of service providers to deliver advice and information to farmers. Quality of extension services depends on a range of technical and support services which must often be provided through public funding agencies even to private extension providers. Key areas include:

- Improving technical support, such as research-extension linkages. Linking service providers to sources of innovation and technical support, including national research programs, is essential if they are to have technically sound advice to offer clients. Technical support generally requires some in-house technical specialists (if the service provider is large enough) in addition to effective linkages to other programs. Extension programs should be structured so that farmers, agribusinesses, and various extension providers can develop demanddriven linkages with researchers, private firms, and universities to access relevant technical support as needed.

- Strengthening training of extension agents. Training is a critical need and often inadequately provided in extension programs. Improvements are needed in both preservice (university) and in-service training for extension agents. Training programs need to emphasize new extension concepts and methodologies, as well as expand attention to marketing, management, environmental issues, and the development of farmer and other client organizations. For sustainable and long-term development, investment in practical and well-rounded curricula for university programs can provide a base for training the future generation of extension agents.

- Improving development communications support. Not enough attention has been given to packaging information and training materials through brochures, radio and TV programs, posters, demonstration materials, videos, and technical reports that help convey information and knowledge to farmers and extension workers, including input suppliers, financial services agency staff, and NGO staff.

- Establishing quality control systems. Quality control becomes increasingly important and difficult with the move to multiple service providers. Standards can vary within decentralized programs and between different providers, who, as with input suppliers, could have vested interests contrary to those of the farmer. At a minimum, publicly funded services should provide a source of unbiased information for farmers. Controls on private extension and information services are difficult to enforce and problems are probably best handled on an a case-by-case basis. Accreditation programs and registries of qualified service providers are useful in many cases and can be maintained by government or an appropriate private sector group.

Supporting the Millennium Development Goals (MDGs). Increased extension support is needed to achieve the MDGs, especially as they relate to poverty reduction, gender equality, and environmental conservation.

- Poverty targeting of investments. Poverty reduction and environmental objectives are often best met through extension investments that increase overall agricultural productivity growth that generates employment opportunities and reduces food costs. In most cases, additional poverty-targeted interventions (such as by geographic, commodity, or production 
systems) will be needed to reach poor people, women, and indigenous and minority groups. Poverty targeting requires priority setting for allocation of public resources, designing and evaluating programs to meet different client needs with emphasis on empowering the rural poor, building individual and institutional capacity, and developing demand for services where there has been little in the past. Services frequently need to address social and organizational constraints to innovation, facilitating rural financial services, obtaining secure land tenure, improving management of community resources, and focusing on issues formerly considered outside the ambit of extension, such as HIV/AIDS education, and access to health, education, and social programs.

- Promoting gender equity. There is an increasingly better understanding and appreciation of the roles, rights, and responsibilities of both men and women in agricultural production and of the greater constraints faced by women. Many examples of extension programs designed with a gender focus now exist, and the gender message has been widely disseminated; however, greater attention still needs to be given to gender analysis, gendersensitivity training, the targeting of women farmers, increasing the number of women extension staff, and gender-sensitive M\&E.

\section{- Promoting environmental conservation.} Intensification of production systems (for example, increased use of agrochemicals, land use changes, shorter fallow periods) requires extension systems to introduce measures to mitigate environmental degradation. All extension programs should incorporate promotional activities for environmental conservation and sustainable management of natural resources. Focused extension programs, often working with and through community groups, should promote collective action for natural resource conservation activities, such as watershed management, biodiversity conservation, and reforestation. General education campaigns are also required to raise public awareness of environmental issues. Because some environmental impacts are long-term and benefits often accrue downstream, user financing of such programs is not usually a feasible option.

EXPANDING USE OF MASS MEDIA AND COMMUNICATIONS TECHNOLOGIES. The mass media has been underutilized by extension, and new communications technologies now offer opportunities to deliver a richer array of valuable information of value to farmers and rural households. Development communications and mass media like radio and print media have long been a part of extension systems but have generally not received adequate attention or financing. New information and communications technologies (ICTs) can make production of mass media and development communications products more efficient and can provide higher-quality products that are more effective in delivering information messages and transmitting knowledge. Many benefits from new ICTs, such as Internet, computer systems, and telecommunications, will come from linking these to traditional communications media. This would enable radio broadcasters, for example, to access global sources of information in preparing programs.

The advances in telecommunications and information technologies also provide extension systems with opportunities to deliver information services in new ways (FAO 2000). Rural telecenters, cellular phones, and computer software provide new sources of information for extension agents and farmers in ways that allow for interactive two-way communications. Private service delivery, cost recovery, and "wholesaling" of informationproviding it to intermediaries (NGOs, private sector, press, and others) which will use it to provide services to farmers-are important strategies for expanding use of ICTs in rural extension systems. 


\section{SCALING UP INVESTMENTS}

Scaling up extension investments should be done within the context of widely shared national extension strategies. Piloting new approaches will often be necessary to develop local capacity and an understanding of extension reforms. Building new institutional arrangements and developing sustainable extension systems requires a long-term perspective and continuity in institutional and program development. When introducing reforms, such as the contracting out of service provision, evaluation of different country experiences should be an integral part of the planning and scaling up process.

Despite the trend toward greater Bank lending under Poverty Reduction Support Credits (PRSCs) and sectorwide approaches, extension investments for long-term institutional development will need to rely on specialized AKIS projects to build institutional capacity and address system issues in a comprehensive way. Funding of extension programs may increasingly rely on community-driven development (CDD) programs that allocate resources to communities and local groups to address their own development priorities. Although such groups initially tend to place priority on small-scale infrastructure, extension services are necessary to assist communities plan, implement, and maintain investments oriented to income generation for sustainable poverty reduction.

The following series of Agricultural Investment Notes (AINs) provide additional guidelines to good practice in selected areas of extension system reform and development. Priority topics for future work in defining good practice in this area include steps to reform public extension agencies, the establishment of cofinancing and costsharing arrangements for extension, promotion of farmer-to-farmer extension services, the development of effective research-extension linkages, transitional arrangements for public extension, and environmental extension services.

\section{SELECTED READINGS}

Asterisk (*) at the end of a reference indicates that it is available on the Web. See Appendix 1 for a full list of Websites.

Alex, G., W. Zijp, and D. Byerlee. 2002. "Rural Extension and Advisory Services: New Directions." Rural Development Strategy Background Paper 9. World Bank, Washington, D.C.*

FAO. 2000. "The Role of Information and Communications Technologies in Rural Development and Food Security." Workshop Report. FAO, Rome.*

Feder, G., A. Willett, and W. Zijp. 1999. "Agricultural Extension: Generic Challenges and Some Ingredients for Solutions." Policy Research Working Paper 2129. World Bank, Washington, D.C.*

Neuchatel Group. 1999. "Common Framework on Agricultural Extension." Neuchatel Group, Switzerland.*

Neuchatel Group. 2002. "Common Framework on Financing Agricultural and Rural Extension.” Neuchatel Group, Switzerland.*

Rivera, W. M. 2001. "Agricultural and Rural Extension Worldwide: Options for Institutional Reform in the Developing Countries." FAO, Rome.*

World Bank. 2002. "Extension and Rural Development: Converging Views for Institutional Approaches?" Workshop Summary, World Bank, Washington, D.C.*

\section{REFERENCES CITED}

Alex, G., W. Zijp, and D. Byerlee. 2002. "Rural Extension and Advisory Services: New Directions." Rural Development Strategy Background Paper 9. World Bank, Washington, D.C.

Alston, J. M., C. Chan-Kang, M. C. Marra, P. G. Pardey, and T.J. Wyatt. 2000. A Meta- 
Analysis of Rates of Return to Agricultural RED: Ex Pede Herculem? Research Report 113. Washington, D.C.: IFPRI.

Ameur, C. 1994. "Agricultural Extension: A Step Beyond the Next Step." Technical Paper 247. World Bank, Washington, D.C.

Antholt, C. 1994. "Getting Ready for the Twenty-First Century: Technical Change and Institutional Modernization in Agriculture." Technical Paper 217. World Bank, Washington, D.C.

Beynon, J., S. Akroyd, A. Duncan, and S. Jones. 1998. Financing the Future: Options for Agricultural Research and Extension in Sub-Sabaran Africa. Oxford: Oxford Policy Management.

Cleaver, K. 1993. "A Strategy to Develop Agriculture in Sub-Saharan Africa and a Focus for the World Bank." Technical Paper 203. World Bank, Washington, D.C.

Evenson, R. 1997. "The Economic Contributions of Agricultural Extension to Agricultural and Rural Development.” In B. E. Swanson, R. P. Bentz, and A. J. Sofranko, eds., Improving Agricultural Extension: A Reference Manual. Rome: FAO.

FAO. 2000. "The Role of Information and Communication Technologies in Rural Development and Food Security." Workshop Report. FAO, Rome.

FAO/World Bank. 2000. "Agricultural Knowledge and Information Systems for Rural Development: Strategic Vision and Guiding Principles." AKIS Thematic Team. World Bank, Washington, D.C.

Feder, G., R. Murgai, and J. B. Quizon. 2003. "Sending Farmers Back to School: The Impact of Farmer Field Schools in Indonesia." Policy Research Working Paper 3022. World Bank, Washington, D.C.
Gautam, M. 2000. Agricultural Extension: The Kenya Experience: An Impact Evaluation. World Bank Operations Evaluation Study. Washington, D.C.: World Bank.

Perraton, H., D. T. Jamison, J. Jenkins, F. Orivel, and L. Wolft. 1983. "Basic Education and Agricultural Extension: Costs, Effects, and Alternatives." Staff Working Paper 564. World Bank, Washington, D.C.

Purcell, D. L., and J. R. Anderson. 1997. Agricultural Research and Extension: Achievements and Problems in National Systems. World Bank Operations Evaluations Study. Washington, D.C.: World Bank.

Rivera, W. M., W. Zijp, and G. Alex. 2000. "Contracting for Extension: Review of Emerging Practice." AKIS Good Practice Note. AKIS Thematic Team. World Bank, Washington, D.C.

Swanson, B. E., B. J. Farmer, and R. Bahal. 1990. "The Current Status of Agricultural Extension Worldwide." In B. E. Swanson, ed., Report of the Global Consultation on Agricultural Extension. FAO, Rome.

World Bank. 2002. "Extension and Rural Development: Converging Views for Institutional Approaches?" Workshop Summary. World Bank, Washington, D.C.

This Overview was prepared by Gary Alex with inputs from the Sustainable Agriculture (SASKI) Thematic Team of the Bank. Peer review comments were provided by David Nielson, Aleksandar Nacev, Matthias Grueninger, Jock Anderson, William Rivera, and Mary Hill Rojas. 


\section{AGRICULTURE INVESTMENT NOTE}

\section{CONTRACTING EXTENSION SERVICES}

With the recognition of the limitations of public agencies in efficient and effective delivery of public services, a trend has developed toward increasing separation of functions of financing and delivery of public services. Governments typically must continue to finance many rural extension services, but provision of services is more commonly contracted to private advisory service firms, NGOs, universities, producer organizations, and other groups. Alternative arrangements assign procurement responsibility to central or local government or to clients themselves. Competitive procedures can improve quality of services, make providers more accountable for results, and improve efficiency. Contracting allows for specialization and selection of service providers according to their individual competitive advantage.

Many countries established public extension services in the 1960 s and 1970 s to promote agricultural sector productivity and rural development. These public extension agencies often produced positive results in early years but soon encountered a range of common problems, including difficulty in measuring impacts, lack of political support, lack of accountability to clients, lack of financial sustainability, and poor links to sources of new technology (Feder, Willett, and Zijp 1999). Many systems were unable to respond to changing priorities, needs, and opportunities due in part to the lack of incentives and flexibility within public agencies for the efficient delivery of quality services to widely dispersed rural people.

Although the public sector will continue to finance (at least an important share of) the costs of extension programs, the increasing diversity of extension service providers will mean that delivery of services will often be contracted out rather than provided by civil servants (see box 3.4). Potential providers could include combinations of the private sector, NGOs, farmers' associations, universities, and other entities with the capacity to provide the services. Contracting out extension services makes it possible to take advantage of all of the talent and experience existing in the field but does not eliminate a government role which, in addition to funding, ensures quality assurance, oversight, and provision of training and information to contracted services providers.

Contracting systems that separate responsibilities for financing, procuring, and delivering extension services rely on diverse contractual arrangements that underlie four types of contracting: private funding for private services, public funding of publicly provided services,

Box 3.4 Chile: evolution of contracted extension services

Chile's extension system, based on contracting private service providers, has evolved since its introduction in 1978. Evaluations report positive results from contracted services, and there is no support for return to a system of government service provision. Until 1983, the Entrepreneur Technical Assistance Program provided vouchers for farmers with potential for commercial development to use in purchasing extension services. Problems with this system resulted in a series of reforms that have made the program more demand-driven, with farmer organizations proposing defined projects for commercialization and modernization of small-farm agriculture. Chile's experience indicates the need for contracted extension programs to evolve over time and to:

- Design different programs to serve different categories of farmers and different program objectives.

- Decentralize program design and contracting to regional and municipal (district) levels to expand participation of farmers.

- Expand market orientation and marketing services within programs.

- Provide good technical support services and training to contracted extension agents.

- Establish good evaluation and monitoring systems at the national level.

Source: Beynon et al. 1998; Cox and Ortega, forthcoming. 
private funding for public service provision, and public funding of private service provision (outsourcing) (Rivera, Zijp, and Alex 2000). Of these, public funding of private service provision is the most common strategy for reform. In such systems, the state usually retains responsibility for establishing criteria for use of funds, quality control, and M\&E, while private entities provide services, define specific objectives for each locality, train extension staff, develop appropriate extension methods, and conduct M\&E studies.

Public contracting of private extension service delivery can involve national agency contracting (for example, Venezuela and Chile), local government contracting, and grants to client organizations to contract services (for example, Uganda). Contracted extension services are likely to spread as agriculture becomes more commercialized and competitive and as public budgets for agricultural extension services demand greater accountability.

\section{BENEFITS}

Government contracting recognizes that, even situations in which public financing of extension is justified, private service delivery is often more efficient in serving clients. Contracting defines responsibilities and encourages clarity in objectives and outputs. In addition, it exploits the comparative advantages of different institutions and, consequently, improves variety and quality of services. Contracting also provides opportunities for the development of the private sector in rural areas and offers other potential benefits (see box 3.5). Extension programs implemented by the private sector are typically more operationally efficient, more accountable for their performance and results, and more flexible in promoting extension staff for good job performance and dismissing staff for poor performance.

Contracts make providers accountable for the quantity and quality of services to be delivered and introduce penalties or nonrenewal of contract if these are not met. Provision of services by a wider set of suppliers makes it possible to

\section{Box 3.5 Outsourcing extension services}

Advantages

- Reduces permanent staff requirements and allows deployment of resources to high-priority areas.

- Allows for accessing providers with special skills to provide specific services.

- Promotes partnerships and working relationships with other providers.

- Enhances flexibility in responding to special needs of diverse clientele.

- Tests innovative and higher risk "new" systems.

- Increases provider accountability and forces more attention to financial management.

Disadvantages

- Institutional memory may be lost; some private providers may not pass on new skills and lessons learned.

- Increases the need for skills of contract negotiation, supervision, and monitoring performance.

- High initial costs (if not offset by staff reductions).

Source: Rivera, Zijp, and Alex 2000.

draw on the best available expertise to provide services to farmers. Competition among potential providers keeps costs down and establishes a market for extension services that should be sustainable as public funding is withdrawn.

\section{POLICY AND IMPLEMENTATION ISSUES}

Procurement agent. Contracting mechanisms can involve different agents in procuring services, such as central, regional, or local governments. For example, Bangladesh experimented with a series of partnership funds for services as part of its extension innovation and reform process (see box 3.6). Alternatively, producer or community groups can procure services directly with funding provided by public extension programs. This arrangement helps ensure service provider accountability to clients. Selecting the service provider, awarding the contract, and approving work plans are procurement functions that can be shared by client groups and different levels of government. Contracting arrangements should increase farmer participation in three areas: selecting extension providers, deciding the content of work programs, and assessing performance of extension providers. 
Box 3.6 Bangladesh: extension partnership initiative funds

In support of its new agricultural extension policy, Bangladesh established three partnership funds at different levels under the Agricultural Services Innovation and Reform Project:

- A Upazila (subdistrict) partnership fund provided US\$1,500 per year of flexible funding for each of the 640 subdistricts to use to promote the collaboration between public and private agencies in delivery of extension services through subdistrict partnership projects. These funds supported on average four to five small-scale projects per subdistrict.

- A competitive grants program in 12 districts financed district partnership projects implemented jointly by two or more service providers from the public or private sector.

- A national-level competitive grants program funded national partnership projects to build the capacity of smaller NGOs to provide quality extension services.

These partnership funds increased collaboration between service providers and increased acceptance of NGOs as legitimate extension service providers. Impacts and sustainability are yet to be determined.

Source: Authors.
Performance-Based contracting. Extension services are typically contracted on the basis of financing inputs needed for delivery of services. An alternative approach involves performance-based contracts that tie payment to outputs or delivery of services, such as the number of women farmers trained, the number of publications distributed or sold, or results and impacts, such as increased production, reduced irrigation water use, or improved product quality. These results-based contracting schemes provide incentives to improve efficiency and/or effectiveness of extension services, but they frequently encounter problems of measuring output and outcome quality, as well as problems with contract costing and negotiations. In these and other schemes, contract performance can also be evaluated by farmers who directly observe performance of service providers.

Competitive Contracting. Contracts can be awarded on the basis of negotiations (often limited to contracts with client organizations or public sector agencies), or on the basis of competitive selection depending on the cost and quality of proposals. Competitive contracting procedures seek to improve efficiency and quality by instilling a private sector attitude of cost consciousness and results orientation, even in public institutions forced to compete to provide services. Program transparency and reputation are enhanced by fair and welldeveloped competitive procedures.

CONTRACTS VS. GRANTS. Contracting involves selection of a service provider to deliver defined services, whereas grant programs allocate resources on the basis of project proposals prepared by client groups or service providers. Either approach can use competitive or noncompetitive procedures. Competitive grants are often suited to research outreach programs (see box 3.7). But the communities that need extension services the most are less likely to be able to prepare competitive proposals, provide cofinancing, demonstrate potential economic impact, and compete for projects.

Transition issues. Moving from public agency service delivery to contracted services frequently encounters problems, especially when there is opposition from extension staff worried about loss of employment or suspicious of private institutions' motivation and capacity. Reforms must be sensitive to and deal with such concerns and opposition. Financing costs of staff retrenchment is often useful and may be combined with training and the reorientation of redundant extension agents to jobs with private service providers which usually offer better salaries, support, and job satisfaction.

\section{LESSONS LEARNED}

Program/contract management. Experience highlights the importance of developing capacity to prepare terms of reference, negotiate contracts, monitor contractor performance and compliance, and exercise financial control. Program management skills are needed at the national level, but training and capacity building require even greater attention if contracting is done by local government or client groups. Contracting requires a collaborative relationship between 
agencies and government commitment to shift from controlling resources and programs to monitoring and supervising contracts.

Contractor Certification. Contracting requires a minimum established capacity within service providers to compete for contracts and deliver services-a major problem in some countries and in remote areas of most countries. A registry of prequalified service providers expedites contracting under governmentfinanced contracting systems. Such a registry is ideally maintained by the private sector in a trade association, farmers' federation, NGO forum, agricultural extension society, or government agency. The registry must be managed in a fully transparent fashion and kept up-to-date.

Quality enhancement. Competition between service providers can discourage information sharing and good practice and can cause service providers to attempt to increase shortterm profits by neglecting training and specialized technical support, both of which are necessary for enhancing quality of services. Institutional arrangements and program funding allocation to quality-enhancing support services (training, technical support, development communications) can exploit economies of scale to provide support to service providers and can emphasize national priority issues (gender equity, environmental conservation).

Community contracting. Contracted extension programs work best when community or producer organization (clients) are heavily involved in selecting extension agents, evaluating services, certifying agents, cofinancing program costs, contracting services, determining program content, and deciding how services are allocated. Such contracting is facilitated for cases in which there have been previous community-managed projects; there is some degree of social cohesion; community organizations have legal status; communities are responsible for program operations and maintenance; and there is provision for capacity building for community organizations (de

\section{Box 3.7 Kenya: competitive grants for research outreach}

In 2000, the Kenyan Agricultural Research Institute, under pressure to ensure that its technologies reached farmers, embarked on the Agricultural Technology and Information Response Initiative to empower farmers to make technology and information demands on agricultural service providers. The initiative targets community-based organizations (CBOs) as beneficiaries or intermediaries (farmer organizations) facilitating member acquisition of appropriate technologies and information. Grants cover acquisition of technologies (for example, planting material), exchange visits to other farmers who have already adopted the technology, visits by the institute's staff, and other costs of observing, learning, and adopting technologies. Smaller grants are given preference over larger ones to expand the number of beneficiaries. The average grant is about US $\$ 3,000$. The iniatiative is now working with $178 \mathrm{CBO}$ s to cover I I,835 farm families. Experience has been quite positive: an example of success is the Shaza Women's Group in the Kwale district, which was able to multiply members' assets four times in 18 months.

Source: Gustafson 2002.

Silva 2000). For situations in which these factors are lacking, contracting on behalf of the community by an intermediary may be warranted. Experience in Africa indicates that a facilitating professional NGO is crucial to successful operation of user innovation funds for producer organizations (Collion 2001).

\section{RECOMMENDATIONS FOR PRACTITIONERS}

Public financing for extension services contracts constitutes an investment in technical services for sustainable agricultural systems development. This requires political will for extension reform; capable service providers; clarity in institutional roles and objectives; and an effective demand for services. There can be no blanket prescription for design of such contracting systems, but the following recommendations should guide contracting programs (see box 3.8):

- Programs need to clearly separate functions of financing and service delivery with procedures and guidelines that maintain the integrity and objectivity of the contracting 


\section{Box 3.8 Potential investments}

- Costs of program and contract management units.

- Training and technical and legal assistance for establishing contracting procedures.

- Studies to establish program priorities and targets.

- Cofinancing of contracts for extension services.

- Training, development communications, and technical support for service providers.

- Training, orientation, and promotion of contracting programs for potential clients and service providers.

- M\&E studies and monitoring systems to assess performance and impact.

Source: Authors.

process. This will often involve a third party in the procurement (contracting) of services financed by public funds and delivered by private or other providers.

- Contracting procedures require clear terms of reference and deliverables for services, as well as a clear means of evaluating completion of contract requirements. This helps in defining and organizing activities and avoids contentious disputes over completion of contract work.

- Service providers need good links to research and other sources of information.

- Contracted extension services should, as far as possible, involve competitive selection procedures. Competition complicates the selection process but introduces a rigor useful in defining plans.

- Whenever possible, contracting directly by clients is desirable. Even in cases in which this is not feasible, clients still need to have some role in contractor selection and evaluation.

- Contracting procedures must be sensitive to broader societal issues of equity, directing services to small and marginal farmers when appropriate and ensuring equal access to services by women, youth, and minority groups.
- Requiring some cofinancing by clients helps to ensure their desire for and commitment to using services. The level of cofinancing will often be fairly low, perhaps 5 percent to 25 percent for small and marginal farmers; for larger farmers, a higher cofinancing rate can be required with provision for eventual graduation to full self-sufficiency.

\section{SELECTED READINGS}

Asterisk (*) at the end of a reference indicates that it is available on the Web. See Appendix 1 for a full list of Websites.

Rivera, W. M., and W. Zijp, eds. 2002. Contracting for Agricultural Extension: International Case Studies and Emerging Practices. New York: CABI Publishing.

Rivera, W. M., W. Zijp, and G. Alex. 2000. "Contracting for Extension: Review of Emerging Practice." AKIS Good Practice Note. AKIS Thematic Team. World Bank, Washington, D.C.*

\section{REFERENCES CITED}

Beynon, J., S. Akroyd, A. Duncan, and S. Jones. 1998. Financing the Future: Options for Agricultural Research and Extension in Sub-Sabaran Africa. Oxford: Oxford Policy Management.

Collion, M.-H. 2001. "World Bank Strategies for Funding Research and Extension." Paper presented at Funding Development-Oriented Agricultural Research and Extension workshop, December 10-14, Feldafing, Germany.

Cox, M., and H. Ortega. Forthcoming. "Chile: Origins and Evolutions of a Privatized Extension System." In W. M. Rivera, and G. Alex, eds., Extension Reforms for Rural Development. Place: Publisher.

de Silva, S. 2000. "Community-Based Contracting: A Review of Stakeholder Experience." World Bank, Washington, D.C. 
Feder, G., A. Willett, and W. Zijp. 1999. "Agricultural Extension: Generic Challenges and Some Ingredients for Solutions." Policy Research Working Paper 2129. World Bank, Washington, D.C.

Gustafson, D. J. 2002. "Supporting the Demand for Change: Recent Project Experience with Farmer Learning Grants in Kenya." Paper presented at New Approaches to Extension: A Workshop for Practitioners, sponsored by the World Bank, USAID, and the Neuchatel Group, November 11-15, Washington, D.C.

Rivera, W. M., W. Zijp, and G. Alex. 2000. "Contracting for Extension: Review of Emerging Practice." AKIS Good Practice Note. AKIS Thematic Team. World Bank, Washington, D.C.*

This note was prepared by Gary Alex, based on a World Bank Good Practice Note "Contracting for Extension: Review of Emerging Practice" with inputs from David Nielson and the Sustainable Agriculture (SASKI) Thematic Team of the World Bank. 


\section{AGRICULTURE INVESTMENT NOTE}

\section{DECENTRALIZING AGRICULTURAL EXTENSION AND INFORMATION SERVICES}

Decentralization reforms that are implemented as part of wider public sector reforms offer opportunities for fundamental changes in the way in which rural extension services are provided. Transferring program governance, administration, and management to the local level facilitates user participation and cofinancing, enhances ability to respond to local problems and opportunities, increases accountability to clients, and increases program efficiency. These reforms are not easy. A comprehensive strategy for decentralizing extension services must ensure service quality, develop capacities needed at all levels in the system, and provide a clear definition of the respective roles and responsibilities of local and national governments and user groups.

National extension agencies were organized to transfer standard technologies to farmers throughout the country. Over time, this often proved inefficient and made it difficult for programs to be responsive to clients. Extension increasingly has been required to provide location-specific services to improve management and efficiency of input use, conserve natural resources, support diversification and value-added production, respond to communityor farmer-specific interests, and provide nonfarm information services relating to poverty reduction. Decentralizing extension services helps to address many problems of extension by facilitating a greater interaction with clients and a better focus on local needs and opportunities.

\section{GLOBALTREND TOWARD DECENTRALIZATION}

Even as national extension systems involve more groups or bodies, state and local governments have become more important with the transfer of responsibility for government services from national to local governments. Decentralization reforms became widespread during the 1980s and 1990s when governments pursued decentralization initiatives because centralized approaches to economic management and service provision had failed. Effective decentralization requires a combination of administrative, political, and financial decentralization (see box 3.9).

\section{BENEFITS}

Decentralization provides the potential to respond more effectively to specific local needs

\section{Box 3.9 Defining decentralization}

Decentralization generally involves a mix of three reform strategies:

- Administrative decentralization is the transfer of authority over regional staff from the central government to regional or local governments.

- Political decentralization (or democratic decentralization) is the selection of local government officials by local election rather than by central government appointment.

- Fiscal decentralization is the transfer of responsibility for raising and spending program funds to lower-level government units.

Three additional reform strategies that are related to but distinct from decentralization are:

- Deconcentration is the central government dispersing staff responsibilities to regional offices without changing the basis for authority and control. This is not true decentralization and can actually increase central control and influence.

- Delegation is the transfer of responsibility for public functions to lower levels of government or to other organizations which implement programs on behalf of the central government.

- Privatization is government transfer to the private sector of managerial, fiscal, and decisionmaking control, while retaining regulatory authority.

Source: Authors. 
and become more accountable to users. Some effective extension systems, such as the United States, Scandinavia, and France, have long been decentralized with responsibility devolved to local governments, often in conjunction with local producer organizations (see box 3.10). Decentralization is generally expected to encourage local financing and ownership of programs, result in more efficient and equitable allocation of government resources, provide incentives for efficient service delivery, ensure lowercost services, build local capacity, and respond more effectively to local needs.

Decentralized development efforts, such as CDD, offer the potential for increased community participation to ensure the inclusion of all groups of society in rural decision-making, regardless of gender, age, class, or ethnicity. In addition to devolving control and decision-making power, these initiatives can help communities build skills (human and social capital) through education and training, as well as by expanding the depth and range of their social networks.

Decentralization offers opportunities to introduce other reforms, such as contracting out services, strengthening M\&E, and improving management. Decentralization facilitates client participation in planning, cofinancing, implementing, and evaluating programs, and it makes greater accountability possible by making program administration closer and more accessible to clients.

\section{POLICY AND IMPLEMENTATION ISSUES}

Decentralization represents a fundamental restructuring of power and financial relationships and is rarely implemented without controversy. A number of key issues in planning such reforms must be addressed:

Phased vs. ABrupt Reform. Deconcentration is nearly always the first and necessary step in any process of decentralization. This puts staff from central administrations in closer contact with local people, problems, and conditions, and it also provides a channel for local interaction. Unfortunately, decentralization reforms

\section{Box 3.10 United States: a decentralized extension system}

The U.S. Cooperative Extension Service is a successful decentralized system. The Cooperative Extension Service was established in 1914 with the objective of "extension education." "Cooperative" refers to the cooperation between the federal, state, and county governments in organizing and financing services. The service worked closely with farmer organizations (Farm Bureaus) for many years and is financed by federal, state, and county governments, as well as state agricultural universities. The federal government provides financing, broad program guidelines, and reviews of program compliance. State governments define specific programs, provide cofinancing, coordinate local programs, and ensure auditing and reporting. State universities provide technical support and coordination; and county governments provide a share of the financing, guide local implementation, participate in selection of personnel, and evaluate programs and personnel. Local volunteers from the community assist in implementation and have been important in extension program development.

Source: Claar, Dahl, and Watts 1980.

frequently stop at this point, and central authorities often retain control over deconcentrated administrative structures. As a result, an important decision must be made about whether to phase reforms and risk getting stalled, or implement total reforms at one time, recognizing the risk of serious program disruptions.

FunDING. Fiscal decentralization is often seen as a way to reduce central government budgets by off-loading tasks that a central government can no longer finance, a practice known as "devolving insolvency." Intergovernmental fiscal transfers or grants are usually needed to finance decentralized programs. Concern over local administrative capacity and accountability frequently leads central governments to impose controls that are costly to administer and that restrict local flexibility in managing funds. However, experience indicates that local governments are generally capable of assuming substantial fiscal responsibility. While grants from the central government are usually necessary to maintain programs, decentralization offers opportunities to introduce cost sharing by local government and users and increase total resources available for extension. 
Coordination. Decentralization involves different institutions and levels of government collaborating in financing and implementing programs. Coordination is essential as program objectives, approaches, training schedules, implementation periods, and incentives vary between decentralized implementation units. There is also potential for overlap of programs in different areas, competition for staff, clients, and markets, and duplication of effort in providing support services, such as training and technical support.

LeVel of Decentralization. Decentralization may involve a decision to decentralize authority to local governments or to local community groups. Devolving program responsibility to local communities fully empowers rural people but bypasses and weakens local government. Community collaboration with local and national governments in managing programs makes it possible to coordinate programs across a broader area, ensures that interests of the poor are represented, facilitates the scaling up of successful initiatives, and overcomes local and often male-dominated authoritarian enclaves.

\section{LESSONS LEARNED}

Decentralization takes many forms, and there are various combinations of fiscal, administra- tive, and political decentralization. Reforms must be tailored to country-specific conditions (see box 3.11). Privatization, deconcentration, and delegation initiatives can complement and reinforce an overall decentralization policy, but these do not constitute-and can in some cases work against-effective decentralization.

Successful decentralization reforms require:

- Providing local men and women with substantial influence over local development activities and the local political system.

- Ensuring availability of adequate financial resources from intergovernmental fiscal transfers or grants and user payments to enable decentralized institutions to accomplish their tasks.

- Ensuring adequate administrative capacity of local units through training and infrastructure investments.

- Establishing reliable mechanisms, such as transparent planning, reporting and evaluation, and routine audits, for accountability of decisionmakers to local people.

Strategies for decentralization must be adapted to the local institutional environment, legal framework, political traditions, administrative structures,

\section{Box 3.II India, China, and Uganda: approaches to decentralized service provision}

India's National Agricultural Technology Project established Agricultural Technology Management Agencies in pilot districts to coordinate agricultural extension and rural development activities. The agencies, registered as civil societies to provide a degree of autonomy, are delegated responsibility for extension, are controlled by governing boards of stakeholders. They also receive guidance from farmer advisory committees established in production blocks; and have administrative offices linked to state and national extension offices and receive technical backstopping and training from regional research staff.

China's Agrotechnology Extension Center System, based on national, provincial, county, and township institutions, guides extension activities and provides technical support to township agrotechnology extension stations. These provide key services from more than 370,000 staff and 500,000 farmer technicians operating at the village level. Funding for each level of the system comes mainly from that level of government. Both are actively engaged in innovative strategies to broaden their funding base through fee for service arrangements, contracts with producers, input sales, and profit sharing with clients.

Uganda's National Agricultural Advisory Services Program represents an ambitious plan to decentralize extension services, scaling up from six pilot districts to national coverage by 2008. An autonomous board coordinates the program at the national level. Local farmer groups are represented in subcounty and district levels. Farmer forums approve project proposals submitted by farmer groups. Funding for projects comes from the program's fund, most of which is allocated to subcounty farmer forums.

Source: Swanson and Samy 2003. 
and social and agro-ecological conditions. Decentralized extension reforms can be appropriate for cases in which there is already a strong political decentralization in the country but should be undertaken with caution when decentralization is not yet well established (see box 3.12).

Decentralization still requires the central government to retain responsibility for cofinancing, quality control, promotion, support services, and M\&E. Clear division of responsibilities and capacity building at all levels is key to successful decentralization reforms. This process depends on a supportive national policy framework and a clear extension strategy within this framework (AKIS 2000). Over the short term, decentralization rarely reduces - and may increase requirements for central government financing.

\section{RECOMMENDATIONS FOR PRACTITIONERS}

Before launching decentralization of extension services, investments in extensive planning, promotion, and training in new operational procedures is essential to sensitize staff to the changes and to the likely opposition from central agencies that lose influence because of decentralization. Extension strategies generally should (see box 3.13):

- Decentralize service provision whenever possible, emphasizing user control over program planning, implementation, and evaluation.

- Provide for extensive planning, wide promotion of the rationale and principles behind decentralization, and training in new operational procedures, in addition to ensuring clear terms of reference for division of responsibilities among different levels of government.

- Provide adequate centralized support for decentralized services, especially for training, subject matter specialists, and the production of extension materials.

- Develop procedures for priority setting to reconcile central government financing and
Box 3.12 Ghana: incomplete decentralization reforms

In 1997, Ghana's Ministry of Food and Agriculture decided to decentralize operations to provide more responsive and effective services. Staff and budget of the ministry were to be transferred to I 10 District Directorates of Agriculture. In 2002, these still remained under the ministry because legislation to establish a local government service for the staff of district government units had not been enacted. Because extension staff have not yet been integrated and because specialized services have been disrupted, frustration has grown, reducing the impact of decentralization. Political commitment was essential to start reforms but because of loss of commitment, implementation stalled. Agricultural extension can not effectively decentralize operations without the framework of overall decentralization policies and structures.

Source: Amezah and Hesse 2002

policy objectives with local people's priorities that emerge from the decentralized program governance.

- Provide for fiscal transfers from central to local government to finance decentralized services, structuring transfers to give users maximum influence over programs and promote institutional pluralism in service provision.

- Develop capacities in a range of public and private providers, such as local governments, executing agencies, and community or producer groups, and introduce competitive

\section{Box 3.13 Potential investments}

- Training and raising awareness for all staff regarding new procedures and rationale for decentralization.

- Development of new regulations and operating procedures.

- Equipment and facilities for local government agencies.

- Training and capacity building for client organizations and service providers.

- Fiscal transfers to local government.

- Central support services, including subject matter specialists, development communications and mass media, and training facilities.

- M\&E systems.

- National and local strategy development and prioritysetting with participation of all stakeholders.

Source: Authors. 
mechanisms that ensure the most competent institutions provide services.

- Establish effective systems to monitor and evaluate decentralized programs and ensure that the data are available at appropriate levels. Central monitoring should be sensitive to equity issues and the possibility of local elite capture of programs, that exclude services to poor people, women, or minority groups.

\section{SELECTED READINGS}

Asterisk (*) at the end of a reference indicates that it is available on the Web. See Appendix 1 for a full list of Websites.

AKIS. 2000. "Decentralizing Agricultural Extension: Lessons and Good Practice." AKIS Thematic Team. World Bank, Washington, D.C.*

Manor, J. 1999. The Political Economy of Democratic Decentralization. Washington, D.C.: World Bank.

Swanson, B. E., and M. M. Samy. 2003. "Decentralization of Agricultural Extension Systems: Key Elements for Success." Proceedings of Regional Conference on Operationalizing Reforms in Agricultural Extension in South Asia, sponsored by The Ministry of Agriculture of the Government of India and the World Bank's South Asia Rural Development Unit, May 6-8, New Delhi, India.*

\section{REFERENCES CITED}

AKIS. 2000. "Decentralizing Agricultural Extension: Lessons and Good Practice." AKIS Thematic Team. World Bank, Washington, D.C.

Amezah, K., and J. Hesse. 2002. "Reforms in the Ghanaian Extension System." Case study was prepared for the Extension and Rural Development: A Convergence of
Views on International Approaches? workshop, sponsored by the World Bank, USAID, and the Neuchatel Initiative, November 12-15, Washington, D.C.

Claar, J. B., D. T. Dahl, and L. H. Watts. 1980. "The Cooperative Extension Service: An Adaptable Model for Developing Countries." College of Agriculture INTERPAKS Series 1. University of Illinois UrbanaChampaign, Urbana-Champaign.

Swanson, B. E., and M. M. Samy. 2003. "Decentralization of Agricultural Extension Systems: Key Elements for Success." Proceedings of Regional Conference on Operationalizing Reforms in Agricultural Extension in South Asia, sponsored by The Ministry of Agriculture of the Government of India and the World Bank's South Asia Rural Development Unit, May 6-8, New Delhi, India.

This Note was prepared by Gary Alex, based on a World Bank Good Practice Note "Decentralizing Agricultural Extension: Lessons and Good Practice" with inputs from David Nielson and the Sustainable Agriculture (SASKI) Thematic Team of the World Bank. 
AGRICULTURE INVESTMENT NOTE

\section{CLIENT GROUPS AS KEY INTERMEDIARIES IN EXTENSION}

Client groups of various types make extension services more accessible to small-scale farmers by providing economies of scale in service delivery and a mechanism for producers to express their demands for services. Working with client groups may enable extension programs to reach more farmers and rural households (increasing efficiency), facilitate participation in extension activities (increasing effectiveness), and develop human resources and social capital (increasing equity). The client group role may entail receiving services for organizational strengthening (client), facilitating delivery of services (partner), providing services to members (executing agency), or financing services (financier). Roles and potential differ markedly between small, informal extension contact groups and formal commercial organizations. Producer organizations are a main focus for agricultural extension, but women's and other community groups are also important partners. Investments are needed to strengthen client group capacities and develop mechanisms for their effective involvement in extension and advisory services.

Past development programs seeking to work through producer or community groups have achieved varying levels of success. In the 1960s and 1970s, donor programs supported cooperatives, many of which failed (often spectacularly) for varying reasons, especially because of excessive governmental control. Rural development programs organized community groups to undertake a wide variety of activities, and agricultural extension services organized contact groups for technology transfer. Such local groups were often effective in facilitating service delivery and increasing client participation in programs, but many were "groups" in name only, with little organizational identity or cohesion and little independence. A study in
India found that community user groups rarely perform as expected, and, although most group members felt group objectives had been achieved, participation was poor, little information was available to members on group activities, and sustainability relied heavily on project staff (World Bank 2002). Despite past efforts, few producer organizations in developing countries have developed as effective organizations with sustainable programs.

\section{PRODUCER GROUPS AND ORGANIZATIONS}

In pluralistic extension systems, various client groups help to formulate client demands for services. Producer groups are the major focus for agricultural extension services, though other organizations, based on community membership, specific social or developmental objectives, or specialized client groups, such as youth clubs or women's organizations, can be equally important to extension programs. Rural producers' groups fall generally into two categories with differing objectives and potentials, as well as differing extension needs (Rondot and Collion 2001).

COMMUNITY-BASED, RESOURCE-ORIENTED GROUPS. These are generally small informal groups of farmers and rural people with diversified production systems. They require extension assistance for community organization, marketing, and collaborative management of natural resources. One type of such farmer grouping is the extension contact group organized for the convenience of extension service delivery. Other informal groups may be semipermanent, coming together for a specific purpose and dissolving when this has been achieved, such as managing natural resources. These seldom evolve into formal organizations and, although they can assume varied roles in extension and information service delivery, their major strength is in serving as a contact point for extension.

COMMODITY-BASED AND MARKET-ORIENTED GROUPS. These are generally larger and more formal organizations, with more sophisticated needs 
for extension assistance in production and marketing, business planning, and development for specific products. These groups can play a wider role in extension because they are more likely to be able to define needs, cofinance service delivery, and coordinate extension and information activities.

Current trends likely to increase the importance of producer organizations and facilitate their involvement in extension include moves to decentralize government, better definition of respective roles of public and private sectors, more competitive markets, improvements in rural infrastructure and services, and better-educated producers. Future support for client organizations will be more effective if based on better understanding of issues involved in strengthening such groups and a more comprehensive strategy for organizational development and sustainability.

\section{BENEFITS}

Extension systems face challenges in delivering information services to large numbers of rural people scattered over wide, sometimes inaccessible, areas. Client organizations help extension "reach" members but, more importantly, serve to organize demand for extension services. They enable members to participate in defining objectives and needs, provide feedback to help programs deliver more relevant services, become more accountable to clients, and establish a base for cofinancing and eventual self-financing of services. In working with client organizations, extension services build important social and human capital, empowering clients to analyze and resolve their own problems (see boxes 3.14 and 3.15). As agricultural markets become more competitive and demand for information and services increases, there will be a growing need for more permanent, formal organizations to provide rural services.

\section{POLICY AND IMPLEMENTATION ISSUES}

VARIED ROLES OF CLIENT ORGANIZATIONS. Client organizations can convene members for disseminating information and training, contract extension services on behalf of members,

\section{Box 3.14 Norway: agricultural research/extension circles}

Norway's agricultural research/extension circles are an example of farmer-owned and led extension services. About 25 percent of Norwegian farmers are Circle members, paying annual fees and electing management boards. Circle programs combine extension and adaptive research and include field experiments, soil testing, farm policy analysis, information and advisory services, and promotion of agricultural communities. Priorities are established in membership meetings, with research ideas and guidelines obtained from the national university. Factors contributing to program success include farmer ownership and leadership, combination of adaptive research and extension, fee-based membership, public sector financing, and adaptation of an existing institutional model.

Source: Haug 1991.

\section{Box 3.15 Malawi: National Smallholder Farmers' Association}

The National Smallholder Farmers Association was formed in 1997 to provide services and promote the social and economic development of smallholders. It is financed through a government levy, member dues, user fees, and donor support and its 96,000 members are organized in about 5,000 local "clubs." Groups of five to 10 clubs are federated into Group Action Committees organized into 32 separate associations.

Services are focused on marketing, using collective bargaining power to negotiate favorable transportation rates and market terms and prices, and providing assistance for feasibility studies, training, and technical and management advice. Associations work with traditional crops (tobacco, maize, cotton, and groundnuts), but are giving increased attention to higher-value and export crops (chili peppers, paprika, ginger, turmeric, and sesame). The associations have field staff and operate farm supply shops that serve as informal information centers.

Source:Walton 2002 
provide input to program governance and priority setting, lobby government for extension services, or assume full responsibility for providing services to members.

Market orientation. Some special interest clients (for example, women's groups, environmental conservation groups) may continue to support extension systems due to personal commitment, but few producer groups will sustain interest if there is no direct economic benefit. For this reason, sustainable extension programs generally must support marketing activities or market-oriented agricultural production to generate the financial benefits that provide a basis for sustainability of the extension systems.

DuAl ROLE FOR EXTENSION. Extension services support clients through establishing client organizations and strengthening their programs and core management systems, in addition to providing technical and advisory services to promote innovation, increase profitability, implement projects, and develop linkages to other sources of assistance.

Level of ORganization. Producer organizations face a dilemma in terms of scale of operation. CBOs (typically 10 to 30 members) can achieve group cohesion and unite around common local objectives, but they lack economies of scale and political influence. National or regional organizations can be more effective advocates with government and achieve economies of scale in operations, but they may lose touch with the rural membership base. A strategy of linking community groups in a national federation seeks to combine these strengths (FAO 2001). West African experience reflects the varied possible roles of producer organizations in providing market-oriented advisory services (see box 3.16).

EQUTTY CONCERNS. Many groups that are dominated by local elites do not truly empower producers or reach disadvantaged groups (Chamala and Shingi 1997). Ensuring participation of women, minority groups, and the poor might require changes to organizational
Box 3.16 West Africa: institutional arrangements

A workshop in Bohicon, Benin in 200 I reviewed experience of 10 West African extension programs that provided management advisory services for family farms. Approaches varied by country and program, but each relied on some form of producer organization to manage services. The management advisory services evolved in response to farmer need to compete in rapidly changing markets. Advisory services analyzed individual farm situations and opportunities, and developed farm management capacity using management tools and decision aids that identify farmers' options. Producer organization arrangements to support these programs included a farmer organization that managed the system in Mali; cotton organizations managing systems in Mali and Burkina Faso; local farmer groups that managed centers providing services in Mali; and a farmer organization in Benin that contracted a private firm to provide advisory services to individual farmer members.

Source: Faure and Kleene 2002.

procedures to ensure that these groups are not excluded. If this fails, establishment of separate organizations might be necessary to provide equal services. Women's political voices can be strengthened by ensuring equality of opportunity to participate in organized governing bodies at the local, regional, national and international levels, as well as by promoting leadership training for rural women and ethnic minorities.

\section{LESSONS LEARNED}

InstiTUTION BUILDing. Extension services can work with producer organizations as full partners, representing members' interests. This requires patience and a long-term perspective. Donor support can strengthen client organizations and stimulate demand for extension, but, having donor funding carries a risk of undermining long-term sustainability of the organizations (Delion 2000).

EXISTING Vs. NEW ORGANIZATIONS. Working with existing organizations is often more successful than starting new ones, especially if groups are formed by a project specifically to qualify for a special subsidy or benefit. In Brazil, such associations rarely survived beyond the subsidy period (Pieri et al. 2002). 
Group PROMOTION. Responsibility for promoting client organizations has often fallen to poorly prepared extension agents with little training or understanding of principles of group formation. Most extension programs need dramatic improvement in staff skills (social, legal, and business) for working with client groups, whether informal community groups or larger formal organizations.

AcCOUnTability and ADVOCACY. Producer organizations are often seen as a mechanism for smallscale farmers to make public extension agencies more accountable and responsive, and as advocates for continued program funding. Accountability is enhanced only if client organizations have real control over program resources and management. There are only a few instances of producer organizations effectively defending extension program funding (as in Venezuela) (Carney 1996). Building effective organizations that can lobby for and influence extension priorities will take time and possibly new organizational arrangements.

\section{RECOMMENDATIONS FOR PRACTITIONERS}

National extension strategies and program mechanisms will vary depending on types of producers/clients, local institutions, and local opportunities and problems. Extension agencies should consider options for working with client organizations in any program. Public support should be oriented toward empowering clients, organizing sustainable groups, developing human capacities, and encouraging participatory problem-solving through extension investments that (see box 3.17) (Chamala and Shingi 1997):
- Define the role of client organizations, which depends on the type of client. Organizations of large farmers and those producing cash crops are most likely to be able to assume full responsibility for organizing and financing extension services. Organizations of small farmers with diversified production systems are likely to be effective partners in planning and implementing programs in conjunction with other service providers but will generally remain dependent on public financing for services.

- Carry out social assessments, including gender analyses, to understand better the dynamics of client groups and their leadership and assess the participation and benefit distribution by gender, age, ethnicity, and income level.

- Devote resources to building client organization capacity and increasing member participation in planning, implementation, cofinancing, and evaluation of extension programs. Extension programs need to emphasize training both for client organization staff and members, as well as for extension service providers.

- Promote independence of client organizations, enabling them to identify extension needs, select service providers, and evaluate program performance. Channeling funding through client organizations to procure services, rather than providing them directly from public agencies or public agency contracts strengthens organizational autonomy and influence.

\section{Box 3.17 Potential investments}

- Technical assistance and training for government and stakeholders to develop a favorable policy and regulatory environment for client organization involvement in extension.

- Training and study tours for client group members and leaders.

- Technical assistance for participatory planning and implementation of extension activities.

- Multi-stakeholder forums for extension planning and evaluation.

- Market linkage development and market information services.

- Support for youth groups, women's groups, and ethnic and cultural minority groups.

- Cofinancing grants for client groups to procure needed services, including information and communication technology equipment.

Source: Authors. 
- Plan for collaboration among client organizations, local government, the private sector, and producers in providing services.

- Encourage transparency in program operations so members are fully aware of program objectives, status, and finances. This may prevent the misuse of organizations by politicians.

\section{SELECTED READINGS}

Asterisk (*) at the end of a reference indicates that it is available on the Web. See Appendix 1 for a full list of Websites.

Carney, D. 1996. "Formal Farmers Organizations in the Agricultural Technology System: Current Roles and Future Challenges." Natural Resource Perspectives 14. ODI, London.*

Chamala, S., and P. M. Shingi. 1997. "Establishing and Strengthening Farmer Organizations." In B. Swanson, ed., Improving Agricultural Extension: A Reference Manual. Rome: FAO.*

Delion, J. 2000. "Producer Organization-Donor Partnerships in Project Implementation in Africa: Risks and Precautions from a Social Perspective." AKIS Discussion Paper. World Bank, Washington, D.C.*

Rondot, P., and M.-H. Collion. 2002. "Investing in Rural Producer Organizations for Sustainable Agricultural Development." Paper presented at Policies and Approaches for Rural Poverty Reduction: What Works in Practice, sponsored by the European Commission and the governments of France, Germany, the United Kingdom and the Netherlands, September 4-6, Agropolis, Montpellier, France.*

\section{REFERENCES CITED}

Carney, D. 1996. "Formal Farmers Organizations in the Agricultural Technology System: Current Roles and Future Challenges."
Natural Resource Perspectives 14. ODI, London.

Chamala, S., and P. Shingi. 1997. "Establishing and Strengthening Farmer Organizations." In B. Swanson, ed., Improving Agricultural Extension: A Reference Manual. Rome: FAO.

Delion, J. 2000. "Producer Organization-Donor Partnerships in Project Implementation in Africa: Risks and Precautions from a Social Perspective." AKIS Discussion Paper. World Bank, Washington, D.C.

FAO. 2001. "The Inter-Group Resource Book: A Guide to Building Small Farmer Group Associations and Networks." Rome, FAO.

Faure, G., and P. Kleene. 2002. "Management Advice for Family Farms in West Africa: Role of Producers' Organizations in the Delivery of Sustainable Agricultural Extension Services." Paper presented at New Approaches to Extension: A Workshop for Practitioners, sponsored by the World Bank, USAID, and the Neuchatel Group, November 11-15, Washington, D.C.

Haug, R. 1991. "Public-Private Cooperation: Farmer-Led Research/Extension Circles in Norway." In W. M. Rivera and D. J. Gustafson, eds., Agricultural Extension: Worldwide Institutional Evolution and Forces for Change. Amsterdam: Elsevier Science Publishers.

Pieri, C., G. Evers, J. Landers, P. O'Connell, and E. Terry. 2002. "No-Till Farming for Sustainable Rural Development.” Agriculture and Rural Development Working Paper. World Bank, Washington, D.C.

Rondot, P., and M.-H. Collion. 2002. "Investing in Rural Producer Organizations for Sustainable Agricultural Development." Paper presented at Policies and Approaches for Rural Poverty Reduction: What Works in Practice, sponsored by the European Commission and the governments of 
France, Germany, the United Kingdom and the Netherlands, September 4-6, Agropolis, Montpellier, France.

Walton, J. 2002. "Malawi: National Smallholder Farmers' Association of Malawi (NASFAM)." Case study was prepared for the Extension and Rural Development: A Convergence of Views on International Approaches? workshop, sponsored by the World Bank, USAID, and the Neuchatel Initiative, November 12-15, Washington, D.C.

World Bank. 2002. "Community User Groups: Vehicles for Collective Actionæor Personal Gain?" PREM Notes 72. World Bank, Washington, D.C.

This Note was prepared by Gary Alex with inputs from Pierre Rondot and the Sustainable Agriculture (SASKI)

Thematic Team of the World Bank. 
AGRICULTURE INVESTMENT NOTE

\section{MASS MEDIA AND COMMUNICATIONS TECHNOLOGIES IN EXTENSION}

Extension systems have yet to exploit the full potential of mass media communications technologies to improve rural people's access to knowledge and information. Development communications and mass media like radio and print media have long been a part of extension systems but have generally not received adequate attention or financing. New technological developments can make these function more efficiently and effectively and provide extension systems with opportunities to deliver new information services in new ways. Private service delivery, cost recovery, and wholesaling of information are important strategies for expanding use of information and communications technologies in rural extension systems.

Communication is the essence of extension services. Extension services, both people and approaches, seek to provide rural people with knowledge and information. The information and communications technology (ICT) revolution provides new options for accessing information by providing it directly to farmers and rural households or to nonfarmer sources of information, such as extension agents, agribusiness, and other intermediaries. Most extension programs have yet to effectively integrate mass media and ICTs into systems for supporting extension staff. These technologies are likely to become increasingly important as extension systems try to provide information to a wider and more diverse client base.

\section{INFORMATION AND COMMUNICATIONS TECHNOLOGY IN EXTENSION SYSTEMS}

ICTs offer opportunities to reach more people and to carry out various functions within extension systems more effectively and efficiently. ICTs can provide easy access to local or global information and knowledge and are simple channels for two-way communications. New technologies can give farm families better access and can be a major empowering resource. Key communications tools for improving extension services include:

- Development communications. This is essential to extension services, providing easily understood information for electronic and face-to-face communications.

- Mass media. This includes broadcast (radio and television), print (newspapers, magazines, and extension brochures), and other approaches, such as poster campaigns, traditional theater, and songs. Public extension services have been slow to realize the potential of mass media, but private firms use mass media effectively in advertising campaigns. Increasing rural literacy and basic education should make mass media communications more effective in reaching large numbers of small-scale farmers.

- Rural telecommunications systems. These range from the pay phone to digital wireless phones and the Internet and are powerful tools for expanding the flow of information of all types, and facilitating market transactions, changes in employment, competition, emergence of new industries, and social transformations (Talero and Gaudette 1996). Phone communications enhance quality of life and make working and living in rural areas more attractive.

- Information technologies. These manage large volumes of information that can be used in planning, administering, and monitoring extension programs. Technologies, such as remote sensing, geographic information systems, global positioning systems, and weather and climate forecasting generate knowledge that extension systems provide to clients.

\section{BENEFITS}

New information technologies and the inventiveness of agricultural scientists, farmers, rural women, and entrepreneurs are leading to new 
mass media and ICT applications in agriculture. Communications technologies can help extension systems provide information better, cheaper, and faster. The ability of information technologies to manage large quantities of data enables these systems provide new services. Desktop publishing, PowerPoint presentations, digital images, and lower-cost audiovisual hardware improve communication effectiveness. Computers and new software allow farmers, producer organizations, and extension agents to access information on a range of new technologies, markets, and other information from local or remote databases.

ICTs and traditional mass media can help the farmer compete in the evolving knowledge economy where competitive advantage is often dependent on timely access to high-quality information. Changes in farming systems also require extension systems to provide more knowledge and information support as producers diversify to new crops, meet higher food quality standards, or adapt to greater resource constraints. Many benefits derive from linking new technologies with traditional media. Internet searches identify global knowledge resources for local print media use; call-in Internet radio shows allow listeners to phone in questions that can be researched on the Internet before the results are then reported over the radio.

\section{POLICY AND IMPLEMENTATION ISSUES}

In expanding use of ICTs, extension systems will need to address the cost and policy issues of reaching clients in rural areas.

The Digital Divide. In 1999, Latin America, Africa, and the Middle East accounted for only 4.2 percent of all people connected to the Internet. There were only 0.7 telephones per 100 people in rural areas of low-income countries, compared to 48.5 in rural areas of high-income countries (Hudson 1998). Rural areas are also much less connected than urban areas. Physical infrastructure is not the only factor: rural people are often less able to use ICTs because of lower education, skill levels, and incomes. Women have less access to ICTs than men. In selected developing countries, women accounted for 6-37 percent of Internet users. Women's lower access to ICTs is due to cultural and social attitudes that restrict women's use of new technologies or that require seclusion of women; financial dependency on male family members; and less educational opportunities for women (Wete 1991).

Cost effectiveness. Public extension services can mainstream mass media in cost-effective extension programs. In Malawi, even in the early 1980s, direct extension agent-to-farmer services cost US\$21 per contact; a one-day farmer training course cost US $\$ 4$ to US $\$ 5$ per participant; a mobile film show cost US\$0.17 per farmer per hour; and a radio program cost US\$0.004 per listener per hour (Perraton et al. 1983). Advances in communications technologies have further reduced costs and opened opportunities for new and better applications of ICTs.

Cost ReCovery. Many extension services (market information and farm level advisory services) provide private benefits that should be paid for by users. Cost recovery is important in expanding rural access to information services. Revenue from advertising associated with information dissemination (radio or television advertising) or subscriptions (magazines, or Internet advisory services) offer opportunities for selffinancing mass media services. Public extension agencies need to establish good business relations with private partners, either by selling advertising to private firms for governmentowned media or providing high-quality information products for use by private sector publishers and broadcasters.

TRAINING AND SUPPORT. Introducing computers and new communications technologies in traditional extension agencies can improve efficiency but can also have major implications for training and technical support costs, in addition to the initial hardware costs. Investments in curricula of training programs and staffing are needed to 
provide extension service providers with the capacity to effectively use new technologies and to link clients and sources of information.

Policies and Regulations. Regulatory constraints may limit rural access to communication technologies. National and international regulations constrain expansion of local radio. Protection of telecommunications monopolies, restrictions on voice-over Internet protocol, and regulation of Internet use often limit rural access to ICTs. Extension programs can identify such policy constraints and raise them with national policymakers. Educating rural constituencies (producer organizations and agribusiness) about these policy issues can create a constituency for reform.

\section{LESSONS LEARNED}

The falling costs and ever-increasing capacity of ICTs, their ease of use and potential for wide coverage, and the entertainment value of cleverly packaged information and educational media present opportunities to mix different types of digital and traditional information technologies.

Matching media to messages. Radio and television reach many people quickly with simple messages. Print is good for getting detailed information to people. Interpersonal communications, group meetings, and demonstrations are best for teaching and developing credibility. A range of media can be combined in an overall communications strategy, but this is something that public extension services often do poorly.

Developing content. The use of ICTs and mass media is not a one-time investment. There must be capability and commitment to continuous development of quality information and educational materials to supply clients through these media. Effective development communications requires active participation of intended beneficiaries and continuous assessment of their interests.
KNOWING THE CLIENT. Knowing audience characteristics, preferences, needs, interests, and access to media are critical to understanding the potential use of specific media, analyzing and targeting audiences, and designing media products.

InSTITUTIONAL ARRANGEMENTS. Support for development communications in public extension services is complicated by the number of government agencies requiring such services. Limited demand from any one institution often makes it desirable for extension services to contract out communications support to specialized agencies. This requires a recurrent budget item for communications support, but avoids investment in costly equipment that may be underused and poorly maintained.

Telecenters. Rural telecenters (or telecottages) have efficiently provided rural people with access to ICTs; however, financial sustainability is still a major problem for such centers. Generally, telecenters work best when Internet access is part of larger information centers and linked to rural radio and other information services. ${ }^{4}$ Telecenter networks are useful in exchanging ideas and good practice experience. Varying institutional arrangements are possible (see box 3.18). UNESCO has produced a useful guide to establishing telecenters in Africa (Jensen and Esterhuyen 2001).

\section{Box 3.18 India: Info Village Project in Pondicherry}

The Info Village Project in Pondicherry, India, supported by the M.S. Swaminathan Research Foundation, has established village information centers managed by villagers. Farmers have been willing to pay for extension and marketing information from these centers. In one village, four women are managing a center effectively. They send and receive e-mails and faxes and download daily news from the Internet and display it on a Bulletin Board outside the info center. The Info Centers are highly user-friendly, demand-driven, managed by local people, and cater to a variety of information needs.

Source: MSSRF 2002.

4. See the IAP,"Russian Federation: Using Information and Communications Technologies for Rural Information Services" 


\section{RECOMMENDATIONS FOR PRACTITIONERS}

Extension systems can use mass media and ICTs in three interlinked information subsystems for accessing and developing knowledge products, supporting intermediaries and service providers, and linking rural people directly to sources of information and knowledge. Investments are needed so that public extension services can:

- Develop extension strategies that identify available communications resources; assess needs for communications; and determine the type of communications support needed. Many traditional uses of ICTs in extension are proven technologies that still need to be piloted and adapted to specific countries.

- Analyze information needs through knowledge, attitude, and practice surveys, including gender analyses, that can be conducted through rapid rural appraisals and do not need to be costly or lengthy.

- Expand use of mass media, especially radio, to complement other extension services and integrate use of various media for distribution of information.

- Establish capacity in development communications to package information for use in extension and advisory service programs, including provision for building capacity for local input of content and for supply and distribution of local material (see box 3.19).

\section{Box 3.19 Potential investments}

Expanding use of ICTs in rural extension systems will require investments in the $4 \mathrm{Cs}$

- Connectivity (equipment and infrastructure).

- Capacity building (training and institution building for use of ICTs).

- Content (preparation of materials and linkages for obtaining information and knowledge products).

- Conducive environment (policy and regulatory reforms to facilitate use of ICTs).

Source: Authors.
- Build into programs strategies that promote equal access and opportunity for the poor and disadvantaged groups, including women, to use mass media and ICTs.

- Assess telecommunications policies and regulations that might constrain rural access to information and communication services.

- Promote use of the Internet and establishment of self-financed telecenters.

Cost efficiency and practicalities dictate the need to develop multipurpose information systems that provide health, educational, cultural and other information, as well as agricultural information. Extension programs can also achieve efficiencies by wholesaling public information services-packaging information and distributing it through electronic and other means for use by frontline extension service providers.

\section{SELECTED READINGS}

Asterisk $\left(^{*}\right)$ at the end of a reference indicates that it is available on the Web. See Appendix 1 for a full list of Websites.

FAO. 2001. "International Workshop on Farm Radio Broadcasting." Workshop Report. FAO, Rome.*

Fundacion Chasquinet. http://www.chasquinet.org.

Garforth, C. 1986. "Mass Media and Communications Technology in Investment." In G. Jones, ed., Rural Extension: Strategies and Goals. London: Elsevier Applied Science Publishers.

Hafkin, N., and N. Taggart. 2001. "Gender, Information Technology and Developing Countries: An Analytic Study." Office of Women in Development. USAID, Washington, DC.*

\section{REFERENCES CITED}

Hudson, H. E. 1998. "Global Information Infrastructure: The Rural Challenge.” In D. 
Richardson and L. Paisley, eds., The First Mile of Connectivity-Advancing Telecommunications for Rural Development through a Participatory Communications Approach. FAO, Rome.

Jensen, M., and A. Esterhuysen. 2001. "The Community Telecentre Cookbook for Africa: Recipes for Self-Sustainability: How to Establish a Multi-Purpose Community Telecentre in Africa." UNESCO, Paris.

M.S. Swaminathan Research Foundation. Information Village Research Project. http:// www.mssrf.org/.

Perraton, H., D. T. Jamison, J. Jenkins, F. Orivel, and L. Wolft. 1983. "Basic Education and Agricultural Extension-Costs, Effects, and Alternatives.” Staff Working Paper 564. World Bank, Washington, D.C.

Talero, E., and P. Gaudette. 1996. "Harnessing Information for Development: A Proposal for a World Bank Group Strategy.” Discussion Paper 313. World Bank, Washington, D.C.

Wete, F. 1991. "New Technology for Transferring Agricultural Information." In W. M. Rivera and D. J. Gustafson, eds., Agricultural Extension Worldwide: Institutional Evolution and Forces for Change. Amsterdam: Elsevier Science Publishers.

This Note was prepared by Gary Alex with inputs from Matthias Grueninger and the Sustainable Agriculture (SASKI) Thematic Team of the World Bank. 
INNOVATIVE ACTIVITY PROFILE

\section{ESTONIA:TRANSITIONTO PRIVATE EXTENSION ADVISORY SERVICES}

Since independence in 1991, Estonia has followed an open and liberal reform path with agriculture important to economic growth and export earnings. Before independence agricultural production was organized in approximately 350 large state cooperatives, each managing some 3,500 hectares with about 300 employees. Assets of the state and collective farms were privatized after independence, and the farm structure evolved toward smaller-size family farms. The agronomic advisory service before independence was highly specialized, aimed at servicing state and collective farms, and ensuring delivery of centrally planned production targets. Advisors did not provide business- or market-related advice. After independence, new private farmers lacked business experience and needed advice on production techniques, business operations, and farm management.

What's innovative? Establishing a Private Advisory Services Development Fund and using different extension strategies, including the Internet for different categories of farmers.

\section{PROJECT OBJECTIVES AND DESCRIPTION}

The objectives of the agriculture project were to increase rural incomes and stimulate the rural economy. Project components included land reform, farm drainage rehabilitation, land use management, agricultural advisory services, food quality and veterinary laboratories, and project management.

The extension component targeted different categories of farmers using different extension strategies, depending on information needs, purchasing power, and access to technologies and solutions. To make the strategies demanddriven and relevant, a National Agricultural Extension Task Force was created whose members included farmers, advisers, and public officials. For two years, the group generated ideas, monitored developments, and formulated concepts and strategies. The group's function is continuing under an informal advisory concept group made up of major stakeholders.

Privately operated advisory services were intended to provide agronomic and farm business advice for the most commercially viable farms (about 3,700). The project established a Private Advisory Services Development Fund to support a demand-driven advisory service, which funded certified private advisers on a contract basis. Private advisers were trained in methodology and technical subjects, and an Association of Rural Advisors in Estonia was created. A system for certification of advisers was put in place under the Ministry of Agriculture, and only certified advisers qualify for advisory contracts that are partly subsidized by the Fund. Government subsidies for individual advisory contracts between farmers and advisers were to be gradually reduced over a nine-year period (from 90 percent in 1996 to 0 percent in 2004). However, phasing out of the subsidy has been delayed for a few years in response to slower-than-anticipated growth in farm incomes.

The middle category of farmers received public extension services through mass media, farmers' organizations, and information networks. The project supported publications from various agricultural institutions and it also funded a large number of group advisory sessions conducted by farmers and federation advisers or by private advisers in response to requests made by county councils and/or farmers' groups. In addition, the project supported the establishment of an Agricultural Information Coordinating Center (AICC) and an internet-based agricultural information network connecting the farming community to rural advisers, the ministry, and other domestic and international resources for information. The central portal and Web site of the AICC (http:// www.epk.ee) is maintained and continually updated under a contractual arrangement with the Foundation for Rural Development. 
A large number of marginal farmers (about 6,500) need information on both farming and alternative employment opportunities. Rural Information Centers (RIC) in almost all communities, linked to the AICC, provide this information electronically. The project has supported the establishment of the Centers with training for staff and provision of computers and office equipment. The information activity has strong links with other initiatives, including banks, insurance companies, and commercial companies promoting their services through the Internet. The ministry provides printed information for RICs and electronic information through the AICC.

\section{BENEFITS AND IMPACTS}

Over the project period, 13,572 private advisory contracts were approved. The number peaked at 2,894 in 1998 and then declined to 2,689 in 1999; 2,350 in 2000; and 1,410 in 2001. The number of active certified advisers participating in the scheme declined from a high of 189 in 1997 to 69 as of September 2002 (with 10 more waiting to be certified). Reasons for the decline include: the emergence of private input suppliers furnishing "free" topical advice; the establishment of private advisers who prefer to operate outside the state-supported system; and the increase in farmers' basic know-how and a subsequent decline in their need for advice. Most advisers have expertise in plant production (29 percent), animal husbandry (20 percent), or farm economics (36 percent), with only a limited number experienced in fields, such as forestry, marketing, or business planning. About two-thirds of current certified advisers are part-time and hold other jobs, as well (for example, university teachers, researchers, private farmers). Many of the advisers who left the advisory support system are employed with private companies.

Dairying is the dominant farming system and, with project support, has become quite profitable: with average net farm incomes increased by an estimated 35 percent during the five years of the project. Farmers increased their knowledge in grain production and animal husbandry, and they adopted improved agricultural practices, especially in plant protection, animal nutrition, and fodder production.

There is now broad understanding and acceptance among farmers that advisory services have to be paid for by the beneficiaries. Annual customer satisfaction surveys, conducted in 1996 through 2000, showed very high levels of satisfaction with the advice given (more than 90 percent), and more than one-half of the respondents indicated that they continue to buy advice.

\section{LESSONS LEARNED AND ISSUES FOR WIDER APPLICABILITY}

Government does not need to "own" the rural advisory system for it to be effective and efficient. The Estonian experience shows that an effective public-private partnership can satisfactorily meet the varying information needs of the rural clientele, and can very quickly adapt to changing client characteristics and needs.

Internet-based information services are proving to be a cost-effective and efficient way to link rural populations in sparsely populated areas to the world.

Having a nationally agreed agricultural and rural policy and strategy in place is beneficial for designing a project targeted at national priority objectives.

\section{PROJECT COUNTRY: ESTONIA}

$\begin{array}{ll}\text { Project Name } & \begin{array}{l}\text { Agriculture Project (Agricultural } \\ \text { Advisory Service Component) }\end{array} \\ \text { Project ID } & \text { P008403 } \\ \text { Project Component Cost } \\ \text { US\$5.3 million } \\ \text { Dates } & \text { FY I997 - FY } 2002 \\ \text { Contact Point } & \text { Gotz Schreiber } \\ & \text { The World Bank, I8I8 H Street } \\ & \text { NW, Washington D.C. 20433 } \\ & \text { Telephone: (202) 473-4495; } \\ & \text { E-mail: Gschreiber@worldbank.org }\end{array}$


INNOVATIVE ACTIVITY PROFILE

\section{INDIA: PARTICIPATORY AND DECENTRALIZED AGRICULTURALTECHNOLOGY TRANSFER}

From the mid 1960s to the late 1980s, agricultural extension played a central role in improving agricultural productivity in India.

What's innovative? Decentralized agricultural technology management agencies increase user participation in extension programs, involve nontraditional partners, and make extension more accountable to farmers.

The T\&V system was broadly implemented and initially worked well in irrigated areas, providing rapid dissemination of green revolution technologies, but T\&V was much less effective in rainfed areas. While the overall extension system grew rapidly, it was unable to adapt to changing needs and grew less efficient and effective. Constraints included a multiplicity of public extension agencies; lack of coordination; limited technical capacity; weak community organizations and poor communications capacity; and weak financial support. A new approach was needed to develop technologies applicable to diverse agro-climatic conditions; focus on sustainable agriculture; adopt community participatory approaches; use a farming systems approach to serve the poor in marginal areas; develop a broader skill base; and adjust to financial constraints.

\section{PROJECT OBJECTIVES AND DESCRIPTION}

A component of the National Agricultural Technology Project implemented an effective and efficient demand-driven extension service with strong linkages to researchers and farmers, improved coordination among the line departments, and public-private partnerships for technology testing and extension. The Project's institutional innovations include Agriculture Technology Management Agencies
(ATMAs) at the district level; Farmers' Information and Advisory Centres and Farmers' Advisory Committees (FACs) for continuous production areas (blocks); Farmer interest groups and self-help groups at the village level; and strengthened institutions for training, coordination, and M\&E at the state and national level.

To provide operational and financial flexibility, ATMAs are registered as independent societies under the Societies Registration Act. Their management structure provides for improved interagency coordination and accountability to all stakeholders, including farmers and its governing board includes the district collector as chair; the project director as secretary; and membership from district line departments, zonal research stations, farmer representatives, NGOs, the private sector, and others. At the block level, FACs have a rotating farmer representative as chairperson; a member secretary; and farmer representatives, block level functionaries, and others as members. Village level groups work closely with FACs and public and private extension agents.

ATMAs provide for decentralized participatory operation of farmer-driven extension services and have institutionalized bottom-up planning processes through preparation of Strategic Research and Extension Plans, based on participatory rural appraisals and Block Action Plans. Aggregation of block plans forms the district's annual work plan. The ATMA program relies on a group approach based on village level groups, as well as training of volunteer farmers to be paraprofessionals.

ATMAs support private extension initiatives by contracting NGOs to take on extension responsibilities in selected blocks/areas, using farmer-to-farmer extension services provided by individuals or through farmer organizations, in addition to developing partnerships with input providers (seeds, fertilizers, and crop protection chemicals) for demonstrations and farmer training. The ATMAs use teams of 
research and extension personnel to prepare Strategic Research Extension Plans; identify research priorities in joint workshops with state agricultural university scientists and district/block functionaries; and finance some technology refinement and validation work in response to location-specific needs.

\section{BENEFITS AND IMPACTS}

ATMAs in most districts have developed in such a way that farmers and other stakeholders have a sense of program ownership. Operational flexibility allows extension services to respond to local needs and to improve program relevance and effectiveness, but program sustainability is still uncertain.

ATMA success stories include the diversification of production systems for greater income and/ or sustainability (for example, the cultivation of high-value crops including flowers, fruits, vegetables, and medicinal plants); improved natural resource management, such as vermiculture; integrated pest management; organic farming; well recharging; integrated plant nutrient management; resource conservation technologies; and the development of new enterprises, such as cashew processing, beekeeping, dairying, value addition through processing, and group marketing.

\section{LESSONS LEARNED AND ISSUES FOR WIDER APPLICABILITY}

The Farmer Interest Groups effectively mobilized men, women, and young people to join common interest groups such as producer groups for flower, fruit, vegetable, milk, and other products, as well as marketing groups for seed. These groups have developed federations for mutual support. Training of farm leaders in technology and leadership skills is important, and successful groups can help promote new groups. Strong farmer organizations/federations can be a positive link in the cost-effective provision of extension support to small and marginal farming communities, as well as an alternative to privatization of extension service.
FACs are operational in most project blocks, and they are recognized by government line departments; however, ATMAs have yet to fully assert their authority and overcome the challenges of providing greater representation for female members and more leadership training.

Internal conflicts between ATMA priorities and departmental responsibilities persist, and extension staff require considerable motivation to work in a farm advisory role with multiple funding sources.

\section{PROJECT COUNTRY: INDIA}

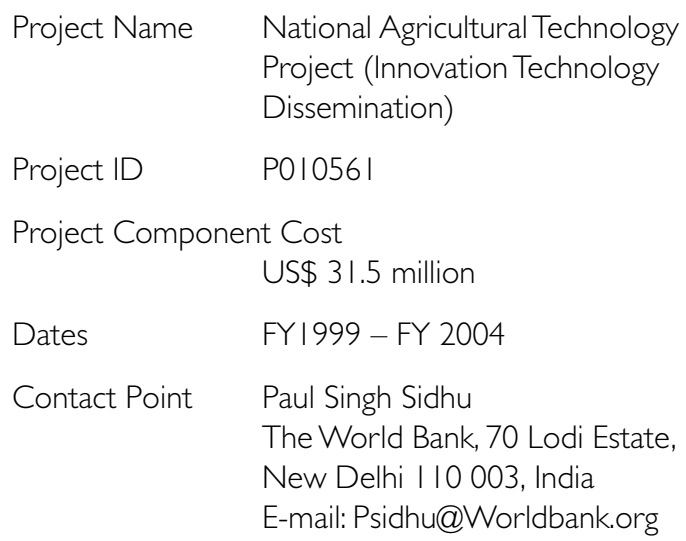


INNOVATIVE ACTIVITY PROFILE

\section{RUSSIAN FEDERATION: USING INFORMATION AND COMMUNICATIONS TECHNOLOGIES FOR RURAL INFORMATION SERVICES}

In the early 1990s, when the centrally managed economy changed to a market-based economy, Russian farmers and policymakers faced serious constraints to improving agricultural production systems. These obstacles included inefficient farm structures, lack of competitive markets, and an outdated information system designed to meet the requirements of a centralized bureaucracy. Strengthening and expanding agricultural information and knowledge systems was seen as a way of addressing a wide range of linked issues.

What's innovative? Regional agriculture and market information made available through a Web site and a computing network linking 28 regions, nearly onethird of all the regions in the Russian Federation.

In the past, the government used Goskomstat (State Statistical Committee) and Ministry of Agriculture and Forestry statistical systems in Moscow to generate information necessary for managing a centrally planned economy. The ongoing privatization, deregulation, and decentralization of the economy led to the emergence of private farmers, restructured farms, and agribusiness enterprises which has generated a need for new statistical and information services to improve marketing decisions, such as opportunities to adjust production and marketing activities in response to changes in prices, demand, and supply of agricultural commodities and inputs.

\section{PROJECT OBJECTIVES AND DESCRIPTION}

The main objective of the market information development component of the Agricultural Reform Implementation Support Project was to make available information and knowledge to improve decisionmaking by farmers, public institutions, and private enterprises. Central to this was the development of a national market information system for collecting, processing, and disseminating market information on about 50 agricultural commodities and inputs. This would aid the agricultural sector in its transition from a centralized command economy to a market economy.

The information system was designed on the basis of pilot projects. Oblast (regional level) offices collect and process information locally and from rayon (district level) offices, and manage the database. A central Market Information Unit in the ministry draws information from commodity exchanges, Goskomstat, international sources, and databases at the oblast level. The system consists of a Price Information Service for farmers, traders, processors, and consumers, and a Price Monitoring Service for government agencies and policymakers.

The project provided equipment, supplies, training, and technical assistance to ministry, and to its departments at oblast and rayon levels. The ministry released the market information, initially as a public good, through television, radio, electronic, and print media, and it phased in the introduction of cost recovery through provision of commercial information services. During the 1995-2000 period, the project established:

- An initial framework for the development of a rural information and knowledge system needed during Russia's transition to a market economy.

- A computing network connecting 28 regions and more that 300 districts across Russia. This network provided agriculture and market information and a Web site (http://www.aris.ru) and included sections on price information, markets, and agriculture information.

- A modern press and video center in the ministry, using a variety of media to dis- 
seminate multidisciplinary material on agriculture and related topics to regions, institutions, and farm producers.

\section{BENEFITS AND IMPACTS}

The market information system is currently operating in 28 regions and about 300 rayons across Russia (roughly one-third of all Russia). It provides weekly and biweekly producer, wholesale, and retail prices on a wide range of agricultural products (by grades and quality, as well as prices for inputs, such as agricultural machinery, fertilizer, chemicals, and fuel). These prices are disseminated through the Internet, the Agricultural Reform Implementation Support Web site, answering machines, mass media, and on information boards in the ministry. Periodic market reports and analytical reports are produced and placed on the Internet. The services offered by system are now the main source of producer, wholesale, and retail prices used by agricultural producers, traders, banks, donor agencies, and others interested in entering the agricultural sector in Russia.

Econometric studies commissioned by the project show that the market information system led to a substantial reduction in the variation of prices of 10 products covered by the information system within the participating regions (a 20 percent reduction in price variation). This indicates substantially improved efficiency of agricultural markets and increased access to market information by market participants.

\section{LESSONS LEARNED AND ISSUES FOR WIDER APPLICABILITY}

Access to relevant market and production information benefits farm and consumer households through reduction in regional and temporal variations in price and product availability. Effective and efficient rural information systems should:

- Build on the local culture, customs, and media and incorporate these into local information and knowledge-transfer project activities.
- Tailor information packages to local situations.

- Incorporate flexibility and scalability in technology hardware, using internationally accepted standards.

- Expect only partial cost recovery, recognizing that information can be a public good, especially in transition economies.

- Link various information technologies (for example using Web page material to produce a series of newsprint reports to be distributed regionally).

The revolution in information and communications technologies provides a host of opportunities to improve farmer access to market, technical, and other information needs. Most extension programs, and probably most rural programs, can incorporate new information technologies and systems to advance their objectives.

\section{COUNTRY: THE RUSSIAN FEDERATION}
Project Name Agricultural Reform Implementa- tion Support Project (Market Information System Component)

Project ID P0088II

Project Component Cost

US\$9.3 million

Dates FY 1995 - FY 200I

Contact Point Mark Lundell

The World Bank, 1818 H Street NW, Washington, D.C. 20433 Telephone: (202) 458-4655; E-mail: mlundell@worldbank.org 
INNOVATIVE ACTIVITY PROFILE

\section{UGANDA: EXTENSION DECENTRALIZATION, PRIVATIZATION,AND REFORM}

In Uganda, current real incomes of rural people and real agricultural GDP are still below levels of the 1970s; however, recent agricultural growth (more than four percent annually over the past 10 years) provides momentum for rural development. This growth has been accompanied by a profound reorientation of the public sector role in the agricultural economy and public institutional reforms. However, agricultural productivity is still low.

\footnotetext{
What's innovative? A decentralized, private extension system that allows farmer groups to contract their own extension service providers and researchers in technology development and marketing.
}

Low productivity is in part a consequence of inadequate communication among researchers, extension, and farmers. Farmers' needs, both agricultural and socioeconomic, such as the impact of HIV/AIDS on farming households, are not sufficiently reflected in research and extension efforts. Research and extension are overly dependent on donor funding, and require a more stable institutional base of both financial and political support.

\section{PROJECT OBJECTIVES AND DESCRIPTION}

The National Agricultural Advisory Services (NAADS) project, part of the Plan for Modernization of Agriculture, is based on strong government commitment to decentralization and private sector development. Its objective is to improve the productivity and livelihoods of farmers, by establishing a relevant and responsive contract-based agricultural advisory service. This involves the transforming of the existing publicly-delivered national level extension service to a decentralized, largely farmer-owned, private sector advisory services system. Components of the project are:
- Advisory and information services to farmers. NAADS provides funding and training for initiatives from farmers groups, working in conjunction with local government, to contract for private agricultural advisory services.

- Technology development and linkages with markets. NAADS provides funds to farmers to contract researchers to work with them in their fields on technology and market development and adaptation.

- Ensuring quality of services. NAADS funds the development of a regulatory framework and service standards for service providers.

- Promotion of private sector institutional development. NAADS provides limited funding on a competitive basis for retraining and technical upgrading for service providers. In addition, the project provides a comprehensive package of benefits, including training, which will enable public sector extension providers to transition to employment in the private sector.

- Program management, monitoring, and evaluation. NAADS establishes and supports national and district level entities to coordinate, monitor, evaluate, and administer the project.

Brochures, radio spots, and rural drama groups are used to disseminate information on the NAADS project. Market and commodity studies will provide a better understanding of the local economic conditions and help identify project priorities.

The project philosophy, consistent with the government vision, includes:

- Independence and flexibility. The NAADS board is a small and semi-autonomous unit. It is not housed within either the Ministry of Agriculture or the National Agricultural Research Organization. 
- Further decentralization. Responsibility and funding for agricultural advisory services are being moved from the district level to the subcounty and farmer level.

- Contracting out services. The government has decided to give districts strong incentives to reduce the number of extension providers employed as civil servants, in favor of contracting the services of agricultural advisers.

- Cost sharing. The government has decided to institute, at a gradual and deliberate pace, the requirement that farmers and local governments pay part of the cost of the project.

\section{BENEFITS AND IMPACTS}

Sixteen districts, which cover a total of 224 subcounties, are in a pilot phase of the NAADS project. Organized into local groups some 8,000 farmers participate collectively in decisionmaking processes. The framework developed for extension services provides a strategic base for rural information and communication services.

Farmer control of resources provides and strengthens previously weak linkages to the research system, makes technologies more accessible, and facilitates the use of farmer innovations and local knowledge.

The private sector advisory partners have begun to register as companies and eventually extension services will be completely privatized. Current extension workers, who will soon become private sector service providers, are involved in retraining to match their skills with what is required by private sector advisory services.

\section{LESSONS LEARNED AND ISSUES FOR WIDER APPLICABILITY}

- Participation of local professionals, such as policymakers, researchers and extension agents and beneficiaries throughout the project planning and implementation stages is of critical importance.

- A responsive training program must be established for the staff of the extension system.

- Flexibility is required to meet the needs of a heterogeneous population of beneficiaries. When the delivery of extension services has been limited to one delivery mechanism this has often been difficult to achieve. Enabling subcounties and beneficiaries to contract with any qualified institution or entity to deliver advisory services will permit great flexibility in the types of delivery mechanisms that might be employed.

NAADS is still in its pilot phase, but the project has attracted a great deal of attention and support in Uganda and from donors interested in sustainable approaches to extension and information service delivery in Africa.

\section{PROJECT COUNTRY: UGANDA}

$\begin{array}{ll}\text { Project Name } & \begin{array}{l}\text { National Agricultural Advisory } \\ \text { Services Project }\end{array} \\ \text { Project ID } & \text { P044695 } \\ \text { Project Cost } & \text { US\$107.92 million } \\ \text { Dates } & \text { FY 2000 - FY 2008 } \\ \text { Contact Point } & \text { Christine E. Cornelius } \\ & \text { The World Bank, I8I8 H Street } \\ & \text { NW,Washington, D.C. 20433 } \\ & \text { Telephone: (202) 458- I882; } \\ & \text { E-mail: Ccornelius@worldbank.org }\end{array}$


INNOVATIVE ACTIVITY PROFILE

\section{VENEZUELA: CONTRACTING DECENTRALIZED EXTENSION SERVICES}

In Venezuela, the existence of chronic rural poverty, despite abundant natural resource wealth, has created a sense of urgency for improving the productivity and competitiveness of its agriculture sector. By the mid-1990s, it was clear that agricultural extension services were not capable of modernizing agriculture and promoting rural development. The government did not know how many extension agents it had or how much it was spending on extension. Several different agencies provided extension services, but extension agents were rarely in the field. Small farmers claimed that services never reached them, and larger farmers felt the extension agents had nothing to offer. Research programs claimed to have many new technologies "on the shelf," but these technologies were not being adopted by farmers.

What's innovative? Decentralization, and contracting of private extension services to improve accountability, flexibility, and responsiveness to farmer needs.

PROJECT OBJECTIVES AND DESCRIPTION A fundamental premise for the Agricultural Extension Project was to ensure that extension services were accountable to clients, and this is incorporated in its institutional structure. The decentralized program, focused at the municipal (district) level, relies on extension agents contracted through private firms and NGOs. This provides flexibility and responsiveness to clients. Client participation is encouraged through establishment of Civil Associations for Extension (ACEs) at the municipal level. The ACEs, consisting of representatives of the municipal government and beneficiaries of extension services, coordinate the implementation of extension activities. Cofinancing by clients and municipal and state governments ensures that recipients value the services being provided.
The project specifically targets poor farmers and their families with small but viable farming operations and finances four component activities:

- Establishment of institutional structures to coordinate and administer the decentralized agriculture extension system. Among other expenditures, the project funded the development of national and state-level subject matter specialists.

- Extension services contracted out to private firms or NGOs for 180 municipalities.

- Training for private extension agents, members of ACEs and local government, and national and regional extension staff.

- Technical assistance and analytical studies to improve extension service planning and implementation.

Municipal agricultural extension services are provided in each participating municipality through contracted services of executing bodies (private firms, universities, and NGOs). Each municipal agricultural extension office prepares an annual municipal project outlining the objectives and the proposed activities to achieve each objective. This plan is submitted to the Board of the ACE for approval, after which participating municipalities submit plans to the implementing agency-the Foundation for Training and Innovation for Rural Development-for approval of matching funds to cofinance the project. The foundation negotiates agreements with municipalities, relevant state governments, and ACEs in the municipalities for cofinancing contracted extension services and then employs competitive procedures to contract services from NGOs or private firms.

The costs of the municipal project are shared between four contributors: participating farmers, the municipal government, the state government, and the national government. It is expected that farmer contributions will generally be small to begin with but will increase over time. 
Extension approaches are based on farmer preference, the results of an annual diagnostic survey, and technical assistance available from subject matter specialists. Extension program design focuses on providing services targeted to small farmers in an effort to enhance social and gender equality. Environmental and natural resource conservation impacts of projects are given priority attention, and the project includes activities to increase the environmental awareness of farmers.

\section{BENEFITS AND IMPACTS}

Benefits from the extension project are increased awareness by farmers with a better of their own extension needs, as well as increased visibility and credibility of extension agents. Farmers are now organized into 76 ACE groups, representing about 10,000 farmers. Countrywide, 492 extension agents deliver services to 45,000 clients (not all clients are members of the ACEs) in 123 municipalities.

Program monitoring systems indicate that there has been wide adoption of the innovations introduced by the extension teams, with more than 4,000 innovations adopted in participating municipalities. While impact evaluations are being undertaken, demand from municipalities to participate in the program now exceeds the resources available to the program.

Nearly 25 percent of extension agents are women, and extension services for women have emerged as an important part of the overall municipal extension program.

\section{LESSONS LEARNED AND ISSUES FOR WIDER APPLICABILITY}

Contracting extension service delivery from private firms and NGOs is becoming more common and is an effective way of enhancing accountability to clients, which is an important part of any service. Using existing or creating new social mechanisms is an effective way to make service providers more accountable to clients.
The project has already attracted considerable attention and has had visits from delegations from several African and Latin American countries that are also considering extension service reforms. A regional workshop held in 2001 provided an opportunity to share Venezuela's experience with other countries in the region.

\section{PROJECT COUNTRY: VENEZUELA}

$\begin{array}{ll}\text { Project Name } & \text { Agricultural Extension Project } \\ \text { Project ID } & \text { P008222 } \\ \text { Project Cost } & \text { US\$79.0 million } \\ \text { Dates } & \text { FY 1996 - FY } 2004 \\ \text { Contact Point } & \text { Matthew McMahon } \\ & \text { The World Bank, I8 I8 H Street } \\ & \text { NW,Washington, D.C. 20433 } \\ & \text { Telephone: (202) 473-8586, } \\ & \text { E-mail: mmcmahon@worldbank.org }\end{array}$





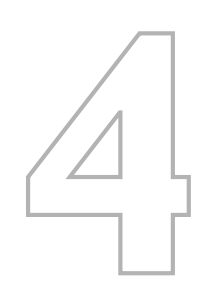

\section{INVESTMENTS IN SUSTAINABLE AGRICULTURAL INTENSIFICATION}

growing population and limited natural resource base means that if current and future food and fiber needs are to be met, these resources will have to be used in a more sustainable way. Promoting sustainable agriculture requires that farm management techniques foster synergies, conserve nutrients, increase economic stability, and promote equitable outcomes for male and female small-scale farmers. This overview summarizes the basic underlying principles and approaches for planning investments in sustainable agricultural production systems, including technologies to intensify production. These issues and investments complement investments needed for the sustainable management of off-farm natural resources important to agricultural production systems.'

I. See Module 5, "Sustainable Natural Resource Management" for more information on the sustainable management of off-farm natural resources important to agricultural production systems. 


\section{Box 4.I Household strategies to improve livelihoods}

- Intensification of existing farm production patterns through increased use of inputs or better quality inputs.

- Diversification of production with emphasis on greater market orientation and value addition involving a shift to new, generally higher-value products.

- Increase farm size, an option limited to a few areas where additional land resources are still available.

- Increase off-farm income to supplement farm activities and provide financing for additional input use.

- Exit from agriculture, including migration from rural areas. Source: Dixon et al. 200I and FAO 200I.

\section{RATIONALE FOR INVESTMENT}

Future global food and fiber demand is expected to increase substantially as populations grow, and average incomes rise. However, there is limited new land and water resources that can be brought into production to satisfy this demand. The expected ecological impacts from doubling food production using past production strategies may result in production systems becoming unsustainable. Agricultural systems must therefore intensify existing land and water resources using more sustainable methods, and by changing current production systems and diversifying into new, more productive enterprises.

Agricultural intensification is an increase in the productivity of existing land and water resources in the production of food and cash crops, livestock, forestry, and aquaculture. Generally associated with increased use of external inputs, intensification is now defined

Table 4.I Comparison of farming systems and relative importance of different poverty reduction strategies

\begin{tabular}{|c|c|c|c|c|c|}
\hline Category & $\begin{array}{l}\text { Wetland } \\
\text { rice based }\end{array}$ & $\begin{array}{l}\text { Rainfed } \\
\text { humid }\end{array}$ & $\begin{array}{l}\text { Rainfed } \\
\text { highland }\end{array}$ & $\begin{array}{l}\text { Rainfed } \\
\text { dry/cold }\end{array}$ & $\begin{array}{r}\text { Dualistic } \\
\text { mixed } \\
\text { large/small } \\
\text { farms }\end{array}$ \\
\hline \multicolumn{6}{|l|}{ Characteristics } \\
\hline Agr. population (million) & 860 & 400 & 520 & 490 & 190 \\
\hline Total land (m ha) & 330 & 2,013 & 842 & 3,478 & 3,116 \\
\hline Irrigated (\%) & 58 & $\mathrm{II}$ & 20 & 18 & 9 \\
\hline Agr. pop./cultivated ha & 860 & 400 & 520 & 490 & 190 \\
\hline \multicolumn{6}{|c|}{ Alternative Strategies for Poverty Reduction ${ }^{a}$} \\
\hline Intensification & $*$ & $*$ & - & - & $* * *$ \\
\hline Diversification & $* * *$ & $* * *$ & - & ** & $* *$ \\
\hline Increased farm size & - & - & - & - & $*$ \\
\hline Increased off-farm income & $* *$ & $* *$ & $* * *$ & $*$ & - \\
\hline Exit from agriculture & - & - & $* *$ & $* * *$ & - \\
\hline
\end{tabular}

a. Assessments of relative importance based on expert judgment:

***** Highest priority.

* Second highest priority.

* Third highest priority.

Source: Dixon et al. 200 I. 
as the more efficient use of production inputs. Increased productivity comes from the use of improved varieties and breeds, more efficient use of labor, and better farm management (Dixon et al. 2001). Diversification, which represents a change in the farm enterprise pattern to increase profitability or reduce risk, is one option for sustainable intensification.

Although intensification of production systems is an important goal, these systems need to be sustainable to provide for current needs without compromising the ability of future generations to meet their needs. Sustainable agricultural can be defined as the management and conservation of the natural resource base, and the orientation of technological and institutional change to ensure the attainment and continued satisfaction of buman needs for present and future generations. Such sustainable development in the agriculture, forestry, and fisheries sectors conserves land, water, plant, and animal genetic resources and is environmentally nondegrading, technically appropriate, economically viable, equitable, and socially acceptable (FAO 1995).

A recent study investigating alternative household strategies for farming systems in developing countries reinforced the need for greater development attention to diversification and intensification (see box 4.1) (Dixon et al. 2001). For five categories of farming systems that cover approximately 98 percent of cultivated lands, the characteristics and relative importance of alternative poverty reduction strategies are presented in table 4.1. Intensification and diversification are important in all cases. However in the relatively constrained circumstances of rainfed highlands and rainfed dry/cold climates, off-farm employment and exit from agriculture are more important (though not always easily achievable).

Sustainable agriculture is not a clearly defined production model, but rather a set of complementary approaches that seeks to minimize negative environmental impacts from agriculture, by increasing efficiency of input use and

\section{Box 4.2 Production practices relating to sustainable}

\section{intensification}

Integrated pest management (IPM) is an ecosystem-based strategy that seeks to control pests or their damage through a combination of techniques (biological control, pest monitoring against economic thresholds, habitat manipulation, modification of cultural practices, use of resistant varieties), using less toxic chemical pesticides only after pest monitoring indicates their need.

Conservation farming (CF) encompasses four broad, intertwined management practices: minimal soil disturbance (no plowing and harrowing), maintenance of a permanent vegetative soil cover, direct sowing, and sound crop rotation.

Low external input and sustainable agriculture (LEISA) uses farmers' knowledge and a range of management practices (agroforestry, IPM, intercropping, crop-livestock integration, microclimate management) to minimize the need for purchased inputs.

Organic agriculture employs agronomic, biological and mechanical methods to control pests and maintain soil fertility with virtual elimination of synthetic chemicals for crop and livestock production.

Precision agriculture maximizes productivity of inputs, often using a global positioning system (GPS), to match input application and agronomic practices with soil attributes, seasonal conditions, and crop requirements as they vary across a field or between small plots.

Diversification is an adjustment of the farm enterprise pattern in order to increase farm income or reduce income variability by reducing risk, by exploiting new market opportunities and existing market niches, diversifying not only production, but also on-farm processing and other farm-based, income-generating activity (Dixon et al 200I).

Source: Authors.

by making greater use of biological and ecological factors in production processes (FAO 2003). A range of new technologies, management strategies, and analytical tools relevant to sustainable agricultural intensification has emerged in recent years (see box 4.2).

The heterogeneity in developing countries of productive resources, infrastructure, inputs, 
Box 4.3 Pakistan: effects of resource degradation on agricultural productivity

The Pakistan Punjab illustrates the potential problems arising from agricultural intensification and resource degradation.

Average growth in total factor productivity since the green revolution has been moderate at 1.26 percent, but with wide regional variation. Negative growth observed in the wheat-rice system relates in large part to continuous and widespread resource degradation measured by specific indicators of soil and water quality. This resource degradation has offset much of the gain from investments in technology, infrastructure, and education. Policy distortions, especially water pricing, and lack of research and extension on more sustainable cropping systems, contributed to this resource degradation.

Source: Ali and Byerlee 200 I.

skilled labor and access to new technologies means that development initiatives have be targeted to locally specific problems. For instance, in many African countries intensification will likely involve increasing the use of underutilized resources and external inputs (especially fertilizer), whereas in some Asian countries that have fully capitalized on green revolution technologies, substituting better knowledge to reduce external input use will be key to sustainable development (see box 4.3).

Environmental and social sustainability of productive resources depend in part on economic profitability that must provide for reinvestment in the maintenance of these resources (including the natural environment) and on a satisfactory standard of living for owners and employees involved in the production process. In turn, economic sustainability is dependent on a productive workforce and productive natural resources.

Sustainable agricultural intensification investments are particularly relevant to poor people in developing countries, where poverty, agricultural productivity, and resource degradation are closely interrelated, and negatively affected by increasing population pressures on the natural resource base. Poverty often results in overcropping, which contributes to a loss of biodiversity, soil degradation, and reduced water availability and quality, and these further reduce future agricultural productivity.

\section{PAST INVESTMENT ACTIVITY}

Commodity-focused investments in the 1970s and 1980s sought to expand and intensify production systems, such as basic food crops and traditional cash crops that have broad impacts on poor people and/or national economies. These investments generally supported monocropping and expansion of a single dominant technology or production system, and often focused on more productive regions of a country. Since the 1980s, World Bank financing for production of specific agricultural commodities has declined steadily, in line with the decrease in total Bank financing for agriculture, and consistent with the growing recognition that the public sector is not well suited to picking commodities or production activities that were likely to be economically successful.

Only 26 of the Project Appraisal Documents (PADs) for current projects specifically mentioned sustainable agriculture practices. This may reflect a significant and worrisome weakening of the technical analysis and input into project preparation and appraisal. As sustainable agricultural intensification is a key strategy for achieving goals of rural poverty reduction and environmental conservation, there is an urgent need to increase support to this area. There is also a related need to increase technical expertise, to ensure sound planning for investments in the intensification and sustainability of production systems.

New investments for intensification of agricultural production systems since the mid 1990s have generally been based on a better understanding of the underlying social, economic, and environmental elements of sustainability, and a general commitment to the principles underlying sustainable agriculture and development. These investments have focused mainly on high-value commodities, minimum tillage, and integrated pest management (IPM). 


\section{KEY ISSUES FOR INVESTMENT}

Future investments are likely to support more diverse products and production systems and to include less favorable production regions. Investments will need to apply modern science and new marketing systems to help both women and men farmers move into more productive and sustainable production systems. Investments in sustainable agricultural intensification must be economically, environmentally, and socially sound, efficient, and based on sustainable institutions. Common characteristics for these investments are described as follows:

- Based on holistic systems approaches. Farming systems are defined by economic, social, and environmental conditions within which they operate. Interventions must be based on an understanding of the interrelationships between these factors, and will therefore frequently require a holistic, multidisciplinary approach. For example, introduction of a new production system or an innovation in an established system will often require attention to the policy environment, agro-ecology, market systems, social system (including the gender and social group-based division of labor and access to resources), and the farm/house- hold economy. In addition, marketing supply chains and a wide range of stakeholders are part of the holistic approach required for sustainable agricultural systems (see figure 4.1).

- Sensitive to social change. The transition from one farming system to another is often as much an issues of behavioral change as of economic change. Production systems are rooted in cultures and traditions and major changes may require two or more generations of farmers to make the transition, such as from subsistence farming to commercial farming; from nomadic pastoralism to settled agriculture; and from traditional to nontraditional crops. Since social resistance to change may be strong, a sound social analysis should be in the plan for new investments in agricultural intensification. Extension services must help farmers address and adapt to social change, but these services are frequently very weak in their ability to deal with social issues.

- Targeted to specific production environments. There are 72 major categories of farming systemsæeach with numerous variationsæefound in the various agro-

FIGURE 4.I STAKEHOLDERS INFLUENCING AGRICULTURAL PRODUCTION AND SUPPLY CHAINS
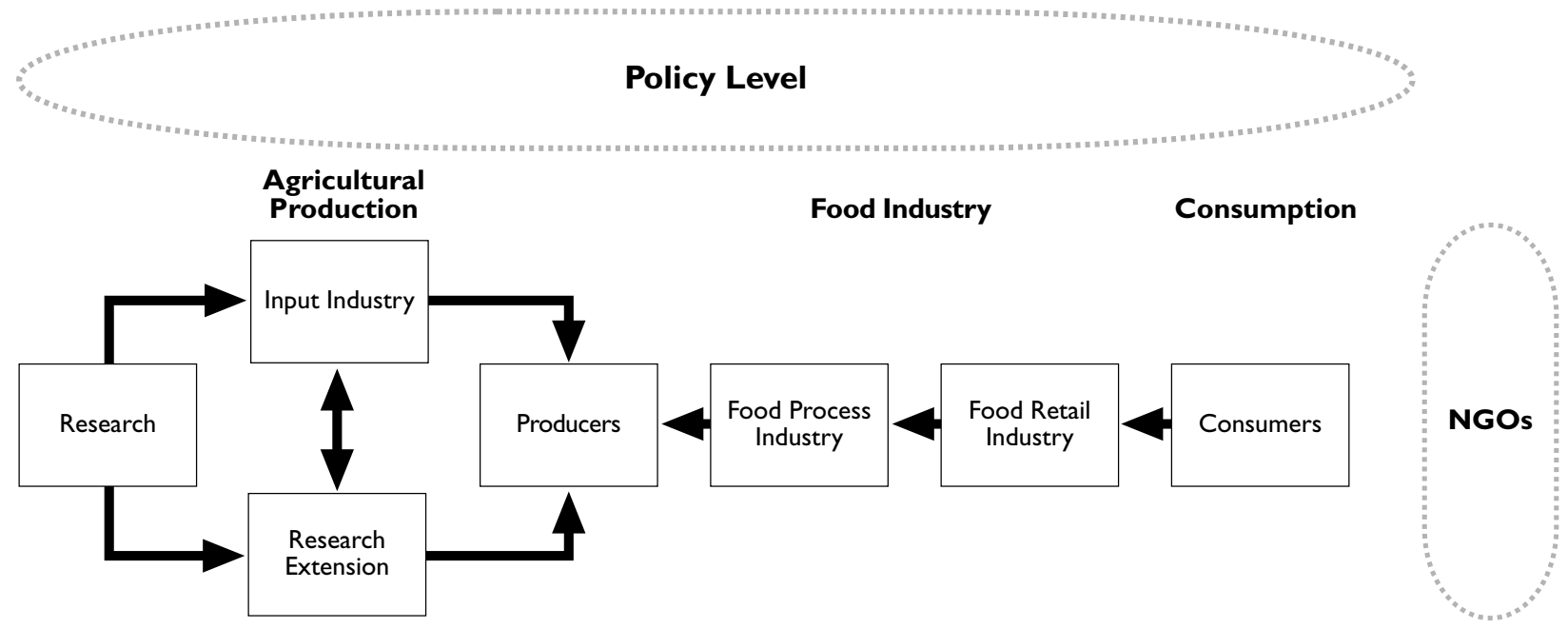

Note:The arrows represent the direction of major influences in the supply chain, though influence can flow both ways. Source: Sorby, Fleischer, and Pehu 2003. 
ecological regions of the developing world (Dixon et al. 2001). Investments in sustainable intensification must be designed within the context of established agricultural systems and the level of technology, resource availability, and market opportunities in the area. In areas for example where high input use already threatens environmental resources, the challenge will be to use less purchased inputs more efficiently. In other areas, as in most of Africa, increased use of production inputs will be necessary to provide sustainable livelihood options to growing populations.

- Supported by a sound policy framework. As the private sector is largely involved in agricultural production and marketing systems, governments have a key role in establishing a facilitating policy and regulatory environment for sustainable agriculture. To maximize agriculture's efficiency and sustainability, public policy should seek to internalize all costs and benefits in the prices of production inputs, such as improving pricing mechanisms for irrigation water, facilitating land market development, and eliminating distorting taxes and subsidies on chemical inputs, including fertilizers. Government investment programs must also provide for critical infrastructure, such as roads, and other public goods, such as regulatory frameworks, administration of property rights, research, and information services, especially for small farmers.

- Built on knowledge-intensive innovations. Sustainable intensification must build on a strong understanding of the system and its components. Research and extension (R\&E) will need to provide the technical and management recommendations suited to specific farms and fields rather than broad general areas. "Precision farming" systems will help apply the knowledge to field-level production. Investments in biotechnology, information and communications technologies (ICTs), and processing, and marketing technologies are also needed.
- Focused on poor and marginal farmers. If countries are to achieve social objectives and improve political stability, investment in sustainable agricultural production should be directed at poor people. But, this does not mean that all can find sustainable livelihoods within agriculture and some marginal farmers with little potential to improve incomes in agriculture must seek off-farm employment. Practitioners must consider wider social impacts of investments, and the need for alternative employment.

- Equitably shared by all gender and minority groups. Agricultural production system innovations are socially sustainable only when all members of society share in the benefits. Since, on a global basis, nearly one-half of all farmers are women, and since in most rural areas women carry out many specialized production activities (planting, weeding, vegetable gardening, managing small animals, postharvest handling), investments must ensure their participation in programs and avoid negative impacts. Men may displace women farmers, as has occurred in some parts of Africa, when export horticultural market opportunities have encouraged men to take over women's traditional plots of land. The same is true for many minority ethnic and cultural groups, who have more limited access to education, loans, property rights, and technical information. Social analysis is needed to guide project design and investment, draw on traditional knowledge, and identify and mitigate negative environmental impacts on different groups. Gender analysis is a particularly important tool for predicting gender-specific impacts of agricultural intensification investments, and this facilitates the mitigation of adverse impacts, such as increases in women's workload or reduced access to land.

- Participatory processes. All relevant stakeholders should be included in the design and implementation of sustainable intensifi- 
cation activities as this will empower farmers to plan and execute these activities, and to obtain information and develop options needed in the decision-making process. With these skills, farmers have a better ability to negotiate their interests with agribusinesses and governments. Strengthening representative rural producer organizations (RPOs) and other advocacy groups for the agricultural sector can facilitate this empowerment.

- Environmentally sound. Sustainable agricultural production systems must be environmentally soundæneither depleting the natural resource base on which they depend nor contributing significantly to the depletion of downstream resources. Agricultural intensification investments should seek to reduce soil erosion and land degradation, avoid loss of biodiversity, and improve efficiency of land and water resource use. In general, more efficient use of existing resources avoids pressures on more marginal production areas, thus preventing more widespread environmental degradation.

- Nonpolluting. As agricultural production systems use inputs more intensively, avoiding pollution of environmental resources (water, land, air) and food products through minimizing downstream pollution from agrochemicals, livestock manures, and soil erosion is critical to the sustainability of downstream production systems. Government regulation relating to pollution, both mitigation measures and charges, is relevant to environmental assessments of new production systems.

- Market and private sector based. Lack of input and output markets required for production system intensification affects particularly small farmers. Investment is needed to develop these markets and infrastructure as they will expand producers' production options and facilitate production changes to satisfy consumer de- mand for quality, safety of products, and information on method of production. In these circumstances, an effective response requires that agribusinesses, government and commodity organizations develop standards, grades and certification of processes. The latter may relate to farm practices, including environmental and social conduct (that is, encouraging environmentally sustainable or "good" farming practices). Farmer organizations have a central role in scaling up production to develop new markets and meet market demands.

- Low risk. Agricultural production nearly always involves substantial risk due to weather, pests and diseases, and market prices. Farmers, particularly resource-poor farmers, are risk adverse, and may maintain traditional production systems and practices even when market, environmental, and technological changes make these no longer sustainable. Sustainable intensification innovations are most acceptable to farmers when these involve minimal risk or reduce risks. Where this is not the case, investments may be needed to help deal with risk by providing financial, information, and risk management services, as well as improved infrastructure. In addition, financial incentives such as matching grants may be needed to encourage resource-poor farmers to try out more sustainable methods of production.

- Trade-offs. Options for intensification will not necessarily involve win-win scenarios. In practice there are trade-offs between productivity (and income), environmental sustainability, and various social objectives. Common trade-offs include efficiency/ equity, specialization/flexibility, profits/ environmental benefits, and long-term/ short-term paybacks. These trade-offs present difficult choices for policymakers and sound cost/benefit analysis accounting for economic variables, and their social and environmental implications, must be em- 
ployed. This will involve building the capacity of both public and private sector decision makers to make effective decisions within complex decision environments. It will also require that compensatory mechanisms are used to mitigate adverse effects on those groups that are negatively affected by initiatives that provide positive overall net benefits to the target population.

\section{FUTURE DIRECTIONS FOR LENDING}

Public investments to intensify sustainable production systems are generally best focused on facilitating the capacity of farmers, government, and the private sector to make decisions about the appropriate technological and resource allocation and on providing the necessary social/ organizational and physical infrastructure. It is critical that agricultural production systems be sufficiently flexible to adapt to changing environmental and economic conditions.

New technologies will be developed and variations on established production systems are likely to continue. At present, improved production practices that may warrant public sector support include:

- Varietal improvement will remain crucial as it becomes increasingly difficult to "adjust the environment to the plant." Plant varieties adapted to specific production environments and sustainable agricultural practices, and to pest and disease resistance will become increasingly important. Livestock improvement will increase productivity and make more efficient use of scarce land and water resources. Biotechnology's potential as a tool for sustainable production systems should be evaluated and supported on a case-by-case basis.

- Conservation farming practices can reduce unnecessary input use. Minimum tillage or no-till crop production reduces labor and equipment costs, enhances soil fertility, reduces erosion, and improves water infiltration, thereby reducing unit costs and conserving land resources. Improved crop residue management, including mulching, is often a necessary component of these systems. No-till systems of conservation farming have proven a major success in Latin America, and are being used in South Asia and Africa. ${ }^{2}$

- Organic farming eliminates use of chemical inputs and can be sustainable as long as practices maintain productivity at a reasonable level, consistent with price incentives provided by growing market opportunities for organic produce. Organic farming depends mainly on the development of niche markets with reliable standards and certification systems for production. ${ }^{3}$

- IPM systems have been developed for many crops to control pests, weeds, and diseases, while reducing potential environmental damage from excessive use of chemicals. Scaling up IPM technologies is a challenge, as these management systems rely on farmers understanding complex pest ecologies and crop-pest relationships. Thus, IPM systems require continuous research and technical support and intensive farmer education and training. ${ }^{4}$

- Precision agriculture improves productivity by better matching management practices to localized crop and soil conditions. Relatively sophisticated technologies are used to vary input applications and production practices, according to seasonal conditions, soil and land characteristics, and production potential. However, with help from extension and other services, resource poor farmers can also apply such precision agriculture principles for differential input application and management on dispersed small plots. Appropriate technologies

2. See the AIN, "Conservation Tillage"

3. See the AIN, "Organic Agricultural Production Systems"

4. See the AIN, "Integrated Pest Management" 
suitable for use by small farmers include simple color charts to guide decisions on fertilizer application, and laser leveling of fields for irrigation.

Public investment can also support transition to more profitable and sustainable farming systems. Some of the system adaptations that are options for sustainable intensification of production include:

- Integrated crop-livestock production can enhance environmental sustainability by feeding crop residues to animals, thus improving nutrient cycling. This croplivestock approach is likely to become increasingly profitable given the large, worldwide increase in demand for meat, milk, and animal fiber. The suitability of many livestock enterprises to small farm production systems holds considerable potential for poverty reduction.

- Agricultural diversification which must be pursued where existing farming systems are not environmentally sustainable or economically viable. Diversification into highvalue, nontraditional crops and livestock systems, such as horticulture are attractive because of the growing market demand for these products, high labor intensity and high returns to labor and management. In contrast to other low-input strategies for sustainable intensification, diversification to high-value products frequently requires use of relatively high levels of inputs, which must be monitored and managed carefully. ${ }^{5}$

- Aquaculture has potential for sustainable growth in many countries, as declines in global capture fisheries (that is, non-farmed fishing) has put upward pressure on retail prices for fish. Investments must take into account the potential environmental impacts due to habitat loss, land use change, and introduction of new species. Many intensive aquaculture systems are highly profitable and generate substantial employment and foreign exchange, but require safeguards to ensure that poor people benefit equitably. In some areas, family fish ponds can provide important family nutrition benefits. ${ }^{6}$

- Tree crops, including fruit, beverage, timber, and specialty crops, offer opportunities for environmentally sound production systems as these maintain vegetation cover, and can reduce soil erosion. Tree crops, especially multiple species plantations, help maintain a relatively high level of biodiversity. They are important to export earnings in many countries and, while often suited to largescale plantations, are also important to smallholders with mixed cropping systems.

Sustainable intensification will frequently require activities that provide an enabling environment and support services for the market-led changes, or component technologies, including management practices. Much investment will come from private sector-based market supply chains, including input supply and output marketing and processing enterprises and farmers. Public investment will need to focus on a number of key areas.

New KNOWLedge AND INFORMATION SERVICES. A key investment area is in technology associated with management innovations to improve overall productivity and sustainability of agricultural systems. Much research will focus on development of improved management systems, with emphasis on understanding agricultural ecology, farm management and social systems. Biotechnology offers opportunities to diversify and intensify agricultural production systems-tissue culture for production of virusfree planting stock (for example, bananas) and transgenic crops with pest resistance or other beneficial characteristics (see box 4.4).

Agricultural extension, education and training investment is needed at all levelsæfarmers, technicians, and university graduatesæ- to

5. See the AIN," Market-Driven Diversification"

6. See the AIN, "Aquaculture Production Systems" 
Box 4.4 South Africa: Bt cotton and sustainable development of the Makhathini Flat

South Africa has been a leader in Africa in research, production, and commercialization of biotechnology products. In the Makhathini Flat, an arid region, smallholders grew cotton as a subsistence crop, but since growing Bacillus thuringiensis (Bt) cotton (genetically modified cotton producing a protein that acts as insect control), they have seen the following benefits:

- Environmental/agronomic benefits: more than 50 percent reduction in pesticide spraying; easier crop management; reduced risk of bollworm attacks.

- Economic benefits: 20 percent to 60 percent yield increases; higher gross margins (on average US\$50 per hectare); reduction in labor requirement.

- Social/health benefits: school enrolment improvement; fewer pesticide poisonings; general community livelihood improvement; less drudgery in weeding for women.

Box 4.5 Policy issues affecting adoption of sustainable agriculture practices

Price, trade, and tax policiesæinput subsidies encourage excessive use; minimum support prices for cereals discourage diversification; electricity or fuel subsidies encourage groundwater depletion; subsidized milk/dairy imports discourage local production; and fuel or machinery subsidies discourage conservation tillage.

- Investments: analytical work, advocacy, stakeholder inclusion, policy formulation.

Insecure property rightsæno incentive for long term investments.

- Investments: land titling, group ownership, conflict resolution, gender-based division of labor and access to resources, intellectual property rights (IPRs) required to promote private sector research and development.

Externalitiesæwater and air pollution, siltation, salinization, climate change.

- Investments: advocacy, information campaigns, and regulations.

Financial marketsæenvironmental conservation investments commonly have long gestation periods and high initial investment costs; and traditional banking services are often inaccessible and compounded by insecure land tenure.

- Investments: new financial services mechanisms for agriculture.

Source: Authors. introduce principles of sustainable intensification and to develop human resources in this field. Many sustainable intensification investments have significant information requirements, such as weather forecasts, market information, natural resource conditions, and pest incidence, for which investments in rural information and communications systems are needed.

Public POLICY AND REgUlatory SYSTEMS. In many cases, government policies limit agricultural intensification and diversification, by distorting production decisions and by encouraging monocropping through input and output subsidies (see box 4.5). Pricing policies on water, land resources, and other natural resource inputs to agricultural production systems should encourage efficient allocation and use, an issue especially important to irrigation water management. Public policies should encourage investment in productive infrastructure, such as small-scale irrigation and erosion control. However, these policies must be complemented by regulatory systems and incentives that minimize pollution from agricultural production and processing activities. Government monitoring of changes in environmental conditions is an important input to guide policy formulation on sustainability.

Market AND PRIVATE SECTOR DEVElopment. While investments in the policy and regulatory environment and in public goods knowledge and information services benefit the private sector, additional public investments may be needed to facilitate private investment. Governments must provide key infrastructure for rural transportation and communications, and may need to share the risks that private companies undertake with new sustainable intensification investments. Targeted and time-limited grants promoting specific investment initiatives, such as pilot production trials, marketing trials, training, and extension activities, are useful to test and introduce new production systems and innovations. Access to efficient financial services is key to enabling farmers to intensify production systems. RPOs provide a mechanism for collec- 
tive action for input procurement, testing new technologies and innovations, and establishing sustainable output markets.

\section{SCALING UP INVESTMENTS}

Investments in intensification of sustainable agricultural production systems require monitoring systems that evaluate economic, social, and environmental changes throughout and following the program's implementation. Key impact indicators are investment profitability, poverty, and environmental conditions. Useful outcome indicators include: area coverage, numbers of producers, value of production, equity in employment generation, and productivity changes of natural resources and other inputs.

A more clearly poverty-focused approach to lending, and better understanding of the principles of sustainable agriculture, are likely to result in increased lending either as project components or as a project, integrating various elements of sustainable intensification. Increased technical input for project design and supervision to support additional lending is critical in order to complement those skilled in process and policy issues. Attention to two World Bank safeguard policies is especially relevant to investments in intensification and diversification of agricultural production systems:

- Environmental assessment (Operational Policy (OP)/Bank Procedure (BP) 4.01)æan Environmental Assessment is required if a new agricultural production system has potentially adverse environmental risks or impacts.

- Pest management (OP 4.09)æany agricultural production investment involving procurement and use of pesticides, or that could expand the use of pesticides and unsustainable pest management practices, requires an Environmental Assessment, a Pest Management Plan, and a list of the pesticides authorized for procurement.

\section{SELECTED READINGS}

Asterisk (*) at the end of a reference indicates that it is available on the Web. See Appendix 1 for a full list of Websites.

Bruinsma, J., ed. 2003. World Agriculture: Towards 2015/2030: An FAO Perspective. Earthscan Publications Ltd.: London.*

de Haan, C., T. S. van Veen, B. Brandenburg, J. Gauthier, F. Le Gall, R. Mearns, M. Simeon. 2001. Livestock Development: Implications for Rural Poverty, the Environment, and Global Food Security. Directions in Development 23241. Washington, D.C.: World Bank.*

Rosegrant, M. W., X. Cai, and S. A. Cline. 2002. World Water and Food to 2025: Dealing with Scarcity. IFPRI: Washington, D.C.*

Scherr, S. J., and P. B. R. Hazell. 1994. "Sustainable Agricultural Development Strategies in Fragile Lands." EPTD Discussion Paper 1. IFPRI, Washington, D.C.*

U.K. Department for International Development, Overseas Development Institute, Netherlands Ministry of Foreign Affairs. Keysheets for Sustainable Livelihoods. http:/ /www.odi.org.uk/keysheets.

\section{REFERENCES CITED}

Ali, M., and D. Byerlee. 2001. "Productivity Growth and Sustainability in Post-Green Revolution Agriculture in the Indian and Pakistan Punjabs." World Bank Research Observer 16 (2): 199-218.

Bruinsma, J., ed. 2003. World Agriculture: Towards 2015/2030: An FAO Perspective. Earthscan Publications Ltd.: London.

Dixon, J. A., D. P. Gibbon, and A. Gulliver. 2001. Farming Systems and Poverty: Im- 
proving Farmers' Livelihoods in a Changing World. Rome: FAO; Washington, D.C.: Word Bank.

James, C. 2002. Global Review of Commercialized Transgenic Crops: 2001 Feature: Bt Cotton. ISAAA Briefs 26. Ithaca, N.Y.:

ISAAA.

Pétry, F. 1995. Sustainability Issues in Agricultural and Rural Development Policies.

Training Materials for Agricultural Planning. 2 vols. Rome: FAO.

Sorby, K., G. Fleischer, and E. Pehu. 2003. "Integrated Pest Management In Development: Review of Trends and Implementation Strategies." World Bank, Washington, D.C.

This Overview was prepared by Sam Kane, Eija Pehu, Wayne Frank (USAID), and Gary Alex, with inputs from the Sustainable Agriculture (SASKI) Thematic Team of the Bank. Peer review comments were provided by Peter Hobbs (Cornell University), Maria Fernandez, and Arja Vainio-Mattila (University of Western Ontario). 
economically viable and environmentally sustainable, diversified production systems.

\section{MARKET-DRIVEN} DIVERSIFICATION

In many cases diversification can lead to improved agricultural productivity and income, through integrated resource management and responding to changing markets. Important issues for diversifying into market-oriented production systems include: developing markets and market access, managing risks, targeting small farmers, and promoting an enabling policy environment. Donors and governments will need to provide the training, infrastructure, and analytical support necessary to improve the ability of farmers to make the transition to
Diversification at the farm level is the adoption of multiple production activities that are complementary in economic and/or ecological dimensions - this complementarity contributes to the overall sustainability of the farming system. The diversification process generally involves introducing new farm enterprise activities (for example, crops, livestock, processing) and reflects a reallocation of production resources and inputs, as well as a change in production methods and the outputs produced. This note discusses the framework that will encourage market-driven diversification conducive to sustainable intensification, through improved crop rotations,

\section{FIGURE 4.2 INDIA: PER CAPITA CONSUMPTION INCREASE BY FOOD GROUP, 1977-99}

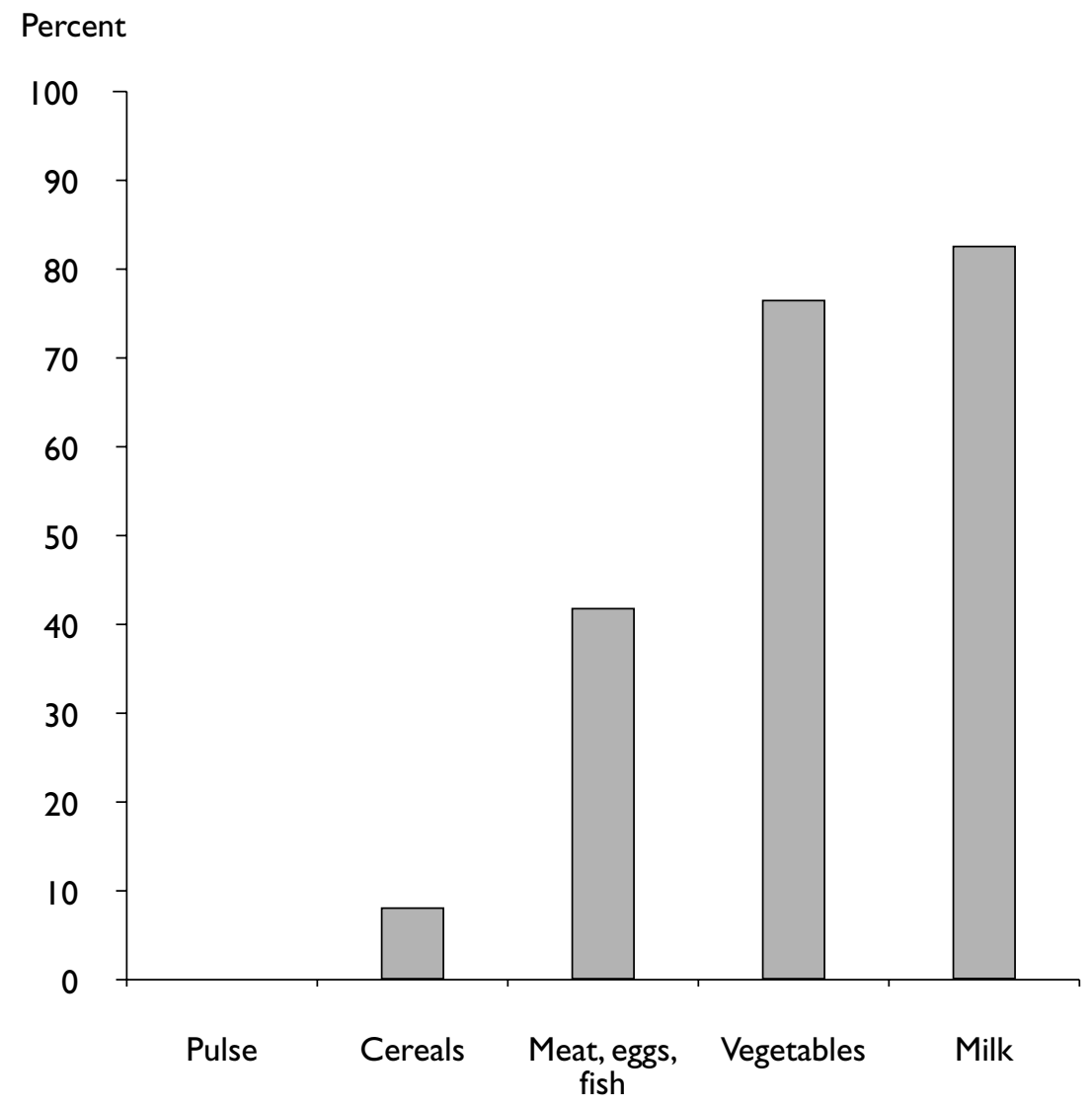


complementarities among different farm enterprises (livestock and crop), and improved risk management.

\section{NEED TO ADJUST TO CHANGING MARKET FORCES}

Increasing international migration, global media and marketing systems, rising average incomes, and urbanization are rapidly changing the structure of consumer demand throughout the world. This is true for markets in both industrial and developing countries, and for food and nonfood products (see figure 4.2). These changes give rise to new market opportunities (both domestic and export) at a time when prices for traditional commodities-such as rice, cotton, coffee, and tea-are declining.

On the supply side, technological advances have expanded the range of production possibilities at the farm level. Improved agricultural machinery, biotechnology, new herbicides, and IPM have facilitated better use of the sources of competitive advantage unique to developing countries (for example, unique microclimates and soil types, low labor costs, and counterseason production). New technologies have also increased the feasibility of integrating different systems within any one "mixed" farming system (multipurpose machinery for integrated crop rotations). Supply-side changes that expand the range of feasible options, and demand-side factors that alter the relative profitability of those options, are requiring that farmers make a transition from traditional enterprises (often monoculture) to new and unfamiliar ones. The new enterprises can be

\section{Box 4.6 Benefits of diversification to livestock production}

- Provides a source of organic fertilizer.

- Buffers food supply, reducing climatic and price risks of crop production.

- Provides meat, milk, and fiber for household use or sale.

- Provides transport and traction, spreading labor demand and offering alternative sources of income.

- Uses crop residues as livestock feed.

Source: Authors. more environmentally sustainable while also responding to market signals profitably.

\section{BENEFITS}

Farm-level diversification involving mixed production systems can exploit potential synergies and complementarities among different operations for more productive and more sustainable use of the resources upon which farm systems depend. Replacing monoculture systems with mixed systems can improve biodiversity, and can reduce production risks associated with droughts and pest infestations. The increased variety of outputs produced reduces marketing risks associated with unexpected declines in the price of any one product. Diversification may also allow labor and machinery requirements to be more evenly distributed throughout the year, seasonal cash flows to be better managed, product ranges to be broadened, and marketing risks to be reduced (see box 4.6).

The transition to more profitable production systems increases demand for farm and nonfarm labor (largely due to the more laborintensive nature of high-value crops), and is associated with increasing incomes for wage employees. Diversification can have large multiplier effects, creating off-farm employment opportunities in downstream and upstream economic sectors.

\section{POLICY AND IMPLEMENTATION ISSUES}

Diversification must be a market-oriented process, driven by consumer demand and initiated by private sector agents. However, public sector participation will remain critical in certain areas such as the regulatory and policy environment and the provision of pure or partial public goods (for example, infrastructure and research).

A STABLE AND SUPPORTIVE POLICY ENVIRONMENT. Perhaps most important is an overall agricultural policy that does not skew production incentives, and that promotes efficient decision- 
making based on market demand and resource constraints. In many countries, agricultural policies distort production decisions toward food grains undermining competitiveness and the long-term sustainable management of natural resources. Support policies aimed at encouraging adjustment to market-led production should be transitory and crop neutral.

LibERALIZATION OF RULES AND REGULATIONS. Rules and regulations governing market activity, curbing abuse of market power (particularly in network industries such as transport, energy, and communication), and enforcing contract law help to strengthen markets and ensure that the poor benefit equitably. Policies that protect resource use rights (land and water in particular) and encourage investments on a long-term basis are essential for successful diversification initiatives (see box 4.7). Insecure land title dampens the incentives for farmers to make the initial investments needed to transform their production systems. Secure land and water ownership rights improve farmers' ability to provide collateral to lenders, thereby facilitating access to financial resources required for initial investments.

\section{Markets AND INFRASTRUCTURe. Transition to new} production enterprises must be based on market demand and sustained competitiveness of producers (typically from either low-cost production or high-value and differentiated products). This depends on competitive nonfarm private enterprise at each stage of the supply chain, and requires strengthening of processing and logistical systems, input supply systems, and financial services.

RISK ENVIRONMENT. Natural resource suitability, crop yields, market prices, and adequacy of infrastructure provide more uncertainty for new crops than for traditional products. Irrigation, integrated capital markets (to reduce price variability through risk pooling), stable government policy, and reliable information and communication systems all help to reduce risk. Technical services are needed to minimize risks of pests and diseases devastating new crop or livestock enterprises.

\section{Box 4.7 Turkey: policy reform}

Turkey recently reformed its agricultural policies to promote diversification. In phasing out input and output subsidies, a system of decoupled subsidies was used to partially cushion the blow to farmers. Because prior subsidies had led to a surplus of hazelnut and tobacco production, a project provided financial and advisory support to farmers to switch production to alternative crops. Support includes incentives for uprooting existing tree crops, and technical and business advice on alternative production systems. Strengthening of national land administration systems and cooperatives are further elements of reform. Improved information systems will provide an additional foundation for comparing the cost, speed, and transparency of alternative production methods, and facilitate monitoring of new production systems introduced in each region.

Source: World Bank Internal Documents.

Organized FARMERS. RPOs are useful in facilitating innovation and diversification into new farm enterprises. Collective action enables small farmers to source inputs in bulk and at competitive prices, explore market opportunities and linkages, obtain market and technical support, pool output to improve bargaining power, and form partnerships with commercial enterprises, governmental agencies, R\&E entities, and other community groups.

GENDER EQUITY. Diversification can offer new employment opportunities to both women and men, but safeguards are needed to ensure equity of opportunity. Women are often disadvantaged by traditions that discriminate with regard to participating in market networks, accessing financing and inputs, and entering into contracts. Furthermore, diversification can result in women being displaced from traditional production and marketing activities. Processing plants frequently employ a high percentage of women in their workforce, but labor standards are often low and potential for exploitation of women is high. Activities involving diversification should allow for the empowerment and participation of women and minority groups. 
Box 4.8 Key considerations for diversification

- Government policy and stability of policies - exchange rate trends, volatility, and risks; trade tariffs, quotas, and taxes.

- Economic and environmental compatibility of alternative farming activities and potential conflicts among different enterprises.

- Infrastructure and distribution channels and participants in the supply chain.

- Market demand and sustainability.

- Asset ownership patterns and security of access to land, water, loans.

- Food security (household and national).

- Storage requirements, critical product volumes, food safety requirements.

- Existing research and extension systems.

- Potential for value-added processing.

Source: Authors.

\section{LESSONS LEARNED}

Assessing alternatives. The process of assessing alternative diversification opportunities requires intensive analysis and research and farmers typically do not have the resources required for in-depth feasibility analyses (see box 4.8). The public sector can facilitate this process, but must maintain a supportive rather than a lead role, encouraging farmer and private sector initiative as opposed to "picking winners."

INFORMATION AND COMMUNICATION. Cost-effective, dependable communication systems are essential to convey market information to processors and producers, so that the products produced are competitive in markets and satisfy consumer demands. APROFA, a governmental agency in Mali, uses agribusiness centers and reference centers to disseminate new technologies and products to producers. It has become increasingly important to invest in forward information systems that maintain product identity and traceability throughout the entire supply chain.

TARgeting Smallholders. Diversification opportunities are not always equal, and small-scale farmers are often relatively less able to access information and financial resources that will allow them to enter new markets (see box 4.9). Research and extension systems can be de- signed to respond to the needs of small and marginal farmers, providing technologies suited to small farms. Improved transportation and communication systems reduce isolation common to small farmers in less productive areas, and thereby reduce transaction costs for market participation.

Public InVestMents. Diversification must be based on private investment, but co-investment by the public sector is likely to be required to facilitate adjustment and the introduction of new production and marketing systems. Investments must be appropriately timed and sequenced, with adequate market analysis before productspecific investments are made. Initial investments should be as generic and flexible in nature as possible to reduce risk of market volatilities and production uncertainties for specific products. The public sector can finance or cofinance feasibility studies and investment strategies to promote private investment and can share start-up costs and risk by providing matching grants that are time limited and targeted. Public financing is also appropriate for public goods investments for removing infrastructure bottlenecks and ensuring adequacy of technical support systems.

SHARING LEARNING COSTS. Diversification usually involves technology development and learning that can best be provided through R\&E systems that enable costs of learning and experimentation to be pooled and shared equitably (see box 4.10). In most cases, production and marketing technologies will not be readily available in-country, but can be "imported" from other countries. This may involve sourcing the technology from either a private firm or a public research center. Local research capacity is useful - if not essential- to facilitate technology import and to address secondgeneration problems.

\section{RECOMMENDATIONS FOR PRACTITIONERS}

Diversification initiatives must be market led and based on sustainable comparative advantage. Public investments (see box 4.11) should: 
Many components of the Uttar Pradesh Diversified Agriculture Support Project were chosen because of their "self-targeting" character in reaching poor and disadvantaged groups. The seclusion of women required that they be provided access to homebased income-earning opportunities. Also, the extent of landlessness required that activities not be biased against those with little or no land. Households with small or marginal landholdings benefit from horticulture activities, since fruit trees can be planted along plot boundaries or in home gardens. Livestock activities, including small ruminants (sheep and goats), and cow and buffalo milk production, provide significant benefits to the poor, including those with little or no land (provided they also have access to commons, cut fodder, or crop residues).

Source:World Bank Internal Documents.

\section{Box 4.10 Vietnam: technical support for diversification}

In Vietnam, the Agricultural Diversification Project provided technical support for intensifying crop and livestock production, focusing on participatory research and extension, for example, piloting fruit tree plantings and nurseries. Inclusion of farmers in the research process ensured that technologies responded to farmer needs. The project promotes a mix of farm activities, such as investment in rubber, livestock, and food crops, in a "smallholder technical package" that introduces sustainable management practices (such as terracing and contour farming on sloping and degraded lands).

Source:World Bank Internal Documents.

- Seek farmer collaboration through participatory evaluation of the suitability of alternative production systems and products.

- Sequence investments and activities such that they systematically build markets and capacity to supply them.

- Invest in flexible skills and technologies (rather than those that are highly product specific) and target products with multiple uses and markets.

- Establish appropriate means to manage risk through development of infrastructure that reduces uncertainty in production and marketing processes.

- Facilitate development of producer organizations to promote the interests of smallholders through collective action.

- Make production inputs and markets "user friendly" (for example, available in small packages and convenient locations) so that farmers can test the new production system without committing to a complete transition.

\section{Box 4.I I Potential investments}

- Analytical support for market and technical feasibility.

- Development of output and input markets.

- Policy support and guidance for the sequencing of investment activities.

- Financial markets and risk management tools to encourage private investment.

- Infrastructure to improve market access - roads, ports, cold chains, telecommunications.

- Public good R\&E.

- Regulatory and certification systems to satisfy market and trade standards.

- Market and technical information systems.

Source: Authors.

\section{SELECTED READINGS}

Asterisk (*) at the end of a reference indicates that it is available on the Web. See Appendix 1 for a full list of Websites.

Delgado, C. 1995. "Agricultural Diversification and Export Promotion in Sub-Saharan

Africa." Food Policy 20 (3): 225-243.

World Bank. 1990. "Agricultural Diversification: Policies and Issues from East Asian Experi- 
ence." Policy and Research Series 11. World Bank, Washington, D.C.*

\section{REFERENCES CITED}

Joshi, P. K., A. Gulati, P. S. Birthal, and L.

Tewari. 2002. "Agriculture Diversification in

South Asia: Patterns, Determinants, and

Policy Implications." MSSD Discussion

Paper 57. IFPRI, Washington, D.C.

This Note was prepared by Sam Kane, Kristina Sorby, and

Shawki Barghouti with inputs from the Sustainable Agricul-

ture (SASKI) Thematic Team of the World Bank. 


\section{AGRICULTURE INVESTMENT NOTE}

\section{SMALLHOLDER DAIRY PRODUCTION}

Smallholder dairy production is common in many parts of the developing world, providing an important source of nutrition and income to millions of households. Income from such production often accrues to women who use this to provide better nutrition and education for their children. Projections for future growth in demand for livestock products show good growth prospects for the dairy industry. Public support is often needed to put in place appropriate policies, establish marketing chains, and provide services for growth of smallholder dairying.

Globally, there are about 300 million rural and periurban poor whose livelihoods depend on the daily income and nutrition they receive from milk production. In India, about 40 million landless poor families get a major part of their income from milk. Since there are fewer economies of scale involved in dairy production than in some other livestock production systems, the strong concentration of production evident in the pig and poultry sector is not yet seen in the dairy sector. Markets in developing countries are secure, as demand for milk and milk products is expected to increase by more than 3 percent annually over the next 10 to 20 years (Delgado et al. 1999). Per capita milk consumption will then still be only one-fourth of the per capita consumption in the industrial countries.

\section{SMALLHOLDER DAIRY DEVELOPMENT}

Smallholder dairy production takes many forms and is often combined with cottage industry (small household) processing activities. Smallholder dairy production is mostly carried out by the family, with some very limited hired labor. Examples of smallholder dairy production are the mixed farms in Central America with 25 cattle; small mixed farms in the high- lands of Ethiopia with one or two cows; rice farmers in the Punjab of India with 10 buffaloes; and Sahelian pastoralists with herds of up to 100 animals.

Although future regional market developments are difficult to predict, it seems that developing countries have a good chance of benefiting from new market opportunities. Milk production growth in developed countries is constrained by land and water availability, and increasingly by strict environmental legislation and reforms in subsidies provided to the dairy industry. Because of the comparative advantage of temperate climates, production expansion is most likely to come from North America, the Southern Cone of South America, and areas such as the Ukraine, though there remain opportunities for growth in other areas, such as China, India and Eastern Africa (see box 4.12).

Box 4.12 India: Operation Flood-how a commodity project can reduce poverty

Operation Flood was supported by the Bank and other donors from the mid 1970s to the mid 1990s. It originally started as a marketing project but gradually developed into production and input services. It is based on a three-tier cooperative system that includes:

- Village-level dairy cooperative societies, which are farmer controlled, with an elected management committee, including at least one woman.

- Regional milk producers' unions that own the dairy plants and transport equipment for milk collection and processing.

- State federations for interstate sales and coordination. The National Dairy Development Board, a government apex organization, provided the technical support. Operation Flood now has 9 million members (60 percent are landless), with a daily milk throughput of about 30 million liters. It has made important contributions to poverty reduction, human health, and nutrition and is the most successful Bank operation in the livestock sector. Operational issues included interference by government, in particular in the federations, and its search for monopoly positions when support from outside sources was phased out.

Source: de Haan et al. 200 I. 


\section{BENEFITS}

Certain characteristics of smallholder dairy production systemsæintensive, year-round labor needs, the provision of regular income, and easy substitution of the product between home and marketæmake dairy production a good example of pro-poor approach to agriculture and rural development. The production characteristics of smallholder dairying, such as use of crop residues, fodder-crop rotation, and production of organic fertilizer, provide a strong synergy with other parts of the farming system. Milk's perishable nature and the limited marketing leverage of an individual small producer make it highly suitable for cooperative marketing, and hence an important tool for farmer empowerment. However, smallholder dairying carries risks. In many cases, a small herd constitutes a large part of the farmer's assets, and disease and death can wipe out these assets entirely, potentially leading to increased indebtedness and poverty.

\section{POLICY AND IMPLEMENTATION ISSUES}

SUBSIDIES AND DUMPING. With milk production mainly being a smallholder activity, and milk seen by many as a being a staple product, the dairy sector is the subject of political attention and inappropriate policies. Thus the sector has suffered from excessive price controls, and greatly distorting subsidies both in OECD countries and in developing countries. In developing countries, the dairy sector has been negatively affected by the dumping of surplus subsidized dairy products by the European Union (EU) and the United States. With global trade negotiations in the World Trade Organization (WTO) on the issue of agricultural subsidies, producer groups, local industry, donors and finance ministries need to discuss issues of domestic liberalization and appropriate adjustment that may be needed as a transition mechanism. Other policy issues encountered in Bank projects include cooperative monopolies (India), excessive interference of government in the sector, the introduction of unsustainable subsidies, for example for artificial insemination (AI) (India, Kenya, Morocco) and health services, and excessive food safety regulations.
MARKETS. Milk, being highly perishable, requires daily collection and market delivery. Many past investments have focused on developing western-style collection, processing, and distribution systems, with pasteurized products. However, there is growing evidence, for example from Nairobi (Staal 2002), that this approach might be counterproductive. Pasteurization and packing costs nearly double the price of milk to consumers, thus reducing farm gate prices and limiting access by the urban poor. Giving the formal sector the exclusive right to distribute milk and milk products also affects employment opportunities for many small intermediaries involved in the distribution system. In addition, marketing through a formal collection system introduces one of the few economies of scale in dairy production, as it is often accompanied by a requirement for onfarm cooling equipment, which is normally profitable only with a production level of 100 liters or more per day. Such requirements, in situations where milk is boiled before consumption, are unnecessary, as boiling obviates the need for pasteurization.

\section{LESSONS LEARNED}

Success in smallholder dairy production can be evaluated at three levels; farm, market, and institutional (see box 4.13). Dairy production normally requires a high quality of support services as dairy breeds are generally more costly and more vulnerable than other cattle to disease and health problems.

VETERINARY. Because smallholder dairy development is a rather risky endeavor, good, easily accessible veterinary services are essential. Experience in many countries, such as India and Kenya, shows that private veterinary services (also supplemented by public services for the "public goods" such as vaccination) are highly desirable, and can provide the flexible, dynamic services the smallholder dairy producer requires.

BREEDING. The choice of dairy breed has been subject to much debate. Past introductions of pure exotic breeds have almost universally 
failed (with the exception of restocking programs in areas such as the Balkans). Generally, a combination of selection in local breeds and cross-breeding with exotic genetics is more appropriate, leaving it to the skill of the individual smallholders to decide on the level of exotic germplasm they can manage. This approach has been quite successful in India, Northern Brazil, and Kenya.

Breeding systems are also subject to considerable debate. AI systems, often demanded by Bank clients, have high costs and logistic and maintenance requirements, because of the need for liquid nitrogen to store semen. Such facilities can be organized in areas with good communications and infrastructure, but many AI systems have proven unsustainable without continued subsidies. Terminating subsidies, as in Kenya, can then cause collapse of the system, which in the absence of alternatives, results in a considerable deterioration in the genetic base of the dairy herd. AI requires adequate producer skills, infrastructure, and communication facilities. Where AI is to be introduced, it should be privatized, and where appropriate conditions do not exist, bull camps or the use of fresh semen have given good results, as in Indian Watershed projects.

ExTENSION. Most general extension staff members have little experience with livestock and dairy farming. Key areas requiring additional extension training include fodder production and livestock feeding schemes, husbandry (in particular calf raising), and dairy hygiene. Health and breeding services can best be handled by specialized professional services. Extension staff must also help producers cope with social change, such as changing gender roles and issues of access and control over resources.

CREDIT. Capital requirements for smallholder dairy producers are high and may be especially constraining for women farmers. Credit schemes need to be long-term. If, for example, a pregnant three-year-old cow is the starting stock for the family dairy, credit terms should be for at least three years. Loans are ideally

\section{Box 4.13 Indicators of success}

A successful smallholder dairy sector is characterized by the following:

- At the farm level: calving rate of 80 percent or more, a production level (depending on conditions) of 600 to 3000 liters per lactation (that is, about 300 days), mostly fodder based, and economically attractive.

- At the marketing level: a viable formal collection system (private or cooperative), supplemented by small traders.

- At the institutional level: an influential national organization.

Source: Authors.

accompanied by an insurance system to mitigate animal loss risks. However, experience with livestock insurance has not been very good, because of the moral hazard problems involved.

The credit-in-kind system, whereby animals are provided on condition that some of the offspring are passed on to other members of the community, has been effective in many programs. If the program is adequately integrated in the local community, peer pressure ensures sustainability of the passing-on mechanism. A number of nongovernmental organizations (NGOs), such as Heifer Project International, Oxfam, and Farm Africa, are specialized in this area (see box 4.14).

FARMER ORGANIZATIONS. The perishable nature of dairy products gives individual farmers little

\section{Box 4.14 Indonesia: in-kind credit in Java}

The Provincial Development Program of Central Java Province introduced a new in-kind loan project in the 1980s to replace the existing small ruminant credit system. Target farmers were divided into groups of 10 with each farmer receiving two female goats or sheep. Each group leader received small ruminant management training and a good quality buck or ram. Each recipient had to repay four lambs or kids over a threeyear period. Post-program evaluation in 1988 found the program to be successful in introducing new technology, increasing farmer income, improving production performance, and improving dynamics within farmer groups. The system can work equally well for dairy cattle.

Source: de Hann et al. 200 I. 
leverage in marketing. However, the involvement of many smallholders in milk marketing makes dairy products suitable to cooperative processing and marketing systems. Most cooperatives also provide services such as health and breeding, although cross subsidies of these services through the price of the milk become an issue. Government interference can however be a constraint to building organizational capacity.

FeED supply. Feed supply is a major issue for smallholder dairy systems, as most systems operate under conditions of extreme land pressure (Kenya, India) or labor availability (West Africa with high labor needs at the end of a marked dry season). Feed conservation for dry season supplementation has been a major issue, as most technologies, such as silage, haymaking, and urea treatment are not suitable for smallholder or humid tropical environments. Fodder trees and mixed tree-legume protein banks can be a solution.

\section{RECOMMENDATIONS FOR PRACTITIONERS}

Key conditions for successful dairy development involve market access and availability of services to smallholders and require public policy and institutional development and targeted investment. Sound investments generally must (see box 4.15):

Potential investments:

- Conduct a detailed assessment on the extent and nature of market demand. Key questions to consider include: Do local consumers want pasteurized milk and can they afford it? Are there opportunities to export? What safety and quality standards must be met? All initiatives to promote smallholder dairying must be led by market demand.

- Promote private sector development of supply chain infrastructure required for efficient production and marketing. This includes transportation and communication systems, food testing and certification facilities, and cold chain infrastructure.
- Establish an appropriate balance between public and private involvement in the supply of services. In many instances public sector involvement is best restricted to limited-term cofinancing arrangements that encourage private sector investment. A direct government role is appropriate in areas such as auditing of certification systems and management of quarantine procedures and epidemic risks.

- Promote establishment of effective financial markets and risk management mechanisms. This is largely the role of the private sector, and private investment may be best initiated through limited-term cofinancing schemes.

- Provide technical assistance to both male and female farmers. Assistance is needed in areas such as breeding policy (what breeds are most suitable to the production and market environment?; where to source breeding stock?; is AI appropriate?), animal health (control of internal parasites, mastitis management), milk hygiene, and feeding policy (managing feed supply, conservation of surpluses, supplementary feeding).

\section{SELECTED READINGS}

Asterisk (*) at the end of a reference indicates that it is available on the Web. See Appendix 1 for a full list of Websites.

de Haan, C. 2000. "Livestock Breeding Technologies and Rural Development: Development Experiences." World Bank, Washington, D.C.*

de Haan, C., H. Steinfeld, and H. D. Blackburn. 1997. Livestock and the Environment: Finding a Balance. Brussels: European Commission Directorate-General for Development.*

de Haan, C., T. S. van Veen, B. Brandenburg, J. Gauthier, F. Le Gall, R. Mearns, M. Simeon. 2001. Livestock Development: Implications for 
Rural Poverty, the Environment, and Global Food Security. Directions in Development 23241. Washington, D.C.: World Bank.*

LEAD Initiative. Livestock, Environment and Development. http:// www.leadvirtualcentre.org.

Rangnekar, D., and W. Thorpe, eds. 2002. Smallholder Dairy Production and Marketing - Opportunities and Constraints. Proceedings of a South-South workshop held at National Dairy Development Board, Anand, India, March 13-16, 2001. Anand, India: National Dairy Development Board; Nairobi, Kenya: International Livestock Research Institute.*

World Bank. Sustainable Agriculture. http:// lnweb18.worldbank.org/ESSD/ardext.nsf/ 26ByDocName/SustainableAgriculture.

\section{REFERENCES CITED}

de Haan, C., T. S. van Veen, B. Brandenburg, J. Gauthier, F. Le Gall, R. Mearns, M. Simeon. 2001. Livestock Development: Implications for Rural Poverty, the Environment, and Global Food Security. Directions in Development 23241. Washington, D.C.: World Bank.

Delgado, C., M. Rosegrant, H. Steinfeld, S. Ehui, C. Courbois. 1999. Livestock to 2020: The Next Food Revolution. Washington, D.C.: IFPRI; Rome: FAO; Nairobi, Kenya: ILRI.

Staal, S. 2002. "The Competitiveness of Smallholder Dairy Production: Evidence from Sub-Saharan Africa, Asia and Latin America." In D. Rangnekar, and W. Thorpe, eds., Smallholder Dairy Production and Marketing - Opportunities and Constraints. Proceedings of a South-South workshop held at National Dairy Development Board, Anand, India, March 13-16, 2001. Anand, India: National Dairy Development Board; Nairobi, Kenya: International Livestock Research Institute.

\section{Box 4.15 Potential investments}

- Animal health and breeding services, with a focus on developing private systems. Costs would be about US $\$ 2,000-5,000$ for breeding services, and US $\$ 10,000$ 20,000 for veterinary practices.

- Extension services to provide specialized skills for dairy production.

- Market development and infrastructure. Cooling systems vary between US\$1000 and US $\$ 20,000$. Wood-fueled pasteurization plants at nominal costs can be effective up to about 500 liters per day; small pasteurization plants (2,000 liters per day) cost about US\$10,000; and larger processing plant costs vary according to individual design.

- Financial services (savings and credit) need to be included in the overall microfinance systems, eventually supported by special credit in-kind schemes.

- Producer organization support, mostly in the form of technical assistance.

Source: Authors.

This Note was prepared by Cees de Haan with inputs from the Sustainable Agriculture (SASKI) Thematic Team of the World Bank. 


\section{AGRICULTURE INVESTMENT NOTE}

\section{AQUACULTURE PRODUCTION SYSTEMS}

With possible future food shortages and declining yields of capture fisheries, the potential for aquaculture production in developing countries continues to rise. Worldwide production from aquaculture is growing rapidly, far outstripping the growth rate in the catch of wild fish from both freshwater and marine sources. Future public sector investments need to provide a policy environment and the technological base necessary to promote aquaculture investments by private farmers, while ensuring compliance with environmental regulations and encouraging sustainable production practices.

Aquaculture is the farming and husbandry of aquatic organisms such as fish, crustaceans, mollusks, seaweed, and the production of freshwater and marine pearls. It has grown at an annual average rate of 10 percent since the mid 1980s, reaching 33.3 million tons (or about 26 percent of global fish supply) in 1999. During the same period, capture fisheries averaged an annual growth rate of less than 2 percent, and its contribution to human nutrition actually declined by about 10 percent because of an increase in wild catch species of lower value (typically used to produce fishmeal for feed and fertilizer).

\section{CONTEXT FOR AQUACULTURE INVESTMENTS}

Aquaculture development is driven by an increased demand for products and a need to reduce dependency on overexploited inland and marine capture fisheries. In 1999 per capita annual consumption of fish products worldwide was about 21 kilograms. Capture fisheries are close to their limits, and the growing world population means that annual aquaculture production must increase by about 21 million tons to maintain the current level of per capita fish consumption. This is a challenging goal, but aquaculture production could conceivably rise to nearly 90 million tons if the 10 percent annual rate of increase between 1985 and 1999 can be maintained. Doubling of the 1999 production level (33 million metric tons) will require global expansion of aquaculture systems and an estimated overall capital investment of US\$20-30 billion (see box 4.16).

The development of reliable production technologies that often require only simple management skills has facilitated the recent rapid expansion of the industry. Options for aquaculture development can involve production at household, community, or industrial scale, employing ponds, net pens, net cages, flowthrough raceways, and water recirculation systems. Fish monoculture systems have also been developed for a wide range of species that are most often grown on processed feed diets in ponds or raceways, and in irrigation canals with flowing water.

\section{BENEFITS}

Aquaculture can be integrated with other farming systems. Inland fish culture is often carried out in farm ponds with direct links to animal husbandry and agriculture, where byproducts of each subcomponent are recycled as resources for the others (for example, fish waste that enters irrigation canals becomes a supplementary fertilizer for crops). Pond culture on farms of this kind often includes the culture of many fish species that feed on grasses, legumes, benthic invertebrates, detritus, zooplankton, and phytoplankton. Fish culture has been gaining application in rice fields where a second benefit is control of insect pests and reduced the need to apply pesticides.

Areas that are not suitable for agriculture and are not critical habitats for wildlife can often be effectively used for aquaculture pond development. Publicly-owned lands and waters suitable for conversion to aquaculture can be developed or leased to poor households that otherwise lack productive assets. Furthermore, aquaculture often produces direct management roles for women. In addition to generating 
income and employment opportunities at the local level, aquaculture can generate foreign exchange from exports and can improve food availability and quality for local consumers.

In China, filter-feeding bivalves (clams, oysters, scallops), seaweed, and bottom-dwelling sea cucumbers are often reared near fish cages as a means of capturing fish wastes and improving water quality. Although somewhat more complex to manage, these integrated marine aquaculture systems improved environmental impacts of aquaculture, and have an added advantage of reducing market risks to farmers from potential diseases or price fluctuations that affect any one product.

Aquaculture is increasingly used to produce fingerlings and seed materials for communitybased programs for stocking open water such as irrigation and hydropower reservoirs, lakes, and coastal areas. This also provides lessons on proper management of greater (nonfarm) aquatic environments.

\section{POLICY AND IMPLEMENTATION ISSUES}

Rapid growth of aquaculture has not been without problems, including disease pandemics such as those with global shrimp farming and carp culture in South Asia. Exceeding carrying capacity has in some cases led to levels of fish waste that caused toxic conditions that can kill aquaculture crops and degrade water quality. Proper planning and facility monitoring (including new tools for predictive modeling of water quality) have helped to manage most systems, although consistent disease control still has not been achieved for some species.

Public and private sector roles need to be defined. Although a high percentage of aquaculture production is generated through private sector investment and management, the public sector can play an important role in formulating a regulatory framework. Licensing private aquaculture enterprises helps ensure minimal adverse environmental and social effects and mitigation of any such impacts. Public sector services can provide support for research programs, exten-

\section{Box 4.16 Aquaculture goes global}

Most aquaculture development has occurred in Asia, particularly China, which produced about 57 percent of the world's aquaculture products (FAO 1997). However, production from the rest of the world nearly doubled between 1984 and 1995. Fish farmers in Latin America, the Caribbean, Europe, the Middle East, and Africa have a valuable base of knowledge and experience upon which to build. Technological advances, such as hatchery development, feed formulation, disease control, engineering, and production system management, particularly from Asia, have global significance and applicability as the demand for aquaculture spreads to other, less experienced regions.

Source: Zweig 1998.

sion and training, as well as assistance in disease diagnosis, prevention, and control. For example, the Shrimp Farming and Environment consortium provides useful guidelines on better management practices for shrimp aquaculture, and the Food and Agriculture Organization (FAO) has technical guidelines in a Code of Conduct for Responsible Fisheries (FAO 1995).

Environmental and social impact assessments need to be included in the process of site selection. Integrated coastal zone and rural development plans can help identify suitable areas for aquaculture development. These plans help ensure that development does not negatively affect critical natural habitats or entail an unacceptable level of risk from possible industrial or municipal pollution. A summary of generic environmental issues and an assessment strategy for aquaculture has been prepared (World Bank 1991. Social implications, such as the ability of small farmers, the landless, women, and minority groups to participate in, and benefit from, the development of aquaculture systems, must be carefully evaluated. This would require evaluation of possible impacts on gender-based division of labor and access to resources.

Capacity building, both in terms of knowledge and physical and institutional infrastructure, is necessary to promote sustainable aquaculture (see box 4.17). Hatcheries for supply of fingerlings and specialized input suppliers of fish feed and other inputs and services are best 
Box 4.17 China: coastal and inland aquaculture

The objective of the Sustainable Coastal Resources Development Project is to establish integrated coastal zone management plans that include zoning of mariculture (that is, marine organisms raised in their natural habitat). This involves the production of fish in cages and ponds, oysters, hard clams, several species of seaweed, and shrimp in four coastal provinces. In addition to improved shrimp culture methods, the project provides training in seafood processing techniques and upgrades processing plants. The Southwest Poverty Reduction Project includes an aquaculture component to provide employment for people from impoverished inland areas in Guangxi through enterprises involved in the production of seafood products, including fish, shellfish, and pearls.

The Freshwater Fisheries Project developed integrated fish farming complexes around eight major Chinese cities, providing a source of fish close to markets. The Guangxi Agricultural Development Project achieved its objectives of providing employment for about 2,200 households and production of about 8,500 tons of fish a year from the development of I,500 hectares of integrated fish ponds on saline, alkaline, or waterlogged soils. It introduced yeast as a protein-rich feed supplement to replace fish meal, reducing the cost of feed and dependency upon foreign exchange to import fish meal. Tourism emerged as an unexpected benefit, because tourists are attracted to view migrating birds drawn to some of the project fish ponds.

Source: Zweig 1998.

developed in the private sector. Research and extension systems must develop and promote production technologies (stocking, disease control, feeding practices), suited to small and landless farmers. Infrastructure needs include processing facilities and cold-chains, and regulatory systems must provide for compliance and certification of food safety standards.

\section{LESSONS LEARNED}

Greater reliance on aquaculture reduces dependency on aquatic natural resources, and enhances the capacity to foster conservation of natural aquatic habitats and biodiversity (see box 4.18).

Collection of wild seed stock should be discouraged, as should the collection of fish for feed purposes. Harvesting of wild species can adversely affect biodiversity and fish populations, and use for feed may transmit diseases to cultured organisms (as documented for brackish water shrimp). Processed feeds should be used instead of feeds derived wholly from wild fish and mollusks. Alternatives include lysine-rich yeast, a single-cell source of protein that is being widely used in China and other countries.

Transfer of species used for aquaculture between river basins, countries, and regions must be carefully evaluated with regard to impacts on other indigenous aquatic species, habitats, and genetics, as well as for the possibility for inadvertent transmission of disease.

Water quality standards are important to ensure the optimal growth and quality of aquatic organisms. With the ongoing expansion of aquaculture development, countries that lack guidelines for water quality will need to create them to assist potential entrepreneurs with site selection, and to help protect the consumer from unsafe aquaculture products.

Postharvest fish handling methods and infrastructure should ensure that a safe product reaches domestic and export markets which may have specific requirements. For example, the United States National Oceanic and Atmospheric Agency (NOAA 1993) and the European Community have developed specific requirements for the seafood processing industry that also require safe and environmentally sound production methods. Existing facilities often need only simple changes requiring modest investments to ensure quality standards are met.

\section{RECOMMENDATIONS FOR PRACTITIONERS}

There is broad scope for investment in aquaculture development to improve food supply; provide employment and income, diversify and intensify farming systems; and improve resource use. Most investment will come from private enterprise, but public sector investment will need to (see box 4.19): 
- Develop mechanisms for the poor, both men and women, to participate. Aquaculture development can take place at multiple levels, from small-scale household operations through to community projects and industrial plants. Land and water tenure rights policies are central to making it possible for the poor to engage in aquaculture production. Leasing public land and water bodies to poor households can be an important tool for poverty reduction.

- Finance research and training on aquaculture systems to address problems and seek ways of exploiting new technological opportunities.

- Identify where aquaculture can be integrated effectively into existing farming systems, or can make profitable use of lands that are unsuitable for other purposes.

- Combine various types of aquaculture in integrated systems to take advantage of symbiotic relationships among species, such as bivalves and caged finfish.

- Encourage proper planning and monitoring to maintain healthy stock, prevent disease, mange cash flows and production cycles.

- Ensure environmentally sound development of aquaculture systems, based on environmental impact assessments and monitoring of environmental impacts.

- Ensure that international quality and safety standards are met, and that certification systems are established and operative.

\section{SELECTED READINGS}

Asterisk (*) at the end of a reference indicates that it is available on the Web. See Appendix 1 for a full list of Websites.

Network of Aquaculture Centres in Asia-Pacific. http://www.enaca.org.
Box 4.18 South Asia: experiences with aquaculture

In Bangladesh, the Third Fisheries Project was designed to enhance floodplain fisheries, improve shrimp farming, and develop aquaculture by groups of women. In addition to increasing fish production, the project helped improve understanding of aquatic ecology and production dynamics and of the social complexities and policy issues that affect the livelihoods of local people. These findings are being applied in the proposed Fourth Fisheries Project, which emphasizes community participation and organization.

In India, the Shrimp and Fish Culture Project focuses on increasing shrimp production on government lands converted to shrimp farms. Some 75 percent of ponds were to be leased to poor coastal families who could not otherwise afford to become involved in shrimp farming. An inland component of the project supports efforts by cooperative societies to gain access to fishing rights in lakes and reservoirs, and offers credit to begin rearing fingerlings and purchase appropriate fishing gear and boats.

Source: Zweig 1998.

\section{Box 4.19 Potential investments}

- Establishment of a favorable policy and regulatory environment for development of aquaculture.

- Matching grants for small-scale aquaculture in poor regions.

- Research and development of seed stock production systems, alternative feeds for fish, and improved production technologies.

- Development of improved postharvest processing and storage systems.

- Training and management advisory services.

- Market research and promotion.

- Environmental assessments, mitigation measures, regulatory mechanisms, and monitoring.

Source: Authors.

World Aquaculture Society. http://was.org/ main/FrameMain.asp.

\section{REFERENCES CITED}

FAO. 1995. Review of the State of World Aquaculture. Fisheries Circular 886, Rev. 1. FAO Inland Water Resources and Aquaculture Service, Fishery Resources Division. Rome: FAO. 
FAO. 1997. The Status of World Fisheries and Aquaculture: 1996. Rome: FAO.

NOAA. 1993. "National Marine Fishery Products Inspection Manual (Hazard Analysis at Critical Control Points Submission Guide)." NOAA, National Marine Fisheries Service, Inspection Services, Department of Commerce, Silver Spring, Md.

World Bank. 1991. Environmental Assessment Sourcebook: Vol. II, Sectoral Guidelines. Technical Paper 140. Washington, D.C.: World Bank.

Zweig, R. 1998. "Sustainable Aquaculture: Seizing Opportunities to Meet Global Demand." Agriculture Technology Notes 22. World Bank, Washington D.C.

This Note was prepared by the Sourcebook team based on a World Bank Agricultural Technology Note "Sustainable Aquaculture" with inputs from Ronald Zweig and the Sustainable Agriculture (SASKI) Thematic Team of the World Bank.

7. This AIN has been adapted from O. Damiani, "Small Farmers and Organic Agriculture: Lessons from Latin America and the Caribbean" (IFAD, Rome, 2002). 
AGRICULTURE INVESTMENT NOTE

\section{ORGANIC AGRICULTURAL PRODUCTION SYSTEMS}

Organic agriculture can improve farmers' incomes and the management of natural resources, but entails additional production and certification costs and a significant time lag for transition to organic certificate and to realize profits. Organic production must be based on sustainable comparative advantage and is likely to be most successful in areas with effective research and extension systems, a supportive policy and regulatory framework, necessary infrastructure, adequate certification systems, and good access to foreign markets. Producer associations have been key to accessing markets, disseminating production technologies, and monitoring compliance with organic standards. ${ }^{7}$

Over the past 50 years, agricultural production has increased dramatically, in part through the use of chemical fertilizers, pesticides, and antibiotics. These technologies and the intensive production systems they support can result in increased human and environmental health risks. As a result, a market has developed for "organic" food products, which consumers perceive as being safer and more environmentally friendly. Retail sales of organic products were estimated at US\$19.7 billion worldwide in 2000, and have grown more than 20 percent annually in major markets over the past 15 years. However, these growth rates are from a low base, and organic food sales generally account for less than 2 percent of total sales in most markets. Thus opportunities to profitably enter this market are somewhat limited by demand. Organic agricultural production, given its limited production levels and variability in yields, is unlikely to impact substantially on global food supplies.

\section{ORGANIC PRODUCTION SYSTEMS}

Organic agricultural production systems employ agronomic, biological, and mechanical methods in place of chemical inputs. Cultural and biological practices control pests and crop rotations, and animal and green manures maintain soil fertility. There is a virtual prohibition on use of synthetic chemicals for crop and livestock production. Most organic agricultural systems also apply improved land husbandry techniques, such as soil-conservation measures, crop rotation, and reduced crop residue burning.

Organic production usually involves annual inspection of production sites by independent specialized certification agencies, interviews with producers, review of organic fertilizers and other inputs used, and laboratory tests of soils, water, and agricultural products. Requirements include: land must not have been used for conventional agriculture relying on chemical or synthetic inputs for a minimum time period (usually three years); conventionally grown crops must be a minimum distance from organic crops, and a forested area may be required as a barrier between organically and conventionally grown crops; inputs must be organic with no chemical or synthetic inputs permitted; soil-conservation measures must be applied; and farmer associations must be able to organize supervision to ensure that organic standards are met by all members. Certification focuses on the process of production rather than the end product itself.

\section{BENEFITS}

Small farmers may have competitive advantages in organic farming and can benefit in several ways (see box 4.20). First, production costs may be reduced by substituting labor and organic inputs for chemical inputs that are often more expensive and difficult to obtain. Second, prices may be higher for organic products. Third, organic production may reduce health risks from handling chemical inputs. Finally, soil conservation measures and control of pests and diseases with manual and biological methods may reduce contamination of natural resources.

Benefits of organic production are by no means guaranteed as crop yields may fall, price 
Box 4.20 El Salvador: benefits of fresh organic vegetable production

Three farmer associations in the Las Pilas region are producing organic vegetables on 36 hectares. The 52 members of the associations previously cultivated cabbage and tomato with conventional technologies, selling them through intermediaries in the wholesale fruit and vegetable market in San Salvador. Their shift to organic production involved a wide variety of new vegetable crops, planning of cultivation in order to sell yearround, and direct marketing to supermarkets, restaurants and hotels in San Salvador. Organic production in Las Pilas successfully competes against imports, mainly because of product quality and product differentiation.

Source: Damiani 2002.

premiums may diminish as production increases, distribution systems may prove inadequate, and unexpected negative environmental impacts (for example, weed migration from fields to natural habitats) may result. Investment in organic production should be made only after feasibility studies based on realistic production and market assumptions indicate that benefits are likely to be sustainable over the long term.

\section{POLICY AND IMPLEMENTATION ISSUES}

YIELD OF ORGANIC PRODUCTS. Typically, yields fall (by up to 10 percent to 30 percent) as a result of the conversion to organic production, and there are commonly significant pest and soil fertility problems throughout the transition period. The extent of declining yields depends on physical farm characteristics, farm management, and previous chemical input usage. Small producers who use little or no chemicals may see no change, or even an increase in yields due to better management. Also, yield volatility is likely to be greater with organic production due to pest losses.

TRANSITION TO ORGANIC PRODUCTION. The transition from conventional to organic production usually takes three years and during this period, farmers cannot obtain organic certification and its resulting price margin. Access to affordable credit throughout the transition period is critical. While shifting to organic production does not require major on-farm investment, there are costs, such as certification costs, some additional investments in soil conservation and equipment, higher labor costs, and sometimes lower yields.

LAND TENURE. Most organic producers own their land. Small farmers lacking secure land tenure are reluctant to move into organic production, as they need to invest in land-conservation measures.

Technology issues. Organic production requires a high level of managerial knowledge and ability to protect crops from pests and diseases, and to comply with the production process requirements. Access to adequate quantities of organic inputs, such as natural pest enemies, livestock manure, mineral rock phosphate, and organic matter can be a problem. Lack of technology can be an advantage for some organic producers as their success is related to not previously using chemical inputs and: they can be certified as organic with little or no change in production practices; training and technical assistance costs are likely to be significantly lower; and the transitional period can be shorter and less expensive, and yield decreases are likely to be less.

ENVIRONMENTAL IMPACTS. Organic production systems can have some negative environmental impacts, such as overuse of animal manures that can lead to nitrite pollution of water supplies. Insufficient application of organic manures can lead to soil "mining" and longterm productivity declines.

Certification ReQuirements and costs. Reliable independent accreditation and control systems are essential to enforce organic standards and regulations, and to meet phytosanitary standards and general quality requirements. For organic farmers, certification is one of the most important cost items, with costs varying as they depend on availability of a certification agency, farm size and volume of production, and the product. Total certification cost usually involves both a fixed cost and a variable cost that covers certification and inspection. For example, costs are: US\$18.50 per hectare for coffee farmers in 
Guatemala, US\$11 per farmer for cacao producers in Costa Rica, and 4.4 percent of gross revenue for sugarcane farmers in Argentina.

LABOR COSTS. Organic production systems often use more labor because they need additional soil conservation measures-such as, construction and upkeep of terraces and live barriers; new management practices; manual control of weeds, pests, and diseases; and applying large volumes of organic fertilizers. They also have potentially increased harvest costs (see table 4.2). The combined effect on production costs from increased labor requirements and lower chemical inputs will vary and must be assessed in relation to other factors, particularly yield and price changes. In places where chemical input is low, total costs are likely to rise because labor cost increases are likely to exceed chemical savings.

Processing and marketing facilities. Marketing of most organic products requires certified sorting, processing, and packing facilities, handling only organic crops. This additional cost means the minimum volume of organic product needed for a viable enterprise is more than for conventional crops. Stable relationships with importers, traders, or wholesalers in the target market are important to coordinate distribution and access information.

Gender Issues. Because of less business experience and gender-based discrimination, women organic farmers may find it more difficult to make required contacts, negotiate agreements, and obtain access to credit. Women find low paying jobs in organic farming, providing labor for weeding and harvesting (for crops like coffee, cacao, banana and vegetables) and in packing facilities.

\section{LESSONS LEARNED}

Research, EXTENSION and training. Extension services have, with the exception of coffee, faced problems in finding professionals trained

\section{Table 4.2 Production costs of organic and conventional crops (US\$/ha)}

Crop

Organic

Conventional

\section{Sugarcane (Argentina)}

\begin{tabular}{lrr}
\hline Production cost (PC) & 490 & 562 \\
Labor cost (LC) & 238 & 154 \\
LC/PC (\%) & 49 & 27 \\
\hline Coffee (Mexico) & & \\
\hline Production cost (PC) & 680 & 452 \\
Labor cost (LC) & 522 & 360 \\
LC/PC (\%) & 77 & 80 \\
\hline Banana (Dominican Republic) & & 2,370 \\
\hline Production cost (PC) & 2,560 & 1,218 \\
Labor cost (LC) & 1,826 & 51 \\
LC/PC (\%) & 71 & \\
\hline
\end{tabular}

Source: Damiani 2002. 
in organic agriculture. Including organic production systems into research and education programs is essential to supplying technologies and well-trained professionals for the future. For small organic producers, extension services are particularly important to improve product quality and ensure compliance with organic production methods.

Strengthening farmer associations. Producer organizations play a major role in enabling small farmers to begin organic production as they make possible economies of scale by marketing product in quantities that attract foreign buyers. These buyers find it easier and cheaper to contract with organizations rather than with a large number of individual farmers (see box 4.21). Associations train large numbers of small-scale farmers, and organize monitoring systems to ensure compliance with production standards. Compliance is very important because if only one member fails to comply with production standards, buyers' trust is lost and there are severe consequences for the entire group.

Marketing ORganic PRODUCts. Supermarkets are the fastest growing sales outlets for organic produce but small-scale farmers often do not sell to these because they lack marketing skills and connections. As a result, marketing through farmer associations has been key in helping small farmers obtain better prices. Marketing contracts (that is, contract farming) may secure and stabilize prices, and may provide access to extension services and credit. Outgrower schemes are common, but may require high costs for monitoring and enforcing contract provisions. In developing countries, domestic markets for organic products are attractive because they can be less demanding in terms of quality, than export markets.

\section{RECOMMENDATIONS FOR PRACTITIONERS} Organic production is one of several options for improving production and incomes of small farmers. Investments in organic agriculture (see box 4.22) should:

- Strengthen associations of small producers that play a major role in marketing, production, dissemination of organic technologies, and monitoring members' compliance with organic methods of production.

- Provide financial support during the transition period by covering start-up costs of certification systems, and organization of an effective and participatory monitoring system.

- Strengthen government policies and institutions dealing with organic agriculture, such that appropriate regulations protect producers, consumers, and exporters.

- Use NGOs with experience in organic production as preferential partners for projects. NGOs have frequently promoted production based on local resources, rather than on purchased inputs and often have skills in supporting small farmer associations and marketing of organic products.

- Consider using domestic markets as an entry point to gain experience with organic production processes, certification requirements, and quality standards.

- Target producers with the highest potential for success, concentrating on small farmers with stable land tenure, access to financial resources and other inputs for organic farming.

\section{SELECTED READINGS}

Asterisk (*) at the end of a reference indicates that it is available on the Web. See Appendix 1 for a full list of Websites.

Coote, C., P. Greenhalgh, and J. Orchard. 2003. "High Value Horticulture and Organic Export Markets for Sub-Saharan Africa." Natural Resources Institute, U.K. 


\section{Box 4.2I Costa Rica: farm associations and organic cacao and}

banana

The Talamanca Small Farmers Association (APPTA) created in 1987 had 1,500 members by 2000. Most members abandoned cacao plantations in the 1970s because of disease and low prices, and were making a living from subsistence crops and poultry. APPTA promoted a revival of cacao production and, with help of an NGO, established contacts with buyers of organic cacao in the United States. By the early 1990s, APPTA had a significant area of cacao certified by a United States certification agency (Organic Crop Improvement Association), allowing members to regain an important source of cash income. Following this initial success, APPTA obtained organic certification for banana production for baby food (puree of organic banana) for export to Europe and the United States.

Source: Damiani 2002.

\section{Box 4.22 Potential investments}

- Training for producers on organic production and markets and problems of noncompliance.

- Extension services for organic production and maintenance of product quality.

- University training and research programs to develop resources and technologies for organic agriculture.

- Support for soil conservation measures and for certification costs during the transition period.

- Support for farmer associations, NGOs, and marketing firms developing organic agricultural markets.

- Financial resources to support investment in packing and processing facilities.

Source: Authors.

Damiani, O. 2002. "Small Farmers and Organic Agriculture: Lessons from Latin America and the Caribbean." IFAD, Rome.

FAO/ITC/CTA. 2001. World Markets for Organic Fruit and Vegetables: Opportunities for Developing Countries in the Production and Export of Organic Agricultural Products. Rome: FAO/ITC/CTA.*

Scialabba, N. 2000. "Factors Influencing Organic Agriculture Policies with a Focus on Developing Countries." IFOAM Scientific Conference, August 28-31, Basel, Switzerland.*

\section{REFERENCES CITED}

Damiani, O. 2002. "Small Farmers and Organic Agriculture: Lessons from Latin America and the Caribbean." IFAD, Rome.

This Note was prepared by the Sourcebook team based on an IFAD publication "Small Farmers and Organic Agriculture: Lessons from Latin America and the Caribbean" by Octavio Damiani. 


\section{AGRICULTURE INVESTMENT NOTE}

\section{URBAN AND PERIURBAN AGRICULTURE}

Agricultural activities in and around cities and towns contribute significantly to meeting the needs of these urban areas, providing employment to urban dwellers, especially women, and absorbing city wastes. Institutional and technological innovations are needed to integrate urban and periurban agriculture (UPUA) with evolving urban marketing systems, and to satisfy demands of urban consumers. Other investment needs include capacity for supply and demand analysis, awareness campaigns on food quality and environmentally sound practices, technological and institutional innovation for production and monitoring food safety and quality, and an enabling environment for the private sector to distribute inputs and services.

Migration of the poor from rural to urban areas (where basic services are more available and costs of living are less) will continue to be a major trend in developing countries. This results in shifting poverty from rural areas to urban slums and increasing urban and periurban agriculture. Sustainable production, processing, and distribution of food in and around cities and towns contribute to the goal of a safe, affordable, and reliable food supply for the urban poor, and provide income and employment to a large number of urban poor, especially women. Critical issues concerning UPUA include: use of pesticides; use of urban waste in agricultural production; environmental pollution caused by agricultural activities in densely populated areas; conflicts over land and water between agricultural, industrial, and housing uses; unhygienic food marketing; and an inability of producers, wholesalers, retailers, and other agents engaged in food processing and marketing to integrate within coordinated food chains.

UPUA includes activities within or on the fringe of a town or city that use natural, physical, and human resources to grow, process, and distrib- ute food and nonfood agricultural products for both local urban markets and for export. As the UPUA production system is close to urban consumers, it can be well connected in terms of input and output markets. UPUA products may reach urban consumers and processing points the day they are harvested. These systems are also characterized by the small scale of production, high proportion of perishable crops (especially leafy vegetables), disease and insect pressure, intensity of input use, crop diversity, and low use of mechanical power.

\section{BENEFITS}

Poor men and women engage in UPUA to increase household food security and to generate income. The contribution of food produced in UPUA to meet the total food needs of different cities varies widely. For Hanoi, it supplies about one-half of the food demand, and engages more than 10 percent of the urban labor force in processing and marketing, retailing, input supply, and seed and seedling production (Anh, Anh, and, forthcoming). These percentages are higher for many African cities and some Latin American cities. Even in cities like Manila where little land is left for crop-based agriculture, the contribution of agricultural business activities to income and employment remain significant (Ali and Porciancola 2001). UPUA systems can play an important role in environmental and public health by reusing and managing urban wastewaters and solid waste. Maintaining a large number of trees in cities and home gardening contribute to air quality as well as employment. Urban agriculture can also be seen as a survival strategy for the urban poor during crisis periods, and contributes to household food security, especially for women and the elderly.

\section{POLICY AND IMPLEMENTATION ISSUES}

Key issues of UPUA in production, livelihood earnings, environmental protection, and input supply at the household, institutional, and policy levels are included in table 4.3.

INPUTS AND SERVICES SUPPLIES. In the provision of 
Table 4.3 Issues of sustainable urban and peri-urban agriculture (UPUA)

\begin{tabular}{|c|c|c|c|}
\hline Issue & Household level & Institutional level & Policy level \\
\hline $\begin{array}{l}\text { Production, } \\
\text { processing and } \\
\text { marketing } \\
\text { (both food and } \\
\text { nonfood } \\
\text { agricultural } \\
\text { products) }\end{array}$ & $\begin{array}{l}\text { - Farmer } \\
\text { understanding of } \\
\text { urban markets, and } \\
\text { appropriate } \\
\text { selection of farm } \\
\text { and nonfarm } \\
\text { enterprises. } \\
\text { - Competent } \\
\text { enterprise } \\
\text { management. }\end{array}$ & $\begin{array}{l}\text { - Institutes to develop and } \\
\text { monitor standards for } \\
\text { agricultural practices and } \\
\text { food quality. } \\
\text { - Public-private sector } \\
\text { collaboration for input supply } \\
\text { and market infrastructure. } \\
\text { - Technologies to reduce } \\
\text { seasonality of supply. } \\
\text { - Enable small enterprise } \\
\text { integration with emerging } \\
\text { food chain structures. }\end{array}$ & $\begin{array}{l}\text { Recognition of the } \\
\text { role of UPUA in } \\
\text { urban planning, and } \\
\text { appropriate price, } \\
\text { trade, and land } \\
\text { policies. } \\
\text { Policies for } \\
\text { improving farmer } \\
\text { access to } \\
\text { information. }\end{array}$ \\
\hline Liveliho & $\begin{array}{l}\text { - Targeted } \\
\text { technologies to } \\
\text { improve the } \\
\text { livelihood of urban } \\
\text { poor. }\end{array}$ & $\begin{array}{l}\text { Recognition of the role of } \\
\text { UPUA in economic crises. } \\
\text { Strengthening the backward } \\
\text { and forward linkages } \\
\text { between rural and urban } \\
\text { agriculture. }\end{array}$ & $\begin{array}{l}\text { Food and trade } \\
\text { policies to reduce } \\
\text { the impact of high } \\
\text { food prices. }\end{array}$ \\
\hline $\begin{array}{l}\text { Environment, } \\
\text { health, and } \\
\text { equality }\end{array}$ & $\begin{array}{l}\text { - Adoption of } \\
\text { sustainable } \\
\text { - practices. } \\
\text { Monitoring } \\
\text { pesticide residues. }\end{array}$ & $\begin{array}{l}\text { Create awareness about } \\
\text { fresh, hygienic, and quality } \\
\text { food, and adopting food } \\
\text { quality and safety standards. } \\
\text { - Institutional arrangements to } \\
\text { manage environmental and } \\
\text { social externalities of UPUA } \\
\text { (e.g. heavy metal and } \\
\text { microbial contaminations of } \\
\text { the environment and food). } \\
\text { - Regulating use of city wastes. }\end{array}$ & $\begin{array}{l}\text { - Policies to } \\
\text { encourage people } \\
\text { to keep the city } \\
\text { green. } \\
\text { - Awareness of } \\
\text { environmental } \\
\text { perspectives of } \\
\text { consumers. } \\
\text { - Appropriate labor } \\
\text { policies. }\end{array}$ \\
\hline
\end{tabular}

Source: Authors.

agricultural services, especially those with some element of public good such as extension and irrigation, UPUA is often ignored. If these constraints to UPUA are not addressed, there may be major consequences in terms of the regularity and quality of food supply, poverty and gender equity, resource conservation, and human health in urban areas. Removing such public sector biases against UPUA would encourage private sector involvement in the supply of services and inputs critical to profitable and sustainable farming in urban areas.
INFORMATION SYSTEMS. The diversity of UPUA is often high to maximize the efficiency of resource use, meet market demands, and to reduce risk. Off-farm employment options for family labor and the possibility of hiring labor add to the complexity of decision-making. Changing market structure, increased demand for food quality, and fluctuations in output prices are additional dimensions of decisionmaking. To cope with these, farmers and especially the poor ones, require efficient agricultural information systems and sophisticated 
managerial skills. Urban farmers are closer to markets than are their rural farmers and have an advantage in targeting specific consumer segments (high income, for example) and responding quickly to changes in the demands of these, provided they have good access to market information. There is always a danger that resource poor farmers and disadvantaged groups in UPUA will be left behind.

New Market STRUCtures. The shares of high-value crops such as fruits and vegetables and livestock products are rapidly increasing in urban diets, and consumers are demanding better quality and safe foods. In response, the organizational structure of urban markets, including those in developing countries, is changing. Smallholder urban producers and small retailers and wholesalers in urban areas typically lack resources, organization, and skill to provide quality food of the standard demanded by urban consumers, or to integrate with new coordinated market structures.

Health and environmental issues. Input use, especially for fertilizer and pesticides, is relatively high in UPUA, leading to potentially high residues in food, especially vegetables. This may create health hazards for both consumers and producers, and degrade resources such as soil and underground water reserves. Farmers have little incentive to reduce pesticide use in view of low pesticide costs, inadequate knowledge of conservation farming options (IPM for example), low availability of extension services, and inadequate market premiums for providing consumers with products that have been produced using environmentally sound and socially acceptable production practices. Farmers need technical advice to improve food quality, and institutional innovations to monitor agricultural practices and food standards.

USE OF URBAN WASTE. The use of solid waste and wastewater in UPUA has both advantages and disadvantages. It saves farmers money, and reduces environmental pollution. However, it may create microbial infections in food, and heavy metal contamination of soil, water, and food.
LAND TENURE ISSues. The long-term continuity of agricultural production from a given piece of land in UPUA remains uncertain, because the opportunity cost of using it for agriculture is high due to demand for industrial, housing, and development purposes. The right to use land for UPUA is sometimes not well defined, especially when it is practiced on vacant municipal or encroached lands. This can create conflicts and can lead to underinvestment as well as exploitative production practices and degradation of the land.

\section{LESSON LEARNED}

TECHNICAL AND MANAGERIAL CAPACITY OF FARMERS AND FOOD MARKETERS. Effective UPUA requires the provision of nondiscriminatory extension services for farmers that are linked with demand-driven research systems. The public sector can help to build and reform systems to supply farmers with required inputs and link them to downstream markets. It can also play an active role in building the capacity of farmers and food wholesalers and retailers to meet emerging market demands. It can also improve the capacity of the private sector to supply farm inputs and more effectively process and market outputs.

Promote the ADOPTION OF ENVIRONMENTALLY SOUND FARMING PRACTICES. The application of city wastes (both solid and liquid) and the large number of trees can help clean the city environment. However, to ensure that applications are not negatively affecting environmental indicators, and that they are not risking the safety of the food produced, effective regulatory systems are required. These include the quality of waste applied in agricultural production, and levels of pesticide residue and microbial contamination on food. To be effective, these regulatory systems should be based on sound technical planning, and credible monitoring systems. Extension is also important to bring to farmers new technologies that can ensure long-term environmental sustainability of the system. The public sector can play an important role in providing advice in planning and promoting effective supply of technical services to farmers, 
particularly involving the private sector and producer organizations.

Producer organizations. Because of the very small operations, input purchase and output marketing are typically a problem in UPUA. Organization of producers can benefit from economies of scale in markets (see box 4.23). These organizations can identify opportunities and constraints, and organize funds to overcome bottlenecks. They can arrange inputs and organize training as new opportunity arises, and can lobby to protect the UPUA from unnecessary regulations.

\section{RECOMMENDATIONS FOR PRACTITIONERS}

UPUA must be given due importance in urban planning, encouraging its contributions in supplying food and engaging the labor force in food production, processing, and distribution. Other recommendations relating to investments in UPUA include (see box 4.24):

- Create an enabling environment for the private sector to supply inputs and services by providing training and information.

- Promote the development of responsive agricultural extension and training programs to enhance farmers' ability to make efficient decisions under the complex environment of UPUA. This would include skill training especially on good agricultural practices for crop and livestock production, business analysis, and developing information systems at the PO level.

- Encourage organization of associations in the food chain to enable farmers and small enterprises to integrate with changing market structures in cities. Involvement of women and disadvantaged groups in these associations is necessary to improve social equity.

- Introduce pilot projects on innovative methods and tools to produce, process, and monitor the distribution of hygienic and safe food.
Box 4.23 South Asia: the AVRDC/CIRAD UPUA project

In 2002, AVRDC/CIRAD initiated a 3-year coordinated project with national partners in Hanoi, Ho Chi Minh City, Phnom Penh, and Vientiane to diagnose problems and introduce technological and institutional innovations in UPUA. The project has undertaken an analysis of the supply of and demand food in urban and periurban areas, as well as an analysis of the vegetable, fish, and livestock production and marketing systems. Other accomplishments include:

- The development of producer organizations (POs) for improving the dissemination of technical innovations, and strengthening farmer access to markets by carrying out pilot operations for vegetable and fish production systems.

- Introduction of off-season tomato varieties and technologies and efficient marketing systems on a pilot basis.

- Analysis of the pesticide residues and lead content of selected vegetables that has been supported by the introduction of tool-kits for spot-checking of pesticide residue for selected pesticides.

- Training of farmers for off-season vegetable production and integrated pest management (IPM) technologies.

- Improved regional cooperation to share breeding material, information, and literature related to UPUA.

These activities and innovations are contributing to enhanced safety and year round supply of food, as well as providing income and employment in urban and peri-urban areas, both on and off farm.

Source: AVRDC/CIRAD Internal Documents.

- Promote reform of land tenure arrangements where this is a major constraint to market- oriented environmentally sustainable UPUA. Well documented land records

\section{Box 4.24 Potential investments}

- Market analysis of the supply and demand for food and evolving marketing structures.

- Training inbusiness management for food retailers and wholesalers.

- Promotion of innovations to produce and market safe and hygienic food.

- Awareness campaigns for consumers and producers about food safety and environmentally safe production.

- Technical capacity and equipment for environmental monitoring, particularly with regards to high input use and applications of city wastes.

Source: Authors. 
can encourage sustainable, profitable, and equitable resource use.

- Develop cost-effective water treatment and manure decomposition plants to enable productive disposal of UPUA waste with minimal environmental risks. Equipment and procedures for lead and microbial contamination will also force producers to carefully use urban wastes to avoid environmental contamination or rejection of outputs for safety reasons.

\section{SELECTED READINGS}

Asterisk (*) at the end of a reference indicates that it is available on the Web. See Appendix 1 for a full list of Websites.

Smit, J., A. Ratta, and J. Nasr. 1996. Urban Agriculture: Food, Jobs and Sustainable Cities. Habitat II Series. New York: UNDP.

IFPRI. 1998. "Does Urban Agriculture Help Prevent Malnutrition? Evidence from Kampala." Food Consumption and Nutrition Discussion Paper 45. IFPRI, Washington, D.C.*

\section{REFERENCES CITED}

Ali, M., and F. Porciancola. 2001. "Urban and Peri-urban Agriculture in Metro Manila: Resources and Opportunities for Food Production." Technical Bulletin 26. Asian Vegetable Research and Development Center, Shanhua, Tainan, Taiwan.

Anh, M.T.P., H.L. Anh, and M. Ali. Forthcoming. "Urban And Peri-Urban Agriculture In Hanoi: Resources, Opportunities And Constraints For Sustainable Food Production." Technical Bulletin. AVRDC/CIRAD, AVRDC, Shanhua, Tainan, Taiwan.

This Note was prepared by Mubarik Ali, with input from Gary Alex and Sam Kane. 


\section{AGRICULTURE INVESTMENT NOTE}

\section{CONSERVATIONTILLAGE}

Conservation tillage (CT) can significantly improve rural agricultural productivity, and incomes. At the same time it can conserve the natural resource base for agricultural production, as part of an overall approach to the management of natural resources. Widespread adoption in Latin America and expanding use in South Asia have shown that investment in research and extension (R\&E) systems, capacity building, and the development and distribution of necessary equipment are effective means of promoting the use and benefits of conservation tillage.

Conventional tillage practices of plowing and tilling the land evolved largely to control weeds. Although widespread, these systems have some serious disadvantages by exposing soil to wind and water erosion, and by incurring high energy costs for tilling operations. Production systems using CT are becoming more common and offer a range of benefits, such as increased land productivity, reduced production costs, and prevention of soil erosion.

\section{THE DEVELOPMENT OF CONSERVATION TILLAGE SYSTEMS}

CT farming covers four broad, intertwined management practices: minimal soil disturbance with no plowing and harrowing; maintenance of a permanent vegetative soil cover; direct sowing; and sound crop rotation. Introduction of these practices requires a supportive social environment and institutional framework. Many CT practices have evolved from farmer innovations supported by farmer-led organizations, in partnership with private business. CT farming is a sustainable land resource management system that combines productivity gains and increased profitability with ecosystem management for environmental protection. However, CT farming should not be seen as a "quick fix" or a blueprint that solves all sustainability or profitability problems. It is highly locationspecific, must be adapted to specific farmer circumstances, and requires time to change traditional attitudes and approaches and to demonstrate benefits (see box 4.25). A successful transition to CT farming generally requires three to five years.

Key factors in the successful introduction of CT farming include the willingness of governments to: empower rural communities and POs; develop effective R\&E systems; support experienced producer groups or community organizations; and develop systems to secure land tenure and water rights. Other facilitating factors include effective input and output markets, and access to cover crop seed and appropriate machinery.

\section{BENEFITS}

Economic. CT increases farm profitability by improving land productivity through residue mulching practices that allow sowing at the optimal time, conserve moisture, and reduce vulnerability to drought or moisture stress. CT also reduces costs of labor, inputs and machinery (longer life and lower maintenance costs). In Brazil, net farm incomes increased by as much as 59 percent over five years and in animal traction systems CT farming has increased maize yields by up to 20 percent.

Environmental. CT adoption is likely to result in: decreased soil erosion and water loss through runoff; decreased carbon dioxide emissions and higher carbon sequestration; reduced fuel

Box 4.25 Brazil: key elements of smallholder no-till systems for maize and bean production in Parana

- Use of animal traction, family labor, and limited use of purchased inputs.

- Biomass management with animal-drawn knife-roller and planting with animal-drawn no-tillage planter.

- Management of crop residues with knife-roller.

- Use of cover crop management.

- Runoff control with contour bunds built with animal-drawn moldboard plow.

- Planting of dwarf elephant grass on contour bunds for livestock feed.

Source: Pieri et al. 2002. 
Box 4.26 India: impact of no-till in the Indo-Gangetic Plains

In the rice-wheat system conservation tillage (CT) saves up to one million liters of irrigation water and about 60 liters of diesel per hectare. No-till has the potential to save six-to-ten plowing operations, reducing costs by US\$50-60 per hectare as compared to conventional tillage. Reducing turnaround time between rice harvest and wheat planting also increases wheat yields.

No-till has proven very effective in controlling weeds in wheat because most weed germination is triggered by sunlight or by lower temperatures. Since the soil is disturbed less with no-till, less weed seed is exposed and so less germinates. Recent data suggest that no-till reduces weed infestations over time, and eventually no herbicides are required in some seasons.

Custom machinery services allow small-scale farmers to use no-till and reduce operating capital requirements, since fewer tractor hours are needed. Farmers no longer need to maintain bullocks all year on the farm. In Haryana in 200 I, 70 percent of farmers who adopted no-till did not own a tractor and used custom tractor services, and 40 percent of the adopters were small landholders with farms smaller than two hectares.

Source: Ekboir 2002.

Box 4.27 Responses to common criticisms of conservation tillage farming

Limited to deep soils and high rainfall conditions: Conservation tillage (CT) farming practices can be adapted to a wide range of soils under semi-arid or humid tropical or temperate climatic conditions.

Suited only to large mechanized farms: In Brazil and Paraguay, private entrepreneurs have made CT equipment for small farms available in local marketplaces and enabled family farms to successfully adopt CT farming practices using animal power. In South Asia, whole villages adopted no-till wheat after rice using rental farm machinery.

Results in increased herbicide use. Full adoption of CT practices (cover crops, crop rotations, and integrated weed management) over a two-to-five year period can reduce weed pressure, and practitioners claim that they use less herbicide (and other pesticides) than under conventional tillage systems.

Source: Pieri et al. 2002. consumption; increased water productivity; less flooding; and recharging of underground aquifers. Other benefits are increased fertilizer efficiency, improved drainage, reduced waterlogging, and increased diversity of desirable insects. In South Asia CT farming is estimated to save 60 liters of diesel per hectare per year.

Social. CT initiatives are generally scale neutral, so that smallholders benefit equally (see box 4.26). Reduced labor requirements free up more time for nonfarm employment, child education, and care of the elderly. Increased stability of production can increase food security.

\section{POLICY AND IMPLEMENTATION ISSUES}

TECHNOLOGICAL BASE. Effective CT implementation initiatives are based on a sound understanding of technical aspects of production, including CT plant cover and cover crops, crop rotation, equipment and IPM. Transition problems, such as increased weed growth in direct-seeded rice, occur in early years of CT production. Development and supply of appropriate equipment and improved seed for both crops and cover crops facilitates farm-level adoption. Research systems must be able to provide solutions to varied location-specific production problems. Technologies, including biotechnology-assisted development of herbicide-resistant varieties, and development of safer pesticides and pesticide application strategies, will likely be important for increasing the use of CT.

Disincentives to World Bank INVESTMENTS. Factors that deter Bank investment in CT farming include the often lengthy time taken to develop and disseminate relevant technologies; high initial investments in equipment and farmer training and education; deferred benefits; and the Bank's pesticide safeguard policies on investments associated with increased use and their impact on CT herbicide use. There have also been misconceptions about CT farming (see box 4.27).

CAPACITY BUILDING. Farmer organizations are key to changing traditional attitudes and practices, and are able to do so because of their under- 
standing of local conditions. CT investments must strengthen such farmer organizations and extension systems, and link farmers to the scientific community.

OTHER ENVIRONMENTAL CONCERNS. In some circumstances CT farming can result in pest and weed buildup, requiring increased application of pesticides and herbicides, with negative implications for local biodiversity and water quality. Some farmers also burn mulch contributing to air pollution and loss of organic matter. No-till and low-till systems may also increase growth of fungi in humid climates, risking contamination of agricultural produce by aflatoxins and mycotoxins, with possible loss of markets and negative impacts on human health. Research investments are needed to develop systems for sustainable management of crop residues, such as using drills to plant into residues, baling and removal for livestock feed, and microbial sprays to speed decomposition.

\section{LESSONS LEARNED}

Changing farming practices that have evolved over many generations is difficult. CT is more than a switch from one technical package to another, and demands an integrated approach including collaborative efforts on social mobilization, education and training, and marketing. Such action can be undertaken in discussion groups and seminars, and through field visits.

The two main driving forces behind the development and adoption of CT are farmers faced with acute and highly visible land degradation, and a few innovators who realize that radical changes to farming practices are required. A CT development strategy can create the conditions to capitalize on experiences of initial innovators and regional agents for change, such as farmers, technical specialists, private input sector, and extension agents, to promote the spread of CT innovations through a network of local, state, and national POs.

Adaptive research systems guided by the concerns of farmers and other interest groups.
Box 4.28 Priorities for conservation tillage adaptive research

- Cover crops - collection of locally available germplasm and introduction as appropriate.

- Crop residues - on-field management (both mechanical and chemical) and for productive uses.

- Integrated production and pest management (IPPM) limited pesticide use.

- Fertilizer - mineral/organic requirements, (needs, timing, and methods of application).

- Machinery/tool adaptation - adaptation and fine-tuning of conservation tillage (CT) planters.

- Integration of crops and livestock production - best crop rotations, increase biomass.

- Pathways of change - on-farm test of pathways best suited to local/zonal typology.

- Land/soil benchmark - characterization of representative on-farm soils.

- Soil as a rooting environment - rooting depth, root distribution for crops and cover crops.

- Socioeconomic studies - reasons for adoption and nonadoption, gender considerations.

Source: Pieri et al. 2002.

are essential to CT farming, (see box 4.28). Extension programs should foster linkages among those involved, synthesizing feedback from the field, prioritizing needs, and assisting with implementation of adaptive on-farm research. In Brazil, CT education and training in university courses has been an effective means of extension. In South Asia, traveling seminars were effective in bringing farmers to see CT systems in operation, and to hear other farmers' experiences with the systems.

CT systems take considerable time to implement, with a lag between investment and realization of tangible results. This means that in the initial stages of CT introduction significant support (subsidized equipment, local meetings) may be required until benefits become apparent and sufficiently compelling for stakeholders to independently support the system. Planning should provide for phase-out of such incentives, particularly subsidies.

\section{RECOMMENDATIONS FOR PRACTITIONERS} Implicit in CT activities is that governments and other major stakeholders give priority to 


\section{Box 4.29 Potential investments}

- Farm and community group organization and orientation to conservation tillage (CT).

- Research systems for adapting CT technologies to local conditions.

- Extension systems that support the design, manufacture, and distribution of required equipment.

- Seminars, meetings, and demonstrations of CT equipment and practices.

- Support for institutions to improve rural financial services and land administration systems.

- Support workshops and study tours for private sector equipment manufacture, input supply, and services.

- Grant programs to encourage socially and environmentally beneficial practices where market forces fail to do so.

Source: Authors.

appropriate policies and coordinated interventions that help to achieve more rational land use, improve land management practices, and develop an updated knowledge and information base. CT investments should (see box 4.29):

- Ensure that implementation plans account for context-specific attributes of the environment (slope, soil type, water resources). Establishing a geographical database may be helpful for this purpose.

- Identify and train innovative and entrepreneurial leadership, and stimulate a cooperative approach involving all interest groups.

- Ensure private sector participation in machinery supply, chemical and information supply, sponsorship of farmer organizations, financing, research, and extension.

- Develop effective coordination and communication mechanisms and networks to share ideas and knowledge between farmers and interest groups. Farmer-tofarmer contact is often the most costeffective means of communication.

- Develop research systems with an on-farm research perspective that provides solutions to local problems identified by farmers and the wider community.

- Involve local manufacturers in the development and manufacture of required equipment that is within the budget of farmers. Farmers must be shown how equipment works and allowed to experiment with it.

- Pay special attention to the integration of crops and livestock in CT systems. A particular challenge is the development of rotational grazing patterns on cover crops that do not jeopardize the sustainability of CT systems.

- Use targeted, short-term subsidies to support small farmer testing and adoption of no-till practices.

\section{SELECTED READINGS}

Asterisk $\left(^{*}\right)$ at the end of a reference indicates that it is available on the Web. See Appendix 1 for a full list of Websites.

Alberta Reduced Tillage Linkages. Alberta Update on Direct Seeding. Direct Seeding Factsheet Summaries. http:// www.reducedtillage.ca/ directseedingfactsheets.html.

Ekboir, J., K. Boa, and A. A. Dankyi. 2002. Impact of No-Till Technologies in Ghana. Economics Program Paper 02-01. Mexico, D.F.: CIMMYT.*

Hobbs, P., and R. Gupta. 2002. "Resource Conserving Technologies for Wheat in RiceWheat Systems." In J. K. Ladha, ed., Improving the Productivity and Sustainability of Rice-Wheat Systems: Issues and Impact. Proceedings of an International Symposium held at the 2001 Annual Meetings of the American Society of Agronomy, Crop Science Society of America, and Soil Science Society of America, Oct. 22, Charlotte, N.C. Madison, Wisc.: American Society of Agronomy, Crop Science Society of America, Soil Science Society of America. 
Hobbs, P. R., Y. Singh, G. S. Giri, J. G. Lauren, and J. M. Duxbury. 2002. "Direct-Seeding and Reduced-Tillage Options in the RiceWheat Systems of the Indo-Gangetic Plains of South Asia." In S. Pandey, M. Mortimer, L. Wade, T. P. Tuong, K. Lopez and B. Hardy. Direct Seeding: Research Issues and Opportunities. Proceedings of the International Workshop on Direct Seeding in Asian Rice Systems: Strategic Research Issues and Opportunities, January 25-28, Bangkok, Thailand. Philippines: International Rice Research Institute.*

FAO. Intensifying Crop Production with Conservation Agriculture. http://www.fao.org/ag/ ags/AGSE/Main.htm.

\section{REFERENCES CITED}

Ekboir, J., ed. 2002. Developing No-Till Packages for Small-Scale Farmers. Mexico, D.F.: CIMMYT.

Pieri, C., G. Evers, J. Landers, P. O'Connell, and E. Terry. 2002. "No-Till Farming for Sustainable Rural Development." Agriculture and Rural Development Working Paper. World Bank, Washington, D.C.

This Note was prepared by Sam Kane with inputs from the Sustainable Agriculture (SASKI) Thematic Team of the World Bank. 


\section{AGRICULTURE INVESTMENT NOTE}

\section{INTEGRATED PEST MANAGEMENT}

Integrated pest management (IPM) practices have produced substantial environmental and economic benefits in various agricultural systems. Introducing IPM requires a coordinated strategy of enhancing management skills of producers, awareness of food chain operators and consumers, an appropriate regulatory and policy environment, and economic incentives for incorporating external benefits of improved practices into farm-level decisionmaking. Training and capacity building at the level of the individual producer and service provider is essential.

The use of chemical pesticides in agriculture has produced impressive yield gains, but has

\section{Box 4.30 Integrated pest management technical toolbox}

Integrated pest management (IPM) combines natural forms of control, taking advantage of ecological relationships in the agricultural system, with economically derived rules for application of pesticides with low toxicity to minimize negative effects on human health, beneficial organisms, and the environment. Nonchemical methods of pest control, include:

- Biological control. Use of natural enemies of crop pests (beneficials), such as parasites, predators, and insect pathogens, and environmentally friendly chemical interventions such as pheromones and feeding attractants and biopesticides.

- Cultural and crop or livestock management controls. Tissue culture, disease-free seed, trap crops, cultivation, refuge management, mulching, field sanitation, crop rotations, grazing rotations, and intercropping.

- Strategic controls. Planting location, timing of planting, and timing of harvest.

- Genetically based controls. Insect- and disease-resistant varieties and root stocks.

Biologically based pest control strategies may often be feasible only in the long term. In such cases, rationalization of existing patterns of pesticide use may be the first step toward making more sustainable pest management.

Source: Sorby, Fleischer, and Pehu 2003. led to concerns over risks to human health, the environment, and food quality. In some cases, particularly where chemical inputs are subsidized, pesticides have been over-used and the long-term sustainability of agricultural systems has been undermined. IPM is seen as a way of achieving sustainable agricultural production with less damage to human health and the environment, while at the same time increasing incomes in rural areas.

\section{INVESTMENT IN IPM}

IPM is essentially a diverse mix of management practices used to keep pest incidence below economically damaging levels. These include targeted and judicious use of synthetic pesticides, biological control, and other nonchemical means (see box 4.30). In addition to this mix of technical options, IPM focuses increasingly on enhancing farmer skills to use agro-ecological knowledge to manage production ecosystems. Application of IPM tools and tactics is therefore highly situation- and location-specific.

Investment in public IPM research has yielded returns comparable to research on other agricultural technologies. Recently, the Bank's competitive research grants programs have channeled substantial funding into IPM-related research. Pest-resistant seed varieties developed through genetic modification techniques add new technological options to the IPM toolbox.

Constraints to IPM adoption include a lack of incentives for participatory multidisciplinary research, a gap between scientific IPM information and user-friendly management systems and extension materials, and unfavorable national policies, especially pesticide subsidies. In addition, in some cases such as rice, a critical proportion of farmers must adopt IPM practices to avoid pest invasion in IPM plots from neighboring non-IPM fields. Future priority should be given to action-oriented research, involving individual farmers and farmer groups in technology use, participatory research, and technology evaluation. 
R\&E investment alone is unlikely to result in broad-based adoption of IPM systems, which tend to be complex and management-intensive. Mass media campaigns and social marketing can shape the awareness and behavior of pesticide users. In Vietnam the simple message "do not spray early in the season" was successful in changing commonly-held perceptions and contributed to significant reduction in pesticide use.

\section{BENEFITS}

Adoption of IPM practices can reduce pesticide costs, increase production, and reduce damage to the environment and human health. Concerns focused on groundwater pollution, pesticide poisonings, loss of biodiversity, and negative effects on soil health, provide strong justification for public sector investment in IPM (see box 4.31). Increasing food quality and safety standards have specific implications for pesticide residues in agricultural products. However, developing the certification systems and the necessary monitoring capacity can be a major hurdle to attaining this market access. Investment in this area is critical. Evidence on cost effectiveness on IPM is mixed. Most analysts suggest that IPM programs contribute to a decline in pesticide use but labor costs may increase.

\section{POLICY AND IMPLEMENTATION ISSUES}

PERNICIOUS EFFECT OF SUBSIDIES. Efforts to promote IPM often must struggle against the legacy of policies aimed at promoting pesticide use as a means of modernizing agriculture. Such policies, ranging from explicit subsidies to preferential tariffs and foreign exchange regimes to chemical-oriented agricultural R\&E services, serve to reduce the cost of using chemical pesticides and can seriously undermine IPM adoption (see box 4.32). Promoting input market pricing that reflects the true costs associated with production and consumption is critical to encouraging IPM adoption in areas where it can be beneficial.

TIME LAG FOR ADOPTION. IPM skills and practices do not spread as easily as information embedded in
Box 4.3I Turkmenistan: biological control

Since 1998, the Government of Turkmenistan has reestablished its biological control scheme for cotton production, a scheme that had been nearly abandoned. Biological control was introduced in the early 1980s after chemical pesticides became ineffective and residues, especially persistent organochlorine compounds, were found in water, soil, and food. The breakup of the centrally planned economy of the Soviet Union led to a deterioration of the rearing facilities for predators to control insect pests in cotton. Since 1998, the government rehabilitated insect rearing facilities (primarily for Trichogramma and Bracon), and introduced cost recovery from farmers. With over 90 percent of cotton crop protection now under biological control, there are greatly reduced environmental and health risks.

Source: Schillhorn van veen et al. 2000.

technologies such as improved seeds or chemicals. Extension services play a key role in providing IPM information, though the complexity of some IPM approaches requires a heavy emphasis on teaching agro-ecological concepts as a basis for farmer adoption of IPM practices.

Cost/BenEFIT Issues. Attention to economic viability of IPM investments is particularly important in large-scale extension and training programs. Extrapolating costs and potential benefits based on pilot project experience may

Box 4.32 Pakistan: incoherent policies constrain IPM adoption

Adoption of IPM in Pakistan is still in its infancy, despite significant investment in R\&E. The government sees IPM as a key element of agricultural policy, yet deregulating imports of generic pesticides has improved farmer access to inexpensive chemicals. Emerging pest resistance due to misuse of pesticides led to a decade-long decline of productivity in the cotton sector, in which poor rural women, who pick cotton as their only source of income, were most affected by the health impacts of increasing insecticide use. Reviving the cotton economy has been the main motive behind changes in pesticide policy. After thorough analysis of the economics in the pesticide subsector, and consultation with all relevant stakeholders in 200 I, a comprehensive national IPM program was designed, including farmer training, tightening regulatory control, and removal of pesticide subsidies.

Source: FAO/UNDP/Government of Pakistan 200 I. 
Box 4.33 The Farmer Field School concept for IPM training

The Farmer Field School (FFS) approach stressing experiential learning of fundamental agro-ecological principles evolved in the 1980s in Southeast Asia to address the problem of insecticide overuse. Excessive use of broad-spectrum insecticides in irrigated rice, stimulated by the lack of pest resistance of early high-yielding varieties, was disrupting the ecosystem thus affecting farmer's yields and profits. FFS farmers, trained in weekly sessions throughout the cropping season, conducted hands-on experimentation in the field. Capacity building for extension staff and farmer groups has been central to pilot projects for IPM training in FFSs in over 25 countries.

While the FFS model might be a promising approach to promoting participatory IPM, after mixed experience with large-scale projects in Indonesia and Vietnam, there are serious reservations as to the advisability of financing FFS programs on a large scale through public extension services. Large-scale programs have proven financially unsustainable and had insignificant impacts on pesticide use and IPM diffusion (Feder, Murgai, and Quizon 2003).

Source: Authors.

overestimate training impacts and underestimate costs, as these investments in human capital development may produce benefits only in the long term. Program initiatives must assess expected and actual changes in production costs, yields, output prices, and pesticide use and the sustainability of these changes. In addition, yield variability is likely to increase, and farmers must have access to tools for managing production risks.

ROLE OF GENETICALLY MODIFIED ORGANISMS (GMOS). Varieties resistant to pests and diseases, possibly developed through use of biotechnologies, have potential to eliminate the need for multiple applications of pesticides. Biosafety issues and impacts on the overall ecology are controversial, and must be addressed in considering the use of GMOs.

LONG-TERM SUSTAINABILITY. IPM initiatives will be most successful in situations where there is overuse of chemicals for pest control, and where supportive R\&E systems and policy and regulatory frameworks are in place. Also, economic viability is enhanced where markets place a premium on IPM-produced products.
However, the number of cases where these criteria are met is limited.

\section{LESSONS LEARNED}

NEED FOR COMPREHENSIVE APPROACH. In many countries, IPM interventions have been planned without a clear understanding of pest management problems. IPM initiatives are often "addons" to regular R\&E projects, and tend to be isolated activities. A comprehensive approach to pest management, integrating interventions within an IPM national strategic plan, is preferred. Coordinated interventions based on identifiable targets and benchmarks are likely to be more effective than isolated activities. Verification of IPM outcomes (for example, reduction of pesticide use) is more important than simply measuring inputs such as the number of farmers trained.

IPM TRAINING. Participatory training and extension are important to changing attitudes of farmers and their service providers. One such approach - the Farmer Field School (FFS)—has received particular attention (see box 4.33). An alternative strategy targets IPM for cropping systems with significant potential to reduce inefficient pesticide use and raise farm income, for example cotton and horticultural crops. In cropping systems with a low level of external inputs, integrating IPM messages into a program to promote overall good agricultural practice is more effective than focusing on pest control alone. Training for input suppliers, extension agents, financial services providers, and produce buyers is important to develop the overall IPM knowledge system.

NEW MARKET OPPORTUNITIES. In global markets, maintaining competitiveness requires producers to be sensitive to changing consumer preferences regarding product quality. This provides new opportunities for cooperation between producers and the private sector. However, where IPM is to be used to increase product value, supporting certification systems must be established to assure downstream participants (including retailers and consumers) that IPM principles have been followed (see box 4.34). 


\section{RECOMMENDATIONS FOR PRACTITIONERS}

Given the lessons emerging from past experience, investments related to IMP should (see box 4.35):

- Promote policy changes required to allow the emergence of undistorted input markets that price pesticides at levels reflecting the true economic and environmental costs of production and consumption of chemicallybased pest control inputs.

- Develop a sound research base for developing and supporting IPM technologies and management systems.

- Address the larger institutional and policy environment issues governing pesticide use, before focusing on knowledge transfer to extension agents and farmers.

- Develop a reliable information base on trends in pesticide use and productivity of pest management systems to support design of a sound pest management strategy.

Identify likely changes in markets and prices and production options, including the potential for adding value through certification of compliance with IPM standards.

- Include stakeholders from agriculture, environment, and health sectors in activities to build consensus on approaches to use of IPM (Fleischer and Waibel 2003).

- Invest in IPM training of farmers and extension workers, adopting a demanddriven approach to target training inputs to address producers' pest management problems, and to respond to emerging market opportunities.

\section{SELECTED READINGS}

Asterisk (*) at the end of a reference indicates that it is available on the Web. See Appendix 1 for a full list of Websites.
Box 4.34 Options for cooperation with the private sector

High-value niche markets for tropical products grown in an environmentally and socially responsible manner are a fastgrowing market segment (for example, "sustainable" coffee). Integrated pest management (IPM) is an indispensable tool for delivering a good-quality product through a "sustainable" production process. Private firms developing specialty product lines are good partners for local authorities, farmer associations, and $\mathrm{NGOs}$.

IPM programs may support the development of the biopesticide industry, which is still small, but relevant to crops with limited markets that are neglected by large pesticide producers. Cooperation with the chemical industry can be rewarding, as both the public and private sector share an interest in reducing pesticide overuse, and in promoting resistance management strategies. Initiatives for "Safe Use" of toxic chemicals have been started by the pesticide industry and sometimes supported as public-private partnerships.

Source: Authors.

CABI Bioscience. Sustainable Agriculture:

Promoting an Integrated Approach to Food

Security and Productivity. http://www.cabibioscience.org/Html/

SustainableAgriculture.htm.

CGIAR. The Systemwide Program on Integrated Pest Management. http://

www.spipm.cgiar.org.

Farah, J. 1994. "Pesticide Policies in Developing Countries: Do They Encourage Excessive Use?” Discussion Paper 238. World Bank, Washington, D.C.*

Gallagher, K. D. 1999. "Farmer Education for IPM." Sustainable Developments International, International Edition 1.*

\section{Box 4.35 Potential investments}

- Policy analysis and strategy development.

- Research on pests and diseases.

- Training of extension staff and other service providers.

- Training of individual farmers and farmer groups.

- Awareness campaigns among farmers, consumers, and food chain operators.

Source: Authors. 
Global IPM Facility. http://www.fao.org/ globalipmfacility/home.htm.

Integrated Pest Management Collaborative Research Support Program (IPM CRSP). http://www.ag.vt.edu/ipmcrsp/index.asp.

Murray, D. L., P. L. Taylor. 2000. "Claim No Easy Victories: Evaluating the Pesticide Industry's Global Safe Use Campaign." World Development 28 (10): 1735-1749.*

\section{REFERENCES CITED}

FAO/UNDP/Government of Pakistan 2001. "Policy and Strategy for Rational Use of Pesticides in Pakistan. Building Consensus for Action." Food and Agriculture Organization, United Nations Development Programme, Government of Pakistan. United Nations Systems in Pakistan Publicaions No. UN-PAK/FAO/2001/02, Islamabad 2001.

Feder, G., R. Murgai, and J. B. Quizon. 2003. "Sending Farmers Back to School: The Impact of Farmer Field Schools in Indonesia." Policy Research Working Paper 3022. World Bank, Washington, D.C.

Fleischer, G., and H. Waibel. 2003. "Pesticide Policy and Integrated Pest Management." In K. M. Maredia, D. Dakouo, and D. MotaSanchez, eds., Integrated Pest Management in the Global Arena. Wallingford, U.K.:

CABI Publishing.

Schillhorn van Veen, T. W., D. A. Forno, S. Joffe, D. L. Umali-Deininger, S. Cooke. 1997. Integrated Pest Management: Strategies and Policies for Effective Implementation. Environmentally Sustainable Development Studies and Monographs Series 13. Washington, D.C.: World Bank.

Sorby, K., G. Fleischer, and E. Pehu. 2003. Integrated Pest Management in Development: Review of Trends and Implementation Strategies. Agriculture and Rural Development Working Paper 5. World Bank, Washington, D.C.
This Note was prepared by Gerd Fleischer (GTZ) with inputs from the Sustainable Agriculture (SASKI) Thematic Team of the World Bank 


\section{INTEGRATED NUTRIENT MANAGEMENT FOR SUSTAINING SOIL PRODUCTIVITY}

Future food and fiber must be produced on existing agriculture land, with less negative impacts on natural resources and the environment than in the past. The timely supply, efficient use, and careful monitoring of nutrients in integrated crop, forage, and tree production systems offer the potential for significant improvement of efficiency in plant nutrient use. Farmers, researchers, and other stakeholders need to be more actively involved in the generation and use of the knowledge required for integrated nutrient management.

Although science-based agriculture has made major contributions to both the quantity and quality of the global food supply, the rate of yield increase for major food crops has begun to slow in recent years. In many parts of the world, agricultural production increases have been accompanied by significant degradation of natural resources including nutrient depletion on agricultural lands.

Integrated nutrient management (INM) is an approach that involves the management of both organic and inorganic plant nutrients for optimal production of cultivated crops, forage, and tree species, while conserving the natural resource base essential for long-term sustainability. Nutrient flows occur at different scales in any agroecosystem, and soil nutrient budgets for a given area and time can be calculated by the difference between the nutrient inputs and outputs (see figure 4.3). Large soil nutrient surpluses can lead to environmental pollution, whereas persistent soil nutrient deficits usually indicate nutrient mining.

Effective INM involves four interrelated strategies:

- Conservation and efficient use of native soil nutrients. Conservation practices help to reduce loss of nutrients from agroecosystems due to surface water flows and from erosion of soil by wind and water. Vegetative barriers minimize off-farm transport of dissolved nutrients, dust, and sediments, and deep-rooted plants act as nutrient safety nets, intercepting leached nutrients from the root zone and returning these to the soil surface via litter fall, mulch, or as green manure. In general, conserving existing nutrient resources is easier and cheaper than replenishing and rehabilitating degraded resources.

- Recycling of organic nutrient flows. Returning crop residues and/or animal manure to

FIGURE 4.3 NUTRIENT FLOWS IN AGROECOSYSTEMS

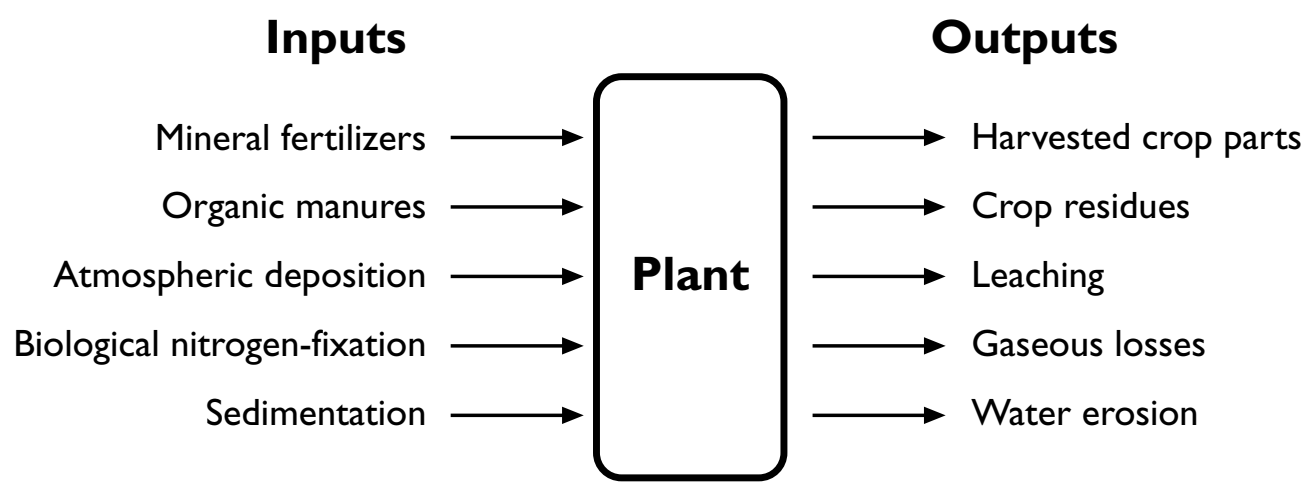

Source: Smaling 1993. 
cropland is important for system sustainability. Composting crop residues and animal manures enhances the utilization efficiency of easily lost nutrients such as nitrogen. Converting linear flows (lost from the system) of organic nutrients to cyclical flows (returned to the system) can reduce the need for external nutrient inputs. There are related potential price benefits in organic product markets. Livestock are important for processing crop residues, adding value to farm outputs, improving labor efficiency, and providing manure.

\section{- Enhancing biological nitrogen fixation and} soil biological activity. Nitrogen fixing crop, forage and tree/shrub species scavenge nitrogen from the soil and/or fix nitrogen from the atmosphere when soil levels are below plant requirements. Most nitrogenfixing plant species also form symbiotic relationships with mycorrhizal fungi that improve soil aggregation, nutrient and water use efficiencies, and protect the plant roots from a variety of pathogens. This is

\section{Box 4.36 Soil nutrient recapitalization}

Researchers estimate that the croplands of many smallholder farmers, especially in Africa, have become depleted of the nutrients that are removed by crop harvests. Published estimates from 40 African countries indicate a net negative annual balance of $22 \mathrm{~kg}$ of nitrogen, $2.5 \mathrm{~kg}$ of phosphorus, and $15 \mathrm{~kg}$ of potassium per hectare of cultivated land. To meet increasing demand for food, soil scientists have recommended a major capital investment to replenish soil nutrients in Africa. Social scientists, however, caution against blanket nutrient recapitalization as nutrient deficit statistics are based on limited datasets, and fail to account for nutrient variability and transfers at the farm and watershed level. Furthermore, many socioeconomic and institutional factors influence farm management decisions. For example, smallholder farmers in western Kenya are gradually but significantly improving both crop yields and soil fertility because of the availability of locally repackaged one to five kg bags of fertilizer that they can afford, transport, and use on selected crop fields. As crop yields and input-output markets improve, they invest further resources for more fertilizer nutrients and improved seed.

Source: Anderson et al. 2002. one example of an INM practice that also contributes to IPM. Integration of nitrogenfixing species into cropping systems diversifies inputs/outputs and reduces risk on both economic and ecological fronts.

- Addition of plant nutrients. The nutrient content of highly weathered soils is very low. In most cases, the export of nutrients in harvested products results in one or more plant nutrients becoming limiting. In the humid tropics, calcium and phosphorus are often limiting for crop growth and productivity. Appropriate amounts of lime and nutrients are essential to optimize plant root growth, enhance the efficiency of added nutrients, and avoid soil degradation (see box 4.36). Although inorganic fertilizers such as limestone and rock phosphate are consistent with organic agriculture, inorganic fertilizers are often the most efficient means of adding soil nutrients. In many places (such as in Africa) they are essential for improving productivity to levels that will then enable adoption of wider INM practices.

In the past, the cost of soil and crop sampling and nutrient analyses made site-specific fertilizer application recommendations prohibitively expensive for most agricultural programs. Blanket fertilizer recommendations were common, but blanket application of fertilizers is often uneconomic and can lead to pollution. Recent advances in plant nutrient decision support models, improved access to high-resolution satellite images, and the improved interpretation of crop and soil spectral signatures make sitespecific recommendations possible.

\section{BENEFITS}

The reduced erosion and increased cycling of organic residues in INM can increase or at least maintain native soil organic matter levels, and thus improve both nutrient and water retention capacity of the soil. Soils with around three percent soil organic matter content and dynamic soil fauna populations generally have better soil structure, water infiltration, soil 
aeration, and plant root growth than soils with lower organic matter. Improved soil water infiltration and retention significantly reduces surface flow of water, soil erosion, and nutrient removals, and also minimizes the risk of downstream flooding.

INM can reduce plant requirements for inorganic nitrogen fertilizer, and reduced use of purchased fertilizer nutrients can result in a significant saving of scarce cash resources for small farmers. INM practices can also significantly reduce the emissions of greenhouse gases (nitrous and nitric oxides). Excessive applications of nitrogen fertilizer can result in increased leaching of nitrates into ground water, increasing health risks to newborn infants and cancer risk in adults. Organic nutrient flows cycled through the return of organic residues as compost, manure, and/or mulch have significant implications for conserving soil fauna biodiversity.

\section{POLICY AND IMPLEMENTATION ISSUES}

Precision farming. For large-scale farming, there has been significant private sector investment in fertilizer-based nutrient delivery and tracking systems. This has resulted in precision farming that uses satellite-based global positioning systems on tractors and harvesters to monitor and manage soil, plant, and grain nutrients by location in the field. Most smallholder farmers in the tropics, however, will need public support for participatory, multidisciplinary R\&E services to apply INM principles to the varied infrastructure, soil, and climatic conditions of their farms. This will require extensive local adaptive testing of technologies supported by comprehensive databases on soil characteristics, crop nutrient use and productivity, organic and inorganic fertilizer properties, and market prices.

Results take time. Benefits from INM are often seen only in the medium to long term, and in many cases the benefits are to populations living downstream of INM practitioners. Costs and benefits of INM practices should be monitored and quantified at farm and landscape levels so that appropriate premiums and taxes can be assessed to facilitate and promote the widespread adoption of INM practices. INM programs need to consider also the impacts on water and air pollution, siltation, salinization, biodiversity impacts, carbon sequestration and greenhouse gas mitigation in research programs.

FERTILIZER, SOIL, AND PLANT-TESTING LABORATORIES. Accurate information on the nutrient composition of available fertilizers and site-specific application recommendations are important to INM, which relies on a good understanding of nutrient contents and flows. Consequently, there is a need for reliable soil, plant, and nutrient input testing facilities that can provide low-cost testing services to farmers in the initial stages of INM adoption. Opportunities exist for use of properly tested and treated urban waste and sludge, and these and local rock phosphates need to be tested to ensure that materials with high concentrations of heavy metals or toxins are not supplied to farmers. Public laboratories (especially for soil testing) are often inefficient, inaccurate and poorly managed, whereas private laboratories are relatively rare and costly. Country-specific strategies are needed to establish and maintain accurate analytical laboratory capacity.

Price, trade and taX policies. Fertilizer prices for many tropical smallholder farmers, especially in Africa, are more than double the prices paid by farmers in industrial countries. Crop prices are also too low or too unstable to allow farmers to profitably invest in nutrient replenishment of their depleted or degraded farmlands. Public policy needs to seek ways of reducing high fertilizer prices to farmers through more efficient marketing systems, but rarely should consider introducing subsidies.

LABOR SUPPLY. Labor markets can be constraining as INM often requires more labor inputs than do systems relying solely on inorganic fertilizers. Labor supply is affected by the dynamics of labor markets and the impact of disease (HIV/AIDS, for example). Appropriate tools and machinery for small farmers, that can be locally produced, refined, and maintained, can significantly reduce the drudgery of field work and 
facilitate the adoption of labor-intensive INM practices. Excellent examples of such tools can be found in the cover crop and conservation tillage systems of southern Brazil.

\section{LESSONS LEARNED}

FARMER LEARNING. Adding fertilizer nutrients will not be enough to improve and sustain crop productivity. It is essential to also engage farmers in the diagnosis and design of farm and watershed nutrient management and facilitate farmer learning. As farmers become familiar with INM principles, they begin to innovate with different strategies in their own environments (see box 4.37).

INORGANIC FERTILIZERS. In most tropical soils and integrated cropping systems, inorganic fertilizers must supplement organic nutrients. On degraded soils, inorganic nutrients are needed to prime the biological potential of native vegetation to produce the organic inputs prior to the adoption of INM strategies. The availability of appropriately formulated fertilizers at accessible prices is important for increasing the use of these nutrient sources by smallholder farmers.

PROPERTY RIGHTS. Land and resource tenure rights influence the relative values of land, labor, and capital. Secure tenure is important in providing incentives for investment in land resources, soil nutrient buildup, erosion control, perennial crops, and other critical elements of INM. Land

Box 4.37 Nutrient budgeting tools: NUTMON

A consortium of African and Dutch research institutes has worked with farmers in Sub-Saharan Africa to establish a program called NUTMON to monitor farm level nutrients. Participating farmers know that land productivity has been declining for years, and that continuous cropping, loss of nutrients in harvested products, and manure shortages are to blame. NUTMON increases farmer awareness of the role of soil nutrients, and gives them a tool to assess nutrient balance on the farm. Researchers have documented changes in crop management as a result of NUTMON.

Source:Vlaming, Gitari, and van Wijk 1997. tenure security helps in accessing financial services to improve farmers' access to credit for these investments.

INFRASTRUCTURE AND SERVICES. INM strategies are adapted to many situations, but are most likely to thrive in an environment in which supporting infrastructure and services exist and agriculture can be profitable. Roads are needed to bring in appropriate inputs and take out marketable products. Farmers must also have access to market information and INM knowledge obtained from productive research systems and extension information services. Good information services and other means to help manage risk provide a basis for farmer innovation and adoption of INM.

LEGUMES AND ADAPTED SPECIES. Legumes are central to the INM strategy, and leguminous species that combine moderate seed yield with high root and leaf biomass (and thus have a low harvest index) can help farmers meet household food needs while improving soil fertility.

Soll microbes. The selection and use of adapted soil microbes (rhizobia and mycorrhizal fungi), together with the active manipulation of soil macrofauna ("soil engineers"), organic residues, and modest levels of inorganic nutrients, can promote significant synergistic responses in plant growth and yield.

\section{RECOMMENDATIONS FOR PRACTITIONERS}

Investments designed to facilitate widespread adoption of sustainable INM practices will need to consider the (see box 4.38):

\section{- General environment for agricultural} profitability. INM investment planning must assess adequacy of infrastructure (roads, communications, markets), financial services, and technical support, and structure INM programs accordingly.

- Policy and price environment. Fertilizer pricing policies as well as regulations governing environmental impacts of agri- 
cultural production (such as pollution from overuse of fertilizers) affect acceptability of INM innovations, and need to be assessed in program planning.

- Knowledge base. R\&E information systems are central to INM. NGOs and farmer organizations can be allies in promoting INM technologies, but sound research and soil/plant/fertilizer testing laboratories are essential backups.

\section{SELECTED READINGS}

Asterisk (*) at the end of a reference indicates that it is available on the Web. See Appendix 1 for a full list of Websites.

Department for International Development. Soil Fertility and Nutrient Management. http://www.odi.org.uk/keysheets/ green_7_soil_fertility_and_nutrient_mgt.html.

Havlin, J. L., S. L. Tisdale, W. L. Nelson, J. D. Beaton. 1998. Soil Fertility and Fertilizers: An Introduction to Nutrient Management. 6th ed. Upper Saddle River, N.J.: Prentice Hall.

Integrated Plant Nutrition Systems (IPNS) Compendium. http://www.fadinap.org/ ipns/ipnscompendium/documents.htm.

International Fertilizer Industry Association. http://www.fertilizer.org.

Vanlauwe, B., J. Diels, N. Sanginga, and R. Merckx, eds. 2002. Integrated Plant Nutrient Management in Sub-Sabaran Africa: From Concept to Practice. Wallingford, U.K.: CABI Publishing.

\section{REFERENCES CITED}

Smaling, E. M. A. 1993. "Soil Nutrient in SubSaharan Africa." In H. van Reuler and W. H. Prins, eds., The Role of Plant Nutrients for Sustainable Food Crop Production in Sub-Sabaran Africa. Leidschendam,

\section{Box 4.38 Potential investments}

- Policy analysis and formulation and regulatory system development relevant to fertilizers and soil fertility management.

- Training and extension to facilitate farmer access to knowledge on integrated nutrient management (INM) and advocacy and information campaigns.

- Soil-plant, and fertilizer testing facilities and incentives for private investment in testing facilities.

- Participatory research on soil nutrient management, including site and crop-specific fertilizer use recommendations.

- Regional fertilizer purchasing, mixing, and local repackaging.

- Processing of urban waste and sludge for use as soil amendments.

- Transportation infrastructure.

- Systems for environmental services payment (including quantifying on-farm and off-farm costs and benefits of INM).

Source: Authors.

Netherlands: Dutch Association of Fertilizer Producers.

Anderson, J., M. Blackie, M. Eilitta, E.

Fernandes, N. Sanginga, E. Smaling, and D. Spencer. 2002. "A Consultative Review of the Rockefeller Foundation's Activities to Improve and Sustain Soil Fertility in East and Southern Africa." The Rockefeller Foundation, N.Y.

Vlaming, J., J. N. Gitari, and M. S. van Wijk. 1997. "Farmers and Researchers on Their Way to Integrated Nutrient Management." ILEIA Newsletter 13 (3): 6.

This Note was prepared by Erick Fernandes with input from the Sourcebook team. 
INNOVATIVE ACTIVITY PROFILE

\section{CHINA: FRUIT PROMOTION IN THE MID-YANGTZE}

Only about 137 million hectares of China's 960 million hectares of land are arable. Farming systems are intensive with heavy use of inputs. Foodgrains occupy about 70 percent of total cropland and, although intensive farming has allowed China to meet its basic food needs, the government's central concern in recent years has been stagnating grain production. One element of the agricultural strategy involves exploring ways to increase use of uplands and other underused areas to expand productivity of nonstaple food and commercial crops to meet demand, increase farmer incomes, and reduce the pressure on land suited to production of grains.

What's innovative? Focusing on bringing hillside lands, traditionally considered uncultivable, into sustainable production systems to increase farmer incomes by using improved technologies and commercial solutions along the entire value chain.

\section{PROJECT OBJECTIVES AND DESCRIPTION}

The main objectives of the Mid-Yangtze Agricultural Development Project were to increase the production, productivity, and marketability of fruit production in low-income areas of Sichuan, Hubei, and Chongqing, and thus increase incomes and alleviate poverty. The project was designed to provide a demonstration model for the development of hilly wastelands into orchards. Specific objectives were to:

- Develop 12,000 hectares of new orchards and rehabilitate 2,500 hectares of existing orchards.

- Increase the provincial agriculture bureau's ability to: identify, propagate, and distribute healthy, disease-free planting materials; institutionalize virus indexing and budwood registration programs; provide technical assistance for R\&E programs, and training for managerial and technical staff.
- Establish commercially independent Fruit Development Corporations to market fruit in local, distant, and export markets.

- Provide a demonstration model for fruit production that could be applied elsewhere.

The project was designed to develop unused and underutilized hilly areas into productive high-value citrus production. It emphasized the extension of already existing research results to farmers, community participation in investment and operation, and an integrated approach along the value chain from selection of better varieties to market-enhancing postharvest treatment. Villagers participated in both the land terracing and planting, and soil conservation measures, such as terracing, contour planting, and use of green cover crops, were introduced to improve environmental conditions. The new and better varieties included some with longer harvesting seasons, allowing greater production in off-peak months and consequently higher prices. New irrigation, planting, and postharvest technologies were adopted. Grading, packaging, and storage facilities were installed, and independent commercial corporations set up to market the output.

Farmers were responsible for contributing to the investment in orchard development through uncompensated labor during terracing, planting, growing, and harvesting. The county governments of the project area, which received IDA funds, passed on orchard development costs, such as for terracing and technical services, to project farmers as 10-year loans at commercial rates of interest.

Commercial Fruit Development Corporations (CFDCs) invested in and managed modern treatment, packing, and storage facilities, and purchased fruit from farmers. They sell the fruit purchased from farmers in local, distant, and export markets, although farmers are free to use other distribution channels. Provincial Fruit Development Corporations provide marketing 
services, such as market information, and interprovincial and export trading services to the CFDCs on a commission basis, but the CFDCs are also free to use other channels, such as Foreign Trade Corporations and direct export sales.

\section{BENEFITS AND IMPACTS}

- Household income increased dramatically, for example, orange growers income increasing by Y13,000 to Y26,000 depending variety of orange grown.

- Income generating activities and employment opportunities for participating farm families have increased with 13,000 extra jobs during construction and implementation.

- Large numbers of nonproject farmers now use technologies developed under the project. It appears that acreage of new orchards developed by farmers outside the project area amounts to four to five times that in project orchards.

- Soil erosion has been reduced through introduction of terracing and planting of vetiver grass for stability. In one example, eroded acreage has been reduced from 48 percent in 1990 to only 13 percent in 1995.

\section{LESSONS LEARNED AND ISSUES FOR WIDER APPLICABILITY}

The project, providing demonstration models for the development of waste hilly lands into orchards, has proven highly satisfactory. Key lessons learned include:

- Participation of farmers with a sense of ownership from the beginning made a big difference in how the project was implemented.

- A strong research and scientific base drawn from domestic and international experience, and the involvement of a science and technical committee, were essential to the success of this project.
- Cooperation among the Ministry of Agriculture, provincial and local governments, and research institutes is essential to effective implementation.

- Implementing agency staff must have strong technical skills relevant to program operations.

The project has applicability to other regions of the world that need to expand production to fragile hillside lands, or to reduce soil erosion while still improving production on these lands. If the baseline characteristics of the Chinese example (labor surplus, government support, market demand) are used as a guide, such a project could be applied to other similar regions.

\section{PROJECT COUNTRY: CHINA}

\begin{tabular}{|c|c|}
\hline Project Name & $\begin{array}{l}\text { Mid-Yangtze Agricultural Develop- } \\
\text { ment Project }\end{array}$ \\
\hline Project ID & P00354I \\
\hline Project Cost & US\$130.8 million \\
\hline Dates & FY199I - FY 1997 \\
\hline Contact Point & $\begin{array}{l}\text { Rapeepun Jaisaard } \\
\text { The World Bank, I } 8 \text { I } 8 \text { H Street } \\
\text { NW,Washington, D.C. } 20433 \\
\text { Telephone : (202) 458-4057; email } \\
\text { Rjaisaard@worldbank.org }\end{array}$ \\
\hline
\end{tabular}


INNOVATIVE ACTIVITY PROFILE

\section{INDIA: COMMUNITY ORGANIZATION FOR SODIC LANDS RECLAMATION}

Uttar Pradesh State in India has about 17 million hectares under cultivation, and accounts for 10 percent of India's net sown area and 25 percent of the total irrigated area. It produces nearly 20 percent of India's food grains. A major concern in the state is the declining productivity of food grains, especially of rice and wheat. This is mainly due to water-induced land degradation (salinization, sodification, groundwater depletion), and loss of soil fertility with the sustained removal of nutrients associated with more intensive cropping and the inappropriate use of heavily subsidized nitrogenous fertilizers.

What's innovative? Making participation a necessary condition for sustainable land reclamation and development by investing heavily in participatory processes, community mobilization and organization, before and during implementation.

\section{PROJECT OBJECTIVES AND DESCRIPTION}

The main objectives of the Uttar Pradesh Sodic Lands Reclamation Projects (Sodic I and Sodic II) were to:

- Develop models for environmental protection and improved agricultural production through large-scale reclamation of sodic lands.

- Strengthen local institutions to manage such schemes.

- Contribute to poverty reduction of the families concerned.

The Sodic I pilot took the approach that for any physical investments in the land to lead to effective reduction in sodicity, the investments would have to be partnered and owned by a community that recognizes their value. It thus built a project design based on participation, decentralization, and linking research and technology institutions to farmers. Under Sodic I, approximately 64,000 hectares of barren lands were brought under green cover for the first time. Sodic II seeks to use the approaches tested in Sodic I to increase agricultural productivity in ten districts of Uttar Pradesh. Essential elements for sustained land quality improvements were defined to include community participation and ownership, rehabilitation of drains, improved irrigation management, and increased research on appropriate technologies. The research-extension link was also found to be weak and was to be strengthened through community-based mechanisms. Important components relating to participation and the characteristics of these include:

- The on-farm development and land reclamation component focuses on beneficiaryled, on-farm reclamation efforts.

- The technology dissemination component establishes a community-based, demanddriven system, building on the successes of the pilot project in developing grassroot organizations and their participation in supporting technology dissemination.

- Human resources development and institutional capacity building of support services focuses on staff training and institutional strengthening in the Panchayats (village governance institutions), NGOs, and executing government agencies.

- Adaptive research verifies and refines available technologies to suit the specific needs of local farmers, and to bring about sustainable increases in the productivity of sodic lands through reclamation. Support for additional research on improving cost effectiveness and efficiency of land reclamation is made available through a Competitive Agricultural Research Fund accessible to both the private sector and national institutes. 
Beneficiary participation occurs through targeted project interventions including:

- Formation of Water User Groups (WUGs) consisting of 10-15 farmers responsible for a pump set and shared wells. WUG formation is supported by local NGOs that are also supported through project activities (capacity building).

- Establishment of Site Implementation Committees comprised of two members (one male and one female) from every sodic landholder household, in combination with WUG representatives and indirect beneficiaries such as school teachers and local leaders. These committees have a mandate for resolving conflicts, monitoring progress, selecting resource people and trainers, and maintaining infrastructure.

\section{BENEFITS AND IMPACTS}

Yields of rice and wheat doubled as compared to original project estimates, wage rates doubled, and land values increased by a factor of four. By the end of the first project, cropping intensity had increased from 62 to 222 percent, wheat and rice yields had reached 2.7 and 3.0 tons per hectare, respectively, and more than one million people had directly benefited from project activities.

\section{LESSONS LEARNED AND ISSUES FOR WIDER APPLICABILITY}

Success has been attributable to: flexibility in project design; strong commitment of project management and staff; strong beneficiary participation facilitated by effective use of NGOs as supporting and motivating agencies, and a systematic approach to a full reclamation package including beneficiary involvement, construction of drains, on-farm development, application of chemical amendments, and crop production. Some of the key lessons learned include:

- Mobilization and involvement of communi- ties in project implementation is essential. An important ingredient for motivating beneficiaries was that they were able to see returns in a short period by participating in the project.

- Joint partnership with all organizations that have key roles in project implementation helps to ensure that they are fully supportive and complete their functions on time.

- Public corporations/societies have more flexibility than line departments.

- Capable NGOs are important for forming, training, and supporting farmer groups.

\section{PROJECT COUNTRY: INDIA}

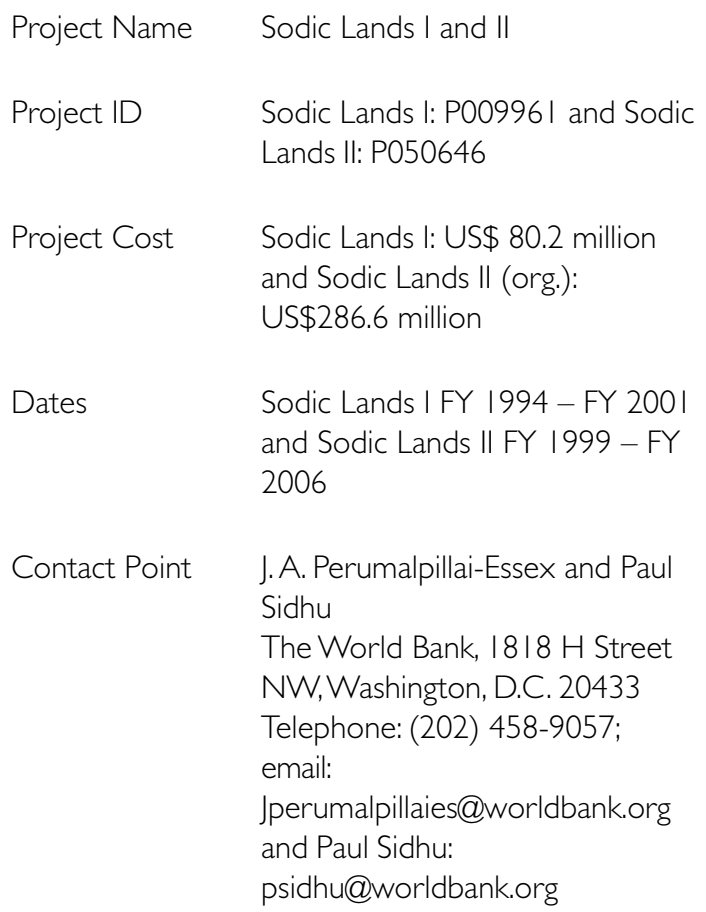


INNOVATIVE ACTIVITY PROFILE

\section{INDIA: INCOME GENERATION THROUGH AQUACULTURE}

The fisheries subsector contributes only about 2.4 percent of India's agricultural GDP, and less than one percent of total GDP. However, fisheries are important in providing employment to an estimated nine million people predominantly from poorer coastal communities. Furthermore, fisheries contribute to improved nutritional standards and foreign exchange earnings. The development of fresh and brackish water aquaculture has been necessary for India to continue to meet its growing domestic needs and maintain its position in the export markets.

What's innovative? Using technical assistance to build fishing cooperatives and to reform the regulatory and institutional practices needed to improve the efficiency and poverty impact of inland fisheries managed by small farmer-owned cooperatives.

\section{PROJECT OBJECTIVES AND DESCRIPTION}

The overall project objective of the Shrimp and Fish Culture Project was poverty reduction through employment from increased shrimp and inland fish production, tapping underutilized intertidal areas and inland water bodies. Interventions included:

- A brackish water shrimp component (three states and about 80 percent of project costs).

- An inland fisheries component (four states and about eight percent of project costs).

- Project management, including environmental management and training (about 12 percent of project costs).

In the past almost all shrimp culture was based on a traditional, extensive shrimp culture system, with ponds frequently used for paddy cultivation in the rainy season, and converted to shrimp and fish culture the rest of the year. As a result, shrimp yields were low (average below 300 kilograms per hectare), reflecting poor infrastructure, low density of stocking, inadequate water exchange, lack of feed, and low level of technology. The project's shrimp component supported the first attempt to introduce the technologically advanced semiintensive shrimp culture.

For shrimp aquaculture, the project brought together entrepreneurs to work with beneficiaries from the weakest socioeconomic sections of the community (with a ratio of 3 entrepreneurs to 7 beneficiaries). Pond site and infrastructure development account for 73 percent of total project costs and involved development costs of about US $\$ 11,000$ per hectare. Close coordination between shrimp production, hatcheries, and feed suppliers was important. Other activities financed include credit for private entrepreneurs for establishment of support infrastructure and services (hatcheries, nurseries, feed mills, ice plants, individual quick freezing machinery) and initial working capital for stocking ponds and feed to benefit poorer farmers. The participating state governments constructed basic infrastructure and common facilities on state-owned lands, and recovered costs through lease charges.

Although individual ponds are owned by individual beneficiaries, the interlinkages in the system required coordinated management through an association of pond owners. Technical assistance and training to promote development of fish cooperatives was an important aspect of the project. Some of the ponds were leased to the private sector firms to provide opportunities for improved technology access and transfer to the community farmers. High investment needs, the ongoing need for intense management and coordinated decisionmaking, and high risk aversion of poor farmers made the system complex, and required the project to focus on developing solutions for these problems.

Overall, the project focused on reform and 
capacity building of the cooperatives; reform of regulations and lease and management practices; strengthening of the cooperative position vis-à-vis large contractors and downstream water user associations; increase in cooperative members' knowledge of the ecosystem, natural cycle of species and catch management; and capacity building for increased market orientation.

\section{BENEFITS AND IMPACTS}

Specific impacts included: fish catch increased by up to 250 percent; in Bihar, Andhra Pradesh, and Orissa, approximately 15,000 members of the 118 project-assisted cooperatives are engaged in rearing fingerlings and marketing fish; cooperative membership has expanded to include women; and per capita income of fishermen has risen by between Rs6,000 to Rs13,250.

However, following the mid-term review the number of shrimp farm sites was reduced to six from 13, largely due to: the identified shrimp sites proving to be impractical on detailed technical surveys; and private sector developments overtaking project developments. Subsequently support services to infrastructure (shrimp hatcheries, ice plants and feed mills) were also reduced. This reflected the low demand resulting from a lower number of project-assisted shrimp production farms, and private sector investment in supporting infrastructure and service provision, reducing the need for project investment.

\section{LESSONS LEARNED AND ISSUES FOR WIDER APPLICABILITY}

The project highlighted the potential for successful community-based semi-intensive shrimp culture. However, the technology and investment intensiveness of the farms, complexities of management at group level by risk-averse farmers, environmental impact and resource linkages between farms, and the need for effective supply chains for an efficient industry, pointed to the need for follow-on work at an industry and watershed level to develop the

sector overall. It has been learnt that project impact is enhanced by:

- Maximizing participation of the poor through clear selection processes and detailed information.

- Providing in-service training to fisheries extension officers, especially in the areas of physical planning, optimizing fish production, marketing, and business management.

- Initiating accurate monitoring of fish/shrimp yields, and feeding this information back into planning to ensure fair rental charges by state governments.

Aquaculture systems need to be guided by appropriate policies embedded in a functioning regulatory framework. Aquaculture development must be accompanied by support from institutions capable of addressing collateral problems, such as displacement of existing fishermen and health and sanitation problems. A similar approach could be replicated in other freshwater and intertidal areas, though additional work would be required to refine the program model for use in other situations.

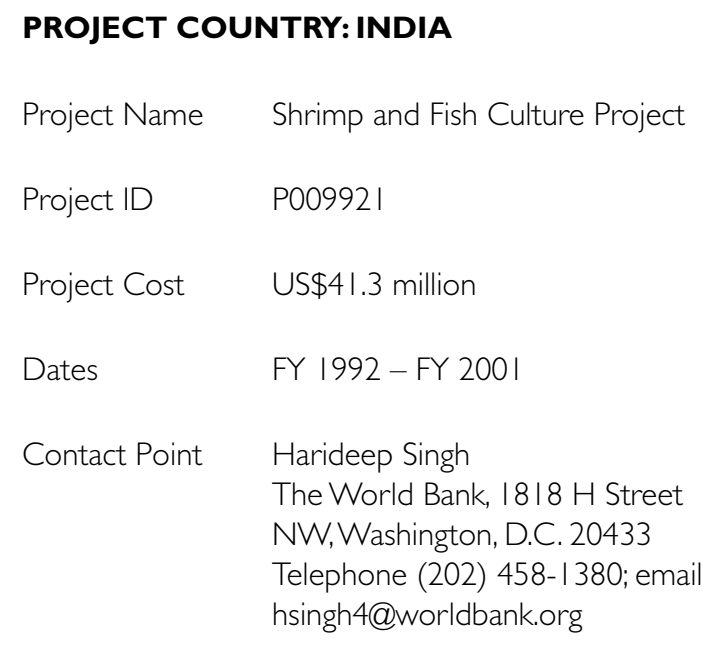





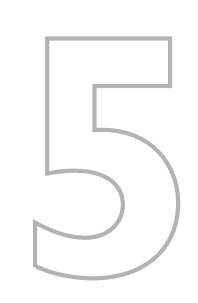

\section{INVESTMENT IN SUSTAINABLE NATURAL RESOURCE MANAGEMENT FOR AGRICULTURE}

$\mathrm{n}$ recent years, increases in agricultural productivity have come in part at the expense of deterioration of the natural resource base on which farming systems depend. It is urgent that this trend be reversed, by encouraging farmers to adopt more sustainable methods of farming that will have longterm benefits in environmental conservation and development of sustainable livelihoods. Public sector investments are critical to reversing trends in degradation of natural resources. Specific objectives for sustainable natural resource management (NRM) include: improving agroecosystem productivity; conserving biodiversity; reducing land degradation; improving water management; ensuring the sustainability of forests; managing the sustainability of wildlife and fisheries; and mitigating the effects of global climate change.

NRM refers to the processes and practices relating to the allocation and use of natural resources. Sustainable NRM optimizes the use of resources to meet current livelihood needs, while maintaining and improving the stock and quality of resources so that future generations will be able to meet their needs. 
NRM decisions are made at various levels - household, farm, community, national, and global. This Module focuses on off-farm investments and activities at the local and community level that have direct implications for sustainable agricultural systems. Farm-level practices or technologies with a benign or positive effect on the natural environment are outlined in the Sustainable Intensification Module.

\section{RATIONALE FOR INVESTMENT}

Agricultural production systems depend on natural resourcesæland (over 55 percent of nonforest land), water (about 80 percent of total fresh water), biodiversity, forests, pastures, and wildlife. Farm activities can also have major impacts on the quality and availability of these resources well beyond the boundaries of the production system (for example, downstream pollution and soil erosion). Although natural resources are critical to agricultural production, farm households also frequently depend on them to meet other needs, such as fuel, construction materials, and supplemental foods. Thus rural livelihoods are intricately linked to the condition of natural resources, particularly for those 1.3 billion people living on fragile lands.
Over the last 40 years as food production has doubled, agricultural production systems have expanded, with significant impacts on the natural resource base (see figure 5.1):

- The amount of agricultural land going out of production each year due to soil erosion is about 20 million hectares, and approximately 40 percent of the world's cropland is now degraded.

- Irrigated agriculture consumes about 70 percent of the total volume of fresh water used by humans, resulting in major environmental consequences: salinization, lowering of water tables, waterlogging, and degradation of water quality, with subsequent impacts on ecological systems affecting fisheries and wetlands.

- Agriculture currently contributes about 30 percent of the global emission of greenhouse gases resulting from human activity. This has major implications for global climate change.

- The unplanned expansion of intensive production systems, which are typically

FIGURE 5.I GLOBAL CHANGE IN AGRICULTURAL AREA, 1960-2000

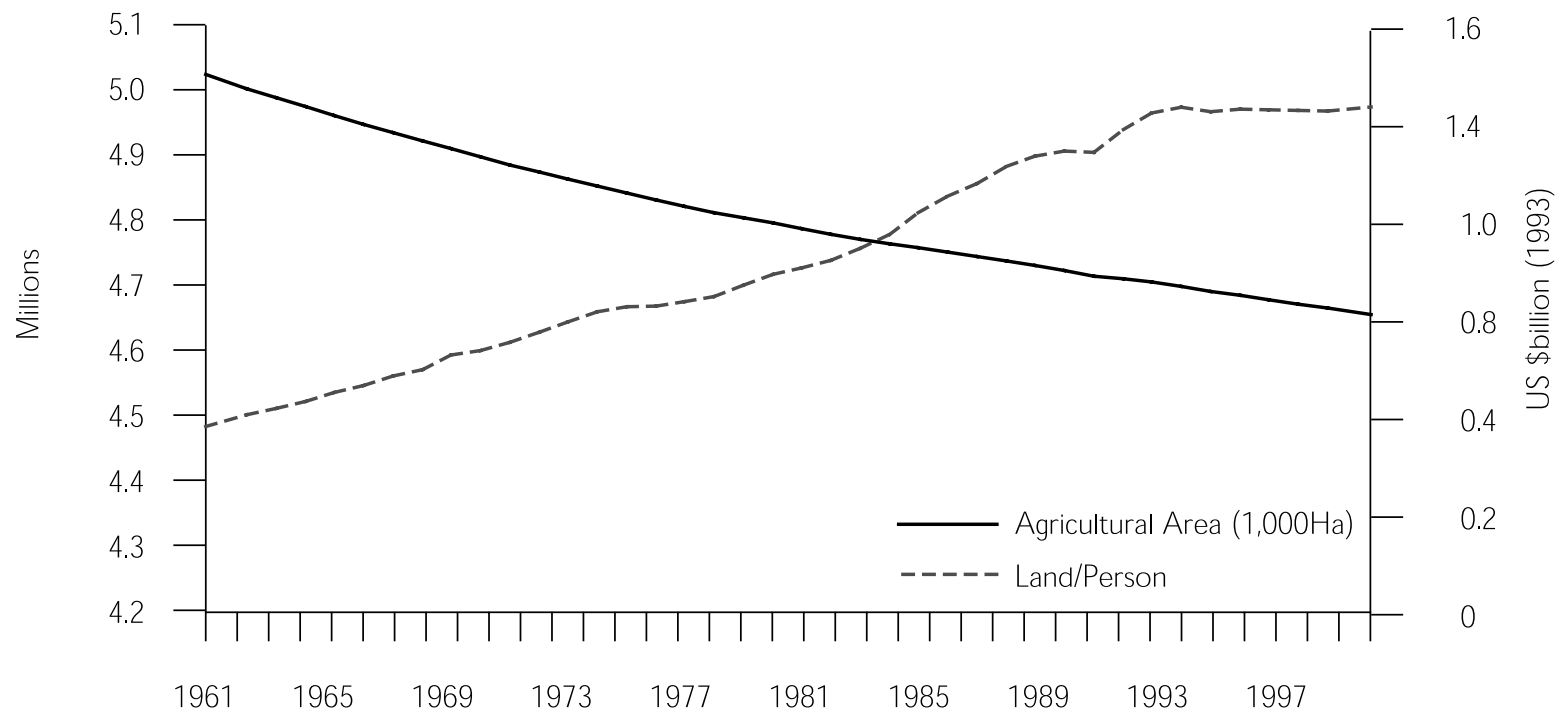

Source: FAOSTAT 2003. 
monoculture, can contribute to a significant loss in biodiversity.

- Deforestation rates have reached almost one percent per year in some regions.

Sustainable NRM is critical to reducing poverty. If productive capacity continues to erode, satisfying future food needs will be seriously compromised and the poorest will suffer the most through increased food costs and greater vulnerability to their livelihood. Further, increased agricultural production and productivity and increased incomes provide more resources in the long run for addressing environmental problems. Improving natural resources facilitates farmers' transition to production systems that are better matched to the available natural and human resources, can respond to market signals, and are more profitable, stable, and sustainable. Good NRM also expands income and employment opportunities throughout the wider community-for instance, through eco/agrotourism or through agroforestry production that attracts downstream processing industries.

Sustainable NRM is important to agricultural development as a basis for:

- General agricultural productivity. Agriculture is the major user of most available land and water resources (see figure 5.2). However, many farmers lack essential knowledge, resources, and skills to manage intensive farming operations on a sound basis. This leads to use of inappropriate technologies and unsustainable practices that contribute to exhaustion of natural resources and environmental pollution.

- Off-farm agricultural uses. Many agricultural systems rely on "off-farm" natural resources, such as livestock grazing on roadsides and woodlots. Forests provide building materials for farms, fences, and homes.

- Non-farm employment. Natural resources provide off-farm incomes through
FIGURE 5.2 WATER USE; DEVELOPING COUNTRIES, 1995

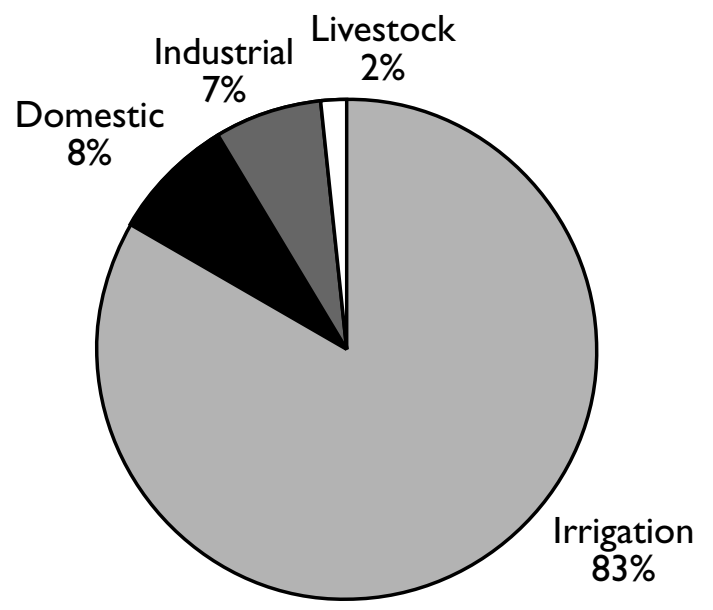

Source: Rosegrant, Cai, and Cline 2002.

employment in industries, such as fishing, timber extraction, tourism, and other uses, such as power generation. This income is often critically important for purchase of production inputs to maintain the productivity of the farming system.

- Risk and vulnerability reduction. Sustainable NRM reduces vulnerability of both farm and urban communities to natural resource disasters, such as droughts, landslides, and floods and to the loss of biodiversity from overgrazing and deforestation. A healthy resource base helps mitigate vulnerability to climate variability and reduces risks of failed harvests.

- Pollution reduction. Pollution from agricultural production and processing can have major impacts on "off-site" natural resource quality. Water pollution from agricultural chemical use and livestock manures is a potential health hazard; irrigation use can cause salinity problems; and burning crop residues may affect air quality and human health.

- Environmental services. Improved NRM provides extensive downstream benefits in 
the form of "environmental services" such as hydrologic function, sediment control, nurseries for fisheries, and biodiversity conservation. Environmental resources contribute to the health of the global ecosystem as wild races of the major food crops and semi-domesticated crops, located in forest reserves and natural ecosystems, are important sources of genes for crop improvement programs and semi-domesticated crops represent new market opportunities. Maintaining tree cover and appropriate hillside grazing and crop cultivation practices preserve soil and water resources and enhance the hydrologic functions of watershed areas. Coastal zone protection, mangrove and wetlands preservation, and border areas of parks and protected areas are important for the maintenance of environmental services.

- Cultural integrity. Indigenous cultures use land and other natural resources in unique ways, which often help to define national identities, even in industrial countries. Indigenous technical knowledge coupled with scientific research provides significant scope for management innovations to conserve natural resources and develop new marketable products (for example, nutraceuticals).

\section{PAST INVESTMENT ACTIVITY}

Prior to the 1980s, most natural resource investments by the World Bank were extractive: timber, fishing, and water for irrigation. In the late 1980s, the Bank shifted attention to conservation and sustainable management of natural resources, with a dramatic increase in NRM and forestry investment. Annual investments, including all forestryrelated investments, peaked at over US $\$ 1$ billion in 1994 but have since declined to approximately US\$250 million annually (see box 5.1).

Recent projects have relied on local capacity building and user groups to improve resource management. Decentralization, communitydriven development mechanisms, stakeholder participation, and local ownership of natural resources have shown a steady increase in Bank-assisted projects, which are becoming increasingly multisectoral. This is partly in response to stakeholder demands to complement NRM investments with activities to produce more immediate impacts on incomes and poverty reduction. As a result, the number of integrated projects, especially watershed and micro-watershed projects, is increasing, as well as the number of projects incorporating rural development funds and alternative livelihood options.

Box 5.I Key trends in past lending for improved NRM by area of intervention

- Biodiversity_Earlier approaches introducing "fortress" protection systems to restrict access to parks and protected areas were generally unsuccessful. These have been replaced by programs relying on local peoples' participation in the conservation and rehabilitation of protected areas and buffer zones.

- Forests/forestry - Forestry lending has declined, but there is increased emphasis on forestry in watershed conservation investments and agroforestry.

- Land resource management-Lending continues to focus on combating land degradation and promoting sustainable land management, especially relating to arid land management and watershed management. Major past investments have been for intensification of agricultural production.

- Natural resource management (NRM) institutionsælnstitutional capacity development focused on local institutions tasked with managing natural resources, has led to increasingly decentralized NRM and development of a range of participatory management systems.

- Water resourcesælnvestments in new irrigation construction have declined due to their high costs, environmental impacts, and low returns on investments. Attention is now focused on water use efficiency, water resource planning, and watershed development.

Source: Authors. 


\section{KEY ISSUES FOR INVESTMENT}

NRM investments are generally focused on conservation and sustainable use of resources, with institutional strategies emphasizing local management, equitable access, and provision of alternative livelihood options. Because of the environmental externalities associated with NRM decisions, investments are increasingly considered from a basin or eco-regional perspective, and analyzed in terms of ecological, economic, and social systems. Key implementation issues are as follows.

Political nature of NRM. Power and politics are central to many NRM issues, as natural resources, a major source of wealth, tend to be at the center of many governance issues and intercommunity conflicts. Any change in access will almost certainly create "losers": often the powerful, with strong incentives and ability to resist change or the poor, who are powerless and lose access to a resource. Efficient, equitable, and sustainable NRM is often difficult for this reason and governments must balance competing demands for use of resources and conflicts among the parties. Negotiating skills of community groups are essential for brokering agreements and facilitating decisionmaking by local users. For many NRM programs, however, the sustainability of these local institutions has been a problem as they become inactive once a project ends.

Policy AND REgUlatory ENVIRONMENT. Ineffective NRM policy and regulatory environments (particularly subsidies, taxes and property rights), together with poor infrastructure affecting access to markets, often discourage sustainable long-term investments by distorting incentive systems and increasing uncertainty. However, relationships between policy and incentive structures and product prices are complex. Agricultural producers compete for natural resources with other users such as industry and municipalities, whose needs increase with population growth and increasing affluence. In these circumstances, in a complex and uncertain decision-making environment, choices generally involve tradeoffs among sustainable resource use and other objectives. Resource preservation objectives are frequently at odds with production objectives, and while conservation and development goals can be complementary, they can also be in conflict.

ECONOMIC CHARACTERISTICS OF NATURAL RESOURCES. Land, water, forests, and biodiversity are generally regarded as public goods (to which access is nonrival and nonexcludable) or common pool goods (to which access is nonexcludable but rival). Investment in "developing" these natural resources may shift the status of the resources to that of a private good, negatively impacting poor people by affecting their access to these assets. In addition, as investment benefits accrue only in the medium to long term, it may be difficult to persuade resource users to undertake NRM investments. Success may depend on appropriately valuing these resources with incentives for conserving and maximizing their productivity; and developing markets and appropriate pricing mechanisms that reflect the true value of the resource, incorporating externality values. Since resources have different values for different stakeholders, accruing over different periods of time, a variety of interventions are required to strengthen the different sources of value (see table 5.1). Farmers should pay for use of natural resources (for example, irrigation water) and for costs of mitigating agricultural pollution (agrochemical runoff, manure disposal), and should be reimbursed for the positive externalities such as planting trees for carbon sequestration.

Promoting adoption of NRM PRACTICES. Most farmers place a high priority on improvements in land, water, and forest resource management as these resources are central to their livelihoods. Although generally sympathetic to improving environmental conditions, they are often unwilling or unable to invest to improve these conditions or to produce long-term benefits. NRM programs must deal with such problems by providing appropriate incentives, monetary or otherwise, to make small farmers' investment possible. This may require public funding for development activities or economic incentives, linked to introduction of sustainable 
Table 5.I Investment strategies to enhance value of natural resources

\begin{tabular}{|c|c|c|c|}
\hline Source of value & & Examples of value & $\begin{array}{l}\text { Strategies to } \\
\text { enhance value }\end{array}$ \\
\hline \multirow[t]{2}{*}{ Value from use } & Direct & $\begin{array}{l}\text { Agricultural production, } \\
\text { timber, recreation }\end{array}$ & $\begin{array}{l}\text { Investment in increasing } \\
\text { productivity and efficiency in } \\
\text { use of resources }\end{array}$ \\
\hline & Indirect & $\begin{array}{l}\text { Watershed protection, } \\
\text { natural beauty, carbon } \\
\text { sequestration. }\end{array}$ & $\begin{array}{l}\text { Development of } \\
\text { environmental services } \\
\text { markets }\end{array}$ \\
\hline \multirow[t]{2}{*}{$\begin{array}{l}\text { Value from } \\
\text { preservation }\end{array}$} & Future options & Possible future uses & $\begin{array}{l}\text { Investments in natural } \\
\text { resource conservation; } \\
\text { environmental education }\end{array}$ \\
\hline & Existence & $\begin{array}{l}\text { Biodiversity, religion and } \\
\text { culture, inheritance }\end{array}$ & $\begin{array}{l}\text { Conservation of protected } \\
\text { areas }\end{array}$ \\
\hline
\end{tabular}

Source: Authors.

NRM practices. An improved understanding is needed of the factors influencing farm and household decision-making. In many areas farmers have invested heavily in NRM (for example, terracing in northern Ethiopia, Eritrea, and parts of Asia; and tree planting in hill areas of Kenya), irrespective of the government policy and program frameworks.

Environmental services markets and government transfer payments should reward farmers for sound resource management, encourage conservation, and provide an additional source of income for farmers. Payments ideally should come from downstream beneficiaries, such as industry, urban areas or downstream farmers using water resources. However, for many resources, identifying and collecting data on resource use is difficult (for example, aesthetic values of maintaining a "clean" environment, or the conservation of biodiversity), and government transfer payments might be necessary. This may introduce the problem of "moral hazard" with beneficiaries accepting program incentives and then reneging on their commit- ments. More experience is needed to identify effective ways of enforcing these arrangements.

DELIVERING NRM SERVICES. NRM investments should be based on sound technical analyses provided within a framework and mechanism that effectively delivers NRM services at the community level. Turkey's East Anatolia Watershed Rehabilitation Project, with its participatory watershed management planning, provided a framework for ensuring that performance would be measured against specific indicators. Local government institutions decided how they could most effectively deliver NRM-related services based on the stated needs of the community. Decentralized approaches for planning and local organization of service delivery are important because most NRM problems and recommended practices are sitespecific, requiring a high level of managerial input and adaptation to local ecological, economic, and social circumstances.

Providing alternative livelihood options. Appropriate incentives are key to NRM program success. 
Direct income benefits accrue to the farmers, men and women, who adopt new management practices, and government incentive systems can benefit others. However, this frequently leaves many others not benefiting from NRM programs and who, consequently, may be tempted or forced to over exploit natural resources. To reduce such pressures on natural resources, investments are often needed to provide alternative income opportunities within agriculture. This can be done by intensifying production systems and expanding processing and marketing opportunities, or through education, business development services and micro-finance programs, which may or may not be linked to natural resource use.

POVERTY Focus. Past NRM projects have not been very satisfactory in their poverty focus or socioeconomic impacts analysis. Although impacts may be indirect and long term, NRM investments must emphasize rural poverty reduction, especially in marginal areas, where pressure on the natural resource base makes improved NRM a priority (see box 5.2). Providing for the critical needs of clean water, fuel, and income of poor people is a prerequisite for effective incentive systems and market mechanisms to improve NRM.

Maintaining PROtected areas. Protected area management plans now recognize the need to educate farmers and other rural peoples about the value of biodiversity and its potential benefits, especially buffer zone arrangements to conserve protected areas and critical ecosystems, and the preservation of biological corridors for movement of wildlife (see box 5.3). Continued rapid deforestation in many areas underscores the threat to protected areas (see figure 5.3). The development of income opportunities for local people is important to provide direct incentives for conservation as biodiversity conservation is often a difficult "sell" to farmers, because benefits are long term and not always obvious.

Global and Regional considerations. The many natural resource issues with regional and inter-
Box 5.2 Marginal areas: a special focus

Agricultural systems in marginal areas that are less favorable for agricultural production often provide farmers with only a precarious existence. As a general rule, natural resource conservation is a priority for these less-favored production areas. Sound NRM may require public policy initiatives to establish markets, strengthen or establish property rights, and ensure realistic pricing of natural resources. In some systems, traditional usage rights (for example, for grazing or use of forest resources) can be effectively and sustainably maintained through internal social discipline. Mechanisms that provide better drought preparedness are particularly important for food security and environmental management. In areas with sufficient agricultural potential, public investment is needed to support technology development, roads, and irrigation.

Source:World Bank 1999.

national impacts require concerted regional and international action, as provided for in part by the Global Environment Facility (GEF) (see box 5.4). Mechanisms and institutions are needed to facilitate global financing and support for global public goods, such as biodiversity conservation and carbon sequestration. Regional public goods are an even more common phenomenon with many shared resources and ecosystems, dictating coordinated and integrated actions by neighboring countries to sustainably manage

Box 5.3 Biodiversity: careful management can help diversify rural livelihoods

Biodiversity is a unique asset to rural communities. Many herbs are used for medicinal purposes; plant extracts can be used as biopesticides; roots and tuber crops contain novel carbohydrates for use as functional food ingredients; and many woody species produce polymers of interest to industry. Indigenous ethnic groups and rural women have extensive knowledge and management skills relating to plant and animal biodiversity. Adding value to these resources can come from combining the indigenous knowledge of local communities and the knowledge of the science and business community. The resource management challenge is to ensure the environmental sustainability of the resource, including sustainable harvest of the species of interest, or its domestication. A social and economic challenge is to design contracts for use of the resource with sound mechanisms for fair sharing of the benefits among the different stakeholders.

Source: Nickel and Sennhauser. 
FIGURE 5.3 ANNUAL RATE OF FOREST COVER CHANGE, 1990-2000

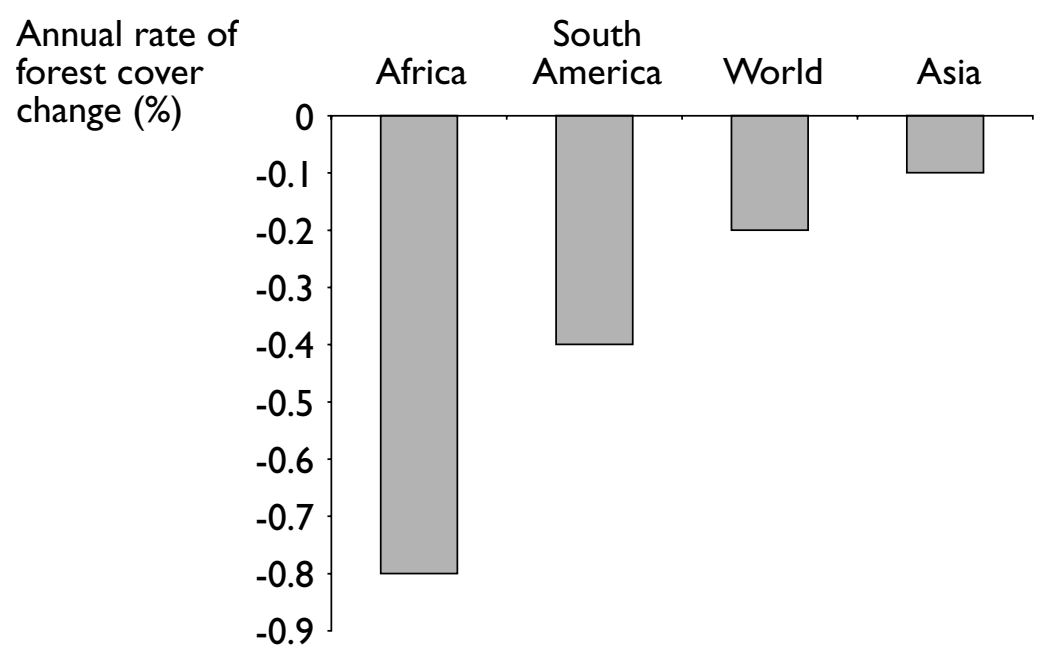

Source: FAO 2003.

resources such as shared pasture lands, water bodies, and eco-regions.

\section{FUTURE DIRECTIONS FOR LENDING}

Future investments must promote interventions and policy that respond to major government and market failures underlying current trends in natural resource degradation. When there are positive externalities and net societal benefits, individuals and organizations underinvest. They may overinvest where environmental costs are borne by the wider community

\section{Box 5.4 Global Environment Facility}

The Global Environment Facility (GEF) program is an important resource for expanding investment in sustainable NRM. GEF financing provides grants for projects and studies, strategy development, and project preparation for activities that address six critical threats to the global environment-climate change, biodiversity loss, degradation of international waters, ozone depletion, land degradation, or persistent organic pollutants. GEF cofinancing can support conservation of protected areas and biodiversity, sustainable land management, and water resource planning and management.

Source:World Bank 2000
Improved natural resource management requires the integration of sound policy, innovative technical solutions, and effective and sustainable institutions.

ESTABLISHING A SOUND POLICY AND REGULATORY ENVIRONMENT. Policies and programs must put in place appropriate incentives for sustainable NRM and the removal of subsidies that discourage sustainable NRM. Where short-term subsidies are provided, recipients' actions need to be monitored.

ESTABLISHING SECURE PROPERTY RIGHTS. Secure property rights to natural resources for individuals or organized community groups are essential in both conserving these resources and, in cases where this is appropriate, valuing and developing markets for them. Clearly defined and legally recognized property rights are critical to long-term investments in land improvement. In practice, rights to resources are often unclear and conflicts develop. Because of the difficulties in registering formal title to resources, seeking secure usufruct right is often more appropriate than attempting to establish full ownership rights to the resource. Traditional use rights, especially communal rights of 
indigenous groups, are important in many areas, and investments should be sensitive to these and ensure that they are safeguarded.

DeCentralizing NRM. Government willingness to devolve legal, fiscal and administrative decision-making power to the appropriate level is critical to strengthening tenurial rights and key to effective and sustainable NRM. Decentralization coupled with community-based natural resource management facilitates farmer participation in NRM through:

- Community-driven development with devolution of natural resource use rights and decision-making to community groups. ${ }^{1}$

- Rural investment funds that provide demand-driven grants for natural resource management subprojects, such as tree planting or the development of resource management plans.

- Participatory management plans or joint management systems under which government retains control over natural resources, but communities are consulted on key issues (for example, user rights), and may be given roles in monitoring and evaluation.

- Communal management of a common resource such as pasture or tribal lands.

STRENGTHENING NRM InSTITUTIONS. Investments to build institutional capacity to equip local communities and governments with the skills to manage resources in a sustainable and productive manner is key to ensuring that decentralization works. Management systems must preferably be democratic in action, ensure transparency and accountability, have well-defined mechanisms for conflict resolution and for establishing secure property rights, and empower vulnerable populations, such as women, indigenous people, and very poor people.
NEW TECHNOLOGIES/EKNOWLEDGE AND INFORMATION SERVICES. New technologies and approaches have been developed to improve NRM. For example, private rainwater harvesting technologies are useful in mountainous areas where more conventional irrigation options are not available. Integrated watershed management combines water harvesting, groundwater recharge, and vegetative cover with the development of viable agricultural systems to increase agricultural carrying capacity. Land management systems use integrated management packages including conservation tillage practices, soil treatment, weed control, vegetative cover, and agroforestry. Mass media communication approaches will help deliver to the widest audience possible extension and information services about new technologies and approaches to improve NRM, and thereby increase the potential for sustainable use.

Developing market-BASed StRategies. Establishing a base for commercial profitability for sound NRM depends on a favorable policy environment with an appropriate incentives structure. Models for private sector investment are being used successfully in management of forest areas and plantations. Recent NRM projects have supported private insurance companies providing index-based livestock insurance for pastoral systems ${ }^{2}$, development funds for accredited microfinance institutions, and business centers facilitating development of smalland medium-sized enterprises in fragile areas.

IMPROVING ENVIRONMENTAL MONITORING AND INFORMATION SYSTEMs. Establishing the science and knowledge base for monitoring and evaluating interventions is important to planning and monitoring natural resources. New technologies, such as satellite imagery, geographic information systems, and the Internet, will facilitate more efficient and reliable data collection on land cover, water usage and quality, biodiversity, and other measures of resource inventory and quality needed for sound management.

I. See the AIN, "Community-Based Natural Resources Management"

2. See the IAP," "Mongolia: Sustaining Livelihoods in Areas with High Natural Disaster Risk" (Module 10). 
Providing a Range of LIVElihood options. Project investments will generally need to integrate activities contributing to natural resources conservation, sustainable productivity, and improved rural livelihoods. The linkages between NRM interventions and poverty reduction are critical to project design, and should give special emphasis to involving women and vulnerable populations in decision-making processes. Many local development and production-oriented activities can be financed through matching grants. Cost sharing and parallel development of rural financial services to support productive projects are helpful in broadening impacts and enhancing financial sustainability of NRM program investments.

Reducing agricultural system POLLution. The impacts of agricultural production, processing, and marketing systems on downstream environmental resources result in "brown environmental impacts." These are growing concerns that require greater attention in environmental impact assessments for agricultural investments. "Green environmental impacts" from production systems impact on forest cover, biodiversity, and ecosystem stability, require substantial investment in research, extension, and training relating to NRM practices.

Developing ENVIRONMENTAL SERVICES MARKETS. Creating markets for environmental services is a developing issue. For example downstream beneficiaries such as cities, power plants, and farmers pay for sound natural resource management and conservation of watershed areas. Ecotourism is another example. Payment for carbon sequestration is another potential source of income for developing countries, providing incentives for conservation of pasture and forest resources. Innovative approaches to market such services require extensive feasibility studies and extensive testing through pilot activity before they can be scaled-up. ${ }^{3}$ One risk of market arrangements for environmental services is that local elites capture the benefit, with poor people suffering from a loss of access to resources.

\section{SCALING-UP INVESTMENTS}

Strengthening national data collection, monitoring, and evaluation systems should be an element of most NRM projects, providing a basis for improved monitoring and evaluation of the projects themselves. Key impact indicators for NRM investments will be rural incomes, quality and stock of the natural resources, and rates of change in natural resource indicators. Outcome indicators should relate to the numbers of adopters and adapters of new management systems, area coverage of adoption, impact per unit of adoption of new practices, changes in agricultural and resource productivity, and development of social capital relevant to sound NRM.

Scaling-up is a challenge for NRM investments. There are many successful NRM pilot activities and models for development that have often not been successful in scaling-up to the national level. Frequently, the problem relates to the level of technical and managerial support required for programs, the site-specific nature of most NRM interventions, and the need to negotiate implementation arrangements suited to local power structures and institutions. However, community management systems and decentralization are increasingly being scaled up and incorporated into wider government programs and policies. Ensuring sitespecific adaptations of NRM investments is challenging in larger projects, and will be even more critical in any attempts to incorporate NRM into program investments. Safeguard policies are often critical to NRM investments (see box 5.5).

The complex nature of NRM issues requires that integrated program approaches be promoted to achieve sustainable outcomes. Investments must be multidisciplinary and multiactivity, and financed over relatively long

3. See the IAP,"Latin America and Caribbean: Payments for Environmental Services in Silvopastoral Systems" 
- Environmental Assessment (Operational Policy (OP)/Bank Procedure (BP) 4.0I)æan environmental assessment is required if an NRM project has potential for adverse environmental risks or impacts.

- Natural Habitats (OP 4.04)æprotection of natural habitats (land and water areas where most of the original plant and animal species are still present) is required for any NRM investment that may cause degradation of the habitat.

- Projects in International Waterways (OP 7.50)æthe borrower must notify other riparian countries of any proposed NRM investment involving a body of water that flows through or forms part of the boundary of two or more countries.

- Involuntary Resettlement (OP/BP 4.12)æa Resettlement Action Plan is required if an NRM investment results in physical relocation, loss of land or access to land or other assets, or impacts on livelihoods due to restrictions on access to parks or protected areas.

- Indigenous Peoples (Operational Directive 4.20)æan Indigenous Peoples Action Plan is required if an NRM investment affects indigenous people.

- Forestry (OP 4.36)ægovernment commitment to undertake sustainable management and conservation-oriented forestry is required for any investment with potential to impact significantly on forested areas. (Investment with an exclusive focus on environmental protection or supportive of small farmers may be appraised on its own merits.)

Source: World Bank, Operational Manual.

periods, making the Adaptable Program Lending (APL) approach potentially valuable. Efforts to achieve a better balance between conservation and poverty reduction objectives can be expected to lead to greater cross-sector coordination in development and implementation of ecotourism, watershed, agroforestry, and silvipastoral approaches.

Future work is needed to develop good practice recommendations and to synthesize experience with investments in: indicators for sustainable NRM investments; technologies and metrics for NRM program monitoring and evaluation; investing in wetland conservation; investment in marginal lands; conserving agro-biodiversity; and minimizing agricultural pollution.

\section{SELECTED READINGS}

Asterisk (*) at the end of a reference indicates that it is available on the Web. See Appendix 1 for a full list of Websites.

Borrini-Feyerabend, G., ed. 2000. Beyond Fences: Seeking Social Sustainability in Conservation. 2 vols. Gland, Switzerland: IUCN.

Borrini-Feyerabend, G., Farvar, M. T., Nguinguiri, J. C. \& Ndangang, V. A. 2000. "Co-management of Natural Resources:
Organising, Negotiating and Learning-byDoing." GTZ and IUCN, Kasparek Verlag, Heidelberg, Germany.*

Clark, T. W. 2002. The Policy Process: A Practical Guide for Natural Resource Professionals. New Haven, Conn.: Yale University Press.

Institute of Development Studies. 1997. "Community-Based Sustainable Development: Consensus or Conflict?" IDS Bulletin 28, no. 4.*

Thomas-Slayter, B., A. L. Esser, and M. D.Shields. 1993. "Tools of Gender Analysis: A Guide to Field Methods for Bringing Gender into Sustainable Resource Managment." Clark University, Worcester, Mass.*

World Bank. 2003. "The Little Green Data Book 2003." World Bank, Washington, D.C.*

\section{REFERENCES CITED}

FAO. 2003. "State of the Worlds Forest's 2003." FAO, Rome.

FAOSTAT. 2003. FAO Statistical Databases. http://apps.fao.org/default.htm.

Nickel, W. and E. Sennhauser. Medicinal Plants: Local Heritage with Global Importance. http://wbln1018.worldbank.org/sar/sa.nsf/ 
0/fae63d87e2bd14038525687f0057edd1?

OpenDocument.

Rosegrant, M. W., X. Cai, and S. A. Cline. 2002. World Water and Food to 2025: Dealing with Scarcity. IFPRI: Washington, D.C.

World Bank. 1999. "Drylands, Poverty and Development: Proceedings of the June 15 and 16, 1999 World Bank Round Table." World Bank, Washington, D.C.

World Bank. 2000. "The World Bank and The Global Environment: A Progress Report." World Bank, Washington, D.C.

World Bank. Operational Manual. http:// wbln0018.worldbank.org/institutional/ manuals/opmanual.nsf/.

This Overview was prepared by Jaime Webbe, Sam Kane, Gary Alex, and Idah Pswarayi-Riddihough with inputs from the Natural Resources Management Thematic Team of the Bank. Peer review comments were provided by Gunars Platais, Agnes Kiss, Nadim Khouri, John Pender (IFPRI), and Mary Hill Rojas (WIDTECH). 


\section{AGRICULTURE INVESTMENT NOTE}

\section{COMMUNITY-BASED NATURAL RESOURCES MANAGEMENT}

Community-Based Natural Resources Management (CBNRM) is an approach under which communities become responsible for managing natural resources (forests, land, water, biodiversity) within a designated area. The communityæoften assisted and monitored by outside technical specialistsæutilize and protect natural resources within established guidelines or according to a detailed, mutually-agreed plan. The active participation of stakeholders in natural resource decision-making and use increases economic and environmental benefits. Critical investment areas include: introduction of viable management systems; securing legal control over resources and resource utilization; improving environmental governance; and information management.

Population growth and economic development are increasing pressure on land, water, forest, and biodiversity resources. Government attempts to conserve natural resources through top-down regulatory systems have often failed. Limited government capacity to enforce laws and regulations compounds management problems, particularly when regulations are inappropriate to the social, cultural, and ecological environments. In seeking an alternative, natural resource managers have found that increasing the role of local people in managing their natural resources is often the most appropriate solution.

CBNRM is an approach that gives communities full or partial control over decisions regarding natural resources, such as water, forests, pastures, communal lands, protected areas, and fisheries. The extent of CBNRM control can range from community consultations to joint management to full decision-making and benefit collection responsibility, using tools such as joint management plans, community management plans, stakeholder consultations and workshops, and communal land tenure rights.
Community based institutions are key to any CBNRM project and selecting and building the capacity of local institutions is critical. The selection process must ensure transparency and accountability and minimize conflict. Together with decentralization reforms, CBNRM ensures stakeholder participation, increases sustainability, and provides a forum for conflict resolution. Such a communitybased approach often leads to more equitable and more sustainable natural resource management for the following reasons (Brown et al. 2002; Brown 1999):

- Proximity to resources. Those in closest contact with, and whose livelihoods are impacted by, natural resources are best placed to ensure effective stewardship.

- Equity. Natural resources should be managed to ensure equitable benefits for the diverse interest groups within a population.

- Capacity. Communities often have better knowledge and expertise in the management of the natural resources than government agencies/private industry.

- Biodiversity. Multiple purpose management of natural resources by communities generally provides more varied land use, with greater species diversity than private/ industrial management systems.

- Cost-effectiveness. Local management may help reduce government costs.

- Development philosophy. Local participation, decentralization, and subsidiarity may, in themselves, be considered important development objectives.

\section{BENEFITS}

Sound CBNRM optimizes the use of the natural resource base to enhance agricultural productivity goals, ensure long-term sustainability, and protect the livelihoods of farm families. Improved natural resource management has 
increased soil fertility and water retention, reversed soil erosion, improved water management, maintained and/or improved biodiversity, reduced habitat destruction, and reduced deforestation. Economic opportunities from sustainable use of natural resources can act as a catalyst in reducing poverty and improving food security (see box 5.6). Early economic benefits equitably distributed to stakeholders from NRM, are important to develop the commitment to continue sustainable management systems. Also, the transfer of control over development funds to community institutions

\section{Box 5.6 Armenia: Natural Resources Management and} Poverty Reduction Project

In Armenia, the Natural Resources Management and Poverty Reduction Project contributes to sound resources management and poverty reduction through:

- A small grants scheme for biodiversity investments that supports alternative livelihoods to increase rural incomes, while reducing pressure on natural resources.

- A community infrastructure and income generation fund that supports the rehabilitation of access roads and the stabilization of land at risk from landslides and erosion.

- A forest management component that supports the generation of employment opportunities targeted at surplus household labor.

Source:World Bank Internal Documents. enables them to contribute to decision-making processes. This increases rural peoples' ability to demand and obtain rights and services. The Access Initiative, a new Bank tool, is an effort to assess people's access to information, participation, and justice in decisions that affect the environment (The Access Initiative).

\section{POLICY AND IMPLEMENTATION ISSUES}

CONFLICT RESOLUTION. Control over natural resources is often highly political, since natural resources can be the basis of production and wealth (see box 5.7). Powerful interest groups, hesitant to give up control over natural resources, often come into conflict with local stakeholders over scarce resources. Devolving control to community groups can lead to conflicts between local authorities and communities as roles and responsibilities change. Without adequate traditional or formal mechanisms for conflict prevention, management, and resolution, conflicts among different interest groups often result in inequitable sharing of economic benefits, and unsustainable natural resource use practices.

INTERESTS OF POOR PEOPLE. Natural resources are the basis for most rural economic activities and therefore are especially important for poor people. Improving access can increase livelihood opportunities, while restricting access can disrupt traditional economies. Since changes to NRM practices can have disproportionate impacts on poor people and marginalized groups such as indigenous populations, their interests must be considered in any intervention (see box 5.8).

GOVERNANCE AND RIGHTS TO RESOURCES. Resource use rights are central to CBNRM programs and governance reforms have profound implications for management of natural resources. Good governance can promote economic growth, but mismanagement of natural resources can exacerbate conflict and corruption. Many NRM systems may serve one community's interests over those of another. For example, wetlands can be important to 
both fisheries and agriculture; pasture lands for pastoralists or settled agriculturalists; and forests for downstream hydrology or for shifting cultivation. This situation requires development of institutions that protect the rights of different stakeholders, resolve differences, and balance investments that might develop one use over another.

SCALING UP. CBNRM is by definition a local intervention, and is by nature a relatively slow process of participatory decision-making. However, scaling up successful activities is important to expand the scope of benefits. Since CBNRM is reliant upon a number of location-specific criteria, such as available natural resources and the strength of community groups, scaling up CBNRM can be slow and costly. It is made easier by flexible project designs, demonstration of benefits to policymakers, and a focus on scaling up of community processes rather than a particular project.

SUSTAINABLE FINANCING. Long-term viability of NRM requires sustainable funding for operation and maintenance of local institutions. This requires innovative mechanisms for cost-sharing and cost recovery for program operations and the establishment of income generation schemes to provide incentives to participate in the program.

\section{LESSONS LEARNED}

Effective community participation comes from empowerment, which depends largely on government commitment to the time and resources needed to build consensus among stakeholders, establish new institutional arrangements with appropriate rules and incentives for local involvement and capacity building, and decentralized finance and administration (see box 5.9).

INFORMATION SYSTEMS. Reliable and timely information is critical to sound NRM and to good economic and governance decisions. Types of information relevant to CBNRM include: stream flow surveys, species composition indices, vegetative cover mapping, and changes in land
Box 5.8 Argentina: Indigenous Community Development Project

Since indigenous populations in Argentina have high poverty levels, the National Institute for Indigenous Affairs was created to engage indigenous populations in development activities. The Indigenous Community Development Project empowers vulnerable groups by:

- Strengthening the capacity of pre-existing indigenous organizations.

- Ensuring legal recognition of customary indigenous land and resource use rights.

- Introducing gender concerns into social programs through gender workshops.

- Building social and cultural assets in indigenous communities.

- Involving nonindigenous stakeholders in consultations to minimize conflict.

- Establishing a transparent system for the allocation of project development resources.

Source:World Bank Internal Documents.

use over time. Information from farmers, including traditional knowledge, needs to be at the forefront of any CBNRM program. Sciencebased knowledge and information tools, including geographic information systems, can complement this and be integrated into CBNRM programs, especially in building management capacity of government institutions.

\section{Box 5.9 Criteria for well-functioning community} organizations

- Groups/communities address a felt need and have a common interest.

- Benefits to individuals outweigh the costs of their participation in the project.

- There is clear understanding of the benefits to be derived from the project.

- The groups/communities have the capacity, leadership, knowledge, and skills to manage the tasks for implementing the project.

- Groups/communities are capable of making and enforcing their own rules and regulations.

- An inclusive decision-making process exists throughout the project life.

Source:World Bank 1996. 
Combining PRODUCTION AND CONSERVATION. Sound NRM strategies must encourage subsistence farmers to use better manage production systems. Since this often depends on their ability to finance investments in resource management, income generation activities are an important component of CBNRM initiatives as are extension and information services that build farmers' skills and confidence to invest in NRM.

STAKeHOLder PARTICIPATION. Critical to long-term sustainability of CBNRM is the ability to institutionalize stakeholder participation.

"Operationalizing" participatory development rests on a willingness to share power and be receptive to new ideas; to listen to people instead of lecturing them; and to take risks by opening up management processes rather than trying to control them. Tools for facilitating stakeholder participation include Participatory Rural Appraisal (also termed Participation Reflection - Action) (Institute of Development Studies) and community driven development (World Bank, Community-Driven Development). While community empowerment and participation are ultimate objectives, external agencies are often helpful in awareness raising, catalyzing group formation, and facilitating identification of community projects.

\section{RECOMMENDATIONS FOR PRACTITIONERS}

Three general implementation themes important to CBNRM initiatives-institutions, policies, and technologies-provide a framework for CBNRM investments (see box 5.10).

InstiTUTIONs. Investments in CBNRM must build local capacity to assume responsibility for NRM. This requires:

- Accepting that CBNRM is a time-consuming and labor-intensive process. Program supporters must be patient and willing to work collaboratively with local groups.

- Ensuring that stakeholders and partners have a thorough understanding of natural resources and their complexities and potential changes that occur over time.

- Fostering accountability and responsibility, by establishing mechanisms, such as public posting of information on resource allocations, broad representation in local institutions, and requiring external audits of community organizations.

- Avoiding overly complex management and administration systems, or capital and technical inputs that can overwhelm the capacity of local institutions

Policy. A sound legal framework for local institutions is necessary to enable them to enter into contractual agreements, collect fees, levy sanctions, access loans for investments, and own and manage property. Investments must strengthen resource use, access, and ownership rights, including, as appropriate, intellectual property rights. Effective enforcement of rights to resources relies on sound arrangements for checks and balances, pluralistic approaches, and conflict management.

TECHNICAL. CBNRM programs should avoid dogmatic approaches and "technology packages", but rather seek alternatives adapted to diverse agro-ecological and cultural contexts. Demand-driven research/extension services and programs that foster innovation and adaptive NRM and social learning, are needed to develop location-appropriate technologies. Onfarm research, and socioeconomic research support CBNRM, while farmer-to-farmer extension and farmer group approaches contribute to efficient and effective extension service delivery. These often need to be complemented by general environmental education.

\section{SELECTED READINGS}

Asterisk (*) at the end of a reference indicates that it is available on the Web. See Appendix 1 for a full list of Websites.

World Bank. 1996. "Participation in Forest and Conservation Management." In The World 
Bank Participation Sourcebook. Washington, D.C.: World Bank.*

World Bank. 1999. "The International Workshop on Community-Based Natural Resource Management (CBNRM): Workshop Report." May 10-14, Washington, D.C.*

United Nations Development Programme, United Nations Environment Programme, World Bank, World Resources Institute. 2002. A Guide to World Resources 20022004: Decisions for the Earth: Balance, Voice and Power. Washington, D.C.: World Resources Institute.

\section{REFERENCES CITED}

Brown, D. 1999. Principles \& Practice of Forest Co-Management: Evidence from WestCentral Africa. EU Tropical Forestry Paper No. 2, London: ODI.

Brown, D., Y. Malla, K. Schreckenberg, and O. Springate-Baginski. 2002. "Community Forestry, From Supervising 'Subjects' to Supporting 'Citizens': Recent Developments in Community Forestry in Asia and Africa." Natural Resources Perspectives 75. ODI, London.

Grimble, R and M. Laidlaw. 2002. "Biological Resource Management: Integrating Biodiversity Concerns in Rural Development Projects and Programs." Biodiversity Series Paper 85. World Bank, Washington, D.C.

Institute of Development Studies. http:// www.ids.ac.uk/ids/particip/index.html.

The Access Initiative. http:// www.accessinitiative.org.

World Bank. 1996. "Participation in Forest and Conservation Management." In The World Bank Participation Sourcebook. Washington, D.C.: World Bank.*

\section{Box 5.10 Potential investments}

- Government policy formulation.

- Capacity building for community organizations and local government.

- Development of community management plans.

- Rural investment funds for community projects.

- Detailed environmental communication strategies and research and extension support.

- Baseline studies and comprehensive monitoring and evaluation systems.

- Training for local stakeholders.

- Assistance to local organizations in obtaining legal status and legal recognition of traditional resource use rights.

- Enforcement systems to reduce illegal resource use.

Source: Authors.

World Bank. Community-Driven Development. http://www.worldbank.org/transport/training/ arms_01/dongier.pdf

This Note was prepared by Timothy Donnay (USAID) and Jaime Webbe with inputs from the Natural Resources Management Thematic Team of the World Bank. 
AGRICULTURE INVESTMENT NOTE

\section{WATERSHED MANAGEMENT FOR AGRICULTURAL DEVELOPMENT}

Watershed management harmonizes the use of soil, water, and vegetation in the watershed area in order to increase agricultural productivity and conserve natural resources. Conservation measures include revegetating barren land to assist in the control of runoff; introducing sustainable agricultural practices for hilly areas to improve soil and water management; and constructing water reservoirs for irrigation purposes. Watershed management often requires collective action among diverse stakeholders, among whom costs and benefits may be distributed unevenly. Accordingly, watershed investments must rely on people with the experience, incentives, and skills needed to organize stakeholders. Complementary investments may be needed to improve access to agricultural inputs and services (seedlings, veterinary services, land titling, etc.) and output markets (processing facilities, roads).

Rainfed agriculture in much of the world is characterized by low yields, low and declining soil fertility, severe soil erosion, and low investment in land improvement. Soil and water conservation efforts have treated these problems in a piecemeal manner, and have failed to capture synergies among various components of a watershed system. As a result, development efforts are often threatened by deteriorating environmental conditions in the watershed area, due in part to inappropriate resource use and increasing population pressures.

\section{KEY INVESTMENTS IN WATERSHED MANAGEMENT}

Watershed management seeks to make the best use of soil, water, and vegetation within constraints of watershed's agro-climatic and topographic conditions to strengthen the natural resource base (soil, vegetation cover) and to increase agriculture productivity, thereby improving peoples' livelihoods. Watershed management strategies vary. For example, in dry areas, increasing water availability raises potential returns, making the land more attractive to investment; in areas with short, intense rainy seasons, watershed management harvests water in surface reservoirs; and in areas with excess moisture, facilitating safe runoff through contour plowing or drainage systems reduces waterlogging and erosion. Investments in technology, social institutions, and markets are frequently needed to maximize the impact of improved watershed management.

Technical investments. Soil conservation, water harvesting, increasing vegetative cover, and safe disposal of excess water are basic watershed management technologies. In dry areas the focus is on water harvesting (capturing rainfall otherwise lost to runoff), whereas in wet areas it is disposal of excess water. In many upland watersheds in seasonally waterscarce areas, upper catchments are often degraded lands used for grazing, gathering firewood, or cultivation (often on unproductive plots). Lower watershed areas typically contain better agricultural land. Harvesting water from the upper catchment areas makes it available for irrigation and other uses downstream. Irrigation can transform agricultural systems from single-season, rainfed cropping with livestock subsisting on degraded grazing land, to multiple cropping of irrigated land, cash crops, and intensive livestock production (such as stall-fed dairy cattle). Watershed management technologies must be appropriate to local resource conditions, population densities, crop types, institutional capacities, and must ensure that poor people benefit (see box 5.11).

Social institutions. At the community and national levels, watershed management improvements rely on the development of social institutions for the resource user groups for water, forests, and land, as these groups are key to most watershed programs. The groups also represent social capital formation that can have wide applicability in empowering rural 
Box 5. II India: positive and negative effects on poor people

If watershed management succeeds in expanding irrigated area substantially, demand for labor may rise sufficiently to raise incomes, thus benefiting the poorest people in a watershed community. The nongovernmental organization (NGO) Social Centre in Ahmednagar, India, offers several examples of such success. In Adgaon village watershed, annual employment rose from 75 to 200 days, and laborers' incomes rose above those of small farmers. After four years of watershed management, laborers in Mendhwan could find employment eight months of the year, compared with three months of work previously. In Sherikoldara, landowners began to lease land to laborers rather than pay the high wage costs.

Watershed management also can make people worse off if it limits their access to uncultivated common lands on which they depend. A survey in ten villages covered by watershed projects found that respondents' perception of benefits from the projects rose with landholding size. Landless people were much more likely to indicate that projects had harmed their interests, with the unanimous complaint relating to loss access to common of lands.

Source:WOTR 1999

people, enabling them to undertake additional development activities. Such groups must often deal with problems of unequal distribution of benefits in which downstream land users benefit at the expense of upstream land users.

INVESTMENT IN MARKETS. Sustainable watershed development relies on well-developed markets to give farmers incentives to invest in sustainable production systems, facilitate access to inputs, and increase agricultural productivity. Increasing productivity and decreasing marketing costs lead to increased profitability and this reduces the need for farmers to expand into marginal areas, such as steep slopes. Where market access is poor, watershed projects may need to invest in infrastructure and communications systems to improve access to input and output markets.

\section{POLICY AND IMPLEMENTATION ISSUES}

UNIT OF IMPLEMENTATION. A watershed is defined by topographic boundaries. However, implementation of watershed management projects may be much easier if the area is aligned to boundaries defined by human settlement patterns or political units to make it easier for stakeholders, including women, to work collectively to establish and abide by new landuse patterns and to establish benefit-sharing mechanisms. Such action, which is difficult even within a village, is much harder when working across village boundaries. When small watersheds combine to form larger ones, good management of a large-scale watershed will require harmonizing the use of water resources between small watersheds, not just within them. Projects in Northeastern Brazil have had considerable success with watershed management implemented at the community level (see box 5.12). This decentralized approach facilitates the design of projects that reflect the needs and interests of local groups. Such community-based approaches are not always appropriate, when watersheds extend over large areas with large populations.

LAG TIME FOR RECEIPT OF BENEFITS. Watershed management investments are complicated by the fact that benefits are generated only slowly. Natural vegetation can take years to establish and, since watershed management aims to

\section{Box 5.12 Brazil: micro-watershed management}

Micro-watershed management is often chosen as an alternative to projects that include entire watersheds. The Brazil State of Santa Catarina Natural Resource Management and Poverty Reduction Project identified a number of reasons for this including:

- Greater ease in measuring results.

- Stronger social cohesion within micro-watersheds.

- More manageable size when compared to large watersheds.

- Greater ease in scaling micro-watershed management projects to other areas such as downstream communities.

Source:World Bank Internal Documents. 
arrest all forms of degradation, some benefits may not even be visible. Under such circumstances, maintaining support requires active local involvement, avoiding high costs, and providing complementary funding (grant or loan) for income-generation activities, especially in the early stages of work. Projects must consider tradeoffs between cost and participation, in that initial participation may be improved if costs are allowed to rise, but the initiative may prove to be financially unsustainable in the longer term.

Sharing OF BENEFITS. Watershed development can either help or harm poor people (see box 5.13). Improved watershed hydrology generating benefits largely for downstream water users, may only be successful if upstream land users limit grazing and other activities and this requires cooperation of all. One option to minimize this problem is to establish environmental service markets or other such mechanisms, so that benefits can be transferred from

\section{Box 5.13 India and Ethiopia: sharing benefits}

Well-publicized watershed projects in India and Ethiopia provide good examples of how benefits of watershed development can be shared with those who bear the costs.

- In Sukhomajri village, India, a project aimed at providing irrigation water from a small runoff pond. Landless families used the pond's catchment area for grazing, but the resulting lack of vegetative cover caused erosion that threatened the pond with siltation. To resolve this problem, villagers proposed that landless families receive rights to irrigation water in exchange for eliminating grazing in the catchment area. Irrigators paid for the water they used, with proceeds distributed equally among households regardless of landholding status.

- The village of Echmare, Ethiopia, on its own initiative, assigned degraded land to community members for the purpose of private tree planting. Everyone in the community was assigned a small plot under the condition that their rights would be revoked if they did not manage the land well. Results were quite positive. Participants managed their plots very well; tree survival rates were high; and household wealth increased. This demonstrates how harnessing private incentives can result in the achievement of broader social benefits.

Source:World Bank Internal Documents. one group to another. For example, downstream water users would lease land from upstream landholders in order to take it out of production or limit the types of use. Under such circumstances, downstream users profit from increased water supplies and improved water quality, while upstream users receive compensation payments for nonuse. Such benefit transfers contribute to ensuring participation of all.

ACCessing SOCiAl DEVElopment skills. The design of social institutions to ensure that all land users support watershed investments is contextspecific. Many government agencies responsible for watershed management employ only technically trained people, who are not well-equipped to address social problems of watershed development. As many nongovernmental organizations (NGOs) have strong social organization skills, it may make sense for government agencies to use these NGOs to implement projects.

Program coordination. Watershed development cuts across traditional administrative boundaries relating to soil conservation, forestry, irrigation, and agriculture, requiring coordination and involvement of these departments from the outset of a project. National or state governments must also harmonize planning with local level participatory planning and implementation activities. This helps to avoid duplication of efforts or conflicts among different localities about activities and objectives. However, this coordination amongst government agencies is often more difficult to achieve at the national or state/provincial level than at the district or local level.

Monitoring. Monitoring the social and biophysical impacts of watershed management assesses the usefulness of watershed management investments, and the best approaches to such management. Monitoring can range from using sophisticated instruments to collection of simple indicators involving various interest groups. Watershed management initiatives must build capacity and systems for the routine monitoring of watershed conditions. 


\section{LESSONS LEARNED}

CONDITIONS FOR SUCCESs. Watershed development is most likely to be successful where agro-ecological conditions are conducive to major improvements in water management; where local people have the capacity to work collectively for the common good; and where markets are accessible. Watershed development involves long-term investments; requires a long-term vision within user groups; and requires keeping user costs low, particularly during the early stages of a project, to avoid discouraging local participation. Experience suggests that good management practices and social institutions must be undertaken at the small watershed level before taking steps to improve watershed management of a larger area.

Priority innovations. Water harvesting in dry climates and drainage in areas with good soils, but excess moisture, is likely to yield the greatest water management benefits. Projects that reduce soil erosion and incrementally raise the moisture content of soils in rainfed areas may find it more difficult to demonstrate quick benefits needed to persuade producers to participate in programs.

Institutions. Reliance on NGOs to establish institutions at the local level can have drawbacks. Such outsourcing may result in government agencies failing to make staff investments in these skills; and to take the outsourced work less seriously than the technical work, even though it is essential to project success. Such contracted services may be restricted to a short period at the start-up of a program, even though the need may be ongoing.

Sustainability. Evidence suggests that farmers are more likely to maintain soil and water conservation investments when they contribute at least part of the cost, providing it is relatively low, and where conservation measures provide direct benefits. Ensuring that benefits from improved watershed management are equitably shared is key to ensuring that all stakeholders are willing to participate in project activities.

\section{RECOMMENDATIONS FOR PRACTITIONERS}

- Watershed management investments must be planned to fit local conditions and needs (see box 5.14). Where upper catchments are denuded due to overgrazing, firewood extraction, or cultivation, heavy soil erosion can cause siltation of water harvesting and storage structures, making the watershed investment unsustainable in these areas. Revegetating uplands is a high priority in such areas. In gentle sloping areas, investments may need to focus on increasing soil moisture. In high rainfall areas, better soil and water management can result in higher land productivity. On steep slopes, contour hedgerows reduce erosion and retain fertilizers and other inputs, thus raising yields. On flatter lands, use of furrows and drains reduces waterlogging and raises productivity.

- Projects may offer landless people employment such as planting vegetation or constructing soil and water conservation structures, to compensate for their loss of

\section{Box 5.14 Potential investments}

- Revegetation of pastures and forest areas based on a conservation plan agreed to by all stakeholders.

- Development of social institutions to support revegetation and eliminate future denuding of pasture and forest areas, particularly by ensuring that everyone benefits from revegetation.

- Soil conservation and water harvesting infrastructure.

- Environmental monitoring systems to determine changes in water availability, moisture levels, soil erosion, and vegetative cover, coupled with livelihood monitoring systems to identify those benefiting and those hurt from watershed management efforts.

- Extension services to introduce profitable new cropping systems and conservation measures and environmental education to ensure that local people understand the potential economic benefits of watershed management.

- Infrastructural improvements such as roads, bus service, communication.

- Improved access to credit and input and output markets for crops and livestock.

Source: Authors. 
access to uplands. This, however, may not give them an intrinsic interest in watershed management, which is a basis for long-term sustainability, if they lack incentives to maintain vegetative cover on upper watershed lands. Institutional mechanisms to share watershed benefits among all concerned users are preferable to only providing landless people with access to projectsponsored employment.

- If desired economic benefits are to be realized, watershed development programs must ensure the incentives and inputs needed to stimulate agricultural productivity.

- Developing cooperation between departments of soil conservation and agriculture and with other government agencies, although frequently difficult, is essential to planning and implementing effective watershed management programs.

\section{SELECTED READINGS}

Asterisk (*) at the end of a reference indicates that it is available on the Web. See Appendix 1 for a full list of Websites.

FAO. 2000. "Land-Water Linkages in Rural Watersheds Electronic Workshop: Summary of Conclusions and Recommendations, September 18 - October 27, 2000." FAO, Rome.*

Kerr, J. 2002. Watershed Management Projects in India: An Evaluation. In collaboration with G. Pangare and V. Lokur Pangare. IFPRI Research Report 127. Washington, D.C.: IFPRI.*

Kerr, J., G. Pangare, V. Lokur Pangare, P.J. George, and S. Kolavalli. 1998. "The Role of Watershed Projects in Developing Rainfed Agriculture in India." World Bank, Washington, D.C.*
Michigan State University. Watershed Window: Resources for Developing Countries' Watershed Management.

www.watershedwindow.org

Revenga, C., S. Murray, J. Abramovitz, and A. Hammond. 1998. "Watersheds of the World: Ecological Value and Vulnerability." Washington, D.C.: World Resources Institute.

Watershed Management Council. www.watershed.org

\section{REFERENCES CITED}

WOTR. 1999. "Watershed Development and the Landless." The Watershed Family: Newsletter of the Indo-German Watershed Development Programme 2. WOTR, Maharashtra, India.

This Note was prepared by John Kerr (IFPRI) with inputs from the Natural Resources Management Thematic Team of the World Bank. 


\section{AGRICULTURE INVESTMENT NOTE}

\section{AGROFORESTRY SYSTEMS}

Agroforestry has long been recognized for its potential as a stable and sustainable production system and for its potential contribution to broader agricultural systems. Agroforestry can extend the amount of time that a given area can be productive, improve livelihoods, and contribute to forest and biodiversity conservation. Constraints to agroforestry systems include: high interest rates, unclear institutional responsibilities, limiting policy frameworks, poorly developed markets, and inadequate research and extension. Support to agroforestry needs to address this broad range of issues, within flexible program designs.

Agroforestry investments present opportunities to address NRM and agricultural needs through on-farm and off-farm tree production (see box 5.15). Agroforestry investments have been accepted as an appropriate investment area for many years, and are frequently combined with other rural development activities. Generally, agroforestry investments aim either at ensuring environmental sustainability through the conservation of soil or forests or at reducing poverty by generating new income opportunities.

\section{AGROFORESTRY INVESTMENTS}

Agroforestry investments can take one of two forms: simultaneous agroforestry, in which trees are intercropped with crops or livestock, and sequential agroforestry, in which trees and crops are rotated. There is a broad range of specific investment choices representing different agroforestry technologies including:

- Boundary planting. Trees are planted as living fences along field borders to provide fodder and limit soil erosion and water runoff.

- Hedgerow intercropping. Leguminous, nitrogen-fixing trees are planted in rows,
Box 5.15 Agroforestry defined

'The World Agroforestry Centre defines agroforestry as a dynamic, ecologically based, natural resources management system that, through the integration of trees on farms and in the agricultural landscape, diversifies and sustains production for increased social, economic and environmental benefits for land users at all levels.'

Source:World Agroforestry Centre.

interspersed with rows of crops in areas where fallow periods are not possible.

- Parkland system. Trees and crops are grown together with trees acting as a permanent upper canopy providing shade or protection from wind.

- Silvopastoral system. Trees are planted on pastureland to provide shade and forage for grazing livestock.

- Home gardens. Trees are planted for productive purposes within small plots with other crops, including vegetables, fodder, grains, herbs, and medicinal plants.

- Multistrata system. Trees and crops are interplanted with multiple tree species maturing at different rates and occupying different canopy positions.

- Improved fallow. Tree species are planted either just before or just after crops have been harvested in areas entering a fallow cycle.

- Taungya system. Trees are intercropped with other crops until the trees become mature, at which point cultivation of the other crops is abandoned.

- Relay cropping. Trees and crops are planted together with planting dates staggered such that crops mature before trees become very large at the end of the rainy season.

Agroforestry technology investment choices balance forestry and agricultural production 
and conservation and production goals. However, agroforestry is not appropriate in all areas, as trees take up space on a more-or-less permanent basis and may compete with crops for water, sunlight, and nutrients, thereby limiting crop production.

\section{BENEFITS}

POVERTY REDUCTION. Agroforestry projects can reduce poverty directly by providing lumber, fuelwood, fruit and nuts, and livestock fodder, all of which can be sold to generate income or fulfill basic family needs (see box 5.16). The sale of timber is particularly important to poverty reduction, as returns are long term. Indirectly, agroforestry can increase crop production and incomes through conservation of soils and soil moisture.

REDUCING VULNERABILITY. Agroforestry has long been a traditional coping mechanism to reduce production-related risks, particularly during times of drought or crop failure. Trees store biomass during good production seasons and, when annual crops fail, can be harvested to provide income to purchase food and other needs.

EnVIRONMENTAL SUSTAINABILITY. Agroforestry is associated with positive environmental

Box 5.16 Benefits of agroforestry

- Agroforestry plantings in Indonesia currently harbor 50 percent of the plants, 60 percent of the birds, and 100 percent of the large animals that would normally be found in a natural forest.

- Cocoa agroforestry in Cameroon conserves 62 percent of the carbon found in a natural forest, and contains a plant biomass of 304 tons/hectare (compared to 85 tons/ hectare in crop fields).

- In southern Africa, improved fallow agroforestry systems (including species such as Sesbania) add soil nutrients equivalent to approximately US $\$ 240$ worth of chemical fertilizers per hectare.

- In Burkina Faso, the planting of live fences (including Acacia nilotica, Acacia senegal, and Ziziphus mauritiana) has increased farm incomes by US\$40 per year.

Source:World Bank 2002; Adesina et al. 200 I; Sanchez, Izac, and Scott 1999. outcomes because of the role trees play in larger ecosystem functions. Trees can improve soil quality in various ways: root systems prevent soil erosion, leguminous species fix nitrogen, improve nutrient recycling, and detritus from trees increases the organic content of soil. Welldeveloped agroforestry systems provide habitat for wild animals and contribute to biodiversity. Agroforestry affects climate change by storing carbon, and offsets deforestation by providing an alternate source of wood products. Finally, agroforestry can act as a buffer between protected forests and surrounding agricultural land and minimize edge effects in natural forests.

\section{POLICY AND IMPLEMENTATION ISSUES}

LAND TENURE. Because agroforestry requires a long-term investment, with benefits delayed by three years or more, farmers must be willing and able to invest in medium to long-term land improvements. Where land tenure is not legally established, landholders will seldom commit to long-term land improvements. Land tenure issues are complex, but must be addressed if agroforestry is to be promoted as an investment.

MARKET ACCESS. Agroforestry's contribution to poverty reduction is dependent on people's access to forest product markets. Market access can be improved through construction of roads, development of farmer organizations to increase the bargaining power of producers, or negotiation of contracts between farmers and larger forestry companies. Market analysis is essential to assess suitability of tree species as cash crops (see box 5.17).

GENDER. In the many situations where it is women's responsibility to gather fuelwood and tend the household gardens, agroforestry can give women more control over a productive resource. In other cases, where men exert traditional ownership rights over trees, they may not have control over use of agroforestry products or proceeds from their sale. Gender issues and site-specific factors affecting these, should be addressed by gender assessments to ensure equitable access to agroforestry benefits. 
Monoculture PlantaTIONS AND PESTS. Monoculture plantings are often a pragmatic choice in agroforestry activities, simplifying provision of planting materials and technical recommendations, and responding to demands for highervalue species. However, such single species plantings are vulnerable to pest attacksprudent planning requires a technically sound assessment of pest risks for any agroforestry program.

\section{LESSONS LEARNED}

PARTICIPATION OF POOR PEOPLE. Care needs to be taken when designing an agroforestry activity to ensure that vulnerable groups are not excluded. This is especially so when considering the landless poor and people with poorlydefined land rights. Inclusive implementation mechanisms need to be incorporated into the activity to enable the sharing of benefits and the encouragement of democratic approaches to decision-making in the community.

Species Selection. Appropriate species selection is important, and varies by location depending on agroclimatic conditions, markets, and farmer experience. Species selection should also be coordinated across areas to ensure that the market is not flooded due to the overproduction of a single species. Agroforestry can have other negative effects on surrounding ecosystems if non-native tree species spread beyond the farm boundaries. Where such risks are substantial, agroforesty programs should consider the use of native species instead of exotic trees. ${ }^{4}$

POLICY FRAMEWORK. The policy and regulatory framework must ensure that agroforestry products are marketable. Many governments have enacted limitations on the sale of timber to curb illegal logging. These limitations can result in small-scale farmers either being prohibited from selling timber and fuelwood, or being harassed and forced to pay informal

4. See the IAP, "China: Commercial Plantations to Help Conserve Forests"
Box 5.17 China: Sustainable Forestry Development Project

The China Sustainable Forestry Development Project strengthens monitoring of markets for both forest species and fruit trees. Product market and price information is stored in a database used to project trends in market prices and aid in selecting species for future plantings. Market monitoring will help to avoid flooding the market with one tree species, while ensuring that producer groups are able to make harvesting and marketing decisions to obtain the best return on their agroforestry investments.

Source:World Bank Internal Documents.

"fees" to do so. Policies can support agroforestry production by establishing certification systems or easing restrictions on sale of certain, noncritical species.

INSTITUTIONAL BASE FOR AGROFORESTRY. Government agencies (forestry and agricultural ministries) need to clarify roles and responsibilities, since agroforestry incorporates aspects of both agriculture and forestry. Local NGOs can be effective in disseminating agroforestry technologies and in market development (see box 5.18). Building capacity in producer organizations can strengthen the marketing abilities of small producers and provide a base for longterm sustainability of both small producers and their organizations.

\section{Box 5.18 Brazil:The Agroecological Laboratory of the} Transamazon Highway

The Agroecological Laboratory of the Transamazon Highway is a Brazilian NGO that seeks to fill a gap in extension services by addressing both agricultural and natural resource management issues (such as agroforestry). The NGO brings together different actors, including researchers, other NGOs, small farmers, and farmer organizations to facilitate the exchange of agroforestry information and it has also helped to establish a commercialization center for negotiating contracts between agribusiness and small agroforesters.

Source: Authors. 
Technical support. Agroforestry technologies tend to be highly location-specific, requiring demanddriven adaptive research and extension services that can draw on local knowledge, address different user group problems, and provide incentives for work on the real problems of farmers. Demonstration plots have proven to be effective in promoting agroforestry technologies, and farmer-to-farmer extension has worked well in incorporating local knowledge into programs. Formal training programs and workshops are needed to train extension staff and community leaders and an effective information dissemination strategy for agroforestry projects is necessary. At another level, better integration of agriculture and forestry programs in universities can be beneficial.

PRIVATE SECTOR ROLES. In general, private sector entities such as nurseries and forest product manufacturers are more efficient suppliers of services such as marketing contracts and inputs than the public sector. With the private sector emphasis on profit, manufacturers are likely to contract with large agroforestry producers whose economies of scale enable them to be more efficient producers. This situation presents problems for small-scale farmers who lack bargaining power and who may be less efficient producers.

COMmUNITY-BASED AGROFORESTRY. With agroforestry activities on communal lands, the community's

\section{Box 5.19 Potential investments}

- Community nurseries to provide seedlings.

- Demonstration plots, in-country study tours and workshops, and development of farmer-to-farmer extension networks.

- Adaptive research on agroforestry technology, markets, and social issues.

- Capacity building in farmer organizations, NGOs, government and private sector.

- Marketing studies/strategies.

- Assistance with improving access to credit.

- Establishment of production databases and land-use mapping.

- Facilities for postharvest processing.

Source: Authors. collective management can provide advantages of economies of scale, minimize individual investment costs, and provide equitable distribution of benefits. However, community management often loses the advantages of individual management, such as more timely and responsive decision-making and lower transaction costs. To be successful, communitybased agroforestry must be supported by a strong institutional base and conflict resolution processes. Decentralizing of control over resource and establishing institutions for farmer participation facilitate community management. Community action can be a means of introducing a new resource management system such as forest certification which increases the value of timber products. This is widely practiced in Mexico where 70 percent of forests are owned by the community.

Monitoring and eVAluation. Monitoring and evaluation are important to support flexible program management. Mapping technologies such as Geographical Information Systems (GIS), provide information on program impacts, such as land use changes and environmental conditions and feedback from farmers on knowledge, attitudes, practices and income relating to agroforestry activities, markets, and benefits is critical to refining the technologies used and the management of the program.

\section{RECOMMENDATIONS FOR PRACTITIONERS}

Agroforestry investments require flexible design, and focus on markets, adequate technical support, and attention to financial sustainability (see box 5.19). Reviews repeatedly emphasize the importance of agroforestry investments being flexible and responsive to the demands of local producers. Projects should generally:

- Build capacity in NGOs, line ministries, producer organizations, and the private sector to develop or strengthen local networks for transferring information.

- Assign adequate resources for research and extension. 
- Facilitate access to credit that takes into account the unique characteristics of agroforestry, especially the time required to realize returns on investment.

- Supply reliable and high-quality seed stock through local nurseries or cooperation with the private sector.

- Facilitate market access through road building and/or maintenance programs.

- Promote security of land tenure rights and the ability of farmers to benefit from their agroforestry investments.

\section{SELECTED READINGS}

Asterisk (*) at the end of a reference indicates that it is available on the Web. See Appendix 1 for a full list of Websites.

Arnold, M., and P. Dewees. 1998. "Rethinking Approaches to Tree Management by Farmers." Natural Resource Perspectives 26.

ODI, London.*

Carter, J. 1995. "Alley Farming: Have ResourcePoor Farmers Benefited?" Natural Resource Perspectives 3. ODI, London.*

Franzel, S., and S. J. Scherr. 2002. Trees on the Farm: Assessing the Adoption Potential of Agroforestry Practices in Africa. Wallingford, U.K.: CABI Publishing.

Franzel, S., P. Cooper, G. L. Denning, and D. Eade, eds. 2002. Development and Agroforestry: Scaling up the Impacts of Research. Nairobi: ICRAF; Oxford: Oxfam.

ODI Rural Development Forestry Network. http://www.odifpeg.org.uk/network/ index.html.

United Nations Forum on Forests. http:// www.un.org/esa/forests/.
World Agroforestry Centre. http:// www.worldagroforestrycentre.org.

\section{REFERENCES CITED}

Adesina, A., J. Gockowski, B. A. Nkongmeneck, \1 "O Ndoye" O. Ndoye, D. J. Sonwa, M. Tchatat, S. F. Weise. 2001. "The Role of Coca Agroforests in Community and Farm Forestry in Southern Cameroon." July Rural Development Forestry Network. ODI, London.

Sanchez P., A.-M. Izac, B. Scott. 1999. "Delivering on the Promise of Agroforestry." September CGIAR Newsletter. CGIAR, Washington, D.C.

World Agroforestry Centre. http:// www.worldagroforestrycentre.org.

World Bank. 2002. "Integrating Forests in Economic Development." In A Revised Forest Strategy for the World Bank Group. World Bank, Washington, D.C.

This Note was prepared by Jaime Webbe with inputs from the Natural Resources Management Thematic Team of the World Bank. 


\section{AGRICULTURE INVESTMENT NOTE}

\section{PASTORALISM ON ARID AND SEMI-ARID LANDS}

Natural resource management (NRM) on arid rangelands used by pastoralists is important to environmental and social sustainability, especially in Africa and the Middle East. Poverty is often acute in these areas where population pressure can lead to overgrazing and conflicts over land use, accentuating problems of natural resource degradation and economic vulnerability. Early donor support for range livestock development failed because it did not take into account local social, economic, and environmental conditions. More recent interventions have taken more of a NRM approach, working with herder organizations and using participatory approaches. Public investment is essential to improve public services and policy frameworks, strengthen local institutions, and improve management of rangeland resources.

At least 10 million square kilometers of the earth's land surface is categorized as arid or semi-arid rangeland. These areas provide a direct livelihood for about 180 million people living in close association with about 960 million ruminant livestock. Social deprivation is acute in these areas, which are among the most degraded in the world. Sustainable use of rangeland resources remains a key issue in many developing countries.

\section{SUSTAINABLE PASTORALISM}

Pastoral systems use free-ranging or grass-fed animals as the principal means of utilizing natural range and grasslands. Grasses and woody plants (browse) provide feed for animals, but, if overgrazed, productivity decreases and lands can become susceptible to erosion or weed infestation. Incomes from pastoral activity also decline. Further, the sustainability of pastoral systems is threatened if rangeland is converted to cropland, as much rangeland is marginal land, susceptible to accelerated resource degradation. Improving sustainability of pastoral livelihoods depends on ensuring access to the land suited to pastoral systems, and that pastoralists have the knowledge and resources to manage it sustainably. Pastoral systems differ in certain key features:

- Mobility is a common feature though its practice varies in range, seasonality, and links between movement of people and livestock. For example, nomads move as whole families with their livestock; transhumance pastoralists move livestock according to set seasonal and geographic routes; and others are sedentary or semi-sedentary.

- Livestock species associated with pastoral systems are determined by the environment, local culture and traditions, and required functions (meat, milk, transport).

- Economic orientation of land use for subsistence or market activity will significantly influences management practices.

- Social-territorial organization describes the pastoralists' relations with markets, settled agriculture, and nonpastoral communities, all of which are shaped by customary ethics, environmental factors, and accumulated management experience.

\section{BENEFITS}

Poverty is often endemic in arid zones, but it can be reduced by producing marketable products, such as meat and wool and by adding value to these through meatpacking and yarn production. Inequality can also be reduced, if poor people can effectively participate in such activities. If climatic conditions permit and some diversification of economic activities can be introduced, this will reduce pastoralists' dependence on only one economic activity and their vulnerability to economic loss, especially if drought conditions occur.

Environmental benefits from sustainable management of pastoral systems result from the 
reduction of overgrazing that causes loss of browse and desirable grasses, spread of weed species, soil erosion, and deterioration of key resource areas, such as water sites, salt licks, and bottom lands. Sustainable pasture management prevents loss of plant and animal biodiversity and negative livestock-wildlife interactions. The role of grasslands as a storehouse of carbon makes them potentially important in efforts to mitigate global climate change, and carbon sequestration and may provide a future income opportunity through transfer payments.

\section{POLICY AND IMPLEMENTATION ISSUES}

POPULATION PRESSURE. Increasing population numbers will add pressure to the resource base and can greatly affect development of a sustainable pastoral system. Therefore agro-ecological assessments need to embrace the entire system and changes over time. Assessments would cover: population, especially numbers of both people and animals; household indicators of wealth and well being such as herd or flock size; and social support mechanisms such as extended family or tribal obligations. Environmental indicators would include the condition and health of the resource base, particularly for key resource areas such as flood plains, bottom lands, and drought refuges which are important in more arid zones.

Enabling policies. Policy issues that have affected or currently affect sustainable pastoral development include:

- Exchange rate policies. The 1994 devaluation in the CFA countries of francophone West Africa affected livestock prices.

- Trade policies. Open trade regimes are generally desirable but these can result in food imports such as meat affecting local production.

- Crop input prices. If governments support agriculture with pricing policies that favor crop production (as has been the situation) to the disadvantage of pastoral systems, then considerable crop encroachment into marginal range areas can occur.

- Feed subsidies. If governments provide subsidies in general or to cover drought, then these may have detrimental environmental effects on range areas and raise equity issues.

LAND TenuRe AND LAws. Pastoralists often graze land that is owned by the state, but whose use is actually governed by a complex interaction between customary institutions and their rules, and national law. Land tenure laws become important to protect pastoralists' rights when pastoral land is sought by outsiders for pasture or other uses. In arid regions, land and water rights must be dealt with together, as pastoralists may have to compete with cultivators or urban dwellers. Laws are important in providing pastoralists with a legal basis for access to and control over their lands. However, these laws and tenurial systems are often quite complex, and may differ between adjacent countries through which pastoralists move. Hence, familiarity with both customary and formal land law, especially its effectiveness, is necessary in preparing for investments in pastoral systems. Key questions involve the types of local organizations recognized under law, and the possibility of recognizing the authority of traditional leadership.

Project strategies may differ: in some cases it may be possible to define exclusive areas for grazing by pastoralist communities; in other situations it may be better to maintain the traditional flexibility that allows groups to renegotiate grazing territories according to the year's rainfall. The subdivision of pasture among individuals or families has not worked well in most pastoralist situations.

SOCIAL SERVICES. Pastoral areas are usually among the worst-served parts of any country in terms of basic social services. Mobile services tend to be preferred over fixed facilities. Health services usually separate human and animal health, even where there is little reason to do 
this. While literacy programs are increasingly important as more responsibility passes to literate members of the community, investment is needed in general and technical education. Major constraints to development of input and output markets for pastoralists' products are deficiencies in communication and transportation infrastructure.

InSTITUTIONAL ARRANGEMENTS. Technical services, such as extension, research, animal health, and water supplies, and financial services such as marketing, banking, and credit, are key to improving livelihoods of pastoralists. Institutional options for delivering these services include allocation of responsibilities to local government or development of capability for communities to assume responsibility for services. The balance between public and private responsibilities is defined by type of good or service to be provided (see table 5.3). The present trend is toward devolution of service delivery to the private sector, with central government focusing on policy formulation and providing infrastructure.

\section{LESSONS LEARNED}

ANALYSIS OF THE PASTORAL SYSTEM. Understanding the pastoralist's rationale for mobility or reduced mobility in the pastoral system and the integrity of the pastoral system as a whole is essential in

\section{Table 5.3 Activities and responsibilities in support of pastoral development}

\begin{tabular}{|c|c|c|}
\hline Support area & Activity & Implementing responsibility \\
\hline $\begin{array}{l}\text { Policy } \\
\text { framework }\end{array}$ & $\begin{array}{l}\text { Strategy for resource use, policy } \\
\text { statements, legislation, advocacy for } \\
\text { national pastoral organizations }\end{array}$ & $\begin{array}{l}\text { Central government with the possibility } \\
\text { of contracting out some technical } \\
\text { assistance }\end{array}$ \\
\hline $\begin{array}{l}\text { Environmental } \\
\text { conservation }\end{array}$ & $\begin{array}{l}\text { Tree planting, wildlife management, } \\
\text { alternative fuels/stoves, fire control }\end{array}$ & $\begin{array}{l}\text { Private sector with local government } \\
\text { and community involvement }\end{array}$ \\
\hline $\begin{array}{l}\text { Drought } \\
\text { management }\end{array}$ & $\begin{array}{l}\text { Early warning systems, contingency } \\
\text { measures, recovery measures, } \\
\text { insurance }\end{array}$ & $\begin{array}{l}\text { Central/local government, with } \\
\text { essential contributions from pastoral } \\
\text { communities and possibly from traders } \\
\text { and banks }\end{array}$ \\
\hline $\begin{array}{l}\text { Basic } \\
\text { infrastructure }\end{array}$ & $\begin{array}{l}\text { Physical infrastructure, institutional } \\
\text { framework }\end{array}$ & Central/local government \\
\hline Social services & $\begin{array}{l}\text { Health services, primary education, } \\
\text { adult literacy }\end{array}$ & $\begin{array}{l}\text { Central/local government support for } \\
\text { private services, and public inputs for } \\
\text { vaccination and other public goods }\end{array}$ \\
\hline $\begin{array}{l}\text { Technical } \\
\text { services }\end{array}$ & $\begin{array}{l}\text { Extension, credit, animal health } \\
\text { services, water supply systems, } \\
\text { marketing support, agronomic inputs }\end{array}$ & $\begin{array}{l}\text { Private provision of credit and } \\
\text { technical services subcontracted by the } \\
\text { public sector as required. Local } \\
\text { government and producers can manage } \\
\text { extension }\end{array}$ \\
\hline $\begin{array}{l}\text { Institution } \\
\text { building }\end{array}$ & Counseling/training & $\begin{array}{l}\text { Local government and national and } \\
\text { regional herders' federations }\end{array}$ \\
\hline
\end{tabular}

Source: de Haan, Pratt, and Le Gall 1997 
designing effective interventions. Analysis of the overall system should consider: the roles of livestock, access to resources and decision-making processes, drought likelihood, population changes, trading systems, and equity issues.

INFORMATION NEEDS. An adequate information base is essential to designing sound investments in pastoral systems. Information derives from databases characterizing the project area, field appraisals, and special studies. Investments in pastoral systems require information on all of the area used by a pastoral population, including all seasonal grazing areas and drought reserves.

HERDER ORGANIZATIONS. Herder organizations can manage communal resources and coordinate members' management of their own household resources, facilitate grazing and water management, secure territorial rights, resolve conflicts, and provide services such as animal health, borehole operation, and marketing. Development of herder organization requires a three-step approach of understanding the existing socialterritorial organizations; formulating development objectives; and identifying or establishing associations that build on customary institutions.

Market development. Herders frequently lack access to formal markets and capacity (relating to production, marketing and inputs) to supply these markets. Improving market access requires investment by both public and private sectors in: market infrastructure (communication and transport systems, cold-chain facilities), systems for certification of grades and standards, policies and regulations that facilitate trade, and technical services to improve product quality.

Drought management. Drought is a natural feature of arid and semi-arid areas, and projects need to be designed with drought management consideration permeating all components, or with a separate drought management component (see box 5.20). Investments should provide for drought preparedness, customary drought strategies, drought management capabilities, and drought recovery assistance.
Box 5.20 Kenya: drought management for pastoralists

The arid lands of northern Kenya are home to around one million pastoralists, most living below the poverty line. Herders practice opportunistic grazing management to take advantage of the unpredictably variable ecology. Growing pressures on rangeland resources and the lack of legal recognition of pastoral land rights are undermining customary arrangements for regulating resource access, control, and management. The Kenya Arid Lands Resource Management Project institutionalizes drought mitigation and management tools, including a drought early warning system, marketing outlets for livestock and livestock products, infrastructure, and community development subprojects to promote alternative livelihood strategies. The project develops institutional mechanisms for managing all phases of the drought "cycle," including preparedness, mitigation, and recovery.

Source: Bruce and Mearns 2002

TeChNiCal InPuts. Technological interventions require an understanding of how inputs interact within a holistic system that considers market and economic interactions, social impacts, and the institutional base. New inputs, such as fencing; new breeding stock; pest control and pasture improvement, require management systems that make effective use of these inputs, for example, supplementary feeding, breeding management, marketing, and grazing practices. Investments in processing innovations can improve market access and generate new employment opportunities.

Process monitoring. Pastoral system development projects often need to emphasize a "process" approach that enables managers to make adjustments as the project proceeds. A sound management information system must have data collection procedures and performance indicators for ecological, socioeconomic, and institutional changes and must ensure that objectives and perspectives of all project stakeholders are reflected.

\section{RECOMMENDATIONS FOR PRACTITIONERS}

Participation, flexibility, and sustainability must be incorporated into project designs to support development of economically, socially, and 
environmentally sustainable systems. This requires pastoral development investments to:

- Consider the pastoral system as a whole, assessing its potential to provide a basis for sustainable livelihoods, but recognizing inherent limitations.

- Improve baseline knowledge of pastoral systems and their environments, developing a comprehensive understanding of resources, resource users, and the geopolitical system in which they operate.

- Develop mechanisms to ensure feedback from project implementation experience to design of future program activities (see box 5.21).

- Strengthen existing pastoral institutions to minimize dependence on external inputs and enable them to undertake activities on a sustainable basis.

- Promote market development to most efficiently use available resources.

\section{Box 5.2I Potential investments}

- Policy studies and policy formulation.

- Land tenure laws and dispute resolution.

- Information systems, databases, and mapping of pasture conditions and soil erosion, using remote sensing, field surveys, and other methods.

- Herder association strengthening and training.

- Animal health service provision systems based on paravets and private veterinarians.

- Livestock markets, marketing systems, and market information services.

- Drought monitoring and preparedness.

- Diagnostic studies of social systems and traditional management systems.

- Research on pasture and herd management and use of alternative feedstuffs.

Source: Authors.
- Ensure adequate provision of technical inputs and knowledge relating to pasture and livestock management, grazing practices, and drought management.

\section{SELECTED READINGS}

Asterisk (*) at the end of a reference indicates that it is available on the Web. See Appendix 1 for a full list of Web sites.

de Haan, C., B. Brandenburg, F. Le Gall, J. Gauthier, M. Simeon, R. Mearns, and T. Schillhorn van Veen. 2001. Livestock Development: Implications on Rural Poverty, the Environment, and Global Food Security. Washington, D.C.: World Bank.

de Haan, C., D. J. Pratt, F. Le Gall. 1997. Investing in Pastoralism: Sustainable Natural Resource Use in Arid Africa and the Middle East. World Bank Technical Paper 365. Washington, D.C.: World Bank.

Øygard, R., T. Vedeld, and J. Aune. 1999. Good Practices in Drylands Management. As, Norway: Noragric Agricultural University of Norway; Washington, D.C.: World Bank.*

\section{REFERENCES CITED}

Bruce, J., and R. Mearns. 2002. Natural Resource Management and Land Policy in Developing Countries: Lessons Learned and New Challenges for the World Bank. Drylands Programme Issue Paper 115. London: IIED.

de Haan, C., D. J. Pratt, F. Le Gall. 1997. Investing in Pastoralism: Sustainable Natural Resource Use in Arid Africa and the Middle East. World Bank Technical Paper 365. Washington, D.C.: World Bank.

This Note was prepared by Gary Alex and Francois Le Gall based on a World Bank Agricultural Technology Note "Investing in Pastoralism" and inputs from the Natural Resources Management Thematic Team of the World Bank. 


\section{AGRICULTURE INVESTMENT NOTE}

\section{INTEGRATED LIVESTOCK- WILDLIFE MANAGEMENT}

Differing objectives of biodiversity conservation and rural livelihood improvement have at times led to competing land-use options. Agricultural cultivation or intensive livestock grazing up to park boundaries has led to conflict due to wildlife damage to crops and property and disease transmission to livestock. The integration of wildlife with extensive livestock management can bridge potentially conflicting interests. Integrated livestock and wildlife management (ILWM) offers potential benefits by mainstreaming sustainable biodiversity conservation in rangeland management. ILWM can create alternative sources of income from livestock ranching and reduce land degradation. Game or mixed game and livestock ranching can provide higher and less volatile returns than livestock ranching in arid and semi-arid landscapes.

Conventional livestock farmers in arid and semi-arid areas often have problems due to dry and unpredictable climates, infertile soils, tickborne diseases, and limited support services. Wild game species are better adapted to harsh environments than livestock, as they are adapted to heat stress, water shortages, and endemic diseases and can feed on available local vegetation. Game, which includes browsers and mixed feeders as well as grazers, is less impacted by bush encroachment in rangeland which is a phenomenon resulting from overgrazing, droughts, and land degradation. Extensive livestock husbandry in an integrated wildlife-livestock environment maintains habitat for wildlife and can improve overall rangeland productivity.

There is growing recognition of potential complementarities between wildlife protection and extensive livestock production systems, if these systems are well managed. Wildlife and livestock are generally more compatible than wildlife and crop agriculture, and both can thrive in arid and semi-arid rangelands. In areas with variable rainfall, livestock and wildlife resources have a competitive advantage over crops.

A driving force for ILWM is the profitability of game and mixed game/livestock ranches, particularly in arid and semi-arid landscapes in Africa as livestock ranchers move into game ranching to reduce their exposure to a volatile market and extreme climatic conditions. In South Africa, there are now 5,000 game ranches and more than 4,000 mixed farms (see box 5.22) (ABSA 2003).

Another driving force behind ILWM is the recognition that there are opportunities for conservation and sustainable use of biodiversity within the productive landscape. In countries with large populations of wildlife outside protected areas (for example Namibia, South Africa, and Botswana), IWLM approaches offer the opportunity for both wildlife conservation and socioeconomic benefits. This is especially the case since wildlife areas

Box 5.22 South Africa: profitability of game ranch management

Profits from game ranch management depend on sufficient critical mass, a large diversity in wildlife, stocking with rarer animals, an emphasis on ecotourism, and a natural equilibrium between carnivores and prey animals. Game ranching is sensitive to economies of scale. In South Africa, very small game ranches (below 150 large stock units - LSU) struggle to be economic, while medium-sized hunting ranches (around 600 LSU) on average obtain an annual return of 9.1 percent on the capital invested. Although up-front capital investments (land and fencing, game/cattle, buildings and infrastructure, vehicles, operating costs) are lower for cattle farming than for game ranching, cattle farming is rarely economic below a production size of 400 LSU. Even large farms ( I,000 LSU) usually do not exceed annual returns of 4.5 percent on capital invested (compared with 10.3 percent for a game ranch of comparable size). Hunting or professional game-capturing for sale of game at auctions increases the profitability of game ranches. Game ranching can further increase profits and create job opportunities for skilled and semiskilled labor, if combined with ecotourism.

Source: ABSA 2003 
and extensive rangelands all over Africa are under pressure from human population growth, deforestation, and agricultural expansion. Wildlife and livestock are being pushed onto marginal lands, arid rangelands, and buffer zones around protected areas. Competition for water access and grazing areas, especially in the arid rangelands, increases with seasonal influx of migratory species as the dry season progresses and as diversity and quantity of grasses become less.

\section{BENEFITS}

Efficient management of domestic and wild stock can increase incomes and reduce livelihood vulnerability. Traditional practices of maximizing the number of cattle have changed where revenue from wildlife has become an important alternative to livestock. Wildlife can provide a steady income during times of drought or floods (Boyd et al. 1999) and provide varied economic benefits:

\section{- Harvest and export of wildlife meat can} provide substantial income, as long as sanitation and hygiene requirements are met. Wildlife meat is important for personal consumption and for sale. Close monitoring of wildlife harvest areas is necessary to avoid over-harvesting with its effect on wildlife numbers.

\section{Box 5.23 Tanzania: wildlife policy}

The Wildlife Policy in Tanzania aims to empower local communities to establish Wildlife Management Areas (WMAs), and manage these to obtain benefits from wildlife conservation outside protected areas in addition to livestock. The WMAs are defined as "areas declared by the Minister to be so and set aside by village governments for the purpose of biological natural resource conservation." Communities may lease trophy hunting or game viewing concessions to tourist outfitters or may engage in hunting. As part of the process of establishing a WMA, village assemblies must pass a resolution and develop a village land-use plan based on a sound resource survey and approved by the District Council, the regional authorities, and the line ministry.

Source: Shauri 1999.
- Trophy bunting provides income from fees that professional hunters and their clients pay to hunt and camp. About 6,000 trophy hunters visit South Africa annually, spending on average US $\$ 6,000$ on fees, not including the price for trophies hunted (ABSA 2003). Overhunting and diversion of funds may occur with trophy hunting and so adequate safeguards must be taken to avoid these problems.

- Fees for capture permits for wild animal trappers who sell game to zoological gardens, game parks, and wildlife management areas provide another income possibility.

- Wildlife tourism is becoming more popular (see box 5.23). Although the average hunter spends more than four times as much as the ordinary tourist, far more tourists can be accommodated than hunters. The main income for larger-sized game ranches is from tourism (ABSA 2003). In Kenya, wildlife tourism generates more than 100 times more revenue than all other wildlife businesses together (Ashley and Elliott 2003).

A critical mass of conservation areas can have a synergistic marketing effect as an area becomes known for wildlife tourism and the total number of visitors grows. It also has had a positive impact on stocks of rare species as the competition among the enterprises for tourists, based on the diversity of wildlife, has encouraged the breeding of rare species, such as rhino, giraffe, and oryx, and fuelled a market for translocation this game.

\section{POLICY AND IMPLEMENTATION ISSUES}

REMOVING BARRIERS TO ILWM. The most critical problems of wildlife and livestock mixing are disease transmission, competition for forage and water, and predators. Profitable ILWM generally requires establishment of animal health service centers, extension services and early warning systems based on disease and pest monitoring. Private ranchers are likely to use animal health extension service systems, while pastoralists, 
such as nomads and transhumance herders, are more likely to benefit from community-based, low-input veterinary support service units. Some problems can be reduced if locally adapted breeds are the main livestock rather than high-producing but exotic breeds, as disease and parasite transmission are likely to be reduced. Damage by predators and other "problem animals" can be minimized by fencing off homesteads and gardens; killing problem animals; and locating community areas away from known game trails and watering points.

ENCOURAGING ACCEPTANCE OF ILWM. Wildlife in many countries contributes to a country's economy through hunting or ecotourism, and it is important that this is recognized by all, especially farmers and rangeland managers. Local governments, communities, and private landowners need an understanding of the trade-offs involved of different land use scenarios for people and for wildlife conservation. Individual farms or communal group land may often not have sufficient size for profitable game or mixed game and livestock management, but, as in southern Africa, adjoining private farms and communal groups can organize to operate under comanagement agreements for ILWM to conserve biodiversity and realize sustainable profits (see box 5.24).

CAPTURING BENEFITS FOR RURAL POOR PEOPLE. In extensive rangelands that are larger than national parks and reserve networks, wildlife and livestock can coexist. Wildlife do exert a "cost" on livestock production, competing for feed and water, becoming predators and possible pest and disease transmitters. These costs to rural communities need to be offset by benefits from wildlife, most of which currently flow to government and the largely foreignowned private sector. In some countries, transfer of wildlife management rights to communities has established a basis for them to benefit. For example, safari hunting, commercial ranching for meat, hides and live sale, and ecotourism, provide opportunities for improving rural livelihoods, and meeting conservation and development objectives.
PAyments For ENVIRONMENTAL SERVICES. ILWM might not always be the preferred land-use options as rural communities or private landowners, may consider that other land uses provide better shortterm returns, even though these may not be sustainable. If an area is important for biodiversity conservation, interested parties, such as local conservation NGOs, government, and international donors may pay the community or landowner to maintain wildlife-compatible land-use practices. Such a compensation scheme provides income to rural people who bear costs of global biodiversity conservation, but have minimal direct benefits from wildlife (see box 5.25).

\section{Box 5.24 Key criteria for profitability of game ranching}

The following criteria and costs need to be taken into account in estimating the potential returns prior to establishing a game ranch:

- Minimum ranch size required for specific game.

- Purchase and selling price of game.

- Additional expense of fencing to ensure that large and dangerous animals remain inside/outside a dedicated area.

- Operating costs including disease management and food supplements during droughts on smaller farms.

- Infrastructure such as water provision, roads, lodges, and/or hunting camps.

- Abattoir facilities, vehicles and housing.

Source: ABSA 2003.

\section{Box 5.25 Namibia: "conservancy" policy}

In Namibia about 75 percent of wildlife exists outside protected areas. An industry has developed based on consumptive and nonconsumptive use of wildlife. Wildlife management units called "conservancies" can be established on commercial and communal land. Conservancies gain rights of the use and benefits from wildlife and tourism concessions. They must be legally constituted and have clearly defined boundaries, defined membership, a committee representative of the membership, and a basis for equitable distribution of benefits to members. By 2003, there were 14 conservancies registered covering 38,500 square kilometers of land, and a further 30 conservancies were being formed. All have the objective of conserving and utilizing wildlife, while integrating traditional livestock-raising activities. Despite the progressive nature of the existing policies, a lack of secure group tenure, still undermines the ability of conservancies to enforce zoning of areas for different land-use purposes.

Source: Namibia Ministry of Environment and Tourism. 


\section{LESSONS LEARNED}

BENEFITS FOR PASTORALISTS VERSUS AGRO-PASTORALISTS. Potential benefits from ILWM differ significantly for pastoralists whose livelihood is primarily from livestock and agro-pastoralists whose livelihood is from integrated livestock and agriculture. The lifestyle of pastoralists is likely to facilitate ILWM while for agro-pastoralists, conflict with wildlife is much higher, as crops can be damaged and predators damage livestock. Under these circumstances, it may be more difficult to introduce ILWM in agropastoralist situations but they also may see financial advantages resulting from their more secure land tenure and lifestyle which facilitate the development of tourism.

NeW MONITORING AND DATA MANAGEMENT TOOLS. Ecological information models capable of tracking the full range of land-use options are important tools for long-term land-use planning and policy formulation at local, regional, and national levels. Technology such as SAVANNA (Coughenour et al. 2000) allow for prediction of future range conditions, wildlife migratory corridors, livestock distribution, and populations. The models and technology facilitate land-use

\section{Box 5.26 Potential investments}

- Development of policy and regulatory frameworks for ILWM.

- ILWM feasibility and baseline studies on ecosystem status and biodiversity.

- Development of models to support informed decisionmaking at all levels.

- Support to participatory land-use planning.

- Institutional strengthening of community and local government levels.

- Sustainable consumptive and nonconsumptive wildlife use enterprises (ecotourism enterprise development, sport hunting, game cropping).

- Establishment of animal health centers and animal health extension services.

- Establishment of early warning systems for diseases and pests.

- Training in livestock marketing and upgrading of livestock marketing infrastructure.

Source: Authors. planning. For wildlife conservation planning, being able to examine those ecosystems that are under pressure for conversion into farmland and other uses that are often unfavorable to wildlife conservation, is very important.

\section{RECOMMENDATIONS FOR PRACTITIONERS}

Establishing ILWM systems to conserve natural resources and improve livelihood options for rural people requires investment strategies to (see box 5.26):

- Encourage wildlife-compatible land use by providing services necessary to improve incomes of pastoralists, and by removing policy barriers to income generation from ILWM.

- Support participatory land-use planning by village councils or land-use planning forums representing all key stakeholders, investing in strengthening institutional capacity at the community and local levels, and providing technical support for resource assessments, planning and monitoring of ILWM systems.

- Emphasize habitat management, rather then species management.

- Develop markets for ecosystem services by establishing innovative payment schemes for maintenance of ecosystem goods and services such as habitat maintenance.

- Provide for holistic evaluation of ILWM systems with comprehensive impact studies measuring both environmental and socioeconomic impacts.

\section{SELECTED READINGS}

Asterisk (*) at the end of a reference indicates that it is available on the Web. See Appendix 1 for a full list of Web sites.

ABSA. 2003. "Game Ranch Profitability in Southern Africa." SA Financial Sector Forum, South Africa.* 
Boyd, C., R. Blench, D. Bourn, L. Drake and P. Stevenson. 1999. "Reconciling Interests Among Wildlife, Livestock and People in Eastern Africa: A Sustainable Livelihoods Approach." Natural Resource Perspectives 45. Overseas Development Institute, London.*

Burn, D., and R. Blench., eds. 1999. Can Livestock and Wildlife Co-exist? An Interdisciplinary Appraoch. London: ODI.

Reid, R. S. "Livestock and Wildlife in Pastoral Systems of East Africa: Inevitable Conflict or Unexpected Synergy?" International Livestock Research Institute, Nairobi, Kenya.*

\section{REFERENCES CITED}

ABSA. 2003. "Game Ranch Profitability in Southern Africa." SA Financial Sector Forum, South Africa.

Ashley, C., and J. Elliott. 2003. “Just Wildlife?' or A Source of Local Development?" Natural Resources Perspectives 85. ODI, London.

Boyd, C., R. Blench, D. Bourn, L. Drake and P. Stevenson. 1999. "Reconciling Interests Among Wildlife, Livestock and People in Eastern Africa: A Sustainable Livelihoods Approach." Natural Resource Perspectives 45. ODI, London.

Coughenour, M., R. Reid, and P. Thornton. 2000. The Savanna Model: Providing Solutions for Wildlife Preservation and Human Development in East Africa and the Western United States. Washington, D.C.: Future Harvest.

Namibia Ministry of Environment and Toursim. http://www.met.gov.na/.

Shauri, V. 1999. "The New Wildlife Policy in Tanzania: Old Wine in a New Bottle?" Lawyers' Environmental Action Team, Dar es Salaam, Tanzania.

This Note was prepared by Nina Doetinchem and Cristophe Crepin with inputs from the Natural Resources Management Thematic Team of the World Bank. 
INNOVATIVE ACTIVITY PROFILE

\section{BRAZIL: PARTICIPATORY MICROCATCHMENT STRATEGY FOR INCREASED PRODUCTIVITY AND NATURAL RESOURCE CONSERVATION}

Before the 1980s in Brazil, agricultural production increases were primarily the result of expansion in areas under cultivation. After 1986, the agriculture sector rebounded with intensified production so that by 1996, agriculture accounted for about 10 percent of GDP. This period left a legacy of deforestation and increased soil erosion, and questions about sustainability, specifically of soil productivity and water quality. In the state of São Paulo, 62 percent of total land areas is considered to be cultivable, although most soils are of moderate or marginal quality and declining productivity.

What's innovative? Developing participatory processes on a microcatchment scale to reverse land degradation and improve watershed health.

\section{PROJECT OBJECTIVES AND DESCRIPTION}

In 1986 the Government of São Paulo commissioned a study on the risks of erosion in the Peixe-Paranapanema River watershed. The findings emphasized the seriousness of sheet and gully erosion. The purposes of the Land Management Project were to increase agricultural production and farm incomes while ensuring the conservation of natural resources. Major components included:

- Technology and institutional development to increase awareness of natural resource management issues, and facilitate participatory management of land resources.

- Adaptive agricultural research to provide technical solutions for soil conservation, integrated pest management, disposal of residual inputs, and crop diversification.
- An incentive program for sustainable NRM and conservation through community awareness building, the provision of grants for demonstration plots, and greater enforcement of land legislation.

- Training of extension agents and beneficiaries.

The above interventions at a microwatershed level take advantage of: geographical units of a more manageable size, linked by hydrological processes; stronger social cohesion within microwatersheds; ease of monitoring and measuring results; and ease of scaling microwatershed management projects to other areas such as downstream communities.

The Technology and Institutional Development component finances (i) rural extension; (ii) rural organization; and (iii) agro-ecological mapping at the microcatchment level. To change the crop-focused orientation of the extension system and farmers toward a microcatchment orientation, the project provides operational and technical guidelines and intensive training to all extension staff, including municipal and private extension workers.

Incentive grants are provided to farmers adopting sustainable technologies and practices that have a demonstration value. Farmer groups may receive grants for (a) collective purchase of specified farm implements for tillage and improved land management practices; and (b) construction of water supply systems for agrochemical mixing points to avoid pollution of streams and water sources. Individual farmers may receive grants for (a) land management practices, such as contour farming and strip cropping, vegetative contours, bunding and terracing; (b) protective fencing along water courses; and (c) provision of seeds for green manure crops.

Based on the results of a participatory socioeconomic and agro-ecological survey and on the agro-ecological maps produced under the project, project extension workers, together with 
the microcatchment beneficiaries, prepared a mutually-agreed Microcatchment Development Plan. This identified the principal agronomic and environmental problems, and proposed solutions through collective land and water management activities. The Plan set technical targets for all community works and farm level interventions and is supported by individual farmlanduse plans and by plans for collective activities. These are reviewed and approved by the Regional Microcatchment Commission and by the Project Coordination Unit.

\section{BENEFITS AND IMPACTS}

So far, the project has produced important behavioral changes among technical staff, local governments, and project beneficiaries. It has also supported synergies between project activities and other state and local initiatives. Project management has approved and implemented 310 microwatershed management plans, established 71 demonstration plots for new technologies including 51 for no-till pasture rehabilitation and 20 for smallscale dairy production; approved 4,270 management plans for individual properties; disbursed incentive grants to 710 beneficiaries; replanted or restored 626 hectares of riparian vegetation; and engaged 24,810 beneficiaries in project activities.

\section{LESSONS LEARNED AND ISSUES FOR WIDER APPLICABILITY}

- Management and implementation structure must set out clear responsibilities at state, regional and local levels, with emphasis on strong local participation (government, beneficiaries, and private sector).

- NRM strategies should be based on technological changes adapted to local needs and conditions to produce immediate benefits.

- Creative, motivated, and well-trained extension workers, provided with intensive training in group dynamics and use of participatory methods are essential.
- Participatory methods for selecting microwatersheds and activities to be undertaken, based on technical, environmental, and social criteria, should be used.

- Financial incentives for adopting technology/behavioral changes are needed.

- Robust monitoring and evaluation systems must be in place, with strong management units able to adjust implementation plans.

- Legal framework, including sanctions against activities detrimental to the environment and community efforts, is essential.

- Inputs need to be supplied in a timely manner to prevent implementation delays.

\section{PROJECT COUNTRY: BRAZIL}

$\begin{array}{ll}\text { Project Name } & \text { São Paulo Land Management } \\ & \text { Project }\end{array}$

Project ID P006474

Project Cost US\$123.0 million

Dates $\quad F Y 2000-F Y 2006$

Contact Point Graciela Lituma

The World Bank, I8I 8 H Street

NW, Washington D.C. 20433

Telephone: (202) 473-I 892

Email: glituma@worldbank.org 
INNOVATIVE ACTIVITY PROFILE

\section{CHINA: COMMERCIAL PLANTATIONSTO HELP CONSERVE FORESTS}

In China, the forest sector is critical to rural livelihoods, supplying 40 percent of rural household energy, and raw material for construction projects and the pulp and paper industry. Wood supply is limited, with forest cover of only 0.13 hectare per capita (in comparison to a global average of 0.6 hectare per capita). Recently China has been losing 500,000 hectares of natural forest per year, due largely to poor governance of the logging industry. To address these issues, the Government announced a ban on logging in natural forests, introduced new land laws, initiated reforestation programs with investments in plantations, and promoted environmentally sustainable logging practices.

What's innovative? Promoting commercial plantations to ensure forest conservation, with public assistance focused on facilitating initial market development and ensuring public good benefits.

\section{PROJECT OBJECTIVES AND DESCRIPTION}

The China Sustainable Forestry Development Project aims to develop a participatory framework for the sustainable management and conservation of forests and associated biodiversity, while minimizing the social and economic costs of the new government policy. The project includes a protected area management component, a national forest management component, and a plantation component. The plantation component accounting for 81 percent of the total project costs, and 99 percent of the World Bank loan, involves individual farmers and local organizations in commercial tree plantations with the objectives of narrowing the gap between domestic wood supply and demand, and generating new employment and income opportunities for rural households. This is addressed through four plantation subcomponents including:
- Establishing of timber plantations (to control soil erosion, contribute to watershed management, and support forestry research).

- Establishing economic tree crops.

- Precommercial thinning of existing plantations.

- Provision of technical support for planting stock development and nursery management.

Plantation establishment is accompanied by the appropriate market and technical research with much drawn from other Bank projects and Chinese research institutions. This research coordination effort allowed the task team to gather information, such as the identification of ecotypes and the development of plantation species lists, in a cost efficient manner.

Provided that they are managed and monitored appropriately, commercial plantations can reduce pressure on natural forests by providing fuelwood and lumber that might illegally be cut from natural forests. A clear system for monitoring and evaluation provides for monitoring on three levels: implementation progress, growth and quality of plantations, and environmental and social parameters.

Appropriate species selection taking into account soil, water, and slope conditions is important for growth and for market potential. So that the market is not flooded by any one species, the project addresses this issue by monitoring market prices for both lumber and fruit trees so trends can be forecast. This information, made available to plantation owners, is an effort to reach the private sector and their species investment decisions.

\section{BENEFITS AND IMPACTS}

The project has only recently begun to be implemented. Some 115,090 hectares of commercial wood plantations for fiber and pulp, plywood, and construction timber will be 
established in nine provinces to meet the forecasted national and local shortages of wood. The main afforestation beneficiaries are individual households, shareholding cooperative forest farms, village-township collective forest farms, and state forest farms.

Some 57,940 hectares of economic forest crops, including fruit, nut, and medicinal trees, will be established in eleven provinces. The tree crops include chestnut, walnut, ginkgo, eucommia, apricot, jujube, apple, pear, prickly ash, pomegranate, and Chinese yew. Those participating in this subcomponent include individual households, shareholding cooperative forest farms, village/township forest farms, and state forest farms.

\section{LESSONS LEARNED AND ISSUES FOR WIDER APPLICABILITY}

Experience during planning and project development has helped identify a number of key factors associated with the management of plantations:

The conservation of forests and biodiversity can be achieved through establishing protected areas, improving management of community forests, and developing alternative sources of forest products. By establishing plantations on nonforested land, local and regional demands for wood products can be more easily met without threatening natural forests. As government legislation prohibits the acquisition of wood products from natural forests, private sector plantations are the favored investment choice.

The establishment of large-scale commercial plantations requires the cooperation of government agencies and the private sector and this should be considered early in the project development cycle.

Finally, establishing plantations requires credible empowerment mechanisms so that owners are able to invest in land improvements with the assurance that they will receive the benefits from such an investment.

\section{PROJECT COUNTRY: CHINA}

$\begin{array}{ll}\text { Project Name } & \begin{array}{l}\text { Sustainable Forestry Development } \\ \text { Project (Plantation Component) }\end{array} \\ \text { Project ID } & \text { P064729 } \\ \text { Project Component Cost US\$174.96 million } \\ \text { Dates } & \text { FY } 2003 \text { - FY20I0 } \\ \text { Contact Point } & \text { Mohamed Benali } \\ & \text { The World Bank, I8I8 H Street } \\ & \text { NW,Washington D.C. } 20433 \\ & \text { Telephone: (202) 473-7357 } \\ & \text { Email: mbenali@worldbank.org }\end{array}$


INNOVATIVE ACTIVITY PROFILE

\section{EGYPT: MATRUH RESOURCE MANAGEMENT TO ENSURE SUSTAINABLE LIVELIHOODS FOR REMOTE BEDOUIN PEOPLE}

Egypt's poverty rate remains approximately 20 to 25 percent, with it being a disproportionately rural phenomenon. With limited irrigation potential, NRM issues are critical to sustainable economic development, this being especially so in the more marginalized Bedouin areas along the northwestern Mediterranean coast.

What's innovative? Engaging an isolated group in a broad natural resource management project through the incorporation of existing tribal structures.

The Bedouin people who make up 85 percent of the population in the area rely on rainfed agriculture and herding. Given that from 1992 to 2002 , the population in this area was expected to increase by more than 20 percent, the sustainability of such livelihood systems is in question. The Government of Egypt has sought to maximize the agricultural potential in dryland areas while managing natural resources in a sustainable manner but there have been several problems as the tribes have tended to remain isolated, and the government has had little experience addressing Bedouin concerns.

\section{PROJECT OBJECTIVES AND DESCRIPTION}

The Matruh Resource Management Project I was aimed at 1) conserving water, land, and vegetation resources in the project areas, and 2) alleviating poverty and improving the quality of life of the local Bedouin population. The following project components were designed to achieve these objectives:

- Water harvesting and watershed management, which would introduce several environmentally-sound water-harvesting interventions.

- Rangeland and grazing management, which would focus on improvement and effective utilization of rangeland and vegetative cover.

- Adaptive research implemented on a demand-driven basis.

- Extension and training, which would provide funding for establishing an effective agricultural extension service.

- Rural finance, which would give special attention to promoting on-farm incomegenerating activities targeted to small farmers, the landless, and rural women.

All activities are implemented within the framework of traditional tribal organizations, resulting in a demand-driven development process. This tribal framework ensures that government personnel become sensitized to Bedouin needs and concerns and it mobilizes local populations to manage natural resources in a sustainable manner. To incorporate tribal systems into their management framework, community groups which determined their composition and structure, were established.

\section{BENEFITS AND IMPACTS}

The first Matruh project (1994-2002) was recognized for its innovative participatory approach. With the objective of conserving the natural resource base, 1.2 million cubic meters of water storage facilities have been constructed, exceeding the estimated target by about five times, and representing an increase in water availability of 45 percent. The project also established 250 rangeland management units, and established fodder trees and shrubs on approximately 5,000 hectares. In terms of poverty reduction and improving the livelihoods, construction of safe drinking water storage facilities resulted in agricultural and health benefits for the local Bedouin population. Increased fodder availability and genetic improvement led to increased income from livestock and the adoption of high-yielding varieties led to increases in productivity of barley, olives and figs, and vegetables (with increases ranging from 27 to 70 percent). 
Overall, socioeconomic conditions of 10,440 households have been improved. In addition, the project built a good foundation for local capacity in resource management through technical assistance, training, and support for project staff, farmers and community representatives.

The second Matruh project (2003-2009) is continuing to improve local capacity by supporting local representatives, training in Community Action Plan development and implementation, providing access to information and communication facilities, and developing literacy classes and women's groups. All community development activities take place within the framework of traditional tribal systems.

Based on the first project experiences, the second project also added a component specifically directed at conserving biodiversity; increased the focus on off-farm income generation; and provided for rehabilitation and construction of feeder roads.

\section{LESSONS LEARNED AND ISSUES FOR WIDER}

\section{APPLICABILITY}

- A multisectoral/multidisciplinary approach in NRM and poverty reduction projects is more likely to achieve objectives than single-sector projects.

- Participatory project implementation requires flexible budgeting that is not constrained to predetermined outputs, but relies on a demand-driven identification of activities.

- Adequate initial training and capacity building is a prerequisite to the start-up of activities requiring beneficiary participation.

- Rural credit programs, particularly in remote areas, require innovative mechanisms that adapt to constraints on the financial institutions and on the beneficiaries.

- Targeting the poorest sections of a society where communities have strong traditional structures can be a challenging process.

\section{PROJECT COUNTRY: EGYPT}

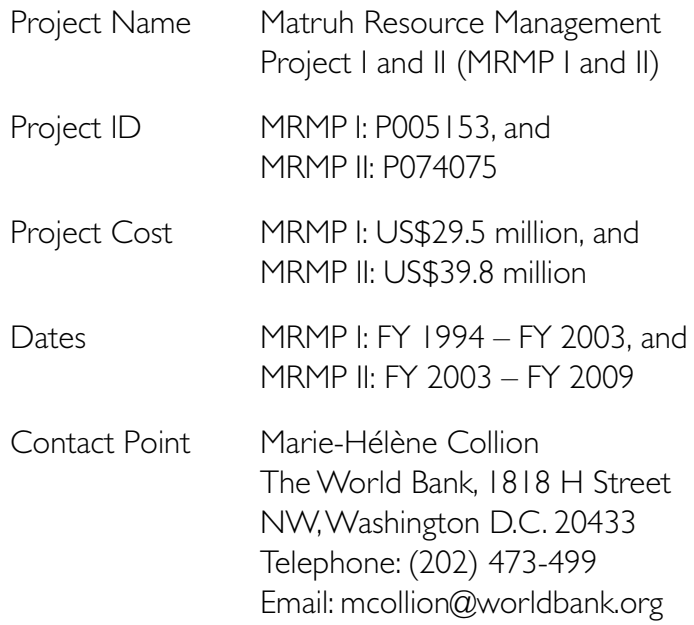


INNOVATIVE ACTIVITY PROFILE

\section{LATIN AMERICA AND CARIBBEAN: PAYMENTS FOR ENVIRONMENTAL SERVICES IN SILVOPASTORAL SYSTEMS}

In Central America, approximately 38 percent of the total land area is classified as permanent pasture. This represents a substantial increase over the last decade, due in part to conversion of tropical rainforest to pasture. In Colombia, Costa Rica, and Nicaragua, the rate of deforestation in natural forests over the past decade has been between 6 percent and 25 percent. Much of past deforestation in the tropical areas could be accounted for by distorted incentives, such as subsidized interest rates, and export subsidies used to promote large ranching operations. More recent deforestation has largely been a function of poverty, unemployment, and inequitable land distribution and landless poor people have cleared tropical forests for subsistence farming. While current practices of preserving forests within protected areas are necessary, they are not sufficient to ensure forest protection.

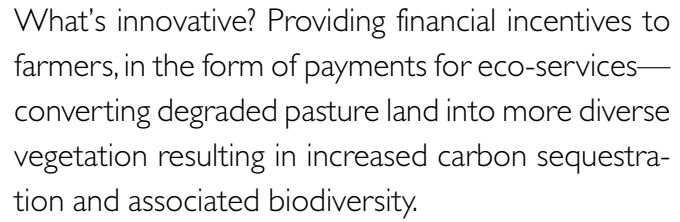

\section{PROJECT OBJECTIVES AND DESCRIPTION}

Providing forest protection beyond protected area borders, the Regional Integrated Silvopastoral Approaches to Ecosystem Management Project was established, encompassing sites in Colombia, Costa Rica, and Nicaragua. Its objectives are to institute a system of incentive payments to farmers who adopt silvopastoral techniques on degraded pasture lands. These techniques include replanting degraded lands with vegetation such as trees, legumes, and fastgrowing shrubs that are environmentally sound and financially productive so that the resulting system broadly mimics a forest ecosystem. The silvopastoral project consists of five components:

- Ecosystem enhancements through institutional capacity building and the development of community training programs.

- Environmental monitoring to measure changes in land use, carbon sequestration, biodiversity, and water quality.

- An eco-services fund for payment of environmental services provided by the silvopastoral systems.

- Policy formulation and dissemination focusing on sector and environmental policies associated with the sustainable intensification of livestock production.

- Project management through international NGOs.

Environmental services payments are distributed through individual contracts with farmers based on land-use changes compared with the baseline. These land-use changes are measured using satellite and Global Positioning System technology and this technology helps control monitoring costs. While development programs typically make payments ex-ante (that is, for costs of inputs), participating farmers are paid ex-post (that is, when they have made the change).

The relation between the land-use changes, and carbon sequestration and biodiversity, is closely monitored to be able to provide precise estimates of the contribution of different land uses to these "global public goods." The effects of payments on the adoption of silvopastoral systems, and farmers' views, especially related to risk, are the main socioeconomic variables monitored. This tests whether payments for environmental services are needed to "tip the balance" in favor of the adoption of silvopastoral systems.

Payments will total about US\$1.2 million. To sustain payments in the long term, the project 
is exploring various funding sources. The Government of Costa Rica has already earmarked general tax funds for the incentives. Possible revenues-a cost recovery approachmay come from those benefiting directly from biodiversity conservation, such as municipalities for the improved quality of water.

\section{BENEFITS AND IMPACTS}

Socioeconomic surveys, technical/information workshops, and preliminary studies have begun. The number of farms participating in the payment program will be 300. Initial feedback indicates that:

- The farmer response to the incentive scheme has been positive. Farmers say that although the payment offered is small compared to the costs of establishing the more intensive silvopastoral systems, the payment is very important, as is the technical assistance.

- The most likely land-use changes expected are more trees in pasture; improved pasture; live fences and windbreaks; and "protein" banks (shrubs etc. for livestock).

- Policymakers see this as an opportunity to improve the environment and productivity. The Minister of Environment of Costa Rica has already indicated that silvopastoral activities will be eligible for government environmental payment schemes.

\section{LESSONS LEARNED AND ISSUES FOR WIDER APPLICABILITY}

A virtual platform 5 has been established by FAO-LEAD (Livestock, Environment And Development Initiative, co-financier and partner in the project) for the dissemination of information, dialogues, and e-mail conferences on issues related to the project. The platform allows the project to be known worldwide, and to benefit from interaction with global experts.
Past experiences in similar projects have shown that economic incentives, such as those developed in the Latin America and Caribbean project, are especially important for ensuring individual participant buy-in, since payments are directly linked to participation level. The process has previously been used with hesitation as land rights were poorly established. This project has circumvented risks associated with weak land rights by not requiring land titles to make payments.

Initial experience has shown the need for wellestablished institutional mechanisms to manage and monitor the process, and for valuing the opportunity cost of alternate land uses when calculating appropriate payments.

\begin{tabular}{|c|c|}
\hline PROJECT C & $\begin{array}{l}\text { NTRIES: } \\
\text { COLOMBIA, COSTA RICA, } \\
\text { AND NICARAGUA }\end{array}$ \\
\hline Project Name & $\begin{array}{l}\text { Integrated Silvopastoral } \\
\text { Approaches to Ecosystem } \\
\text { Management }\end{array}$ \\
\hline Project ID & P072979 \\
\hline Project Cost & US\$8.4 million \\
\hline Dates & FY 2003 - FY 2008 \\
\hline Contact Point & $\begin{array}{l}\text { Paola Agostini and Cees De Haan } \\
\text { The World Bank, I8 I8 H Street } \\
\text { NW,Washington D.C. } 20433 \\
\text { Email: pagostini@worldbank.org } \\
\text { and cdehaan@worldbank.org }\end{array}$ \\
\hline
\end{tabular}


INNOVATIVE ACTIVITY PROFILE

CHINA:WATERSHED MANAGEMENT APPROACHTO OPTIMIZING INCOMES AND ECOLOGY IN POOR HIGHLANDS

Although the productivity of China's irrigated areas is now among the highest in the world, progress in dryland agriculture has lagged, particularly in rainfed regions in Northwest and Southwest China. High population pressures and unsustainable agricultural practices characterize these areas. The Loess Plateau in Northwest China is one of the poorest areas. Early efforts to address environmental issues (soil erosion) of the Loess Plateau included campaigns to terrace slopes, plant trees and shrubs, and build dams in the gullies to intercept sediment runoff. These interventions were not integrated with efforts to raise agricultural productivity and farm incomes. Planners and farmers now realize that land conservation is compatible with sustainable and productive agriculture, and that these are mutually reinforcing. This strategic approach has been implemented with considerable success on more than 700,000 hectares of land in the first Loess Plateau Watershed Rehabilitation Project (Loess I).

What's innovative? Using an integrated small watershed management approach in highlands, drawing on local knowledge resources and integrating land tenure, grazing management, farming and conservation priorities to optimize both productivity and the ecological balance.

\section{PROJECT OBJECTIVES AND DESCRIPTION}

The Loess Plateau Watershed Rehabilitation Project II aims to implement the interventions tested by Loess I in other provinces, promoting sustainable development by increasing agricultural production and incomes, and improving ecological conditions in tributary watersheds of the Yellow River. Specific objectives are:
- Introducing more efficient and sustainable uses of land and water resources.

- Reducing erosion and sediment flow into the Yellow River.

The project targets several of the poorest counties in Shanxi, Shaanxi, and Gansu provinces, and the autonomous region of Inner Mongolia. The project follows an approach of integrated planning and treatment of small watersheds and:

- Creates productive farmland for sustainable production of field crops and orchards, replacing crop areas on erodible slopelands.

- Plants the slopelands with trees, shrubs, and grasses for the production of fuel, timber, and fodder increasing the per hectare productivity on improved farmland.

The project follows a participatory approach and key involvement of local public institutions so that there is an integrated approach to interventions. Small watershed development involves integration of forestry, soil and water conservation, agriculture, and livestock. The various interventions include terracing, sediment control structures, and irrigation for cropland improvement. Slopeland protection is achieved through livestock management, afforestation, vegetative cover, and horticulture. The projects have involved specialists in these areas. Following a two-year participatory planning process, during which staff collected information about local soil erosion control practices, the project proceeded to assist participating farmers to complete over 80,000 hectares of terracing, and replant 160,000 hectares with forest trees and income-generating shrubs and trees, such as apple, pear, walnut, and apricot.

While the private sector has been reluctant to provide financing for the types of investments involved, farmers share project costs by providing labor (up to 25 days per year) and by paying for part of the investment costs, with the share 
paid depending on the extent of private and public benefit of the investment. Overall, the farmers contribute about one-third of the total investment. Local and provincial governments pay most of the remaining investment costs.

The leading implementing agency is the Ministry of Water Resources. Four provincial water resources bureaus and twenty county water conservancy bureaus have led project implementation.

\section{BENEFITS AND IMPACTS}

Within two years, participating farmers were able to double and in some cases triple crop yields and replant previously barren hillsides, enabling over 500,000 farmers to improve their standard of living. Over 3,000 villages are now actively involved and working with over 1,200 microcatchments and, by the end of Loess II, over 3 million people will have benefited directly from the projects.

\section{LESSONS LEARNED AND POTENTIAL FOR WIDER APPLICABILITY}

Much of the project success has been due to keeping project activities focused and simple, and allowing each watershed group to develop its own terracing and reforestation plans. Overly complex designs for extension and agricultural programs can complicate implementation, take authority out of the hands of farmers, and limit potential for success. Major lessons learned were that similar projects are well advised to:

- Insist that, from the very start, farmers plan for grazing and livestock management.

- Allow local procurement for construction, terracing, and land reclamation, but use a strict quality control system for work at all levels, including random spot-checking.

- Import improved tree seedlings that can improve farmers' abilities to protect hillsides.
- Provide farmer-to-farmer exchange trips to pilot/project areas.

- Use a comprehensive media campaign to publicize project objectives and activities for a sustained period of time to ensure it is widely known.

- Keep projects as simple as possible, given local circumstances and the objectives set.

\section{PROJECT COUNTRY: CHINA}

$\begin{array}{ll}\text { Project Name } & \text { Loess Plateau Watershed } \\ & \text { Rehabilitation Project (I \& II) } \\ \text { Project ID } & \text { Loess Plateau I: P003540 and } \\ & \text { Loess Plateau II: P0562 I6 } \\ \text { Project Cost } & \text { Loess Plateau I: US\$ I } 50 \text { million } \\ & \text { and Loess Plateau II: US\$ I50 } \\ & \text { million } \\ & \text { Loess Plateau I: } \\ \text { Dates } & \text { FY 1995 - FY 2003 and } \\ & \text { Loess Plateau II: } \\ & \text { FY 2000 - FY 2004 } \\ & \text { Jurgen Voegele } \\ & \begin{array}{l}\text { The World Bank, 9th Floor } \\ \text { Contact Point }\end{array} \\ & \text { No. 8, Chaoyangmen Beidajie } \\ & \text { Dongcheng District } \\ & \text { Beijing I 00027, China } \\ & \text { Email: jvoegele@worldbank.org }\end{array}$





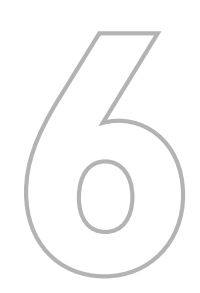

\section{INVESTMENT IN AGRIBUSINESS AND MARKET DEVELOPMENT} the basis for capitalizing on market opportunities and benefiting from increased farm productivity. Private sector and market development require a suitable enabling environment, characterized by a stable macroeconomic climate with adequate commercial laws and financial services, a well functioning legal system, and adequate infrastructure. Enhancing private sector and market development in a way that includes the poor presents a key challenge to development efforts.

\section{RATIONALE FOR INVESTMENT}

The farm sector includes, in addition to agricultural producers, a diverse range of large and small enterprises, sometimes referred to as agribusiness, that include farm input and service suppliers (seeds, fertilizer, equipment), downstream processors, traders, and retailers. These enterprises are interlinked in networks that together constitute agricultural market systems that match buyers and sellers, provide a 
venue for consolidating small lots and grading, facilitate physical exchange and price discovery, transmit information, and manage risk. Markets coordinate the activities of input providers, producers, and downstream agents. Nongovernmental organizations (NGOs) such as industry associations and producer organizations play supportive roles.

Although a well-functioning private agribusiness sector is a precondition for a productive farm sector, the environment for private sector operations frequently has serious limitations. Rural areas often lack infrastructure, effective local government, adequate commercial and social services, and information and communication systems. In addition, product and often factor markets do not function well, and considerable interregional market rigidities exist. This increases risks associated with doing business and contributes to interregional disparities. When agro-enterprises find it too costly or risky to rely on small-scale farmers for raw material supply, these farmers are excluded from market opportunities. For agricultural growth to be propoor, the rural poor must be successfully integrated into expanding markets.

Competitiveness of agricultural production and market efficiency are becoming more important with the commercialization of agriculture and the growing importance of global market access provided under the World Trade Organization (WTO). Increased competitiveness in national and international markets has become a core issue for national policy (see box 6.1). Privatization and market liberalization reforms continue in many countries and, even where they are completed, must be accompanied by a thorough review and reform of public policy relating to private sector and market development.

Many requirements for effective market and private sector development have public good characteristics. Public good dimensions include: contract law and other legal provisions, trade agreements, competition policy, food safety regulations, establishment and enforcement of grades and standards, infrastructure, training, market information services, and overall coordination of public and private sector activity. While some of these can be provided by the private sector, this often requires regulation and cofinancing or approval by the public sector. Public investment to improve the rural investment climate improves the competitiveness of agriculture and rural enterprises. Without the support of public sector enabling institutions, private sector agro-enterprises and markets will remain inadequately developed and inequitable.

Improved market efficiency and greater private sector activity are essential to aid the transition

\section{Box 6.I Competitiveness and supply chains}

Competitiveness is the ability of enterprises to earn a sufficient income for employed labor and capital. If a firm is competitive, it can invest to expand, innovate, and adjust to market changes. Competitiveness depends on the cost structure and on prices realized on sales which are factors dependent on the firm's own performance; on public infrastructure and services; and on performance of other institutions providing the firm with inputs and services. Since firms that are linked to distant input or product markets often depend heavily on other firms and the public sector, competitiveness may need to be analyzed for clusters of enterprises with interrelated activities.

Competitiveness frequently depends on a chain of firms that together produce, collect, process, transport, and sell products. In agriculture, many firms and farms are strongly interdependent in such supply chains. For example, to be competitive, fruit producers in Ghana must be effectively linked with suppliers, technology providers, traders, processors, transporters, and retailers in the United Kingdom to earn sufficient income for their labor, land, and capital. Supply chains provide for market linkages that ensure the supply, quality, and safety of agricultural products. Performance of the chain depends on effective cooperation and coordination among all partners in the chain.

Source: Authors. 
from subsistence farming to more commercialized agricultural systems. The latter produce and market food staple crops more efficiently, or higher-value products (mainly livestock, aquaculture and horticulture products) that require more inputs, processing, and handling. Market efficiency improves competitiveness in local and foreign markets, and increases incomes to farmers, laborers, and small entrepreneurs involved in input supply and downstream processing and distribution. Private sector development typically generates employment opportunities distributed across a broad spectrum of the economy. Increased market efficiency can also improve living conditions for poor consumers by reducing food prices, improving quality and variety, and increasing accessibility of food and other consumer goods. This results in increased real household income and improved nutritional status.

\section{PAST INVESTMENT ACTIVITY}

In the 1960s and 1970s, governments in many countries played a direct role in input supply, production, trade, transport, and distribution, or at least had a dominant role in the control or management of these markets. The World Bank and other donors provided significant direct investment in parastatals (state-owned companies), government controlled cooperatives, and public marketing. When government-dominated systems fell into disgrace in the 1980s and 1990s because of their poor performance, lending for these types of investments disappeared. Difficult, lengthy, and sometimes disruptive processes of privatization and market liberalization marked the ensuing transition from government-dominated systems to market-based systems. World Bank support focused mainly on lending for adjustment and reform. Direct investment was left to private investors, commercial banks, and within the World Bank Group, to the International Finance Corporation (IFC).

Although privatization and liberalization were often necessary to stabilize economies and provide a basis for economic growth, in many cases these reforms did not result in a quick response from private investors. The long legacy of state-controlled and parastatal-managed markets in many countries left the institutional and policy frameworks for liberalized and private sector-led markets underdeveloped, and private sector capacities relatively limited.

More recently attention has focused on strengthening a new architecture for agricultural market institutions and incentives, promoting private commercial activity and reorienting state activity to the provision of enabling regulatory and physical infrastructure. As a result, Bank lending for agricultural markets and trade and agro-industry has begun to increase again (see figure 6.1).

\section{KEY ISSUES FOR INVESTMENT}

The expanding role of the private sector is increasingly realized, as is acceptance that markets are the best vehicle for rural economic growth, and for facilitating specialization and diversification. The increased focus on private enterprise and market development for poverty reduction emphasizes improvement of the enabling environment, and an adjustment of priorities to facilitate market participation by the poor. Key issues in this regard include: adapting to globalization pressures, defining public and private roles, communicating with the private sector, public-private cooperation, managing risk, improving market access, promoting competition, addressing food safety issues, and ensuring gender equity of growth.

Adapting to globalization and dynamic market change. Rapid changes in consumer demand, technologies, and organization of markets and supply-chains present continuous challenges to producers. Competitive forces require producers to regularly adjust the technologies employed in production and marketing processes, and to improve the efficiency of linkages within supply chains. Agribusinesses must have the flexibility to adapt as new technologies emerge, as new trade and market requirements are established, and as consumer demand evolves. Grades and product and process standards are taking on greater importance in light of consumer (and the retail 
FIGURE 6.I WORLD BANK LENDING TO "AGROINDUSTRY" AND "AGRICULTURAL MARKETS AND TRADE", 1990-2002

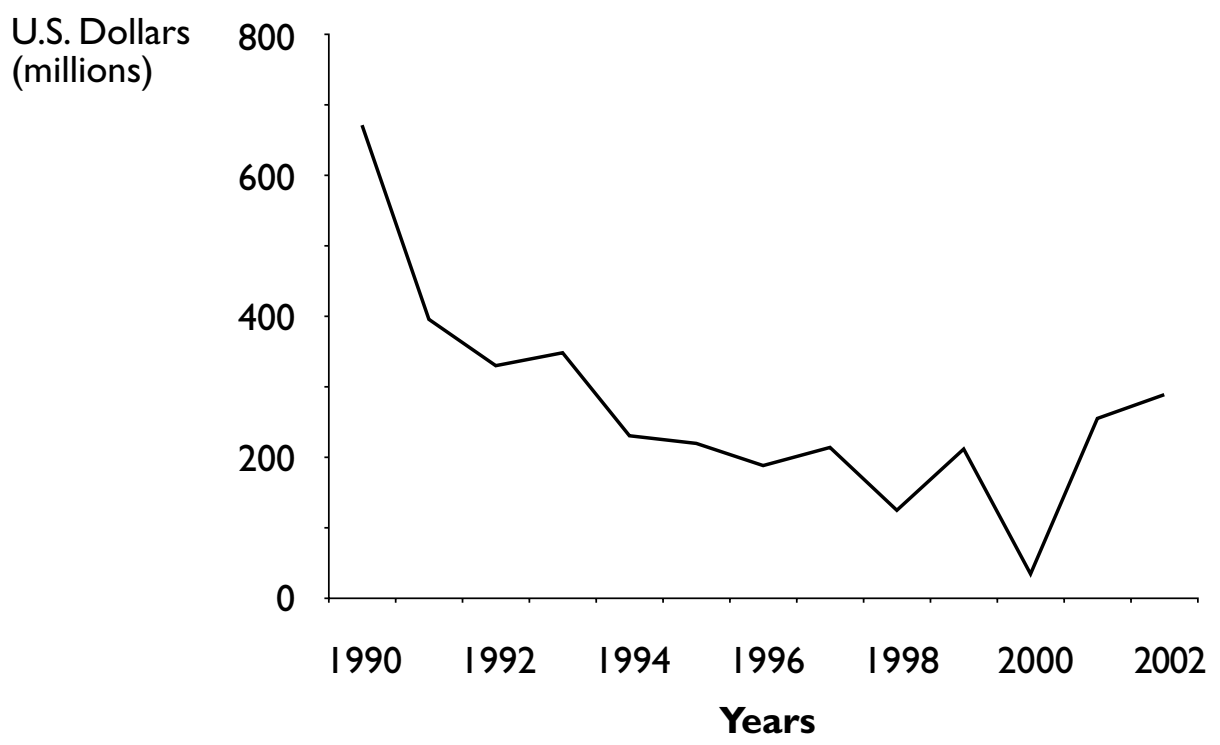

Source:World Bank Internal Documents.

gatekeeper) demands for quality, safety, authenticity, and sustainability of products. The need to meet these demands can represent a major challenge to market entry or continued market access. The government role is to efficiently provide the public goods that enable private enterprises to competitively produce for local and international markets, and to ensure that the benefits of these interventions do not bypass the poor but expand their production and income opportunities.

Defining PUBlic and PRIVATE ROles. One of the most difficult challenges for policymakers in a developing market economy is to find a good balance between public and private responsibilities. Although public goods are the responsibility of the public sector and private goods of the private sector, many goods and services, the so-called impure public goods, have shades of public and private characteristics that may require joint public-private actions. Markets function imperfectly due to externalities, economies of scale, asymmetric information, nonexcludability, and excessive contracting costs. These market imperfections often require public sector intervention. But the identification of market failures and justification of public interventions is complex and requires significant analytical capacity. Public sector involvement must be guided by highquality analytical work with regard to markets and commodity chains, that ensures that the costs of public intervention do not exceed the benefits. Important information needs relate to the following issues and guidelines:

- The public sector should not do what the private sector can do (for example, direct provision or distribution of agricultural inputs such as seed or fertilizer).

- Public interventions should go to those activities that have the highest potential net benefits (that is, where objective policy research and analysis indicate the greater economic and social returns-not where powerful political lobbyists prefer).

- Subsidization of variable inputs and credit are usually undesirable-exit strategies for subsidization and border protection are needed where they exist, and some transition mechanisms (such as direct income support) may be appropriate. 
- Public-private cofinancing of lumpy one-time investments is often a preferable strategy (for example, for information systems, transport and storage infrastructure).

Communicating With THE PRIVATE SECTOR. In developing countries with a legacy of state dominance of the economy, the voice of entrepreneurs is often weak. Communication between government and the private sector is not well institutionalized and often limited to larger companies with greater political influence. Smaller enterprises, in rural areas in particular, have little access to systems for public policy dialogue and therefore limited ability to influence political outcomes. In such situations government decision makers may overlook important information and private sector concerns when preparing and implementing policies.

Similarly, donors also have little experience in working with the private sector because they are often legally confined to dealing with governments. Major efforts are needed to establish good communication and cooperation between private sector entities and donor agencies, to develop better mutual understanding, and to overcome past mistrust and antagonisms.

Public-private cooperation. Development of market institutions and provision of supporting public good services remain areas in which synergies can be obtained through cooperation between the private and public sector. Public-private cooperation is especially important for:

- Developing and maintaining market infrastructure that reduces costs of exchanging physical products.

- Developing and maintaining information systems for data on supply and demand, trade, prices, and technology.

- Preparation and implementation of new rules and regulations related to the agricultural, trade, fiscal and economic policies.
- Facilitating efficient marketing functions through standardized terms for the delivery of products, their conditioning (sorting, packaging, grading, and labeling), the mode of payment, arbitration of commercial disputes, and policing of markets.

- Monitoring quality of products through technical standards and norms.

- Research and development and training to improve skills of technical staff.

- Generic promotion of agricultural and food products in foreign markets.

Reducing risks faced by private firms. As a result of market liberalization, price risk has been shifted from governments to producers and consumers. The risks associated with private sector investment are exacerbated by ineffective systems for enforcing property rights and rules for contracts, and by distortionary trade policies. High rates of inflation and shortages of foreign exchange contribute to investment uncertainty and the inaccessibility of intermediate inputs. Farmers and firms have "traditional" means of managing their risks (that is, through savings, diversification, selective market relationships), but these may result in lower than optimal investment and missed opportunities. A high-risk environment encourages a short-term perspective-it constrains transition away from subsistence farming toward commercial systems, and acts as an overall disincentive to the integration of the poor into the economy.

Governments can reduce risk for private entrepreneurs through a stable policy climate, better information services, technologies, and infrastructure. A functioning or enabling legal and regulatory environment and contract disputes mechanisms (for example, arbitration in the absence of an effective judicial system) are also important. Further, the public sector can facilitate the use of existing traditional commodity exchanges (for example, spot markets) as well as more complex markets for risk management (for example, futures, hedg- 
ing, and insurance), and in certain cases can promote the establishment of new commodity exchanges. ${ }^{1}$ Safety nets will be needed in some instances to cushion some groups from adverse social and economic aspects.

REDUCING BARRIERS TO MARKET ACCESS AND ENSURING EQUTTABLE OUTCOMES. The impacts of market development are highly differentiated across rural enterprises, community groups, and individuals. Some stakeholders (the landless or women for example) stand to lose from the development of more open and competitive markets and targeted efforts to mitigate potential negative impacts and promote equitable access to the benefits are often necessary. Small enterprises are more dependent on public services than larger enterprises, because they lack economies of scale for contracting their own technical and management services. Moreover, they have less political influence, and public sector officials often have little knowledge of the needs of small enterprises and the obstacles they face. Furthermore, new technologies and new market requirements may tend to exclude small producers. Market forces alone will not ensure such participation because of the potentially high transaction costs faced by upstream and downstream economic entities involved in transactions with small, dispersed groups. Public support initiatives, especially technology, information and advising services, and strengthening of producer organizations (POs) are often required to provide a level playing field that enables small enterprises and small farms to participate in free markets.

Promoting competition. In government-dominated markets, competition was seldom encouraged, whereas in a market economy it is crucial. An important issue for government policy is to promote competition through free market entry, and to curb monopolistic and monopsonistic market power. Since globalization forces can concentrate enormous market power, government capacity to apply legal and regulatory checks and balances is essential to ensure a level playing field for local enterprise. Promotion of regional markets across national borders with harmonized regulations, grades and standards, research and information systems, and business certification, can all expand the scale of production and marketing. This will improve market efficiency and also reduce market entry costs and expand opportunities for local farmers.

LABOR MARKETS. Availability of skilled labor and flexibility of labor markets are important considerations in investment decisions for private sector enterprises. Labor market regulations can have major impacts on the cost of labor. For instance, if layoffs are very expensive as a result of employment contract regulations, employers may be discouraged from hiring new labor. An important trade-off in designing labor policy is to accommodate the needs of and compliance costs for, local industry, while ensuring that the interests of the local workforce (the poor, women, and the underrepresented in particular) are fully addressed. Application of sound labor laws (following International Labour Organization standards) encourages pro-poor growth and increases the ability to access some international markets and meet the labor standards set by foreign buyers.

FOOD SAFETY AND STANDARDS. International public sanitary and phytosanitary standards pose important problems for exporters from developing countries with their limited institutional and financial resources. These standards involve protection of public health, prevention of the spread of harmful animal diseases and plant pests, and protection of ecosystems. Of increasing importance are requirements of private sector buyers in Organisation for Economic Cooperation and Development (OECD) countries, who often set product and process standards, involving environmental and social requirements that are well in excess of minimum legislated

I. See the AINs, "Commodity Price Risk Management" and "Agricultural Insurance" (Module I0). 
food safety standards. With the rapid increase in proportion of food products marketed through supermarkets (both in industrial and developing countries), it is critical that coordinated supply chains enable producers to meet the specific requirements of modern retailers. They should also certify that the grades and standards they set (as well as government implemented safety standards) have been satisfied.

GENDER. In many countries, the management of certain crops and particularly agricultural processing is traditionally viewed as "women's work." Increasing numbers of women are participating in the formal labor force (in field production, in pick-and-pack operations, in food processing plants, and in managerial and supervisory positions). It is important to ensure that women producers are not discriminated against in terms of opportunity to participate in national and international markets through producers associations and contract farming. Similarly, female workers should have acceptable employment conditions, and women entrepreneurs should have equal access to credit, training, and market contracts. Gender-related issues in market and agribusiness development must be fully explored through sound gender assessments, as a basis for planning any new public investments.

\section{FUTURE DIRECTIONS FOR LENDING}

Public support for development of agricultural markets and private sector capacity can involve: improving the policy and regulatory framework; privatization; provision of public goods infrastructure and services to enhance competitiveness; development of entrepreneurial capacity, industry and producer associations, and new market chains; and information and communication systems. The most crucial government responsibility is that of formulating economic policies. This requires continuous policy and market analysis. Most direct investments are the responsibility of the private sector, but large-scale public sector investment may be required for public infrastructure.
For donor agencies, priority investments should be directed at economic and sector work to support policy formulation and competitiveness planning. Lending for infrastructure can be significant, but most other investment needs (generally related to capacity building) are likely to be relatively small, even though they may be crucial to market and enterprise development and, hence, to rural growth and poverty reduction.

IMPROVING POLICY AND REGULATORY FRAMEWORKS. Lending in support of policy formulation and regulatory frameworks will typically need to focus on policy analysis, restructuring of public services, and building public and private sector capacity. Although many countries have implemented major policy reforms, the business environment is often still far from conducive to private sector growth, especially in rural areas. Investment Climate Assessments (ICAs) have become a common tool to identify major obstacles for private sector development. While these assessments are being adapted to cover rural areas to provide input to policy dialogue, and the preparation of lending operations, it is important to consider the full range of analytical methods and frameworks, and to adopt innovative approaches where appropriate.

Effective legal and regulatory policies for efficient functioning of markets (for example, contract enforcement rules, labeling regulations) are critical to increasing investment. Many developing countries have complicated systems of business regulations that increase costs of private sector operation and open avenues for corruption. A sound legal framework and effective mechanisms for efficient and fair adjudication of contract disputes is necessary in any country to enable efficient market transactions. Trade policy, including duties and quotas on imports and taxes and subsidies for exports, may distort relative prices and can have a major impact on investment. Monetary policy affects investment through direct effects on interest rates (the cost of capital). Property rights (intellectual, land) must be protected to encourage investment and innovation. 
Privatization. Privatization continues to be an important area for reform, because many inefficient parastatal enterprises still exist. The complexity of privatization of agricultural industries is due to the interlinkages of input supply, financing, and commodity markets and the political sensitivity of food supply and prices. The transition from public to private ownership has major implications for financing production and processing systems, since implicit in the previous financing for such systems was the de jure or de facto exclusive commodity procurement and marketing rights of the state enterprise. Privatization therefore may require reengineering of the entire farm to factory to buyer supply chain. Particular attention should also be given to market-making (see box 6.2).

IMPROVEMENT OF PUBLIC GOODS AND SERVICES. The ability of private enterprises to compete depends very much on the availability and quality of public goods (incentive structures, infrastructure, public services) and public "bads" (cost and disincentives of misguided interventions, poor governance). Investors will invest capital where infrastructure and services enable them to compete in the marketplace. Well-targeted public investments in roads, ports, telecommunications, marketplaces, and water supply have

Box 6.2 Privatization and market-making

The "privatization as asset-transfer" approach has frequently given insufficient attention to the range of market-making functions and services (risk management, price discovery, quality control, market intelligence, production statistics, remote area collection services, farm extension) formerly undertaken by state enterprises. Key to fostering development of new institutions is the need to:

- promote government commitment to "sell" the reform to stakeholders and support the implementation process;

- Develop a consultative process that sharpens understanding of key issues and provides a grounding and record for public debate; and

- Plan for a 2-3 year transitional period that maintains the momentum of reform while avoiding the emergence of function/service gaps.

Source:World Bank 200I. an important bearing on private investment and competitiveness. The same can apply to government support for, or direct provision of, agricultural, postharvest, and food technology research, training, and dissemination. If these basic needs are not met, there will be underinvestment in the local economy.

DeVELOPING ENTREPRENEURIAL CAPACITY. Entrepreneurial and managerial skillsæincluding market research, promotion, pricing strategies, marketing channel management, and other skillsænecessary for effective private sector investment are not widely developed in many countries. This is due, in part, to the past dominance of processing/marketing activity by parastatal (and/or foreign) enterprises and the concentration of trade in unprocessed standard commodities. This limited skills base inhibits the ability of entrepreneurs to penetrate international markets for nontraditional products, and to compete with established companies in domestic and regional markets. Business development services (BDS) that help firms improve quality and efficiency of processes, reduce costs, and expand operations are important to all firms, but are especially critical to small firms and new start-ups. Needs assessments indicate scope for programs of training, internships, and technical assistance to build skills in small business management, so that small firms and those in rural areas develop capacity to participate in markets. BDS are best provided by financially autonomous entities, capable of securing much of their funding through the recovery of costs from users. Examples in agriculture are agribusiness development centers (ADCs), project development facilities, learning through exchange schemes, and nonprofit private sector institutes (see box 6.3).

Business ASSOCIATIONS AND EMPOWERMENT. Business associations have valuable roles to play as vehicles for connecting producers and clients, crystallizing and expressing the viewpoints of affinity groups, taking collective action, networking among members, and providing economic services in training, information, facilitation, 
technology, and legal support. They include chambers of commerce, regional business councils, and business associations that include seed trade associations, fertilizer importers and dealers associations, fruit and vegetable exporters associations, rice millers associations, and others. These associations often represent influential private sector entrepreneurs-although not necessarily the poorest ones-who constitute a potential engine for growth, and could therefore contribute substantially to government policy and strategy formulation.

Governments can facilitate association development, but must be cautious in initiating activities, as this may be perceived as government control. It may also undermine the legitimacy and private sector members' ownership, making continued funding uncertain once public sector support is withdrawn. Any program providing financial, technical, and/or human resource support to associations should involve a commitment of the association itself. At the local level, building capacity of local private sector associations can facilitate dialogue with local government, and be an important element in empowering small businesses.

COOPERATIVES AND PRODUCER ASSOCIATION-OWNED ENTERPRISES. A special type of private collective enterprise is that of the producer group-owned enterprise, usually based on small farmers associating in cooperatives, producer associations, or informal marketing groups. These group enterprises build economies of scale and improve small farmer marketing options, providing direct impact on the welfare and competitiveness of small producers, as well as being social safety nets (see box 6.4). As producers become more "market-savvy" their interest in such group enterprises is likely to increase, and enterprise development becomes more feasible and important.

A first requirement for public support for cooperatives and other producer group-owned enterprises is the establishment of a facilitating legal, regulatory, and policy framework for such enterprises. Additional support is often

\section{Box 6.3 Agribusiness development centers}

Between 1993 and 2003, project-based agribusiness development centers (ADCs) have been established to provide advisory and analytical services to private sector agro-enterprises in a number of countries. They have played a variety of catalytic and facilitation roles, although they generally focus on technical and market information. The experience of ADCs points to the importance of: clear definitions of objectives and clientele; credibility and competence of staff (dependent in part on the extent to which the ADC board is led by the private sector); a realistic strategy for financial services; and the separation of technical and financial services.

Source:World Bank 200I.

\section{Box 6.4 Guinea: Foutah Jalon (Guinea) potato growers} successfully competing with European farmers

The Federation of Foutah Jalon Farmers has 13,500 members who produce approximately 4,000 tons of potatoes every year. The Federation markets an additional 3,000 tons of nonmember production each year. Besides support to marketing, the Federation provides members with technical advice and inputs (imported potato seeds and bags). Marketing of potatoes is managed by a group of women called "Dioulamoussous" who collect produce from 2I Federation warehouses and resell it in the capital city of Conakry. The farmers and the women traders agree upon the producer price as well as the women's margin.

After negotiation with the Federation, the government agreed to limit potato imports from Europe during the period when Fouta Jalon potatoes are marketed. This protection measure allowed Fouta Jalon farmers to develop their production through improvements in productivity, storage, and marketing. In four years, yields per hectare increased from 3 to 20 tons. Protection measures have now been lifted and Foutah Jalon farmers are competitive with European farmers. This scheme has been so successful that in certain villages people speak of urban-rural migration: urban people are moving back to Foutah Jalon to grow potatoes.

Source: http://www.paysansdufouta.org/.

warranted to help these groups become established and overcome their disadvantages of limited business management experience, education, and poverty. Similar to support to other private entrepreneurs, direct public subsidies must be approached with caution. There must be a clear justification for public support to overcome initial constraints and a 
defined exit strategy to avoid dependency and continuing subsidies.

Supply Chains For market integration. Perishable, high-value products with stringent quality and safety requirements typically require complex contracting arrangements to control quality and coordinate specialized production, trading, and processing activities. ${ }^{2}$ Effective supply chains transmit demand signals to suppliers who in turn can respond flexibly and efficiently to satisfy consumer demand. This allows private entities to share information and technology, pursue marketing strategies, reduce risks and transaction costs, and safeguard quality and safety. Public support, through independent intermediaries with adequate knowledge of tools and technologies, can play an important role in enhancing the emergence of effective supply chains. ${ }^{3}$ This must be based on sound industry or chain analysis, and must take into account the resource availability constraints and implications for small farmers. Producer organizations are important for linking small farmers to market chains.

INFORMATION SERVICES. Information is crucial to efficient agricultural markets. The availability of accurate price and other market information helps to reduce risks and transaction costs, and to enable market participants to plan and coordinate more effectively their production

Box 6.5 Key safeguard policy issues for private sector and market development investments

- Environmental Assessment (Operational Policy (OP)/Bank Procedure (BP) 4.0I)æan Environmental Assessment is required if private sector or market development activities may have potential adverse environmental risks or impacts.

- Pest Management (OP 4.09)æprivate sector and market development investments involving procurement and use of pesticides or that might expand use of pesticides and unsustainable pest management practices require an Environmental Assessment, a Pest Management Plan, and a list of pesticides authorized for procurement.

Source:World Bank Operational Manual. and trading activities. Although market information has public good elements, most of the efforts to develop public sector market information systems have failed, as most systems have lacked commercial utility and have been unsustainable. Building sustainable market information systems will require: identifying mechanisms for private management; obtaining at least partial cost recovery; having a modest scope covering only one or a few commercially important commodities; ensuring a participatory process with users defining their needs; including some non-price data (market closures, quality comments, food safety problems); and making costeffective use of available information technologies to achieve timely and wide dissemination.

\section{SCALING UP INVESTMENTS}

Prior to scaling up, public investments in agricultural private sector and market development need to be oriented toward, and critically evaluated against, the objectives of poverty reduction, efficiency, and sustainability. Key outcome criteria will relate to market efficiency, including reductions of subsidies and market distortions, increases in quality and value addition, enterprise profitability, and employment generation. Two key safeguard policies generally relevant to investments in agricultural private sector and market development must also be considered (see box 6.5). Various operational policies and safeguards relating to subsidies and grants may also be relevant.

Although the following five investment notes are important themes for practitioners involved in private sector and market development, they by no means reflect a comprehensive collection. Future editions of this Sourcebook will include notes on other areas of best practices that are equally as important as those in this edition. Such future work will include: Facilitating Food and Commodity Markets, Managing Standards and Grades, Producers Organizations, and Trade Associations.
2. See the AIN, "Horticultural Exports from Developing Countries".

3. See the AIN, "Supporting Market and Supply Chain Development". 


\section{SELECTED READINGS}

Asterisk (*) at the end of a reference indicates that it is available on the Web. See Appendix 1 for a full list of Websites.

Dolan, C. S., and K. Sorby. 2003. "Gender and Employment in High-Value Agriculture Industries." Agricultural and Rural Development Working Paper 7. World Bank, Washington, D.C.*

Jaffee, S. 1992. Exporting High-Value Food Commodities; Success Stories from Developing Countries. With the assistance of P. Gordon. World Bank Discussion Paper 198. Washington, D.C.: World Bank.*

van der Meer, K. 2003. "Public-Private Cooperation in Agricultural Research: Examples from the Netherlands." In D. Byerlee and R. G. Echeverria, eds., Agricultural Research Policy in an Era of Privatization. Wallingford, U.K.: CABI Publishing.

World Bank. 2001. "Promoting Agro-Enterprise and Agro-food Systems Development in Developing and Transition Countries: Towards an Operational Strategy for the World Bank Group." World Bank, Washington, D.C.*

\section{REFERENCES CITED}

Fédération des Paysans du Fouta Djallon. http:/ /www.paysansdufouta.org/.

World Bank. 2001. "Promoting Agro-Enterprise and Agro-food Systems Development in Developing and Transition Countries: Towards an Operational Strategy for the World Bank Group.” World Bank, Washington, D.C.

World Bank. Operational Manual. http:// wbln0018.worldbank.org/institutional/ manuals/opmanual.nsf/.

This Overview was prepared by Sam Kane, Kees van der Meer, Derek Byerlee, and Gary Alex. Peer review comments were provided by Steven Jaffee, Kathleen Cloud (University of Illinois), and Ousmane Badiane. 
AGRICULTURAL INVESTMENT NOTE

\section{SUPPORTING MARKET AND SUPPLY CHAIN DEVELOPMENT}

Trade liberalization, urbanization, concentration of retailers, and quality and safety requirements are leading to rapid changes in the organization of markets. Market-driven systems are replacing supply-driven and product-oriented systems. Closed and coordinated supply chains can bypass open wholesale and spot markets. Supply chain development enables integration of market functions and linkages between different participants in the system, and allows for better coordination and planning. Access to supply chains and supply chain competitiveness are issues that have become important for growth and poverty reduction in agriculture. Analysis of supply chains is important in planning investments to enhance competitiveness and market participation by small farmers.

Globalization, changing consumer demands, and new information and communication technologies are key driving forces in global agro-food industries. Consumers are demanding more information on the food safety, ecological, and social aspects of the products they buy. Rising per capita incomes, urbanization, the increasing numbers of women in the formal labor force, and market liberalization have spurred the rapid growth of modern retail chains. Large supermarket chains, sourcing food from global markets, are increasingly acting as gatekeepers for consumer markets. In developing countries supermarkets are rapidly increasing their share in the food market.

\section{INVESTMENT IN INTEGRATED SUPPLY CHAIN SYSTEMS}

Closed and coordinated supply chain organization and management are rapidly replacing open markets, especially for perishable food, but increasingly also in food staple markets. Coordinated supply chains are institutional arrangements that link producers, processors, traders, retailers, and consumers. They regulate the flow of products, payments and capital, technology, ownership rights, and information among these participants and exploit synergies for market expansion and cost reduction. Closed chains perform the same functions within one company that controls various stages in the product chain.

The development, organization, and management of supply chains is primarily a function of the private sector requiring private investment in inputs, equipment, market information, technology, and skills. The public sector role is that of creating favorable conditions for development of supply chains, for fostering publicprivate cooperation, and for enabling inclusion of smallholder and small enterprises.

Supply-driven systems producing heterogeneous commodities in uncertain quantities and qualities, once typical of agriculture, are becoming obsolete and are being replaced by demand-driven supply chains, requiring major changes in production, technology, and logistics. Coping with these challenges exceeds the capacity of most individual entities. Public investment associated with policy and regulatory reform, improving infrastructure services, demand-driven public research and development, training, and advisory services may be beneficial for boosting the competitiveness of supply chains.

Private entities have commercial interests in cooperating in coordinated supply chains to share information and technology, pursue common marketing strategies, reduce risks and transaction costs, and safeguard quality and safety of products. Nevertheless, cooperative supply-chain strategies require high initial transaction costs and are not without risks of noncooperation (trust of partners). Public involvement may be appropriate to facilitate the transition from product-based, supplydriven marketing systems to demand-driven arrangements, especially if involvement of smallholders can be maximized. 


\section{BENEFITS}

Benefits of well-coordinated supply chains derive from stable markets that can result in greater profitability and employment. Supply chain coordination can:

- Provide access to new market outlets and thus increase the producers' ability to match production and demand.

- Provide access for producers and small enterprises to information on technology, financing, and market requirements for qualities and quantities.

- Better control product quality and safety through tracking, tracing, and certification.

- Share risks among chain partners, especially for large investments.

- Reduce lead-time and losses of perishable products through joint planning and coordination of supply.

- Provide a means to pool production and thus develop economies of scale.

- Increase employment from enhanced participation in value-adding activities.

\section{POLICY AND IMPLEMENTATION ISSUES}

Policy and Regulatory ENVIRONMENT. Private sector investment requires a sound enabling environment for enforcing laws related to trade, labor, environmental, contracts and intellectual property. This is especially important for participation of foreign partners and international trade as well as public welfare measures.

INFRASTRUCTURE LIMITATIONS. Traditional market and infrastructure services (wholesale markets, transport and communication systems, inspections, storage facilities) are often not conducive to the development and functioning of supply chains. Supply chains for perishable products in particular need reliable cold storage facilities at every link of the chain. The public sector can address infrastructure constraints through cofinancing arrangements that promote private investment in infrastructure.

Smallholder Inclusion. Small-scale producers, especially women producers, are often at a disadvantage in adjusting to new market conditions, because they lack technical and market knowledge and investment funds. The contribution of individual smallholders is often of low marginal benefit for chain partners, while the cost of uncooperative behavior by a smallholder (for example, moral hazard in the use of antibiotics and pesticides) may be high. Contract farming can be a suitable arrangement to link farmers to supply-chains, but in many cases other arrangements may be preferable (see box 6.6). Special assistance (training, capacity building of POs) to make smallholders attractive chain partners can also be justified for externality and equity reasons. Large farm participation in supply chains can have substantial poverty impacts, as they often generate considerable employment, demonstrate ways to

\section{Box 6.6 Contract farming}

Contract farming is a forward agreement between farmers and processing and/or marketing firms for the supply of agricultural products, frequently at predetermined prices. This can provide the necessary backward and forward market linkages for profitable smallholder production. The approach is widely used for cash crops, fruits and vegetables, and dairy.

For farmers, contractual arrangements can provide access to production services, credit, and knowledge of new technology. Pricing arrangements can reduce risk and uncertainty and give farmers the opportunity to diversify into new crops. Contract farming may be more efficient than plantation production, and is often more politically acceptable. It can give agribusinesses the opportunity to organize a reliable supply of products of the desired quality and access to land not otherwise available.

Contract farming requires a long-term commitment from farmers and the agribusiness, with both recognizing that honoring contractual arrangements is to their long-term benefit. The public sector can facilitate contractual arrangements by promoting development of producer organizations (POs), establishment of appropriate contract law, provision of required infrastructure, and development of effective land administration systems.

Source: Eaton and Shepherd 200I. 
diversify income and security risks, and establish new market outlets from which smaller farmers may subsequently benefit.

TIME tO BUILD TRUST AND ACCUMULATE KNOWLEDGE. Development of supply chain entities involves much trial-and-error type organizational learning. Knowledge about chains is essential for developing a workable structure, and knowledge within chains (such as product design, packaging and distribution, market and customer preferences), is essential for ensuring the chain's sustainability and efficient functioning.

\section{LESSONS LEARNED}

CAPACITY OF GOVERNMENT TO ASSIST. Supply chain competitiveness depends on good logistics and low transaction costs. The public sector can create conditions for development of efficient private-sector supply chains, but government capacity to support supply chain development and increase involvement of smallholders is typically limited. Pilot programs for supply chain development, based on public-private cooperation, can be useful to build capacity within the private sector and government (see box 6.7). Specialized intermediaries are useful in collecting and sharing information on tools,

Box 6.7 Building private and public sector capacity through chain pilots

In pilot projects, partners collaborate to identify and resolve problems, "learning by doing" and "learning from best practices," as chain partners analyze operations and look for practical ways to reduce costs and improve quality. Collaboration allows dissemination of information on new technologies, and means to improve collaboration among chain partners. Pilot projects show partners how to improve quality, certification, logistics (reduction of lead-time and storage), information exchange, consumer responsiveness, and innovation. The pilot project approach should be bottom-up, with initiatives for vertical chain coordination coming from potential chain partners. A typical pilot project lasts one to three years and consists of a fourphase cycle of orientation/analysis, definition, implementation, and monitoring and evaluation.

Source:Van Roekel, Willems, and Boselie 2003. approaches, and experiences in supply chain development (Agri Chain Competence Center).

FLEXIBILITY. As profitability of products and markets change with frequent changes in consumers' preferences and new competition, supply chain partners need to learn how to deal with changing market conditions through flexible organizational arrangements, production and market diversification, and new technologies.

Technological innovation. Private enterprises generally have access to state-of-the-art technologies, but adapting these to local conditions might require additional testing and research. Government research and extension (R\&E) systems are usually not well suited to providing timely and specialized support needed by private sector supply chains. The public sector can support innovation by maintaining core scientific expertise (in laboratories and key technical areas such as entomology, soil science, pathology), and by providing matching grants on a competitive basis to the private sector for technology development.

DOMESTIC MARKETS. Emergence of modern retail systems in developing countries presents new challenges and opportunities for producers. The new retail systems have product requirements for quality, safety standards, and timely delivery that are higher than the traditional markets, but still lower than export markets. These local markets provide an avenue for learning and gradual improvement of supply chains (see box 6.8).

\section{RECOMMENDATIONS FOR PRACTITIONERS}

Orienting production and marketing systems to customer demand must be the driving force behind the operation of agriculture supply chains. Investments should seek to:

- Develop trust, commitment, and transparency among partners in the chain to improve communication and information exchange. Awareness-raising activities that 
In 1998, Royal Ahold and the Thai Central Retail Corporation began a supply chain project aimed at providing Thai consumers high-quality fresh fruits and vegetables at affordable prices; reducing lead times and postharvest losses; and raising knowledge of supply chain functions and principles. The project built a fresh distribution center for quality control, sorting, washing, packaging, and processing. Standardized crates, pallets, and crate-washing facilities were introduced and widely accepted by the Thai retail industry.

A network of contract farmers sells through buyers who are preferred suppliers, due to their ability to exert backwards control on the supply chain. Informal farmer associations are also in direct long-term business relationships with retailers. The emphasis of the supply chain development strategy has changed from supply chain optimization activities such as reducing postharvest losses, shrinkage, and handling costs, to integral chain care such as Hazard Analysis Critical Control Points (HACCP) good agricultural practices certification. Supply chain partners have established alliances with research institutes and the Ministry of Agriculture to improve food safety assurance and certification systems.

Source: van Roekel et al. 2002; http://www.haccpforexcellence.com/.

provide chain partners opportunities to get acquainted and build up relationships help chain partners jointly plan flow of goods, information, technology and capital.

- Rely on initiative and leadership of a private company for sustainability of a chain project. Leadership and power should not be concentrated within one company and different chain partners can provide leadership in different areas.

- Promote public-private partnerships with stakeholders that include representatives from business, universities, ministries, and public agencies. Limiting the number of chain participating partners helps to achieve a chain market orientation.

- Recognize that social and cultural differences can lead to misunderstandings and miscommunication between chain partners, especially when chains include foreign participants.

- Recognize that different chain partners are often responsible for supply chain strategies at the policy level and that strategies need to be translated into incentives at the operational level to avoid conflicts among chain partners.

- Provide incentives to discourage key individuals from leaving the chain, as

\section{Box 6.9 Potential investment}

Boosting national capacities in supply chain development:

- Pilot projects for developing expertise of enterprises, producer groups, service providers, and public agencies (for example, research, inspection, certification bodies).

- Support to specialized independent service providers to develop and share expertise, promote public-private cooperation, organize training, and facilitate the development of supply chains.

Boosting capacities of individual supply chains:

- Review of policy and regulatory frameworks for supply chain development.

- Market and infrastructure services.

- Support for public-private cooperation in infrastructure services, research and extension, training and other skills for supply chain management.

- Develop Good Agricultural Practices/Good Manufacturing Practices to meet buyer standards.

- Build capacity of producer organizations (POs) to participate in coordinated supply chains.

Source: Authors.

collaboration is often based largely on commitment and knowledge of one or a few persons (see box 6.9).

\section{SELECTED READINGS}

Asterisk (*) at the end of a reference indicates that it is available on the Web. See Appendix 1 for a full list of Websites. 
van Roekel, J., R. Kopicki, C. J. E. Broekmans, and D. M. Boselie. 2002. "Building Agri Supply Chains: Issues and Guidelines." World Bank, Washington, D.C.*

van Roekel, J., S. Willems, and D. M. Boselie. 2002. "Agri-Supply-Chain Management: To Stimulate Cross-Border Trade in Developing Countries and Emerging Economies." World Bank, Washington, D.C.*

\section{REFERENCES CITED}

Agri Chain Competence Center. http://www.kcacc.org/.

Eaton, C., and A. W. Shepherd. 2001. "Contract Farming: Partnerships for Growth." FAO Agricultural Services Bulletin 145. FAO, Rome.

HACCP for Excellence. http:// www.haccpforexcellence.com/.

van Roekel, J., S. Willems, and D. M. Boselie. 2002. "Agri-Supply-Chain Management: To Stimulate Cross-Border Trade in Developing Countries and Emerging Economies." World Bank, Washington, D.C.

This Note was prepared by Kees van der Meer, Sam Kane, and Gary Alex. 


\section{AGRICULTURAL INVESTMENT NOTE}

\section{HORTICULTURAL EXPORTS FROM DEVELOPING COUNTRIES}

International demand for horticultural products with high unit value and income elasticity is growing rapidly. Growers in developing countries often have a comparative advantage due to low labor costs, seasonality, and favorable natural resource endowments. Exploiting these opportunities may increase the income, skills, and employment of the rural poor. A highly integrated, demand led supply system, cold chain infrastructure, and technical support are necessary to realize the potential benefits of horticultural production for export.

Low prices for cereals, coffee, tea and cotton are forcing developing country producers to shift away from supply-led production and open market selling. The emergence of highly organized and integrated supply chains is opening new opportunities for these producers. The coordinated supply of perishable products to targeted high value consumer markets requires demand oriented production and marketing systems.

\section{EXPANDING OPPORTUNITIES FOR EXPORT HORTICULTURE}

Horticultural products include fresh, frozen, and processed fruit and vegetables, and products such as medicinal herbs, ornamental plants, and cut flowers. Key characteristics of horticultural production are high technological and managerial requirements, seasonality of production, perishable nature, and challenging requirements for export and marketing. Rising consumer income, urban lifestyles, demand for convenience food, ethnic niche markets, and trade liberalization have increased the volume and value of the international horticultural trade (see figure 6.2). Growing demand for convenient consumer packages gives develop-

FIGURE 6.2 FRUIT AND VEGETABLE EXPORT VALUES; 1992-94 AND 1998-200 I AVERAGES (DEVELOPED AND DEVELOPING COUNTRIES)

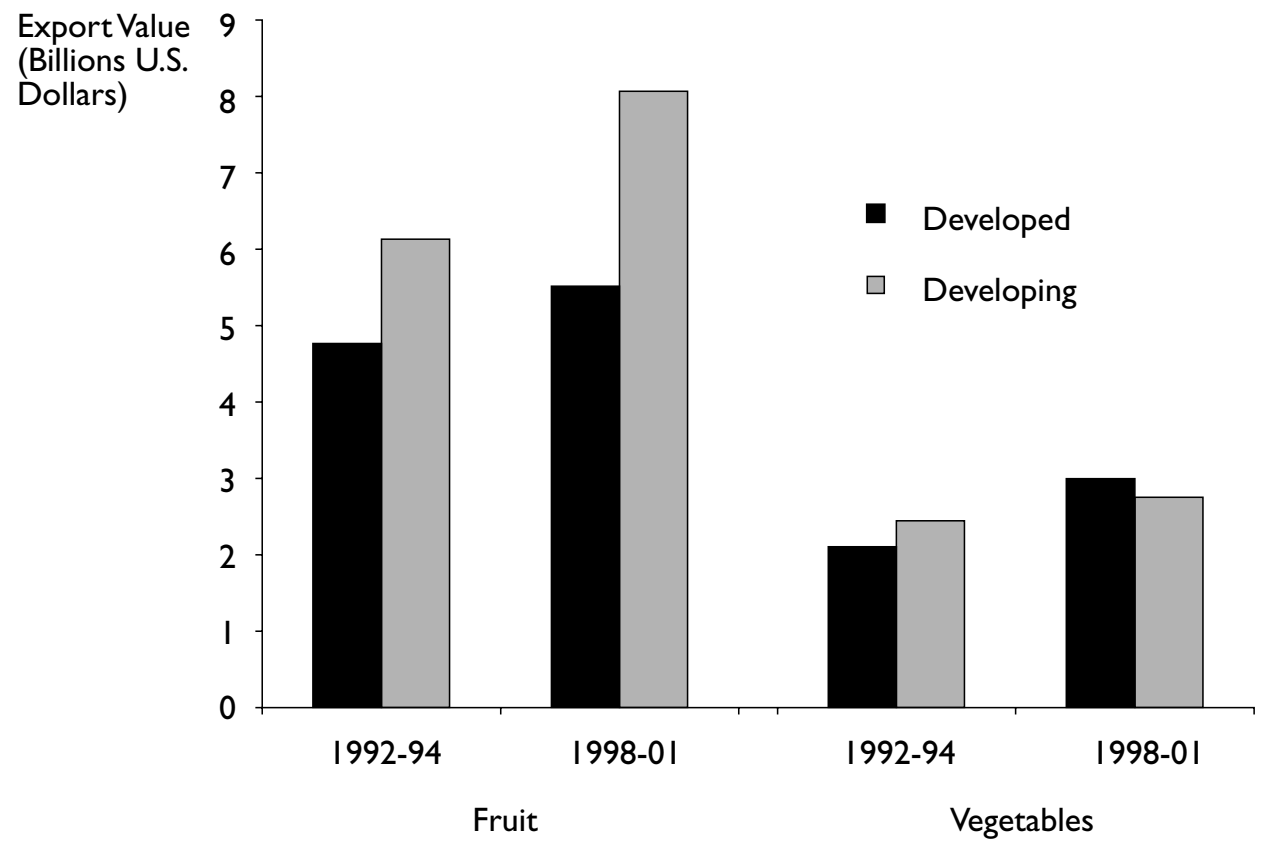

Source: FAO 2003. 
ing countries a chance to add value by grading and packaging prior to export.

North America, Western Europe, and Japan have been the main markets. Russia and Eastern Europe provide promising opportunities. The Middle East is important already for slightly lower grades. On local markets demand is growing for produce that is not export quality and this allows growers and traders to generate revenue and experience which will help them to penetrate the high value markets of industrial countries.

Exports of fruits and vegetables from developing countries are likely to rise in the coming years. As competition is likely to intensify and erode profit margins for established fruit and vegetable exports, product differentiation will increasingly be necessary in order to retain and capture new markets. Producers must

\section{Box 6.10 Egypt: the benefits of horticultural exports}

In 1997, a donor implemented an export promotion project for horticulture to expand exports of grape, strawberry, melon, mango, green bean, and cut flowers to regional and European Union markets. The agency provided assistance for:

- Management of production and marketing including cold chain and logistics;

- Accessing cultivars that were disease resistant and better suited to market windows;

- Management of labor engaged in production and post harvest tasks;

- Accessing production technologies, including farm water management.

By 2001 , grape exports had tripled, strawberry and melon exports had doubled, and green bean exports had increased by 30 percent, compensating declining mango exports. These increases generated 8,000 jobs in production and processing, 5,500 of which were taken by women. In addition, it spawned 22,000 jobs in related activities. Quality assurance and compliance with market requirements improved while transport costs fell by US\$1.7 million for grapes. Exposure to new production techniques for as many as 100,000 small and medium farmers led to significant adoption rates. The project trained female packinghouse workers to take on supervisory and management roles.

Source: Lambert 2002. adopt a strategy aimed at supplying changing products to changing markets to generate new value adding activities. Inflexible suppliers that are unable to compete will be forced to exit the industry.

\section{BENEFITS}

Horticultural production for export benefits the poor in several ways (see box 6.10). It creates employment in production, transport, input supply, processing, sorting and grading. These activities offer job openings to the unskilled segment of the work force, many of whom are women. The poor benefit also from the increased employment on large farms and plantations, and from opportunities to produce for markets that these enterprises offer to small farmers. Export horticulture production enables small growers to acquire new knowledge and technology which is valuable in producing and marketing other high quality products.

\section{POLICY AND IMPLEMENTATION ISSUES}

Market orientation. Profitable horticultural export systems must satisfy consumer demand in end markets. Identifying demand and supplying markets is largely a private sector activity-government attempts to lead in this field have usually failed. Traditional open markets that facilitate price discovery and valuation based on product specification remain essential to match buyers and suppliers of traditional commodities. Highly integrated market structures are similarly vital for horticulture. ${ }^{4}$

Enabling investment climate. Non-interference by government in commercial activities was a key factor in past successes but the public sector must make the environment conducive to private investment (see box 6.11). It must often take action to overcome market failure, reduce unnecessarily high transaction costs, and in some cases provide support based on an "infant-industry" justification.

4. See the IAP,"Bangladesh:Autonomous Organization for Facilitating Market-led Export". 
Gender. Women are often the ones who grow and market horticultural crops for the domestic market but they are often not involved as contract growers in export supply chains. Instead, they become employed in the fields and in packing houses. In Guatemala, for example, women hold only three percent of snow pea production contracts, but contribute more than one third of total field labor, and virtually all processing labor. Projects should promote women's access to contract farming and marketing in addition to encouraging fair employment practices.

INFRASTRUCTURE. Information and communication systems, power and water supply, quality control, testing, and certification services are essential to access competitive markets (see box 6.12). Cold storage must be operational at each distribution stage, to avoid losses of quality and value. ${ }^{5}$ Roads, rail, port and airport facilities are particularly important as freight costs can amount to 30 or 40 percent of import prices. However, high costs, economies of scale, and an inability to make users pay for services from which providers cannot exclude them, often deter private investors. The public sector may need to finance or co-finance such investments, on condition of defining exit strategies and private sector management and maintenance responsibilities.

KNOWLEDGE AND TECHNICAL SUPPORT. Horticulture production systems are technologically and managerially intensive. They therefore require strong R\&E support. Current public R\&E systems are often geared to traditional food crops and offer little support to export horticultural crops. Much horticultural technology has to be imported to meet export market demands. To help farmers and traders make the most of these imported goods, domestic public research institutions must become more demand driven and responsive to markets, facilitate technology imports and address second generation problems such as outbreaks of new pests.

\section{Box 6.I I An enabling environment}

- Macroeconomic and trade policy: elimination of tariffs and other trade barriers, exchange rate policy, and nondistorting agricultural policies.

- Legislation on plant variety rights (PVR): drafting and enforcing PVR legislation that facilitates access to improved plant varieties ("imported technology").

- Certification capacity: complying with market grades and standards has public good aspects that may complement national labor and environmental policies.

Source: Authors.

\section{Box 6.12 Kenya: key findings in horticulture}

In response to the secular price decline of coffee and tea, and Kenya's comparative advantages, nontraditional horticultural crops are replacing them as the major export crops. A recent survey found that export horticulture initiatives led to poverty reduction. Other findings included:

Access to irrigation is as critical as access to land.

Young farmers are more willing than older ones to adopt new horticultural crops, especially when helped by family labor, older or experienced labor in particular.

Horticultural production requires considerable investments in post harvest and transport infrastructure, including air cargo.

Managerial skills to link production with marketing and distribution are essential.

Policy should aim to reduce barriers to the participation of the poor.

Exporters should provide credit and extension services to smallholders.

Source: McCulloch and Ota 2002.

Grades and STANDARDS. Horticultural exports must satisfy stringent safety and quality standards (see box 6.13). This can put small growers at a disadvantage because they typically cannot produce large volumes of homogeneous high value produce and there are risks associated with pooling production that must meet stan-

5. See the IAP,"Mali: Building Export Mango Systems". 
Box 6.13 European Union marketing standards: compliance with EC No. I 148/200I

EU Regulation EC No. I | 48/200 I, introduced on July I, 2002, requires all fresh produce arriving in the $\mathrm{EU}$ to undergo an ISO 9000 style inspection to verify conformity with marketing standards. This inspection is carried out at the port or airport before release into circulation. The only exceptions are for consignments with certificates of compliance from countries whose systems of export quality inspection have been approved by the EU. Such consignments with both a phytosanitary and a quality conformity certificate are released when customs procedures are complete. Exporters with approved certification systems obviously have a competitive edge. Some countries, such as Jordan, have established a pesticide residue testing laboratory and a heavy metals testing laboratory, and issue conformity documents on consignments to the EU.

Source: Authors.

dards. Certification costs can also be a hurdle. Public investment may be needed to help farmers and other market chain participants meet standards. Outgrower schemes can help farmers meet the certification requirements required for some markets.

\section{LESSONS LEARNED}

FEASIBILITY ANALYSIS AND PLANNING. Horticultural exports are potentially profitable but risky. They require matching consumer demand with production potential and capacity for risk management, and take time to develop. Significant financial resources and a flexible long term perspective are essential for potential market entrants. Where farmers and entrepreneurs often lack the skills and resources to conduct market analyses, develop personal contacts, and run marketing trials, government support can be crucial. But as the public sector is not good at "picking winners", it should limit its support to providing unbiased market analyses and technical assistance.

Risk. Horticulture products are perishable but must meet strict quality standards. Failure to deliver produce on time affects the exporters' credibility and reputation. Producers have two options to reduce their risks: offer a variety of products to importers, or exploit comparative advantage and specialize in producing one product. Specialization is often necessary and can be supported by innovations in irrigation, pest monitoring, crop rotations, and controlled atmosphere storage to maintain production levels and protect product quality.

Link between local and export production. Local markets provide growers and traders with experience with which to enter export markets and with outlets for surplus produce that does not meet export standards. The demand and standards in export markets often differ from those in the domestic market, and technologies and systems are needed to establish the competencies needed to supply the primary market.

INDUSTRY AND TRADE ASSOCIATIONS. Most successful horticultural ventures are assisted by a trade association representing the interests of the sector. The association helps to organize production, negotiate contracts, develop analytical capacity, improve market information systems, promote products, coordinate research, enforce quality standards, and pool risks. The public sector can, with appropriate restraint, assist these associations through cofinancing schemes.

Finance. Grower access to finance is often a problem. Domestic banking systems are typically not well developed, and commercial banks are reluctant to lend due to a poor knowledge of the sector, perceived high credit risks, and concerns over collateral. Contract production agreements involve agribusinesses and exporters supplying outgrowers with production inputs and committing to buy the produce, and provide one solution to the lack of credit for production.

\section{RECOMMENDATIONS FOR PRACTITIONERS}

Export horticulture is not new to the Bank portfolio but it is somewhat difficult to define what the Bank has financed and how it has 
affected the poor. This is partly due to the complex nature of agricultural supply chains, and the need for multi component activities that in appropriate sequence meet the needs of multiple stakeholders and enterprises. Future investments must (see box 6.14):

- Base analysis and planning on identified market demand and recognize the risk inherent in horticultural markets, along with the need to enter them with a long term perspective. Strategic planning must be flexible enough to adapt to changing competition and demand.

- Enable private investment and capacity to comply with standards and certification requirements for product quality and safety, environmental and labor standards.

- Provide public goods such as information systems, R\&E, certification capacity, and risk management that reduce supply chain transaction costs. Public involvement must not distort market mechanisms. It should foster participation. Grant schemes can be effective but exit clauses are usually necessary.

- Build capacity in government agencies to certify product safety and standards, and expedite inbound products and outbound produce at national borders.

- Monitor impacts on the poor, on women and on minority groups, recognizing that most poverty reduction impacts will be indirect.

\section{SELECTED READINGS}

Asterisk (*) at the end of a reference indicates that it is available on the Web. See Appendix 1 for a full list of Websites.

Jaffee, S. 1992. Exporting High-Value Food Commodities: Success Stories from Developing Countries. With P. Gordon. Discussion Paper 198. Washington, D.C.: World Bank.*

\section{Box 6.14 Potential investments}

Technical assistance to build capacity to meet export standards and certify compliance.

Development of horticultural, producer, and trade associations and business development service providers.

Public good infrastructure such as transport and communication systems.

Industry feasibility and planning studies.

Source: Authors.

Reardon, T., and J. Berdegué. 2002. "The Rapid Rise of Supermarkets in Latin America: Challenges and Opportunities for Development." Development Policy Review 20 (4): 371-388.*

\section{REFERENCES CITED}

FAO, 2003 "The Market for Non-Traditional Agricultural Exports (NTAEs)." FAO, Rome.

Lambert, A. M. 2002. "A Scoping Study for Detailed Case-studies of Trade Facilitation/ Export Promotion Projects for Non-Traditional Agricultural Products in Sub-Saharan Africa." World Bank, Washington, D.C.

McCulloch, N., and M. Ota. 2002. Export Horticulture and Poverty in Kenya. IDS Working Paper 174. Brighton, U.K: Institute of Development Studies, University of Sussex.

This Note was prepared by Sam Kane,Tijan Sallah, Gary Alex, and Kees van der Meer. 
AGRICULTURAL INVESTMENT NOTE

\section{PRIVATE SEED ENTERPRISE DEVELOPMENT}

Donor investment strategies should support the development of private seed enterprises to make quality seeds available to small farmers. This requires a long-term outlook, recognizing that the first steps will likely be taken with higher-value seed crops (such as hybrids), and the strengthening of various elements of the seed system (which may be pursued by independent enterprises or combined in a single firm). Support must enhance development of competitive markets. Seed enterprise development includes attention to the policy environment, support to public sector plant breeding, seed regulatory reform, and strengthening input and output marketing capacities.

Seed provision is at an important crossroads in many developing countries. Donor support to public seed enterprises has diminished because these have not been efficient. Strategies for supporting the private seed sector are still evolving. As a result, many farmers have little access to commercial seed, and this has restricted the choice of crops and varieties. Since benefits of modern plant breeding can only reach farmers through an efficient seed system, there is an urgent need to develop the private seed sector.

\section{DEVELOPING PRIVATE SEED ENTERPRISES}

Public seed enterprises have introduced new crop varieties and have been important in development efforts, but it is increasingly difficult to defend their continued support, as seed production and marketing are inherently private sector activities. Public enterprises generally lack the incentives that a competitive private sector can offer to respond to changing demands or new markets or to increase industry efficiency.

An emerging private seed industry faces many obstacles, some relating to the general business climate and others specific to the seed industry.
Public sector interventions should be marketbased to the extent possible, using competitive grants, matching grants, and vouchers. Publicprivate cooperation can realize synergies in policy preparation and implementation, developing new varieties, and developing efficient and effective marketing outlets. Public investment can be justified because of the large spillover benefits to society. The seed sector comprises the following different activities with varying opportunities for private and public investment.

- Plant breeding. Seed enterprises require access to new varieties. Although private plant breeding capacity is increasing, many crops will depend on public sector breeding programs for the foreseeable future. Public plant breeding organizations must have adequate links to private seed distribution mechanisms.

- Source seed production. Production of commercial seed entails multiplication of several generations of source seed (for example, breeder seed, foundation seed). Enterprises managing commercial seed multiplication may or may not have capacity to produce and maintain source seed.

- Seed multiplication. Source seed is multiplied to produce commercial seed. In most cases, a seed enterprise supervises contract farmers to multiply seed.

- Quality control. The multiplication process must ensure both the genetic purity and physical quality of the seed. Quality control systems may range from managing a mandatory seed certification scheme to only requiring that seed be truthfully labeled. Responsibility for quality control is now shifting to seed enterprises.

- Seed conditioning. Seed must be cleaned, dried, treated, and stored before sale. This requires specialized equipment and (for certain crops) considerable storage capacity.

- Seed marketing. Seed is sold through input dealers, requiring distribution capacity 
through a competent, independent network of wholesalers and retailers.

These components of seed provision may all be managed by a single firm or in the hands of various linked enterprises (see box 6.15). Any investment in seed enterprise development must examine the options of supporting smaller, specialized operations versus larger, integrated firms with the choice depending in large part on the resources and capacities available and the stage of evolution of the seed industry.

\section{BENEFITS}

The potential benefits of investing in seed enterprise development will depend on whether investment is for varieties or for seed. The former represents the genetic gains to be derived from access to new products of plant breeding, while the latter represents gains from the physical quality of commercial seed. The two are different, and commonly used phrases such as "improved seed" tend to confuse the issue.

Estimating the gains from access to new varieties may be relatively straightforward, if data are available on the yield (or other) advantages of new varieties over those currently in farmers' fields. Investments in varietal development have no payoff unless the new varieties reach farmers and, in many cases, absence of a commercial seed system results in new varieties not being used. Farmer-to-farmer seed diffusion helps spread varieties, but is rarely sufficient. Once in their hands, farmers can often maintain new varieties by saving their own seed, in some cases maintaining varieties for many years with little loss in purity or performance. In other cases (especially for crops subject to significant cross-pollination) farmers need access to new seed supplies more frequently, and in the case of hybrids, should purchase fresh seed each year and commercial seed may offer few advantages.

\section{POLICY AND IMPLEMENTATION ISSUES}

VARIETAL DEVELOPMENT. Although private plant breeding is developing for certain crops, public research systems will continue to play an
Box 6.I5 India: the private provision of public rice varieties

Private companies produce almost one-half the rice seed sold in Andhra Pradesh State, even though all varieties are publicly developed. The state agricultural university system's transparent procedure for selling breeder seed to private companies has facilitated private seed enterprise development. Andhra Pradesh is a leader in development of the private millet and sorghum hybrid seed industry. This experience with hybrids is now utilized for the lower profit (but high volume) rice seed industry.

Some enterprises specialize in only certain aspects of seed provision. Some individuals supervise seed multiplication by farmers, contracting their services to seed companies that do not have a presence in the area. Other individuals own seed cleaning and storage facilities that they contract out. Such specialized services allow medium-size enterprises to fill gaps in their capacities. At the other end of the spectrum, the larger seed companies have integrated operations and take responsibility for foundation seed production, supervision of growers, processing, and marketing. This range of capacities and "clustering" of facilities in the state allows dozens of enterprises to contribute to rice seed provision in Andhra Pradesh.

Source:Tripp and Pal 2001.

important role, requiring support to strengthen scientific capacities and define respective responsibilities between the public and private sectors. In most cases the public sector will need to maintain breeder seed of its varieties, establish an efficient system to provide commercial enterprises access to this seed, and enforce a system of plant variety protection (ensuring access royalties).

National SEed Regulatory fRAmeworks. Systems for variety release and registration must be equally accessible for private and public plant breeders, and must allow for rapid assessment and release. Harmonization of national release procedures across a region allows access to new varieties across a number of countries rather than being delayed by individual and idiosyncratic country reviews. Seed certification and quality control procedures are generally managed by a public sector certifying agency. Consideration should be given to shifting these functions by licensing private seed companies to do their own certification and testing and by enforcing truthful labeling laws. 
Neglected areas/Crops. Given that farmers save seed from one season to the next, one major challenge for seed enterprises is to ensure repeat sales. The emergence of a private seed industry is almost always based on hybrid seed (that must be replaced each year to maintain its yield advantage), or on seeds that farmers find difficult to save (such as vegetables). Seed of many crops (particularly those grown by isolated and/or less commercially oriented farmers) is less likely to be included in a nascent private seed sector. This does not, however, argue for continued public seed production, as public seed enterprises have also failed to reach this market. Instead, appropriate incentives for seed productionæoften local, informal, small scalexcan encourage enterprises to serve these markets before they are gradually included in a growing conventional private seed industry (see box 6.16).

Gender. Because women have responsibility for seed selection and preservation in many traditional farming systems, commercial seed production presents good opportunities for including women as contract farmers and marketers as well as employees.
Box 6.16 Nepal: small-scale vegetable seed production

The Seed Sector Support Project funded by the United Kingdom's Department for International Development (DFID) helped organize and train Nepalese farmers in vegetable seed production and arranged annual "workshops" in which seed dealers and producers meet to establish contracts for the coming season. The project initially acquired source seed for the seed producers, but has evolved to the point where the Seed Entrepreneurs Association of Nepal facilitates meetings with producers and helps members to organize source seed production.

Such efforts have expanded the amount of vegetable seed for sale in Nepal and in certain cases (such as radish) established Nepal as a seed exporter to neighboring countries. However, the model has so far had little success in establishing commercially viable small-scale seed production for crops such as rice, wheat, or maize.

Source Authors.

\section{LESSONS LEARNED}

START-UP CROPS/vARIETIES. Commercial seed production must begin with products that have a high probability of repeat sales: hybrid seed, seeds that are difficult to manage on-farm, or seed of crops that have a market premium for quality. Although commercial seed production has limited economies of scale, it does offer economies of scope, so that once a production and marketing system is in place for more profitable seed crops, other types of seed can be added.

Mini-PaCK DistRibution. The production and sale of small packs ("mini-packs") of seed of new varieties can provide additional business to emerging seed enterprises, help to develop a market for a wider range of seed types, and support the diffusion of new crop varieties. Such schemes often attract outside support from donors interested in promoting use of new seed or responding to emergency situations characterized by loss of seed stocks (for example droughts, conflicts). There have been a number of successes with contracting seed enterprises to package seed in small quantities that are attractive and affordable. Distributing these through rural input suppliers helps develop markets for quality seed. Where there are noncommercial elements in such mini-pack schemes, quality control and strategies for phase-out of subsidies are particularly important.

SeEd entrepreneurs. Seed provision entails a range of skills (plant breeding, seed production, marketing) that no one person is likely to possess. Seed businesses tend to be initiated by people already with some experience: plant breeders (establishing their own seed businesses, "privatizing" their plant breeding skills and developing marketing expertise); contract growers for seed companies with knowledge of seed multiplication; seed company production agronomists; and the commercial sector, either people involved in the grain trade or input marketing (see box 6.17).

Community seed production. Many development projects have used community-level seed production as the starting point for commer- 
cial seed development. Results have been disappointing with little commercial sustainability. Reasons for lack of success are twofold: inattention to transaction costs (for making contracts for source seed, ensuring quality control, and obtaining information) and a lack of experience and resources for marketing. Community-level seed projects need more appropriate goals to be successful, such as testing and disseminating new varieties, developing farmers' experimentation capacities, and forming better links between farmers and researchers.

EMERgENCY SEed programs. Donors and governments have often been involved in the free distribution of seed, in the context of emergencies related to drought or civil unrest. Even in these cases, externally provided seed is not always a priority, but many of these programs still acquire a semi-permanent status based on ideas of support to agriculture or introduction of new technology. Such interventions are difficult to stop, but must be designed to do as little damage as possible to the prospects for seed enterprise development. This usually means using local seed enterprises, paying attention to farmer feedback and demand for varieties, and distributing the seed through retail outlets (using vouchers). If this is not done, it is very difficult for the commercial seed sector to develop, and farmers acquire the idea that seed is an input (often of low quality) that is given away.

\section{RECOMMENDATIONS FOR PRACTITIONERS}

Key public sector investments include sector analysis, development of sector strategies, policy reform, establishing the regulatory framework and capacity building (see box 6.18). Donor support for seed enterprise development requires careful assessment of options, with the most useful assistance often coming not from large projects, but from welltargeted support to specific policy initiatives or to lowering transaction costs for commercial development. This requires donors to have capacity for sustained monitoring of

\section{Box 6.17 Small African seed enterprises}

The recent emergence of small seed enterprises in Africa illustrates the possible sources of skills and resources that can support seed enterprise development.

Uganda: Harvest Farm Seeds. A grain trading company in Kampala became involved in procuring grain suitable for seed for relief operations in neighboring countries. With this experience it established Harvest Farm Seeds, to produce and sell commercial seed of public varieties. It is planning to establish its own plant breeding capacity. Much of its sales are still to relief organizations, but it is strengthening its marketing network in Uganda.

Ghana: seed producers. The collapse of the parastatal Ghana Seed Company left producers without a formal source of seed for maize and cowpea. A Sasakawa-Global 2000 funded project approached former contract growers about establishing their own enterprises. The project supervised their seed production, facilitated contacts with local input dealers to purchase and market the seed, coordinated access to public seed processing facilities and provided seed certification services.

Source: Authors.

\section{Box 6.18 Potential investments}

Needs assessment, training, study tours, and matching grants to support a national seed industry, including support to establish a seed trade association.

Support for transparent, well-managed systems for breeder seed and foundation seed production and sale.

Financial services support to seed enterprises.

Competitive grants for applied research in breeding and variety improvement.

Seed regulatory reform and regional harmonization of seed laws.

Training and support for seed retailers, preferably through grants and vouchers schemes.

Source: Authors.

institutional development. Other investment considerations include:

- Investments in building capacity of private enterprises and associationsæoften through matching grants-to develop of new varieties and retail systems. 
- Attention to the advantages of industrial "clusters," and promoting the sharing of knowledge, facilities, and personnel.

- Emerging seed enterprises that can profit from technical and organizational support and links with enterprises in other countries.

- Support to regulatory harmonization across a region which allows resources to be used more effectively and have broader regional impact.

- Public agricultural research institutes efforts to become more supportive of private seed sector development.

- Support for the development of rural input retailing and produce marketing which is essential for promoting private seed sector development.

\section{SELECTED READINGS}

Asterisk (*) at the end of a reference indicates that it is available on the Web. See Appendix 1 for a full list of Websites.

Almekinders, C., and N. P. Louwaars. 1999. Farmers' Seed Production. New Approaches and Practices. London: Intermediate Technology Publications.

Louwaars, N. P., ed. 2002. Seed Policy, Legislation, and Law: Narrowing a Wider Focus. Binghamton, N.Y.: Food Products Press.

Tripp, R. 2000. Strategies for Seed System Development in Sub-Saharan Africa: A study of Kenya, Malawi, Zambia, and Zimbabwe. ICRISAT Working Paper Series 2. Bulawayo, Zimbabwe: ICRISAT.

Tripp, R. 2001. Seed Provision and Agricultural Development: the Institutions of Rural Development. Oxford: James Currey.

Tripp, R., and D. Byerlee. 2000. "Public Plant Breeding in an Era of Privatisation." Natural Resource Perspectives 57. ODI, London.*

\section{REFERENCES CITED}

Tripp, R., and S. Pal. 2001. "The Private Delivery of Public Crop Varieties: Rice in Andhra Pradesh." World Development 29 (1):103117.

This Note was prepared by Robert Tripp (ODI) with inputs from Kees van der Meer, Gary Alex, and Sam Kane 
distort demand and hinder the development of a sustainable fertilizer marketing system.

\section{PROMOTING PRIVATE SECTOR FERTILIZER DISTRIBUTION SYSTEMS}

Competitive markets for agricultural inputs are critical to agricultural development. Farmers need access to a wide range of fertilizer inputs so that they can more sustainably manage soil nutrients, improve productivity and diversify into new production enterprises. Fertilizer market development largely depends on reform of policies and regulations relating to imports and exports, to subsidies and protection of inefficient production and marketing entities, to market entry, and to truth-in-labeling requirements. A competitive private sector fertilizer distribution network will also benefit from investment to address training needs, reduce transportation costs, and facilitate development of fertilizer sector trade associations.

Throughout the developing world, governments are disbanding and divesting parastatal fertilizer marketing organizations that have proven inefficient, costly, and unsustainable. Governments now see their role as that of establishing an enabling environment for private fertilizer market development. However, fertilizer distribution systems have been slow to emerge in many countries that lack a tradition of private enterprise. Additional public support may be necessary to catalyze the development of efficient fertilizer distribution systems.

\section{FERTILIZER MARKET DEVELOPMENT}

Efficient fertilizer systems are needed to provide producers with competitively priced fertilizer products that meet the needs of local farming systems. Demand at the farm level for fertilizer must be induced ultimately by profitable production technologies and attractive prices for agricultural products at the farm-gate. Government policy, laws, regulations, and services should reflect a commitment to an expanded role for the private sector. Experience has shown government subsidies can
The market development process typically includes an agribusiness development project, public policy reform, extensive training in business development and fertilizer technology, and formation of a fertilizer distributors trade association. Activities focus on business development, private extension services, market information systems, private sector advocacy, and media information campaigns.

Public sector interventions to promote fertilizer markets must have the clear objective of producing independent, sustainable, and financially viable business entities. Donors can provide resources, methods, and tools for effective delivery of business development assistance to client firms. Assistance should enable farmers and fertilizer suppliers to make informed market choices and operate in open and competitive markets. The capacity of local intermediaries that provide services to agribusiness should be expanded, and in many instances, support for market and enterprise development (rather than direct producer assistance) will be the most appropriate mechanism to reduce poverty, albeit a relatively indirect route.

\section{BENEFITS}

Farmers, taxpayers, and consumers benefit from public investment that enables the emergence of private sector fertilizer markets (see box 6.19). Specific benefits include:

\section{Box 6.19 Bangladesh: withdrawal of subsidies}

During 1988-94, the Government of Bangladesh saved about US\$1 19 million by withdrawing fertilizer subsidies. The 800member Bangladesh Fertilizer Association was created, and the fertilizer retail network employed 170,000 people. Fertilizer sales increased at an annual rate of eight percent, and government fertilizer imports declined from 100 percent to nil. The government instituted monthly fertilizer market monitoring to improve the industry information base.

Source: IFDC 1994. 
- Private fertilizer distribution replaces inefficient parastatals and subsidies that are often a substantial burden on public expenditures.

- Private fertilizer distribution results in lower prices to farmers, more timely supply, greater variety in fertilizer formulation to meet local requirements, and production diversification (see box 6.20).

- Improved availability of fertilizer and other inputs contributes to supply chain integration and increased agricultural productivity.

\section{POLICY AND IMPLEMENTATION ISSUES}

Parastatal competition. Public sector enterprises and subsidized fertilizer distribution discourage development of competitive private agribusiness. Protection of inefficient domestic producers and traders typically reduces the product range available, and increases fertilizer prices. An enabling environment for agribusiness development is critical. Structured dissolution of state enterprises-with incentives for the private sector to fill the void-is essential to market development (see box 6.21).

WinNers AND Losers. Although privatization of parastatals and abolition of subsidies generally has many benefits, there are typically also some losers: users may face higher prices; producers in isolated areas may lose access to fertilizers; and employees in parastatals may lose jobs. Some phasing of reforms and some compensa-

\section{Box 6.20 Malawi: fertilizer for diversification}

Malawi's heavy dependence on tobacco for export earnings has been a cause for concern. The government is promoting increased fertilizer use to make food crops and other export crops more profitable. This strategy relies on applications of diammonium phosphate and urea top-dressing for maize cultivation, followed by groundnuts or pulses, both of which have good export potential. Use of residual phosphate and atmospheric nitrogen fixation by follow-on crops, reduce costs of providing crop nutrients. Training for fertilizer dealers and fertilizer demonstrations for farmers were key to program success.

Source: Bumb 2002. tion through safety nets or public investment, such as access roads, may be needed.

Distribution NETWORK COVERAge and cost. Private sector firms will target those agricultural areas in which they can make the most profit. This generally means that the more productive and accessible areas develop a dense distributor network first. Remote or sparsely populated areas are left unserved, or are required to pay higher prices. Public sector interventions may be necessary to overcome logistical constraints, reduce transaction costs, and improve poorer farmers' access to competitively priced fertilizer products in remote areas.

TRAde CReDit. Trade credit may be important to enable distributors to import adequate quantities of fertilizer. However, past experience has shown that direct public sector involvement in credit provision must be approached with care. Trade credit will generally be accessible to firms with good credit records, sound cash and profit projections, and good relations with suppliers. Long-term relationships lead to greater confidence in repayment, and thus improved access to credit.

PARTNERShips. Fertilizer supply chains are often fragmented and uncoordinated. Strategic alliances among manufacturers, traders and importers, distributors and retailers, regulatory authorities, and farmers can enhance the flow of information (farm-level demand in particular) and products throughout the supply chain. Such alliances are an invaluable means for identification of problems and opportunities for practical field initiatives.

Producer organizations. Producer organizations can be an important link in input marketing systems, usually in retail distribution or group purchasing from private retail distributors. In some cases, large formal producer organizations may become fertilizer importers or wholesalers.

\section{LESSONS LEARNED}

IMPROVING THE REGULATORY FRAMEWORK. The primary role of government is to provide a 
transparent and predictable policy environment, especially on trade and regulatory issues, so that economic forces can guide fertilizer production and use decisions. Government must also ensure fertilizer product quality and integrity through truth-in-labeling laws so that farmers get the quality and quantity of fertilizer they purchase. An appropriate government agency should collect and test samples based on both complaints and spot inspections, particularly at the retail level. Safe, maximum limits are needed to regulate fertilizer content of heavy metals and other impurities that could damage public health, crop production, or the environment. Enforcement of regulations is often more effective at the local than at the national level, though a national fertilizer information system facilitates effective dialogue between farmers and the fertilizer industry.

Trade association development. Trade associations can be important to fertilizer market development. Benefits of a fertilizer trade association include: improved access to trade and investment credit and business services; development of a market information system; better coordination of supply chain activities; identification of new products and markets; and development of trade relationships. Governance and election of association officials should be democratic, open, and transparent. Revenue can be generated through membership dues, fees for services, and other means to enable the association to become financially independent and sustainable (see box 6.22).

FERTILIZER IMPORTS AT OPTIMAL ECONOMIES OF SCALE. The competitive supply of fertilizer on local markets usually requires importers and distributors to operate on a relatively large scale. As efficient minimum orders are large and there is a lag between product ordering and arrival, traders must anticipate demand accurately. Regional harmonization of market regulations can facilitate trade, eliminating need for repackaging or relabeling, preshipment inspections, border taxes, and unnecessary testing. Groups of importers can pool imports to facilitate operations at an optimal scale. Forward selling

\section{Box 6.21 Free distribution of fertilizer}

Government or donor distribution of free fertilizer, as in some "starter pack" programs, can harm local fertilizer market development. Free distribution of samples for trials can be an effective marketing tool in demonstrating the value of fertilizer and in some circumstances, such as post-disaster situations, government assistance is appropriate to help farmers get land back into production. However, when free distribution continues over time, there is danger of driving local retail distributors out of business. Voucher systems or mechanisms by which fertilizers are supplied through local retailers can avoid such risk, while helping build sustainable distribution networks.

Source: IFDC Internal Documents

\section{Box 6.22 Kosovo: establishment of input supplier networks}

In Kosovo between 2000 and 2002, the International Fertilizer Development Center assisted with establishment of five agriinputs trade associations that obtained credit independently and imported fertilizer. As a result:

Fertilizer use increased from 40,000 to 71,000 metric tons, commercial seed from 16,000 to 43,900 metric tons, and crop protection products from 25 to 80 metric tons.

Agro-inputs sales increased by 64 percent to US $\$ 18$ million with US\$9 million in fertilizer sales.

Modern fertilizer use technologies contributed significantly to yield increases for wheat and maize of 69 and 150 percent, and increases in net added income of US $\$ 200 /$ hectare and US\$726/hectare.

Trade associations established under the project lobbied successfully to eliminate tariffs on imported fertilizer.

The European Agency for Reconstruction financed and supplied 35,000 metric tons of fertilizer, which was auctioned for distribution by the private sector.

Source: IFDC 2003.

contracts by importers to distributors and retailers shorten cash cycles.

Training In Business management. Training in fertilizer business management involves financial and business planning, strategic management, competitive analysis, and procurement and marketing planning. The public sector must not assume a direct role in these areas, but can promote development of managerial 
Box 6.23 Ethiopia: extension services for fertilizer sector development

A recent World Bank project sought to increase agricultural productivity by developing an enabling environment for a competitive fertilizer sector, promoting increased and environmentally safe fertilizer use, and addressing supply-side constraints. Extension agents were trained in the technical aspects of fertilizer use and soil fertility maintenance, with the intention that they would provide advisory services to farmers on improved fertilizer use practices. While the extension service was not meant to get involved in fertilizer distribution, extension agents began to spend 50 to 70 percent of their time on fertilizer distribution and credit administration. This left them little time to focus on advisory services. Occasional adversarial encounters relating to loan recovery negatively affected the relationship between agents and farmers.

Source:World Bank Internal Documents.

\section{Box 6.24 Potential investments}

- Agricultural sector analyses to identify constraints to market development.

- Policy and regulatory reform in the fertilizer sector.

- Establishment of government regulatory capacity.

- Systems to monitor and enforce truth-in-labeling, including analytical laboratories.

- Training in the public and private sectors to improve analytical and managerial capacities.

- Facilitation of regional regulatory harmonization and procurement to achieve economies of scale.

- Port, rail, and road transportation and information infrastructure.

Source: Authors.

skills by cofinancing BDS providers or subsidizing initial use of these services.

Agricultural extension Services. Extension services are often best provided by the dealers themselves, as extension can be viewed as a marketing activity to cultivate customer loyalty, and as a cost of doing business (see box 6.23). Public support can assist fertilizer dealers provide extension services that involve advice, field monitoring, soil testing, export opportunities, input demonstrations and field days.

\section{RECOMMENDATIONS FOR PRACTITIONERS}

Once organized, the private sector can become a key partner in lobbying for removal of constraints to private fertilizer market development. In the meantime, development of competitive private sector fertilizer distribution and marketing systems may rely on investments to:

- Privatize parastatals and avoid free or subsidized fertilizer distribution.

- Promote regulatory liberalization and ensure that business registration is not a barrier to new entrants.

- Establish capacity for government to monitor and enforce regulations on fertilizer sales, with particular regard to truth-inlabeling.

- Encourage development of fertilizer industry trade associations.

- Encourage economies of scale in operations by sound import and export regulations, regional harmonization, efficient logistical systems, and collective procurement.

- Encourage private fertilizer distributors to provide extension services as a necessary business promotion service and focus public extension services on addressing issues, such as nutrient management and negative environmental externalities.

- Use study tours to market economies for government officials and fertilizer sector policymakers to promote understanding of advantages of markets and liberalization of regulations (see box 6.24).

\section{SELECTED READINGS}

Asterisk (*) at the end of a reference indicates that it is available on the Web. See Appendix 1 for a full list of Websites.

Bumb, B., ed. 2002. An Action Plan for Developing Sustainable Agricultural Input Supply 
Systems in Malawi. Muscle Shoals, Ala.:

IFDC.

Gisselquist, D., and C. Van Der Meer. n.d.

"Regulations for Seed and Fertilizer Mar-

kets: A Good Practice Guide for

Policymakers.” Rural Development Working

Paper 22817. World Bank, Washington,

D.C.*

IFDC. 2000. A Strategic Framework for African Agricultural Input Supply System Development. Muscle Shoals, Ala.: IFDC.

\section{REFERENCES CITED}

Bumb, B., ed. 2002. An Action Plan for Developing Sustainable Agricultural Input Supply Systems in Malawi. Muscle Shoals, Ala.:

IFDC.

IFDC. 1994. "Fertilizer Distribution Improvement Project-II (End of Project Report)." Ministry of Agriculture, Bangladesh.

IFDC. 2003. "Kosovo Agribusiness Development Program: Completion of Project Report, June 2000-January 2003." IFDC, Muscle Shoals, Alabama.

This Note was prepared by Thomas Thompson (International Fertilizer Development Center) with inputs from Kees van der Meer, Gary Alex, and Sam Kane. 
AGRICULTURAL INVESTMENT NOTE

\section{GETTING MARKETS RIGHT IN THE POST-REFORM ERA IN AFRICA}

Many small farmers in low-income countries are excluded from markets for agricultural products and inputs because the costs and risks of market participation are simply too high. As a consequence, they often do not adopt new technologies to improve crop yields and natural resource management (NRM). Getting markets right is therefore a critical issue for increasing the food security and incomes of smallholder farmers and expanding smallholder access to new market opportunities. Government investments are needed to create an appropriate institutional framework, address risk management, complete reforms, and invest in appropriate infrastructure.

Structural adjustments and economic liberalization have had mixed and generally limited impact on improving livelihoods of the poor, particularly in Africa. Producers do respond to market opportunities, but many markets function poorly even in the post-liberation period (see box 6.25). The large markup from producer price to export price or, in the case of imported goods, from import price to final consumer price, is a symptom of weakly functioning trade and distribution systems (see

\section{Box 6.25 Producers' response to functional markets}

In Mali, liberalization of the rice market led to a tripling of production over the 1990s, as small-scale processors and traders successfully halved the marketing margin from producer to consumer. In Kenya, liberalization of dairy markets led to dairy production becoming the fastest growing source of income for over 600,000 small farmers with one to three cows.

However, where markets do not function, productivity gains do not translate into increased income. In Ethiopia, a quintupling of maize production since 1995 resulted in a collapse of maize prices in 2002. This led to a disengagement of farmers from maize production and a drop in fertilizer application by onethird.

Source: Authors. box 6.26). In many places, these high transaction costs keep small-scale producers and the poor out of the market altogether. On average, only one-quarter to one-third of agricultural production reaches the market in Sub-Saharan Africa, and producers remain trapped in lowyield, subsistence production. Thus, an important lesson learned in the aftermath of structural adjustment is the critical importance of moving beyond "getting prices right," which entailed the removal of policy distortions, to "getting markets rights." Getting markets right involves creating an enabling environment for the private sector to operate, and strengthening market institutions to reduce transaction costs and improve market performance.

\section{INVESTMENTS NEEDED TO GET MARKETS RIGHT}

The weakness of market distribution systems is partly a problem of poor infrastructure, particularly roads and communication systems. The road density in India in the 1950s was five times greater than that of all SubSaharan Africa today. But the poor distribution system is also due to the absence of key market support institutions, such as market information systems, grades and standards, contract enforcement mechanisms, and auctions and exchanges. Sales by order, forward contracts, and other more sophisticated marketing arrangements are virtually unknown. Agricultural market development requires investment in:

\section{- Institutional framework. Institutional} changes are needed to support the development of competitive and efficient agricultural markets and increase the access of small farmers to these markets. Institutional innovation should reduce transaction costs related to market coordination, facilitate expansion of exchange outside of personalized networks, and enhance market specialization (see box 6.27).

- Risk management. With the decline of public buffer stocks and price stabilization schemes, private risk management markets are emerging as an important force in 
coping with risk. Market-based instruments for managing risk (for example, forward and options contracts) enable producers and consumers to cope with an increasingly integrated global economy.

- Full implementation of the reforms. Full implementation of structural reforms will require more effort to stay-the-course on liberalization and to introduce other policy measures supportive of sectoral reforms.

- Infrastructure. Investments in key marketing infrastructure are needed to support agricultural production and marketing and improve the access of small farmers and traders to markets. These investments can be based on publicprivate partnerships.

\section{BENEFITS}

The welfare of the poor is intimately tied to their ability to efficiently acquire food and inputs from markets, and accessing output markets to generate cash income. The poor have little land, but derive much of their income from agricultural production-ranging from 40 percent in Kenya to over 80 percent in Mozambique and Ethiopia. However, most of the rural poor are net food buyers. Africa's rural poor spend up to 40 percent or more of their scarce cash income on food. Research in Southern Africa has shown that improved food marketing policies in the early 1990s improved real household income by 7-13 percent among the poorest urban households, and by up to 20 percent among the rural poor (Jayne et al. 2002).

Despite attempts to reform African agricultural markets, the development of a policy environment conducive to competition and private investment has remained elusive, and crucial market institutions remain rudimentary and weak. A significant proportion of small farmers opt not to participate in markets because the costs and risks of market participation are simply too high. Thus, investing in an institutional framework to make markets work, in

\section{Box 6.26 Impact of transport costs}

In much of Sub-Saharan Africa, the final price of agricultural goods is three to five times the price that producers receive. As an example, in 1995, while it cost only US\$38 to transport a ton of maize from Kansas to the Kenyan port of Mombassa, it cost US\$1 10 to transport that same ton from Mombassa to the town of Kisumu some 300 kilometers inland.

Source: Graeme Donovan, personal communication.

\section{Box 6.27 Mali:"Silicon Mali"}

Mali's success in establishing a market information system earned it the title of "Silicon Mali" by Forbes Magazine in 2002. Mali's market information system (Observatoire des Marchés Agricoles) is based on enumerators visiting 58 markets around Mali and recording the high and low prices for grains, crops, and livestock. They enter these on laptop computers and e-mail the information by FM radio waves - all solar-powered equipment - to other regional offices where data are compiled and reports prepared for different types of producers.

The system built up over a decade has made Malian grain farmers more efficient, knowing when and where to sell, and for what price. With better information, the government can now rely on the private sector to shift surpluses to areas with shortages without resorting to foreign aid. Mali's information system has become a model for the rest of West Africa, where such countries as Niger and Burkina Faso are setting up similar systems that will be linked together. Soon, farmers will be able to do more selling across national boundaries.

Source: Sansoni 2002.

private sector capacity, in risk management, and in appropriate infrastructure would significantly improve the welfare of the poor.

\section{POLICY AND IMPLEMENTATION ISSUES}

In the post-reform era, the fundamental market challenge facing developing countries is to understand how markets function, what roles different institutions play, and how to design, transfer, and maintain these institutions. Getting markets right depends on getting the underlying set of institutions right and developing private sector capacity. 
Defining the public sector role. Defining the appropriate role of the state vis-à-vis the private sector is critical to getting markets right. The failure of markets should not imply a reversal of market reform policies, but rather signal a new role for the public sector, in providing the institutions and infrastructure for the private sector to function.

ESTABLISHING DIALOGUE WITH THE PRIVATE SECTOR. Governments often are unwilling to engage the private sector in discussions and dialogue regarding the market. Thus, the private sector operates without clear trust or knowledge of the policy environment, leading to a vicious cycle of mistrust and inappropriate behavior.

LACK OF PRIVATE SECTOR CAPACITY. Private sector capacity is often a major constraint on market development. Most agricultural traders lack formal skills and trade finance. They operate small-scale businesses with few assets and trade only with people they know, in cash terms and over very short distances. Contracts are verbal and there is no legal system of enforcement. In countries such as Malawi and Ethiopia, twothirds of traders cannot get bank loans, only six percent own a vehicle, and less than one-half have a telephone or permanent storage facilities.

\section{LESSONS LEARNED}

Following market reforms in many countries, investments to strengthen market institutions have involved development of market information systems, vertically integrated smallholderto-export schemes, warehouse receipt systems, and smallholder associations. Little is known of the cumulative impacts of these investments.

Smallholder participation. A great deal of emphasis has been placed, rightly, on strengthening smallholder participation in markets and on developing high-value export markets for smallholders.

However, several gaps exist in market development. Many interventions are relatively short-term with an emphasis on quick results, without necessarily addressing the root causes of market failures. Root problems have to do with access to trade finance, human capacity in agribusiness and market promotion, logistics and supply chain management, and quality control.

IMPORTANCE OF DOMESTIC MARKETS. While the great thrust of donor efforts has been on the development of export markets, domestic food markets remain undercapitalized, risky, rudimentary, and relatively thin, with little scope for forward contracting or quality differentiation. Development of viable domestic food grain markets requires investments in market, transport, and storage infrastructure, information systems, domestic grades and standards, and access to inventory finance. Increasing storage by smallholders and warehouse receipts systems can help to dampen volatility of domestic markets.

IMPORTANCE OF MARKET TRADERS. Many efforts to develop agricultural markets have targeted smallholders directly, often bypassing or excluding other key economic actors, such as traders and processors. This neglects the capacity of those already in the market (for example, small independent traders and food processors) who may be well-placed to promote market activities. Building on the comparative advantage of traders is an important strategy for many market development efforts.

Contract enforceability. Very little emphasis has been given to the critical area of contract enforceability. Institutional innovation to reduce contract risk in domestic and export markets can build institutions that monitor trade behavior (for example, a credit referral agency or better business bureau), as well as mechanisms to ensure contract performance (for example, dispute settlement mechanisms).

InPut Distribution. Relatively little emphasis has been placed on input distribution, which is perhaps the area most adversely affected by market liberalization. Expansion of programs to improve input marketing and reduce costs of fertilizer to smallholders needs to be explored further.

WAREHOUSE RECEIPTS FOR RURAL FINANCE. Because of difficulties accessing adequate finance, farmers, 
traders, and processors have been unable to take advantage of opportunities created by globalization and market liberalization. Warehouse receipt financing is a possible solution. A warehouse receipts system allows farmers to store their products in a reliable warehouse until prices increase, using the product as loan collateral and accessing funds before they sell the product. Receipts are typically issued to producer groups rather than individual farmers.

Policy Reform. Finally, at a more fundamental level, policies in many countries remain unfavorable and in need of further reform. This requires development of analytical capacity for market analysis, and to cope with a changing global economic environment.

\section{RECOMMENDATIONS FOR PRACTITIONERS}

Practitioners aiming to get markets right need to focus on developing private sector capacity and investing in the institutions and appropriate infrastructure to enable the private sector to function in areas of input distribution, domestic food grain markets, traditional export markets, and export markets for nontraditional, highvalue products.

Policy-related investments must complete the implementation of market reform, with adoption of appropriate accompanying measures to alleviate negative impact of reforms. This will require attention to maintaining credible and stable macroeconomic policies.

Institutional investments are needed to develop official systems of grades and standards for agricultural products, market information systems, and functioning systems of trade finance and warehouse receipts, as well as to institute dispute settlement mechanisms and legal reform. Market coordination can be facilitated through commodity exchanges and auctions, and by supporting contract farming, outgrower schemes, farmer organizations, and traders' associations. Overall there is a need to promote effective governance and capacity building of state agencies for regulation and monitoring of markets.
Risk management initiatives to help farmers cope with changing markets can include investment in information on market trends, forecasting future trends, and developing capacity to react to this information. Market chains will need to make greater use of instruments such as forward, futures, and options contracts, requiring training and capacity building for farmer organizations to use these.

Infrastructure investments are needed to improve transport infrastructure, both in terms of transport fleets and roads, and mechanisms such as transport exchanges to coordinate logistics services and maximize utilization of transport capacity. Other investments in telecommunications, particularly mobile communications, are needed to facilitate market information flows.

In sum, productivity gains brought about through research and technology diffusion must underlie the future African agricultural revolution. However, markets must play a key role in bringing technology, namely inputs, to producers and in enabling them to realize income gains from increased production. Making markets work for the poor in Africa is a critical challenge and pivotal to reducing poverty and hunger in Africa.

\section{SELECTED READINGS}

Asterisk (*) at the end of a reference indicates that it is available on the Web. See Appendix 1 for a full list of Websites.

Gabre-Madhin, E. Z. 2001. Market Institutions, Transaction Costs, and Social Capital in the Ethiopian Grain Market. Research Report 124. IFPRI: Washington, D.C.*

Kherallah, M., C. Delgado, E. Gabre-Madhin, N. Minot, and M. Johnson. 2002. Reforming Agricultural Markets in Africa. Baltimore: Johns Hopkins University Press.

\section{REFERENCES CITED}

Jayne, T. S., J. Govereh, A. Mwanaumo, A. Chapoto, and J. K. Nyoro. 2002. "False 
Promise or False Premise? The Experience of Food and Input Market Reform in Eastern and Southern Africa." In T.S. Jayne, I. J. Minde, and G. Argwings-Kodhek, eds., Perspectives on Agricultural Transformation: A View from Africa. New York: Nova Science.

Sansoni, S. 2002. Silicon Mali. Forbes Global, February 4. http://www.forbes.com/global/ 2002/0204/042.html.

This Note was prepared by Eleni Gabre-Madhin (International Food Policy Research Institute) with inputs from Kees van der Meer, Gary Alex, and Sam Kane. 
INNOVATIVE ACTIVITY PROFILE

\section{BANGLADESH:AUTONOMOUS ORGANIZATION FOR FACILITATING MARKET-LED EXPORT}

Reduction of rural poverty in Bangladesh clearly requires improved agricultural growth and diversifcation into products, including export products, with higher income elasticities. This requires improved farm technology, both for intensification of food-grain production (to release land for higher value crops) and to enable farmers to grow diversified crops for which Bangladesh has a comparative advantage. However, Bangladesh has very limited experience in commercial horticultural production and marketing, and lacks extension systems that can provide improved production technologies and marketing information for export horticulture.

What's innovative? An autonomous agency to facilitate market linkage and export competitiveness for producers and exporters in a young horticulture export industry

\section{PROJECT OBJECTIVES AND DESCRIPTION}

The goal of the Agricultural Services Innovation and Reform Project is higher agricultural productivity and incomes through production intensification and diversification supported by more demand-driven and locally responsive agricultural services. The project provides support through a quasi-private organization (HORTEX) to pioneer horticultural production and export activities that emphasize contract farming with NGOs or private entrepreneurs using participatory approaches to extension.

HORTEX is an autonomous, nonprofit, facilitating organization that is not itself commercially involved in production and export. A managing director and a governing body consisting of 11 membersæthree from government, one from the central bank, five from the private sector, and two from NGOsæprovide the management structure.

HORTEX works with private entrepreneurs, NGOs, and government agencies to forge productive alliances and provide catalytic technical services, combined with limited investment, in export operations that may operate at a loss until adequate export volumes are developed. HORTEX provides assistance in grading, packaging, quality control and export logistics, assists in marketing, facilitates contracts with overseas interests, and explores potential joint venture investments.

In its first season of successful operation (1998), HORTEX arranged with an NGO for contract production of French beans, identified interested buyers in Europe, selected appropriate varieties, developed and contracted for supply of export-quality boxes, trained NGO extension staff, and organized export logistics. HORTEX initially bore the costs of seeds, fertilizer and cartons as demonstration costs. Based upon analyses of market opportunities and domestic production possibilities and constraints, HORTEX has identified other potentially profitable products such as chili peppers, okra, bitter gourd, yard long beans and baby pineapple. These include both new export commodities and traditional exports. For traditional exports, quality has historically been poor; packaging has not conformed to international trade standards; shelf life has been limited; and prices have been low. For these commodities HORTEX facilitates entry into nontraditional markets and improves returns from traditional markets by introducing improved production practices, post-harvest handling, and packaging to improve quality and reduce spoilage.

HORTEX organizes trial shipments of new products, or of traditional products to new markets such as Singapore and the Middle East. While the HORTEX business plan provides a basis for operations, flexibility is maintained to adjust for market developments and interest expressed by importers in particular products. 
In later stages of the program, HORTEX is likely to concentrate more on quality monitoring and promotion of Bangladeshi horticultural products. Its future role might include establishment of a recognized trademark and reputation for Bangladeshi products leading to longrun profitability. Evidence of success will be measured by the number of NGOs and private entrepreneurs able to export profitably without HORTEX services.

\section{BENEFITS AND IMPACTS}

Strengthened partnerships among NGOs and the private sector has resulted in improved extension services that enable farmers to undertake highly profitable diversified production activities. Market-oriented penetration of export markets has yielded higher farm incomes, with benefits accruing mainly to the poor and with significant multiplier effects throughout the local economy.

\section{LESSONS LEARNED AND ISSUES FOR WIDER}

\section{APPLICABILITY}

- As farming systems become more complex and market demand becomes increasingly sophisticated, agricultural extension systems need to become more decentralized to reflect location- and market-specific issues.

- Cooperation between a technical agency with access to international marketing experience and NGOs that have gained the trust of small farmers can be extremely useful in introducing new higher-value crops in a country dominated by small farmers.

- Agencies adopting a catalytic role (for example, HORTEX) should focus on providing critical technical services rather than making direct investments in infrastructure.

\section{PROJECT COUNTRY: BANGLADESH}

Project Name

Agricultural Services Innovation and Reform (HORTEX Component)

Project ID P058468

Project

Component Cost US\$2.4 million

Dates FY 2000 - FY 2003

Contact Point Wahida Huq

The World Bank, G.P.O. Box 97 ,

Dhaka 1000, Bangladesh

Email:Whuq@worldbank.org 
INNOVATIVE ACTIVITY PROFILE

\section{CHINA: SMALLHOLDER CATTLE DEVELOPMENT FOR IMPORT SUBSTITUTION}

Livestock raising is a large part of the household farming system in China, with farm families traditionally keeping a few animals, mainly pigs and chicken, for sale and home consumption. Beef production has mainly been from cattle that have outlived their usefulness as draft animals.

What's innovative? Developing markets and market linkages to enable smallholders to respond to a growing market demand for high-quality, safe beef.

Over the last 20 years, per capita meat consumption has increased from 0.4 to 2.4-3.0 kilograms per year, while domestic production has increased at only one-half that rate. The increased demand for quality beef cannot be fully satisfied due to generally weak infrastructure in marketing, slaughtering, and processing, and a weak market information system linking producers, processors, and commercial buyers. There is an urgent need for a better-integrated system involving forward and backward linkages among producers, processors, and buyers.

\section{PROJECT OBJECTIVES AND DESCRIPTION}

The Smallholder Cattle Development Project aims to: improve smallholder cattle production within existing crop farming areas using crop by-product surpluses; and improve the quality and marketability of cattle to enhance farmer incomes and reduce poverty.

The project supports the government policy of developing the beef cattle subsector in response to emerging market demand for quality beef, and to develop meat production that does not use grain. The project puts special emphasis on assisting smallholders, who have surplus labor and by-products, but are constrained by low productivity and poor quality of existing cattle operations. The project involves improvements to animal husbandry technology and processing and marketing infrastructure. Strengthening the commercial infrastructure to link production and markets through development of live-cattle markets, processing facilities, market information services, and quality assurance programs is an innovative component of this project.

The Market Linkage Development component aims to provide linkages from producers to cattle markets. The project supports the construction of nine, small, live cattle markets that act as centers for trade and market information, as well as places to access technical knowledge and veterinary services. They give farmers a competitive alternative to direct sale to slaughterhouses and processors.

The project also supports the construction, expansion, and rehabilitation of five cattle slaughterhouses and processing plants to expand markets for farmers and provide valueadding opportunities. These processors provide key linkages between production and finalproduct markets by producing quality beef of specified grades on delivery schedules required by end markets. This is achieved through integrated planning and management by processing facilities, feedlots, and farmers. Processors match supply and demand on a year-round basis through their purchasing and storage activities. Contracts specifying the quantity to be supplied and date of delivery are negotiated between processors and farmers with payments based on quality, schedules, and grades. This sends essential signals to farmers and feedlots about the type and quantity of beef required, which results in a production response with production of cattle of the quality demanded by consumers, utilization of grading standards, and presentation and packaging of product to the specifications of customers.

The entire process provides an avenue for inducing farmers to respond to markets. The information collection system collects market information and feeds it back to cattle markets, 
feedlots, processors, local bureaus of animal husbandry, and farmers. The participating slaughtering and processing enterprises use beef grading and assurance programs and work toward achieving the HACCP or ISO-9002 bestpractice level. Introduction of a quality-based differential beef pricing system serves as an incentive scheme for small farmers to produce improved cattle.

\section{BENEFITS AND IMPACTS}

The project provides employment for about 3,000 people through the development of nine cattle markets, 130 feedlots, and five processing enterprises, and provides additional employment opportunities in the rural economy through general commercial development. Development of improved markets and linkages to consumers has increased incomes of producers, expanded on-farm employment opportunities, and improved the supply of safe, high-quality beef to local consumers. The improved information system enables producers to respond more effectively to consumer demand, and thus has improved competitiveness vis-a-vis foreign producers. The improved quality assurance in meat inspection, food safety, and processing technology has reduced the health risk from unhygienic handling of beef, and reduced food safety risks to consumers.

\section{LESSONS LEARNED AND ISSUES FOR WIDER APPLICABILITY}

- A market-based orientation is essential to compete with international suppliers, particularly for China and other countries that have recently joined the WTO or other trade agreements.

- Contracts must be based on demand in end-markets and have clear quantity and quality specifications with transparent payment schedules. Specific mechanisms must be included for contract enforcement, although compliance is best assured through well-aligned incentives that benefit both partise to the contract.
- It is essential for meat and other fresh foods that accepted food safety practices are strictly followed at all stages of the supply chain, that appropriate testing procedures are followed, and auditing systems are established.

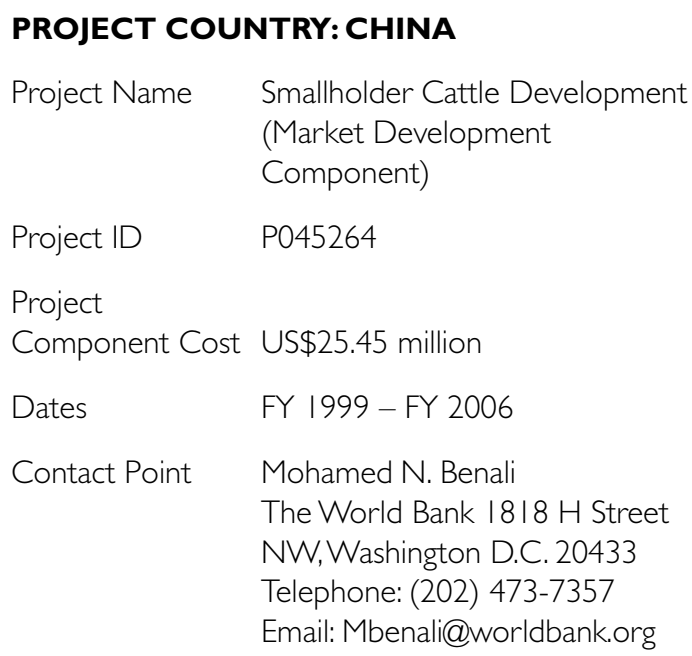

Project Name Smallholder Cattle Development (Market Development Component)

Project ID P045264

Project

Component Cost US\$25.45 million

Dates FY 1999 - FY 2006

Contact Point Mohamed N. Benali The World Bank 1818 H Street NW, Washington D.C. 20433 Telephone: (202) 473-7357 Email: Mbenali@worldbank.org 
INNOVATIVE ACTIVITY PROFILE

\section{COLOMBIA: PRODUCTIVE AGRIBUSINESS/FARMER PARTNERSHIPS}

Liberalization of the economy coupled with an overvalued peso and falling world prices for commodities have led to fundamental changes in the composition of Colombia's agricultural production. However, limited education and business skills of the rural population, the high cost of and limited access to capital (particularly for smallholders), and the prevalence of rural violence have impeded the ability of smallholders to capitalize from these changes. The challenge of the rural sector is to increase its competitiveness in a free market economy. The government strategy seeks to promote farming systems that combine both perennial crops (agro-ecological conditions permitting) with subsistence and annual crops and animal husbandry. This is expected to allow farmers to reduce debt levels, diversify risk, and increase employment and incomes.

What's innovative? Building sustainable win-win partnerships between rural producer organizations and agribusinesses.

\section{PROJECT OBJECTIVES AND DESCRIPTION}

The Productive Partnerships Support Project objective is to establish economically viable and sustainable productive partnerships between agribusiness and small farmer producer organizations, by providing an integrated package of incentives and assistance. Demand-driven, sustainable, productive partnerships are expected to generate income and employment opportunities for participating small farmers. A productive partnership is considered any collaborative arrangement between a small farmer producer organization and an agribusiness enterprise that reduces technical, commercial, financial, and/or social risks; increases productivity; and produces income gains in a valuechain, such that all parties benefit.
Project implementation is based on three principles: the (limited) responsibilities of the public sector are specifically defined; execution of project activities is completely decentralized and transferred to the private sector; and participation of stakeholders structured through a clear distribution of roles and responsibilities based on recognized competencies and capacities of each party. Operational procedures are designed to provide transparent rules, clear eligibility criteria for identification of beneficiaries and allocation of resources, efficient flow of funds, and adequate supervision.

Participation of relevant stakeholders at the strategic level of the project is ensured by including representatives of the financial sector, agricultural producer organizations, and small farmers organizations in the National Technical Committee, which ensures consistency of project implementation with agreed conceptual and technical design. A Coordination Group (consisting of a team of dedicated professionals with relevant disciplinary backgrounds) reporting to the Committee conducts a public information campaign, selects productive partnership ideas presented jointly by interested partnership participants, arranges the contracting of Technical Assistance Providers to facilitate preparation and implementation of productive partnerships, and establishes agreements with partnership representatives for administration of incentive programs.

The project supports the implementation of productive partnerships by financing: cost sharing transfers as a financial incentive for participating small-farmer producer organizations; and technical assistance and training to productive partnership participants. The incentives can be used for: access to output markets and inputs (for example, high quality seed, and credit for working capital purposes) for the farmer, and opportunities to expand food processing activities by securing supplies from small producers that meet certain predetermined quality standards, without the need to expand own production capacity for agribusiness firms. 
Specific applications may include: on-farm infrastructure such as irrigation canals, aquaculture facilities, greenhouses, storage facilities; durable goods such as machinery, equipment, tools, fences; vegetative materials for nurseries; (iv) operational inputs such as fertilizers and chemicals that do not appear on the negative list; services such as land leveling; special studies, surveys, laboratory analyses and inventories; insurance; publicity, market and communication services; labor usually in the form of remuneration to the beneficiary or family (this is particularly important for organic crops); and purchase of land (financed from counterpart funds). The maximum value of the incentive is 40 percent of the required investment.

Technical Assistance providers (NGOs or consulting firms) support preparation of productive partnership proposals and facilitate implementation of approved partnerships. Development of clear schedules of incentives is a key part of the project, and is essential to the sustainability of the partnerships.

\section{BENEFITS AND IMPACTS}

Development of productive partnerships between agribusinesses and small-farmer organizations has improved the accessibility of both input and output markets to smallholders. This has increased the range of production alternatives available to them, and has improved the profitability of diversification alternatives. In doing so, rural employment has increased, a broader range of production systems has been established, ecological sustainability has improved, and the financial and agroclimatic risks associated with agricultural production have been reduced. Agribusiness investment in the sector has improved the inflow of new technologies, and has improved the linkages between farmers and the end-markets that they serve.

\section{LESSONS LEARNED AND ISSUES FOR WIDER} APPLICABILITY

- A flexible, open design is needed for programs with local governments due to the great diversity in capacity and socioeconomic conditions. An impartial group (such as the National Technical Committee Consortium) is extremely important to adapt implementation to the dynamics of each particular location.

- The process of designing partnerships should be highly participatory, drawing on the contributions of municipal governments and local small-farmer organizations.

- Proper mechanisms must be set in place to provide participating farmers with independent sources of technical assistance to counterbalance dependence and excessive monopoly situations in relationships between suppliers and buyers.

- A simple monitoring and control system should be in place from the start of the operation to rapidly identify and correct problems. It is advisable to separate monitoring and evaluation functions, and rely on an independent agency to conduct periodic impact evaluations.

- Clearly, defining contractual, arbitration, and conflict resolution mechanisms, and operational, monitoring, and supervision procedures can ensure transparency in financial transactions and encourage provision of matching grants by government.

\section{PROJECT COUNTRY: COLOMBIA}

$\begin{array}{ll}\text { Project Name } & \text { Productive Partnerships Support } \\ \text { Project ID } & \text { P04I642 } \\ \text { Project Cost } & \text { US\$52.3 million } \\ \text { Dates } & \text { FY } 2002 \text { - FY } 2008 \\ \text { Contact Point } & \text { Pierre Werbrouck } \\ & \text { The World Bank I8I8 H Street } \\ & \text { NW,Washington D.C. 20433 } \\ & \text { Telephone: (202) 473-0745; } \\ & \text { Email: Pwerbrouck@worldbank.org }\end{array}$




\section{INNOVATIVE ACTIVITY PROFILE}

\section{MALI: BUILDING EXPORT MANGO SYSTEMS}

Mali relies on an agricultural system centered on a few major crops (cereals, rice, and cotton) produced by many smallholders. High production risks and poor productivity contribute to the high incidence of rural poverty. Most smallholders have diversified their production systems to include horticultural crops as complementary cash crops in the off-season. However, diversification into export crops, such as mangos, has been constrained by limited extension and research services, unorganized and inadequate logistical infrastructure, and an ignorance of market requirements.

What's innovative? An autonomous agency improving supply chain coordination and linking smallholders to export markets for horticultural products.

The potential for horticultural exports is due to the good positioning of Mali in the mango sector and the growing demand in European markets. The Agricultural Trading and Processing Promotion Agency, an NGO established as an autonomous body under the Chambers of Agriculture with an agreement with the government, undertook to design and implement an export promotion project for Malian mangoes. The Agency was formed to restructure supply-chains, develop commercialization channels, and promote the application of research and technology.

\section{PROJECT OBJECTIVES AND DESCRIPTION}

The primary objective of one component of the Agricultural Trading and Processing Promotion Project was to improve the supply chain for mango exports by filling the gap left by public sector withdrawal, while strengthening the linkage between the small producers and markets. A second objective was to develop new communication channels for trade exchanges (especially sea-freight logistics), and a third objective was to encourage crop diversification. Overall, the aim of this project is to significantly increase the volume of mangoes exported. On the production side, this is to be achieved by improving product quality to meet market requirements, and on the marketing side, by resolving transportation bottlenecks by developing sea shipment logistics.

The Agency identified a Cote d'Ivoire enterprise willing to set up a joint-venture and share risks. It guaranteed a fixed price to the importer, who bore the logistic and commercial risks associated with exporting the product. The Cote d'Ivoire partner is liable for financing fruit purchases from growers, and packaging material at the pack-house, and for securing forwarding and inland logistics. Fixed prices include a profit margin for each party. If the average selling price exceeds a fixed amount, the additional profit is split equally.

The Cote d'Ivoire partner assigned two experienced pack-house managers (administrative and packing) to implement proper packing, accounting, and shipping procedures. The Agency acts as an intermediary between the producer associations and their trading partners and provides a number of extension services to the growers and pack-house employees to increase productivity, reduce costs, and improve quality. Key intermediaries are involved in technology transfer to growers, and producer associations assist with training and technical assistance activities, as well as working to pool production and negotiate contracts.

Services provided relate to agricultural inputs, quality management, conservation techniques, harvesting techniques, seedling sourcing, varieties, orchard restructuring, quality control and certification, and national regulations on the production side. Services provided on the commercialization side include the organization of the marketing participants, training in export standards application, logistics improvement, and financing.

The Agency exploits new information technology through its agribusiness centers where product exhibits are held, and where there is a reference center and an Internet café. These 
centers serve as a place for growers to access outputs from The Agency's programs. Local radio programs, as well as "audio-technical books" (many villages have a cassette recorder running on batteries) are also used to disseminate information. Given the low literacy rates, a key future challenge will be the development of management information systems and traceability management systems to track production.

\section{BENEFITS AND IMPACTS}

Benefits include: profitability for all partners; reduction by half in transit time to Northern Europe; higher quality products delivered to customers; access to new European markets; timely payments to growers; farm income diversification; training of the rural labor force; introduction of improved technologies; increase of prices to growers by 25 percent; increased pack-house employment (60 percent are women); and improved pack-house working conditions and pay.

\section{LESSONS LEARNED AND ISSUES FOR WIDER APPLICABILITY}

- Successful export systems must establish

\footnotetext{
linkages between farmers and their markets to enable them to satisfy, and adapt to, market demand.

- Incentive structures between partners (particularly between growers/grower associations and agribusinesses) must be designed to minimize enforcement problems.

- Efficient and reliable cold-chain infrastructure is essential to ensure preservation of product quality. "Multi-modal" containers (fitted with "gensets," that is, clipped generator units required to keep the refrigeration going) are important, but must be complemented by good logistical planning to ensure minimal delays.

- Quality control is critical for perishables, especially for exports to the European Union, which requires high compliance
}

levels. All chain participants must receive training on quality standards and market requirements, and internal control systems must be installed at collection and processing sites.

- Integrated technical and extension services for production, processing, and distribution are essential for improving supply chain coordination and efficiency.

\section{PROJECT COUNTRY: MALI}

\begin{tabular}{|c|c|}
\hline Project Name & $\begin{array}{l}\text { Agricultural Trading and Processing } \\
\text { Promotion (Mango Export } \\
\text { Component) }\end{array}$ \\
\hline Project ID & P00।755 \\
\hline Dates & FY 1995 - FY 2003 \\
\hline Contact Point & $\begin{array}{l}\text { Patrick Labaste } \\
\text { The World Bank, I } 8 \text { I } 8 \text { H Street } \\
\text { NW,Washington D.C. } 20433 \\
\text { Telephone: (202) 473-4999 } \\
\text { Email: Plabaste@worldbank.org }\end{array}$ \\
\hline
\end{tabular}




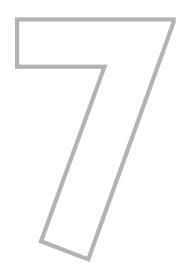

\section{INVESTMENTS IN RURAL FINANCE FOR AGRICULTURE}

roviding financial services to households and agribusiness in poorer and marginal rural areas remains a challenge for the World Bank and other funding agencies. Although the adoption of a financial systems approach and the expansion of the microfinance sector have led to significant breakthroughs in performance, outreach, and lending volumes, this has rarely extended to more marginal rural areas dependent on agriculture. Recent progress in providing financial services have impacted poor rural households with diversified nonfarm income sources or income from nonseasonal agricultural activities. Several factors increase cost and risks of financing agriculture and for these reasons financial service providers perceive investment in agriculture to be unattractive (see box 7.I). However, recent efforts by the World Bank and other organizations are starting to bear fruit in the form of emerging models and successful approaches. Rather than repeating a comprehensive treatment of the well-documented challenges and past failures of agricultural finance (World Bank, forthcoming; IADB 200I; Yaron, Benjamin, and Piprek 1997), this Module explores promising new directions in rural finance for agriculture, and identifies lessons for policy and lending. 
Box 7.I Challenges of providing financing for agriculture

- High, interrelated covariant risks: Due to variable rainfall (especially for nonirrigated crop production); pests and diseases; price fluctuations; and constrained smallholder access to inputs, advice, and markets.

- Dispersed demand for financial services: Due to low population densities; small size of individual transactions.

- High information/transaction costs for service providers: Due to remoteness of clients, and heterogeneity among communities and farms. This creates potential for information asymmetries and moral hazard risks.

- Seasonality of agricultural production (in particular crop production): Leads to a lag between investment needs and expected revenues, and consequent liquidity management challenges.

- Lack of usable collateral: Due to ill-defined property and land-use rights, high cost or lengthy registration procedures, and social constraints to foreclosure.

Source: Authors.

Within the current financial systems approach, financing for agriculture is seen as part of a comprehensive rural finance strategy. The terms Rural Finance for Agriculture and Financing for Agriculture are used interchangeably throughout this Module to define all financial services provided to those engaged in the agricultural sector. The Module focuses on the provision of financial services for agricultural activities and to agriculturally dependent households, though most do not exclusively provide financing for agriculture. They also provide financial services to nonagricultural rural and, in some cases, urban communities. These providers include both formal and informal institutions ranging from full-service banks to specialized agricultural finance institutions to microfinance institutions (MFIs), financial cooperatives, credit unions, savings and loan associations, traders, and processors. They encompass all types of financial services (credit, savings, money transfers, leasing, and insurance $^{1}$ ), for agricultural activities broadly defined to include primarily production, but also processing, distribution, and marketing. In this module, particular emphasis is placed on those who presently have only limited access to financial services, such as poor agriculturally-dependent households in less-favored (low productivity, more remote) rural areas.

\section{RATIONALE FOR INVESTMENT}

Constraints to agricultural development are many, and access to financial services is only one response needed to address these constraints. However, improving the provision of, and access to, financing for agriculture can meet a range of needs, and can be critical to the success of agricultural development programs. Indeed, many investments in agriculture are dependent on access to appropriate financial services. At the production level, financing for agriculture can enable farmers to introduce irrigation or other technologies; finance input and marketing costs; cofinance extension and information services; bridge the preharvest income gap and avoid having to sell immediately following harvest at low prices; smooth seasonal income flows through deposit facilities and access to remittances or insure against price or yield fluctuations. If agribusinesses are not able to access financial services, this will constrain their capacity to finance and supply farmers, and to buy and process farm produce.

\section{PAST INVESTMENT EXPERIENCES}

Since the 1950s the donor community has made large-scale investments in recognition of the importance of supporting financing for agriculture. However, the widespread development of sound and sustainable financial systems for agriculture has not occurred, and the challenges described above still remain. Attention has frequently been drawn to the apparent failure of past approaches, and in particular to the directed credit programs of the 1960s to the mid 1980s. Although these provided a shortterm impetus to agricultural production, they have been criticized as costly, unsustainable, and supporting a misperception of free credit, thus jeopardizing future efforts to create sustainable financial institutions. Since the 1980s,

I. This module is primarily concerned with credit, savings, and leasing. Insurance is addressed in Module 10: "Managing Risk andVulnerability." 
attention has switched to the development of sustainable financial institutions providing services to poor clients. This has entailed greater donor support to the establishment of an appropriate policy, regulatory, and legal environment for financial institutions, and support for the development of innovative approaches to reach poorer clients.

During the 1990s, there was a steady increase in the number of World Bank operations with rural and microfinance components, with average annual lending of US\$630 million (World Bank, forthcoming). However, the relative share of agriculture in total Bank operations with rural and microfinance components has declined from 65 percent during fiscal years 1992 to 1994 to only 27 percent in 2001. This is attributed to the trend to include microfinance and grant components in projects for other sectors, the poor performance of agricultural credit lines and agricultural banks, and the Bank's Operational Policy (OP) 8.30 that limits the use of subsidized credit (see box 7.2). The focus of recent Bank operations has therefore shifted from the provision of credit to agricultural production (especially for larger farms) and agribusiness, to small loans for offfarm activities and savings services. Although these operations have had some success, they do not constitute a replacement for previous agriculturally-focused operations. Viable mechanisms to address specific demands for agricultural financing continue to be a challenge.

\section{KEY POLICY ISSUES}

FinANCIAL SYSTEMS DEVELOPMENT. In response to the deficiencies of past approaches to financing for agriculture, new thinking has emerged that embraces the financial systems approach, while recognizing the specific challenges of the agricultural sector and the rural setting. Financing for agriculture has too often been seen in isolation from wider financial systems development, and has overemphasized credit, as opposed to savings and other financial services. One symptom (and cause) of this is that the ministry of agriculture, rather than the ministry

\section{Box 7.2 Operational policy 8.30}

- Targeted subsidies may be warranted if they are transparent, capped, explicitly budgeted, fiscally sustainable, and economically justified.

- Subsidies should not directly subsidize the ultimate clients, but rather be aimed at building the capacity of financial intermediaries or supporting institutions (for example, supervisory authorities).

- Conditions are specified for acceptable targeted credit that fosters a sustainable flow of financial services to underserved groups (such as the poor, women, and microentrepreneurs), and is accompanied by reforms that address problems in institutional infrastructure and financial markets.

- Financial Intermediary Loans (FILs) should be limited to those that have sufficient institutional capacity.

- New and existing institutions that do not qualify as a "viable institution" may participate in a FIL, if they agree to an institutional development plan that includes a set of time-bound performance indicators that can be monitored, and that provides for a midterm review of progress.

Source:World Bank, Operational Manual.

of finance, is often the partner ministry in a borrowing country for agricultural loans. Within a financial systems approach, financing for agriculture is viewed as part of the wider rural finance market. Underpinning this approach is the fact that institutions adhering to commercial principles are most likely to achieve outreach and sustainability, and that the role of the public sector should be focused on ensuring that the environment is conducive to the emergence and growth of such institutions.

This approach also recognizes that there are a number of institutions (formal and informal) and individuals that together constitute the financial system (see box 7.3). In certain cases, these institutions will be in place, with infrastructure and networks in agricultural communities that can be the basis for improving provision of financial services. The challenge for governments and donors is to identify and work with those institutions that are viable financial service providers, and where these are absent, to create the incentives and environment for such institutions to emerge. 
Box 7.3 Institutions and individuals in the rural finance system

- Agricultural Banks: Whether privatized or state-owned, these banks have a rural network that provides financial services specifically for the agricultural sector.

- Postal and Savings Banks: These often act as the principal source of deposit and money transfer services in rural areas. Traditionally these were owned by the state, although in some countries they have been commercialized.

- Microfinance Institutions (MFls): Specialized institutions that can provide microfinance products targeted at the poor and low-income populations, including small farmers.

- Membership-Based Financial Organizations (MBFOs): Membership-based organizations can include financial cooperatives or credit unions, and savings and credit associations. These organizations usually have a common bond, such as community, geography or activity.

- Processors and Traders: A wide variety of businesses and entrepreneurs in the agricultural market system that are principally engaged in agricultural activities (such as processing, marketing, input provision, storage) also provide credit as part of transactions.

- Informal Financial Intermediaries: Group-based models such as Rotating Savings and Credit Associations (ROSCAs), moneylenders, retail stores offering goods on credit, informal deposit collectors, and others.

Source: Authors.

The financial systems approach recognizes that rural and agricultural clients need a full range of financial services including savings, shortand long- term finance, insurance, money transfers for remittances, and leasing (see box 7.4). Successfully meeting these demands requires designing financial products to meet client needs, by using client and market research, and adapting delivery mechanisms to provide low-cost and convenient access.

DeVELOPING APPROPRIATE POLICY FRAMEWORKS. The public sector plays a vital role in creating suitable conditions for financial market development. Specifically, the public sector must provide the policy environment for rural finance for agriculture to flourish including conditions for macroeconomic growth and stability, and appropriate agricultural and financial sector policies. Agricultural policy reform may be necessary to remove historical biases against agriculture, to help the sector be profitable and thereby encourage investment. Financial sector policy needs to promote the development of financial organizations that are transparent and accountable. This must be supported by a strong legal and regulatory framework, including the provision of a legal basis for secure property rights, financial transactions, and savings mobilization (see box 7.5).

Deficiencies in the enabling environment frequently limit the viability of financial service providers, and therefore the spread of financial services into rural areas and agriculture. This requires institutional strengthening in the broadest sense, of the judicial system, property registries, contracts and markets, infrastructure, and service providers.

ApPropriate StRategies FOR THE POOR. Within the agricultural sector, social groups have different financial (and nonfinancial) needs (see box 7.6). Credit is only suitable in certain circumstances. For example, there is a significant difference between financing a liquidity shortage for a viable activity, and giving money to people or enterprises without a viable business model (including farming), who may not be able to meet repayment commitments. One may lead to poverty reduction and increased employment, and the other to an unsustainable debt burden. Microfinance has demonstrated that careful design of financial products and delivery mechanisms can allow those previously considered "unbankable" to be good clients. However, there are still cases where credit is not suitable, and where grants may be a more appropriate response:

- Where the recipients are too poor to repay a loan, such as some groups of landless poor.

- Where the primary eligibility or targeting criteria are not "ability to pay," but instead is membership of a certain target group (for example, credit to farmers to promote adoption of a certain technology).

- For a "lumpy" or long-term investment, or a risky start-up, neither of which fit a shortterm, high-cost microloan. 


\section{Box 7.4 Financial products demanded by the rural sector}

Savings: Savings mobilization contributes to an institution's sources of funds for on-lending, and is also a financial service that is equally, if not more, important to the rural poor than lending. In the absence of formal savings opportunities, the rural poor often pay depositors or store money in insecure places.

Short-Term Finance: This is finance for working capital, such as inventories or agricultural inputs. Short-term finance for agricultural activities including input supply and processing, tends to be linked to crop cycles, and thus defined by the growing season.

Term Finance: Term finance (FAO, forthcoming), defined as loan terms over one year, may be used for farm machinery, irrigation equipment, land improvements, livestock, tree crops and processing equipment. Term finance does not only imply loans, and may also include leasing of machinery and equipment. The challenges presented in box 7.3 apply even more strongly to term finance, which is more costly and risky than short-term finance, since it ties up larger amounts of money for longer periods, and requires the mobilization of long-term funds (to balance assets with liabilities).

Leasing: In a lease agreement, the leaseholder pays a regular rent/lease for the use of equipment while the legal property remains in the hands of the institution. Due to the ready availability of collateral (the leased equipment), it may be an easier product to provide by rural financial intermediaries than other term finance, but its viability depends on appropriate tax and legal incentives.'

Money Transfer for Remittances: Income from national or international remittances is important in most developing economies, and disproportionately so for many poor rural areas where it may be the principal income source. Remittance monies can make significant contributions to consumption smoothing, and efficient mechanisms for money transfers are widely demanded by the rural poor. However, care needs to be taken to ensure that access to remittance services will not be misused for moneylaundering purposes.

Insurance: Insurance products are in particularly high demand (and short supply) in the agricultural sector, given the risk of crop failure and price fluctuations. Insurance products span loan insurance, crop insurance, and life insurance, but experience with these is mixed. Hedging instruments based on weather or price indices are also increasingly available.

Source: Authors.

I. See the IAP,"Madagascar: Microleasing for Agricultural Production."

\section{Box 7.5 Improving the legal environment for rural finance for agriculture}

Enable Unsecured Loan Portfolios: Change laws to permit unsecured loan portfolios to serve as collateral for accessing loans from the formal sector for refinancing.

Reform Borrower Status and the Law: Reform laws relating to the status of borrowers with regard to age of majority, homestead, literacy, and civil registration. Facilitate the poor, illiterate, and young heads of households in legally conducting business with the formal sector, such as the signing of contracts, opening businesses, and borrowing.

Simplify Bankruptcy Procedures: Simplify and reduce the cost of bankruptcy procedures to have a simple and cheap exit mechanism for paying unsecured debt, recuperating lender funds and returning remaining funds to the borrower.

Expand Collateral Use: Broaden the concept of security interest for immovable property, for example from land titles to land use rights. This requires recording economically important land use rights and simple legal mechanisms for transferring such rights.

Write Civil and Commercial Registration: Create governing legislation for all relevant legal institutions that permits civil and commercial registration systems, and where possible, private systems. This should include a filing system to report security interests for property and land use rights for immovable property.

Source: Fleisig and de la Peña 2003. 
Box 7.6 Categorizing the agricultural poor and their financial needs

The "entrepreneurial poor" are those who are already engaged in viable but low-productivity economic activities (including agricultural production or processing) or who have good investment opportunities, but are constrained principally by lack of access to financing. These include farmers with access to sufficient land and inputs to consistently produce a surplus for marketing, and where demand exists for their produce in accessible (local, national, or international) markets. The development of financial systems that cater to rural and agricultural entrepreneurs can service this group, through increased outreach and sustainability of institutions providing financial services.

The very poor are those who have reasonable economic opportunities but are handicapped by low skills, poor basic economic infrastructure, lack of social capital, a remote location, and lack financial institutions. These include farmers and agricultural businesses in marginal production areas, often distant from markets and poorly served by both public and private sector services. Financial service provision to poor people in these areas may not be viable, and flexible low-cost delivery mechanisms are needed. Savings may be more appropriate than credit, and investments through grants may be necessary to increase the economic potential of such areas.

The extreme poor or destitute, especially those in areas with low economic potential, are most likely not best served by financial services, but may require grant-based approaches to improve livelihoods.

Source: Authors.

- Where the recipient lacks the skills (or health) to productively utilize a loan.

Where there is an element of entitlement or compensation in project design, credit (which is, of course, actually debt) is also not the appropriate tool. For example, if an amount of money is to be given automatically to individuals in a certain target group (such as refugees, HIV/AIDS sufferers, or retrenched workers), a grant should be used. Grants can take the form of start-up equipment for a farm or enterprise, a contribution to transition costs associated with adopting new activities, a grant (or food subsidy) to help a person move out of destitution or recover from an emergency, or a savings-type deposit that can be accessed later at a time of need (as opposed to a cash grant).
Access to flexible and safe savings facilities can enable poor households to reduce their vulnerability to shocks, save for expenses such as school fees, and can provide an important source of funds during the growing season. Transfer payment services, which facilitate access to remittance monies, are unaffected by agricultural production cycles, and can provide important consumption smoothing and riskreducing mechanisms for the poor. Credit is likely not suited to the needs of the extreme poor, who have little likelihood of productive investment and credit repayment.

The success of microfinance in the past 20 years has led some to believe that the development of sustainable institutions providing financial services to the poor on a full cost-recovery basis is sufficient for poverty reduction. However, the causes of poverty are numerous and complex, and although microfinance is an important poverty-reduction tool, its effectiveness is closely linked to other interventions (and vice versa). Nonfinancial services can also help the rural poor "graduate" to become suitable candidates for microcredit and other financial services, for example through building skills and capacities (health and education), and through improving access to markets. The starting point for operations in rural finance for agriculture must therefore be a research and consultative process to develop a solid understanding of the financial needs of the poor, and factors limiting their access to financial services.

SubsidiEs, CREDIT LINES AND GUARANTEES. The revised OP 8.30 (World Bank, Operational Manual) clarifies the Bank's policy by stating the conditions under which subsidies and directed credits may be used. They can be used as part of an operation that aims to foster a marketoriented environment, which in turn enhances access of the poor and micro and small-sized enterprises to financial services. Market failures that result in poorly functioning and shallow agricultural financial markets may justify carefully designed subsidies, provided they are time-bound and used for overcoming those failures, and do not distort prices or target certain clients. Technical assistance, training, 
investment in systems, and other capacitybuilding subsidies can support the emergence of strong rural financial service providers. However, subsidies can also distort financial markets, inhibit the development of the financial system, and reduce access of rural populations to financial services. This type of negative impact results from subsidies being applied to price (interest rate subsidies for the end borrower), or to directing credit to certain groups or for certain purposes, without an overriding goal of creating sustainable financial institutions. Longterm or structural subsidies should also be avoided, because they can create dependence on donor funding. Sustainability in the provision of financial services implies a transition to more commercial sources of funding over time, as donor funding is limited in size, temporary, and its availability is subject to policy changes.

Credit lines and guarantees can also distort markets, and therefore should be used carefully - and only where parallel measures are taken to improve the operating environment for rural financial service provision. ${ }^{2}$ Funding for lending portfolios may be justified in the short to medium term under the following conditions: if the financial institution is not able to take deposits (to avoid the risk of external funding undermining mobilization deposits), if sufficient capacity-building support has been successfully provided, and if commercial sources of finance (investors and banks) are not an available option. In the longer term, however, both deposits and commercial sources of funds are more sustainable (and less distorting) sources of funds for intermediation than donor funding, and do not expose the borrower to exchange rate risks (CGAP 2002).

Financial guarantees can be used to attract commercial financial intermediaries into lending to MFIs with an agricultural portfolio, or to develop financial credit within commodity marketing chains. Such guarantees should decline rapidly over-time, and should be designed to develop sustainable business relationships between providers and recipients through building trust and a good credit history. Guarantees are only useful if a substantial portion of the credit risk remains with the institution, to avoid moral hazard and to allow for the buildup of good credit practices.

\section{NEW DIRECTIONS FOR LENDING}

Approaches are needed that expand the depth, scale, and outreach of financing for agriculture, with a wider range of better-designed financial services, provided at a lower cost and to poorer clients. This requires action on two complementary fronts: improving the overall environment for the development of financial systems, and increasing the capacity of institutions to provide financial services to the agricultural sector.

IMPROVING THE ENVIRONMENT FOR RURAL FINANCE FOR AGRICULTURE. Creating a conducive policy framework for financing for agriculture is consistent with policies for improving the investment climate, supporting financial systems development, and increasing agricultural growth (Yaron, Benjamin, and Piprek 1997). The challenges of providing financial services to small-scale farmer activities do merit particular emphasis on the following:

- Strengthening the capacity of land and property registries, and streamlining registration processes, to make collateral easier and cheaper to use, and promote secure land tenure and land-use rights. This creates an incentive for farm investment (for example, the modernization of the property registration system in Latvia during the Rural Development Project 1997-2001 led to an eightfold increase in mortgage registrations).

\footnotetext{
2. OP 8.30 states that targeted lines of credit, when justified, should be accompanied by reforms to rectify underlying market imperfections. A Bank Financial Intermediary Loan may support directed credit programs to promote sustained financing for such sectors, provided the programs are accompanied by reforms to address the underlying institutional infrastructure problems, and any market imperfections that inhibit the market-based flow of credit to these sectors. Such reforms include measures to (a) address obstacles that impede the flow of funds to the credit recipients, or (b) enhance the creditworthiness of the intended beneficiaries through appropriate approaches such as mutual group guarantees.
} 
- Ensuring that debtor rights do not outweigh creditor rights, and building the capacity of rural courts to process claims efficiently and transparently.

- Eliminating any interest rate subsidies to agricultural lending through development banks or other institutions supported by government or donors.

- Investing in communications and physical infrastructure to lower operating costs for financial service providers, and investing in education and health services to enhance the capacity of clients to take advantage of financial services.

- Reforming financial sector regulation and supervision (if needed) to promote the development of nonbank financial institutions. For example, this could be a shareholder-based entity that is allowed to offer a limited range of financial services (such as credit, deposits, and domestic transfer payments), and that operates within a specialized regulatory framework and set of reporting requirements that do not restrict microfinance activities. This may be necessary to encourage financial sector development, and to enable product diversification beyond credit to deposit facilities and transfer payment services. However, this option should only be considered if there is sufficient will and available resources to invest in building supervisory capacity to enforce the regulations. Poor people's money may otherwise be put at risk. ${ }^{3}$

CAPACITY DEVELOPMENT FOR RURAL FINANCE FOR AGRICULTURE. Bank investment in financing for agriculture has long since moved away from channeling production credit through subsidized public-sector agricultural banks. It now recognizes the importance of building sustain- able financial institutions that can provide longer-term access to financial services in rural areas. Funds for on-lending are of little beneficial use if the financial institution receiving them lacks the ability to use them effectively. Key areas for capacity building include:

- Investment in information systems that provide timely and accurate data to management.

- Training for staff, management, and board members.

- Strengthening internal controls and external monitoring, and improving the transparency and quality of external reporting.

- Assistance in product design and marketing of a range of financial services.

- One-off grants to support innovations (for example, introducing new technology, or a new loan product), or expansion into more marginalized rural areas.

- Building on existing infrastructure (such as post offices, state banks, retail stores, traders) to provide a range of financial services at low cost and at scale.

At present substantial Bank and donor funds lie unused in apexes (second-tier wholesale funds), intended for on-lending by agricultural and microfinance providers. For example, the Social Development Fund in Yemen had only 40 percent of its fund assets (US\$5 million) allocated to MFI investments. ${ }^{4}$ The absorptive capacity for apex funds is therefore limited by the size and expansion capacity of existing providers of financing for agriculture. Funds should only be committed to apexes if: a) sufficient absorption capacity exists for using

3. To enable rural financial service providers to take deposits from the general public, there may be a case for prudential regulation that is aimed at protecting the soundness of the financial system as well as depositors. Given its high cost, care should be taken to avoid using prudential regulation for nonprudential purposes (that is, the formation and creation of MFIs, preventing fraud and financial crimes). The introduction of new regulations often sets off unintended consequences (such as renewed enforcement of interest rate ceilings), and the costs of new regulation and its supervision have to be justified by a critical mass of qualifying institutions. 4. A more efficient apex is the Rural Finance Corporation of Moldova, which claims to have 100 percent of its fund assets (US\$4.8 million) committed to MFI investments (MixMarket). 
the apex funds effectively, and/or b) simultaneous investment in developing institutional capacity of existing providers is carried out. Well designed capacity-building support requires involvement of a financial sector specialist, and need not be limited to direct providers of financial services - there are many other institutions that can play a vital role, from credit bureaus and industry associations to rural producer organizations, community self-help groups, agribusiness development centers, and local nongovernmental organizations (NGOs). Without this capacity-building investment the scale of provision of financing for agriculture will remain limited.

INNOVATION-NEW PRODUCT DEVELOPMENT AND DELIVERY MECHANISMS. Improving the outreach and performance of rural finance for agriculture requires innovations and new or adapted financial products to overcome the challenges presented by agricultural activities and environments. Applying products and approaches that work in urban settings or for nonfarm activities has only worked for those agricultural activities that have a similar income and risk profile to nonagricultural activities, such as egg production or greenhouse-based vegetable production. Rural finance for agriculture needs to match seasonal income cycles and term investment needs, manage risks, mobilize savings, develop lower cost operations, and cope with deficiencies in client information availability.

Diversification of loan portfolios over time and economic sectors, and product diversification toward savings, insurance, and leasing, can be effective risk management strategies. Savingsbased approaches offer particular promise in more remote rural areas. New and promising products that help address the challenges posed by financing agricultural activities merit support for piloting. Innovation involves risktaking on the part of the provider, and there is a legitimate role for donors to support innovation, and provide the resources to scale-up successful innovation for wider application. To improve the viability of rural financial services and lower their cost to clients, flexible delivery mechanisms are needed. Instead of investing in expensive branch networks, financial services could instead be made available through existing delivery outlets, such as an agricultural development bank, a rural post office, retail stores, or rented offices in schools and hospitals. If other financial institutions are present, branch facilities could be shared to lower operating costs. Mobile and automatic teller machine (ATM)-based delivery mechanisms are being piloted by several rural finance institutions, and show significant potential for lowering the costs of providing rural financial service.

CAPITALIZING ON EXISTING INSTITUTIONS AND INFRASTRUCTURE. If existing infrastructure and institutions are already in place, these may be utilized where appropriate to improve financial services. There are advantages and cost savings from working through institutions that are already established in rural areas, though the choice of institution must be carefully considered. There are potentially significant benefits (and risks) of using established branch networks and client bases provided this is combined with extensive reform of bank systems and management. Where the institutional commitment is lacking, or the costs of reforming and building the capacity of existing institutions or rehabilitating infrastructure is too great, starting from scratch may be the preferred option. Membership-based financial organizations can build the capacity of existing community organizations, including, where appropriate, linking these to the formal financial sector. ${ }^{5}$ In some circumstances, financial services may be best provided by organizations falling outside the traditional definition of a financial institution. For example, there is considerable potential for extending and improving sources of production credit for farmers by input suppliers, processors, and buyers. ${ }^{6}$

\footnotetext{
5. See the AlN, "Membership-Based Financial Organizations"

6. See the AIN, "Production Credit from Input Suppliers, Processors and Buyers"
} 


\section{SCALING-UP INVESTMENTS}

The emphasis of donor or government monitoring of finance providers for agriculture should be on institutional performance and progress in institutional capacity, instead of on activities and outputs. Experience has shown that investment in rural financial service providers produces superior results if program design, reporting, and monitoring focus on areas that are considered key for performance. Performance can be defined as the extent and efficiency with which they reach their target group. This is best measured jointly as outreach and sustainability. Outreach is a measure of the scale and depth of penetration of a rural financial service provider to its target group, and sustainability is the ability of an institution to survive over the long term. Sustainability has ownership, governance, and management components, and financial dimensions (see box 7.7).

Tranched funding can be an effective means of enforcing performance targets, with the disbursement of subsequent tranches dependent on the achievement of minimum performance

\section{Box 7.7 Minimum reporting indicators}

All project phases (project appraisal, design, monitoring and reporting during implementation, final evaluation) should use appropriate measures of outreach and sustainability. Such indicators should include:

- Number of clients that are being served (measured by active clients or accounts).

- Client poverty level (through average outstanding loan or savings balance, as a percentage of GDP/capita). ${ }^{2}$

- Performance in loan collection (for example, portfolio at risk beyond a stated number of days).

- Efficiency (operating and/or lending costs as a percentage of the loan portfolio or assets).

- Financial sustainability (use return on assets and/or return on equity. For subsidized institutions, financial self-sufficiency, adjusted return on assets, and/or the subsidy dependency index can all be used to quantify the subsidy that is required/invested for a certain project outcome).

Sources: World Bank, forthcoming; CGAP 2003.

2. This indicator may be less relevant for projects that promote financial services to larger agribusinesses. thresholds or targets. A business plan agreed to by the financial institution can provide key performance targets, and can also be used as the basis for designing institution-building assistance. Capacity building of project implementers, as well as the financial service providers, can also be included within projects if appropriate.

The World Bank is in a strong position to influence borrowing governments and other donors, and can take a lead in the quality and effectiveness of scaling-up financing for agriculture through the following practical actions:

- Incorporating financial expertise into the project team (whether through an in-house specialist or an outside consultant) for rural finance for agriculture projects, or projects that include a component of finance to farmers or agriculture-dependent households.

- Considering rural finance for agriculture projects and components as falling under a wider financial systems approach, and not simply as a contribution to a narrow agriculture sector goal.

- Requiring financial service institutions to follow internationally accepted accounting standards and to practice full disclosure. Where indicators specific to microfinance are used, then standard definitions should be applied (CGAP 2003). External audits and ratings of rural finance for agriculture providers should be required as standard for more formal financial institutions. A professional appraisal of all financial institutions that onlend bank loan funds should be encouraged. For smaller and less formal communityowned organizations, this may be too expensive and other forms of reporting and monitoring should then be used, consistent with full disclosure and accepted indicators.

\section{SELECTED READINGS}

Asterisk (*) at the end of a reference indicates that it is available on the Web. See the Appendix for a full list of Web sites. 
CGAP. 2001. "Disclosure Guidelines for Financial Reporting by Microfinance Institutions." CGAP, Washington, D.C.*

FAO. Forthcoming. Term Finance in Agriculture: A Review of Relevant Experiences. FAO/World Bank Cooperative Program. Place: Publisher.

Fleisig, H. W., and N. de la Peña. 2003. "Legal and Regulatory Requirements for Effective Rural Financial Markets." Paper presented at Paving the Way Forward for Rural Finance: An International Conference on Best Practices, sponsored by USAID and hosted by BASIS CRSP partner, World Council of Credit Unions, June 2-4, Washington, D.C.*

Hollinger, F. 2003. "Financing Term Investments in Agriculture: A Review of International Experiences." Paper presented at Paving the Way Forward for Rural Finance: An International Conference on Best Practices, sponsored by USAID and hosted by BASIS CRSP partner, World Council of Credit Unions, June 2-4, Washington, D.C.*

Yaron, J., M. P. Benjamin, and G. L. Piprek. 1997. Rural Finance: Issues, Design, and Best Practices. ESSD Studies and Monographs Series 14. Washington, D.C.: World Bank.*

\section{REFERENCES CITED}

CGAP. 2002. "Water, Water Everywhere, But Not a Drop to Drink." CGAP Donor Brief 3. CGAP, Washington, D.C.

CGAP. 2003. "Microfinance Consensus Guidelines: Definitions of Selected Financial Terms, Ratios, and Adjustments for Microfinance." CGAP and the World Bank Group, Washington, D.C.

FAO. Forthcoming. Term Finance in Agriculture: A Review of Relevant Experiences. FAO/World Bank Cooperative Program. Place: Publisher.
Fleisig, H., and N. de la Peña. 2003. "Legal and Regulatory Requirements for Effective Rural Financial Markets." Paper presented at Paving the Way Forward for Rural Finance: An International Conference on Best Practices, sponsored by USAID and hosted by BASIS CRSP partner, World Council of Credit Unions, June 2-4, Washington, D.C.

IADB. 2001. "Rural Finance Strategy." Sustainable Development Department Sector Strategy and Policy Papers Series. IADB, Washington, D.C.

MixMarket. http://www.mixmarket.org/en/ home_page.asp.

World Bank. Forthcoming. Rural Finance Services: Implementing the Bank's Strategy to Reach the Rural Poor. Rural Private Sector, Markets, Finance and Infrastructure Thematic Group. Place: Publisher.

World Bank. Operational Manual. http:// wbln0018.worldbank.org/institutional/ manuals/opmanual.nsf/.

Yaron, J., M. P. Benjamin, and G. L. Piprek. 1997. Rural Finance: Issues, Design, and Best Practices. ESSD Studies and Monographs Series 14. Washington, D.C.: World Bank.

This Overview was written by Douglas Pearce (CGAP), Andrew Goodland, and Annabel Muelder, with researcher support from Amitabh Brar (CGAP). Peer reviewer comments were provided by Cornelis van der Meer, Carlos Cuevas, Honnae Kim, Renate Kloeppinger-Todd, William Steel, Jock Anderson, and Katrine Saito. 
AGRICULTURE INVESTMENT NOTE

\section{MICROFINANCE INSTITUTIONS MOVING INTO RURAL FINANCE FOR AGRICULTURE}

Microfinance institutions (MFIs) have tended to avoid less densely populated or diversified rural areas, and financing of seasonal or longerterm crop and livestock activities. However, a few innovative MFIs have recently led the way in adapting their operations and products to expand into agricultural lending. Techniques used have included tailoring procedures and products to agricultural seasonal needs, applying risk management techniques, and adopting new technologies. Successful MFIs have important strengths, such as financial sustainability, excellent portfolio quality, financial products that fit diverse client needs, and a clear commitment and orientation to the poor. Prudent risk management techniques can increase the outreach of MFIs to less affluent, more remote rural areas and more diversified farmers.

Rural financial services have benefited significantly from treating the rural household as a unit with diverse activities and sources of income and financing, instead of maintaining a narrow focus on agricultural credit. However, financing for agriculture still tends to fall outside the scope of the mainstream microfinance industry. Where rural microfinance providers do exist, they are mostly limited to diversified rural economies and to clients with a number of income sources. Rural areas that are not densely populated, or that are dependent on a few principal crop and livestock activities, tend to be avoided by MFIs, because of higher transaction costs, price and yield risks, seasonality, and collateral limitations in the agricultural sector. Conventional microcredit relies heavily on short-term loans with frequent, regular repayments, which does not fit well with seasonal crop production or livestock production (except for poultry).

\section{INVOLVEMENT OF MICROFINANCE INSTITUTIONS}

Public investments can help microfinance providers meet the challenges of financing for agriculture. These require adaptations to conventional financial products and delivery mechanisms, including the following:

MATCHING DISBURSEMENT AND REPAYMENT TO AGRICULTURAL PRODUCTION CYCLES. Flexibility in loan disbursement and repayment is needed, with finance made available when farmers need it and repayments matching income from produce sales. PRODEM, a rural MFI in Bolivia, redesigned its lending products by using market research to understand the financial service demands of agricultural clients (see box 7.8).

Several other leading MFIs have also adapted their lending methodology to fit agricultural activities. For example, the agricultural loans product of Calpiá, an El Salvadorian MFI, have been successful largely as a result of their flexibility on timing, amount disbursed, and repayment schedules. With regular bimonthly, trimester, semester, annual or even end-of-cropcycle and irregular payment options, repayment schedules are sufficiently flexible to be attractive to a range of agricultural activities. Calpiá's agricultural lending product still treats the farm household as a financial unit, basing lending decisions on overall repayment capacity.

FleXIBILITY IN COLLATERAL REQUIREMENTS. Land may hold little value as collateral, as land-use rights may be difficult to prove, clients may not own land, land markets may be weak, or cost of registering land as collateral may be high. Financial service providers therefore need to be more flexible in terms of the collateral required, even if the value of nonmortgage guarantees is sometimes more significant as a repayment incentive than its real resale value. Personal guarantees, movable assets, and group guarantees can all be adequate alternatives. Because it is time consuming and more expensive to get the notarization required for a mortgage guarantee, Centenary Rural Development Bank (CERUDEB) in Uganda 
also accepts livestock, personal guarantors, land without a title, household items, and business equipment. Since women may be disadvantaged by traditions of registering property in the husband's name, women tend to rely more heavily on their human capital for accessing loans (shown by women's greater participation in solidarity groups).

Using TeCHNOLOGY. Technological innovations can increase operational efficiency and lower costs of operating in rural areas, while improving financial services available to rural clients. ATMs, point-of-sale machines, and smart/debit cards provide flexible payment options and more convenient access to client accounts. They can also reduce branch infrastructure and employee costs. A major advantage of their use in rural areas with poor infrastructure and communications is that financial transactions can be conducted entirely offline with all account information stored in the chip.

Personal digital assistants (PDAs) can streamline loan officer activities and speed decisionmaking. The value of fast, in-the-field decisions can be enhanced by incorporating credit scoring into palm pilots or hand-held computers. However, this requires well-developed client information systems. ADEMI in the Dominican Republic has developed a credit scoring system linked to laptops and PDAs, and estimates that it will substantially reduce loan disbursement time in rural areas.

However, while the potential offered by new technologies is significant, experience has been mixed. There has been a tendency to overestimate the short-term benefits and underestimate the up-front implementation costs. In India, the Swayam Krishi Sangam's experiment combines smart cards with hand-held computers to streamline meetings between clients and borrowers in remote areas. However, this did not produce the dramatic time savings expected, and expansion of the project has been put on hold. ${ }^{7}$

\section{See the IAP,"India: Piloting of Smart Cards in Rural Areas"}

FleXIBLE Delivery meChanisms. Making use of existing delivery outlets, rather than investing in expensive new branch networks, can significantly lower the cost of providing financial services, and can also allow a wider range of services to be provided. This also holds potential for rural women whose opportunity cost of engaging in financial transactions, due to time constraints, not only involves lost income but also internal household substitutions (for example, child labor for female labor).

Options include: working with/through rural post offices, retail stores, rented offices in schools and hospitals, or shared offices with other financial institutions. Mobile staff can help reduce operating costs and improve access in more remote areas. For example, Constanta, an MFI in Georgia, uses temporary "service points" (typically rented rooms in a bank branch) coordinated by nearby branch offices, and linked to mobile loan officers. In Latvia, the Agricultural Finance Company used mobile credit officers to overcome transportation problems faced by farmers. This mobility also enabled loan officers to visit clients frequently and encourage loan repayment.
Box 7.8 Bolivia: PRODEM-using market research to adapt lending methodology

PRODEM is one of the largest providers of rural financial services in Bolivia. It conducted donor-supported market research and product development to adapt its range of financial products to suit client needs, including the financing needs of small farmers. A customized repayment scheme was introduced for small farmers, with differing repayment schedules even for members within a solidarity group to fit harvest calendars. Individual agricultural loans were also introduced, with collateral at a ratio of $1.5:$ I to the loan amount. PRODEM further minimizes risk by restricting final loan payments to a maximum of 60 percent of the loan amount, and by limiting each office's portfolio in each economic sector to 30 percent. Money transfer, microleasing, and savings products were also designed. Agricultural lending now accounts for about one-fifth of PRODEM's loan portfolio.

Sources: Lee 2000; Rubio 2003, Internal report prepared for CGAP. 
RISK MANAGEMENT TECHNIQUES. A principal factor discouraging MFI lending to small farmers is the systemic risk inherent in much smallholder agriculture. Most MFIs that have successfully moved into agricultural lending have used a diversification strategy to reduce lending risk, both in their portfolio and at the household level.

Portfolio diversification helps ensure that a loan portfolio be diversified across sectors and regions/communities, and that repayments do not fall due at the same time. This increases the stability of the portfolio and reduces lending risk from weather events and from price fluctuations in certain crops. Confianza, a Peruvian MFI, which developed from a purely agricultural portfolio, has now set a target percentage for agricultural lending of 30 percent of its overall portfolio. Uganda's CERUDEB, which reached out to rural areas from an urban base, set its upper limit at 25 percent. Household diversification is also important, as many of those MFIs that have developed a stable agricultural lending portfolio minimize risk by excluding households that are reliant on only one or perhaps two crops and have no off-farm income. Other risk management techniques include:

- Limiting the length of loans to agricultural smallholders. However, this can result in a lack of term finance important to agriculture, for such investments as tree crops, erosion control, some livestock activities, and equipment and machinery.

- Testing a new rural market before investing in a branch office. This reduces the risks involved in expanding rural finance outreach. Calpiá reduces the risk of establishing new rural branches by first building the portfolio from neighboring branches and conducting market studies of a new region. Rural branches are set up only if the portfolio size merits the investment in infrastructure and human capital.

- Purchasing hedging instruments on international markets helps to manage potential losses from price or weather risk, and allows greater confidence in moving into agricultural lending. However, this can be expensive and is still to be tested for MFIs.

\section{BENEFITS}

Increased MFI activity in more difficult rural areas and in financing agriculture, results in increased competition, higher volumes of finance, and a wider range of financial services available to farmers and their households. The rapid growth of the agriculture portfolio of MFIs such as Bolivia's PRODEM and Caja los Andes, and El Salvador's Calpiá, suggests that there was significant unmet demand for financing for agriculture.

MFIs can offer credit not just for agriculture but also for nonfarm, household, and emergency needs, as well as savings and transfer payment services (if they are appropriately licensed). Increased competition between financial service providers operating in rural areas (such as product-market credit providers, moneylenders, credit unions) can lead to more favorable and transparent terms of access for the poor. Good practice MFIs can also bring a commitment to efficiency, transparency in reporting, high portfolio quality, and sustainability.

\section{POLICY AND IMPLEMENTATION ISSUES}

Policy ENVIRONMENT. Expansion by sustainable microfinance providers into financing for agriculture will ultimately be limited by underlying constraints arising from poor infrastructure, high-risk or low-return agriculture, deficient client information, poorly functioning property registries and markets, and policy biases/distortions. Improving the enabling environment for rural finance remains an urgent priority.

SERVICES FOR THE POOR. Even those MFIs that have successfully expanded into financing for agriculture have mostly been limited to farmers with diversified household incomes in less-remote areas. Portfolio diversification is a widely used 
risk management strategy. Although effective, it has a clear drawback, from a poverty reduction and market development perspective, of limiting access for poorer farmers from marginal rural areas. Other institutional models also have this problem, although less formal membershipbased financial organizations may have a greater tolerance for operating in these areas, given their responsiveness to their members, and also their relatively low cost.

Term finance. Term finance is more costly and risky than short-term finance, since it ties up larger amounts of money for longer periods, and requires the mobilization of long-term funding. It requires more careful screening and selection of borrowers, increasing transaction costs. Term finance is best provided by competent financial institutions within a well-developed rural financial system, as increased attention is needed to maintain a good lender-borrower relationship over time, and techniques are needed to manage increased lending risks. BAAC in Thailand, a large state-owned bank and one of the largest MFIs in the world, reportedly has over half of its outstanding loans (which total US\$5.6 billion) with terms over one year. BAAC uses donor and government funding and term deposits to supplement its commercial borrowings to match its liabilityasset structure. Longer-term donor funding can potentially address the funding constraint for term loans, but not the higher risk involved.

Liquidity MANagemENT. Disbursements in several installments over a cropping period, repayments at harvest, and a lean time characterized by repeated requirements for cash, all present a liquidity management challenge to providers. An institution's cash flow can therefore become more cyclical, with suboptimal asset productivity. To improve the productivity of staff and assets, and to improve liquidity management, alternative financial products can be developed, such as nonseasonal loans for household needs and deposit facilities. However, in communities that are highly dependent on a few agricultural activities, the demand for these products will also be seasonal. Transfer payments from urban areas or from abroad do not follow the same seasonal patterns, and can smooth demand for loans and facilitate repayment in periods of low agricultural income, as can savings deposits.

\section{LESSONS LEARNED}

Principal lessons learned for supporting MFIs to move into agricultural finance are:

- Flexible disbursement and repayment schedules are key to successful agricultural lending, although they may increase default risk and present liquidity management challenges.

- Diversification at the portfolio and client household levels can reduce the risk for MFIs of expanding into financing agriculture. However, it can also restrict access to financial services for farm households dependent on agriculture. Nonfinancial interventions to improve market access and infrastructure may make these clients more attractive in the longer term.

- Technology can help lower costs and expand rural finance operations, but a careful costbenefit analysis should first be conducted, and the MFI's management information system (MIS) may first need to be upgraded.

\section{RECOMMENDATIONS FOR PRACTITIONERS}

Recommendations for practitioners involved in MFI related investments include (see box 7.9):

- Plan feasibility studies, piloting, and market research to reduce risks of moving into financing for agriculture and enhance usefulness of financial services to farmers.

- Assess the impact on the financial institution itself (for example on cash flow, loan repayment, and staff productivity) of adapting loans to fit agricultural cycles.

- Focus on other financial services as well as credit, as access to remittance monies and 
Box 7.9 Potential investments

- Funding for product design (savings facilities and transfer payments, and not just loans), including funds for market and client research, piloting new products and staff orientation.

- Support for replicating proven approaches (PRODEM or Calpiá) with other MFls.

- Funding for piloting adoption of technologies (ATMs, palm pilots, and smart cards ) and/or the use of flexible delivery mechanisms (postal offices, retail stores, and schools).

- Feasibility studies to assist MFls in making decisions on introduction of new technology.

- Management information systems and equipment for their effective operation.

- Investment in a positive enabling environment to enhance the viability of rural finance for agriculture, through developing infrastructure, legal systems, and communications.

- Research and piloting of innovative sources of collateral for the agricultural sector, to allow economically active poor who are landless or asset-poor, to qualify for loans.

- Nonfinancial support to farmers, through business development services, infrastructure improvements and other means, to bring clients up to a level where they are creditworthy.

Source: Authors.

deposit services can help clients (and MFIs) smooth seasonal income flows.

- Expansion costs (for example, setting-up new rural branches) may merit funding support, but more cost-effective alternatives, such as sharing facilities with other financial or nonfinancial entities (post office, stores), should be explored first.

\section{SELECTED READINGS}

Asterisk (*) at the end of a reference indicates that it is available on the Web. See the Appendix for a full list of Web sites.

Campion, A., and S. S. Halpern. 2001. "Automating Microfinance: Experience from Latin America, Asia and Africa." Occasional Paper 5. MicroFinance Network, Washington, D.C.

Navajas, S., and C. Gonzalez-Vega. 2000. "Innovative Approaches to Rural Lending:
Financiera Calpía in El Salvador." Economics and Sociology Occasional Paper 2571. Ohio State University, Columbus, Ohio.*

Yaron, J., M. P. Benjamin, and G. L. Piprek. 1997. Rural Finance: Issues, Design, and Best Practices. ESSD Studies and Monographs Series 14. Washington, D.C.: World Bank.*

\section{REFERENCES CITED}

Lee, N. 2000. "Client Based Market Research: The Case of PRODEM." Calmeadow, Ontario; Pact Publications, Washington, D.C.

This Note was written by Douglas Pearce (CGAP), Andrew Goodland, and Annabel Mulder with researcher support from Amitabh Brar (CGAP). 


\section{AGRICULTURE INVESTMENT NOTE}

\section{FINANCIAL SERVICES THROUGH STATE BANKS}

Networks of state banks or recently privatized state banks with extensive rural branch networks offer a mechanism for introducing lowcost financial services at scale, as these are frequently the only multiservice financial institutions that have extensive networks in rural branches. Technical assistance to improve management and training can help these institutions fill the gap in financial services for farmers and their households. However, such support is only recommended where both the state bank management and government owners (if any) are committed to allowing sufficient space for good practice financial services to be introduced. Given the long history of directed credit and undue political influence, unqualified support to state banks is not advisable. Also, where privatization is the goal, there is a danger that new owners will change the focus of the bank away from serving poorer agricultural clients.

Financial institutions with large rural branch networks offer the potential for low-cost access to a range of financial services. State-owned banks that may have extensive rural networks of branches or outlets include agricultural development banks, regional development banks, savings banks, and postal banks. Privatized state banks may also have significant rural outreach, and this Note is also relevant to those that do. In many cases, however, the privatization process has resulted in reduced rural branch coverage.

\section{PROVIDING FINANCIAL SERVICES}

Specialized MFIs have tended to avoid clients that depend on agriculture, or live in geographically remote areas. This is due primarily to the risks involved with agricultural lending and the cost of maintaining service points in sparsely populated rural areas characterized by cyclical demand. Moreover, nonbank financial institutions, such as NGOs and credit unions, are more limited in the range of financial services they can provide. Therefore, they may not be able to supplement income from lending with income from transfer payment and deposit services.

Offering diverse financial services through existing banking infrastructure has greater potential for viability if the branch network runs efficiently and at low cost. There is an increasing number of examples of financial services being offered successfully to rural populations through state banks, taking advantage of existing branches, assets, established customer base, existing transfer and remittance services, operating systems, and banking licenses to lower initial and subsequent costs. The shortcomings of state banks are well known, however, and their vulnerability to political influence, associated with a tendency toward subsidized and/or directed credit, ${ }^{8}$ has rightly made working with such banks unattractive for the World Bank and most donor agencies. This Note does not advocate a return to either unqualified support to state banks, or lines of credit through state banks. What it does explore are ways to build on, or take advantage of, their infrastructure, services, and systems to extend a range of viable, demanddriven and low-cost financial services to agriculture-dependent populations and agribusinesses.

There are three main options for engaging with such banks: i) a management-led turnaround of the bank, ii) the creation of a specialized unit that utilizes bank branches and systems, and iii) linkages with other financial service providers. The first is the most ambitious, as it implies a complete reform of the bank. The second does not address the weaknesses of the overall

8. The World Bank's OP and Bank Procedure (BP) 8.30 on Financial Intermediary Lending do not permit directed lines of credit and interest rate subsidies. 
bank, but rather attempts to set up a subsidiary or department with sufficient operational independence to implement good practice micro or rural finance through the existing rural branch infrastructure. The third option makes use of state banks without needing to work through them directly.

MANAGEMENT-LED BANK TURNAROUnd. Management contracts supplemented by technical assistance produced the recent impressive performance turnarounds of two state banks: the Agricultural Bank of Mongolia (AgBank), and the National Microfinance Bank (NMB) of Tanzania (see box 7.10). The respective governments used United States Agency for International Development (USAID) (in the case of Mongolia) and World

Box 7.10 The Agricultural Bank of Mongolia and The National Microfinance Bank of Tanzania

The Agricultural Bank of Mongolia (AgBank) was formed in 199I out of the breakup of the State Bank of Mongolia, and by 1999, after several failed reform attempts, was in receivership. A US consulting firm was contracted in 2000 to improve the viability of its existing rural branch network of 275 service points. AgBank has dramatically improved its profitability through management reform, and introduction of new products. AgBank invested in market research leading to product development and then product marketing to encourage client uptake of services. New loan and deposit products breathed life into previously underutilized branches. After losses of more than US\$4 million in 1999, AgBank attained profitability in January $200 \mathrm{I}$. Although lending activity in many rural branches is at a relatively low level, operating costs are correspondingly low. AgBank was privatized in early 2003 for US\$6.8 million.

The National Microfinance Bank (NMB) of Tanzania with its rural branch network of 100 points of service was created in 1997 in a spin-off of assets of the state-owned National Bank of Commerce. The government contracted a US consulting firm to place an external management team in the bank. Public confidence in the bank grew, as did deposit levels. New microloan products were researched and designed to develop a lending business, and the loan portfolio grew from zero to over US\$4 million, with more than 10,000 loans (average loan size of US\$400), including microenterprise and consumer loans. The number of branches has increased to I I 5 (43 of which offer loans), and performance has improved notably. NMB is now one of the most profitable banks in the country.

Source: Dressen, Dyer, and Northrip 2001.
Bank (in Tanzania) funding to contract a US consulting firm to provide management and technical assistance over a period of at least two years.

These contracts sought to make the bank financially sound; add new financial services tailored to previously neglected yet attractive market segments, such as the poor and low income groups; and prepare the bank to operate independently. The contracts included the cost of temporary foreign senior management, intensive technical assistance, systems and infrastructure improvements, and new product development and marketing to diversify financial services and improve branch viability.

SPECIALIZED MICRO OR RURAL FINANCE UNIT. Creation of a specialized financial service department or subsidiary within a state bank structure can help insulate the bank from political influence and provide freedom to operate along lines of internationally accepted good practice. The success of the local microfinance units (unit desas), state-owned Bank Rakyat in Indonesia, the world's largest sustainable microfinance provider, illustrates the potential of autonomous units within a state bank structure. CrediAmigo, an autonomous microfinance unit set up by Banco do Nordeste, a regional Brazilian development bank, is a more recent example (see box 7.11).

LINKAGES WITH OTHER FINANCIAL SERVICES PROVIDERS. Arrangements that allow specialized financial service providers to take advantage of infrastructure, staff, and systems of state, savings, and postal banks can improve access to diverse financial services for agriculturally dependent populations. An agreement with a postal savings bank, for example, may allow a financial institution to provide money transfer services to their customers. Microfinance NGOs that are not allowed to offer deposit services may be able to negotiate access to savings schemes for clients through state banks. For example, the Senegalese Postal Savings Bank began offering deposit services to client groups of microfinance NGOs in 1995. Small rural credit unions can also 
benefit from state banks by having a safe place to store their excess funds. Donors may support such linkages by providing funding for harmonizing systems and procedures, management information systems, improving transfer payment systems, technical assistance for microfinance product design, and training for staff involved in the linkage arrangements.

\section{BENEFITS}

Improving the quality, efficiency, and range of financial services on offer through rural branches of state banks serves the diverse financial needs of rural populations at scale. Moreover, adding new financial products to an existing network and product range can be cheaper than investing in and maintaining specialized infrastructure, and can therefore allow for lower cost financial services to the end users.

A full management-led turnaround of a state bank is the most ambitious and costly of the approaches presented in this Note, and can appear expensive. The management contract for AgBank in Mongolia was almost US\$3 million. Other donors such as Deutsche Gesselschaft fur Technische Zusammenarbeit (GTZ) also provided at least US\$2 million in direct technical assistance and training. This appears more reasonable when compared with either the eventual privatization proceeds (US\$6.8 million), or AgBank's loan portfolio (US $\$ 25$ million). For Tanzania's NMB this simple cost-benefit comparison is less favorable, with an overall contract of US\$7 million and a smaller portfolio (US\$4 million), but a wide array of deposit products are offered and over 21,000 loans have been disbursed. Moreover, both banks have been turned around from being cash drains to a profitable status. In the case of Brazil's Banco do Nordeste, less than US $\$ 1.4$ million in grant-based technical assistance helped produce a sustainable program with over 100,000 active clients.

\section{POLICY AND IMPLEMENTATION ISSUES}

CREDIT FOR AGRICULTURE. There is no guarantee that small farmers will be able to access finan-

\section{Box 7.I I Brazil: Banco do Nordeste}

In 1995, a new president of Banco do Nordeste implemented a reform of the bank and contacted the World Bank about developing a microfinance program. The bank had 176 branches throughout the northeast region, and was willing to adopt good microfinance practices (interest rates that fully cover costs, and a commitment to high levels of loan recovery) and invest in the training, information, and operating systems needed for microfinance. Preparation and rollout took several years, but the results achieved have been impressive. With over 100,000 active clients and an outstanding loan portfolio of more than US\$24 million, CrediAmigo, an autonomous microfinance unit in the Bank, is now one of Latin America's largest microfinance providers.

During a pilot stage, Banco do Nordeste secured high quality international expertise (through a leading microfinance $\mathrm{NGO}$ ) and learned from microfinance in other countries through management study tours. After CrediAmigo was initiated as a pilot in five branches, the Bank arranged a US\$900,000 Japanese government grant to fund systems development and further technical assistance. Once the Bank decided that Banco do Nordeste was ready to scale-up safely and effectively, a US\$50 million World Bank loan to support expansion was finalized in 2000 .

Source: Schonberger and Christen 2001.

cial products designed for agricultural activities. Neither CrediAmigo nor NMB have yet moved into agricultural lending on any scale. Banks need to take rational decisions as to the relative risk and return from agricultural lending compared to other financial services, and should not be forced into directed agricultural lending. An important first step is to ensure that the bank has the management capacity, systems, procedures, and product development skills to expand into product areas such as agricultural lending. Parallel initiatives to improve the policy and operating environment for rural finance for agriculture and the risk profile of agricultural activities can improve the perceived attractiveness of financing agriculture. BAAC, a reformed agricultural development bank in Thailand, illustrates the potential of state banks in agriculture, as over 90 percent of the loans to its 5 million borrowers are for agricultural activities.

Privatization. If privatization is an eventual goal for a state bank under a management turn- 
around contract, ongoing support beyond the length of that contract might be necessary to ensure that improved performance continues over the longer term. Achieving profitability is an important first step, as commercial owners are unlikely to close profit-making product lines and branches. Mongolia's AgBank will be a test case of the management turnaround approach, and whether the vision of improving branch viability rather than simply closing branches is continued. The same U.S. consulting firm that had helped turn the bank around to profitability has been given an ongoing management contract by the new owners, which is a positive indication of intent.

\section{LESSONS LEARNED}

The following are critical conditions for success in working with state banks through either a management-led turnaround or a specialized unit/department. Where these do not exist, the alternative of facilitating interinstitutional linkage arrangements should be considered, with contractual arrangements designed to hold the state bank to minimum relevant standards of good practice.
COMMITMENT TO GOOD PRACTICE FINANCIAL SERVICES. The government, board, and management of the state bank must agree to introduction of sound financial service practices and refrain from exerting political influence on bank decisions. Good practice includes: strict loan repayment, separate staff incentive and monitoring systems, full cost interest rates, and appropriate reporting and portfolio management practices. The case of BAAC illustrates the danger of not having a clear separation from government influence (see box 7.12).

Demand FOR NEW FinANCIAL SERVICES. Since there is little competition from other financial service providers offering deposit and transfer payment services in rural areas, lack of demand is unlikely to be a constraint, except perhaps in remote underpopulated areas.

Commitment to long-Term engagement. Donors, as well as state banks and government must take a long term view of reforms. In Banco do Nordeste's CrediAmigo program, an initial pilot provided important lessons for subsequent scaling-up, and a World Bank loan was not approved until almost five years after initial contacts were made.

\section{RECOMMENDATIONS FOR PRACTITIONERS}

- Only consider working with state banks if there is sufficient long-term protection from government influence. The BAAC example illustrates the risk of political decisions influencing Bank policies.

- Be prepared for substantial technical assistance and systems investment. Funding will likely be needed to update systems, improve procedures, improve external public image, enhance customer service, and train staff. Such investment is critical to success and should not be seen as optional. If suitable funding is not available, the less ambitious linkage option should be considered (see box 7.13). 
- Proceed ambitiously but cautiously. Banco do Nordeste decided to scale-up the CrediAmigo pilot program too early and too fast, expanding from five branches to 50 , and to 100,000 clients within the first year of operation. The resulting heavy loan losses led to a temporary slowdown in expansion and an intensive loan recovery program.

- Support development and introduction of new financial products. Market research linked to product design and piloting can result in products that better suit the diverse financial needs of rural clients, that are appropriately priced, and that lead to increased client uptake and branch transaction volumes.

\section{SELECTED READINGS}

Asterisk (*) at the end of a reference indicates that it is available on the Web. See the Appendix for a full list of Web sites.

Dressen, R., J. Dyer, and Z. Northrip. 2001. "Turning Around State-Owned Banks in Underserved Markets." Small Enterprise Development 13 (4): 58-67.

Grashof, L. 2002. "Country Case Study: Agricultural Bank of Mongolia." GTZ, Eschborn, Germany.*

Kamewe H. T., and I. A. Radcliffe. 2000. "Reviving Postal Savings Banks in East Africa." United Nations Development Programme, New York.*

\section{REFERENCES CITED}

Dressen, R., J. Dyer, and Z. Northrip. 2001. "Turning Around State-Owned Banks in Underserved Markets." Small Enterprise Development 13 (4): 58-67.

Schonberger, S. N., and R. P. Christen. 2001. "A Multilateral Donor Triumphs over Disbursement Pressure: The Story of Microfinance at Banco do Nordeste in Brazil." CGAP Focus Note 23. CGAP, Washington, D.C.

\section{Box 7.13 Potential investments}

- New senior management to reform the bank.

- Technical assistance to introduce new lending instruments and systems.

- Infrastructure improvements.

- New product development and marketing.

- Funding to improve and harmonize systems, procedures, and reporting.

- Training and orientation for staff and management of the institutions.

Source: Authors.

World Bank. Operational Manual. http:// wbln0018.worldbank.org/institutional/ manuals/opmanual.nsf/.

This Note was written by Douglas Pearce (CGAP), with extensive reference to those documents and authors cited in the "References Cited' section. 
AGRICULTURE INVESTMENT NOTE

\section{PRODUCTION CREDIT FROM INPUT SUPPLIERS, PROCESSORS, AND BUYERS}

Private firms such as input suppliers and product buyers and processors supply a sizable portion of farmer credit needs. The provision of credit fits naturally in established business relationships, facilitated by good mutual knowledge, while collateral constraints are limited by linking credit with nonfinancial services. This Note highlights the largely unexploited potential of supporting these arrangements by improving the development of producer associations, brokering contractual linkages between farmers and private businesses, and developing linkages with specialized financial institutions. However, support in this area must proceed with caution due to limited project experience and thus limited knowledge about good practice. The risks of moral hazard are high especially where contract enforcement is weak. There are also dangers of distorting input and output markets.

Agricultural commodity systems in developing countries are frequently characterized by financial transactions that provide market participants an important source of financial services in the absence of, or in addition to, institutional sources. ${ }^{9}$ Although these financial transactions are largely independent of government and donor support and influence, and fall outside the formal financial sector, they are often vital to farmers for accessing inputs and bridging periods of low income prior to harvests. Usually on the basis of securing access to the farmers' produce, processors or buyers provide inputs on credit (usually in kind), often supplemented with technical advice to ensure quality standards are met, and guaranteeing a market for the farmers' produce. The repayment of the credit (and interest, if charged) is deducted when the farmer sells the produce.

Because these trading arrangements fall outside formal financial system regulation, farmers are vulnerable and the true cost of credit is difficult to ascertain. Smaller and more marginal farmers are particularly at risk as they often have limited access to market information, low bargaining power, and weak business relationships with credit providers. However, successful models have evolved that create clear winwin outcomes for farmers and private credit providers. These have included smaller farmers often through producer groups (see box 7.14). Government and donors can increase the outreach of production credit from input suppliers, processors, and buyers by: developing producer associations that enable small and marginal farmers to engage with agribusinesses; facilitating market brokerage between farmers and agribusiness; and supporting linkages with financial institutions to improve the efficiency and transparency of credit.

DEVELOPMENT OF PRODUCER ASSOCIATIONS FOR SMALLER AND MORE MARGINAL FARMERS. Producer associations or groups can link small farmers into market systems and to credit sources (see box 7.15). Producer associations address the following constraints for processors and other buyers in dealing with small farmers:

- Lowering transaction costs resulting from having to distribute inputs to, collect crops from, and monitor and keep records on many scattered, individual farmers.

- Mitigating unacceptable levels of lending risk resulting from high levels of sideselling (to buyers other than those that provided the inputs). This situation is exacerbated by inadequate contract en-

9. In El Salvador, for example, almost one-half of the rural people who access credit from sources other than family and friends do so from private sector suppliers rather than microfinance institutions or banks (Buchenau and Hidalgo 2002). Four out of every five rice mills surveyed by FAO in India provide advance payments for inputs to farmers, accounting for about one-half of the total value of the crop (Shepherd 2003). In Zimbabwe the number of smallholders receiving input loans from the Cotton Company of Zimbabwe exceeds the total number of clients of formal microfinance institutions in the country (Gordon and Goodland 2000). 
Box 7.14 Cotton Company of Zimbabwe

In 1996, loan proceeds under the World Bank Agricultural Credit and Export Promotion Project were reallocated to establish a credit scheme by the Cotton Company of Zimbabwe (Cottco) to provide inputs to small farmers. Credit is extended to farmer groups with joint liability, and services (including extension advice) are provided by the company.

Since its inception, the scheme has consistently reached over 50,000 smallholders each season, with repayment rates in excess of 98 percent. The scheme has assisted farmers to obtain increased yields and higher grades, with average smallholder yields increasing to 900 kilograms per hectare, compared to the national average of 700 kilograms per hectare. The scheme has captured the loyalty of producers, but competitors complain of the competitive advantage provided to Cottco by concessional financing from the Government. As of 2003, there is only one other competitor in the sector and Cottco has an 80 percent market share.

Source: Gordon and Goodland 2000; Poulton et al.

forcement, but can be addressed by establishing joint group liability.

- Increasing the efficiency of providing technical support services needed to increase the quality and quantity of production that meet buyer requirements.

BROKERING MARKET LINKAgES. The starting point for any credit-based relationship between product market participants is the development of a business relationship. This can take some time and cost to foster, and requires initial networks or contacts, thus excluding many smaller and more marginal farmers. There is a legitimate role for a third party to broker such business relationships to reduce initial transaction costs, and there have been successful experiences in doing so using local NGOs (such as FAIDA, Tanzania) ministries of agriculture (such as the Department of Agrarian Reform, the Philippines), or parastatal agribusiness development centers (for example ZATAC, Zambia) (see box 7.16). The scope of these "broker" technical assistance activities has included: the formation and capacity building of producer groups; market matching - introducing farmers to potential business partners (agro-processors); and, facilitating the negotiation of contracts between farmers and business partners.

LINKAGE ARRANGEMENTS WITH FINANCIAL INSTITUTIONS. Financial institutions specialize in providing financial services, whereas traders and processors usually lack the expertise and systems to
Box 7.15 Mozambique: producer associations linked to processors and exporters

V\&M Grain Company is a leading domestic agribusiness company in Mozambique. V\&M offers interest-free advances to small and large traders, as well as to umbrella groups of producer associations. An overall repayment rate of 98 percent is reported. Advances to producer associations are based on 50 percent of the value of crops at an agreed price, with no other collateral arrangements, and are provided for up to 20 days. The umbrella groups use a portion of the advance to transport their collected produce to a warehouse, and the rest is distributed downwards to producer associations who further distribute them to their producer members. Loans average between US\$ 5,000-10,000. Approximately 10 percent of overall value of trade is reportedly lost in side-sales, where the advance is taken from V\&M but goods are sold to someone else.

Source: de Vletter 2003, Internal report prepared for CGAP

\section{Box 7.16 Tanzania: FAIDA}

In a typical FAIDA market linkage scheme, farmers receive inputs (seeds, fertilizers), extension services, and a small loan from a company, while being assured they can sell their produce to the same firm. To minimize costs, the distribution of inputs, delivery of extension services, and the collection of output are organized through farmer groups. The facilitator from FAIDA assists groups of farmers to organize themselves. Normally farmers open a group savings account, which serves as collateral for the inputs and the loans from the company. FAIDA can assist the company to access additional credit sources to finance the scheme, thereby ensuring that the collaboration is fair to both parties and results in a clear "winwin" situation.

Source: FAIDA 
do this effectively. By unbundling credit from input supply transactions, credit products can be made more transparent and efficient, with explicit interest rates and terms, thus allowing for competition and farmer choice to improve credit product design. Financial institutions can provide credit to farmers either directly in monetary form, or through input suppliers in kind. Risk, information, and operating cost constraints remain for financial institutions entering agricultural lending. Financial institutions benefit from maintaining links to processors, traders, and other market system actors, that lower their costs and risks by ensuring that their farmer clients have a sales outlet, access to inputs, and appropriate product and technical advice (see box 7.17). However, unbundling credit from the sale of farm produce can result in traders or processors losing an important mechanism for securing supply. Before intervening in this area, donors need to be aware of the economic and social contexts in which informal transactions have evolved.

\section{BENEFITS}

In post-liberalized economies, with state withdrawal from input supply and marketing of outputs, facilitating production credit from private sources benefits various stakeholders:

- Small-scale and marginal farmers increase their access to domestic and international markets and to private input suppliers.

\section{Box 7.I7 Peru: linkage arrangements}

Critecnia is a firm that works with small cotton farmers in Peru. The farmers sign a management contract with Critecnia, which buys and markets their produce, and provides inputs relatively cheaply. Prior to Critecnia's involvement, poor repayment by farmers was endemic, and financial institutions were wary of financing farmers. Critecnia now negotiates loans on behalf of the farmers, with the farmers providing land guarantees. Critecnia subtracts loan payments and fees for technical assistance and management at point of sale, and then splits net profits equally with farmers. Critecnia is reportedly profitable, with high repayment rates in most years.

Source:Wenner 2001
- Smallholder farm productivity is increased through the improved access to inputs, often supported by privately provided extension (as an "embedded" market service).

- Agribusiness development is stimulated through the secured access to raw materials and greater influence over production processes (quality and food safety are important for access to international markets).

\section{POLICY AND IMPLEMENTATION ISSUES}

AvoIDING MARKET DISTORTIONs. A central dilemma for the World Bank and donors is how to support the extension and development of financial services to small farmers, without distorting already-functioning product market systems. Providing financial support to specific companies to enable them to establish or extend credit can be beneficial to smallholders in the short term, but it may give the chosen company a market advantage and hurt competition.

CHOICE OF IMPLementation PARTNER. The choice of approach, and the selection of implementation partners by a borrowing government, will depend on local circumstances and in particular the capacity of local institutions. Evidence of commitment to servicing the smallholder sector is an important prerequisite.

Market AND FinANCial SYSTEM DEVELOPMENT. The suitability of producer credit will depend partly on the level of market development and financial systems development. Where these are strong, it may be preferable to support the provision of producer credit through financial institutions, even though credit through private market participants may persist, in competition with financial institutions, to secure access to farmers' produce. Before supporting these approaches, it is also necessary that market development be at a sufficient level for inputs and outputs to be freely traded, and that financial systems can provide funds to processors and buyers to on-lend to producers. 


\section{LESSONS LEARNED}

Producer credit schemes can be successful even where contract enforcement systems are weak, though this requires overcoming the challenge of default - often associated with side-selling. The most successful producer credit schemes have used a combination of mechanisms to reduce default, including group liability, incentives for developing strong business relationships (such as the provision of further services), close monitoring, and rewards for prompt repayment.

The choice of crop is also important. As a general rule, suitable crops are nonfood cash crops (cotton, tobacco) and high-value horticultural crops. Common characteristics are: crops that require high levels of inputs and/or technical knowledge that farmers would find difficult to access in the absence of input credit schemes; lack of alternative markets; and crops requiring specialized postharvest activities (packaging, processing, export), often with specific fixed investment asset (milling plants).

Working with partners to develop linkages between financial and nonfinancial actors, and to promote producer associations, requires substantial technical assistance and capacitybuilding investments. Other donors may in some cases be better placed than the Bank to provide this support, although the Bank could provide complementary support to improve the operating environment for rural finance institutions and for agribusiness.

\section{RECOMMENDATIONS FOR PRACTITIONERS}

Despite the potential for reaching many producers through this type of producer credit, donors and governments must proceed with caution to avoid introducing market distortions and disrupting existing informal financial services. Interventions and investments should be based on (see box 7.18):

- An analysis of marketing systems and an assessment of the competence and commitment of the private sector to engage in

\section{Box 7.18 Potential investments}

Direct public (and donor) investment needs are limited because market-provided production credit is delivered through private firms and individuals. However, public investment can provide:

- Support for development and strengthening of producer organizations.

- Capacity building for institutions providing a brokering role for business relationships between small farmers (and producer groups) and agribusinesses.

- Market facilitation and information.

- Training and technical assistance on marketing and credit program management.

- An environment for the emergence of strong agricultural markets.

Source: Authors.

production credit, as an important first step to understanding options.

- Focused support to groups of farmers and/ or geographical areas that are not presently well integrated into product markets, thus helping develop/extend markets.

- Designing any subsidies (grant, technical assistance, training) to build capacity, not to subsidize costs or price of services or loans provided to farmers, and with a plan for eventual reduction and phase-out over time.

- Making support available through transparent selection criteria, with access open to more than one partner (be it a financial institution, NGO, or processor), and with ongoing access to support dependent on achieving agreed performance targets.

\section{SELECTED READINGS}

Asterisk (*) at the end of a reference indicates that it is available on the Web. See the Appendix for a full list of Web sites.

Dorward, A., Kydd, J. \& Poulton, C., eds. 1998. Smallbolder Cash Crop Production under Market Liberalisation: A New Institutional 
Economics Perspective. Oxon and New York: CAB International.

Eaton, C., and A. Shepherd. 2001. "Contract Farming: Partnerships for Growth: A Guide." FAO Agricultural Services Bulletin 145. FAO, Rome.*

FAIDA. http://www.faida.or.tz.

Pearce, D. 2003. "Buyer and Supplier Credit to Farmers: Do Donors have a Role to Play?" Paper presented at Paving the Way Forward for Rural Finance: An International Conference on Best Practices, sponsored by USAID and hosted by BASIS CRSP partner, World Council of Credit Unions, June 2-4, Washington, D.C.*

Phillips, R., and A. Serrano. 2000. "Case Study: Developing Self-Managed Outgrower Capacity in Zambia and Mozambique." Paper presented at Rural Capacity Building and Poverty Reduction Workshop, sponsored by the World Bank's AKIS thematic group, June 28-30, Washington, D.C.*

\section{REFERENCES CITED}

Buchenau, J., and A. Hidalgo. 2002. "Servicios Financieros Privados en el Area Rural de América Latina: Situación y Perspectivas." Banco Interamericano de Desarrollo Departamento de Desarrollo Sostenible, Fortaleza, Brazil.

FAIDA. http://www.faida.or.tz.

Gordon, A., and A. Goodland. 2000. "Production Credit for African Small-holders: Conditions for Private Provision." Savings and Development, no. 1:55-84.

Poulton, C., J. Kydd, A. Osorio, D. Tschirley, W. Maro, M. Nylandsted Larsen, B. Zulu, B. Hanyani-Mlambo. Competition and Coordination in Cotton Market Systems in Southern and Eastern Africa. Imperial College of Science, Technology and Medicine. Agrar- ian Development - Research Projects. http:/ /www.wye.ic.ac.uk/AgEcon/ADU/research/ projects/cottonE/.

Shepherd, A. 2003. "Financing of Agricultural Marketing - Case Studies from Asia." FAO, Rome.

Wenner M. 2001. "Making Rural Finance Work." Microenterprise Development Review 3 (2): 1-4. IADB, Washington, D.C.

This Note was written by Andrew Goodland and Douglas Pearce (CGAP). 


\section{AGRICULTURE INVESTMENT NOTE}

\section{MEMBERSHIP-BASED FINANCIAL ORGANIZATIONS}

Support to membership-based financial organizations, including relatively formal credit unions, savings and credit cooperatives, and less formal community-based savings and loan associations, has had mixed results. In some cases sustainable institutions have resulted, successfully reducing transaction costs and collateral constraints. In others, donor support has created dependence, and failed to address problems of weak governance, poor internal control, and capture by elites. This note sets out lessons learned and good practice in supporting membership-based organizations that provide rural financial services for agriculture. Support to such organizations is recommended where rural financial markets are underdeveloped, but social, geographic, and economic conditions create a comparative advantage for this low-cost approach.

Membership-Based Financial Organizations (MBFOs) are important long-term sources of financial services in rural areas. Credit unions and savings and loan cooperatives are the leading sources of financial services to the poor in Latin America and in Central and Eastern Europe, and are present worldwide. However, the performance of MBFOs has varied greatly, with problems arising from weak governance, poor internal control, donor dependence, and-for those institutions focused on agriculture-covariant risks.

The term membership-based organization refers to a range of organizations that are memberowned and controlled, with membership defined either geographically (a community) or by activity (farmer cooperatives). More formal membership-based institutions include Savings and Loans Cooperatives and Credit Unions, while village-based Savings and Loan Associations can be much more informal. The degree of formality depends on factors such as scale, resources, level of systems development, financial product range, management capacity, and level of legal recognition. This Note covers only those institutions with a primary focus on financial service provision, not multiservice organizations with nonfinancial aims. ${ }^{10}$

Less formal MBFOs are low cost, relying on primary low-level institutional systems and infrastructure, and local, often volunteer, staff. They can therefore operate in less-favored rural areas that are unreached or underserved by banks and formal MFIs. Their ability to access local information on potential borrowers lowers transaction costs associated with screening and monitoring. Their membership-based nature can provide useful peer pressure in enforcing loan contracts. However, they often suffer from weak internal controls and monitoring, and may be susceptible to deterioration in portfolio quality, capture by well-educated/influential persons, and even fraud. Some MBFOs are run for the benefit of a few members, who monopolize access to loans, or alternatively give loans to members as a "right," with loan amounts simply multiples of member savings or shares. More formal MBFOs, such as savings and loans cooperatives registered with financial institution supervisory authorities, are more protected from these weaknesses, but have higher cost structures, and are less suited to more marginal rural areas.

Support to MBFOs can be directed at four levels: the retail level, the wholesale or secondtier level, support institutions, and the policy and operating environment. All levels may need to be addressed, although not necessarily in a single project:

- Retail level. Capacity building and technical assistance for MBFOs may need to focus on: loan analysis techniques, delinquency

10. This Note does not discuss community-based organizations that engage in financial services as their secondary or tertiary activity, such as churches, welfare, and development associations, or purely informal associations such as ROSCAs and CARE's Village Savings and Loan Model. These approaches will be discussed in a forthcoming Micro and Rural Finance Operational Note. 
control, product pricing, loan loss provisioning, sufficiency of institutional capital, maintenance of adequate reserves, and proper asset/liability management. If financial product ranges are too narrow, product development may be necessary-for example designing loan products for crop production, or deposit services for agricultural traders.

- Wholesale or second-tier level. Capacity building can strengthen or create federations or networks that provide services to better enable members: to negotiate funds from banks or donors; to represent member interests at regional and national levels; to develop common procedures and products; to improve the marketing/branding of the organization; to monitor performance; and to provide a refinancing facility to meet short-term liquidity needs of the members. The SICREDI system in Brazil, for example, depends on a well functioning second-tier structure (see box 7.19).

- Support institutions. Investment is needed to strengthen or create low-cost service

\section{Box 7.19 Brazil: agriculturally oriented rural credit unions -} SICREDI

SICREDI is a savings and loan cooperative/credit union model that serves the needs of small farmers and their households, and that has the following characteristics: savings-first, membership based on a common bond, member ownership, and equal voting rights. SICREDI is now the largest savings-based, member-owned credit union system in Brazil, with membership based on agricultural communities. As of December 2002, SICREDI had US\$5 I 8 million in savings, and outstanding loans of US\$315 million.

SICREDI is composed of 767 agencies joined in 129 Credit Unions, which are audited and refinanced by the National Development Bank. The SICREDI Council develops policies and product, and provides training services. Factors in the success of the SICREDI system include: use of consistent lending practices, system-level management of liquidity risk, and system-wide commitment to uniform standards. To use the SICREDI name and logo, credit unions must pass financial and product quality standards and meet specified policy criteria.

Source: Brian Branch, personal communication; DGRV. providers in such areas as bookkeeping, technical assistance, external audits, or product design. Since technical assistance needs extend beyond the lifetime of most donor interventions, providers that can charge MBFOs fees for their services are more sustainable than continued reliance on subsidies.

- Policy and operating environment. Work with government and other stakeholders to improve the policy framework and operating environment for MBFOs may involve legal reform, removal of interest rate caps, and investment in infrastructure and services.

\section{BENEFITS}

MBFOs can operate effectively in situations and with clients that banks view as unattractive, because they are primarily concerned with providing access to financial services for their members, not maximizing profits. Less formal MBFOs, such as Savings and Credit Associations, are particularly well suited to remoter and poorer rural areas, due to the reliance on (often voluntary or part time) local staff and management, a narrow product range, group and personal guarantees, and client information provided by the community. Investment in community-based MBFOs can contribute to local empowerment. Local ownership also ensures the social and cultural sustainability of the organization.

MBFOs can be more responsive to member needs than other financial institutions. Some have designed loan products to fit agricultural activities or offered financial products tailored to member needs (see box 7.20). They can base product design on agricultural cycles, convenience of payments, and financial needs of different farming activities. However, to do this, the MBFOs need a basic level of product design expertise and systems to cope with more complex financial products. Technical assistance can be valuable in this regard, as long as the product range is kept consistent with staff and systems capacity. 


\section{POLICY AND IMPLEMENTATION ISSUES}

MEMBER OWNERSHIP. MBFOs depend on members exercising influence over the management of their institutions to reduce delinquency and risk of fraud. However, the fact that voting rights are distributed equally among members can weaken the monitoring function, and make institutions vulnerable to dominant chairpersons and management.

DePENDENCY. Donors must be careful not to create dependency. A donor can undermine MBFOs by pushing them to grow too fast, or by providing too much external funding relative to internal member funds. One option is to limit any funding offered to an amount equal to the community's own contribution, particularly when financing a loan portfolio. Funds can be matched to levels of member savings plus share contributions. Some specialists recommend that no external funds be provided for on-lending.

STRENGTHENING VERSUS CREATING MBFOs. Where MBFOs do not exist, as in some former republics of the Soviet Union, they have been created from scratch. This has had mixed results, and is not recommended because it risks creating dependence on external support. For the governance structure of an MBFO to be effective, members must have and exercise ownership.

Prudential Regulation. Prudential regulation and supervision is important in helping ensure the safety of deposits made by the poor. The capacity of financial regulatory authorities to understand microfinance methodologies and effectively supervise MBFOs needs to be improved in tandem with regulatory reforms. However, MBFOs that operate with closed memberships, or at a small scale may well merit exemption from such regulation. The argument for this is especially strong where government lacks capacity to provide effective supervision. Second-tier entities may instead take on a monitoring and supervisory role of their members to ensure effective governance, transparent reporting,
Box 7.20 Mali: village-based savings and credit associations

Village-based savings and credit organizations (CVECAs) are prevalent in parts of West Africa, and survive even in remote areas. The Niono region of Mali has a network of CVECAs with over 9,000 active borrowers and savers. It is financially sustainable overall, with good reported portfolio quality. CVECAs are organized into a network, which borrows from an apex bank and on-lends money to the CVECAs. Loan funds are also generated from member savings. A fee-based auditing and training service provides ongoing support functions.

The highly decentralized structure of the network results in more efficient decisionmaking and lower operational costs each village decides its own interest rates and loan products. This helps to fit financial products to seasonal agricultural cycles. Costs are also kept low by collaborating with the village farmers association for client appraisals, loan guarantees, and repayments.

Source: Chao-Beroff 1999; Ouattara, González-Vega, and Graham 1999.

and protection against fraud. In Guatemala, for example, The Consultative Group to Assist the Poor (CGAP) recently funded the development of a rating agency to set standards for and provide transparency on, credit union performance.

OrganiZATIONAL SUSTAINABILITY. Organizations receiving funding should commit to a sustainability plan, with funding structured to ensure the plan is carried out (with tranches based on performance targets). Capacity building should be emphasized over funds for onlending, which can distort governance and negatively affect portfolio quality.

LENGTH OF SUPPORT. Institution-building processes often take longer and are more costly than originally envisioned. For example, the institution-building project in Mali took over 10 years before the CVECA system reached full technical and financial sustainability. The human and financial resources available within small rural communities limit management and governance capacity. Projects often require more supervision, support, and monitoring than initially assumed. Where community resources and capacity are severely limited (for example 
in remote communities or where economic activity is at a very low level) informal group models may be more appropriate. Institutions should not be pushed to grow more quickly than their capacity allows.

\section{LESSONS LEARNED}

Challenges remain for the Bank and donors to provide cost-effective support that does not create long-term dependency. Any subsidies provided should be tied to a time frame (that is, not permanent), linked to performance targets, and matched with member resources. Accounting at the level of the MBFO should be transparent and clearly identify any subsidies received. Any support to service providers and second tier structures should have service charges built in from the start, and low cost structures should be sought that can be sustainable at project termination.

Deposit mobilization is essential to MBFOs. A savings-first approach contributes to project ownership among members as well as to self-

\section{Box 7.21 Potential investments}

- Long-term, performance-based technical assistance focused on selected MBFOs.

- Monitoring mechanisms for MBFOs

- Capacity building to strengthen or create federations or networks.

- Development of policy and regulatory frameworks for MBFO operations and protection of depositors.

Source: Authors.

Box 7.22 Guatemala: institutional strengthening of savings and loan cooperatives

An approach of selecting and focusing efforts on those leading cooperatives/credit unions most open to change was developed and tested in Guatemala between 1987 and 1994. Rapid growth in outreach and financial performance of 20 selected credit unions resulted in increases in membership from 60,000 to 200,000 , loan portfolio from US\$I 3 million to US\$54.5 million, and deposits from US\$5 million to US\$59 million. Portfolio delinquency (portfolio at risk over 30 days) fell from 19 to 7 percent over the same period.

Source:Westley and Branch 2000. reliance and local autonomy. Effective governance and transparent monitoring and reporting systems are essential to protect against fraud and poor management of savings. Maintaining a balance of depositors to borrowers is important, in order to avoid borrowers putting the institution's deposits at risk.

When considering legal and supervisory reform (for example, prudential regulation of deposittaking institutions), caution is required regarding potential side effects of new legislation, the cost of supervision, and the capacity of the supervisory agency.

\section{RECOMMENDATIONS FOR PRACTITIONERS}

Recent successes in strengthening credit unions and savings and loan cooperatives indicate that a focus on the retail level, combined with addressing policy and legal issues, can be most effective. Investments should (see box 7.21):

- Offer technical assistance to those MBFOs that are most open to receiving it, rather than providing blanket assistance to all MBFOs. These MBFOs can provide a positive demonstration model to others (see box 7.22).

- Link technical assistance and financial support to performance criteria. Reporting and monitoring systems need to track performance against agreed indicators in key areas such as portfolio quality, efficiency, sustainability, and asset protection.

- Ensure strengthening MBFOs is the primary goal, not subsidizing second-tier federations. Increased MBFO capacity and resources should create more sustainable demand for such federations.

- Introduce regulation and supervision mechanisms for MBFOs that have grown beyond a small community base and represent a potential threat to the financial system or to large numbers of depositors. This may require capacity-building of the financial institution's supervisory agency. 
Interim supervision and monitoring by a second-tier structure can offer a level of protection to depositors.

\section{SELECTED READINGS}

Asterisk (*) at the end of a reference indicates that it is available on the Web. See the Appendix for a full list of Web sites.

CGAP. 2002. "Consensus Microfinance Policy Guidance: Regulation and Supervision." CGAP, Washington, D.C. *

Staschen, S. 2001. "Financial Technology of Small Farmer Co-operatives Ltd. (SFCLs): Products and Innovations." Working Paper 2. Rural Finance Nepal, Kathmandu.*

\section{REFERENCES CITED}

Chao-Beroff, R. 1999. "Self-Reliant Village Banks, Mali (Case Study)." CGAP, Eschborn, Germany.

DGRV. http://www.dgrv.org/publish/ article_60.html.

Ouattara, K., C. González-Vega, and D. H. Graham. 1999. "Village Banks, Caisses Villageoises, and Credit Unions: Lessons from Client-Owned Microfinance Organizations in West Africa." Economics and Sociology Occasional Paper No. 2523. USAID Best Practices Project. Bethesda, Md.

Westley, G. D., and B. Branch. 2000. "Safe Money: Building Effective Credit Unions in Latin America." IADB, Washington, D.C.

This Note was written by Douglas Pearce (CGAP), Annabel Mulder, and Andrew Goodland, with researcher support from Amitabh Brar (CGAP). 
INNOVATIVE ACTIVITY PROFILE

\section{VIETNAM: MOBILE BANKING FOR RURAL PEOPLE}

The Rural Finance Project was approved in 1996 with World Bank funding of US\$110 million. The project has supported several key components of the country assistance strategy including: 1) assisting in the transition to a market economy; 2) strengthening the rural finance system through finance to agriculture, small/medium sized enterprises (SMEs), and technical assistance; and 3) reducing poverty by promoting growth. Living conditions are to be improved by encouraging private sector investments, strengthening the banking system, and increasing access of the rural poor to financial services. The seven banks that participated in the project had to complete an institutional development program prior to being accredited into the program. The dominant bank within the project is a public bank. The project has supported several financing initiatives, reflecting the various challenges facing Vietnamese communities. One innovative feature of this rural finance project is its mobile banking operations. ${ }^{11}$

What's innovative? Mobile banking - trimming transaction costs of serving rural and remote areas.

\section{PROJECT OBJECTIVES AND DESCRIPTION}

Mobile banking provides banking services to remote and mountainous areas without bank branches, through the use of specially equipped vehicles. The project's institutional building component financed 159 vehicles at a cost of US\$22,000 each. These vehicles were distributed to bank branches to provide financial services including arranging loans, loan disbursement, collection of loan repayments, and deposit taking. Each vehicle carries three bank employees.

The mobile banking operation has been effective, with 315,000 rural people receiving financial services. Experience so far indicates that each month, on average, one mobile banking unit mobilizes about 2,000 deposit accounts (US\$1.2 million), releases about 1,900 loans (US\$1 million equivalent), and collects 1,400 loan repayments (US\$650,000 equivalent). The operation is profitable, generating a net monthly income before taxes of about US $\$ 1,000$, after deductions are made for provisions (reserve for defaulted loans), vehicle running costs and maintenance, cost of funds, and operating costs.

Given its financial viability, the public bank will maintain these operations. A follow-up project (Second Rural Finance Project) initiated in 2002 builds on the experiences and success of the earlier project. An additional 210 vehicles will be provided to several participating banks.

\section{BENEFITS AND IMPACTS}

By overcoming one of the key impediments to successful rural finance provision (high transaction costs) mobile banking can be a suitable delivery mechanism for remote areas. The main benefits are cost reduction and increased geographical coverage. In Vietnam impact studies of the mobile banking project have found that:

- It provided better financial services to people in remote areas by allowing access to formal banking services. Previous financing opportunities had been limited to informal moneylenders with extremely high interest rates.

- Borrowers served by the mobile offices managed to expand their businesses, and 99 percent of them had increased their income as a result of the project.

\section{LESSONS LEARNED AND ISSUES FOR WIDER APPLICABILITY}

Mobile banking can be considered an alternative to "fixed" delivery mechanisms (branches of financial intermediaries) in areas where it is not feasible to maintain a network of rural branches. The advantage of a mobile office

I I. Sources: "Sustainable Management of Agriculture and Natural Resource Management Case Study, Antalya." Rural Finance Project Implementation Completion Report (200I).World BankTaskTeam managers comments. 
(attached to a branch) is that it can visit remote rural areas for loan analysis, disbursement, and repayment depending on the needs of the area (for example, weekly, monthly). This results in greater geographical coverage achieved by one office and therefore a reduction in fixed costs. This successful project experience in Vietnam, and the continuing use of mobile banking by Vietnam's dominant rural bank, demonstrates that this operation is a cost-effective way of delivering rural finance.

The applicability of mobile banking to other countries and settings will depend on the cost effectiveness in new settings (transportation costs may vary according to road conditions and networks), as well as cultural and social compatibility. Although initial capital investment in mobile offices is substantial, these costs need to be seen in relation to those of establishing and maintaining a fixed delivery mechanism in these remote areas. Indeed, the cost effectiveness of mobile banking services in Vietnam proved to be much better than for the established branches in these remote areas.

The commitment of bank management to increase outreach and provide people in remote areas with access to financial services is seen as a key factor in the success of the project. Given that mobile banking operations require conducting monetary transactions away from the branch office, security is also an important issue. Consequently, a key precondition for successful mobile banking operations is low levels of crime in the countryside and the country as a whole, as well as a well-maintained system of law and order.

\section{PROJECT COUNTRY:VIETNAM \\ Project Name Rural Finance Project \\ Project ID P004847 \\ Project Cost US\$139.7 million \\ Dates FY 1997 - FY 2002 \\ Contact Point Arie Chupak, Task Team Leader The World Bank}


INNOVATIVE ACTIVITY PROFILE

\section{ZIMBABWE:AGENT PROGRAM}

Six million Zimbabweans live in smallholder farming areas, and agriculture accounts for 15 percent of GDP and 70 percent of employment. In the early 1990s the agricultural input distribution and marketing systems were reformed, reducing the role of the state in input distribution. Previously, marketing cooperatives set up by the state supplied up to 70 percent of agricultural input requirements to the smallholder sector. Reforms led to a withdrawal of state funding for marketing cooperatives and the subsequent collapse of the input supply system. Extension services were also cut back. The response from the private sector was weak: input manufacturers and distributors did not supply smallholder areas due to the low aggregate demand and high costs of dealing with small and dispersed communities. Rural traders were further hindered from stocking inputs due to the absence of rural finance markets and limited access to credit. This led to reduced access to inputs by smallholder farmers, and consequently a decline in smallholder agricultural productivity. ${ }^{12}$

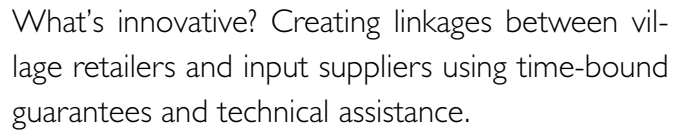

\section{PROJECT OBJECTIVES AND DESCRIPTION} The Zimbabwe AGENT program was initially piloted in 1995 with International Fund for Agricultural Development (IFAD) funding and the support of an international NGO. The objective was to increase access to inputs for smallholders by establishing a network of rural traders providing agricultural inputs. The program was targeted at local input suppliers ("agents"), typically small-scale village retailers.
Agents are identified through nominations from the communities themselves. The NGO provides training to selected agents on input handling, marketing, finance, and bookkeeping. The trained agents place input orders with the NGO, which negotiates prices and terms with input suppliers (seed houses, fertilizer manufacturers, intermediate technology providers). The NGO then consolidates the orders and arranges bulk purchases and delivery of the inputs. The NGO underwrites 75 percent of 30-60-day credits (up to US $\$ 2,000$ ) provided by input suppliers to the agents, who repay as they sell the inputs to farmers. Continual monitoring of stocks is carried out. After two years of good performance, agents graduate and deal directly with the suppliers with no further involvement from the NGO. The role played by the NGO is therefore in the initial identification of suitable agents, the provision of training, and the fostering of linkages between the agents and input suppliers through the provision of financial guarantees.

\section{BENEFITS AND IMPACTS}

The current performance of the program is encouraging. By late 2001, 580 agents had been trained with 60 percent of these having graduated and are now working in the private sector distribution network.

Several benefits accrue to smallholders. Inputs are now readily available and cheaper to purchase, due to lower transportation costs and bulk purchases made by the NGO. The increased variety of available inputs gives farmers a greater choice. And, farmers benefit from the agents' advice on the appropriate selection and use of inputs. Surveys show that the poorest farmers constitute the principal client group of the agents.

The program has not been restricted to recurrent input expenditures, but has also increased

12. CGAP,"Agricultural Microfinance Case Study: CARE Agent Program" (case study presented at the Rural Enterprise and Agribusiness Promotion workshop, CARE Canada, March II-13, 2002). 
access to intermediate production technologies, such as machines to make peanut butter, oil presses, small-scale irrigation equipment, and hand tools. This allows farmers to increase productivity and on-farm value-added.

Agents benefit through increasing their stocks and turnover and increasing incomes. Suppliers are able to access the smallholder market with relatively low initial risk-taking, and thereby increase sales and profits.

\section{LESSONS LEARNED AND ISSUES FOR WIDER APPLICABILITY}

The AGENT approach is successful because appropriate incentives are in place for all participants:

- The benefits to input suppliers and agents are clear, and create favorable conditions for developing strong business relationships. Requiring agents to pay their own training costs increases their commitment to the success of the program.

- The NGO input is strictly time-bound with a clear exit strategy, preventing complacency or dependence of the agents and/or the input suppliers on the NGO.

- The agents themselves monitor the program. They are given training and are required to maintain records of their customers. This enables the NGO to estimate better the level of outreach to target groups.

The scheme has already created considerable interest and demonstrated its potential. The model has been taken up by the largest manufacturer of fertilizers in Zimbabwe, which has launched its own input distribution.

Markets that operate in the absence of excessive government intervention are critical to the success of the scheme. For example, fixing the price of inputs can undermine the system. The Zimbabwe scheme has also come under pres- sure in recent years due to shortages of foreign exchange in the economy. This has hindered input suppliers' access to raw materials for manufacturing fertilizers.

Increasing the productivity of agriculture leads to higher farmer incomes where there are opportunities for marketing their produce. This implies a need for a strong private sector presence, and supportive infrastructure and public institutions.

\section{PROJECT COUNTRY: ZIMBABWE}

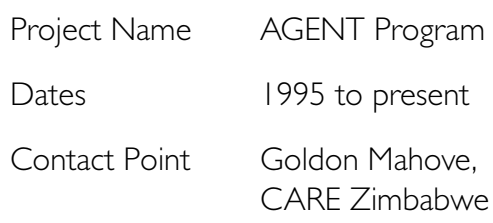


INNOVATIVE ACTIVITY PROFILE

\section{INDIA: PILOTING OF SMART CARDS IN RURAL AREAS}

Swayam Krishi Sangam Microfinance Pvt. Ltd. (SKS) was founded in June 1998 to serve very poor women in India's drought-prone Deccan region. Modeled on dominant South Asian group-lending models, it offers income-generating loans, seasonal loans, and savings products in a sparsely populated area. The main economic activities of SKS clients are agricultural, including horticulture and livestock rearing. The challenge was to deliver small loans to remote areas. As of October 2003, SKS had 23,277 clients and US\$2,108,695 outstanding. All its loans are below US $\$ 300$.

What's innovative? Using smart cards for financial control and improved efficiency in MFls.

Although SKS implemented many efficient MFI processes, it soon hit the so-called "efficiency wall" due to the small size of loans, high travel costs to reach remote villages, and time-consuming and error-prone manual entry systems. An analysis of its microfinance processes showed that the greatest potential to increase efficiency was to focus on the time between 7 and 9:30 in the morning, when borrower groups and loan officers usually met. Observation of the meetings showed that considerable time was spent recording data in customer passbooks. Furthermore, with all transactions recorded manually, there was scope for error and fraud. ${ }^{13}$

\section{PROJECT OBJECTIVES AND DESCRIPTION}

SKS has developed a smart card technology with US $\$ 125,000$ provided by CGAP's 2000 ProPoor Innovation Challenge Award, the Grameen Foundation-USA, and Digital Partners.
The smart card technology was piloted in the field in April 2001 and completed in May 2002. The pilot has had mixed results, and full implementation has been put on hold. However, important lessons can still be drawn.

Smart cards are the size of a credit card, and hold a microchip with personal client information. The major advantage is that financial transactions can be conducted entirely off line with all account information stored in the chip. At SKS the smart card technology works as follows: SKS officers are equipped with small hand-held computers, and clients with smart cards. Prior to the morning meetings, group information is downloaded from the MFI terminal. During the meeting transactions are saved on the computer and the smart card. The client smart card records all transactions he/she has maintained with the financial institution, while the loan officer uploads the day's transactions onto the main terminal upon arrival at the branch office.

\section{BENEFITS AND IMPACTS}

ENHANCED FINANCIAL CONTROLS. Strong financial controls are important to maintain trust with customers and investors. The smart card technology contributed by reducing fraud and error. Given that SKS loan officers manually record around 20,000 transactions per year there is great scope for error. With automated processes, pressing the wrong button or entering a wrong calculation becomes immediately apparent to the loan officer. A single data entry point has been key to reducing errors from manually entering data several times.

Time savings. It was expected that the smart card technology would translate into significant time savings leading to increased productivity and lower operational costs. The time saved from introducing this technology was not as significant as anticipated with regard to client meet-

13. A. Campion and S. S. Halpern, "Automating Microfinance: Experience from Latin America, Asia and Africa" (Occasional Paper 5, MicroFinance Network, Washington, D.C., 200 I); "Grameen Connections:The Newsletter of the Grameen Foundation" 4 (2); SKS Web site: http://www.sksindia.com;V.Akula and R. Bhatia, May 2002, "Summary Report of SKS Smart Card/Palm Project." 
ings. The meeting time was reduced by only 11 percent (rather than the anticipated 50 percent). It took 45 seconds to process each smart card, only marginally faster than manual recording. Furthermore, baseline studies conducted with inexperienced staff overstated meeting lengths, and therefore overestimated potential time savings from the new technology.

Time was also saved by uploading data into the central Management Information System (MIS), and reduced the burden on loan officers who previously had to enter data manually on their return from the field. This allowed management to access client information more quickly than before, and thereby improve monitoring.

\section{LESSONS LEARNED AND ISSUES FOR WIDER APPLICABILITY}

The experience of SKS shows that smart cards can potentially make a contribution toward enhancing financial controls and improving efficiency. For SKS, although benefits did materialize, especially in reducing the scope for error and fraud, efficiency gains from reducing processing time were smaller than anticipated, and the initial startup costs were high. However, as the state of such technology improves, processing time for smart cards is likely to decline, and the technology will become less expensive. Future smart cards will also have the potential to broaden the range of financial services available, including linking to ATM networks and credit from local merchants, and holding additional nonfinancial information, such as health information. Lessons to be drawn from the SKS experience include:

- New technology must be consistent with existing procedures and systems, and sufficient budget must be allocated to developing staff capacity for using the technology and to cover initial familiarization problems.

- Project appraisals should always be based on a baseline that allows for a realistic projection of benefits and costs of technology introduction.

- Technology introduction may take time, for example in SKS it required customization of the MIS, which took four months and increased operating costs.

For smart cards to operate efficiently, SKS had to limit product variety and repayment options initially. Although such restrictions on operational flexibility are common for MFIs that introduce new technologies, such limitations on operations have to be borne in mind.

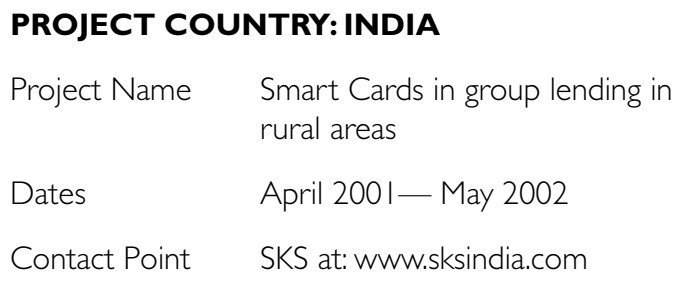


INNOVATIVE ACTIVITY PROFILE

\section{MADAGASCAR: MICROLEASING FOR AGRICULTURAL PRODUCTION}

The Caisses d'Epargne et de Credit Agricole Mutuels (CECAM) - an Agricultural Savings and Credit Union-was created in 1991 by a farmer organization with the technical assistance of a French NGO. The objective was to provide loan and savings services to agricultural households and farmer organizations. CECAM is a network of over 170 local banks and regional credit unions mainly based in less-favored rural regions, with over 52,000 members (largely farm households). By the end of 2002 CECAM had become the largest financial institution in rural Madagascar. It provides a range of financial services, including working capital loans, grain storage loans, and term loans. In addition to these loan products, CECAM provides innovative microleases for agricultural equipment. ${ }^{14}$

What's Innovative? Successful microleasing of agricultural equipment to farmers.

\section{PROJECT OBJECTIVES AND DESCRIPTION}

Recognizing the need for farmers in Madagascar to obtain capital assets, CECAM developed a microleasing product together with a French NGO in 1993. CECAM microleases are offered on capital equipment required for agriculture, equipment for rural craftspeople, and domestic equipment such as sewing machines and solar lighting units. The CECAM leasing product is unique because it is targeted specifically at rural people. Leaseholders are required to be network members and to put down 20 percent of equipment value at lease initiation, with the remaining 80 percent to be repaid with 30 percent interest rate over 10 to 36 months. The down payment must increase to 40 percent in the case of second-hand goods. Farmer groups at village level are involved in the screening of potential borrowers. Since there are few secondary income sources in the area, these are not used for lease qualification. Instead, the microlease is secured by the equipment rental and through a verbal commitment of the member's solidarity group. During the payment term, CECAM retains ownership of the equipment. After the final payment, ownership is legally transferred to the client.

The payment schedule for microlease loans is largely adapted to fit the client's production cycle. For example, for certain agricultural businesses, payments have been structured to meet the business cash flow, with as little as four payments due over the course of a year. By 2002 CECAM's outstanding portfolio in leasing was US\$1 million, or about 27 percent of the credit portfolio. The number of "leasing borrowers" was 2,564, corresponding to 8.9 percent of all borrowers and 5.5 percent of its members. The average leasing amount was US\$390 per leaseholder. Since 1993, CECAM has signed 23,000 lease contracts with 11,500 members. Repayment rate on all leases disbursed has been 95.8 percent. Key factors in the success of this project are its projectspecific product design, a large capital base, and the involvement of farmers in the management of the institution.

\section{BENEFITS AND IMPACTS}

There are essentially two outcomes to this type of lease agreement: either the lease is fully "met" and the client becomes the legal owner of the equipment, or the lease is terminated before the full value of the equipment has been paid. In this case the equipment remains legally

\footnotetext{
14. U.Andriantsivaliana and J.-H. Fraslin, "La Location Vente Mutualiste" (communication presented at the International Seminar Le financement de l'Agriculture familiale dans le contexte de libéralisation : Quelle contribution de la microfinance?, Dakar, Sénégal, 2002); J.-H. Fraslin, "CECAM: A Cooperative Agricultural Financial Institution Providing Credit Adapted to Farmers' Demand in Madagascar" (paper presented at Paving the Way Forward for Rural Finance: An International Conference on Best Practices, sponsored by USAID and hosted by BASIS CRSP partner, World Council of Credit Unions, Washington, D.C., 2003);A. Dowla and J. Herve, "Leasing: a New Option for Microfinance Institutions" (Technical Note 6, Weidemann Associates, Inc., Arlington, Virginia; Development Alternatives, Inc., Bethesda, Md., 2003).
} 
in the hands of CECAM. The following benefits from microleasing can be identified.

Benefits for the leaseholder include:

- Business strengthening. During the lease term, entrepreneurs with scarce resources benefit from using the equipment. The impacts are: more efficient or increased agricultural production; crop or livestock diversification; or involvement and valueadded in postharvest activities. It can also enable the diversification into secondary nonagricultural business. In all cases, the effects are that this strengthens the farmer's business and increases income.

- Asset-building. Since no collateral is needed (except for animals as dairy cows or draft oxen), this product is accessible by individuals who would not have sufficient collateral to qualify for an equivalent loan. If leaseholders can meet the lease term, they become the legal owner of the equipment. This builds the farmer's asset base and increases borrowing capacity for future lending transactions.

Benefits for the microfinance institution are:

- Limited transaction costs and risk. Risk of default is reduced by the MFI remaining the legal owner of the equipment - the collateral-until the lease is met. Transaction costs are lower than mid-term lending for agricultural equipment since lease transactions can be arranged quickly and simply.

\section{LESSONS LEARNED AND ISSUES FOR WIDER APPLICABILITY}

The key advantage compared to lending is that the leased equipment is usually sufficient to secure a lease transaction (but can be complemented with a pledge as in the case of CECAM), whereas lending usually involves the pledging of assets for collateral. The rapid growth of leasing in a number of countries suggests that leasing is addressing an unmet demand for financing. It appears that rural MFIs are equipped to enter this market.

Nevertheless, MFIs should be aware of the risks involved in microleasing. These depend in part on the life span of the asset and salvage value, which influence the cost of the lease. In addition, the up-front costs of leasing may have a negative impact on the MFI's liquidity and profitability. Finally, since there are many fixed costs in signing a lease agreement, these will weigh more heavily with microleasing (due to a higher cost per dollar leased) than with larger-scale leasing.

\section{PROJECT COUNTRY: MADAGASCAR}

$\begin{array}{ll}\text { Project Name } & \begin{array}{l}\text { Microleasing for agricultural } \\ \text { production }\end{array} \\ \text { Dates } & \text { 1993-2003 } \\ \text { Contact Point } & \text { CECAM, Madagascar or } \\ & \text { ICAR: icar@dts.mg }\end{array}$


INNOVATIVE ACTIVITY PROFILE

\section{GHANA: INVENTORY CREDIT FOR SMALL-SCALE FARMERS}

The contribution of warehouse receipt systems to developing agricultural markets is well known. In addition to providing a source of collateral and facilitating access to credit, warehouse receipts help to create standards for weights and measures, and develop grading systems. They also help increase awareness of quality issues, moderate seasonal price variability, and pave the way for the development of futures and derivative markets for managing price risks. However, the spread of warehouse receipts and inventory credit has been limited in those countries without trusted warehouse operators, with weak regulatory and supervisory capacity, and with heavy state intervention in markets. This is particularly the case for SubSaharan Africa, where postharvest price fluctuations are often large and benefits from storage are significant. Where inventory credit has been successful, it has generally excluded small-scale farmers due to high administrative costs and low produce volumes. ${ }^{15}$

What's innovative? Using warehouse receipt systems to provide inventory credit to small-scale farmers.

\section{PROJECT OBJECTIVES AND DESCRIPTION}

In 1989, an international technical service provider pioneered the use of inventory credit for small-scale farmers in Ghana for grain marketing, particularly maize. Given immediate cash needs, small-scale farmers often sell their produce shortly after harvest, when prices are at their lowest. Without adequate storage facilities and access to loan funds, they are unable to hold their crops for later sale during the "lean season," when prices are much higher. The goal of the project was to provide small-scale farmers with an opportunity to take advantage of these seasonal price swings.

The Ghana Inventory Credit Project works in the following way. Farmers form groups typically of 20-50 members to store their produce. The technical service provider operates the warehouse, and a lending institution provides credit based on the warehouse receipt. Upon arrival of the goods at the warehouse, the products are graded according to moisture content and nonproduct materials. The farmers then receive a receipt stating the quantity and quality of the goods deposited. Loans are given to groups on behalf of their members, which then disburse them individually. Once the grain is warehoused, the goods are the collective property of the group, which is jointly responsible for treatment, storage, and sale. Nevertheless, each farmer's account is tracked separately by the group. Throughout this process, the technical service provider gives market advice.

Initially, the credit amount was limited to 7080 percent of the stored grain's harvest value to limit the lender's risk, in case prices did not rise as anticipated. With increasing warehouse activity and competitors entering this market, the interseasonal price gap was narrowed. This resulted in the loan percentage declining to 40-50 percent due to the farmers decreasing debt capacity.

\section{BENEFITS AND IMPACTS}

By the late 1990s the scheme was assisting over 100 farmer groups with loans in excess of US $\$ 170,000$, and with nearly a 100 percent repayment rate. Based on the success of the program, the Agricultural Development Bank of Ghana has promoted large-scale commercial

\footnotetext{
15. J. P. Coulter, G. Kwadzo and S. Bakari, "Warehouse Receipts: Financing Agricultural Producers" (Technical Note 5, Weidemann Associates, Inc., Arlington, Virginia; Development Alternatives, Inc., Bethesda, Md., 2000); J. P. Coulter and G. E. Onumah,"The Role of Warehouse Receipt Systems in Enhanced Commodity Marketing and Rural Livelihoods in Africa" (Food Policy 27 (4): 319-338, August 2002); G. Kwadzo, "Inventory Credit:A Financial Product in Ghana" (presentation at the Advancing Microfinance in Rural West Africa conference, Bamako, Mali, February 22-25, 2000); Technoserve Ghana 2000, and Technoserve home page: http:// www.technoserve.org/africa/ghana-other.html\#Maize.
} 
inventory credit. The schemes have dramatically reduced interseasonal price fluctuations, benefiting those small-scale farmers with no choice but to sell immediately after harvest.

It therefore appears that inventory credit programs can offer farmers marketing and credit options that spur productivity and increase their incomes. Financial institutions benefit from decreased risks and from liquidity as a result of instant collateral to guarantee or reimburse defaulted loans. The farmers benefit from increased profitability due to the ability to delay sales, from improved price transparency, and from enhanced negotiating ability as a result of working in farmers' groups.

\section{LESSONS LEARNED AND ISSUES FOR WIDER APPLICABILITY}

While the project brought almost immediate significant benefits to small farmer groups, its major role has been to contribute to the increased efficiency of agricultural markets. As a result, inventory credit may be viewed more as a means to an end rather than an end in itself. As the markets have improved and inventory credit has spread, price fluctuations have decreased, such that the benefits of farmer inventory credit are diminished.

An inventory credit program is profitable only when the increase in the value of the stored goods exceeds the cost of storage and borrowed funds. This is difficult to achieve where price fluctuations are low and costs high due to small volumes and high administrative costs. This suggests that the model put forward by the technical service provider is best considered as a temporary intervention where markets are weakly developed, as reflected in high price fluctuations, and where obstacles to introducing inventory credit further up the marketing chain will take time to address.

For a model based on small-scale farmers to be sustainable, it is crucial to increase warehouse volumes, and thus reduce unit costs and increase system efficiency, for instance by expanding into other crops or attracting a wider clientele. The use of farmer groups can help to increase unit volumes and share monitoring costs.

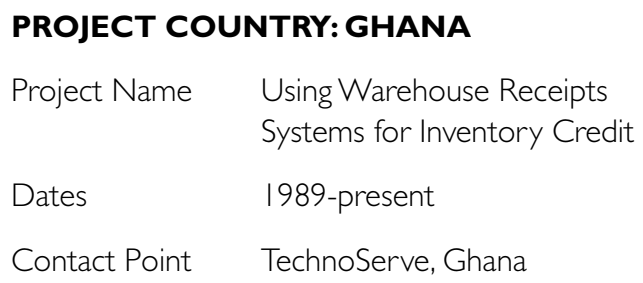





\section{(8)}

\section{INVESTMENTS IN IRRIGATION AND DRAINAGE}

rrigation and drainage systems have traditionally been the largest subsector for World Bank agricul tural lending, and remain important to improving agricultural productivity and reducing poverty in

many countries. However, the context for irrigation and drainage investments has changed, and irrigation systems are now seen to have complex interactions with other rural social and policy issues. Decision-makers must consider these broader issues in the design and implementation of multi-component irrigation and drainage projects.

\section{RATIONALE FOR INVESTMENT}

The World Bank's current rural strategy, Reaching the Rural Poor, recognizes that water is an essential input into agricultural production, as well as the basis for livelihoods of rural communities and the quality of natural resources. Efficient agricultural production for local and export markets will become increasingly important for economic growth and poverty reduction. Over the past 30 years, the world's net irrigated area has increased by almost 60 percent, from less than 170 million hectares in 1970 to over 
270 million hectares in 2000 (FAOSTAT 2002). In developing countries overall, agriculture accounts for more than 85 percent of water utilization (IWMI 2001). Globally irrigated agriculture represents only 17 percent of total land cropped, but provides 40 percent of the world's food. Meeting the food and fiber needs of the global population in the next 25-30 years requires that irrigated agricultural area be expanded by $15-20$ percent (Tiwari and Dinar 2002a).

Given the present land and water resource constraints and shortage of potential areas for new development, most production gains must come from better utilization of existing irrigated area. This is a great challenge as physical deterioration, outdated infrastructure, or inadequate institutional arrangements have resulted in the existing systems performing below expectation. While there has been some institutional reform, national and local irrigation organizations need modernizing and improved management, (both operational and maintenance). These issues are increasingly related to problems of financing.

New investment in irrigation must address issues of poverty reduction through a focus on appropriate smallholder technologies, reducing water scarcity and environmental quality problems and the adoption of efficient water management practices and technologies. Private sector investment in large-scale irrigation requires an investment climate providing security for investments. Such investments must seek income generation opportunities and improved environments for a broad group of beneficiaries including resource poor farmers and the nonfarm population.

The complexity and political sensitivity of water issues have important implications for irrigation and drainage investments particularly as these relate to water allocation and its use which are strongly tied to food security and poverty, the natural environment, regional income distribution and investment profitability. Water-related investments are typically viewed as risky ventures, especially if international borders are crossed. Such investments also incur relatively high transaction costs and must accommodate various safeguard policies.

\section{IMPACT}

In many regions, irrigated agriculture is the main source of rural employment, has higher productivity than rainfed agriculture, and reduces risks associated with climatic uncertainty. Investment in irrigation agriculture can benefit the poor if they are included in the design of projects; they participate in management of irrigation systems; and they are exposed to new economic opportunities through increased private sector investment in irrigation.

\section{PAST INVESTMENTS}

The Bank has lent approximately US $\$ 20.7$ billion for irrigation and drainage investments since 1980 with commitments differing widely among regions (see figure 8.1). Lending for the subsector has varied considerably, and decreased in recent years, dropping from US $\$ 1,040$ million per year during 1994-96 to US\$891 million per year in 1997-99, and US\$490 million per year from 2000-02 (see figure 8.2). This reduced level of funding still represents about 27 percent of the total allocation to the agriculture sector, and 10 percent of total rural lending. The number of projects remained stable from 1999 to 2001, but is roughly one-half of that of the 1980s and early 1990s. In addition to financing full-scale irrigation and drainage projects, an increasing amount of investment in irrigation and drainage is being provided as part of community-based development, natural resources management, and other projects.

The historically high level of investment in irrigation can be attributed primarily to the large potential gains from greater agricultural productivity, and the reduced weather-related risk to production. Opportunities for rewarding new investments are more difficult because of increasing costs, such as water extraction and distribution; new environmental and social costs not previously recognized in irrigation projects; a growing need for drainage investments; and falling commodity prices. 
FIGURE 8.I REGIONAL DISTRIBUTION OF ACTIVE IRRIGATION AND DRAINAGE LENDING, 200 I

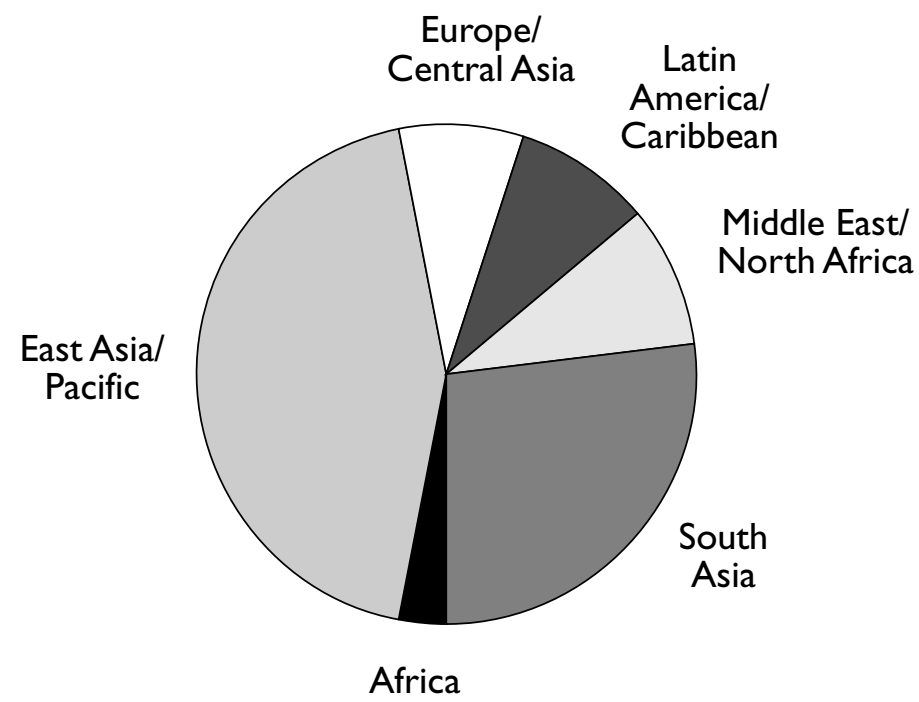

Source:World Bank Internal Documents

FIGURE 8.2 WORLD BANK INVESTMENTS IN IRRIGATION AND DRAINAGE, I979•2002 Commitment of U.S. Dollars
(millions of current dollars)

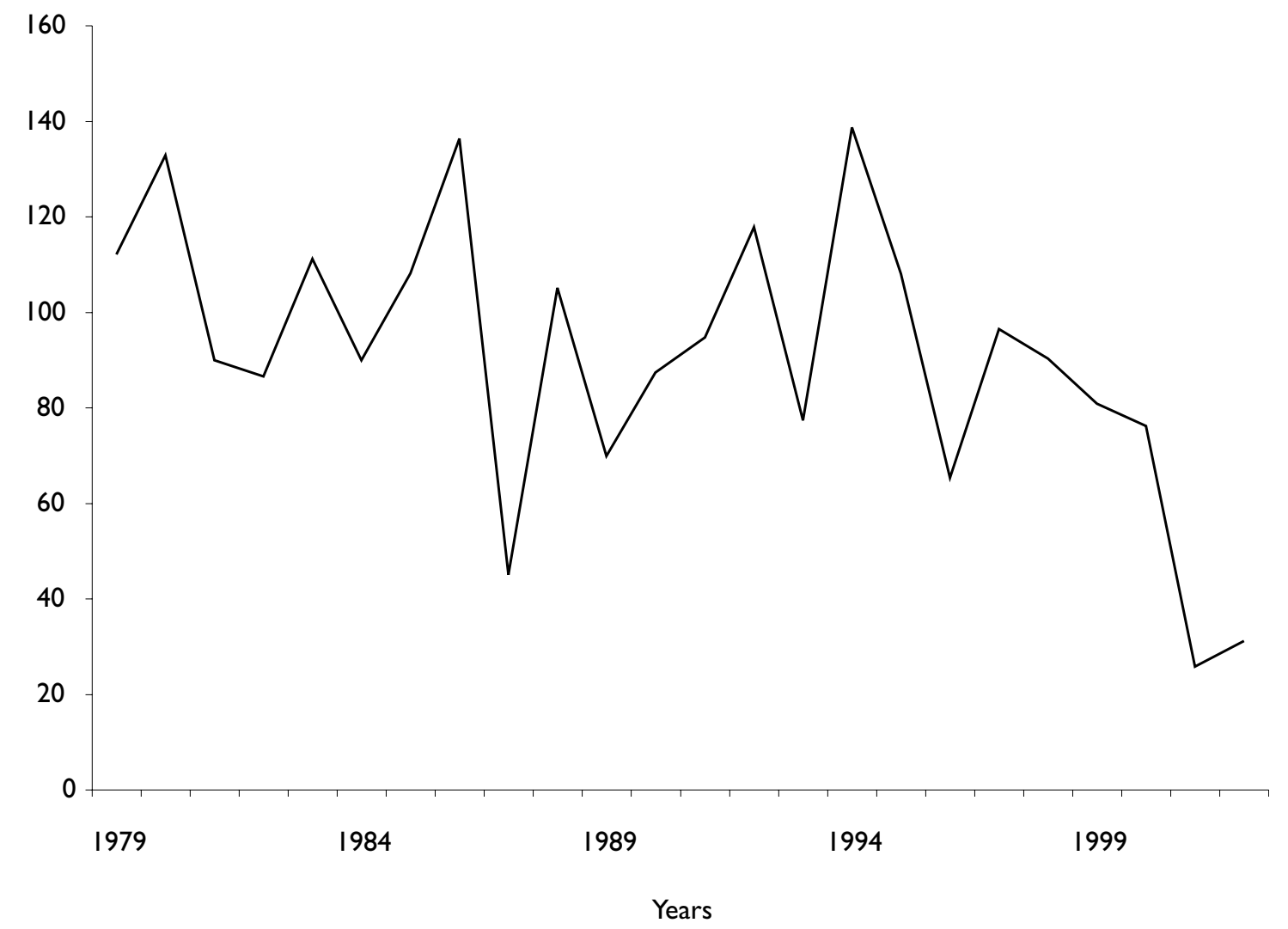


Box 8.I Shortcomings of past investments

The most commonly used economic incentives in irrigation projects are water pricing and user participation. Of the 67 active projects in the irrigation and drainage portfolio in 2000 , 52 (77 percent) used water-pricing incentives and 34 (5 I percent) employed user participation incentives (Tiwari and Dinar 2002b). However, in most cases "water pricing" focused mainly on operation and maintenance cost recovery, rather than as a signal for the scarcity value of water. Relatively few initiatives have successfully attempted recovery of investment costs. Water pricing (along with good management and appropriate fee collection) is important in ensuring efficient water service delivery.

Although recent projects have focused on poverty reduction objectives, fewer than half include data on poverty issues. Project appraisals must now analyze poverty impacts, and monitoring systems must measure long-term impacts on employment, incomes, and other determinants of poverty. Monitoring investment impacts on small-scale farmers, women, and minorities needs to be improved in future irrigation and drainage projects. New small-scale drip irrigation and sprinkler systems (and appropriate drainage systems), and technologies for cultivating high-value crops offer opportunities to improve productivity of assets of the poor.

Source:World Bank 2003.

Irrigation investments changed to respond to changes in the global environment and past experience with irrigation and drainage projects (see box 8.1). In the 1970 s and 1980 s investment involved large irrigation and drainage schemes with considerable infrastructure development. In the 1990s, investment supported system rehabilitation and management and more recently, small irrigation schemes under community-driven development projects. Increased water scarcity has shifted the focus from exploitation of water resources and building infrastructure to improvement of water use efficiency. Accordingly the Bank has shifted toward smaller investments, focused on poverty reduction and community empowerment. Associated with this is a greater emphasis on markets, the private sector, and water user associations (WUA) in managing irrigation. The public sector's limited ability to effectively guide economic activity, and the participation of the private sector for efficient outcomes, is now well recognized. A suitable public sector regulatory framework for equitable distribution of benefits from efficiency-related improvements needs to be established.

\section{KEY ISSUES FOR FUTURE INVESTMENTS}

Issues related to irrigation and drainage sector investments are highly interrelated and there is a need for a holistic approach.

MaXimizing IMPACTS ON POVERTY REDUCTION. Projects will require greater emphasis on targeting the poor, focusing on their empowerment, and designing appropriate regulatory systems. Project design and implementation need to consider the following:

- Does external support improve access to water specifically for smallholders, enabling them to improve their agricultural production, incomes, and food security?

- Are the opportunities optimally used to strengthen resource-poor peoples' access to irrigated or potentially irrigated land?

- Are smallholders protected from expropriation without compensation, and is more equity in resource rights being achieved by linking water rights to the land user?

- What priority is given to women's access to water and lands, and the impact of this on their incomes?

- Are poor people being included from the start in planning procedures and processes?

- Does irrigation provide benefits for the landless?

- Is access being improved to inputs, markets, and other institutions (van Koppen 1988)?

INTEGRATED IRRIGATION AND DRAINAGE AREA DEVELOPMENT. Irrigation and drainage need complementary investments in financial services, research and extension, input supply, and market 
development in order to achieve substantial diversification and intensification of production systems, and to increase the system's productivity and profitability.

Multiple INTEReSTS IN WATER. Competing interests may result in conflicts over water allocation and use. The main water subsectors, namely irrigation and drainage, water supply, hydropower, flood control, and environment, have increasingly adopted a cooperative approach to water management. But, there is still room for improvement in cross-sectoral planning and coordination as only modest progress has been made in integrating water management activities within river basins. Stakeholder participation and the resultant sense of ownership is important in each phase of project design, implementation, and post-project management. Irrigation agencies need to establish links with appropriate basin agencies and various interests (agricultural, urban, industrial, and environmental) to prepare seasonal water management plans with clear water allocation rules. This will ensure that decisionmakers consider the potential impacts that seemingly desirable activities may impose on other interest groups. For example, while there may be agricultural benefits from more efficient farm water use, this may have negative consequences for rural households that rely on seepage and runoff for their domestic water requirements.

Policy and institutional REForm issues. Sustainable water management improvements inevitably require significant adjustment in existing institutional arrangements because past irrigation investments had done little to restructure irrigation agencies and expand private sector participation, within the context of broader national reforms. A few countries, such as China and Mexico, have emphasized financially autonomous utilities that sell bulk water to users. Key policy issues influencing irrigation investments include: effective and efficient institutional structures, transparent and effective regulatory frameworks (water rights and irrigation laws), land tenure, decentralized irrigation and drainage management, and reform of public sector agencies that manage large irrigation systems. Addressing these issues will require improved interaction between ministries of agriculture, finance, planning, and environment.

LAND RIGHTS. As land ownership is typically a prerequisite for water rights, an effective land administration system should ensure that land rights are secure and tradable. Smallholders and especially women have less secure land rights even though they are often the main users. If social, economic, and gender equity issues are to be enhanced, effective land administration systems need to include mechanisms that recognize traditional and formal rights to land.

CAPACITY Building. Training and technical assistance for building country capacity of individuals and institutions, such as local governmental bodies, and public sector water agencies, to reform irrigation and drainage policies and their organizational structures is necessary. The World Bank Institute and other capacitybuilding partners, such as, the IWRM International Network for Capacity Building-CAPNET, and strengthening university curricula on irrigation systems operation and management, can be useful.

WATER PRICING AND COST RECOVERY. A key policy issue is water pricing and cost recovery of investments in irrigation and drainage developmentæor at least of covering system operation and management costs. This requires that managers and users be aware of the value and quantities of water used in order to develop incentive frameworks aimed at recovering costs and reducing water wastage. In many areas institutionalizing water pricing systems and full cost recovery will require many years to fully implement.

PRIVATIZING WATER USE RIGHTS. Private ownership of water and water rights is a contentious issue in many countries, where water has traditionally been seen as a free good, though one controlled to varying degrees by the state or by 


\section{Box 8.2 China: the Hai Basin}

Present development of China's Hai Basin (mainly due to irrigation) has resulted in annual evapo-transpiration (ET) that far exceeds sustainable levels. Annual outflow to the Bohai Sea is about 5 billion cubic meters, but would need to be about 9 billion cubic meters to provide adequate environmental flows. In addition there is about 9 billion cubic meters of overexploitation of groundwater annually. Increasing the outflow to the sea and eliminating the groundwater over-exploitation would require ET in the basin to be reduced by about 13 billion cubic meters per year. Conventional water conservation programs have made the situation worse by increasing ET.The Global Environmental Facility (GEF) Hai Basin Integrated Water and Environment Management Project, presently being prepared, seeks to use a new approach by managing basin water resources in terms of ET, and by seeking "real" water savings that reduce ET to sustainable levels. Remote sensing and ET data systems will be a key tool for providing accurate estimates of actual ET, thus making it possible to plan and manage water resources on a sustainable basis.

Source: Olson 2003.

private individuals. Private ownership is a useful tool in establishing the value of and market for irrigation water. Many reforms in the irrigation and larger water sector would be strengthened by such a policy shift, though enforcement of changes in water rights and water prices are difficult on both technical and political grounds.

In countries where there is acute competition for water, a forum for water users, including the resource poor, should be established to negotiate management plans and the policies and regulations, such as a national water act; to protect all parties; and to carry out these plans. Trade in water rights needs to be established and regulated.

Concept of "Real" Water savings. Experience in China and elsewhere has shown that, if projects concentrate only on improvements to physical irrigation and drainage systems, this may improve water use efficiency, but may not result in much "real" water savings because of the "return-flow factor" (see box 8.2). That is, some losses from existing inefficient systems return to groundwater aquifers or downstream surface water systems and become available for other users and are therefore not lost to the hydrologic system. Even if individual systems are inefficient, overall basin efficiency may be quite high in such areas. Improvements in water use efficiencies by upstream users might reduce water available for downstream use. However, some losses due to inefficiencies are absolute and unrecoverable, and "real" water savings result from reductions of nonrecoverable losses such as evapo-transpiration or losses to nonusable water bodies such as saline aquifers or the ocean. Thus, for water quantity management, the starting point needs to be the water balance (hydrologic cycle) to provide the basis for allocation of water.

EMPHASIS ON PRODUCTIVITY IMPROVEMENT. Increased water supply for agriculture must come from within the sector by increasing "use efficiency" through improved management practices that minimize evapo-transpiration, such as cropping patterns, cultivation methods, timely availability of inputs, and soil-moisture management. New investments may be needed, in areas such as crop genetics, and nontraditional crops such as horticulture, floriculture, and fodder. Investment may also be required to improve marketing infrastructure to respond to changes market opportunities.

Sustainable NATURAL RESOURCES MANAGEMENT. Investments in irrigation and drainage must also provide for sustainable management of natural resources and the physical environment. This is particularly so given that water allocation and use for agricultural purposes are inevitably associated with externalities and conflicts between water development for irrigation for agriculture and for domestic and industrial uses, and the ecological functions of water in the natural environment. Use of irrigation water must be carefully regulated and monitored to ensure sufficient environmental stream flows and to avoid "mining" groundwater aquifers.

Future irrigation development must identify environmental externalities (both positive and negative) related to management, and address 
these in design and implementation of projects (see box 8.3). As an example, improving the marginal productivity of water use may require increased nitrogen fertilizer application, which may contaminate nearby wetlands resulting in loss of biodiversity. An alternative approach might use legume crops, such as alfalfa, clover, and soybean, in crop rotations for nitrogen fixation. Technological and managerial innovations from an effective research and extension system can, with cooperation of the different groups, help resolve conflicts over resource use. Development of such mechanisms is a key investment area for the Bank.

\section{FUTURE PRIORITIES FOR INVESTMENT}

Irrigation and drainage investments must recognize the political sensitivities relating to water access and use, as well as the multiple and competing interests regarding its allocation. A long-term holistic view must see water as a vital resource that needs careful stewardship to ensure sustainability and equitable access and use. Cross sectoral planning and cooperation and a water basin-wide perspective are important, and objectives set should be time specific, realistic, and measurable.

Investments, in addition to achieving greater productivity from land (agriculture) and water resources, need to be linked to broader issues of development and the political economy, including poverty reduction, land reform, and institutional development. Establishing leadership and ownership (from farmer to politician) and building capacity (organizational and managerial skills, and databases) in irrigation and drainage projects and related reforms of policies and organizational structures are important for sustainability of investments.

INFORMATION SYSTEMS FOR DECISION-MAKING. Improved information systems are needed for irrigation and drainage decision-makers. These must measure and routinely monitor project impacts relating to water extraction, allocation, and pricing; environmental impacts; farm water efficiency improvements; and groundwater
Box 8.3 Environmental management issues

Improving management of water sources, return flows, and drainage to avoid damaging wetlands, mobilizing salts and agricultural chemicals, downstream pollution, and waterlogging.

Regulating and monitoring extraction of water for irrigation to ensure sufficient environmental stream flows and to avoid "mining" groundwater aquifers.

Establishing appropriate rules/standards for use of low-quality water in irrigation.

Creating a supporting environment and capacity for adaptation to climate change.

Adopting environmental planning in the design/modernization of new/existing irrigation and drainage schemes

Source: IWMI 200 I.

changes. Governments have a role in establishing such systems and the private sector, the research and development community, and WUAs have critical interests in these information systems.

INFRASTRUCTURE AND TECHNICAL ISSUES. Irrigation and drainage infrastructure is identified as a priority in the Bank's rural strategy. New infrastructure and service investments should be linked to existing infrastructure and services. There are trade-offs between new system development, renovations to bring systems back to original specifications, and upgrading or modernizing infrastructure to accommodate new needs. Priority should be given to making better use of existing infrastructure. Rehabilitation of major distribution systems should focus on modernization to account for present and future needs, rather than those needs for which the system was initially designed. Modernization of infrastructure must be accompanied by improvements in management systems to optimize the use of the infrastructure, and infrastructure design should be demand-driven such that the technologies are well understood and accepted. Access to information and markets for agroinputs and agro-products, agricultural credit, farm roads, and telecommunications services, are basic requirements to achieve full benefits of irrigation and drainage investments. 
Improved infrastructure and technical capacity will also be important for improving reliability of supplies and services. This may require development of new storage facilities to replace capacity lost to sedimentation, minimizing/ eliminating sedimentation, and saving water lost during flood flows. Improved reliability will foster innovative investments that may otherwise not occur because of high production risks associated with unreliable supply.

FoCUS ON SMAllholders. Promoting technologies and services tailored for smallholders is likely to have greater impact on poverty reduction. Such technologies include treadle and smallengine powered pumps, low-cost drip/sprinkler systems, technologies for groundwater extraction, and training and technical advisory services specifically for smallholders. The private sector has much potential to provide these services but is constrained by the high costs associated with transactions with smallscale producers. Rural producer organizations (RPOs) may be a means of overcoming this scale-related problem, and thereby encourage private sector provision of services to smallscale producers. Targeting smallholders (and the diverse interest groups identified by gender and ethnicity) is consistent with the need to more effectively address poverty.

ECONOMIC INCENTIVES AND FINANCIAL SUSTAINABILITY OF INVESTMENT. Irrigated agriculture systems should ultimately be financially sustainable and not require continuing investment by donors. This may require a rethinking of the roles of government and the private sector in irrigation and drainage projects and the nature of their involvement in design and implementation. The government's functions will include environmental monitoring, auditing, and regulation of land and water markets and establishing the policy framework within which the private sector can function. This may require policy changes that provide incentives (for example, taxes, subsidies, water rights) that incorporate principles of equity within the context of customary rights, and provide a workable basis for water transfers among owners and users. While more recent programs focus on recovery of operation and maintenance costs, relatively little has been done on recovery of investment costs. This is particularly important to future proposals for expansion and intensification of existing schemes and is a continuing policy issue.

WATER USER ASSOCIATIONS. Water user associations, usually formed around a group of potential users (farmers), are increasingly important for irrigation management (organizing the extraction, allocation, and distribution of water). They can also undertake other activities, including the provision of extension, technical, and marketing services relating to on-farm agricultural production. These services enhance productivity of the irrigation systems, but may stretch the capacity of the associations. User groups have been found to work well, (that is internalize costs and benefits of schemes) when there is no public body that will "rescue" the group if it fails to mobilize the required funds for operation and maintenance. There are, however, few cases of water user associations covering 100 percent of the costs of operations and maintenance. More work is therefore needed to develop management systems that can make these associations fully sustainable.

\section{SCALING UP INVESTMENTS}

Monitoring and evaluation of irrigation and drainage investments is increasingly important given the growing competition with other sectors for scarce investments and the need to respond to changing circumstances during project implementation. Monitoring and evaluation systems must measure the full range of irrigation and drainage-related benefitsæeconomic, environmental, and social. Key outcome indicators relate to production per unit of water use, real water savings, and changes in land use. Impact indicators focus on incomes, poverty reduction, and system sustainability. Such monitoring can also contribute to the adaptive planning of current programs and scaling up.

Investments will need to conform to World Bank Safeguard guidelines, as summarized in 
box 8.4 and must be accompanied by clear plans for eventual phasing out of support and for the financial independence of the irrigation system that may rely increasingly on private sector investment (see box 8.4). Improved analysis of existing knowledge regarding successes and failures of past investments will provide a basis for identifying key elements of good practice, and innovative approaches for scaling-up irrigation and drainage investments with a high probability of success and beneficial impact on the poor.

Good practice guidelines are needed with reference to irrigation investment and: (i) poverty reduction, (ii) the context of increasing water scarcity and competition for water, (iii) impacts on the environment, and (iv) policies for enhanced private sector investment.

\section{SELECTED READINGS}

Asterisk (*) at the end of a reference indicates that it is available on the Web. See the Appendix for a full list of Web sites.

Easter, W., H. Plusquellec, and A. Subramanian. 1998. "Irrigation Improvement Strategy Review." Water Resources Thematic Group Draft Final Report. World Bank, Washington, D.C.*

IWMI. 2001. "Water for Rural Development." Draft Background Paper on Water for Rural Development Prepared for the World Bank. International Water Management Institute, Colombo, Sri Lanka.*

Rosegrant, M. W., X. Cai, and S. A. Cline. 2002. World Water and Food to 2025: Dealing with Scarcity. IFPRI: Washington, D.C.*

Tiwari, D. N., and A. Dinar. 2002a. "Prospects of Irrigated Agriculture: Whether the Irrigated Area and Irrigation Water Must Increase to Meet Food Needs of the Future." Agriculture and Rural Development Department Water Team. World Bank, Washington, D.C.*
Box 8.4 Key safeguard policy issues for irrigation and drainage investments

Environmental Assessment (Operational Policy (OP)/Bank Procedure (BP) 4.0I)æan Environmental Assessment is required if a project may have potential adverse environmental risks or impacts.

Safety of Dams (OP 4.37)ædam safety measures and/or reviews and safety inspections are required if an investment involves construction of a large or high hazard dam or is dependant upon an existing dam.

Natural Habitats (OP 4.04)æprotection of natural habitats (land and water areas where most of the original plant and animal species are still present) is required for an investment with potential to cause degradation of the natural habitat.

Projects in International Waterways (OP 7.50)æthe Borrower must notify other riparians of any proposed investment involving a body of water that flows through or forms part of the boundary of two or more countries.

Involuntary Resettlement (OP/BP 4.I2)æa Resettlement Action Plan is required if an investment results in physical relocation; loss of land or access to land or other assets; or impacts on livelihoods due to restrictions on access to parks or protected areas.

Source:World Bank, Operational Manual.

\section{REFERENCES CITED}

World Bank. 2003. Reaching the Rural Poor: A Renewed Strategy for Rural Development. Washington, D.C.: World Bank.

FAOSTAT. 2002. FAO Statistical Databases. http://apps.fao.org/default.htm.

IWMI. 2001. "Water for Rural Development." Draft Background Paper on Water for Rural Development Prepared for the World Bank. International Water Management Institute, Colombo, Sri Lanka.

Olson, D. 2003. "Real Water Savings and ET Reduction: The Hai Basin Paradigm." Draft. World Bank, Washington, D.C.

Tiwari, D. N., and A. Dinar. 2002a. "Prospects of Irrigated Agriculture: Whether the Irrigated Area and Irrigation Water Must Increase to Meet Food Needs of the Future." Agriculture 
and Rural Development Department Water Team, World Bank, Washington, D.C.

Tiwari, D., and A. Dinar. 2002b. "The Role and Use of Economic Incentives in Irrigated Agriculture." Working Paper. World Bank, Washington, D.C.

van Koppen, B. 1988. "Water Rights and Poverty

Alleviation: Inclusion and Exclusion of ResourcePoor Women and Men as Rights Holders in Externally Supported Irrigation Development." In D. Merrey, and S. Baviskar, eds. Gender Analysis and Reform of Irrigation Management: Concepts, Cases and Gaps in Knowledge. Proceedings of the Workshop on Gender and Water, 1519 September 1997, Habarana, Sri Lanka. IWMI, Colombo, Sri Lanka.

World Bank. Operational Manual. http:// wbln0018.worldbank.org/institutional/ manuals/opmanual.nsf/.

This Overview was prepared by Safwat Abdel-Dayem, Ariel Dinar, and Sam Kane with inputs from irrigation and drainage specialists in the Irrigation and Drainage Network of the World Bank. Peer review comments were provided by Ohn Myint and ljsbrand de Jong. 


\section{INVESTMENTS TO EMPOWER FARMERS TO MANAGE IRRIGATION AND DRAINAGE SYSTEMS}

Water user associations are important for empowering farmers to manage irrigation and drainage systems and offer potential for reducing costs and improving irrigation services. The optimal size and allocation of responsibilities to such associations is a complex issue dependent on local conditions and capacities. The impact of farmer management of irrigation systems on agricultural productivity may not be substantial if this is not accompanied by investment in physical infrastructure to improve the quality of services. Empowerment of smallholders, and particularly women, also requires investment in water user association capacity. Irrigation agencies need to provide to support to develop sustainable user associations

Following rapid expansion of irrigated agriculture worldwide from the 1950s to the 1980s, many governments found it difficult to manage recurring costs and collect water charges for irrigation. This led to deterioration of infrastructure, shrinkage of irrigated area, poor distribution and wastage of water, waterlogging, and salinity (Vermillion and Sagardoy 1999). Many governments transferred management responsibility to local water service providers, such as WUA or cooperatives, expecting this transfer to reduce financial burdens on government and help increase productivity and profitability of irrigated agriculture since users were expected to operate systems more effectively to meet their own needs. While these transfers have been successful in some cases, in many countries financial considerations continue to dominate the debate on empowering users in irrigation management (see box 8.5). ${ }^{1}$
Box 8.5 Mali: success story

The Office du Niger in Mali, known for many years as an example of an irrigation system with a heavy financial burden, is now seen as a success story. The Office was created during colonial times to produce cotton, but in the 1950s cotton cultivation was abandoned because of waterlogging and rice became the dominant crop. In the 1980s the Office was restructured to focus on both institutional and technical issues. The paddy processing and marketing functions were privatized, and activities now focus on the essential functions of water services, planning, and maintenance. Improved water delivery and land levelling enabled the adoption of transplanting methods and high-yielding varieties, increasing paddy yields from 1.5 to 6 tons per hectare.

Although there are no formal user associations, farmers are represented in decisions on use of water fees through their elected delegates, who are members of joint committees, each covering about 5,000 to 8,000 hectares. These committees decide on the annual maintenance program, budgets, and procurement, while day-to-day management remains the responsibility of the Office. This approach matches the capacity level of the farmers, and may be a suitable model for other low-income countries with a low level of literacy.

Source: Couture and Lavigne 2000.

\section{EMPOWERING WATER USER ASSOCIATIONS- ALTERNATIVE APPROACHES}

Commercial associations of farmers, common in Latin America are legal entities that can enter into contracts and have power to enforce rules and regulations. They are responsible for water distribution, fee collection, maintenance, conflict resolution and representing farmers in discussions with public agencies. Farmer members are not directly involved in management of systems, as the associations hire professional staff for this. Social associations common in Asia, rely on direct participation by all members and daily interaction for decisionmaking, monitoring, and sanctioning. These associations are involved in maintenance activities by providing labor, and in some cases by collecting irrigation service fees. This model is most appropriate in socially cohesive societies with small landholdings and simple irrigation technology.

I. See the IAP,"Mali: Institutional Reform to Focus Public Role on Essential Public Goods" 
The question of optimal size for user associations in large-scale irrigation systems with a large number of small farmers is very complex. Expert opinions vary widelyæefrom 40 hectares to a few thousand hectaresædepending on whether the key performance objective is the extent of cooperation on irrigation activities or financial viability of the associations.

A multitiered organization is now considered an appropriate model for schemes with small farmers. Base-level user groups send representatives to the higher level organization that allocates water among the user groups and negotiates any conflicts. In turn, these units may federate into a higher level, with an apex level organization for the entire system. This approach has been used in Nepal since the early 1990s.In contrast to the gradualist approach used in other Indian states, Andhra Pradesh opted for a "super big-bang" top-down approach to reforming its irrigation sector. After new legislation in 1997, elections created over 10,000 user associations for all major, medium, and minor irrigation schemes, and six months later created user committees at the level of secondary canals.

Box 8.6 Approaches to irrigation management

Participatory irrigation management (PIM) involves users in irrigation management. The irrigation service provider may be a financially autonomous utility or a local entity. It is generally governed, at least in part, by farmers who are involved in key decisions on water resources management, irrigation water delivery, annual budgets, priorities for maintenance and rehabilitation, and personnel.

Irrigation management transfer (IMT) reassigns responsibility and authority from government agencies to non governmental organizations (NGOs). IMT is about replacing the governmentænot just working with itæas is the case with PIM. IMT may include all or partial transfer of management functions, and may be implemented at subsystem levels or for entire irrigation systems. Farmers may hire technical and administrative staff or even contract other organizations to manage the system.

Source: Authors.

\section{BENEFITS}

Typical objectives of transferring management to WUA include:

- Eliminating recurring government expenditures for operation and maintenance.

- Reducing the rate of deterioration of irrigation infrastructure.

- Providing transparency in management and accountability of the irrigation service provider to water users.

- Increasing farmers' income and the productivity of water.

Commercial associations have been very successful in improving the recovery of recurrent costs and stopping deterioration of infrastructure through better maintenance and equipment. However, despite widespread adoption of management transfer programs, there is still inconclusive and conflicting evidence on their impact on agricultural performance (see box 8.6). In most large-scale projects, institutional reforms alone may not improve productivity of irrigated agriculture and promote crop diversification which may be need physical improvement of the system, and this generally requires user participation. In Latin America, raising agricultural productivity is most challenging under systems managed by irrigation agencies according to well-established rules, such as delivery of water to users on prearranged schedules.

\section{POLICY AND IMPLEMENTATION ISSUES}

POLICY REFORMS. Several policy issues must be addressed before embarking on institutional reforms: What functions should be transferred to what organizations? How will irrigation operations and maintenance (O\&M) and rehabilitation be financed after reforms? What policy and legal changes need to be made to support the reforms? What changes should be made in public agency mandates as a result of the transfer? 
SCOPE OF GROUP ACTIVITIES. Water user associations often expand their mandated activities to include input supply, marketing, research and extension, and credit programs. There is a good argument for these activities, which increase the system's productivity, but these can easily overstretch group management capacity.

System Rehabilitation. The most contentious issue is whether physical infrastructure should be rehabiltiated before or after management transfer. Farmers may be very reluctant to take over responsibilities for systems in poor condition, given the lack of funds for O\&M, and the need for even greater funds for rehabilitation. If the government undertakes rehabilitation before transfer, this reinforces a perception that it is a government system and that government will finance future rehabilitation. However, Mexico used financing of rehabilitation works as a bargaining tool to promote transfers that were not very economically attractive to farmers.

LAND RIGHTS. Secure land rights, providing either ownership or secure tenancy, is necessary before users can be expected to invest in irrigation systems.

Boundaries. There is a consensus that WUAs should be based on hydraulic boundaries (that is, at the level of minor or distributary canals) to perform efficiently. However for historical reasons in some countries, user organizations are based on administrative boundaries.

Sustainability. Few WUAs have been able to achieve 100 percent cost recovery for operation and maintenance costs, or have funds for construction. Using traditional user associations to strengthen large-scale agency-managed irrigation systems has met with little success. Users have no incentive to cooperate if water delivery is too erratic or if a rigid delivery schedule is imposedæefrequent deficiencies of large-scale systems. Social associations developed to provide cheap labor for maintenance or to collect water fees are often weak.

\section{Box 8.7 Key elements of a successful management transfer} program

- Absence of strong opposition to IMT by bureaucracies and local elites.

- Supporting legislation and support services for local water service providers.

- Capacity to create (or alter) local organizations to take over water management.

- Irrigation infrastructure suitable for management by farmers organizations.

- Clear land and water rights.

Source: Authors.

\section{LESSONS LEARNED}

There is no "one-size-fits-all" approach to empowering users in irrigation management (see box 8.7). In the early 1990s, Mexico's experience and its successful replication in Turkey and Albania raised great interest. The Mexican model is known as the "big-bang" approach because it covered about 3 million hectares, and was completed in 3-4 years. This contrasts with the gradual piloting approach used in most Asian countries. One advantage of the Mexican approach is the limited number of associations (about 400), which reduces efforts required for transferring procedures, training, and monitoring. Obstacles to replicating the "big bang" approach are unsecured land tenure, low productivity of irrigation systems in many countries and, in some cases the high level of technology required.

With the IMT approach, where irrigation management is transferred to a nongovernmental organization (NGO), stakeholders may have conflicting interests, such as tensions between farmers at different ends of canals; wealthy farmers who pay bribes for extra water may resist the formation of strong water associations; farmers may favor taking over management, but irrigation department staff may resist for fear of losing jobs and revenue; and government finance and planning departments may promote IMT to reduce the burden of financing irrigation.

The role of irrigation/water resources agencies changes with the transfer of responsibilities to 


\section{Box 8.8 Potential investments}

Study tours and exchange visits.

- Assistance in forming user organizations through support to government agencies, community organizations, or NGOs.

- Gender analyses and planning for women's participation in water user associations (WUAs).

- Assistance in changing legislation.

- Assistance in changing the roles of government agencies.

- Training of user organizations (accounting, operation, and maintenance).

- Special equipment for maintenance.

- Office equipment.

- Rehabilitation and upgrading works in severely deteriorated systems.

Source: Authors.

users to that of providing technical guidance and managerial, accounting, and financial advisory services; assisting with dispute resolution; and monitoring performance of associations. Agencies may focus more attention on river basin planning, surface and groundwater resource management and allocation, and environmental monitoring, and enforcement. But, agency reform may result in a drastic reduction in staffæefrequently the cause of resistance to reformsæunless staff can be deployed to other tasks.

\section{RECOMMENDATIONS FOR PRACTITIONERS}

Before making investments in irrigation and drainage projects, it is essential to determine whether water users are motivated to take over responsibilities for management and whether there is likely to be resistance from third parties (staff of the present managing organization or influential water users) (see box 8.8). For lowincome countries, the Mali experience is a good example because it combines user monitoring of maintenance spending with the handling of the finances by the agency.

- Decision to transfer responsibility to users must be made at the highest government level as without this, management transfer programs adopted under donor pressure may fail. Such transfer requires legal action in the form of a decree or legislative act, such as the Agreement of Transfer between the government and the association defining mutual obligations and the By-laws of the Association defining rights and obligations of the association and its members.

- Time-bound lending conditions for official development assistance often conflict with the time required to implement social reforms needed to ensure the effective empowerment of users. In Turkey, a transfer program was initiated first and then a Bank project later contributed to the financing of maintenance and office equipment for the water associations.

- Involving farmers in irrigation management should be part of an overall irrigation reform program that includes irrigation agency reform and improvement in service delivery functions.

- Adequate infrastructure is essential to ensure that institutional and policy reforms lead to effective and efficient irrigation systems so that is water delivered in a reliable and measurable way.

- Technical change must complement management reforms to improve the efficiency and productivity of irrigation systems and farmer organizations with irrigation governance responsibilities may act as the catalyst for this modernization.

\section{SELECTED READINGS}

Asterisk (*) at the end of a reference indicates that it is available on the Web. See the Appendix for a full list of Web sites.

Oblitas, K., and J. R. Peter. 1999. "Transferring Irrigation Management to Farmers in Andhra Pradesh, India." In association with G. Pingle, H. M. Qaddumi, and J. Perera. Technical Paper 449. World Bank, Washington, D.C.* 
Salman, S. M. A. 1997. "The Legal Framework for Water Users' Associations: A Comparative Study.” Technical Paper 360. World Bank, Washington, D.C.*

Subramanian, A., N. Jagannathan, and R. Meinzen-Dick, eds. 1997. "User Organizations for Sustainable Water Services." Technical Paper 354. World Bank, Washington, D.C.*

\section{REFERENCES CITED}

Couture, J. L. and P. Lavigne. 2000. "Institutional Innovations and Irrigation Management in Office du Niger, Mali (1910-1990)." Seminar at the Institutional Reforms in Irrigation and Drainage, sponsored by the World Bank, December 11-12, Washington, D.C.

Vermillion, D. L., and J. A. Sagardoy. 1999. "Transfer of Irrigation Management Services: Guidelines." FAO Irrigation and Drainage Paper 58. FAO, Rome.

This note was prepared by Herve Plusquellec with inputs from Walter Ochs, Safwat Abdel-Dayem, Ariel Dinar, and other irrigation and drainage specialists in the Irrigation and Drainage Network of the World Bank. 
AGRICULTURE INVESTMENT NOTE

\section{INVESTMENTS IN IRRIGATION FOR CROP DIVERSIFICATION}

Farmers' efforts to diversify production are frequently hampered by inadequate irrigation systems. If diversification results in high-value crop being grown, irrigation system investments may be more economically viable as a result of the higher returns and the increase in water use efficiency. Diversification in irrigated agriculture often requires new or improved technologies for water delivery and drainage, with investment needed to modernize water control so as to increase the flexibility of water delivery and drainage. In order to ensure that farmers benefit from agricultural diversification, investments are required in marketing and processing facilities and services, such as research, extension, and credit, and incentive structures to facilitate growth of high-value crop production.

Adoption of high-yielding crop varieties during the green revolution, combined with rapid expansion of irrigated areas from the 1960s to the 1980s, resulted in a significant increase in food production, especially rice production in Asia. Surpluses resulted in a decline in grain prices in domestic and world markets, and in response to this, farmers sought alternatives to cereal cultivation. Other factors spurring crop diversification include: availability of advanced irrigation technology; development and adoption of improved high-value crops; increased domestic and regional demand for fruits, vegetables, and livestock products; growth of private agribusiness in processing and marketing; and removal of distorting policies that favored selected crops.

However, many farmers in rice-based agricultural systems experienced severe problems in diversifying to other crops, constrained by deficiencies in irrigation infrastructure and management at the farm level and by a poor policy environment and lack of support ser- vices needed for diversification. Because of the importance of rice, many issues discussed in this note deal with diversification of rice-based cropping systems. The lessons learned are also valid for increasing productivity of other irrigated agricultural systems.

\section{IRRIGATION, DRAINAGE,AND CROP DIVERSIFICATION}

Water DELIVERY. Paddy and non-paddy crops require different irrigation management. Both excess water and deficits adversely affect yields of non-paddy crops, whereas rice does well with continuous irrigation and/or field-to-field irrigation, which has been the dominant method of irrigation in most of South and Southeast Asia. Basin irrigation, the method used for irrigated rice, is also used for other crops, such as groundnuts, maize, and soybeans, but is not suited to crops sensitive to wet soil conditions or to soils that form crusts. Delivery of irrigation water to non-paddy crops at discrete, variable intervals with precise flows is more complex than continuous delivery for rice. Flow rates must be carefully controlled to irrigate non-paddy crops whether surface or pressure systems are used.

On-FARM IRRIGATION AND DRAINAGE NETWORKS. Many irrigation projects designed for rice production have a low density of irrigation ditches and farm drains. Such infrastructure is sufficient for field-to-field irrigation, but non-paddy crops require direct plot access to irrigation and drainage that provide intermittent water supply and prevent soil saturation affecting crop production. The density of the tertiary system required for non-paddy crop cultivation depends on factors, including land slope, nature of soils, farm size, mechanization, and method of on-farm water application.

LAND CONSOlidation. Construction of a dense onfarm irrigation and drainage system needed for crop diversification cannot reasonably be implemented where farm plots of random shape are scattered throughout the irrigated area. A land consolidation program is often needed as a basis 
for a cost-effective layout for an on-farm irrigation system suited to efficient water management. Farm plots should be rearranged in a geometric grid that determines layout of irrigation and drainage systems and farm roads. In Morocco, since the 1960s, planning for new irrigation systems starts with a land consolidation program that regroups individual farmers' small plots into rectangular blocks of about 30 hectares. In Japan, Korea, China, and Taiwan where diversification is common, irrigation systems were systematically developed in conjunction with land reform, providing irrigation and drainage access for each plot and crop. Failure of land consolidation programs has been common, and political commitmentæsometimes supported by external stimuliæhas been important in driving land reform.

Drainage. Improving drainage reduces waterlogging and salinization, allowing a wider choice of potential crops and encouraging crop diversification. Complementary on-farm drainage facilities for fast removal of excess water and lowering of the water table may need to be installed and integrated with the main drainage system. Some farmers provide these facilities with rudimentary but costly systems of dualpurpose field ditches and raised bedsæa technique widely used in delta areas in Southeast Asia. These systems, while effective, take up considerable productive land area.

SoIl MANAGEMENT. In many cases, conversion of lands from rice to non-paddy cultivation can be done only at considerable cost as the high clay content of heavy soils that are excellent for rice cultivation result in low infiltration rates and poor suitability for other crops, and impose large power requirements for land preparation. Diversification from rice to other crops therefore has greatest potential on lighter soils.

\section{BENEFITS}

Agricultural diversification creates opportunities for higher and more stable rural incomes through more efficient use of resources and the exploitation of comparative advantage. Diversi- fication generally implies a shift from cereal crops to other field crops or high-value horticultural crops (see box 8.9). These may require less water, but offer opportunities for greater employment, higher incomes, and more valueadded processing.

Two Bank projects - a success story in Brazil and an unsatisfactory result in Thailand illustrate the importance of irrigation system design, access to markets, and farmer training in enhancing crop diversification. In Thailand in 1977 at appraisal time, it was expected that during the dry season about half of the Lam Pao Scheme under the Northeast Irrigation Project II would be cropped with high-yielding rice varieties, with the rest under peanuts and mung bean. Over twenty years later, the cropping intensity during the dry season averages about 32 percent. Dry season vegetables are produced mostly near the larger canals. Expansion of diversified irrigated agriculture is constrained by the lack of tertiary canal service to individual fields, the unreliability of canal water, seasonal migration of rural labor to urban centers, and poorly organized markets in the area.

In Brazil, the Upper and Middle Sao Francisco Irrigation Project, appraised in 1985, consisted of rehabilitation of seven existing public schemes and construction of a new scheme, "Formosa." Irrigation systems were designed to provide high quality of service to each user, with the possibility of adopting sophisticated pressurized farm applications. The expected

Box 8.9 India: Uttar Pradesh sodic lands reclamation project

In 1993 an estimated 1.25 million hectares of land in Uttar Pradesh was completely barren due to sodification. Another I.25 million hectares of low-yielding salt-affected lands covered about 10 percent of the net cultivated area of the state. $A$ Bank-supported project to rehabilitate these lands introduced technology that included drainage, incentives, soil amendments (gypsum), tubewells, and institutional components. Within six months of beginning reclamation activities, productivity and income began to increase. Farmers began to diversify by planting high-value crops, both nontraditional (guava, Cape gooseberry, sunflower) and traditional (mustard, sugarcane).

Source:World Bank 2002. 
Box 8.10 Groundwater and crop diversification: "farmers vote by drilling"

During the last 20 years, with low development costs, there has been great increase in use of groundwater resources for irrigation. Canal water distribution is often erratic or based on rigid scheduling, and large variations between planned and actual allocation of water hamper cultivation of non-paddy crops. Farmers quickly realize the potential operational advantage of groundwater over surface water. Groundwater development in Thailand has largely solved water supply problems. In a project in Phitsanulok, farmers access to groundwater, provides freedom over crop calendars and choice of crops, as they plant at the time best for their own situation and markets, and can water crops at the frequency and duration most suitable to their crop and soil characteristics.

Source: Mainuddin, Loof, and Abernethy 2000

area of crop diversification was greatly underestimated at 13 percent as the area now devoted to fruit crops (mainly banana and mango) averages 61 percent in the rehabilitation sites and 32 percent in the new scheme. Improved market access via a new highway to Brasilia greatly enhanced prospects for output growth in Formosa, and the project has generated considerable off-farm employment.

\section{POLICY AND IMPLEMENTATION ISSUES}

EQUITY IN DIVERSIFICATION. Diversified crop production can have major impacts on employment and stimulate off-farm economic development and these can be important contributors to poverty reduction. However, opportunities for farmers to diversify are not always equal as irrigation and drainage infrastructure can be costly, especially some micro-irrigation equipment and infrastructure. Wealthier farmers are better able to finance such investments, assume risk and access the considerable knowledge and information services required for successful diversification.

Groundwater Development. Deficiencies in water delivery from surface irrigation systems have spurred farmers to tap other sources of water, primarily from drains and groundwater (see box 8.10 ). This has sometimes led to overexploitation of groundwater resources, posing a major threat to health and the environment. A decline in groundwater levels increases pumping costs, affecting sustainability of groundwater supplies and the profitability of new cropping systems.

COMPLEMENTARY INVESTMENTS. Irrigation and drainage investments alone are seldom sufficient to increase agricultural diversification. Complementary investments in roads, research and extension, markets, and financial services are necessary to increase productivity and to maximize the impact of agricultural diversification on poverty and incomes.

\section{LESSONS LEARNED}

Agricultural diversification is an evolutionary process that requires the support of appropriate policies, technologies, infrastructure, and services. Constraints include: limited technologies for alternative crops, irrigation water supply and management deficiencies, poorly developed agricultural markets, weaknesses in research and extension, and unfavorable government policies (Barghouti, Garbus, and Umali 1992). In Japan, South Korea, and Taiwan, the unique role of rice in the agricultural economies of these countries has made it difficult to replace. Social, cultural, and food security considerations have led to heavy government protection for rice farmers.

Crop diversification in irrigated rice systems occurs at a pace determined by markets and policies. Private investment generally grows gradually, as farmers gain experience with new markets and production systems. Market information systems and market access are critical to promoting diversified cropping. Diversification is most advanced where farmers have easy access to reliable water in river delta areas and alluvial areas, where there has been explosive development of groundwater resources. In other surface irrigation systems, diversification will remain constrained if investments support only urgently-needed rehabilitation, and do not upgrade irrigation infrastructure to meet the requirements of a diversified agriculture. 


\section{RECOMMENDATIONS FOR PRACTITIONERS}

Diversification in irrigated areas requires improvement of main canals and distribution systems, and construction of a tertiary (onfarm) irrigation and drainage system to meet precise water delivery requirements of diversified crops. This may need to be complemented by reorganization of farm boundaries, land consolidation, and improvements to main drainage and flood control systems.

Improvement of irrigation and drainage facilities is a prerequisite to crop diversification, but should be complemented by other support services. Governments should encourage investment for the modernization of marketing facilities and more generally by investing in improved roads, communication systems, and storage (see box 8.11). Extension programs with information on irrigation, agronomic practices and economics help farmers decide which crops to grow. An assured and stable market, and readily available inputs and credit, are also essential to sustain crop diversification, as demonstrated in the Middle East and North Africa (MENA) (see box 8.12).

Before initiating a crop diversification program, detailed studies should determine the quality of irrigation service and its suitability for diversified crops; assess the potential markets; and the available level of services and technology. The in-depth diagnosis of the irrigation systems should go beyond an evaluation of the indicators of hydraulic, financial, agricultural, and environmental performance to cover problems, such as obtaining credit, and access to markets participation by women and poor people in their efforts to diversify.

\section{SELECTED READINGS}

Asterisk (*) at the end of a reference indicates that it is available on the Web. See the Appendix for a full list of Web sites.

Burt, C. M., and S. W. Styles. 1999. Modern Water Control and Management Practices in Irrigation: Impact on Performance.

\section{Box 8.I I Potential investments}

- Modernization of the water distribution system to provide reliable and flexible delivery.

- Tertiary and on-farm development (including irrigation, drainage system, and farm roads) serving each farm plot.

- Micro-irrigation.

- Greenhouses, tunnels, and mulching.

- Marketing and food processing facilities.

- Extension and financial services

Source: Authors.

\section{Box 8.12 MENA region: diversification}

The agricultural sector in MENA countries has witnessed remarkable change and modernization, especially in the irrigation subsector, which benefited from a variety of recent advances in water management, crop improvement, and marketing and processing. Changes were often led by private sector companies who introduced modern production technology, such as plastic houses, tunnels and mulches, improved hybrid varieties, drip irrigation systems, soluble fertilizers and herbicides, modern market information systems, and refrigerated transport equipment for long hauls.

Source: Authors.

\section{Water Reports 19. Rome: FAO.*}

Plusquellec, H. 1987. "Crop Diversification in Irrigated Agriculture: Water Management Constraints." In T. J. Davis, and I. A. Schirmer, eds., Sustainability Issues in Agriculture Development: Proceedings of the Seventh Agriculture Sector Symposium. Washington, D.C.: World Bank.*

Plusquellec, H. 2002. How Design, Management and Policy Affect the Performance of Irrigation Projects: Emerging Modernization Procedures and Design Standards. FAO: Bangkok.*

\section{REFERENCES CITED}

Barghouti, S., L. Garbus, and D. Umali, eds. 1992. Trends in Agricultural Diversification: Regional Perspectives. Technical Paper 180. Washington, D.C.: World Bank.

Mainuddin, M., R. Loof and C. L. Abernethy. 
2000. "Operational Plans and Performance in the Phitsanulok Irrigation System, Thailand." International Journal of Water Resources 16 (3): 321-342.

World Bank. 2002. "Implementing the New Rural Development Strategy in a Country Driven Process: Agriculture and Rural Development Project Profiles." Presentation at the Country Director/Rural Sector Board Learning Event, September 8-10, sponsored by the World Bank, Antalya, Turkey.

This note was prepared by Herve Plusquellec with inputs from Walter Ochs, Safwat Abdel-Dayem, Ariel Dinar, and other irrigation and drainage specialists in the Irrigation and Drainage Network of the World Bank. 


\section{AGRICULTURE INVESTMENT NOTE}

\section{INVESTMENTS IN WATERLOGGING AND SALINITY CONTROL}

Salt movement by rising water tables in surface irrigation, and by pumping brackish water from groundwater systems, can lead to land salinization and reduced crop productivity. The primary investments in waterlogging and salinity control involve irrigation and drainage infrastructure, and improved irrigation water management to control seepage losses from canals and reservoirs. This is vital where natural leaching of excessive salts from the soil is not adequate, and where geological conditions lead to salinity in irrigated areas. Proper management and provision for subsurface drainage in irrigation systems can address salinity problems, and enhance productivity and sustainability of irrigation systems.

Waterlogging and salinity problems often require some form of drainage to allow sustainable agriculture production. This must be an integral part of irrigation system investments. However, poor irrigation and agronomic practices have led to salinity, sodicity, and waterlogging affecting 40-50 percent of the world's 270 million hectares of land currently under irrigation. Drainage investments are needed to control waterlogging and salinity on 60-85 million hectares of currently irrigated lands. This investment can yield significant economic benefits (see box 8.13).

\section{WATERLOGGING}

Waterlogging occurs when soil pores stay filled with water, resulting in oxygen deficiency that impairs root growth and its ability to absorb nutrients. Rice plants are an exception, as they transfer air to roots and are able to grow well even when roots are submerged for long periods. Irrigation systems are vulnerable to waterlogging at critical locations such as irrigation supply canals and seepage from reservoirs. Low areas within a command area are vulnerable if farmers on higher ground do not practice good water management. High water tables result from deep percolation and lateral underground water flows. Some soils develop high water tables due to low drainage porosity, whereas others maintain high water tables because of low water-transmitting properties. Slowly falling water tables may affect plant growth even when levels eventually fall below root zones.

\section{SALINITY}

Soil salinization is a concern for irrigation systems in arid and some semi-arid climates, and some temperate or tropical areas close to oceans or saltwater tidal areas. Salts in the temperate and tropical climates are leached from soils profiles over time, but in arid and semi-arid climates salt builds up due to higher evaporation rates. When irrigated areas are developed in arid climates, soils often must be artificially leached before cropping can begin. In semi-arid climates some natural leaching takes place during rainy seasons if adequate drainage is provided.

\section{Box 8.13 Egypt: economic impact of drainage}

Egypt's National Drainage Program ( 1992-00) Implementation Completion Report rated drainage components highly satisfactory and estimated an economic rate of return of 19 percent. Drainage is one of the most important investments for raising agricultural productivity in a country with limited water resources and high population growth. Drainage is estimated to have increased production in 1998-99 as follows:

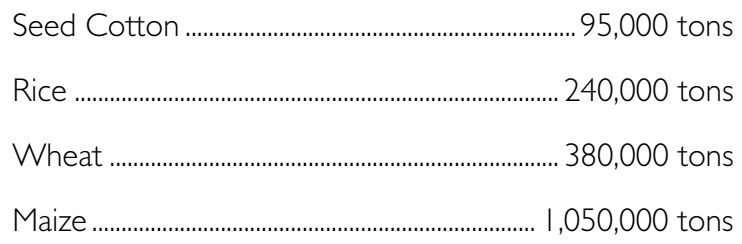

The annual contribution of drainage to the Gross Domestic Product was estimated at US\$0.9 billion or 8 percent of agricultural value added.

Source: Ali, van Leeuwen, and Koopmans 200I.

2. See the IAP, "Egypt: Improving Agricultural Production Through Better Drainage" 


\section{Box 8. 14 India: Sodic Lands Reclamation Project}

Sodification of soil left 1.25 million hectares of land completely barren in Uttar Pradesh so the Sodic Lands Reclamation Project (approved in 1993) helped provide sustainable solutions to the complex problems. Keys to success were farmer participation, incentives, and improved technologies. Farmer groups made major decisions and did virtually all the work, and smallholder receipt of clear titles to land provided incentives to make the barren lands productive. Farmers successfully used a package of technology involving a strict process of soil testing, digging surface drainage, building tubewells, applying gypsum, leaching and flushing with good quality groundwater, good crop husbandry, and regular flushing of salts from link drains.

Source:World Bank 2002.

Irrigation water also contains naturally occurring salts leached from soils of the catchment area or the recharge area of an aquifer. Salt accumulation in soil depends on irrigation water quality, irrigation management, and adequacy of drainage (Hillel 2000). Land salinization initially results in a lowering of crop yields or vegetative growth followed by appearance of salt patches. It can progress to a barren salty landscape if action (such as drainage) is not taken to leach excessive salts from the soil.

Sodic soil is closely related to saline soils. Applying irrigation water to areas with abundant salts (common in arid and semi-arid areas) and more than 15 percent exchangeable sodium leads to the formation of sodic (or alkaline) soils. Low chloride and calcium content in some soil and/or irrigation water can cause clay particles in the soil to adsorb sodium and magnesium salts and swell. The soil then loses its structure and permeability, water infiltration is hindered, and plant roots/soil organisms are deprived of oxygen. The solution to sodic soil problems is the use of soil amendments, such as gypsum, leaching, and drainage (see box 8.14).

\section{INVESTMENT NEEDS}

Irrigation water management is the important first step in controlling waterlogging and salinity. This involves controlling water to minimize losses, thus controlling deep percolation and runoff. Investments may involve improved surface irrigation systems (such as furrow irrigation, border irrigation or basin irrigation) or pressurized systems (such as sprinkler, drip and micro irrigation, or precision land leveling). All require credit or financial assistance, plus extension and training for successful establishment, operation, and maintenance. Improving irrigation efficiency often requires that conveyance and distribution systems be modernized to provide the right amount of water at the time needed by the crop (for example, in China, the number of irrigations was reduced from five to three of additional water to crop requirementsæcommonly less than $10-15$ percentto leach and this did not significantly affect wheat yields as water was supplied at critical growth times).

Seepage control is needed, where seepage from canals and reservoirs causes waterlogging or salinization. Investments to control seepage generally involve canal lining. Farmers, through WUAs, are usually responsible for lining their own (tertiary) canals, whereas governments are generally responsible for the larger canals. Many canal lining systems have joints that transmit large quantities of water to the seepage areas. These rigid canal lining systems may improve hydraulic transport of water in the supply canal, but do not provide adequate seepage control unless a flexible geo-membrane is properly installed under the canal lining. Seepage control from dams is also important for dam foundation safety, and modern lining techniques use geo-membranes to prevent seepage from small- and mediumsize reservoirs. Interceptor drains are used to collect and route seepage water to supply canals.

Drainage investments are critical to remove excess water from irrigation systems and to control waterlogging and salinity (see box 8.15). Surface drainage can control runoff from rainfall, but subsurface drainage is critical to prevent root zone waterlogging and salinization. When poverty reduction is an important goal, and for larger systems, governments make initial investments with some sort of cost-sharing/cost recovery arrangement as in the case of Egypt $^{2}$ and Pakistan. In commercial 
agriculture, drainage investments are often borne by farmers and user associations

Subsurface drainage can be provided by deep open drains, horizontal pipes or tubewells. Open drains normally must be 1-2 meters deep to, and therefore take a significant amount of cropland out of production. Subsurface pipe drains minimize loss of land, are readily accepted by farmers, and although initial investment costs are higher, the cost of operation and maintenance is much less. Tubewells are also used for drainage, particularly where groundwater quality is good and water transmission properties of the substrata are adequate. Tubewell irrigation, however, can draw excess salts from below the root zone and create water-quality problems.

Surface drainage through constructed channels or waterways is important to remove excess water in humid areas. Shaping land surfaces is often necessary to provide uniform water infiltration and to minimize ponding, particularly with surface irrigation. These investments are often financed by credit to farmers from private sources, but poverty reduction objectives may justify subsidies, cost sharing, or government financing.

Biodrainage has not been used extensively in large-scale projects, although it has promise under the right conditions. Biodrainage removes excess groundwater through transpiration by vegetation with high water use, such as Eucalyptus trees (see box 8.16). This maintains groundwater levels below the root zone of crop plants. Other advantages are wind erosion control, elimination of drainage water disposal problems, low investment cost, and ecological benefits. Disadvantages are that biodrainage areas use potential cropland, do not remove salts, and may interfere with water use by crops (FAO 2002).

\section{BENEFITS}

Economic benefits from control of waterlogging and salinity include: improved crop productivity; greater sustainability; and opportunities for

\section{Box 8.15 Egypt:drainage}

Adequate drainage has mitigated the effect of the irrigationinduced waterlogging and salinity in Egypt, which has invested about US\$3 billion (in FY200I dollars) since the 1970s to provide drainage for 2 million hectares. The government and farmers have shown strong commitment to the program, adopting appropriate technologies, improving irrigation systems, transferring management to water users associations, and adopting a well-functioning system of cost recovery. Egypt has a cropping intensity of 230 percent, and crop yields for wheat, rice, and cotton are among the highest in the world. Improved drainage accounts for 15-25 percent of crop yield increases. Reuse of drainage water in irrigation contributes to making overall water use efficiency in the lower Nile River Basin one of the highest in the world.

Source:World Bank 2002.

\section{Box 8.16 Pakistan: biodrainage in the Punjab}

Evaluation of biodrainage project examined an irrigated area of I 8.2 hectares with 4 hectares of six-year-old eucalypt trees planted at 1,340 trees/hectare. The surrounding area was planted to cotton, rice, and sugarcane. The average water table depth under the eucalypts ranged from 1.4 to 2.7 meters, and in the irrigated crop area surrounding the plantation was I.I to 2.I meters. Soil salinity remained below critical limits in the plantation. Water table drawdown resulted in the groundwater moving as a front toward the eucalyptus plantation area and improved environmental conditions in the surrounding area.

Source: FAO 2002.

crop diversification for higher income and lower risk reasons. For the India project even without accounting for incremental revenues from horticulture or benefits from improved education, health, and family income, the rate of return was estimated at 28 percent.

Social benefits primarily relate to poverty reduction, though other improvements in rural quality of life can be significant, such as a reduction of mosquito-breeding areas, improved storm water control, and improved access to fields.

Environmental benefits can include maintenance of wetlands, elimination of barren saline areas, and enhanced habitat and aesthetic 
values. Care must be taken when installing drainage facilities to protect existing wetlands and mitigate any damage. Disposal of drainage water from saline land can be a problem for downstream users.

\section{POLICY AND IMPLEMENTATION ISSUES}

Sustainability of irrigation systems in arid and semi-arid zones is unlikely if waterlogging and salinity problems are not controlled. Drainage needs must be evaluated when irrigation projects are initiated. Monitoring and evaluation of water tables and water quality changes in existing systems are critical. Irrigation budgets must have adequate financing for such monitoring, and for correcting problems that are detected. Decisions on when to undertake drainage work require realistic information from baseline studies, projections, or models, especially for newly irrigated land.

Institutional considerations should be addressed as early as possible in planning for waterlogging and salinity control. Water user associations facilitate participation of stakeholders, which is especially important early in the planning process. Arrangements for monitoring and evaluation of water tables, water quality, and soil quality changes are necessary on a continuing basis, as changes in cropping systems, water supply, seasonal water variation, and chemical use all impact groundwater levels and quality.

\section{Box 8.17 Potential investments}

- Credit and financial services to enable farmers to invest in on-farm drainage and water management improvements.

- Monitoring and evaluation systems for water tables and water quality.

- Surface, subsurface, or biodrainage control measures.

- Environmental impact studies of irrigation and drainage investments.

- Water user association strengthening to allow participation in planning and implementation of drainage and salinity control measures.

- Seepage control measures for dams, reservoirs, and canals. Source: Authors.
Environmental implications should be explored through environmental assessments, baseline studies, and monitoring of environmental changes. Plans for mitigation of environmental problems should be developed early in the project design phase. All investments to control waterlogging and salinity should seek to enhance environmental resources and develop policy packages to protect the environment.

\section{LESSONS LEARNED}

Get to THE SOURCE. The first priority is to find and eliminate (or reduce) the sources of excess water, such as seepage from canals and overirrigation, as this minimizes the drainage needs.

DisPOSAL OF DRAINAGE WATER. Investments in proper disposal or reuse of the drainage water is most important to minimize environmental concerns with water quality in downstream areas. However, water treatment is expensive and normally not feasible for irrigation systems. Systems for reuse of drainage water are sometimes worth consideration, and might include using drainage water from salt-sensitive crops for salt-tolerant crops, and then from these for more salt-tolerant varieties of trees, and finally diverting water to solar evaporators for crystallized salt collection.

Tubewells for Drainage. Public drainage tubewells are impractical when pumped water is too saline for irrigation use, especially if farmers are expected to pay for operation and maintenance.

\section{RECOMMENDATIONS FOR PRACTITIONERS}

Controlling waterlogging and salinity requires investments involving (see box 8.17):

- Timely provision of drainage for irrigation schemes based on sound investigation and planning during the project design phase.

- Use of participatory approaches so that inputs from stakeholders are provided during all phases of implementation.

- Investments to minimize drainage needs, 
such as effective canal lining and good onfarm irrigation water management.

- Consideration of environmental impacts to avoid water quality problems for downstream users.

\section{SELECTED READINGS}

Asterisk (*) at the end of a reference indicates that it is available on the Web. See the Appendix for a full list of Web sites.

Christen, E. W., and J. E. Ayars. 2001. "Subsurface Drainage System Design and Management in Irrigated Agriculture: Best Management Practices for Reducing Drainage Volume and Salt Load." Technical Report 38-01. CSIRO Land and Water, Griffith, NSW, Australia.*

Madramootoo, C. A., W. R. Johnston, and L. S. Willardson. 1997. Management of Agricultural Drainage Water Quality. Water Reports 13. Rome: FAO.*

\section{REFERENCES CITED}

Ali, A. M., H. M. van Leeuwen, and R. K. Koopmans. 2001. "Benefits of Draining Agricultural Lands in Egypt. Results of Five Years' Monitoring Drainage Effects and Impacts." Water Resources Development 17 (4): 633-646.

Heuperman, A. F., A. S. Kapoor, H. W. Denecke. 2002. Biodrainage: Principles, Experiences and Applications. Knowledge Synthesis Report 6. Rome: FAO.

Hillel, D. 2000. Salinity Management for Sustainable Irrigation: Integrating Science, Environment, and Economics. Washington, D.C.: World Bank.

World Bank. 2002. "Implementing the New Rural Development Strategy in a Country Driven Process: Agriculture and Rural Development Project Profiles." Presentation at the Country Director/Rural Sector Board
Learning Event, September 8-10, sponsored by the World Bank, Antalya, Turkey.

This note was prepared by Walter Ochs with inputs from Herve Plusquellec, Safwat Abdel-Dayem, Ariel Dinar, and other irrigation and drainage specialists in the Irrigation and Drainage Network of the World Bank. 


\section{AGRICULTURE INVESTMENT NOTE}

\section{INVESTMENTS IN SHALLOW TUBEWELLS FOR SMALL- SCALE IRRIGATION}

Shallow groundwater supplies provide a basis for small tubewells for both domestic and irrigation water needs. Water supplies for garden areas and small fields are pumped using human or animal power, but mechanized pumps are becoming common in all parts of the world. Small engines constitute about twothirds of shallow tubewell costs, but these can be used for other purposes such as powering boats, hand tractors, and other farm machinery. Shallow tubewells contribute to diversification of cropping systems and improve economic and social conditions. However, problems arise if tubewells overexploit the groundwater supply or contribute to salinization of groundwater. Evaluation of groundwater supply and quality, regulation of tubewell establishment, and technical support to farmers, are essential for sustainable tubewell systems to contribute to poverty reduction.

Tubewells are a cost-effective source of irrigation water for many small-scale farmers, where groundwater is available at shallow depths (less than 20 meters deep). These can irrigate up to 5 hectares depending on the soil, crop, and water conveyance losses. The technology is not complicated, and the acceptance by farmers and poor rural communities is rapid. Tubewells can be one of the better investments for pov-

\section{Box 8.18 India: groundwater wells}

About one-half of the total irrigated area in India depends on groundwater wells, and about 60 percent of irrigated food production is based on groundwater. In 1994, there were 10.5 million dug wells and 6.7 million shallow tubewells in India. The number of shallow tubewells roughly doubled every 3.7 years between 1951 and 1991. Groundwater irrigation results in at least a doubling of yield compared to surface-watered crops. However, some states in India are facing severe problems of declining water level due to overexploitation.

Source: Singh and Singh 2002. erty reduction, where groundwater levels are close to the surface and soils are productive. Shallow tubewells are already common in many parts of the world, particularly in Asia and Africa.

Shallow tubewell irrigation generally results in some form of crop diversification for home or local consumption or for export. Niger, for example, has developed a good export market for green beans shipped by air to Europe, with much of the production related to shallow tubewells. Conjunctive use of tubewell water (mostly shallow) to supplement inadequate supplies of surface water or water that is not available when needed to optimize crop production, is also common in many countries, particularly in Pakistan and India (see box 8.18).

\section{INVESTMENTS}

Shallow tubewells can be drilled by hand with simple soil auger-type tools, by power rotary drilling, or with a drilling method, called jetting or washboarding. They represent a relatively inexpensive way of supplying water for drinking and irrigation. In Bangladesh, wells are typically hand drilled even to depths of 60 meters, and cased with galvanized iron or plastic pipe that is slotted to allow water to enter while keeping the aquifer material out of the well. Wells are normally equipped with centrifugal surface-mounted pumps with 5 to 10 horsepower diesel engines. Each well can provide enough water to irrigate about 4 or 5 hectares.

In the semiarid Sahelian Zone of southern Niger area, groundwater depth is 6 to 8 meters and annual rainfall of 400-800 millimeters provides groundwater replenishment of about 500 million cubic meters. Most villages have at least one dug well for domestic water supply and some irrigation. Some tubewells have been installed with 3 to 5 horsepower portable gasoline-powered pumps, hand-operated pumps, or bucket and rope bailer systems. Irrigated area supplied by these tubewells is about 0.3 to 0.5 hectares, depending on the lift 
encountered and the water losses during transport to the field. ${ }^{3}$

\section{BENEFITS}

Shallow tubewells provide substantial poverty reduction benefits due to improved water supply for domestic use as well as gardens and crops. Increased production and family incomes lead to improved diets and better health. Engines used to pump tubewells represent about two-thirds of the cost of the tubewell. As these are also used to power boats, hand tractors, and other farm machinery, they improve the quality of life in rural communities, and are a low-cost way of providing economic benefits in poor areas with high groundwater levels (see box 8.19).

Negative environmental impacts of overexploiting the groundwater can be avoided if tubewells are not installed too closely together. Increased production from tubewells also reduces pressure on more marginal lands and increases land values, thus providing incentives for conservation.

Benefits from tubewells can also impact water markets. In Pakistan, for example, tubewell owners are sometimes active water sellers to neighbors. Well productivity, delivery potential, and the cost of operation and maintenance have a significant impact on the price of water.

\section{POLICY AND IMPLEMENTATION ISSUES}

Sustainability. Tubewell irrigation systems can contribute to the sustainability of an agricultural area, but evaluation of groundwater hydrology is important to ensure sustainability of shallow tubewell projects. Overpumping of groundwater from shallow aquifers by large numbers of wells clustered in a small area can have negative impacts on the water supply of neighboring tubewells. This can also lead to severe consequences such as lower water tables, decline in water quality, compaction of soil, and increased soil salinity (see box 8.20).

\section{Box 8.19 Nigeria: National Fadama Development Project}

Nigeria's Fadama project is centered on developing small-scale irrigation through extraction of shallow groundwater with lowcost gasoline-driven pumps for tubewells. About 30,000 hectares was irrigated using the complete tubewell-pump package and with 30,500 pumps distributed to farmers. This resulted in a positive impact on farmer income and significant poverty reduction. The economic rate of return of the project was estimated to be 40 percent. Additional benefits were development of a simplified well-drilling technology, training of farmers to help other farmers construct wells, infrastructure for transportation and storage of products, Fadama User Association establishment, and development of an extensive monitoring and evaluation system. Improved welfare of Fadama farmers can be directly attributed to the project.

Source:World Bank 2002.

\section{Box 8.20 China: water overexploitation in Ninjin County}

Groundwater is now the major source of irrigation in Ninjin County, since there has been a reduction in the quantity of Yellow River water. A rapid increase in irrigated areas has resulted in overexploitation of groundwater resources, causing serious environmental problems. The density of tubewells has reached more than one per 5 hectares, and average depth to water level in the wells has increased from 3.7 to 7.5 meters over the last 30 years. About one-tenth of the wells go dry during the summer. Farmers have reduced on-farm losses by using plastic tube to carry water to their farms, but they still use an inefficient method of basin irrigation. Application of water is about twice the standard volume for North China, and irrigation accounts for 30 percent of total production costs.

Overexploitation of groundwater has resulted in a progressive decline in profitability due to an increase in suction lift, and less (and poorer quality) water. The salt content of groundwater is contributing to an increase in soil salinity. Wheat, a major crop, is moderately salt tolerant, but maize (moderately salt sensitive), the other major crop, can fail if irrigated twice using saline groundwater. The area is thus facing a critical groundwater recharge problem, and the present situation is unsustainable. Reversing this trend will require adopting water-saving technologies, changing cropping patterns, and enforcing laws and regulations, or reducing the number of wells.

Source: Zhen and Routray 2002.

3. See the IAP,"Niger: Tailoring Irrigation Technology to Users' Needs" 
Policies to control density of wells in accordance with the groundwater recharge potential are critical to sustainability. It is normally the responsibility of governments to monitor and evaluate groundwater and develop rules that control wells.

WATER QUALITY. Water quality of the groundwater is important because deterioration from salt or mineral build-up can affect its usefulness. Government policies should require evaluation of groundwater quality and likelihood of changes in quality over time, prior to installation of wells. In Bangladesh, high arsenic levels in water have become a major health problem and are blamed in part on expanded use of shallow tubewells. Water quality evaluation is also important to minimize future maintenance costs since poor-quality water can increase encrustation and corrosion. In dry climates, tubewells tend to recycle irrigation water, and in more arid climates, salts leached from the crop root zones tend to degrade the water. Thus, in time the water extracted declines in quality and contributes to soil salinization. This is the case in large portions of the Indus River Basin in Pakistan.

\section{LESSONS LEARNED}

Public-private division of responsibility is important in formulating policy for shallow tubewell development. Tubewell investments are typically private goods that should be the responsibility of those who will benefit from the investment. The public sector role should generally be limited to establishment of a conducive policy and institutional environment for investment. Direct subsidies for tubewell drilling and operation are best avoided unless there is a compelling poverty reduction argument for the subsidies. One-off matching grants may be applicable in situations of high poverty and poorly functioning financial markets.

Water user associations are appropriate for shallow tubewell schemes since they can help control overexploitation and provide an opportunity for joint maintenance of wells and pumping equipment.
Surveying, drilling test wells, water sampling, and water level monitoring are useful to build a database and track long-term trends. The rational management of groundwater resources is difficult without a basic understanding of the distribution and yields of aquifers, and their vulnerability to pollution and overdraft. These monitoring activities are generally a government responsibility, but local authorities or communities can carry out some of the work.

Legislation and regulations are generally needed to control groundwater exploitation. However, lack of political will, lack if awareness among some farmers, but also active farmer opposition and lobbying, have been major constraints to implementing this type of legislation in many countries. Important issues to consider for national or regional legislation are:

- A system of licensing for extracting and using groundwater.

- Registration of existing groundwater users, and penalties for not complying with provisions of licensing.

- Arrangements to protect rights of shallow tubewell users from more influential farmers who are able to drill and power deep wells that lower the water table, and deprive access to water from shallow tubewells.

Training and extension are critical to facilitate good installation, operation, and maintenance of tubewells and for the development of local capacity for maintaining and repairing wells and pumping equipment. To optimize the benefits of tubewell investments, extension and training will be needed for irrigation water management, improved agricultural technology, and marketing systems.

\section{RECOMMENDATIONS FOR PRACTITIONERS}

Successful shallow tubewell systems require government promotion and regulation to ensure that tubewell investments are legally 
protected from overexploitation by excessive drilling or by other users of the same aquifer (see box 8.21). Experience with shallow tubewell projects emphasizes the need for investments to:

- Evaluate the groundwater hydrology and management to be certain that the groundwater recharge potential is in balance with anticipated water usage.

- Monitor groundwater quality to ensure suitablity for irrigation, and make realistic projections on the water quality change with time.

- Establish monitoring systems and laws and regulations to ensure sustainable development and operation of tubewell irrigation systems.

- Ensure provision of technical assistance, training, and extension services to help farmers properly install, operate, and maintain the systems to optimize agronomic benefits. Marketing of products that are new or more abundant in the area may also require advisory services.

\section{SELECTED READINGS}

Asterisk $\left(^{*}\right)$ at the end of a reference indicates that it is available on the Web. See the Appendix for a full list of Web sites.

Kahnert, F., and G. Levine, eds. 1993. Groundwater Irrigation and the Rural Poor: Options for Development in the Gangetic Basin. Washington, D.C.: World Bank.

Koegel, R. G. 1985. Self-Help Wells. FAO Irrigation and Drainage Paper 30. Rome: FAO.*

\section{REFERENCES CITED}

Singh, D. K., and A. K. Singh. 2002. "Groundwater Situation in India: Problems and Perspectives." International Journal of Water Resources Development 18 (4): 563-580.

\section{Box 8.21 Potential investments}

- Evaluate groundwater resources and quality.

- Reform policy and regulations to govern shallow tubewell development and operation.

- Strengthen water user organizations to manage shallow tubewell systems.

- Develop systems for monitoring water table depth and groundwater quality.

- Provide financial services to enable producers to finance:

- Drilling tubewells by hand, power rotary drilling, or jetting.

- Pump set with engine, hand pump or bailer system.

- Small canals or pipe to distribute water to fields.

- Micro-irrigation such as drip, mini-sprinkler, if justified by crop value.

- Provide training and extension to help farmers install, operate, and maintain shallow tubewell systems.

- Provide guidance in irrigation water management, agronomy, and marketing through extension and training.

Source: Authors.

Zhen, L., and J. K. Routray. 2002. "Groundwater Resource Use Practices and Implications for Sustainable Agricultural Development in the North China Plain: A Case Study in Ningjin County of Shandong Province, PR China." International Journal of Water Resources Development 18 (4): 581-593.

World Bank. 2002. "Implementing the New Rural Development Strategy in a Country Driven Process: Agriculture and Rural Development Project Profiles." Presentation at the Country Director/Rural Sector Board Learning Event, September 8-10, sponsored by the World Bank, Antalya, Turkey.

This note was prepared by Walter Ochs with inputs from Herve Plusquellec, Safwat Abdel-Dayem, Ariel Dinar, and other irrigation and drainage specialists in the Irrigation and Drainage Network of the World Bank. Peer review comments were provided by Ohn Myint and ljsbrand de Jong. 
INNOVATIVE ACTIVITY PROFILE

\section{CHINA: CONSUMPTIVE USE IN WATER RESOURCE MANAGEMENT FOR PRODUCTIVITY, EQUITY,AND THE ECOLOGY}

Historical irrigation development in the southern part of the Xinjiang Uygur Autonomous Region in northwestern China has resulted in a severe reduction in downstream flows and in negative environmental impacts. The Tarim Basin is a desert climate ( 50 millimeters annual rainfall), and the water source is principally high mountain snow and glacier melt into tributaries of the Tarim River, as well as some groundwater that is recharged, mainly from irrigation.

What's innovative? Using the concept of beneficial consumption of water in a comprehensive basinwide assessment and strategy that improves the ecological balance and resource use equity, without compromising productivity.

In the past, irrigation development in the Tarim Basin involved continual expansion of irrigated area without consideration of the ecological balance or of other users (such as downstream) affected by reduced water supply. Attempts to restrict water usage were perceived by farmers and irrigation technicians as a regulatory measure that would result in decreased productivity and production potential.

\section{PROJECT OBJECTIVES AND DESCRIPTION}

The Tarim Basin II Project was designed to implement a system of sustainable water resources development and management. The project has the potentially conflicting objectives of increasing downstream flows to preserve the environment of the lower reaches of the Tarim River, while increasing upstream farmers' incomes that are dependent upon irrigated agriculture. The project has supported the establishment and strengthening of the Tarim
Basin Water Resources Commission (TBWRC), with overall responsibility for water resources management in the basin. TBWRC has set quotas for water use in the tributary sub-basins, and has implemented a system to monitor and enforce the quotas. In addition, physical and management measures on the main Tarim River will deliver more water downstream.

The project is based on the concept of Beneficial Consumptive Use which uses the knowledge of the hydrological process and a basinwide approach to optimize the availability and use of water to meet the objectives of increased production and productivity, equitable access across the basin, and long-term preservation of the hydrological and ecological balance.

Water consumption in the upstream sub-basins is presently at the limit allowed by the quotas established and enforced by TBWRC, so no additional water is available, that is the total evapotranspiration (ET) in the sub-basins is fixed at present levels. ET was divided into three components for project planning and management purposes: (i) consumptive use (CU) related to human activity (mostly in irrigated agriculture); (ii) beneficial ET (BET) from trees and green areas along rivers and in and around oases; and (iii) nonbeneficial ET (NBET) mostly in low-lying areas with high water tables (including areas of salinization) and evaporation from nonecologically beneficial water surfaces. In the sub-basins, water consumption is about equally divided between $\mathrm{CU}, \mathrm{BET}$, and NBET and there is considerable opportunity for improvements in water resources management and development. The improvements need to concentrate on preserving BET, reducing NBET, and maximizing the production and particularly the value of production per unit of CU.

The Project includes various components focused on productivity increase as well as restoration of the Tarim River Ecosystem such as:

- Canal linings to reduce seepage in areas where most of the seepage goes to NBET. 
- Conjunctive use of surface and groundwater to allow groundwater to be used during low river flow months in the spring. This reduces the need for high-evaporation surface reservoirs, and lowers the water table in field areas to reduce capillary flux and NBET from ground surfaces.

- Land improvement that involves land leveling to reduce water requirements, and drainage systems to lower water tables thereby reducing NBET and increasing yields.

- Establishment and strengthening of WUAs that receive and pay for water by volume, and thereby conserve water that previously was excessively applied and contributed to high water tables and NBET.

- Agricultural practices, such as growing higher value crops with the adjustments in cropping pattern, improved cultivation techniques, and seed improvements.

\section{BENEFITS AND IMPACTS}

Under the project, more than 300 million cubic meters of water have been delivered to a 300kilometer stretch of the lower Tarim River known as the "Green Corridor," where no river waters had flowed for 30 years prior to 2001. The TBWRC now has a firm commitment to deliver 300 million cubic meters annually to this area. Strong institutional mechanisms, and the combination of establishing and enforcing quotas for the sub-basins and a commitment to deliver water annually to the lower reaches of the Tarim River, provide a solid foundation for sustainable water resources management and future development in the Tarim Basin. The new basin-wide and holistic approach of the project has resulted in a major shift in mentality of farmers and irrigation institutions - people are beginning to see that an ecology and equity-based water use approach that decrees limits on use through quotas does not have to compromise production and incomes.

\section{LESSONS LEARNED AND ISSUES FOR WIDER APPLICABILITY}

The Tarim Basin II Project has shown that, with a solid mix of institutional and technical measures and with strong political will, it is possible to meet the objectives of making more regular water deliveries downstream, while increasing incomes in upstream sub-basins through well-planned interventions. With comprehensive ecological knowledge it may be possible to find symbiotic strategies that serve several objectives, such as improved productivity, improved ecology, and equity of resource access.

\section{PROJECT COUNTRY: CHINA}

$\begin{array}{ll}\text { Project Name } & \text { Tarim Basin II Project } \\ \text { Project ID } & \text { P046563 } \\ \text { Project Cost } & \text { US\$272.6 million } \\ \text { Dates } & \text { FYI999 - FY 2005 } \\ \text { Contact Point } & \text { Douglas Olson } \\ & \text { The World Bank, I818 H Street } \\ & \text { NW,Washington, D.C. 20433 } \\ & \text { Telephone: (202) 473-9227 } \\ & \text { Email: Dolson@worldbank.org }\end{array}$


INNOVATIVE ACTIVITY PROFILE

\section{EGYPT: IMPROVING AGRICULTURAL PRODUCTION THROUGH BETTER DRAINAGE}

Approximately 97 percent of Egypt's population live and work on only 4 percent of the land, under conditions of extremely low rainfall. An estimated 3.5 million farmers cultivate average holdings of 0.85 hectare, making agriculture the largest employment sector. Farming is made difficult by an irregular and insufficient supply of irrigation water, and a rise in the water table following completion of the Aswan High Dam in 1970. This increased the irrigation potential of the area but also caused waterlogging and increased salt content of irrigation water. Given the extremely limited water and arable land resources of the country, efficiency of resource utilization is critical for agricultural productivity.

What's innovative? Improving agricultural drainage, an often neglected technical solution, may sometimes be as critical for productivity enhancement, as irrigation.

\section{PROJECT OBJECTIVES AND DESCRIPTION}

Through a series of projects-called the National Drainage Program-the World Bank and partners, such as the German Development Bank and the Netherlands Government, are working with the Government of Egypt to introduce gradual reforms to introduce technologies and improve the management of irrigation and drainage systems. Goals are to enhance agricultural productivity and the incomes of smallholder farmers by improving drainage conditions, reclaim land lost to waterlogging and salinity, and improve the institutional capacity of the Egyptian Public Authority for Drainage Projects (EPADP). A second objective is to redress the negative environmental effects of the discharge of untreated industrial and domestic waste into open drains.
In Phase I of the program, 302,400 hectares of irrigated farmland were targeted for drainage improved technical design and system management. A second phase, yet to begin, will target another 336,000 hectares of land, and will involve technical training and institutional reforms. Project activities include:

- Subsurface drainage - development, renewal, and rehabilitation.

- Open drain rehabilitation.

- Institutional support to EPADP and for the development of an Environment Management Plan. The project also has provision for social and participatory activities in two project areas.

During National Drainage Program I, EPADP organized farmers into drainage associations (Collector User Associations, CUAs) to facilitate interface with the end-users. By 1999, 2,269 CUAs were formed. NDP II will continue the development of CUAs. Additionally the project will develop two pilot schemes to explore the potential of integrating irrigation associations (Water User Associations, WUAs) with CUAs.

While the immediate need is for drainage system improvement, the projects are also focusing on creating institutional and community mechanisms for the long-term development and maintenance of the systems, and the systems for cost recovery. Beneficiaries pay for drainage investments over a 20 -year period with no interest charged, effectively amounting to about 45 percent of the cost in real terms.

\section{BENEFITS AND IMPACTS}

All major objectives of the first phase of the project have been achieved. Over 248,000 hectares have been provided with new subsurface drainage. Including renewal areas, subsurface drains have been installed on more than 311,000 hectares. On this area, yields of major crops increased by up to 20 percent. Estimates show that improved drainage accounts for 15 
to 25 percent of this yield increase. Many farmers switched to higher-value crops as a result of this project, particularly in the Nile Valley and the Delta region. Reuse of drainage water in irrigation, guided by appropriate criteria and guidelines, has resulted in one of the highest water use efficiencies in the world. The second phase will benefit about 400,000 farm households.

Different Egyptian public sector agencies have improved their management capacity, such as EPADP which monitors and evaluates both the technical aspects of drainage (for example measurement and analysis of hydraulic conductivity, salinity, and crop yields), and important social and institutional issues. Cost recovery for drainage investments and maintenance has improved, as is reflected in a 25 -year time frame for full recovery of capital costs, shared between government (50-55 percent) and beneficiaries (40-45 percent).

\section{LESSONS LEARNED AND ISSUES FOR WIDER}

\section{APPLICABILITY}

- Flexibility in implementation is key to guaranteeing success in this type of project.

- Although EPADP has improved its institutional capacity, further institutional building is needed, especially support to computerize various aspects of its daily activities.

- Compensation for crops damaged during subsurface drainage installation should be incorporated into the drainage installation contract, to be paid directly to farmers by contractors. This will circumvent the delays farmers experience in getting compensation when a government agency manages the compensation.

Drainage has often been a neglected component of irrigation system development, but can have a substantial effect on crop yields and system sustainability. Institutional innovations, training, and capacity building may be needed to reorient irrigation agencies and farmers from new irrigation investments to equally important drainage issues and investments.

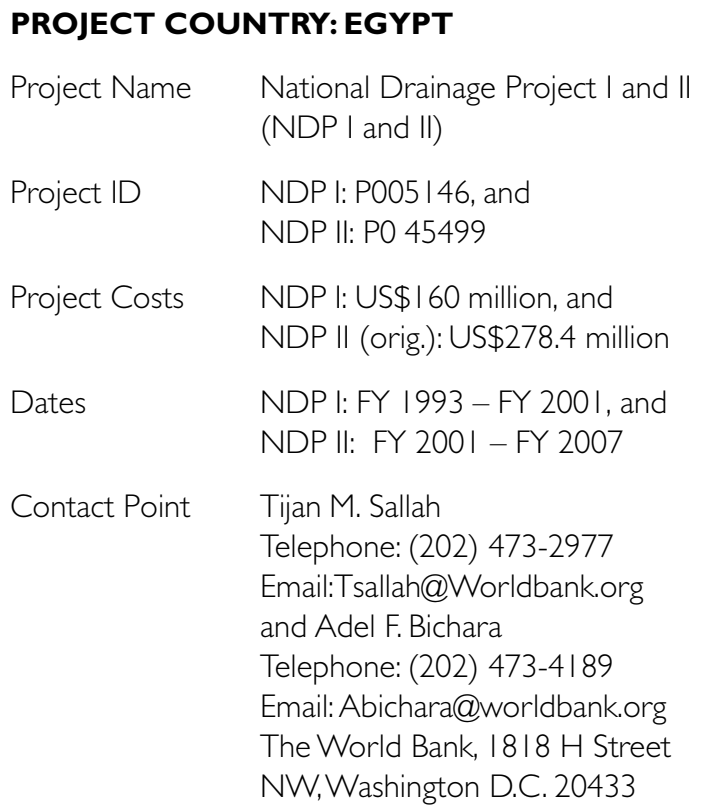


INNOVATIVE ACTIVITY PROFILE

\section{INDIA: RATIONALIZED PUBLIC, PRIVATE,AND FARMER ROLES IN GROUNDWATER MANAGEMENT}

Rajasthan, the largest state of India (supporting about 50 million people) is a desert state with 10 percent of the national area and only one percent of the country's water resources. The present major user of water is agriculture ( 83 percent of consumptive use), but projections to 2025 indicate a rapidly increasing demand for nonirrigation use. Water scarcity and a deterioration in water quality restrict the availability of water for domestic uses and irrigation supply.

\footnotetext{
What's innovative? A participatory approach to sustainable groundwater management and surface irrigation system/services management, with a rationalized and improved public sector, and increased role for farmers and the private sector.
}

The critical challenge is ensuring Rajasthan's long-term, sustainable use of increasingly scarce water resources, and improving the water use efficiency for agriculture. Water resources management is affected by weak capacity and uncoordinated effort among current water sector departments, a weak regulatory framework, poor management practices and unsustainable use in some areas, and high recurrent cost of delivery. Problems are inherent in past approaches based entirely on public sector resource management, with a lack of beneficiary participation in scheme management and financing.

\section{PROJECT OBJECTIVES AND DESCRIPTION}

The Rajasthan Water Sector Restructuring Project (RWSRP) aims to improve the efficiency of agricultural water use by increasing the productivity of irrigated agriculture through improved performance of surface irrigation systems and strengthened agricultural support services. The project aims at increasing system efficiency through downsizing, and improved coordination and rationalization of the public sector agencies, increased involvement of users and the private sector in design and management of systems, and increased cost recovery from users. To achieve these objectives the project finances the following:

- Water sector institutional restructuring and capacity building through (i) creation of a state water planning department, (ii) modernization of the water sector department, and (iii) piloting a community-driven institution for groundwater management.

- Improving irrigation system performance through (i) the formation and fostering of 620 WUAs, (ii) rehabilitation of irrigation schemes, (iii) strengthening of agricultural extension, and (iv) enhancing safety of 16 dams supplying the project area.

- Capacity building for a project management unit to ensure the effective implementation and coordination of activities involving several government departments.

The WUAs, over time and in close coordination with the Irrigation Department, are expected to take over the operation and management of surface irrigation systems up to the distribution level. The Government of Rajasthan has committed to moving toward full cost recovery of O\&M costs. The rehabilitation of irrigation schemes (about 90 major, medium, and minor schemes) also involves participation of WUAs, which contribute 15 percent of the rehabilitation costs.

The project would support at least three pilot schemes for a community-driven approach to groundwater management. This would involve the establishment of groundwater conservation districts (GCDs) covering identified aquifer areas with water depletion and quality problems. The GCDs would include an elected body of stakeholder representatives (rural and urban communities, farmers, industry, state agencies, and local government) empowered to develop and implement groundwater management plans, involving both supply- and de- 
mand-side approaches for groundwater management. The plans would be prepared at the village level by the Groundwater Management Associations, and integrated at the community level by the Gram Panchayat Level Committees, with assistance from NGOs and technical support groups.

The project includes a pilot scheme on "commercialization of irrigation services" in a distributory command, which would develop a farmer owned and managed utility for the management of a larger command area on a commercial basis. The core function of this entity is to provide water to farmers and other users, and to manage and maintain the water supply assets, including irrigation and drainage facilities. The farmer company would develop into an autonomous entity that would operate on commercial lines and have a bulk water entitlement from the Irrigation Department.

\section{BENEFITS AND IMPACTS}

The project is in the early stages of implementation, but is expected to benefit about 250,000 farm families. The annual value of additional agricultural production resulting from the improved delivery of irrigation water and agricultural support services under the project could reach Rs 2.1 billion (US $\$ 45$ million) by the end of the project. The project would stimulate additional demand for labor, estimated at about 29,000 jobs per year, (mainly of hired labor) and provide employment opportunities for the landless. Construction of civil works would generate an additional temporary 5-year increase in labor demand in the project area. Other benefits include reduced pollution, fewer water-related diseases, and improved public health.

\section{LESSONS LEARNED AND ISSUES FOR WIDER APPLICABILITY}

- A strong government commitment to fiscal and institutional reform at the highest level, and a sound legal framework, is critical to the successful formation and operation of WUAs. WUAs can effectively and efficiently

implement rehabilitation, if they are empowered early in the process.

- Agricultural demonstration programs for application technology should focus on a few high-quality demonstrations that can be replicated with good results.

- Minimizing the turnover of senior staff will improve the effectiveness and timeliness of the implementation of project activities.

- Funding from increased water charges can make funds available for operation and maintenance, improving the state's overall recurrent budget situation.

- Hybrid policy and multisectoral, statewide investment projects are complex. Investments are better concentrated on a few critical issues. This lesson is reflected in the design of this project with its limited project period objectives, but set in a longer-term context.

\section{PROJECT COUNTRY: INDIA}

\begin{tabular}{|c|c|}
\hline Project Name & $\begin{array}{l}\text { Rajasthan Water Sector } \\
\text { Restructuring Project }\end{array}$ \\
\hline Project ID & P040610 \\
\hline Project Cost & US\$180.2 million \\
\hline Dates & FY2002 — FY 2008 \\
\hline Contact Point & $\begin{array}{l}\text { R.S. Pathak } \\
\text { The World Bank, } 70 \text { Lodi Estate } \\
\text { New Delhi I I0 003, India } \\
\text { Email: Rpathak@worldbank.org }\end{array}$ \\
\hline
\end{tabular}


INNOVATIVE ACTIVITY PROFILE

\section{MALI: INSTITUTIONAL REFORM TO FOCUS PUBLIC ROLE ON ESSENTIAL PUBLIC GOODS}

A 1998 survey estimated 72 percent of Mali's people live below the poverty line, with poverty widespread in rural areas. Mali has areas with good agricultural potential. In the short and medium term, poverty reduction in Mali is dependent on accelerated growth in the agricultural sector.

What's innovative? Redefining responsibilities and core activities of a public sector organization to create a clear and viable focus on essential public goods.

Increased irrigation was expected to be one effective means to enhance productivity. However, without effective policy reform, major investments in the irrigation sector cannot be expected to result in significant benefits. This required i) reorganization of the management of the major public regional development agency specializing in irrigation-Office du Niger's $(\mathrm{ON})$, ii) the establishment of secure land tenure for farmers, and iii) the liberalization of pricing and marketing policies for paddy and rice. ON's mandate included the construction, operation, and maintenance of irrigation facilities; extension and applied research; and commercial activities, such as procurement and distribution, agricultural credit, paddy and rice marketing and processing. Redefinition of ON's activities was achieved over time and completed with this project.

\section{PROJECT OBJECTIVES AND DESCRIPTION}

The ON's Consolidation Project sought to reduce poverty, increase agricultural production, and reduce government subsidies for agriculture by providing strong incentives to farmers to increase production, improve the efficiency of irrigation management, and create mechanisms for sustainable irrigation development. ON's mandate has been redefined, and is now limited to activities directly related to the management of the land and water resources, with most commercial activities being progressively transferred to farmers or other economic agents.

The project financed the following:

- Sectoral policy reforms: (i) progressive divesting of ON's commercial activities, (ii) liberalizing rice prices and marketing, and (iii) establishing land tenure security for $\mathrm{ON}$ farmers.

- Institutional reforms: (i) streamlining ON's relationship with the government through performance contracts, (ii) reorganizing and capacity building of $\mathrm{ON}$, and (iii) restructuring ON's finances to eliminate its chronic deficit.

- Irrigation infrastructure and agricultural services in five areas: (i) rehabilitation and modernization of the irrigation network and perimeters, (ii) a pilot scheme to test the farmers' capacity to participate in irrigation rehabilitation and development, (iii) applied research on agricultural services, (iv) improved resource management, and (v) agricultural training and extension to promote improved production practices and crop diversification.

Market activity of ON was progressively divested to market agents, and the credit function to the National Agricultural Credit Bank. Relations between $\mathrm{ON}$ and the government was streamlined to ensure the autonomy of $\mathrm{ON}$ and to establish a contractual agreement between the two. ON was internally reorganized, its financing restructured, and investment made in capacity building. Village Associations (active in other parts of Mali) were promoted to partner with $\mathrm{ON}$, and take on some of its agricultural support functions over the longer term. 


\section{BENEFITS AND IMPACTS}

Significant gains made in the productivity and output of Mali's agricultural sector included:

- Increases in agricultural output, including nearly tripling total rice production and substantially improving vegetable production, resulting in an annual increase in real per capita income of US\$70.

- Liberalization of the rice trade and reduction in government expenditures on subsidies to the rice sector.

- Successful restructuring of ON, including a shift of some of its functions to other agencies and restoration of its financial health.

- Rehabilitation and modernization of 57 kilometers of canals and main drains.

- Improved water fee collection rates from 60 to 97 percent, with fees now being retained in the areas where they are collected.

- Improved land tenure and increased incentive for farmers to invest in productivity improvement.

\section{LESSONS LEARNED AND ISSUES FOR WIDER APPLICABILITY}

- Sectoral reforms should be accompanied by adequate complementary sectoral investments to have a major impact.

- Difficult institutional reforms, particularly those that go beyond a single ministry, should be headed by an independent agency outside the concerned ministries/ agencies.

- Greater farmer empowerment and involvement is one good way to ensure sustainability of irrigation investments.

- Greater transparency in land management increases farmers' land security even in the absence of official land titles. Land tenure security is one of the necessary conditions for private sector investment in irrigated farming.

- The mechanism for setting water fees should be an independent and transparent negotiated process based on clear needs, and free from government interference.

Under some conditions, reorienting institutional objectives for a specific administrative agency may be key to broad success. This is particularly true where the agency has a portfolio of responsibilities that are not closely related, and for which adequate staff expertise is not available and where public sector institutions undertake commercial activities.

Divesting authority within a state structure is never a simple or easy process. Sometimes, however, this is necessary to enable an agency to better serve its clients. As shown in Mali, the institutional realignment must also be accompanied by changes in attitude and behavior of employees.

\section{PROJECT COUNTRY: MALI}

$\begin{array}{ll}\text { Project Name } & \text { Office du Niger Consolidation } \\ \text { Project ID } & \text { P00 I7I8 } \\ \text { Project Cost } & \text { US\$83.6 million } \\ \text { Dates } & \text { FYI989 _ FY I999 } \\ \text { Contact Point } & \text { Eustacius N.Betubiza } \\ & \text { The World Bank, I I I H Street } \\ & \text { N.W.Washington, D.C. 20433 } \\ & \text { Telephone: (202) 458-56 I8 } \\ & \text { Email: Ebetubiza@worldbank.org }\end{array}$


INNOVATIVE ACTIVITY PROFILE

\section{NIGER:TAILORING IRRIGATION TECHNOLOGYTO USERS' NEEDS}

Three-quarters of Niger's 1.3 million square kilometers is desert, leaving 3.8 million hectares cultivable, most of which is in the south. Even in cultivable areas, variable and declining rainfall, and frequent drought cycles, make rainfed agriculture a risky enterprise. Niger has the potential to irrigate 270,000 hectares, using ground and seasonal surface water sources, but only 22 percent of this potential area is actually irrigated.

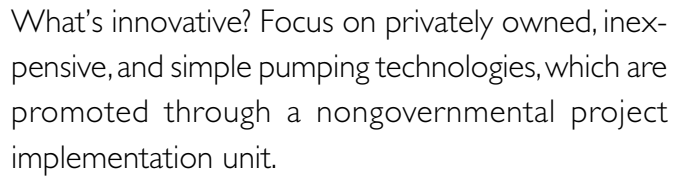

Large-scale, publicly funded irrigation schemes have the potential for positive returns based on existing technical capacity. Such schemes, supported in the past, were extremely costly, plagued by weak institutional support, and lacked costrecovery measures to finance operations and maintenance. The government also supported small- to medium-scale irrigation cooperatives on the perimeter of these large-scale projects. The National Office of Hydro-Agricultural Perimeters was to provide technical extension support to these schemes, but with no budget nor incentives for efficient service provision, its technical support has been quite weak. State-controlled cooperatives have neither been able to fully control nor to profit from their enterprises in a sustainable manner, due to state intervention and political interference in cooperative affairs.

\section{PROJECT OBJECTIVES AND DESCRIPTION}

The factors limiting farmers' use of irrigation technologies included lack of knowledge of technologies, lack of availability of tested technologies and maintenance services, and lack of finance. The Pilot Private Irrigation Project aimed to address these issues through assisting Niger in testing and evaluating the following: capacity building of the private sector, improved low-cost technologies for small-scale irrigation, improving grassroots saving, and erosion control works and monitoring of replenishable shallow aquifers. The project focused primarily on the poorest farmers, and on selected private commercial irrigators. Farmers interested in adopting technologies were asked to form economic interest groups.

The private irrigation association, Nigerien Association for Promotion of Private Irrigation (Association Nigérienne de Promotion de l'Irrigation Privée, ANPIP), was the implementing agency for the project. One distinguishing features of the project is the private legal status of ANPIP, free from political and bureaucratic interference, with adequate legal and administrative flexibility. Promotion of small-scale irrigation technologies was undertaken through information and assistance to farmers to access the technical and financial resources required to adopt the technologies.

ANPIP (i) carried out promotional campaigns in support of the government's private irrigation development strategy; (ii) facilitated small farmers' access to legal and administrative assistance for obtaining tenurial security; and (iii) provided assistance, upon demand, in preparation of irrigation projects and in establishing economic interest groups. Tasks contracted out to consulting firms included: (i) testing and evaluating technologies; (ii) promoting grassroots savings and credit schemes (by an NGO); and (iii) project related evaluation studies and periodic audits.

\section{BENEFITS AND IMPACTS}

The project has strongly supported the national agricultural strategy to increase productivity. Significant gains made in Niger's irrigation sector included:

- ANPIP grew gradually from a small group of ten people to 19 decentralized committees constituting 13,500 farmers. 
- An information campaign about the new national irrigation policy (through printed booklets, a prospectus, and radio and TV commercials) reached 2,000 representatives of farmers, and administration and traditional authorities. Following this, over 1,500 economic interest groups were established with membership of over 15,000 farmers.

- The training component included 382 training sessions covering 4,150 participants, and was complemented by radio, TV, newspaper, printed handbook, and demonstrations in the local market.

- The project introduced the treadle pump and promoted the tubular borehole, submerged pumps, motor pumps, and irrigation via buried pipes as components of comprehensive on-farm water systems. Farmers pay full cost for the technologies.

- Cultivated area increased by about 63 percent and there was an increase in yield of the major crops of between 27 and 32 percent (onion and sweet pepper respectively).

\section{LESSONS LEARNED AND ISSUES FOR WIDER APPLICABILITY}

- The shift of project administration from government to a private agency (ANPIP) enabled a private sector management style, and the legal and administrative flexibility to execute the project.

- Promotion of private ownership of treadle pumps and improved irrigation technologies, with incentives for good operation and maintenance were undertaken In relying on genuine demand in deciding the location of local pump manufacture, the project increased the chances that the nascent treadle pump market would be sustained in the long run.

- Giving farmers a menu of technology options, allowed them to choose the level of technology and investment appropriate to their farming conditions.

- Making available simple, locally made and affordable technologies, and training local craftspeople to manufacture and repair treadle pumps, kept the supply chain between farmer and manufacturer as short as possible, ensuring that pump parts and repair expertise would be locally available. Adaptations to irrigation technologies reduced their prices.

- Linking these basic technical changes with other changes, such as a sound irrigation policy, available credit, land tenure security procedures, and effective monitoring of project success, facilitated adoption and contributed to the program's success.

\section{PROJECT COUNTRY: NIGER}

\begin{tabular}{|c|c|}
\hline Project Name & $\begin{array}{l}\text { Pilot Private Irrigation Project; } \\
\text { Niger Private Irrigation Promotion } \\
\text { Project }\end{array}$ \\
\hline Project ID & Pilot Private Irrigation: P00।994 \\
\hline $\begin{array}{l}\text { Private Irrigation } \\
\text { Promotion: }\end{array}$ & P072996 \\
\hline Project Cost & $\begin{array}{l}\text { Pilot Private Irrigation: } \\
\text { US } \$ 7.5 \text { million }\end{array}$ \\
\hline $\begin{array}{l}\text { Private Irrigation } \\
\text { Promotion: }\end{array}$ & US\$48.4 million \\
\hline Dates & $\begin{array}{l}\text { Pilot Private Irrigation: } \\
\text { FY } 1997 \text { — FY } 2002\end{array}$ \\
\hline $\begin{array}{l}\text { Private Irrigation } \\
\text { Promotion: }\end{array}$ & FY $2002-F Y 2008$ \\
\hline Contact Point & $\begin{array}{l}\text { Daniel M. Sellen } \\
\text { The World Bank, I8I8 H Street } \\
\text { NW,Washington D.C. } 20433 \\
\text { Telephone: (202) 473-2 I } 74 \\
\text { Email: Dsellen@worldbank.org }\end{array}$ \\
\hline
\end{tabular}





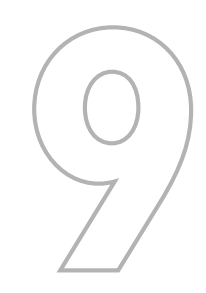

\section{INVESTMENTS IN LAND ADMINISTRATION, POLICY AND MARKETS}

and is the main asset of agricultural households in developing countries and is a key determinant of household welfare. Most land is used for agricultural production, which provides the basis for economic sustenance. Access to land plays an important role in improving agricultural productivity, achieving sustainable poverty reduction, and creating broader economic development. This overview provides a rationale for investments in land administration and reform, reviews past World Bank lending experiences, and provides guidance on new investment directions for land-related projects.

\section{RATIONALE FOR INVESTMENT}

The Bank's 1975 Land Reform Policy Paper highlighted the importance of land access and sound land policy for poverty reduction and economic growth. However, prior to the 1990s, the Bank's recognition of this importance was not always matched by a strong portfolio of land-related investments, and landrelated operations have often been complex, underfunded, lacking in political commitment, and limited in terms of stakeholder consultation and social assessment. The World Bank's current rural strategy, 
Box 9.I Impact of secure land tenure on poverty reduction

Smallholder tenure security can play an important role in increasing productivity and reducing poverty. More secure land tenure based on formal land titles and record systems can enhance farm productivity and income by providing incentives to smallholders to make productivity-enhancing investments (a security effect), facilitate access to credit and other service and inputs (a collateral effect), and facilitate land transfers and efficiency of use (a transaction effect). A detailed study before and after land titling in Honduras estimated that the combination of these effects on productivity provided an annual rate of return of 17 percent.

Source: López 1997.

\section{Box 9.2 Land tenure, land distribution, and poverty}

Redistributing land can be a powerful mechanism to benefit poor people. Typically, landless rural people have a higher incidence of poverty (see figure 9.1). More equitable land distribution is associated with lower poverty rates and more rapid agricultural growth, due in part to higher productivity and greater use of labor on small farms. Secure tenure status raises productivity and access to land broadens employment options and provides incentives for families to employ their labor and management skills in productive, income-generating activities. Importantly, land ownership (or secure tenure) confers social status in most cultures and improves opportunities to build social and human capital.

Reaching the Rural Poor, reflects a renewed interest in, and recognition of, the broader relevance of land issues for sustainable and equitable development. The Strategy acknowledges that efficient allocation and optimal use of land is an essential precursor for broader economic growth and poverty reduction. Accordingly, the Bank is working to increase land tenure security, to facilitate the development and effective operation of land markets and to improve land access by promoting land reform in countries with inequitable land distribution.

Greater security of tenure for small holders is associated with increased productivity and reduced poverty (see box 9.1). Secure property rights encourage landholders to manage resources sustainably, increase the value of household endowments, and allow household members to temporarily move off-farm to improve their earning capacity. Insecurity of tenure has negative impacts on governance and economic outcomes by increasing conflicts and reducing investment in agricultural production and agribusiness development. Well-defined property rights reduce the need by landholders to expend scarce resources to maintain or defend their claims. Land reform involving the redistribution of land can be a means to correct historical injustices resulting from control of land, as well as an effective way of reducing poverty (see box 9.2).

The public good elements associated with providing the technical infrastructure typically required for securing property rights, and the potential network effects associated with this, provide a strong rationale for government involvement in establishing the infrastructure and mechanisms needed to record, administer, and enforce land rights and by these actions strengthen the rule of law.

Tenure security in the form of well-defined, secure, and transferable land rights is a key precondition for land markets. Well-functioning land markets are important in that they transfer land to its best use and improve overall production efficiency and provide the basis for operation of financial markets in which land can be used as collateral. Although land sales markets provide incentives for long-term investment and structural change, they may be less accessible to poor populations. Land rental markets may provide access to land at lower cost and facilitate family response to outside shocks and off-farm employment opportunities.

During the 1990s, the Bank accumulated broad expertise in land-related issues, policy dialogue, and investments. The main focus of the Bank's land-related investments has been formalizing land rights through registration, and improving access to credit. Projects include facilitating free, public sector-managed registration in Central and Eastern Europe, and the improvement of land administration systems in Latin America and East Asia. The Bank has also supported transformation of the farming sector 


\section{FIGURE 9.I BANGLADESH: POVERTY PROFILE BY LANDHOLDING CLASS}

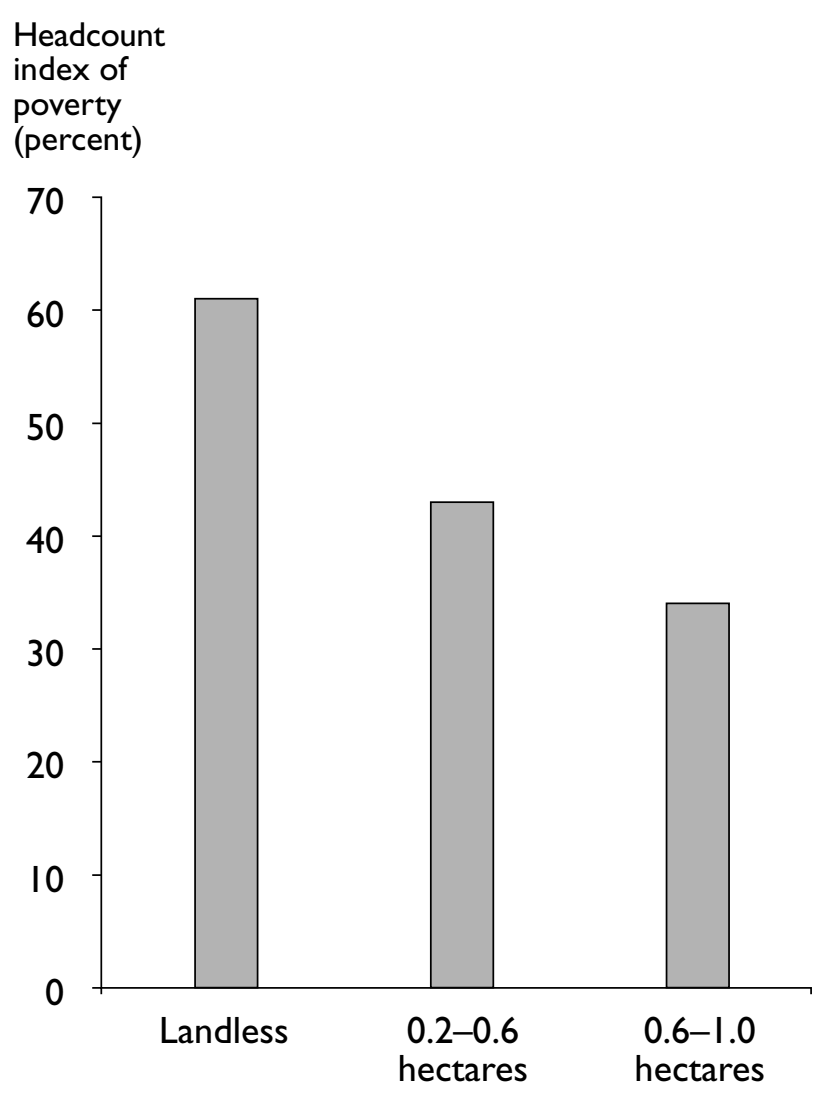

Landholding size

Source: IFAD 200I.

in transition economies, and promoted community-managed land reform programs in Brazil, Colombia, and South Africa.

\section{KEY ISSUES IN LAND ADMINISTRATION}

Lending for Bank land policy and administration projects in 2001 totaled US $\$ 195$ million, 92 percent of which was for land titling and administration. Limited financing was provided for land policy and governance (7 percent), land reform (1 percent), and common property resources (less than 1 percent). More recently, Bank land projects broadened to address the operational and financial sustainability of land administration systems by supporting the
Box 9.3 The World Bank land thematic team

The Bank's thematic team on land policy and administration works on issues related to land rights such as the control of and access to land, and the use of associated natural resources to promote sustainable development. The Team's work also encompasses efforts to provide policy advice, technical assistance, and guidance on the content of land policy reform programs.

Source:World Bank, Land Policy and Administration.

creation of property rights and mechanisms for titling, registration, transfer, dispute resolution, and revenue collection. Projects have also supported the development of infrastructure required to facilitate land market transactions, such as standards, processes, information systems, and mapping technologies (see box 9.3).

LEGAL FRAMEWORK. In a land reform project, if a pilot approach is to be used, then refinement of the legal framework may be necessary. Uganda, Sri Lanka, and Colombia had welldeveloped legal frameworks which were difficult or impractical to implement. Their land reform experience suggests the importance of starting with a pilot program in high-priority areas and linking legal drafting to implementation, adjusting the drafting to take into account feedback from the implementation process.

EFFICIENT AND EQUITABLE LAND ADMINISTRATION. from the use of new information and communication technologies. Much of Thailand's success in its land titling program was due to improvement of the land registry system and to the establishment of the one-working-day standard for completion of the registration of a parcel. Recovery of costs of land administration is a factor in deciding where and when land titling programs will be implemented. While full cost recovery may not be possible or desirable (negative effect on poor people), the cost structure and the revenue from registration, transaction fees, and land taxes provide a basis for long term sustainability of the land registry and the administration system. Lack of social equity in land titling and registration is a major 


\section{Box 9.4 Lessons for a sound land administration system}

- Develop a sound legal framework and a well-functioning land registry.

- Use administrative titling, as this has proved to be more efficient than judicial titling.

- Provide nationwide coverage, though not necessarily a uniform system throughout the country.

Combine cadastre and registration functions in a single institution to improve efficiency.

- Use a systematic titling and registration program in areas with high priority for regularizing titles, as this can be cost effective and facilitate uniform coverage.

- Establish an effective means of resolving disputes. This is essential and can include empowering field teams to resolve conflicts with participation of local community at the time of adjudication.

- Use public relations campaigns to educate property holders and encourage collaboration.

Source: Authors.

criticism as rights are granted for family/ household property (land or housing) to one person, usually the male head of household. Equity should also ensure that the claims of smallholders and marginal groups, including women, are given the equal legal protection. ${ }^{1}$ Such protection is particularly critical in situations of conflict, rapid social or economic change, or when property values escalate.

Devolving to state, local, and district offices that operate within a consistent national framework can increase efficiency, cost-effectiveness, transparency, and accessibility of land administration systems (see box 9.4). For situations in which public sector capacity is limited, use of the private sector (for example, contracting out land surveying and mapping work) and involving local community groups can greatly facilitate implementation of land administration activities.

Focus of PROGRAMs. Although most Bank land administration projects-such as those in the Lao People's Democratic Republic, Moldova, and Peru-have focused initial titling efforts on areas of high economic potential, other projects in Cote d'Ivoire, Tanzania, Indonesia, and Colombia have emphasized more marginal areas. The location decision will have implications for the cost of the land titling system, its fiscal sustainability, and its impact on poverty. Results of land consolidation programs have been mixed, although clear benefits occur in irrigation and drainage projects such as in the Indian Punjab. Programs tend to be costly and slow to implement, often due to difficult negotiations and trade-offs in the consolidation process. However, cultivation of dispersed small land parcels can also provide important benefits to smallholder in reducing risk of total crop failure.

LAND REFORM. A one-time redistributive reform effort may be necessary in countries where land ownership is highly unequal. But conventional land reform programs that are limited only to the transfer of land with no allowance for complementary investment, technical assistance, and supplementary resources, have generally yielded few equity and efficiency benefits. For example, restricted access to credit markets and insecure property rights in Nicaragua and the Philippines led to land reform beneficiaries selling their land, often at prices well below the productive value of the land (Jonakin 1996).

Community-managed land reform programs (also referred to as "market-assisted" or negotiated programs) funded by government grants provide an alternative to conventional land reform approaches by decentralizing land acquisition and allowing the self-selection of beneficiaries to choose the type of project, identify land, and arrange for investments and technical support needed for their projects. Given the political and sensitive nature of land reform, it is important to demonstrate that the community-managed approach can usefully complement other land reform efforts. At the local level, strong support by local governments and nongovernmental organizations (NGOs) has been critical to the success of community-based models.

I. See the IAP,"Lao PDR: Preserving Women's Rights in Land Titling" 
Community-managed land reform projects have been substantially delayed by slow government acquisition of land. Although the Bank has allowed land purchase costs to be considered as project counterpart funding since 1977, Bank financing has been limited to supporting the nonland costs of land reform projects. The Bank's inability to fund land acquisition has prevented it from funding integrated land reform pilots for demonstration purposes. Recent changes in Bank policy have eliminated the overall prohibition on the use of funds for land acquisition providing conditions are met, such as land market analysis, including productivity assessment, and project management, including monitoring and evaluation, and administration of funds.

\section{KEY ISSUES IN LAND POLICY FRAMEWORKS}

Land policy refers to the public choices that determine how land rights and land use are established, changed, restricted, and enforced in order to promote specific goals within a society. For land policy to be an effective instrument of poverty reduction and sustained economic growth, emphasis on the administration and delivery of basic services must be complemented by a focus on strategic objectives for land policy (see box 9.5). Policy frameworks should establish property rights regimes appropriate to regional conditions, define and protect the rights of poor and vulnerable groups, and facilitate efficient land administration systems. Policies must also promote economic efficiency and ensure environmental conservation of land resources.

Property Rights Regimes. The Bank does not have an operational policy on property rights, but its land projects recognize the importance that strong property rights have in creating incentives for investment. The main challenge in establishing any type of property rights regime (customary tenure, common property, state land ownership, or individual ownership) is to ensure its acceptance. Effective enforcement mechanisms taking into account social needs aimed at maximizing social welfare and economic growth are vital (Feder and Feeny
Box 9.5 Key objectives of land policy frameworks

- Security of land tenure, including legal recognition and support for customary land tenure systems.

- Equitable access to land, including legal recognition and support for land rights of women and minority groups.

- Sound management of public lands.

- Efficient use of land with well-functioning market mechanisms for land transactions.

- Protection of land resources through provisions for conservation and sustainable use.

- Linkage of land administration to poverty reduction strategies.

Source: Authors.

\section{Box 9.6 Land policy issues vary by region}

Government land policy will vary by region and country conditions. In Africa, strengthening and working with customary community management systems is important. In Eastern Europe and Central Asia, the focus is on defining and strengthening private property rights and land markets. In Latin America and parts of Asia, ensuring indigenous people's tenure rights is a key issue. Government policies are stated in various ways, including legislation, regulations, and "white papers" (policy statements). Policies must also be disseminated widely to ensure that citizens are aware of their rights and responsibilities in relation to land matters.

Source: Authors.

1991; Feder and Noronha 1987). Choosing the optimal regime will depend primarily on the type of land resource and its potential use; on the ability to minimize negative or external effects through regulation; and on the costs involved in establishing and enforcing rights (see box 9.6).

These typically involve land ownership by the community rather than the individual. Property rights are enforced through existing social norms, and market transactions are generally limited to the community. These arrangements have often been viewed as economically "inferior" and are seen as equivalent to collective cultivation. However, communal arrangements can be a cost-effective way to ensure land access and security of tenure for the poor rural people under conditions of low population density, of high ecological variability, and 
Box 9.7 New perspectives on customary land tenure

Customary land tenure is the predominant form of land tenure in indigenous areas of Latin America and South Asia, in Africa, and in some countries of East Asia. It may be recognized by national law or exist independently of national law, grounded in and legitimized by community consensus. Customary land tenure systems often include important communal rights as well as family and individual land rights. These were seen as obstacles to nation-building because customary land law varied widely and was implemented by ethnically based traditional leaders, whose power often came from control over land. The rules of customary land tenure are not static and have evolved to meet new needs; attempts to replace such systems often fail, leaving greater tenure insecurity in their wake.

In many parts of Africa, for instance, it may prove too expensive to maintain modern land administration institutions in poor rural areas. Traditional land administrators, while they have limitations, represent a low-cost, community-based system of land administration. These perspectives are increasingly reflected in Bank policy and programs. In Cote d'lvoire, the Bank is financing the titling and registration not of reformed rights but of customary rights. In rural Ghana, the Bank is supporting registration of community territories and land administration by traditional authorities.

Source: Authors.

of low resource values (see box 9.7). Working within these customary tenure rights in the context of a national land policy framework can often increase security of tenure and lead to major equity and efficiency benefits.

By building on successful experiences, the Bank can promote legal recognition of customary tenure arrangements in countries that do not recognize such rights (particularly in Africa and the former Soviet Union) and can build the capacity of customary institutions. Existing customary tenure arrangements should be assessed before legislation is drafted. This will ensure that the legal framework for land tenure appropriately complements existing conditions of land ownership and use, and that the statutory rights of women and minority groups are recognized and protected. Efforts should be made to recognize such systems through legislation and to build the capacity of existing customary institutions that could implement property rights laws and maximize tenure security. Robust private rights (often "ownership") are necessary if land rights are to be acquired by individuals through market transactions or exchanged in formal and informal settings. Individual title ownership is a common means of providing secure and transferable land rights and a source of credit and investment once an economy has become highly commercialized.

In a transition from customary tenure to individual private property regime, legal and regulatory provisions are needed to avoid disenfranchising individuals, particularly women, who may be illiterate, poorly educated, or who lack influence. Tenure security can be significantly enhanced by less formal measures, such as secure and transferable long-term leases and at a lower cost than formal titling. These measures can provide many of the advantages associated with full ownership rights.

COMMON PROPERTY RIGHTS. COmmon property resources, such as public forests and pastures are often difficult to manage and effective regimes require legal and practical control over resources, adequate institutional arrangements for decisionmaking and enforcement, and sufficient social capital for implementing decisions. The Bank's experience with common property regimes has been experimental to date, but there is growing appreciation that poverty reduction can sometimes best be realized through community natural resource management under common property regimes, using a variety of contractual arrangements. In these cases, fair, efficient, and equitable rules for resource access for the community are needed rather than individual titled ownership. State and community lands such as national parks and restricted areas, forest reserves, community forests and woodlots, may be covered by national policies that define uses, restrictions, and responsibilities for management and control. Privatization of state lands is an issue relevant to many countries and has been an important aspect of economic reform in Eastern Europe and Central Asia. While full privatization can be politically sensitive, an 
alternative approach, successful in China and East Asia, is the provision of long-term leases for use of state lands.

Social AND ECONOMIC ASPECTS OF LAND POLICY. Social targeting of poor people, women, and minority groups should be included in nation land policy frameworks to improve their welfare by enhancing their access to and control of land. For this objective, detailed and adequate legal frameworks, streamlined procedures for transferring tenure, and capacity building for supporting institutions are still required. In Latin America, the Bank has moved beyond an abstract recognition of women's legal rights to ensuring such rights through joint titling of conjugal property. Countries in Asia and Latin America recognize customary land rights in principle and allow for the internal management of land by indigenous communities with the Bank actively involved in Bolivia, Nicaragua, and the Philippines. Pilot projects in Peru and Brazil have helped to streamline procedures for giving ownership title to indigenous populations (Roldan 2002).

LAND TAX. Land tax policy is a difficult political issue as a system for land taxation, based on productivity and land values, it can be an efficient means of revenue collection for national or local governments. This approach is generally more effective than taxes based on outputs. Land revenues typically derive from annual property taxes or taxes on land market transactions. Thailand's land titling program produced a substantial increase in land transfer tax revenues and facilitated collection of annual land taxes.

\section{KEY ISSUES IN LAND MARKET DEVELOPMENT}

Efficient land markets should maximize land productivity and introduce flexibility to the rural economy and to family livelihood strategies. If government policies try to address social inequities through ownership ceilings, fixed prices for land, restrictions on transfer, and land subdivision for inheritance, these policies often introduce market distortions that
Box 9.8 Government interventions and land markets

Government interventions in rental market, such as sharecropping restrictions, self-cultivation requirements, and rent controls, often motivated by considerations of social justice, may have unintended detrimental consequences. Legal and administrative restrictions on rental markets negatively affect agricultural productivity and household welfare, discourage investment, and decrease security of tenure. Typical interventions in sales market, such as prohibiting foreign ownership, land ownership ceilings, and land price limits, can limit access to much-needed capital in markets, and ultimately undermine the ability of banks to engage in lending.

Source: Deininger 2003.

undermine the functioning of land markets and unintentionally reduce opportunities for more equitable access to land (see box 9.8). Landholding size and its impact on productivity may be a public policy concern. Family farms may be more productive where production processes are not overly capital intensive, and access to credit and capital is broadly similar across farm sizes. But imperfections in factor and credit markets may give advantages to larger farms who expand their holdings. Broader agricultural sector policy changes, such as eliminating credit subsidies and dismantling agricultural protection, can improve the functioning of land markets and can contribute to land price declines. Under these circumstances, small farmers may have better access to land through market mechanisms. Consequently, land projects should seek to eliminate factor market distortions, land market restrictions, and broader sector policy distortions.

LAND RENTAL MARKETS. These can provide a lowcost mechanism for poor people to eventually become landowners provided that property rights are long-term, enforceable, and fully transferable. Rental markets may improve the allocation of land and enhance equity, but the impact on equity depends on the landlord and tenant arrangements, and these may depend on alternative employment opportunities. Productivity tends to be comparable between owned plots and fixed-rent plots. Share cropping (share tenancy) is a second-best option in rental mar- 
kets, with studies indicating that it may be associated with some productivity loss compared to fixed-rent agreements. There is evidence that eliminating the share-cropping option leads would-be renters to rely on wage labor which is both less efficient and less equitable. Rental markets may enable landowners to increase the size of their farming operations and may provide land-owning, non-farm households with a sustained income by renting out their land.

Transaction costs associated with land rentals are normally lower than those in sales markets but can be further reduced by making information on land ownership, contractual forms, and rent prices more widely available. Legal or other restrictions on land rental markets, such as rent ceilings and tenancy restrictions tend to reduce security of land rights, introduce market distortions, and force land owners to adopt measures to protect their claims to land and may negatively impact agricultural productivity and household welfare. Such restrictions may also discourage investment and increase off-farm employment and migration. While both rent ceilings and tenancy restrictions may transfer resources to poor people in the short term, the long-term impacts are not likely to be advantageous. Secure property rights, the ability to enforce contracts, and availability of necessary information are key to facilitating longer-term contracts and determining the impact of tenancy on equity and investment.

LAND SALES MARKETS. Land Ownership provides incentives for investment in land, facilitates structural change, and, through the ability to sell, provides a basis for using land as collateral in credit markets. In environments where credit markets do not function well, land sales markets are more likely to lead to undesirable, efficiency-reducing outcomes, such as speculative purchases, high transaction costs, distress sales, and reduced opportunity for small producers to purchase land.

Some restrictions on ownership are difficult to enforce and wide experience indicates that these are not justified, are likely to be evaded, have undesirable side effects, and should be avoided with two possible exceptions. Rapid changes in the external environment justify ceilings on land ownership and giving local communities authority to restrict transferability of land (as is the case in most customary systems). Such restrictions are best phased out as rapidly as possible.

In summary, governments have three options for improving land rental and sales markets:

- Eliminate distortions to improve functioning of markets.

- Reduce transaction costs, for example through better land records.

- Impose direct restrictions on market transactions to avoid undesirable outcomes.

The focus is usually on the first two, as direct restrictions seldom yield expected outcomes and generally have resulted in efficiency losses. Existing restrictions should generally be eliminated in such a way as to minimize disruptions and negative effects on equity. Restrictions on land markets are unlikely to lead to significant redistribution of land, but will result in large bureaucracies with an interest in maintaining these restrictions.

\section{FUTURE DIRECTIONS FOR LENDING}

Recent experiences with land-related investments provide a basis for new approaches to land access and use that may improve land administration and reform programs and ultimately enhance economic and social benefits. Land policy issues need to be addressed in World Bank Poverty Reduction Strategy Papers (PRSPs) as access to land is often critical to the wellbeing of poor people, and land tenure security is essential to the investment needed to increase agricultural productivity and rural incomes.

Land Policy and Administration. Bank land projects need to provide more emphasis on ensuring the operational and financial sustainability of land administration systems.

- Developing sustainable land administration systems and land registries. Sustainability 
requires greater attention to cost recovery, a client-service orientation, and cost-effective administrative systems. Programs will have to strengthen land valuation skills and improve land tax administration, through building capacity of both public and private sector institutions. New technologies for mapping and monitoring land use and land quality will improve the ability of public agencies to plan and manage land for conservation and sustainable use. ${ }^{2}$ Implementing systematic titling and registration programs will need to complement ondemand titling activity, with country analyses identifying priority areas and options. For situations in which greater economic activity is not a factor, on-demand titling and registration procedures are likely to be adequate. The greatest impact of providing land titles is improving farmers' access to credit as land can be used as collateral. Programs must be designed with greater attention to their ability to improve access to financial markets.

- Increasing involvement of local communities in land policy debates and titling programs. Projects will increasingly need to engage local communities, including women, landless people, and minority groups, in the analysis of tenure arrangements and the promotion of greater stakeholder participation in project design. Community participation will be enhanced if there is a national policy on such participation. Financing local-level pilot projects co-managed by communities can test what will work in practice.

- Enhancing security of tenure for common property resources and promoting legal recognition of customary tenure arrangement. Land policy and administrative arrangements are recognizing the value of traditional community institutions and tenure arrangements, as these are cost effective and socially acceptable; however, these may need to evolve in order to be reconciled with formal tenure systems and with changing conditions.

\section{- Promoting wide dissemination of land} policy and administration information. Analysis of the legal and institutional frameworks for land administration is a standard component in Bank-sponsored projects and should be widely disseminated.

- Increasing equity of land tenure and titling programs. Recognition of women's land rights will need to be reflected in the law, in land rights awareness campaigns, and in the provision of legal assistance. Legal reform programs should address land inheritance inequities and make mechanisms for land tenure enforcement more accessible to women. Educational campaigns on gender-related land issues should target national policymakers, local officials, and communities. Indigenous land rights should be recognized in the policy framework. Community access to restricted areas and community control over traditional lands may require innovative legal and implementation arrangements at the field level.

- Strengthening land rental markets. Bank land projects should seek to establish the legal and institutional conditions for longterm leasing arrangements and to improve the functioning of land rental markets by supporting the dissemination of land price information, the simplification of contractual mechanisms, and strengthening the enforcement of rental contracts.

Land Reform. Poverty is due to low income and to lack of access to productive assets. There is considerable evidence that smallholders are usually more efficient producers. However lack of credit may be a factor in their inability to purchase land and governments may need to

2. See the IAP,"Armenia: Benefits of Securing and Registering Land for Rural Development" 
intervene to counter the failures in land and financial markets. Land reform is seen as a direct and sustainable means of addressing poverty. The Bank's support for land reform, provides funding to land reforms that have involved compulsory acquisition of land. In these cases, those losing land are compensated according to the Bank's Safeguard Policy on Involuntary Resettlement. As the Bank was, until recently, prohibited from disbursing money against land, it supported resettlement and related investment costs rather than land acquisitions in those reforms. The Bank is still open to supporting well-conceived and executed land reform programs based on compulsory acquisition or redistribution.

In the early 1990s, Bank staff working in Latin America and Asia developed a new and more efficient model of land redistribution that used market mechanisms. Using client government funds, Bank-funded projects channeled funds to associations of beneficiaries who would purchase land on the market. These programs redistributed land without coercion, respected established property rights and were coupled with policy reforms to facilitate the operations of land markets. ${ }^{3}$ An exception to the Bank's disbursement rules now allows funding to support the purchase land.

It is not a matter of either community-driven land reform or compulsory land reform. Each may play a useful role. For example, in Brazil, the federal government acquired large blocks of land compulsorily, and the Bank supported state land reform programs which acquired land, usually smaller holdings, on the market. In some cases, compulsory acquisition and redistribution of land will remain an important alternative. Future land reform investments will likely stress:

- Community-managed landreformmodels. The model of community-managed land reform that is implemented in a number of countries provides an effective means of dealing with inequitable land access.
- Inclusion of technical assistance and support. Land reform programs will support the development of viable agricultural enterprises through technical assistance and credit or grant support for sound business plans. These are likely to greatly increase the returns to investment in land reform. Strong support by local governments and NGOs has been critical to the success of community-based approaches, and land reform programs should include an institutional capacity building component.

In some countries, where the government retains title to and control over substantial amounts of productive land, privatization or long-term leasing arrangements may be an effective means of increasing employment and productivity, as well as promoting better management and conservation of the land.

\section{SCALING UP INVESTMENTS}

As land project investments are increasingly linked to broader macroeconomic and poverty issues, it is important to evaluate the contribution these projects make to improved household welfare, poverty reduction, and economic development. To establish the effectiveness of a land investment project to these goals, relevant indicators should be used to identify economic, social, and environmental impacts. Economic indicators may include productivity, economic growth, land tax revenue, and cost of land transactions; social indicators may include the incidence of land disputes, labor mobility and land distribution profiles, including female ownership; and environment indicators may include land use changes, erosion control and deforestation. In this regard the World Banks safeguard policies are relevant for practitioners involved in land administration initiatives (see box 9.9).

These impacts are likely to be measurable only over many years, usually well after project completion which will affect the timing of

3. See the IAP,"Brazil: Participatory Negotiations and Market-Assisted Land Reform" 
impact studies. Multipurpose household surveys provide an opportunity to measure land investment indicators at a relatively low cost.

There appears to be substantial interest and opportunity for expanding investments in land administration, policy, and market development. Market economies which emphasize governance issues facilitate those land reforms projects that need functioning land markets. Future land investments would benefit from definition and analysis of good investment practice in the following areas: customary land tenure systems, indigenous people's land rights, land institutions, technologies for land administration to deal with issues of consolidation, registration, land taxes, and revenue systems and analysis, and resettlement in post-conflict situations.

\section{SELECTED READINGS}

Asterisk (*) at the end of a reference indicates that it is available on the Web. See the Appendix for a full list of Web sites.

Deininger, K. 2003. Land Policies for Growth and Poverty Reduction. A World Bank Policy Research Report. Washington, DC: World Bank; Oxford and New York: Oxford University Press.

Ghimire, K. B., and B. H. Moore, eds. 2001. Whose Land? Civil Society Perspectives on Land Reform and Rural Poverty Reduction: Regional Experiences from Africa, Asia and Latin America. Rome: Popular Coalition to Eradicate Hunger and Poverty; Switzerland: United Nations Institute.*

Toulmin, C., and J. Quan, eds. 2000. Evolving Land Rights, Policy and Tenure in Africa. London: IIED.

World Bank. Land Policy and Administration. http://lnweb18.worldbank.org/ESSD/ ardext.nsf/24ByDocName/ LandPolicyandAdministration
Box 9.9 World Bank safeguard policies relevant to land policy and administration

The Bank's work in land policy and administration is affected by policies defined in Operational Policies (OP) documents designed to build safeguard activities into a project:

- OP 4.01 on environmental assessment requires that the environmental impact of land projects be assessed and minimized.

- OP 4.12 on involuntary resettlement requires that involuntary displacement from land be minimized and that adequate compensation be paid to those whose land is taken. For land titling projects, OP 4.12 excludes from consideration disputes between two private parties where the losing party is displaced. But OP 4.12 does apply to disputes between private displaced parties and government as these are given protection even if they have no legal right to be on the land. Bank-funded titling projects may avoid titling in such areas. If a government complies with OP 4.12, an agreement must be reached on an involuntary resettlement framework.

- OP 4.20 on indigenous peoples emphasizes the importance of land to traditional ways of living and culture by protecting land rights under customary law that are recognized by national law. It seeks to avoid disrupting those rights which, if affected, must be compensated.

Other key safeguard policies include OP 4.04 on protecting natural habitats; OP 7.60 on requiring consultations among neighboring countries to ensure there are no objections in a disputed area; and OP 4.36 on committing governments to undertake sustainable management and conservation-oriented forestry.

Source: World Bank, Operational Manual.

\section{REFERENCES CITED}

Deininger, K. 2003. "Land Policies for Growth and Poverty Reduction." A World Bank Policy Research Report. Washington, DC: World Bank; Oxford and New York: Oxford University Press.

Feder, G., and D. Feeney. 1991. "Land Tenure and Property Rights: Theory and Implications for Development Policy." World Bank Economic Review 5 (1): 135-55.

Feder, G., and R. Noronha. 1987. "Land Rights Systems and Agricultural Development in Sub-Saharan Africa." World Bank Research Observer 2 (2): 143-69. 
IFAD. 2001. Rural Poverty Report 2001: The Challenge of Ending Rural Poverty. Oxford and New York: Oxford University Press.

Jonakin, J. 1996. "The Impact of Structural Adjustment and Property Rights Conflicts on Nicaraguan Agrarian Reform Beneficiaries." World Development 24 (7): 1179-91.

López, R. 1996. "Land Titles and Farm Productivity in Honduras." Department of Agricultural and Resource Economics. University of Maryland, College Park, Md.

Roldan, R. 2002. "Indigenous Land Rights and Natural Resource Management: Legal and Institutional Issues." Paper presented at the Regional Workshop on Land Issues in Latin America and The Caribbean, May 19-22, Pachuca, Mexico.

World Bank. Land Policy and Administration. http://lnweb18.worldbank.org/ESSD/ ardext.nsf/24ByDocName/ LandPolicyandAdministration

World Bank. Operational Manual. http:// wbln0018.worldbank.org/institutional/ manuals/opmanual.nsf/

This Overview was prepared by Danielle Typinski (USAID) based on the World Bank Policy Research Report. "Land Policy for Pro-Poor Growth and Development" by the Bank Research Department and the Land Policy and Administration Thematic Group of the World Bank and with further inputs from Wael Zakout, John W. Bruce, Klaus Deininger and other members of the Land Thematic Group. Peer review comments were provided by Frank Byamugisha, and Susana Lastarria (University of Wisconsin). 
AGRICULTURE INVESTMENT NOTE

\section{INVESTMENTS IN SYSTEMATIC LAND TITLING AND REGISTRATION}

The security, duration, and enforceability of property rights have major impacts on land investment incentives, land market operations, and the development and functioning of financial markets. In situations characterized by high land values, conflict over land, and increasing population densities, formalized property rights systems with a strengthened tenure of security have important economic and social benefits. Systematic titling and registration offers equity and cost advantages when implemented under supportive policy, legal, and institutional frameworks.

Land tenure insecurity, exacerbated by population pressure, escalates conflict over land use, inhibits land transactions, and discourages investment in farming, industry, housing, and the physical infrastructure necessary to support economic growth. Property rights within a land administration framework increase land tenure security. The main mechanisms for formalizing property rights are land registries and title documents. These provide protection against challenges to individual rights and facilitate transfer of rights and the development of secondary financial instruments, such as mortgages.

\section{TITLING AND REGISTRATION}

The Bank has accumulated broad expertise on land administration investments which have focused mainly on formalizing land rights through systematic or sporadic registration. Systematic registration identifies, adjudicates, and registers rights to all adjacent land parcels in a selected locality and within a given period of time. Sporadic registration processes land rights on an ad hoc basis, usually when customers request registration of their parcels of land. The Bank favors the systematic approach because of benefits of equity, cost, and the externalities from a complete registry. Most projects embed land titling in a national land policy framework.

The two main instruments of a land titling and registration program are the land registry and the cadastre. The registry provides authoritative information on all properties within a jurisdiction. The cadastre provides information on boundaries, use, and value of properties and is used as a basis for land use planning, valuation, taxation, and the generation of maps. Support to systematic titling has been more successful than activities aimed at building sustainable land registration agencies. Greater attention must be given in future land investment projects to strategies and pilot operations that will enable the establishment of sustainable land registries.

\section{BENEFITS}

Land titling programs can create secure, clearly defined, and easily transferable land ownership rights which ensure benefits to recipients/ owners and improves incentives for long-term investment. Case studies from Thailand Vietnam, China, Honduras, and Paraguay demonstrate positive impacts of land titling on investment and agricultural productivity (see box 9.10). In contrast, studies in Africa show little

Box 9.10 Thailand: institutionalizing an effective land titling and registration system

Thailand's land titling program began in 1984 and by 1998 , about 5.5 million title deeds had been issued to 2 million rural households, 35 percent of which were poor farmers. An additional 3.5 million titles were converted from lower level certificates. Implementation involved large community participation in an innovative, systematic, village-by-village, and parcel-byparcel approach involving local government and community leaders, landholders, and departmental staff. About 10 million people ( 6 percent of the national population) have directly benefited from the program, mainly as a result of increased agricultural productivity and improved household incomes. The program resulted in an increase in revenue from land transaction taxes from US\$300 million in 1984 to US\$1.2 billion in 1995 and facilitated collection of annual land taxes.

Source: Brits, Grant, and Burns 2002. 
Box 9.II Lao PDR: building land administration policy and

\section{legislative frameworks}

The Lao People's Democratic Republic project used an incremental, evolutionary policy, legal development process, and pilot activity involving field-testing to implement land titling and registration in the absence of a legal and institutional base. A cabinet-level committee was mandated to identify key policy issues and develop corresponding decrees. With interim ministerial regulations for adjudication and registration in place, pilot projects were able to issue titles in advance of final legislation. This allowed titling and registration to take place without waiting for lengthy legislative procedures. Lessons from pilot projects were then integrated into more substantive legal reforms. Pilot activities were used to identify and work through policy and legislative issues, educate the public about land titles, adjust field methodologies from Thailand to the Lao environment, and train staff in systematic adjudication.

Source: Authors.

\section{Box 9.12 Characteristics of a sound land registry}

- Registration of all properties (private, state, and customary) and all land transactions.

- Well-developed, implemented, and monitored service standards.

- Self-financed to ensure long-term sustainability.

- Computerized land record management and/or land registration.

- Accessible at reasonable costs.

- No informal payments required.

Source: Authors.

relationship between land titling and productivity, largely due to the existence of well-developed indigenous land rights, lower level of agriculture intensification, and lack of formal credit markets.

Formal land titles also increase credit availability by enabling loans to be secured through a lien on land which serves as collateral in both formal and informal credit markets. The existence of well-documented, transferable property rights and institutional arrangements that facilitate low-cost transfer of land titles is likely to contribute to development of financial markets. Evidence from Thailand and Honduras points towards improved credit supply as the main benefit from titling (Feder et al. 1988).

\section{KEY POLICY AND IMPLEMENTATION ISSUES}

LEGAL FRAMEWORK. An appropriate policy and legal framework for land tenure is a necessary condition for realizing benefits of land titling and registration programs (see box 9.11). The legal framework must provide for effective enforcement of laws and ensure that landholders' rights are secure. Legal and institutional reform can occur in parallel, but should be undertaken by one cohesive management unit. Land policy decisions should be kept separate from land administration management but can be implemented in conjunction with preliminary legal reform efforts.

EQUTTY Issues. Formal land titling and registration is more likely to have a strong impact where there are operational credit markets, and the latent demand for credit cannot be satisfied due to a lack of formal title. When these conditions do not exist, a broader approach to rural development policy will often be required to facilitate the use of titling in supply of credit. When other markets (such as credit) are characterized by distortions that disadvantage small farmers, formalized individual property rights can lead to land transfers that cause greater inequity.

One vs. TWO AGENCY MODELS. Cadastre and registration functions should be connected and managed by a single institutional entity wherever possible (see box 9.12). Under projects in Thailand, Indonesia, Lao PDR, and El Salvador, one agencyætypically the Department of Landsæundertook base mapping for cadastral purposes, development of standards for adjudication, cadastral surveying, and registration functions, as well as policy coordination. This model generally works better than the twoagency model, which has cadastral and registries under separate departments.

GENDER EQUITY. If there are no adequate safeguards, titling can permanently deprive certain 
groups, such as women or indigenous peoples, of their land rights. In Latin America titling programs have developed promising new approaches that include joint titling provisions and guarantees for women's land rights, but these efforts have faced social and cultural constraints (see box 9.13). Preferential treatment of women in titling programs has increased gender equity and contributed to improving women's rights.

Community titles. More formalized property rights systems are needed in situations characterized by high property values, land conflicts, and increasing population densities. Customary collective action to define and enforce property rights is generally effective in smaller communities with low-value properties, and where land transactions affect only the community (see box 9.14).

UNIFORMITY OF STANDARDS. Nationwide coverage of a systematic registration program does not imply uniform standards, as differences in land values within a country (for example between rural and urban areas) may make it useful to have different standards of evidence and precision for different types of land. An official registry can be relatively less precise in measurement but cheaper and still increase tenure security. This situation can be gradually upgraded as needed.

FinANCIAL EFFICIENCY. Land administration systems must balance cost-effective service provision and cost-recovery mechanisms necessary to make the system sustainable. Estimates of cost per hectare for land titling vary considerably from country to country, ranging from US\$5.50 to US $\$ 50.00$ (depending in part on what costs are included). Major cost components include mapping, registration, surveying, adjudication, and institution building. Most countries have elected not to charge the full cost of registration but to recover some costs from fees on subsequent land transactions. Governments, especially those in economic difficulties, may not extend titling programs to areas where land transactions are low.
Box 9.13 Nicaragua: joint titling efforts

From 1993 Nicaragua instituted joint titling of land to wife and husband. Sensitivity training was directed at high-level officials and at technicians involved in the land legalization process. Meetings were held with regional leaders and the local population. Radio and television spots and brochures written in clear language and in graphic format were developed to support training efforts. Despite sensitivity training, the titling program ran into difficulties in its attempts to legalize women's rights to land. In 1997, an evaluation found that most titles issued were granted to individuals (64 percent), and that joint titling to family members (for example, father and son, two brothers) represented 25 percent of total titling. Joint titling for couples only reached 7.8 percent of the total number of titles issued.

Source: Authors.

Box 9.14 Botswana: improved tenure security through group rights

Botswana provides a good example of a gradual change in type of land rights that an individual can enjoy in the absence of a formalized property rights system. Since 1970, individual land rights gradually strengthened, with the exclusion of other people's animals and the fencing arable lands, and later by allocating land to all adult citizens, both male or female, and introducing common-law residential leases for commercially valuable land.

Source: Authors.

\section{LESSONS LEARNED FOR SYSTEMATIC LAND TITLING AND REGISTRATION PROJECTS}

Effective land administration institutions need to be legally valid, authoritative, accessible, and transparent. Lack of these conditions in Eastern Europe resulted in abuse of bureaucratic power, increased transaction costs, and delayed emergence of financial markets based on land/ real estate as collateral. Titling programs should strengthen enforcement mechanisms because legally defined rights are of little value if these are not recognized and enforced.

Poorly defined institutional responsibilities and overlapping mandates can undermine land tenure security, increase transaction costs, increase land conflicts, and erode public confidence in the land 
Box 9.15 Lithuania: decentralized and upgraded systems

Lithuania established a temporary, decentralized system that will eventually be absorbed into a more unified framework. Registration of rights, both ownership and use, was done by village authorities, who established a temporary person-based cadastral register of landowners. A parcel-based integrated system under the National Agency for Cadastre will integrate these two registers and eventually replace them. First-time registration is based on low-level precision sketch maps, with more detailed surveys developed for subsequent market transactions as money becomes available. A single department of land management with broad jurisdiction over rural, urban, and forest land and municipal registry offices ensured progress of the processes.

Source:Valetta 2000

\section{Box 9.16 Key areas for public investment}

- Land policy formulation and development of legal and regulatory framework.

- Institutional reform and development.

- Dispute settlement.

- Systematic land titling, involving community participation and gender awareness activities.

- Cadastral surveying and mapping, aerial photography, adjudication activities, and issuance of land titles.

- Information technology support.

- Property valuation.

- Establishment of land registries.

- Monitoring and evaluation.

Source: Authors.

administration system. There is often a lack of coordination among the different entities that deal separately with rural, urban, and state land and these compete with one another.

Contracting out services, such as surveying and mapping, to the private sector providers can reduce the scope for political interference and allow reduction in public sector staffing. While the public sector must oversee and enforce proper regulation of land administration, developing private sector capacity is an essential feature of effective land administration.

Land administration is typically a central government function, but a central land administra- tion agency may operate through local offices. Systematic land titling programs require rapid decisions and processing capability. Day-to-day management delegated to branch offices helps to ensure transparency and provide easier access to information for local people. Decentralizing implementation responsibilities, as in Lithuania, can reduce costs, increase efficiency, enhance accountability, and promote good governance(see box 9.15).

\section{RECOMMENDATIONS FOR PRACTITIONERS}

Practitioners involved with investment in systematic land titling and registration initiatives should consider the following recommendations (see box 9.16):

- A policy and legal framework needs to be in place and land registration needs to be planned and implemented in the context of a broader market economy. If the registration process itself does not guarantee ownership then registered rights must be clarified and supported by land administration institutions and the judiciary. For example, if a legal framework does not exist as in the case of Lao PDR, caution must be observed with the registration process.

- A strong commitment from implementing agencies, both governments and donors, is essential to successful implementation of long-term, multiphased titling programs.

- Coordination arrangements of government agencies with clearly defined responsibilities and a shared vision is essential for timely and effective implementation. Lack of such coordination can stall project activities, undermine tenure security, increase transaction costs, and erode public trust in the system.

- Introduction of new technologies, such as computerized information systems, should be phased in and tested on a small scale before being widely adopted. 


\section{SELECTED READINGS}

Asterisk $\left(^{*}\right)$ at the end of a reference indicates that it is available on the Web. See the Appendix for a full list of Web sites.

Benjaminsen, T. A., and C. Lund, eds. 2003.

Securing Land Rights in Africa. London and Portland: Frank Cass \& Co.

Holstein, L. 1996. "Towards Best Practice from World Bank Experience in Land Titling and Registration." Paper presented at the International Conference on Land Tenure Administration, organized by the Geomatics Program University of Florida, November 12-14, Orlando, Fla.*

Larsson, G. 1991. Land Registration and Cadastral Systems: Tools for Land Information and Management. Harlow, Essex, England: Longman Scientific and Technical; New York: Wiley.

Plant, R., and S. Hvalkof. 2000. "Land Titling and Indigenous Peoples." Sustainable Development Department Technical Papers Series. IADB, Washington, D.C.*

\section{REFERENCES CITED}

Brits, A.-M., C. Grant, and T. Burns. 2002.

"Comparative Study of Land Administration Systems with Special Reference to Thailand, Indonesia, and Karnataka (India)." Paper presented at the Regional Workshops on Land Issues: Asia Program, sponsored by the World Bank, June 4-6, Phnom Penh, Cambodia.

Feder, G., T. Onchan, Y. Chalamwong, and C. Hongladarom. 1988. Land Policies and Farm Productivity in Thailand. Baltimore: Johns Hopkins University Press.

Valetta, W. 2000. "Completing the Transition: Lithuania Nears the End of Its Land Restitution and Reform Programme." FAO Legal Papers Online 11. FAO, Rome.
This Note was prepared by Danielle Typinski (USAID) with inputs from Wael Zakout, John Bruce, Klaus Deininger and other members of the Land Administration Thematic Group of the World Bank. 


\section{AGRICULTURE INVESTMENT NOTE}

\section{COMMUNITY-MANAGED LAND REFORM}

Improving land assets of poor people through land reform can be an effective way of reducing poverty, facilitating broader economic growth through enhanced agricultural productivity, and producing greater social harmony. Community-based land reform relies on grants and/or loans to help beneficiaries purchase land through voluntary sales. In some circumstances, this provides an attractive model for land reform. Additional support typically includes production credit and technical assistance because these increase the productivity and sustainability of farming operations. This support can be provided with the same funding as that for land acquisition or through parallel programs. Producer and community organizations are key implementing agencies in this model for efficient and equity-enhancing asset redistribution.

Colonialism, civil upheavals as a result of internal power struggles, and government policy distortions that affected land markets, have resulted in extremely inequitable distribution of land ownership in many developing countries. Land reform is an important issue, especially in countries where land has been a central demand and in post-conflict countries where land distribution remains highly unequal. Land reform carried out in an ad hoc manner under political pressure rarely reflects the needs of poor communities. Conventional land reform programsæincluding expropriation and privatization of state landæhave often expensive, slow, and have not sufficiently addressed the needs of beneficiaries for capacity building and training. Government-directed programs of compulsory land purchase and settlement are suited to some circumstances but are only one of several possible models for land reform.

In the early 1990s, Bank staff working in Latin America and Asia piloted the use of market mechanisms to make land redistribution more efficient, cost-effective and better tailored to local conditions. With the strong support of NGOs and governments, community-managed land reform pilot projects were undertaken in Colombia, South Africa, and Brazil. Due to the limited experience, best practices cannot yet be definitively established, but these pilot projects offer some useful lessons.

Community-managed land reform provides potential beneficiaries with grants and/or loans to purchase land on the market and differs from government-directed land reform initiatives involving the government taking land from a large farmer and transferring it free-ofcharge to poor people. Selection of beneficiaries and land acquisition is handled at the local level with the government's role limited to establishing the necessary policy and regulatory framework for making grants and for land purchase. Land is transferred voluntarily between willing parties with community organizations, NGOs, or other implementing agencies helping beneficiaries identify available land for purchase, negotiate and reach agreement with the seller, and submit this agreement for approval to a local coordinating entity, such as a district, municipality, or development committee. The local coordinating entity verifies the eligibility of beneficiaries, ensures that there are no legal impediments to transfer of the land, and confirms that the negotiated price is at fair market value.

Community-based land reform has the broader goal of establishing productive farm enterprises so beneficiaries receive a grant, loan, or combination grant/loan in a fixed amount, to be used for investment purposes as well as for land acquisition, and they are expected to make a cash or in-kind contribution of their own (see box 9.17). A systematic program of training and preparation assists beneficiaries choose a land investment project and identifies suitable land. Beneficiaries submit their investment plan to a local implementing agency which is typically a private or public financial institution for appraisal, based on clearly defined technical, economic, environmental, and poverty-reduction criteria. Once approved, the agency 
transfers funds to the beneficiary, an implementing agency, or directly to the seller. In Brazil, beneficiaries assume a loan with a local bank using the acquired land as collateral.

\section{BENEFITS}

Improving small shareholders' access to land enhances equity and may ultimately increase agricultural productivity as smaller familyoperated units are generally more efficient. With a focus on productive projects, rather than on land transfers, sustainable poverty reduction and entrepreneurial development are at the center of community-managed land reform efforts. Farm enterprise planning and identification of markets before land is transferred enables beneficiaries to start production immediately. In South Africa, 23 percent of the projects generated positive cash flows in the initial period following land transfer.

When land and related investments are limited, beneficiaries can be encouraged to purchase undeveloped or underutilized land, and, with the lower land prices, funds are then available for productive investments. Three elements help prevent overpayment for land. First, communities must demonstrate that a minimum supply of land is available on the local market. Second, beneficiaries contribute to financing the project, and are selected through a transparent process. Finally, programs must document local land ownership patterns, land prices, and farming models.

\section{POLICY AND IMPLEMENTATION ISSUES}

POLICY FRAMEWORKS. Policy distortions, such as restrictions on ownership, use, rental, or land sales, can negatively impact land use and development of rural credit markets. Land ownership ceilings can make land of limited value as collateral; rent controls and tenancy laws also hinder development of land rental markets. Policies that drive land prices above the capitalized value of agricultural profits increase land reform costs and may reduce sustainability by encouraging land reform beneficiaries to sell land to large farmers. An

\section{Box 9.17 Colombia: funding land acquisition and investments}

The 1994 Colombian Land Reform Law provided for land purchase grants of up to 70 percent of the negotiated land purchase price. Grants were restricted to land purchase and could not be used for complementary investments. This created incentives for collusion that inflated land prices and divided sales surpluses among buyers and sellers. It also strongly biased sales in favor of developed agricultural land close to infrastructure and already well-endowed with necessary complementary investments. This approach to land reform resulted in a redistribution rather than the creation of existing assets. Allowing grants to finance nonland investments results in better targeting of underutilized lands and helps beneficiaries make other needed investments.

Source: Deininger 1999.

undistorted land policy environment supportive of smallholder agriculture is critical if land reform interventions are to be sustainable.

Grants vs. LOANS. Financing for land purchases and investments may be on a grant, loan, or mixed grant-loan basis, but good practice would require beneficiaries to make at least some financial contribution.

FinANCIAL SERVICES. In rural areas, beneficiaries with access to land but without access to markets for products and credit may fail to improve their status, and this can lead to widespread selling of land. Community-managed land reform programs need to also address access to markets for credit, inputs, and outputs. In Nicaragua and the Philippines, financial intermediaries also provided input credit in-kind and helped land reform beneficiaries to establish productive enterprises.

Participation ANd Social equity. Communitymanaged land reform programs must rely on beneficiaries and participation of all social groups in the community taking the initiative for land purchase and farm development. Successful land reform depends on an adequate local institutional structure and education programs to facilitate participation. A common problem is the exclusion of women. In South Africa, guidelines for land reform do not ensure gender equity so officials continue 


\section{Box 9.18 South Africa: institutional constraints}

Redistributive land reform is an important component of South Africa's post-apartheid land policy. Grants are provided for poor households to acquire land plus associated productive infrastructure in the market. After three years, approximately 200,000 hectares of land were transferred to 20,000 households, representing only 0.6 percent of the target. Factors limiting program impact were a highly centralized approval process in the Department of Land Affairs operating independently of the Department of Agriculture and provincial authorities that slowed implementation, as well as a limited beneficiary participation in the planning process resulting in approval of large projects based on collective production. These have not done well. The government has since issued policy directives allowing for a more decentralized program implementation with active beneficiary involvement and participation of the private sector, NGOs, and local governments.

Source: Deininger 2003.

to believe that women are not capable of managing economic production projects; therefore, project activities are focused on men. Even though national agrarian reform policy states the need for gender equity, local offices lack he mechanisms to implement this policy effectively (see box 9.18).

TeChNical support. Conventional land reform programs, with land transfer but no technical assistance and training, has not enabled beneficiaries to increase agricultural productivity and income. Land reform programs, whether community-managed or conventional, should generally ensure that adequate technical support is provided to beneficiaries both during and after the land acquisition process. Local institutions, such as NGOs, farmer organizations, and government agencies can assist beneficiaries in selecting viable farm projects, evaluating land productivity potential, negotiating purchase prices, and arranging financing for land and capital requirements not covered by the purchase grant.

Program evaluation. Community-assisted land reform projects are recent and have not been thoroughly evaluatedæa priority for future programs. A monitoring and evaluation system focused on project quality indicators rather than on physical quantity indicators helps to identify and rectify implementation problems and assess long-term impacts (Deininger 1999).

BANK LAND PURCHASES. There has been a substantial delay in many community-managed land reform projects caused by limits on Bank financing to nonland costs of projects. The inability to fund land acquisition has prevented the Bank from financing integrated land reform pilot projects. Recent policy changes have eliminated the blanket prohibition on condition that analysis demonstrates that land purchase is an efficient means of acquiring land; the land is for community-based land reform projects and is purchased by beneficiaries; the program results in increased productivity; there is a strategy for dealing with any land market distortions; and that there are satisfactory management arrangements covering use of funds, monitoring and evaluation, and analysis of political risk.

\section{LESSONS LEARNED}

IMPROVING LAND MARKETS. Land reform involving land purchase or rental requires transparency in land markets - that is information on land prices. In addition, land reform beneficiaries need to be able to assess the value and productive potential of the land. To deal with these challenges, strategies include providing technical assistance at the community level, cofinancing of land purchases through private financial intermediaries, and development of a market information system for land sales prices.

FocUsing ON PRODUCTIVE PROJECTS. Productivityoriented projects are key to community-based land reform because they offer an objective criterion for establishing land prices, provide a basis for evaluation and support by financial institutions, and require beneficiaries to plan to become independent farmers.

ASSESSING POTENTIAL SUPPLY AND DEMAND FOR LAND. The potential demand for and supply of land for a project should be identified at the local level with the support of the central government. Assessing this demand requires raising 
awareness among potential beneficiaries, incorporating land reform into an overall local development strategy, and developing realistic expectations for land reform. Local agencies should ensure that the supply of family-sized parcels of land exceeds demand. A general rule used in some cases has been thatæto prevent an increase in land pricesæthe supply of available land should be at least three times the amount needed for the land reform program. A land inventory is useful to classify land by parcel size and to identify target areas not already characterized by very small landholdings that are suitable for agriculture.

DeCEnTRAlizing implementation. Negotiations at the local (decentralized) level have proven to be faster and more cost-effective than conventional centralized reform programs. Participation of community organizations facilitates land reform implementation, and local training programs improve the ability of beneficiaries to negotiate with landowners over prices (rental or sales) and to plan use of their land.

MaXimizing uSE OF MARKET MeChanisms. Two lessons are evident in financing of communitybased land reform. First, a grant used for land purchases and investments is clearly preferable to subsidized loan schemes, though provision for some payment for land is appropriate. Second, without assured access to financial markets, the sustainability of land reform is limited. An integrated land reform project develops land markets jointly with other factor markets, and helps beneficiaries with technical assistance to improve their skills.

\section{RECOMMENDATIONS FOR PRACTITIONERS}

Investments in community managed land reform should be guided by the following considerations (see box 9.19):

- Analysis through economic and sector work determines the project's context and evaluates the appropriateness of using market mechanisms for land reform.

\section{Box 9.19 Potential investments}

- Studies of land availability and functioning of land markets.

- Training and technical assistance to strengthen local coordinating agencies (local government, NGOs, citizen groups, or consulting companies).

- Operating costs for local coordinating agencies.

- Financing for land purchase and for investment and operating costs for farming operations.

- Technical assistance and training for new landowners.

- Program monitoring and evaluation.

Source: Authors.

- Project appraisals examine local land markets to ensure their robustness to facilitate efficient land acquisition. If not, a policy component is needed to address constraints and facilitate the operation of land markets.

- Projects ensure that land purchase prices are in line with market prices.

- Technical assistance and training provide assistance to beneficiaries to negotiate land acquisition, plan on-farm investments, manage farm operations, and access credit.

- Local implementing agencies establish capacity to verify land status, confirm market prices, and appraise community subprojects.

\section{SELECTED READINGS}

Asterisk (*) at the end of a reference indicates that it is available on the Web. See the Appendix for a full list of Web sites.

Adams, M. 2000. Breaking Ground: Development Aid for Land Reform. London: ODI.

Prosterman, R. and T. Hansted. 2003. "Land Reform in the 21st Century: New Challenges, New Responses." RDI Reports on Foreign Aid and Development 117. Rural Development Institute, Seattle, Wash.*

Strachan, L. W. 2001. "Assets-Based Development: The Role for Pro-Poor Land and Land 
Tenure Reform.” Discussion Paper. CIDA, Quebec.

\section{REFERENCES CITED}

Deininger, K. 1999. "Making Negotiated Land Reform Work: Initial Experience from Colombia, Brazil, and South Africa." Policy Research Working Paper 2040. World Bank, Washington, D.C.

Deininger, K. 2003. Land Policies for Growth and Poverty Reduction. A World Bank Policy Research Report. Washington, D.C.: World Bank; Oxford and New York: Oxford University Press.

This Note was prepared by Danielle Typinski (USAID) with inputs from Wael Zakout, John Bruce, Klaus Deininger and other members of the Land Administration Thematic Group of the World Bank. 
INNOVATIVE ACTIVITY PROFILE

\section{ARMENIA: BENEFITS OF SECURING AND REGISTERING LAND FOR RURAL DEVELOPMENT}

Since independence in May 1991, the Government of Armenia has pursued objectives of consolidating national independence, promoting market reform, and changing the government's role in the economy.

What's innovative? Computerized cadastral and land registry systems to assist development of land markets, financial markets, and taxation inflows.

One of the areas pursued was land reform. Agricultural land was distributed as private property to more than 320,000 farmers on a freeof-charge basis but with area allocated in proportion to family size and with a five-year ban on the land resale. Following land distribution, private agricultural land accounted for 366,000 hectares or approximately 26 percent of all rural land.

This approach resulted in fragmentation of agricultural holdings, with families owning noncontiguous plots and inefficient farming due to an inability to use agricultural machinery. In order to achieve more efficient land use, it was necessary to establish a land market to enable farmers through sales, exchanges and leases, to consolidate family plots and to use land as collateral.

\section{PROJECT OBJECTIVES AND DESCRIPTION}

The Armenia Title Registration Project promotes private sector development by implementing a transparent, parcel-based, and easily accessible registration system for land and other real property. Specifically, it aims to:

- Increase the productivity and value of land and other real estate by securing property rights and facilitating consolidation of land parcels.
- Facilitate the use of property as collateral and to reduce transaction costs in title transfer and mortgaging.

The project also promotes least-cost registration procedures by building on existing databases of property information, by adding only market-relevant information to these databases, and by contracting through private surveyors. The project consists of two main components:

- Support for establishment of a nationwide network of Information and Registration Centers (IRCs) for secure registration of real estate parcels and associated rights.

- Support for land surveys to produce cadastral maps.

The project computerized and simplified the cadastral and land registry systems to make the deed and title search process easier, thereby lessening property transfer and mortgage costs and enhancing property market development. This also provides updated information on real estate characteristics, thus improving the base for taxation, sale of land, and use of land as collateral. Access to data is demand-driven and administered by the Armenian Unified Cadastral Administration (SCA).

Inefficiencies arise when different cadastres are not integrated within a unified administrative system. The Government of Armenia has three parallel objectives for the Unified Cadastral Administration. The first is to develop and integrate a legal cadastre through an IRC network, focusing on information about location, demarcation, and ownership. The second is to produce a physical cadastre through a classification taxonomy and detailed surveys, for the purpose of city and/or regional planning, public infrastructure development, and environmental management. The third is to assess real property with a fiscal cadastre through its preexisting Inventory Bureaus (IBs), providing information essential for the establishment and the efficient operation of property taxation. 
The registration system set up by the Unified Cadastral Administration has units in each of the marzes (administrative regions). It is responsible for the organization of surveying and mapping, collection of information, issuing of titles, and answering information requests through title reports, as well as for property dispute adjudication.

\section{BENEFITS AND IMPACTS}

The primary beneficiaries of this project are private farmers, small- and medium-sized enterprises, and urban property owners. Title security increases incentives for investment in property and access to credit, thereby improving the operational capacity of farmers and rural enterprises. In rural areas, land titling facilitates consolidation of plots, increases the potential for agricultural productivity growth, and reduces the cost of property transactions. Similarly, in both rural and urban areas, registration documents the owners' rights and obligations, builds up the pool of collateralized real estate property, and reduces transaction costs for land markets. In sum, the project assists the development of a property market and subsequent fair and transparent market valuation. About 477,000 cadastral files have been completed, and certificates have been issued for 288,000 of them. These lags are due to the lengthy process of rectifying mismatches between legal documentation and actual physical situation. The real estate market has begun to grow rapidly in the past three years. The number of registered transactions totaled 60,874 in 2002, compared with 40,803 in 2001.

\section{LESSONS LEARNED AND ISSUES FOR WIDER APPLICABILITY}

Emergence of small private farms as the main producers of food and agricultural products has been the most significant development in the sector since independence. This change has provided much-needed flexibility and promoted entrepreneurial activity in the agricultural sector.
Utilizing privatization committees rooted in the local areas and awarding land based on household size has facilitated land titling. Using household size as a determinant of parcel size was feasible because of the link between the titling system and the IRCs.

Private property ownership provides incentives to increase agricultural productivity. Land reform and titling is important to agricultural reform in transition economies. A critical review of a country's title and cadastral system is an important first step in planning a land reform effort.

\section{PROJECT COUNTRY:ARMENIA}

$\begin{array}{ll}\text { Project Name } & \text { Title Registration Project } \\ \text { Project ID } & \text { P057560 } \\ \text { Project Cost } & \text { US\$10.6 million } \\ \text { Dates } & \text { FY 1999-FY 2004 } \\ \text { Contact Point } & \text { Gotz Schreiber } \\ & \text { The World Bank, I8I8 H Street } \\ & \text { NW,Washington, D.C. 20433 } \\ & \text { Telephone: (202) 473-4495 } \\ & \text { Email: gschreiber@worldbank.org }\end{array}$


INNOVATIVE ACTIVITY PROFILE

\section{BRAZIL: PARTICIPATORY NEGOTIATIONS AND MARKET- ASSISTED LAND REFORM}

The Northeast, accommodating one-half of all Brazilian poor people and two-thirds of all rural poor people, is vulnerable to drought and has a relatively poor resource base. Additional constraints to improved investment and productivity in agriculture include ineffective financial systems and distorted land distribution. Studies have shown that family farms in Brazil are more productive and labor intensive than large farms. The highly distorted land ownership pattern is the result of economic distortions, including subsidized agricultural credit, high inflation, and inappropriate tax provisions. Past approaches to land reform, based on centralized government-administered expropriation and redistribution, have had limited success. As a result, the government was interested in experimenting with faster, cheaper, and less conflictive approaches to land reform.

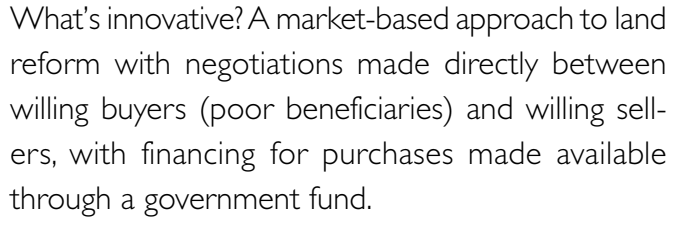

\section{PROJECT OBJECTIVES AND DESCRIPTION}

The objective of the Land Reform and Poverty Alleviation Project was to raise agricultural output and increase poor family incomes by providing improved access to land and funds for complementary investment subprojects planned and implemented by community associations. The project experimented with a program of market-assisted land reform in which beneficiaries are given access to financing for the purchase of suitable lands. The purchases are negotiated between willing sellers and willing buyers. Five states were selected for participation in the pilot project based on the severity of the landlessness problem and conditions for successful implementation (that is, the immediate availability of land in the market and the capacity of the State agencies to implement the project). The project had five components:

- A land purchase fund to finance land purchases.

- Community subprojects (small matching grants to communities for investment projects, technical assistance, and start-up).

- Institutional strengthening (technical assistance and training at the state level).

- Project administration, supervision, and monitoring.

- Impact evaluation and dissemination by the federal government.

Community associations consisting of landless rural workers or rural workers owning land sufficient only for subsistence farming selected suitable land and negotiated its purchase with willing sellers. Following negotiations, the associations consulted with the State Land Institute to confirm that the title was clean and that the negotiated purchase price was consistent with market conditions. Communities then presented their project to the State Technical Unit (STU), which verified the eligibility (based on agricultural skills) of the beneficiaries. At this stage, beneficiaries were eligible for credit from the Land Purchase Fund with credit initially given for a 10 -year period with a threeyear grace period at the government long-term interest rate. Decisions regarding land allocation to individual members and corresponding payment obligations were made internally within the association.

Communities that participated in the Land Purchase Fund program were eligible to present proposals for complementary community subprojects and technical assistance to establish their settlement and improve produc- 
tivity of the acquired land. The community subprojects could be infrastructural, social, or productive, and could be funded through matching grants by the project. Community labor and land constituted the counterpart contribution by the community.

\section{BENEFITS AND IMPACTS}

The process has proven to be fair and flexible. There is self-selection of beneficiaries, who because they are expected to repay their land purchase loan, have an incentive to bid down the land price. Thus, by default, there has been an automatic focus on poor and underutilized lands where social gains are maximized. Other achievements include:

- The number of families estimated to have benefited by the end of the project is 16,439 , about 110 percent of what was expected at appraisal (15,000 families).

- The cost per beneficiary was reduced from US $\$ 11,600$ to about US $\$ 3,000$.

- Newly-acquired farms show favorable expectations for economic and financial viability, generating sufficient earnings to finance debt and improve living standards.

- Beneficiaries are less vulnerable to drought and other climatic/economic risks.

\section{LESSONS LEARNED AND ISSUES FOR WIDER} APPLICABILITY

- Community participation in the identification, financing, and implementation of subprojects that meet the beneficiaries' most pressing needs increases the sense of ownership and sharpens the project focus on poverty reduction. Technical assistance should be provided to rural communities and smallholders to enable them to identify, design, and implement their own subprojects, thereby improving their capacity to compete for investment funds.
- Self-selection of beneficiaries is critical, but information on the abilities of candidates is frequently limited. Technical assistance, cofinancing, and management information systems can reduce these information limitations.

- Decentralized and demand-driven implementation is critical to achieving effective coordination of the various entities involved in the process.

- Long-term viability is dependent on the availability of working capital and marketing of increased agricultural production as a result of diversification and improved productivity. Complementary investment in infrastructure and services is necessary.

- New community associations require special support to build human/social capital.

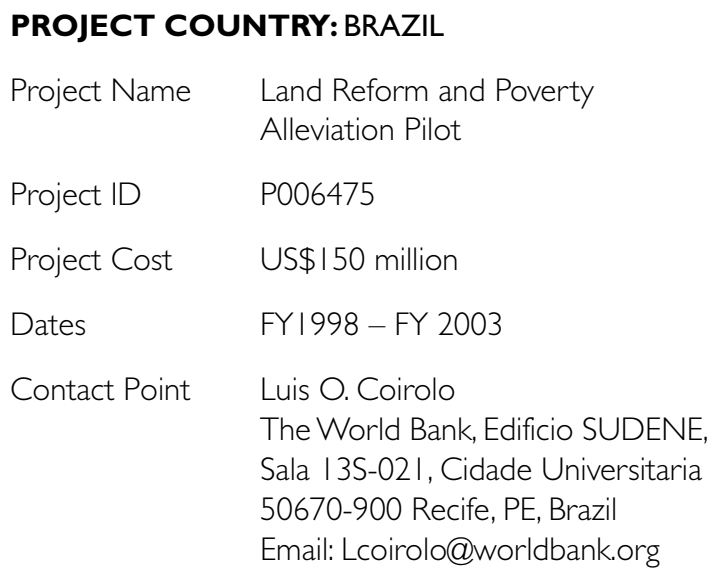


INNOVATIVE ACTIVITY PROFILE

\section{THE LAO PEOPLE'S DEMOCRATIC REPUBLIC: PRESERVING WOMEN'S RIGHTS IN LAND TITLING}

The Lao People's Democratic Republic (Lao PDR) is one of the poorest and least developed countries in the East Asia region. Since 1986, the Lao government has been transforming the economy from a centrally planned to a market-oriented system. Lao law provides that all land is owned by the state, with the state allocating perpetual, inheritable and marketable use rights to individuals based on existing possession and custom.

What's innovative? A conscious, comprehensive approach to including women's issues in land reform program design and implementation provides increased recognition of women's land rights, greater security of tenure, and new access to credit for women.

In practice, women have less access to the land than might be expected under prevailing customs, which differ substantially among different ethnic groups but generally allow women to inherit land. Women tend not to be able to exercise their rights where residence is patrilocal. When women move to their husbands' village, they have less access to land and farm smaller and more dispersed plots. Pressures from men to appropriate women's land are very real.

The Lao government has engaged in the systematic survey and titling of land use rights in urban and periurban areas of seven provinces since 1993. Titling provides security of tenure and improved access to credit markets as land can be used as collateral. Women landholders should benefit from this program as much as men because they comprise 51 percent of the population and 53 percent of the agricultural labor force. Under national law, men and women are now equally entitled to hold property, and the Family Law specifies that any property purchased during marriage is regarded as joint property. Land owned by a woman prior to her marriage remains her individual property, as does any land she inherits from her parents.

But women have been disadvantaged in earlier titling work in which their customary rights had to be proven largely through oral testimony of their kin. Women generally have lower literacy rates, a heavy family workload, and a lesser role in public affairs. As a result, they often do not have the time-or understand the need-to participate in land adjudication and titling processes.

\section{PROJECT OBJECTIVES AND DESCRIPTION}

Since 1995, a collaborative effort by the Lao government, AusAid (Australian Agency for International Development), and the World Bank has sought to address the land use rights and inheritance issues affecting women. The Laos Land Titling Project I has integrated gender-sensitive strategies into its implementation in urban and associated village areas in six provinces where both matrilineal inheritance and patrilocal residence prevail. The overall objectives of the project are to foster the development of efficient land markets and to facilitate domestic resource mobilization by providing a system of clear and enforceable land use ownership rights, as well as by developing a land valuation capacity. The project focuses on development of a legal and policy framework for land management, land titling, valuation, and administration.

The Customer Relations Service of the Department of Lands worked with the Lao Women's Union (LWU) and its nationwide network of branches and members to ensure women's titling rights in project implementation. They have developed a training curriculum to reduce gender bias among field teams and village authorities and produced posters and brochures on land rights for targeted villages specifically for women. They have written weekly news bulletins on activities of the land 
titling project for radio and newspapers, and performed a drama on women's titling issues on television.

In the field, the LWU works closely with local women through a series of meetings: a whole village meeting, women's focus group meetings, and household group meetings. These meetings reached 2,285 people, almost one-half of which were women. In the meetings, the LWU communicates information regarding women's rights under the family law, inheritance law, property law, and land law. Women are urged to make sure they get their names on titles where appropriate and to participate actively in all stages of the adjudication and titling.

The proposed Second Land Titling Project will be the second phase of the long-term land titling program. It is aimed at the development of the land administration capacity to support the country's economic development and poverty reduction goals.

\section{BENEFITS AND IMPACTS}

The number of land titles under women's names or in joint names with their husband has increased. In areas where the systematic titling project is operating, 34 percent of titles are in the name of women, 38 percent are in joint titles, and 24 percent are in the names of men. In areas of the country outside the project area, 15 percent of land titles are in women's names, 28 percent in joint titles, and 56 percent in men's names. Women's names on the titles are defensive measures, protecting them in the event of a change of family status through marriage or divorce and from arbitrary decisionmaking by a husband over the disposition of the wife's lands or conjugal lands.

Women are using their new land titles to secure credit. In the project areas it was found that among those who mortgaged land, 51 percent were men and 49 percent were women.

Women have both the tenure incentive and the credit to invest in sustainable land-management practices and productive activities, which increase household incomes and expand the local economy.

Moreover, a study conducted in 2002 indicated that land titles are becoming more important forms of collateral and that the size of loans has increased with the use of land titles.

\section{LESSONS LEARNED AND ISSUES FOR WIDER APPLICABILITY}

The project has provided an opportunity for the government agencies to interact more effectively with local women at the district and village levels through a key women's organization, and thus make important advances in titling land to women.

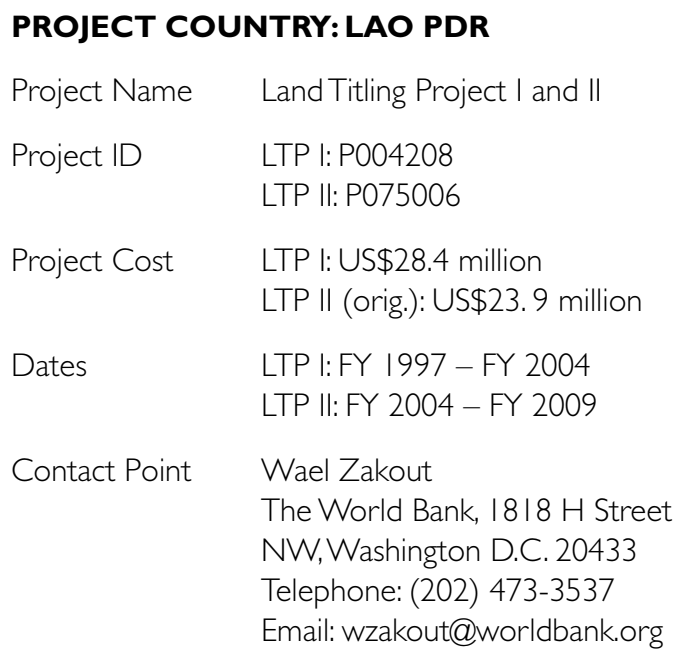




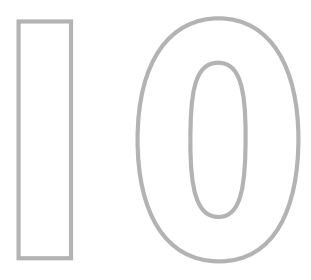

\section{MANAGING AGRICULTURAL RISK,VULNERABILITY, AND DISASTER}

Public intervention can facilitate better risk management through improved information systems, development of financial markets, promotion of market-based price and yield insurance schemes, and ensuring that the poor are able to benefit from these interventions and from participation in emerging systems.

\section{RATIONALE FOR INVESTMENT}

Risk in agriculture is pervasive (see box I0.1). Several risk and vulnerability assessments by the World Bank have shown that commodity price, yield (mainly due to weather), and health risks are the most important risks that rural households face. Households are vulnerable to those risks when a significant loss threatens the sustainability of their livelihood base-a common situation for many small-farm households in developing and transition economies.

Profit is the reward for risk-taking, and therefore any profit-seekers in the business of farming, as in any other business, must be able to bear some risk. Many farmers, however, are highly vulnerable and cannot readily bear additional risk in their farm/herd management or its potential shocks to their households. 
Box 10.I Some risks affecting agricultural production systems

- Climatic risks include risk of crop or herd loss (total or partial) from drought (micro or large-scale disaster, short or long term), flooding, hard rains, hail, frost, snow, hard freeze, or wind.

- Environmental risks result in damage to land from soil erosion and to flora and fauna and from pest and disease attacks.

- Social and economic risks include problems such as theft of crops or stock, damage by careless neighbors (fire, cattle), price fluctuations of commodities and key inputs (fertilizer), family illness and loss of labor (HIV/AIDS, death), loss of land access due to badly designed titling schemes, and infrastructure failure (roads degraded, transport breakdowns).

- Political risks include more remotely generated (and thus significantly less manageable) events such as community resettlement (for example, dam resettlement schemes), conflict and war; and political alienation/redistribution of land.

Source: Authors.

Just what farmers do to moderate the effects of risk is remarkably similar at all economic levels and throughout the world (see box 10.2). The specific components of these mechanisms vary as does the degree and formality with which farmers employ them. The more informal mechanisms for risk coping may reduce the income of farmers (for example, diversification may come at the cost of specialization and higher incomes). Any government intervention targeting risk must take into account how farmer risk management mechanisms are applied, as well as farmers' resource base.

Risk management approaches can be distinguished according to whether undertaken before (mitigating) or after (coping) the event. Other categorizations used relate to whether risk is viewed primarily as an individually experienced phenomenon (idiosyncratic) or a more widely experienced event (systemic).

The incidence of risk in agriculture is important to policymakers at national and international levels. Fluctuations in producer incomes, and particularly the threat of catastrophic loss, may present difficult welfare problems for these same producers, their governments, and the international community. In more extreme cases, international humanitarian assistance may be necessary but that assistance may destabilize markets, create dependencies, or bias management via expectations of future disaster relief.

Creating mechanisms to deal with catastrophic, spatially covariate risks for large populations must be done in ways that do not undermine coping mechanisms that individual households use to deal with chronic day-to-day and yearto-year independent risks. Since the types and severity of the risks confronting farmers vary greatly with farming systems and physical, socioeconomic and political environments, generic guidance for good and relevant investment activity in risk management interventions is scarce. Past failures by governments and donors illustrate both the many pitfalls to avoid and some opportunities to explore in efforts to help resource-poor farmers deal better with risk and become less vulnerable to shocks.

\section{PAST INVESTMENT ACTIVITY}

Although there has been remarkably little Bank assistance explicitly targeting agricultural risk, there has been indirect assistance through rural finance operations, assistance for provision of various public goods, and more recently assistance through disaster relief operations (see box 10.3). Quantifying the levels of World Bank assistance addressing agricultural risk is problematic, and not clearly definable given that investments often target specific types of risk (for example, research on drought-tolerant crops) or risky environments (for example, arid and semi-arid rangeland management) without classifying the funding as relevant to risk per se.

\section{KEY ISSUES FOR INVESTMENT}

With mixed results, governments worldwide have implemented various forms of public risk management policies and programs. Broad quantitative assessments of the costs and benefits of these programs are lacking. However 
Rural producers and communities employ several mechanisms to deal with the risky business of farming, and any interventions must account for the likely effect on these mechanisms and the resources available to farmers. Mechanisms include:

Information gathering:

- Using and improving information available in decision making, for example, market prices, regional rainfall probabilities, new crop varieties, emerging markets etc.

Avoiding risks:

- Adopting a precautionary stance, with the costs balanced against the possible reduction in serious negative consequences.

- Using less risky technologies of lower but reliably yielding drought-resistant crops, or production of crops with more stable markets over those with potentially higher but less certain returns.

Diversification:

- Diversifying production systems through planting a variety of crops for separate markets to mitigate climatic, disease, pest and market vulnerability.

- Acting with flexibility to adjust to changed circumstances, reflecting physical assets and markets.

- Financing farm activities with credit, and borrowing in cash or in kind based on social capital.

Sharing of risk:

- Using informal and formal insurance through making small investments expected to provide returns only in the event of difficulty or catastrophe, for example, cash or gifts, "banking" through social capital.

- Using risk pooling in formal or informal arrangements to share outputs and cost of production.

- Using contract marketing and futures trading mechanisms (such as forward contracting to sell all of a crop at an agreed price, futures contracts, and hedging) to reduce price risks for commodities not yet produced, or for future inputs.

Source: Authors.

results of these programs often raise questions about sustainability (particularly financial), and distribution of benefits to vulnerable groups most in need of assistance (for example, women). Another problem is that subsidized public interventions are generally unsustainable in the long term and undermine risk markets and traditional risk management and coping systems. Key themes associated with sustainability and distribution policy issues are discussed below.

UNDERSTANDING RISK AND PRODUCTION SYSTEMS. Addressing problems of risk and vulnerability within an agricultural production and marketing system requires an understanding of the cross-cutting issues, and the multiple approaches to managing risk. These include market development and access, crop diversification, irrigation and intensification of farming, and development of financial and social capital. Changes in the system, including changes in a risk management strategy, can have both beneficial and detrimental effects. Consolidating scattered plots of land may increase efficiencies, but might make households more prone to loss if all their land is in one parcel. Thus, as is always the case, it is critical that interventions have clear goals, reliable information, and sound analysis.

\section{Box 10.3 Investment in public goods}

Public investments that address risk reduction in farming have been considerable, but they are seldom designed to explicitly target this risk. Irrigation investments are one such case, where the explicit intention has been to boost the productivity of the land and water resources involved, and to increase rural employment and food self-reliance. Indeed, such investment together with varietal improvements formed the core of the Green Revolution in South Asia and elsewhere in the 1960s. But this investment also considerably reduced the inherent variability resulting from dependence on rainfall. Investments in plant breeding have targeted vulnerability to pests, diseases, droughts and floods, and as such targeted some of the more risky conditions facing farmers. These risk-reduction features (along with the corresponding productivity gains) are largely public goods produced by investment in public research agencies. Public investments with collateral benefits affecting risk reduction include range management, veterinary and human vaccine development, HIVIAIDS, rural banking, and earlywarning systems for conflict and weather.

Source: Authors. 
BALANCING PRODUCTIVITY GAINS AND RISK REDUCTION. Farmers' efforts to avoid risks through on-farm management practices, such as plot diversification and use of traditional varieties and crops, help maintain stable but lower production and income levels. Production instability tends to increase domestic food price variability and cause food insecurity problems for the landless poor and increases uncertainty for rural producers. Instability in export crop production and economic returns leads to more volatile foreign exchange earnings, which can destabilize a national economy.

RECOGNIZING THE STRENGTHS AND LIMITATIONS OF TRADITIONAL InSTITUTIONS. Formal risk-sharing institutions such as private insurance, commodity exchanges (spot markets, futures trading, and options markets) are widely available in industrial countries to help farmers cope with production and marketing risks. In developing countries, risk-sharing institutions are usually much more rudimentary, and formal or commercial institutions may not be available for most small-scale producers. Nevertheless, a wide range of informal risk-sharing arrangements has evolved, including share tenancy contracts, traditional money lending, and risk sharing within extended family and other community networks. These informal systems work well most years, in locations where risk events are independent and vary widely in incidence by household over time and between micro-locations. While these approaches do not pool risks as efficiently as they would if they spanned broader regions or sectors of a national economy (as do nation-wide cropinsurance or credit schemes), they are normally available to most poor farmers. Such informal arrangements can help farmers to effectively manage the risk they routinely face on a household level. They can also be relatively effective for independent risks (illness, death), but they do not do so well for systemic risks where most of the community suffers at the same time.
DeAling WITH SYSTEMIC RISK. Most traditional/ informal risk management strategies will fail during years of widespread disaster, such as droughts, pest infestations or floods, where large numbers of people are affected in the same village, district, or region. This is called the problem of systemic risk. Furthermore, if nonfarm income depends on employment generated through sectors affected by the catastrophe, the success of nonfarm income in contributing to risk management can disappear along with surpluses. Rural banks can be severely affected by poor loan collection if many farmers default at the same time because of a shared catastrophe such as a major drought. Governments have too often responded to farmers' difficulties by "forgiving" their loans, thereby undermining the operation of the credit system, and sending the wrong signal to farmers about the need for them to effectively manage their own risks. Governments do have responsibility for some direct involvement to manage severe systemic risk (for example, an extreme drought that may occur only once in, say, 50 years), as the private sector will not generally provide services to manage such risks. Effective government intervention to mitigate severe systemic risks (often couched as social protection measures such as the "food for work" schemes of India), along with an enabling policy and regulatory environment, will encourage private sector provision of services for more frequent and less severe risks.

Past pRice stabilization initiatives. Various mechanisms, such as price supports, buffer stocks, and variable tariffs, have been used to pursue traditional price stabilization objectives, with varying degrees of success and many failures. ${ }^{1}$ Though perhaps theoretically sound, a frequent finding is that the welfare gains from price stabilization are relatively small. Buffer fund schemes supported by variable levies and tariffs have suffered from design and management problems that often have compromised

I. See Module I,"Building Agricultural Policy and Institutional Capacity" 
their performance. As a result, a cautious approach to the use of stabilization schemes is advised to avoid bankruptcy or an unsustainable drain on public resources (such as experienced with the Indian foodgrain reserves in recent years). In general, such schemes should be developed only where specific criteria are satisfied (for example, temporary protection of an internationally competitive infant industry, or significant limitations to development of market-based price risk management schemes), and should be implemented with clear sunset clauses. Future efforts should turn from traditional price stabilization toward mechanisms for market-based price risk management. ${ }^{2}$

RETHINKING AGRICULTURAL INSURANCE PROGRAMS. Agricultural insurance is provided or supported by the public sector in many countries. With few exceptions these interventions have failed, most being financially unviable. Many of the larger all-risks crop insurance programs pay out two dollars or more for every dollar of premium they collect, the difference being paid as government subsidy. Many farmers, despite high insurance subsidies by the government, are still reluctant or unable to purchase insurance. As a result, many of these public insurance programs are made compulsory, either for all farmers growing specific crops (for example, Japanese rice farmers), or for those who borrow from agricultural banks (for example, subsidized crop insurance in Mexico). This further distorts production decisions, reduces incentives for the private sector to provide market-based approaches, and results in little improvement in farm-level risk management capacity.

The high cost of public insurance schemes results from attempts to insure risks difficult to quantify and assess (for example, climate, diseases, and pests), or simply too costly and time consuming to quantify. Loss assessments are prone to severe moral hazard problems, and damage reported can be caused or wors- ened by inappropriate management practices. The common practice of insuring "target" yields rather than compensating for actual losses is problematic in situations where averages do not accurately reflect yearly, or site-specific, fluctuations in yield. Public crop insurers also tend to have high administration costs, since they insure mostly small-scale farmers and do not have a well-diversified portfolio of clients. Although private insurance is growing in some countries, it generally covers specific weather and pest problems faced by large-scale commercial farms growing high-value crops, and is frequently heavily subsidized. In the near future, private schemes are not likely to be adequate for addressing the vulnerability of the larger population of resource-poor farmers. Other approaches (such as index-based insurance) are required, along with efforts to build an environment that enables improved availability of private-sector insurance services tailored to the needs of resource-poor producers. ${ }^{3}$ These new insurance products will likely require considerable time to develop and test.

SOCIAL SAFETY NETS. Since all agricultural production systems are subject to risk, and many small farm households are quite vulnerable to shocks of different types, governments must be prepared to provide direct assistance to farmers under various circumstances, such as those noted above for systemic risk. Disaster response programs are frequently required in post-conflict situations and after natural disasters, to ensure survival and to help restart agricultural and off-farm production. Poverty relief programs may be appropriate where chronic poverty threatens survival and can only be effectively addressed through long-term development and support to education, health, and nutrition programs. Support might be needed to help farmers adjust to: transition from central planning (as in Eastern Europe); changing market environments arising from trade liberalization; changes in consumer tastes; and the banning of production of traditional

\footnotetext{
2. See the AIN, "Commodity Price Risk Management"

3. See the AIN, "Agricultural Insurance"
} 
crops (such as opium poppy). Support programs may feature cash transfers or transfers of in-kind resources.

\section{FUTURE DIRECTIONS FOR LENDING}

The range of interventions being discussed by the development community includes attention to both chronic independent risk and largescale covariate risk. Future interventions must be designed specifically to avoid reducing incentives for farmers to adopt effective preventive measures. Dependency on relief efforts must be avoided, and relief initiatives must not undermine broader development efforts, nor incentives for private-sector involvement.

IMPROVING INFORMATION SYSTEMS. A critical component of most agricultural risk management strategies is access to information-this requires investments to improve the generation and dissemination of agricultural information. Market price information systems have positive affects on the marketing cycles for crops and livestock, such that producers optimize prices obtained and better regulate the timing of sales throughout the year. Weather information systems help farmers make critical production and marketing decisions relating to input and output combinations given their resource constraints. Farmers facing a high likelihood of drought may plant more stress-tolerant varieties of crops. Herders facing drought may sell early to improve sale prices and reduce pressure on drought-stressed rangelands. Donors have a critical role to play in convincing host governments that market and weather information systems are appropriate policy interventions and can support setting up efficient and sustainable information systems and education and training programs to accompany them.

STRENGTHENING RURAL FINANCIAL SERVICES. In principle, having a financial system serving rural areas in a flexible manner is the best single most important approach to enabling effective risk management. Access to reliable and local savings institutions may allow producers to sell at periods of best price and buy at periods of lowest cost. For example, pastoralists sell animals regularly and at periods of better price, but only when they have access to secure savings institutions and no longer have to store their wealth "on-the-hoof." Farmers able to bank small excess profits are less likely to "bank" this excess in informal insurance or gift-giving.

TESTING NEW APPROACHES TO AGRICULTURAL INSURANCE. With traditional all-risk crop insurance schemes largely discredited as being unsustainable and costly, there are no easy answers to the problem of providing insurance for smallholder agriculture. While any approach must distinguish between the government's role of addressing systemic catastrophic risks, and the private sector's role in provision of insurance tools for more frequent events, some new products being developed warrant close monitoring and further testing. Area-based index insurance is one new approach. ${ }^{4}$ Instead of insuring a farmer's crop and its performance, insurance is issued for some more readily measured objectively verifiable index (for example, area rainfall). This can substantially reduce moral hazard and adverse selection problems. However, implementation issues (such as the availability and reliability of longterm rainfall and yield data for specific regions) need to be resolved. Further, if data are available, strong correlations between typical on-farm yields and rainfall levels are required for this mechanism to be effective. The potential to provide effective insurance for rural producers is promising, however, and despite hurdles it seems likely that they may eventually become widely available and handled routinely by the private insurance industry. In the meantime, further field testing should be continued to assist the industry to develop and market insurance products valuable to poor farmers.

PROMOTING MARKET-BASED PRICE RISK MANAGEMENT. Various mechanisms, such as buffer stocks and price bands, used to pursue price stabilization

4. See the IAP,"India: Innovative Rainfall-Indexed Insurance" 
objectives have met with varying degrees of success and many failures. Recent initiatives such as trading in futures and options contracts are not intended to stabilize market prices, but rather to insulate producers from short-term price volatility. ${ }^{5}$ While the government's role in the functioning of these markets is regulatory, governments may need to adopt an active role in facilitating initial development of derivative markets, overcoming technical complexities, and ensuring that the concerns of the poor are adequately addressed. As for agricultural insurance, a key policy issue is if and to what extent poorer countries should (or can afford to) subsidize privately provided, market-based, risk management mechanisms.

TARGETING USE OF CASH TRANSFERS AND SAFETY NET PROGRAMS. The recognition that the poorest farmers might not be able to repay loans, but do require external assistance, has led to increased interest in use of cash (or other resource) transfer programs. Such programs fall into two categories-poverty safety nets to ensure survival or reduce poverty, and transitional support programs that help producers adjust to new market realities or production constraints (for example, the Direct Income Support Program in Turkey). Safety nets have an important role in helping rural households cope with risk and chronic poverty, providing assistance to households to meet short-run basic needs, and possibly also to increase future income. These safety net programs target especially the temporarily poor (households that experience sudden and unexpected drops in household income causing them to fall temporarily into poverty). Transitional support programs target both poor and nonpoor households that are vulnerable to short-term income fluctuations, and poverty due to structural changes in the agricultural economy. Cash transfer programs can yield significant development benefits through income multipliers, stemming from increased household investment. Safety nets are especially useful for reducing the risk associated with increased food prices.
EMPHASIZING DISASTER PLANNING RATHER THAN RELIEF. The policies, or sometimes lack of them, governing disaster relief and planning at both national and international levels are critical areas in need of analysis and reform. Disaster is usually treated separately as a "humanitarian problem," and not the development and political problem that it usually is. Often as a result of public pressure, governments and donors intervene in ways that in the long run actually work to increase the likelihood of a subsequent disaster by discouraging private risk mitigation measures paid for by local populations. The public interventions, in hindsight, are often demonstrably ineffective and distort individual incentives to plan more carefully for what are often normal and recurrent events. Current debate within the area of rural finance centers on this critical and difficult issue. If governments bail farmers out of the effects of otherwise-insurable or manageable natural disaster risks whenever there is political pressure to do so, development of commercial insurance markets will be compromised and the workings of various indigenous (non-commercial) forms of risk-management practice will be affected. Innovative interventions to address specific disaster needs without compromising disaster risk-management practices either have not been developed or have been designed poorly. These interventions need to be informed by sound technical analysis of how they can be better targeted, implemented and evaluated as to their impact and sustainability (see box 10.4).

RESPONDING TO DISASTERS. When planning and mitigation measures fail, there is frequently a need to "jump-start" agriculture to get farms back into production after a disaster has occurred. Agricultural "starter pack" programs that fund free distribution of agricultural inputs have been used to assist resource-poor farmers after a catastrophe. They have also been used to introduce new technologies (seed, fertilizer) in non-emergency situations. Unfortunately, these programs may create higher levels of risk in the long run by undermining local markets,

5. See the IAP,"Tanzania: Accessing Market-Based Price Risk Management Instruments" 
Box 10.4 The World Bank's Disaster Management Facility

The Disaster Management Facility was established in July 1998 to provide proactive leadership in introducing disaster prevention and mitigation practices into the World Bank's development efforts. A recent recommendation of the Facility is that disaster risk management be formally included in all Bank planning for countries with high natural catastrophe exposure. The Facility also recommends that attention to risk by donors include the three steps of risk identification, risk mitigation, and financing. Other donors, such as the U.S. Agency for International Development (USAID), recently mandated that all country development strategies include conflict vulnerability assessments, thus directly including one type of "man-made" disaster into their development planning. The development and humanitarian assistance communities are working to improve links between relief and development planning. While moving slowly toward positive change, there is recognition of the need to prevent dependency on relief and to prevent relief efforts from undermining development efforts.

Source:Web site of the World Bank's Disaster Management Facility (http://www.worldbank.org/dmf/) Accessed January 20, 2004.

thus reducing the availability in good years of commercial input suppliers and inputs. Distributing farm inputs using vouchers and organized fairs as a forum of exchange between market participants has shown potential to strengthen both formal and informal marketing systems. ${ }^{6}$ This also improves the ability of the agricultural system to cope in times of hardship and reduces dependency on external aid.

\section{SCALING UP INVESTMENTS}

For analysts trying to help decisionmakers at government and enterprise levels, the main message is that governments should not contribute to the complexity of the environment in which farm decisions are made, or contribute to the vulnerability of rural households through ill-conceived or inappropriate interventions. Given the poor record of most interventions specifically targeting risk, future efforts must stress rigorous evaluation. Those proven endeavors that target the resource needs of poorer and more vulnerable producers (for

6. See the AIN, "Responding to Disaster with Seed Distribution" example, micro-credit, infrastructure, market and weather information systems) should be increased where sustainable. This will require that outcomes and impacts of risk-related initiatives be better documented so that a knowledge base can be built to guide future activities. Although there are still many persistent problems relating to agricultural risks faced by the poor, there are policy, institutional, resource, and market opportunities for risk management that can benefit vulnerable rural populations.

\section{SELECTED READINGS}

Asterisk (*) at the end of a reference indicates that it is available on the Web. See Appendix 1 for a full list of Web sites.

Anderson, J. R. 2003. "Risk in Rural Development: Challenges for Managers and Policy Makers." Agricultural Systems 75 (2-3): 161-197.

Barry, P. J. 1984. Risk Management in Agriculture. Ames, Iowa: Iowa State University Press.

Duncan, R. 1997. "World Food Markets into the 21st Century: Commodity Risk Management Policies." Australian Journal of Agricultural and Resource Economics 41 (3): 429-443."

Freeman, P. K., L. A. Martin, R. Mechler, K. Warner, and P. Hausmann. 2002. "Catastrophes and Development: Integrating Natural Catastrophes into Development Planning." Disaster Risk Management Working Paper Series 4. World Bank, Washington, D.C.*

Just, R. E. 2003. "Risk Research in Agricultural Economics: Opportunities and Challenges for the Next Twenty-Five Years." Agricultural Systems 75 (2-3): 123-159.

Skees, J.R. 2003. "Risk Management Challenges in Rural Financial Markets: Blending Risk Management Innovations with Rural Finance." 
Paper presented at Paving the Way Forward for Rural Finance: An International Conference on Best Practices, sponsored by USAID and hosted by BASIS CRSP partner, World Council of Credit Unions, June 2-4, Washington, D.C.*

\section{REFERENCES CITED}

World Bank Disaster Management Facility. http://www.worldbank.org/dmf/.

This overview was prepared by Jock Anderson and Kimberly Lucas. Peer review comments were provided by Henry Gordon, Katrine Saito, David Rohrbach (ICRISAT), and Donald Larson. 


\section{AGRICULTURE INVESTMENT NOTE}

\section{COMMODITY PRICE RISK MANAGEMENT}

Commodity price instability has a negative impact on economic growth, income distribution, and the poor. Early attempts to deal with commodity price volatility relying on direct government intervention (for example, floor prices, guaranteed prices) were generally unsuccessful. Although there may be a case for limited direct intervention in some circumstances, liberalization of markets has resulted in marketbased instruments for commodity risk management (for example, futures trading, options). However, there are substantial barriers to development of markets for, and farmer access to these risk management products. Key investments needed to expand access to these services include: public goods (price information systems, data management systems); technical capacity in government and private service providers; and education of potential users. ${ }^{7}$

Although the old paradigm of domestic price protection and price stabilization increased instability in world markets, trade liberalization has increased transmission of international price movements to domestic producers and consumers. Inability to manage this volatility destabilizes exchange rates and affects the governments' ability to maintain a stable economic environment. Low prices limit farmer incomes, and price volatility makes it difficult for farmers to plan production activities, allocate resources efficiently, and obtain credit.

\section{MANAGING COMMODITY PRICE RISK}

Governments in many countries have intervened in markets, often through state economic enterprises, to insulate producers and consumers from world prices. Most interventions have taken a nonmarket approach in the form of quota or buffer stock programs organized through state marketing boards. However, government interventions have been costly and have crowded out private sector initiatives.

New price risk management schemes involve a substantially reduced overall role for government in administration, and are based on development of market-based price risk management instruments rather than government guarantees and subsidies. The long-term objective must be for government to assume a regulatory role, overseeing markets for risk management tools. However, the public sector can facilitate initial development of these markets and/or improve access to established foreign or international markets for these tools, thus ensuring that needs of the poor are adequately addressed. Marketbased systems are most relevant for standardized commodities traded internationally in large volumes, mainly coffee, cocoa, rubber, cotton, grains, sugar, and oilseeds (and some livestock products) (see box 10.5). They are less applicable to high-value, highly differentiated, or perishable products for which price risk is managed through forward contracts, often in the context of integrated supply chains.

\section{BENEFITS}

Use of price risk management instruments provides producers with certainty about the minimum price they will receive for their crop (at the cost of higher revenues forgone), and allows them to make more efficient farm management decisions regarding output mix and input use. Elimination of worst price scenarios can provide incentives for investment in promising sectors (that are often high risk/ high return). Reducing market distortions foster diversification to new and more profitable agricultural enterprises. Further, eliminating the primary reason for nonrepayment of loans (an unanticipated decline in commodity prices) can reduce the risk exposure of producers in the eyes of lending facilities, and is likely to result in improved access to (and terms of) credit for small-scale agricultural producers.

7. This section refers mainly to cash crops for export markets and is less relevant for food crops. 


\section{POLICY AND IMPLEMENTATION ISSUES}

TARGETING USE OF NON-MARKET MECHANISMS. Reforming existing non-market interventions (such as price bands and floors) so that they are minimally distorting will enable the development of market-based mechanisms that "price stabilization" has tended to impede. Key to success of such nonmarket schemes is the ability to accurately define the threshold price, maintain discipline in implementation, and include specific sunset clauses. Such schemes are only appropriate when major barriers to marketbased alternatives will persist into the mediumterm, and where there is a true underlying competitive advantage for the commodity selected for the price floor scheme.

Commodity exchanges. Well functioning commodity exchanges - systems of price discovery-improve marketing efficiency for agricultural products, and open up new production and marketing opportunities to producers. They reduce price risk (faced by both producers and buyers) by improving overall market liquidity, enhancing stability of local trading networks, and providing farmers with more certainty (through better information) of expected future prices (upon which they can make better managerial decisions). Commodity exchanges require effective regulatory oversight to ensure market surveillance, supervision, and compliance with quality standards. These exchanges can provide a platform for future development of a wider range of services for market participants-both buyers and sellers.

Simple cash forward markets such as warehouse receipt systems, offer some advantages of a commodity exchange and can offer performance guarantees, improve credit accessibility, and reduce price risks. Warehouse receipt systems enable farmers to store their products in a reliable warehouse until prices increase, using the product as a loan collateral and accessing funds before the product is sold. This improves access to credit and reduces price risk. Such systems depend on effective grades and standards systems, and contract enforcement mechanisms that can guarantee performance by the seller.
Box 10.5 Definitions of market-based instruments

The rationale and theoretical underpinnings of formal mechanisms for managing price risk are reasonably simple. There are two basic types of risk management tools (generally referred to as derivatives or hedging instruments):

Futures contracts involve the buyer (or seller) of a futures contract agreeing to purchase (or sell) a specified amount of a commodity at a specified price on a specified date. Contract terms (for example, amounts, grades, delivery dates) are standardized, and transactions handled only by organized exchanges. Profits and losses in trades are settled daily through margin funds deposited in the exchange as collateral. Futures contracts are usually settled before or at maturity, and do not generally involve physical delivery of the product.

Options contracts offer the right - but not the obligation - to purchase or sell a specified quantity of an underlying futures contract at a predetermined price on or before a given date. Like futures contracts, exchange-traded options are standardized, over-the-counter options offered by banks and commodity brokers. Purchase of an option is equivalent to price insurance and therefore requires that a price (premium) be paid. Options include: calls (which give the buyer the right to buy the underlying futures contract during a given period and are purchased as insurance against price increases) and puts (which give the buyer the right to sell the underlying futures contract during a given period and are purchased as an insurance against price declines).

Source:Varangis and Larson 1996.

PRICE RISK MANAgement TOOLS. Commodity derivatives markets present opportunities to hedge commodity-related risks. Market-based tools can effectively insulate producers from shortterm price volatility, but are not available in most developing countries and producers and traders (especially small and resource poor farmers, and traders) are typically not able to access these. A key development challenge will be to address constraints to access and technical complexities (both real and perceived) of designing, implementing, and regulating markets for derivatives.

BARRIERS TO PARTICIPATION. Sellers of market-based instruments (for example, international banks and brokerage houses) often resist trading with unfamiliar customers, particularly small-scale producers, as performance risk and transaction costs are greater. Similarly, the minimum size of 


\section{Box 10.6 Colombia: policy barriers}

The Colombian government changed the legal framework so that the private sector was allowed to hedge price risks using external risk management instruments (including commodity derivative markets). However, the institution supervising coffee exports does not allow contracts for longer than three months. As a consequence, the fees to be paid for exports three months in the future remained uncertain, and represent a larger risk than international coffee price risks. Exporters did not use the international hedging market and small producers ended up absorbing the price risk.

Source:Varangis and Larson 1996.

\section{Box 10.7 Mexico: price risk management}

After liberalization of agricultural trade in Mexico increased price uncertainty for farmers, ASERCA, a government organization providing support services for agricultural commercialization, assisted cotton growers to hedge their price risk using international markets. During the planting season, for a fixed fee or premium, farmers can voluntarily participate in a program guaranteeing a minimum cotton price that is fixed using the New York Cotton Futures Exchange. ASERCA offers a guaranteed price (in US dollars) and hedges its own risk by purchasing a "put" option on the Exchange for future delivery at harvest. Should the prices fall, ASERCA pays farmers the difference between the New York Exchange price at harvest and the minimum price. (This difference is equal to the payoff value of the put option.) If prices rise, ASERCA makes no payment to farmers. By participating in the program, a farmer purchases insurance against a drop in prices below a certain level. contracts traded on organized exchanges far exceeds the annual quantity of production of most individual producers in developing countries, who, like many market intermediaries, lack knowledge of market-based price insurance instruments and an understanding of how to use them. Technical and logistical limitations and other policy and regulatory controls can limit the development and use of derivatives markets (see box 10.6).

\section{LESSONS LEARNED}

Policy and Regulatory environment. Policy and regulatory reform should reduce government intervention in markets and establish a legal system that encourages use of innovative financial instruments. This requires overcoming creditworthiness constraints by: improving the security of sources of collateral and insurability through clarification of collateral law and property rights; central bank regulations for using foreign exchange to hedge transactions; use of offshore accounts; and the creation of secure collateral in the form of warehouse receipts backed by appropriate monitoring, licensing, and bonding systems with international standards (Varangis and Larson 1996).

TARget local CliENTS. Stakeholders (including producers, traders, government agencies) must develop an awareness of, and knowledge in, the operation of commodity exchanges, derivative markets, hedging functions, and risk management procedures. Technical assistance is needed on risk assessment and developing internal procedures. Training should increase farmer understanding of basic mechanics of hedging and the costs/benefits of participation. Capacity building initiatives must not neglect the intermediary institutions (especially cooperatives, banks and other financial institutions, and local traders) needed to aggregate demands of individual farmers to enable risk management instruments of a minimum size to be traded on international markets (see box 10.7).

REQUESTS FOR LOCAL COMMODITY DERIVATIVES MARKETS. Several countries have set up their own futures and options exchanges (for example, Argentina, Brazil, China, Hungary, India, Malaysia, South Africa, and Zimbabwe) and others have expressed interest in doing so. This can provide local users with better access to contract exchanges; ensure that contract specifications are appropriate for locally-traded commodities; introduce new contracts of local interest; and remove the exchange rate risk of using foreign exchanges. These benefits, however, must be weighed against the benefits of using existing exchanges that have well-established rules and regulations, confidence of their customers, and a high volume of transactions (liquidity) enabling users to easily find a buyer or seller. Preconditions for establishing new futures and options exchanges include a well-established 
cash (spot) market; a developed financial sector and regulatory framework; sufficient capital to form a viable clearinghouse; and interest of the local business community. In most cases, it makes more sense to support local cash markets and assist the emergence of simple cash-forward markets before considering development of a full-fledged commodity futures market.

SCALING UP RISK MANAGEMENT INITIATIVES. Recent initiatives have confirmed demand for risk management tools by small-scale farmers in developing countries, and the technical feasibility of making these instruments available to them. However, transactions so far have been on a relatively small scale and have required intensive technical assistance and capacity building efforts. Expanding the size and scope of market development activities while bringing down the overall cost will require combining capacity building investments with larger agricultural sector projects, or investing in specialized piloting mechanisms to identify generic good practices and test principles at different scales and in different contexts. Whether technical assistance can lead to viable volumes of demand for market-based risk management instruments depends on several factors, but mainly on the size and financial sophistication/ technical capacity of the organization that would bundle price risks of many small farmers.

The use of derivatives in international commodity exchanges to hedge price risks seems to be more appropriate for internationally traded export/cash crops such as coffee, cotton, sugar, rubber, palm oil and in some cases cotton. But even in these cases, the issue of the basis risk-low correlation between local and international prices-could reduce the effectiveness of hedging. Furthermore, marketbased risk management instruments provide price protection against a short-term drop in prices, but they are not a solution for a longerterm decline in commodity prices. Finding appropriate market-based price risk management instruments for food commodities such as cereals, is even more challenging because of higher basis risk. This is due to high transporta-

\section{Box 10.8 Potential investments}

- Technical support for development of an enabling regulatory and policy environment.

- Support for business development services providers in working with derivatives.

- Technical assistance for potential providers in assessing producer demand, risk analysis, strategy development, tracking derivatives, selecting brokers and developing controls.

- Technical assistance for customers (farmers, traders) on use of derivatives with support provided through producer groups, trade associations, or business development services providers.

- Cofinancing of critical infrastructure for market development, information and communication systems, logistical infrastructure, data management systems, and testing laboratories.

Source: Authors.

tion costs, local market imperfection and inefficiencies, lack of inter-temporal and interregional arbitrage, inadequate storage markets, and government intervention.

\section{RECOMMENDATIONS FOR PRACTITIONERS}

Direct government intervention in price risk management should only be encouraged where there are substantial barriers to the emergence of private providers. General recommendations related to investments related to price risk management include (see box 10.8):

- Focus reforms on regulatory liberalization, reform of the legal system, clarification of collateral law and property rights, central bank regulations for using foreign exchange and offshore accounts, contract enforcement law, and creation of secure collateral in the form of appropriately backed warehouse receipts.

- Promote establishment of trading centers and spot markets that serve as forums for enabling efficient matching of commodity buyers and sellers; conveying product information and price signals; facilitating the flow of information and financial resources; and reducing supply chain transaction costs. 
- Build awareness of the need to manage price risk effectively and develop the technical knowledge and capacity of government to provide an enabling environment, providers to develop and market appropriate services and tools, and customers (farmers, traders) to understand and use the tools effectively.

- Develop relevant technical and logistical infrastructure (for example, data processing capacities and information systems) to reduce access limitations to commodity and derivative markets.

- Target the poor through enabling key clients who can act as intermediaries to pool the demands of producers to create orders of sufficient size to participate in markets.

\section{SELECTED READINGS}

Asterisk (*) at the end of a reference indicates that it is available on the Web. See Appendix 1 for a full list of Web sites.

Akiyama, T., J. Baffes, D. F. Larson, and P. Varangis. "Commodity Market Reform in Africa: Some Recent Experience.” Policy Research Working Paper 2995. World Bank, Washington, D.C.*

International Task Force on Commodity Risk Management. http://www.itf-commrisk.org.

Larson, D. F., P. Varangis, and N. Yabuki. 1998. "Commodity Risk Management and Development." Policy Research Working Paper 1963. Paper prepared for the Roundtable Discussion on New Approaches to Commodity Price Risk Management in Developing Countries, April 28, Washington, D.C.*

Varangis, P., and D. F. Larson. 1996. "Dealing with Commodity Price Uncertainty." Policy Research Working Paper 1667. World Bank, Washington, D.C.*

Varangis, P., U. Hess, and E. Bryla. 2003. "Innovative Approaches for Managing Agricultural
Risks.” In N. Scott, ed., Agribusiness and Commodity Risk Strategies and Management. London: Incisive RWG Ltd.

\section{REFERENCES CITED}

Varangis, Panos and Don Larson, "Dealing with Commodity Price Uncertainty," The World Bank, October 1996.

This note was prepared by Erin Nicholson (USAID), Panayotis Varangis, and Samuel A. Kane. 


\section{AGRICULTURE INVESTMENT NOTE}

\section{AGRICULTURAL INSURANCE}

Concern for risks that stifle investment and contribute to vulnerability of the rural poor are a driving force behind various types of agricultural insurance (typically "crop insurance"). Insuring small farmers against crop losses to adverse weather or other hazards has attracted public sector involvement in the provision of agricultural insurance in many countries. With few exceptions, such interventions have encountered severe problems due to high administrative costs, moral hazard, and adverse selection. Government interventions should be aimed at improving the accessibility and quality of private sector insurance. This will require the establishment of a framework for responding to severe systemic events affecting agricultural production, and establishing an appropriate regulatory environment to foster private sector innovation and investment in services for less catastrophic events.

Agricultural insurance is a financial tool to transfer production risk associated with farming to a third party via payment of a premium that reflects the true long-term cost of the insurer assuming those risks. ${ }^{8}$ Past public sector interventions to provide insurance and enable the poor to cope in times of hardship have typically failed. Government response in times of severe calamity has been ad hoc, and has lacked precise criteria for what "triggers" an insurance payment thus leading to high potential for political interference and reduced opportunity to obtain reinsurance. As a result, comprehensive publicly supported crop insurance programs have been disastrous, being both ineffective and fiscally burdensome. They have involved heavy subsidization of premiums, large delivery and service costs, and high aggregate losses. To be profitable, the ratio of average administrative costs plus average insurance payouts to the average premiums paid must be less than one. However, for most countries the ratio has far exceeded one, indicating that the programs have been unsustainable without heavy subsidization.

Traditional publicly supported crop insurance is all-risk or multiperil, covering either all the supposed production risks or a very broad spectrum of those risks. ${ }^{9}$ All-risk insurance usually involves payments to the grower as compensation for any shortfall when yield declines below a level set in the policy (Gudger 1991). In some instances, this has encouraged inappropriate use of insurance, and led to excessive risk taking or moral hazard, such as growing crops in high-risk regions, thus increasing farmers' exposure to future losses. Assumption by the public sector of massive insurance losses in turn reduces opportunities to participate in broader reinsurance markets. The ad hoc nature of government policy has frequently been coupled with an ineffective and uncertain regulatory framework that increases uncertainty for private sector providers.

\section{BENEFITS}

Where affordable insurance is not available, poor households typically survive less severe situations through informal coping strategies (such as drawing down savings, asset sale, reciprocal exchanges, diversifying crops, nonfarm income). However, informal mechanisms often result in inefficient outcomes and unexploited market opportunities, because the fear of risk leads farmers to forgo potentially profitable production choices. As well, these systems tend to break down in the face of catastrophes because of the correlated nature of such disasters (see box 10.9).

Insurance acts as a guarantee for investment and can serve as a form of collateral, allowing

\footnotetext{
8. This note specifically excludes the area of price insurance; see the AIN, "Commodity Price Risk Management"

9. Worldwide experience has shown that in most cases traditional crop insurance requires public support. This is directly through government insurance companies providing crop insurance, or indirectly where the public sector provides subsidies, reinsurance capacity, and design/pricing of insurance products, but it is the private sector that ultimately delivers the crop insurance to producers.
} 


\section{Box 10.9 Types of risks}

- Correlated/systemic risk. When many farmers experience a negative impact at the same time (drought for example). This cannot be insured in traditional sense.

- Idiosyncratic risk. Unique to a household and unrelated to neighbors and can be due to management factor. Households can be insured against specific risks.

- Covariate risk. Linked to second round effects (example: drought leads to fall in price assets as assets flood the market).

- Basis risk in insurance. When an insured recipient receives payment for greater or less than the insured losses (when risk management tool does not correlate to farm-yield losses).

Source: Authors.

\section{Box 10.10 Typical insurance problems}

Distorted incentives. When insurers know that government will automatically cover most losses, incentive to pursue sound insurance practices when assessing losses is reduced. Insurers may even collude with farmers in filing exaggerated or falsified claims.

Asymmetry of information. Successful insurance programs require that the insurer has adequate information about the nature of risks being insured. However, this is very difficult for farm-level yield insurance where farmers will always know more about their potential crop yields than any insurer.

Adverse selection. Only those who are more prone to risk will purchase public crop insurance, posing a challenge to the viability of an insurer and initiating a cycle of losses. Conversely, the private sector could leave the "bad" risks to the government.

Administrative costs. Providing services to small farmers can raise costs as data for individual farm-yield based insurance are deficient, and monitoring and inspection costs are high.

Moral hazard. Insurance payout based on individual low crop yields as opposed to the causes of reduced crop yields leads to moral hazard - when a farmer's own behavior or management negatively influences crop yield.

Source: Authors

farmers access to credit services, investment opportunities, and protection from mild and severe shocks. Compensating for catastrophic income losses protects the consumption and debt repayment capacity and helps mobilize rural credit at reduced costs. Furthermore, improved ability to manage risk disproportionately benefits the poor.

\section{POLICY AND IMPLEMENTATION ISSUES}

ClasSIFYING RISKS AND ROLES. Agricultural risks vary in terms of severity and frequency. For the more severe and less frequent events (for example, intense and widespread flooding, prolonged drought), markets typically fail to provide adequate insurance services because of limited credible long-term statistical information, an inability to reinsure on international markets, and the possibility of having to make large payments in years of catastrophic loss (especially in the early years of the program). Because of this market failure (undersupplied risk management services for catastrophic events), the private sector is also likely to fail to provide services for the less severe, more frequent disruptive events (such as localized drought, pest outbreak) that services would otherwise be provided for. When it does, services often bypass the poor or smaller farmers. Thus there is a role for the public sector to intervene (at least initially) in the area of catastrophic risk management, as well as facilitating private sector service provision for more frequent, statistically documented disasters that they are better able to insure against. The following distinguishes these, and potential problems are discussed in box 10.10.

\section{- Major catastrophes (unprecedented anoma-} lies) have a severe impact but occur rarely (say once in 50 to 100 years). Since frequency of occurrence is undocumented, insurers cannot establish statistical likelihoods and assign value for premiums. And since frequency is uncommon, farmers have little interest in purchasing such insurance.

- Systemic crop losses pose severe impact but occur with documented frequency (for instance, a drought or flood every 7 to 15 years). Statistical analysis can be derived 
allowing premiums to be established. With insurance often tied to access for credit, willingness to pay for protection on the part of commercial farmers improves and the private sector increasingly has demonstrated its capacity to respond. Some public intervention may be needed, at least in the early stages of developing agricultural insurance for this type of risk.

- Higher frequency but lower impact independent crop losses pose less severe impact but occur with increased frequency, and stem from a variety of mainly independent causes. Independent yield losses that are not systemic can be insured by the private sector and direct public intervention is inappropriate in this area. For very frequent deviations of crop revenues, appropriate savings and credit schemes should enable smoothing of farmers' revenues and the public sector role is more related to promoting rural savings and credit schemes. For high-frequency events (more frequent than 1 in 5 or 7 years) that cause systemic and high crop losses, agricultural insurance is not likely to be the appropriate instrument and a different approach is required based on diversification and changes in crops or production technologies, for example.

\section{LESSONS LEARNED AND RECOMMENDATIONS FOR PRACTITIONERS}

The overall objective for agricultural insurance should be a private sector-led and demandoriented system in which farmers (including smallholders and the landless) are able to access services supplied by the private sector, and insurance products for mainly less systemic and more independent risks, and at a premium that reflects the true long-term cost of assuming those risks. Given this, and given the market failure associated with private sector supply, public sector involvement is important but should be limited to: establishing a favorable environment for private sector initiative; establishing mechanisms for management of catastrophic risk that the private sector is unable to offer insurance
Box 10.I I:Subsidies for crop insurance

Individual crop insurance often requires heavy government subsidization: one important form is through subsidized premiums. This creates several problems since: it encourages farmers to assume more risks on the margin; it benefits large commercial farmers disproportionately; it may cause rent-seeking by the private sector and so require more subsidies to expand coverage, and thus becoming a fiscal drain. If governments wish to support agricultural insurance with some form of subsidization, this should focus on the catastrophic layer of risks (Skees and Barnett 1999). This can be justified in terms of cognitive failure by the farmers (that is, unwilling to pay for risks that occur with remote probability), and the fact that governments already "own" large systemic risks affecting rural people in that losses from large systemic risks are socialized across all taxpayers.

Source: Authors.

against; and building the capacity of the private sector. Good practice for establishing private sector-led insurance is still evolving, but important implementation issues include:

Public SeCtor INITIATION OF AgRiculture RisK MANAGeMENT SERVICES. A critical public sector priority is to address large systemic risks that affect agricultural production, and allow the private sector to develop insurance products for less severe events and for individual, independent farm risks. Large systemic risks must then be identified, and appropriate insurance mechanisms to manage these where markets fail to do so must be developed. Essential to public intervention in this area is making the government's role explicit and transparent (see box 10.11). An unambiguous threshold to trigger government payout (identifying what will and will not be covered and to what degree) must be clearly specified. This must be quantifiable, and ideally measured by an independent, competent, and credible third party. Farmer participation in publicly supported schemes should be voluntary, the service provider should purchase reinsurance on international markets where possible, and administrative costs must be controlled.

DATA COlLECTION AND ACTUARIAL MODELING. In designing insurance products for any type of 


\section{Box 10.12 Index-based insurance}

Using weather-based index and area-based yield contracts to insure against natural disasters offers increased affordability and accessibility of insurance services for the rural poor. Because triggers can be verified independently, vulnerability to political interference and manipulation of farm losses is reduced. It is practical to implement, and has low administrative and transaction costs, so the private sector can provide it with little or no government subsidies.

Weather-based index insurance makes payments proportional to the difference of a measurable weather event (rainfall, temperature) from a certain trigger, as measured at regional weather stations. Area-based index insurance makes payments proportional to the decline of area yields below a certain trigger at the county or district level. For each of these, contracts are written against specific perils/events (area-yield loss, drought, or flood) defined and recorded at a regional level (local weather station). Insurance is sold in standard units (for example, US\$10 or 100 payouts), with a standard contract or certificate for each unit purchased. The premium rate is the same for all buyers, who all receive the same indemnity if the insured event occurs. Buyers are free to purchase as many units of the insurance as they wish. The insurance is written against the average yield for a region (county/district) and a payment is made when the measured regional yield falls below a defined limit (say 80 percent of normal).

Source: Skees, Hazell, and Miranda 1999

\section{Box 10.13 Potential investments}

- Technical assistance to analyze options for restructuring or phasing out traditional, unsustainable public sector agricultural insurance programs.

- Development of appropriate regulatory frameworks to encourage private sector provision of insurance products.

- Technical support for the private sector in design and testing index-based insurance schemes.

- Data collection/information systems to better understand risk characteristics.

- Education and training for farmers to understand risks and insurance options.

Source: Authors.

risk, insurers (both public and private) must understand the relevant statistical properties. This requires both credible long-term statistical information and actuarial models to define the relevant risk probabilities and to predict the likelihood of various events. Various indices (for example, area rainfall or soil moisture indexes) may be particularly attractive for their practicality and cost effectiveness (see box 10.12)..$^{10}$ An important area of public sector support can be the development of information sources such as risk maps that improve the institutional capacity of both public and private sector providers to identify and analyze risk. This information can form a common foundation upon which the transparent identification and pricing of risk (premium rates) can be based. Donors can support both the development of information systems and the building of the capacity of institutions (such as the ministry of agriculture) to build databases that can overcome information-related constraints to private sector participation.

Creating a favorable regulatory environment. To encourage private sector initiative, the policy and regulatory environment must be deemed by all stakeholders as fair, credible, stable, and enforceable. Toward this end, donors can contribute useful policy advice and capacity building support (see box 10.13).

EDUCATING STAKEHOLDERS. Education of stakeholders is important if farmers are to understand the benefits of insuring against certain events. Workshops, information packages, media and other mechanisms are needed to explain the characteristics of insurance schemes and the different opportunities available. Further, technical assistance should be provided to both public and private sector suppliers to ensure that the needs of producers (particularly the most vulnerable) are met. Such assistance might be best provided through cofinancing for business service providers.

Develop efFective financial systems. Generally, when the poor do not have access to credit, there is less incentive and capacity to secure insurance and pay up-front premiums. Development of financial markets should be promoted where possible to facilitate saving and borrowing, and complement the insurance

10. See the IAP,"India: Innovative Rainfall-Indexed Insurance" 
schemes that are established. The ability of resource-poor farmers to access these services being at the forefront of public sector involvement. This will also contribute to improving access to funds required for making up-front margin deposits on futures and options contracts for managing price risk. Linking finance to index-based insurance is an innovative approach that has emerged from recent work (Hess 2003).

\section{SELECTED READINGS}

Asterisk (*) at the end of a reference indicates that it is available on the Web. See Appendix 1 for a full list of Web sites.

Gudger, M. 1991. "Crop Insurance: Failure of the Public Sector and the Rise of the Private Sector Alternative." In D. Holden, P. B. R. Hazell, and A. J. Pritchard, eds., Risk in Agriculture: Proceedings of the Tenth Agriculture Sector Symposium. Washington, D.C.: World Bank.*

Skees, J., P. Hazell, and M. Miranda. 1999. "New Approaches to Crop Yield Insurance in Developing Countries." EPTD Discussion Paper 55. IFPRI, Washington, D.C.*

\section{REFERENCES CITED}

Gudger, M. 1991. "Crop Insurance: Failure of the Public Sector and the Rise of the Private Sector Alternative." In D. Holden, P. B. R. Hazell, and A. J. Pritchard, eds., Risk in Agriculture: Proceedings of the Tenth Agriculture Sector Symposium. Washington, D.C.: World Bank.

Hess, U. 2003. "Innovative Financial Services for Rural India: Monsoon-Indexed Lending and Insurance for Smallholders." Agriculture and Rural Development Working Paper 9. World Bank, Washington, DC.*

Skees, J. R., and B. J. Barnett. 1999. "Conceptual and Practical Considerations for Sharing Catastrophic/Systemic Risks." Review of Agricultural Economics 21 (2): 424-441.
Skees, J., P. Hazell, and M. Miranda. 1999.

"New Approaches to Crop Yield Insurance in Developing Countries." EPTD Discussion Paper 55. IFPRI, Washington, D.C.

This note was prepared by Panayotis Varangis, Samuel A. Kane, and Erin Nicholson (USAID). 


\section{AGRICULTURE INVESTMENT NOTE}

\section{RESPONDING TO DISASTER WITH SEED DISTRIBUTION}

Seed is frequently distributed to farmers in postconflict and post-disaster (for example, postdrought) situations as a way of "restarting" agricultural production and improving food security. Programs must be appropriately targeted, locally adapted, and timely. They should strengthen local institutions and coping mechanisms, and avoid distorting markets and undermining local seed systems. To maximize development impact and program efficiency, programs may need to be accompanied by fertilizer, tools, training, and technical support. ${ }^{11}$

The apparent increase in international emergency situations has led to massive displacement of people due to civil strife, drought, and other emergencies. Drought and other disasters, both natural and artificial, have led to widespread destitution and a need for emergency food programs. Restarting agricultural production disrupted by the emergency is often hampered by lack of adequate seed supplies, which may have been lost or consumed. The distribution of seeds and associated inputs has become a common intervention for addressing the problems of emergency situations, and promoting long-term food security among agricultural communities affected by disaster. By providing the inputs necessary for crop production, such interventions increase agricultural productivity and reduce dependence on food aid.

Seeds interventions merit consideration where displaced peoples are returning to agriculture or in situations where pests, floods, or drought have depleted normal seed supplies. Even in refugee settings, gardens may help people increase food security and exercise a small measure of self-sufficiency. The most commonly distributed seeds are for cereal crops such as maize, wheat, rice and sorghum. Roots and tubers, planting materials and vegetable seeds may also be distributed to be grown close to homes, taking advantage of water recycling. Cassava is especially useful in conflict situations since the plants can be left in the ground and harvested over a long period of time, allowing farmers to harvest depending on the security situation (USAID 2002). In some situations, distribution of fertilizer and hand tools may also be appropriate.

\section{BENEFITS}

Effective seed system interventions can prevent food shortages by enabling a population to grow food, and can decrease emergency costs incurred through the provision of food aid. Compared to subsidies, the targeted supply of seed and other production inputs can benefit smallholders most in need rather than the richer or more influential members of the community. This also can be an opportunity for the introduction of innovations (new varieties, new crops, new management practices) with longer-term positive effects on agricultural productivity. Food security at the household and national levels can be increased, and local markets strengthened.

However, inappropriate uncoordinated interventions can decrease seed system stability and varietal diversity, while bringing a set of unintended negative impacts on the social and political economy of recipient communities. Some interventions can distort production incentives, destroy local seed markets, and prolong the transition to sustainable farming systems. There is now a keen awareness that interventions need to be designed more carefully to alleviate the root causes of specific problems, rather than being viewed as a generic default response to emergencies. Interventions must build on strengths of existing seed systems and alleviate the weaknesses of these, rather than impose new systems from outside.

II. This AIN draws largely from USAID 2002. Disaster Reduction: A Practitioners Guide. Office of US Foreign Disaster Assistance, Washington, D.C. 


\section{POLICY AND IMPLEMENTATION ISSUES}

Availability, access, and utilization. Practitioners of seed interventions are now starting to understand the roles that seed availability, access, and utilization play in agricultural recovery following a crisis, and use this understanding to target interventions better.

- Seed availability refers to the seed supply within the affected district, region, or community. It is described according to the desired type, quantity and quality of seed or planting material available, as well as where and when it can be obtained. Availability may refer to both informal farmer-tofarmer networks and the commercial seed system. Seed availability is often a factor following a long-term drought or a suddenonset disaster when both stored and planted seeds may be destroyed or lost, leaving farmers without seed to plant, and without the ability to obtain new seed through traditional farmer seed systems.

- Seed access refers to the ability of farmers to acquire the seed or planting material that is available. In some cases, seed may be readily available on local markets, but farmers are unable to purchase the needed seed (due to lack of purchasing power or physical access). Poorly planned distribution disrupts markets and eliminates local sources of income and incentives to produce seed for future years.

- Seed utilization refers to the ability of farmers to make use of seed, once it is accessed. This implies that farmers have tools, land, knowledge, and physical ability to plant seed.

FORMAL AND FARMER SEED SYSTEMS. MOst smallholder farmers use their own saved seed for planting. Depending on the crop and situation, farmersaved seed can be of a comparatively high physiological quality (in terms of germination percentage, physical purity, and varietal integrity). Seed quality does not necessarily deteriorate when seed is saved from season to season. Seed is also available from commercial seed companies - the formal seed sector. In most emergency situations, relief agencies obtain seed from the formal sector in relatively large quantities, often because procurement from small farmers is deemed too difficult and seed is needed on short notice. Such seed is not necessarily better than farmer-saved seed, and it is often easy to overestimate the ability of the commercial seed sector to supply seed to effectively satisfy the needs and demands of local producers (Jones et al. 2002).

DePEndencies AND DIsTortions. Inappropriate seed distribution can cause a general dependency on these programs. Many communities come to expect emergency seed aid as a right, thus undermining the advance of local seed systems toward independent and sustainable enterprises. Seed insecurity may increase if spontaneous aid/ relief in the form of free distribution of improved varieties undermines the capacity of local seed systems, and limits adoption of locally suitable plant varieties and farming practices.

SeEd Quality and Health. It is critical that the seed being distributed be labeled accurately (such as seed type, quality characteristics), and that it is appropriate for local conditions. Seed testing should confirm that seed is viable before it is purchased and distributed. Also, when importing seed, attention must be given to the phytosanitary inspection of seed, even when official requirements are waived because of a crisis situation. Introducing new diseases or insect pests to a region may cause long-term problems. In other situations, strict phytosanitary controls make no sense (for example, moving seed across a land border over which seed and grain normally flows freely in both directions). Sound technical advice is required in managing such seed imports.

\section{LESSONS LEARNED}

Situation analysis. Before making decisions about seed system interventions it is important to distinguish between problems of availability and problems of access. In some instances, the costs of intervention (in terms of potential for creating dependency, distorting impacts, and 
Box 10.14 Rwanda: scientist and technician training

Most scientists working for the national research institute and the Ministry of Agriculture before the war of 1994 were killed or fled to neighboring countries. Newly recruited scientists and technicians were generally inexperienced and lacked institutional memory relating to agricultural research and development programs. In this situation, regional research networks helped rejuvenate the national research and extension system. Training of scientists and technicians involved research methods, seed production, technology dissemination strategies, selection criteria, and evaluation techniques. The training enabled scientists to restart field research to address needs of farming communities.

Source: Buruchara et al. 2002.

opportunity cost of donor funding) outweigh the benefits. Food aid alone may suffice to overcome the emergency through reducing the pressure to consume planting seed.

SOURCING THE SEED. Seed distribution programs should be based on an understanding of the farming systems and what kinds of seeds are needed, what varieties are most appropriate and accepted by the community, and what technologies are familiar to local farmers. When distributing new varieties, there should be evidence that these have been tested and have performed well in a similar agro-ecological area, and that cooking and processing quality are compatible with local taste preferences. Ideally, relief seed distribution should be of locally produced seed of locally adapted crops. A program that purchases local seed can support indigenous marketing of both traditional and commercial seeds. Past seed interventions, in both disaster and non-disaster situations, have often failed because of a tendency to assume that modern technology and formal systems are best, and that there is little value in strengthening what already works (Jones et al. 2002).

TREATED SeED. There may be reasons to treat seed with pesticide or other seed treatments to safeguard seed quality and crop productivity, and seed purchased from the formal seed sector may come with seed treatment irrespec- tive of the relief agency preference. Adequate farmer training/orientation and adequate food distribution should ensure that treated seed is not used for food. Training of women in this regard is a priority.

FERTILIZER, TOOLS, AND TECHNICAL SUPPORT. For seed distribution to be effective, it will often need to be linked with fertilizer, tools, and technical support. Even limited quantities of fertilizer (as little as 10 kilograms of nitrogen per hectare) may significantly increase yields. Complementary inputs are best supplied through local markets (traders, local stores), if farmers have the resources to make purchases. New inputs will generally need to be complemented by well-informed crop management advice, including to women. Targeting training to scientists and technicians is also important (see box 10.14).

TIMING. In most countries, the agricultural season presents a short window for planting, so seed must be provided and in farmers' hands at the start of the planting season. If an agricultural crisis is ongoing, seed distribution may need to be coupled with food distribution so that all of the seeds are used for planting rather than consumption.

TARgeting InTERVEntions. The distribution of seeds, tools, or the means to access them (vouchers) must be targeted to the poorest farmers with the greatest need for assistance. A thorough assessment can determine not only what kinds of interventions are best, but also how to target those interventions. Where community organizations are strong, it is preferable for them to define eligibility criteria and take responsibility for allocating seed and inputs among needy families.

VOUCHERS AND SEED FAIRS. Seed vouchers redeemable from certified retailers and seed fairs serve to strengthen farmer seed procurement systems, improve cost efficiency, and allow commercial sector participation and farmer experimentation with new varieties (see boxes 10.15 and 10.16). This provides a level playing field 
Box 10.15 Uganda: emergency seed vouchers and farm tools

After unrest in 2000 had forced Ugandans from their farms, a program was initiated to enable families to reestablish farming systems. The program provided families with farm tools and vouchers for the purchase of seed. The intervention was based on an assessment that showed lack of access to seed (not lack of availability) to be the main problem. Beneficiaries redeemed their vouchers for seed at seed fairs or special market days, with about 12,000 families accessing over 200 metric tons of seed of 10 different crops and 30 varieties.

Vouchers enabled farmers to buy commercial or traditional seed of their choice in the crops and varieties they preferred. They were able to examine the seed themselves and select seed of acceptable quality. Since they were unable to return to their farms until the middle of the rainy season, they were able to choose the seed of crops and varieties that are traditionally planted late. Seed fairs facilitated interaction between seed sellers and farmers, enabling both traditional and commercial seed sellers to market their seeds. Almost 50 percent of the participating grain traders were women. Overall, the assistance was flexible, timely, and cost effective.

Source: USAID 2002

for the commercial seed sector and the farmer seed systems to compete and complement one another. Beneficiaries have a greater choice of crops, varieties, and seed quality, compared with traditional seed-and-tool distribution programs. This voucher and fair system is most appropriate where there is a problem with seed accessibility rather than availability but upward pressure on seed prices, must be considered.

\section{RECOMMENDATIONS FOR PRACTITIONERS}

Important recommendations for practitioners involved in investments related to the response to disasters with seed distribution include (see box 10.17):

- Carry out a situation analysis to identify the true cause and nature of the problem (access vs availability, chronic vs acute) and to understand both the farmer seed system and the commercial seed system and plan the intervention to strengthen existing capabilities.

- If farmers have the resources to purchase seeds, use local markets (traders, local stores) for distribution.

- Target specific groups with limited purchasing power, using nongovernmental organizations (NGOs), local women's groups, or farmer associations to develop eligibility

\section{Box 10.16 Tanzania: seed fairs}

After four years of drought in Tanzania, farming households were ill prepared to cope with the drought of 2000. USAID sought to empower communities to access what they needed from within their communities. The scheme provided vouchers to vulnerable households to enable them to buy seed at special seed fairs organized locally. Prior to the project, seed surveys confirmed that, even after four years of drought, large amounts of seed were available locally. Meetings were held to inform all stakeholders about the voucher system. The most needy households were selected using democratic and transparent guidelines. Each household received six vouchers valued at about US\$1.80 each. Some 14,000 voucher recipients bought seed from more than 400 seed vendors in 30 seed fairs.

Source: USAID 2002

\section{Box 10.17 Potential investments}

- Technical assistance for analysis of needs and alternative ways of addressing seed supply problems.

- Financing of alternatives to seed interventions (for example, food aid) where this will have a more positive impact on poverty and sustainable livelihoods.

- Procurement and distribution of seed where it is the best alternative.

- Vouchers systems for target farmers to purchase seeds and other inputs.

- Seed fairs where vendors (both commercial and local farmers) and buyers can trade seed.

- Information campaigns to inform farmers of seed programs or alternative sources of seed.

- Training for farmers and for scientists and technicians providing support services.

Source: Authors. 
criteria for beneficiary selection, and to handle seed distribution.

- Identify the complementary inputs and training needed to increase productivity and build local capacity.

\section{SELECTED READINGS}

Asterisk (*) at the end of a reference indicates that it is available on the Web. See Appendix 1 for a full list of Web sites.

Buruchara, R. A., L. Sperling, P. Ewell, and R. Kirkby. 2002. "The Role of Research Institutions in Seed-related Disaster Relief: Seeds of Hope Experiences in Rwanda." Disasters 26 (4): 288.*

USAID. 1998. The Field Operations Guide for Disaster Assessments and Response. Washington, D.C.: USAID, Office of U.S. Foreign Disaster Assistance.*

USAID. 2002. "Disaster Reduction: A Practitioners Guide." USAID, Office of U.S. Foreign Disaster Assistance, Washington, D.C.*

\section{REFERENCES CITED}

Buruchara, R. A., L. Sperling, P. Ewell, and R. Kirkby. 2002. "The Role of Research Institutions in Seed-related Disaster Relief: Seeds of Hope Experiences in Rwanda." Disasters 26 (4): 288-301.

Jones R. B., P. Bramel, C. Longley, T. Remington. 2002. "The Need to Look Beyond the Production and Provision of Relief Seed: Experiences from Southern Sudan." Disasters 26 (4): 302-315.

USAID. 2002. "Disaster Reduction: A Practitioners Guide." USAID, Office of U.S. Foreign Disaster Assistance, Washington, D.C.

This note was prepared by Samuel A. Kane. 
INNOVATIVE ACTIVITY PROFILE

\section{KENYA: COMMUNITY-BASED DROUGHT MANAGEMENT}

The pastoralist population in arid districts of Kenya is counted amongst the poorest and most disadvantaged sections of society. The arid lands are well endowed with livestock resources, but lack reliable marketing outlets to provide the full benefit of this resource for either pastoralists or consumers in the region. Environmental constraints in these districts are extreme: fragile, easily degraded physical environments and poor and variable water resources. Drought is a normal and recurring phenomenon that can kill 50 percent or more of the livestock in severe cases. Experience with typical top-down development projects for traditional nomadic pastoralist communities has been so bad that many donors still shy away from financing further development interventions for these communities. However, neither effective conservation of natural resources nor development of the potential of these areas will be realized unless constraints imposed by drought risks are addressed.

What's innovative? Working with communities in drought-prone areas on an Early Warning System, contingency planning, integration into the mainstream economy, and improved district and national level drought and risk management.

\section{PROJECT OBJECTIVES AND DESCRIPTION}

The overall objective of the first Arid Lands Resource Management Project is to build the capacity of communities in the arid districts of Kenya to cope better with drought. To achieve this objective the project focuses on the following three components:

- Drought management institutionalizes at national and district levels a structure to effectively manage all the phases of drought. This includes preparedness (drought monitoring), mitigation (drought contingency planning and rapid reaction), and recovery (continued drought relief activities).

- Marketing and infrastructure addresses the bottlenecks that impede livestock market linkages between the arid lands and the rest of the national economy.

- Community development is designed to achieve the fundamental objective of increasing the communities' capacities to protect and develop their livelihoods by dealing with drought cycles in an effective way. Delivery systems related to services demanded by communities include animal health and livestock production, crop production, water supply and human health, and education.

\section{BENEFITS AND IMPACTS}

Key achievements of the project have been its role in coordination of assistance to the arid lands, and the overall national coordination of donors, in particular through the establishment of the Kenya Food Security Meeting. Adequate and timely information provided by the project has enabled proper scheduling of drought mitigation assistance. The project has also been highly successful in developing a devolved system of implementation with full participation, involvement, and ownership by district governments, institutions, and communities. At the district level, the primary achievements have been the establishment of functional local entities such as the District Steering Groups, the enhanced capacity of line ministries' human resources involved in project implementation (Mobile Extension Teams), the start of effective decentralized planning and implementation, and improved linkage between communities and their local institutions.

As part of the drought management component, the project has helped to finance an Early Warning System which is of vital importance for Kenya as 75 percent of the country has a fragile arid or semi-arid environment. During 
the severe 1999-2001 drought, the improved drought management and coordination system allowed vulnerable groups improved access to food supplies. This enabled US $\$ 300$ million of food aid to be made available to about 3.3 million people.

Livestock production is the mainstay of Kenya's pastoral areas. Fifty-three livestock marketing and infrastructure investments have been implemented by the project. Stock routes have been improved through the rehabilitation or creation of existing watering points. Holding grounds have been created close to livestock primary and secondary market centers to improve the contractual power of the animal holders. Moreover, new markets and sale yards have been promoted at the divisional level, enabling a decongestion of the district markets. Slaughterhouse standards have been raised with consequent improved hygiene, ante- and post-mortem health control, meat quality, and overall environmental conditions.

Over 1,200 microprojects have been implemented on a fully participatory basis benefiting some 180,000 people and addressing several sectoral needs identified by the communities. Animal health interventions contributed to an 11 percent vaccination coverage increase in 2002, and a 15 percent decrease in Contagious Bovine Pleuro-Pneumonia and Contagious Caprine Pleuropneumonia. Average maize and bean yields have reportedly increased by 30 percent. Project-improved access to water has reached an estimated 40 percent or 800,000 of the arid lands population, and an equivalent or higher percentage of livestock population.

Principal shortcomings are the limited progress on establishing a framework for natural resource management, and developing a better understanding of how to monitor, protect, and sustainably develop the arid lands resource base. Further, the exclusively grant-based community development funding may increase dependency. These shortcomings are addressed in the design of the second Arid Lands Re- source Management Project. This follow-on project will support three complementary channels of intervention, which together address vulnerability:

- Strengthening and institutionalizing natural resources and drought management.

- Empowering communities to identify, implement, and sustain development priorities.

- Policy support, advocacy, and improvement in the delivery of essential services.

\section{LESSONS LEARNED AND ISSUES FOR WIDER APPLICABILITY}

- Strengthening of district-level multisectoral institutions can significantly improve the effectiveness of project interventions on the ground.

- Community participation and contribution is key to project impact and sustainability, increasing ownership, and community ability to replicate activities.

- Continuous capacity building is needed at all levels as is strengthening of technical support services for quality interventions and technical follow-up.

- Broader access to main services in arid lands can only be achieved by strengthening communities and support service actors to provide cost-effective and, where possible, profitable facilities that continue beyond credit closure.

- Development is closely linked to education, which provides an important exit or diversification strategy for pastoralists.

- Support for diversification must be targeted so as to not displace existing household activities. The more wealthy and less vulnerable are more able to diversify into higher income activities while maintaining herds. Exit from pastoral activities is not 
risk-reducing "diversification," but usually reflects loss of assets.

- An improved understanding of the arid lands resource base is essential for successful and sustainable project interventions.

\section{PROJECT COUNTRY: KENYA}

Project Name Arid Lands Resource Management I and ||

Project ID ALRMPI: P00I33I, and ALRMP II: P078058

Project Cost ALRMP I (org.): US\$25.I million, and ALRMP II (org.): US\$77.9 million

Dates ALRMP I: FY199 6-2003, and ALRMP II: FY 2003 - 2009

Contact Point Christine Cornelius The World Bank, $1818 \mathrm{H}$ Street N.W., Washington, D.C. 20433 Telephone: (202) 458-5618

Email:ccornelius@worldbank.org 
INNOVATIVE ACTIVITY PROFILE

\section{MONGOLIA: SUSTAINING LIVELIHOODS IN AREAS WITH HIGH NATURAL DISASTER RISK}

Rural poverty in Mongolia has been increasing in depth and severity. Although the number of people living below the poverty line has been relatively stable (around 36 percent of the population from 1995 to 1998), those who are living below the poverty line have become even poorer. Previous projects targeting poverty reduction have fallen short due, in part, to a lack of commitment by the government. In July 2000, however, the government declared that poverty reduction was to be one of its highest priorities. This has paved the way for projects to address one of the root causes of poverty in Mongolia-vulnerability to risk. In particular, a Participatory Living Standard Assessment demonstrated that loss of employment, high costs of health and education, and natural disasters are the most common factors associated with poverty.

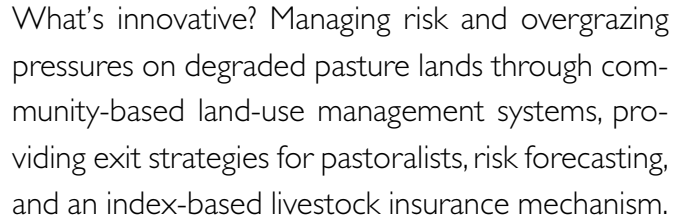

\section{PROJECT OBJECTIVES AND DESCRIPTION}

The Mongolia Sustainable Livelihoods Project was financed to reduce vulnerability and promote the security and sustainability of rural livelihoods in a manner that can be scaled up. In particular, the Mongolia project targets natural disaster risk including drought and dzud (winter disaster) through an integrated approach including:

- A Local Initiatives Fund to be managed in a socially inclusive, community-driven way to diversify incomes and improve local infrastructure.
- Community-based pastureland management based on improved grazing discipline and alternative conflict resolution mechanisms.

- Risk forecasting and contingency planning including an index-based livestock insurance scheme, meteorological monitoring, and an early warning system.

Pastureland throughout Mongolia is classified as "common land," although tenure rights can be granted. As a result of this land tenure system, pasture must be managed on a community rather than an individual basis. Currently five to nine percent of pastureland in Mongolia is considered degraded. This degradation threatens sustainable livelihoods, and may be worsened by poor management associated with overuse, especially during natural disasters such as drought and $d z u d$. Within this project, communal land management is strengthened through the development of community-based grazing management systems that include conflict resolution mechanisms and sanctions for noncompliance. Reducing instances of poor land management is expected to allow herders to sustain productive livelihoods thereby contributing to poverty reduction.

The number of herder families in Mongolia increased from 75,000 in 1990 to over 190,000 in 2000. This increase can be explained by the fact that many families began herding because of a lack of alternative income-generating opportunities. Exit strategies in the project are targeted at presenting these new herders with other income-generating opportunities. Provision of access to microfinance credit is used for alternate employment. Developing exit strategies serves two functions: first addressing the poverty of new herders by providing alternate income opportunities; and second addressing the poverty of established herders by reducing pressure on grazing land and making their livelihoods sustainable.

Another key to achieving the project objectives has been identified as institutional capacity building, which is critical for the return of 
decisionmaking power to a decentralized and local level. Capacity building is especially necessary for the local management of rural investment funds, and for community-based management of common pasture lands.

The pastoral risk management component will improve risk forecasting and contingency planning by improving coverage of weather forecasting data, broadening the range of data used in semi-annual early warning system bulletins and increasing their dissemination to local authorities and herders, and development of sum-level (rural district level) contingency plans.

A risk index-based livestock insurance scheme is being developed, on the basis of which eligible participating private insurance companies would offer livestock insurance to individual herders, herding households, or other juridical persons owning livestock to cover covariant risk arising from dzud, drought, or other weather-related events. The index, based on objective, thirdparty verifiable indicators such as weather data, livestock mortality rates, and/or indices of range vegetation condition, would differentiate relative risk at an appropriate level (most likely at the rural district level) based on historical data. Indemnities under the scheme would be triggered once the index exceeded a given threshold level specific to that rural district. Insurance cover would be for productive activities including: the replacement value of livestock; the value of goods or services to support risk preparedness and/or enhance livestock productivity, such as hay and fodder production or purchase, acquisition of veterinary drugs and services, construction of livestock shelters, and breeding services; and/or the value of goods and services to allow policyholders to engage in alternative or supplementary livelihood strategies. Liability of insurance companies has an upper limit and the government covers claims beyond that amount. The project would also finance training workshops for participating insurance companies and public officials involved, and a nationwide information campaign to publicize the scheme and attract policyholders. The scheme will be launched during the second year of the project, and is expected to become profitable by the end of the project.

\section{BENEFITS AND IMPACTS}

The Mongolia Sustainable Livelihoods project began in 2003, so outcomes have not yet been measured. Experiences during planning, design, and initial implementation have, however, indicated a number of expected benefits, including poverty reduction through pasture land management. Reducing poverty by addressing livestock and grazing land management presents an opportunity to shift from simply managing poverty by providing welfare services to reducing poverty by fostering the emergence of secure and sustainable livelihoods.

\section{LESSONS LEARNED AND ISSUES FOR WIDER APPLICABILITY}

The Mongolia project is designed as a pilot for scale-up in other areas, its flexible policy framework having wider application in the context of an adaptable program loan. The numerous advantages of managing sustainable livelihoods via community-driven development can be applied broadly as its tools allow for better targeting of poverty reduction programs, and is especially useful where welfare approaches have not worked. Decentralization is critical, and there is a growing need to support institutional frameworks through which this can take place.

\section{PROJECT COUNTRY: MONGOLIA}

\begin{tabular}{|c|c|}
\hline Project Name & $\begin{array}{l}\text { Sustainable Livelihoods Project } \\
\text { (Pastoral Risk Management } \\
\text { Component) }\end{array}$ \\
\hline Project ID & P067770 \\
\hline Project Cost & US\$5.4 million (estimated) \\
\hline Dates & FY2003 - FY2007 \\
\hline Contact Point & $\begin{array}{l}\text { Robin Mearns } \\
\text { The World Bank, I } 8 \text { I } 8 \text { H Street } \\
\text { N.W.,Washington, D.C. } 20433 \\
\text { Telephone: (202) 458-40 I0 } \\
\text { Email: rmearns@worldbank.org }\end{array}$ \\
\hline
\end{tabular}


INNOVATIVE ACTIVITY PROFILE

\section{TANZANIA:ACCESSING MARKET-BASED PRICE RISK MANAGEMENT INSTRUMENTS}

The fall of coffee prices to 40-year lows in 2001 and 2002 affected over 400,000 low-income coffee-producing households in Tanzania. The 1993 liberalization of the coffee sector exposed farmers and their marketing organizations to intraseasonal price fluctuations. These fluctuations have made it difficult for farmers to optimize production technology, timing of sales, and use of assets that could eventually result in higher household incomes. Exposure to price volatility, coupled with absolute low prices for coffee, has greatly diminished the overall welfare of coffee farmers.

What's innovative? The use of market-based price risk management instruments to manage price risk, giving farmers and organizations more price stability and the ability to stay financially solvent even if global prices fall.

\section{PROJECT OBJECTIVES AND DESCRIPTION}

To confront the negative effects of short-term price volatility, one of the largest coffee cooperative unions in Tanzania, averaging 20-100 kilograms production of coffee per farmer, utilizes market-based price risk management instruments to hedge price risk, and make multiple payments to farmers throughout the year. Cooperative members receive a uniform minimum first payment price for their coffee when they deliver it, and later in the season, depending on sales and market performance overall, may receive subsequent payments for their product. The guaranteed first payment provides farmers a form of price stability, but can have disastrous financial impacts for the cooperative. If the cooperative guarantees a low first payment at the beginning of the season and the market price rises, farmers, instead of selling to the cooperative, will sell to traders who pay full market price in cash at the time of delivery. If the cooperative guarantees a high first payment at the beginning of the season, and market price falls, it will take losses on the negative margin between first payment price to farmers and actual market prices.

In past years, the cooperative union received loans for its operations from a local commercial bank. However, the loan agreements and the union's access to financing were in serious jeopardy due to a history of poor financial performance, which related in large part to the pricing problems previously described. The government had supported many of the cooperative unions through difficult times, but was indicating an impatience about continuing to do this indefinitely.

To assist the cooperative's attempts to strengthen its operations, the World Bank began working with the union in the summer of 2001 to help it protect its prices with marketbased hedging instruments. The World Bank's Commodity Risk Management Group (CRMG) aimed to provide services consisting of training and education about price risk management markets, principles, and products for the cooperative, the local bank, and others in the Tanzanian coffee sector. The cooperative union used put options to design a hedging strategy that matched its risk profile, using the options in the international market to provide a floor price to protect against declining prices. The objectives of the strategy were to protect the union's break-even position and guarantee a first payment to farmers. Providers of financial products and services had intense due diligence requirements that included detailed information about the ownership, structure, financial status, and trading history of the cooperative union. After completing this due diligence process, the cooperative was approved as a new client and was able enter the market to hedge its price risk.

The union took its first hedge position by buying a put option in October 2002. It continued with market activity (reselling the option when it no longer had exposure in a given month, and 
purchasing new option contracts to cover upcoming months) through the end of the selling season in March. In total, during the 2002-03 crop year, the cooperative hedged about twothirds of the total volume of coffee it handled.

\section{BENEFITS AND IMPACTS}

Thus far a number of positive effects have resulted:

- The union improved its relationship with its local bank and received a loan to cover the cost of the premiums for the hedging instruments as part of its total loan package.

- Union management had a clearer view of overall financial status through the season.

- Improved financial transparency helped the union make better selling decisions.

- The union paid farmers second and third payments. The price floor allowed the union to disperse revenue when it was earned.

Monitoring of the relationship between local Tanzanian coffee prices to the global market is being continued. When the two markets are highly correlated (prices moving in similar ways directionally), hedge quality is high. If, however, the markets become disconnected, hedge quality is low and this negatively affects the cost benefit analysis of the overall risk management strategy. However, in a short period of time, the union in Tanzania has moved from being a very high-risk enterprise to a much more stable entity. Price risk management contributed to that growing stability, and the union's managers have improved their knowledge about price risk management and access to such tools.

\section{LESSONS LEARNED AND ISSUES FOR WIDER APPLICABILITY}

This project provides technical assistance and training, which is necessary to "bridge the gap" between developing country commodity producers and providers of risk management products and services. From the provider's perspective, the technical assistance provided by the CRMG was critical. Without it, private sector participants have indicated that they would not have been willing and able to transact with such new clients in developing countries. From the cooperatives' perspective, the technical assistance and training gave management the confidence and knowledge to utilize risk management methods previously unknown to them. This work is beginning to stimulate demand from developing country organizations and has the potential for wide applicability.

\section{PROJECT COUNTRY:TANZANIA}

$$
\begin{array}{ll}
\text { Project Name } & \begin{array}{l}
\text { Market-Based Commodity Risk } \\
\text { Management Instruments for } \\
\text { Developing Countries }
\end{array} \\
\text { Dates } & \text { FY2002 - FY2003 } \\
\text { Contact Point } & \text { Commodity Risk Management } \\
& \text { Group } \\
& \text { The World Bank, 1818 H Street } \\
& \text { N.W.W.Washington, D.C. 20433 } \\
& \text { Telephone: (202) 473-1718 } \\
& \text { Email: crmg@Worldbank.org }
\end{array}
$$


INNOVATIVE ACTIVITY PROFILE

\section{INDIA: INNOVATIVE RAINFALL- INDEXED INSURANCE}

In much of India, weather volatility is the single most important risk faced by non-irrigated farmers. Drought risk affects the poor especially as they typically have smaller land holdings and less access to irrigation. Due to an absence of formal mechanisms such as insurance, farmers have developed a variety of informal strategies to deal with these risks including accumulation of buffer stocks, diversification of incomegenerating activities, and variation of cropping practices. However, these are often ineffective (particularly with regard to catastrophic events such as widespread droughts), and result in risk adverse decisionmaking and suboptimal resource allocation.

What's innovative? Using rainfall-indexed insurance (combined with other financial services) to reduce systemic risk and improve the supply of financial services to smallholders.

A pilot program in India initiated by KBS Bank (Krishna Bhima Samruddi Local Area Bank) and ICICI Lombard, and supported by the World Bank, shows how farmers in such areas can protect their livelihoods. Weather-indexed insurance does not suffer from the usual moral hazard and adverse selection and high administration cost problems of traditional crop insurance, and it is therefore better suited to small farmers who depend on rainfall. ${ }^{12}$

\section{PROPOSED OBJECTIVES AND DESCRIPTION}

Having worked on crop insurance pilot programss for the previous four years, BASIX (one of India's largest microfinance institutions with nearly 100,000 borrowers in nine states) launched India's first rainfall insurance program in July 2003 through its KBS Bank in Mahabubnagar in Andhra Pradesh, bordering
Karnataka (the district has experienced three consecutive droughts during the last years). One of the main incentives for KBS Bank to offer rainfall insurance was that local area banks are limited to operations in three adjacent districts and therefore face limited portfolio diversification. Rainfall insurance for its borrowers would mitigate the natural default risk inherent in lending in such drought prone areas.

KBS bought a bulk insurance policy from ICICI Lombard and sold around 260 individual farmer policies for three categories of groundnut and castor farmers-small, medium and large. Small farmers are defined as households farming less than 0.8 hectares of land, medium farm between 0.8 and 2 hectares, and large farmers have more than 2 hectares. Premium rates are 456 Rs per year for the small farmers with a liability of 14,250 Rs, medium farmers pay 600 Rs with a maximum liability of 20,000 Rs and large farmers pay 900 Rs for a liability of 20,000 Rs. KBS decided to initially limit liability per farmer rather than imposing per hectare limits in order to manage overall liability. KBS and ICICI Lombard opted for a weighted and capped rainfall index-the payout structure weights the more critical periods for plant growth more heavily than others. KBS decided that only borrowing farmers could buy weather insurance policies, and it hopes to lower the interest rate for these farmers due to the reduced risk of default. One of the top five reinsurers in the world has agreed to reinsure the entire weather insurance portfolio.

\section{BENEFITS AND IMPACTS}

Farmer uptake was immediate, with around 100 farmers signing up the first day. Informal interviews with about 15 farmers who bought the policies revealed that they are very well aware of the rainfall-based index nature of the contracts and the associated basis risk. The farmers value the quick payout of the weather policy, which distinguishes it from the federal crop insurance policy in India. Interviewed

12. This IAP draws largely from U. Hess, "Innovative Financial Services for Rural India: Monsoon-Indexed Lending and Insurance for Smallholders." Agriculture and Rural Development Working Paper 9. (World Bank, Washington, D.C., 2003). 
farmers also understand and appreciate the weighted and capped structure of the contract, as it directly reflects their experience that the distribution of rain throughout the season significantly affects yield.

Overall, a win-win outcome of the scheme can be expected in that not only do farmers benefit (from insurance against catastrophic events, improved income stability, and greater access to credit and lower interest rates), but banks also stand to benefit from secured lending and reduced default rates, improved collateral, and increased lending amounts and savings in rural areas. Further, the public sector can benefit from reduced need to provide emergency assistance.

\section{LESSONS LEARNED AND ISSUES FOR WIDER APPLICABILITY}

Now that weather insurance has been initiated, the immediate challenge is to scale up the distribution and ensure fast claims settlement. It is important to manage expectations of the farming community for the insurance product. Other important lessons emerging from this pilot and other past index-based insurance initiatives include:

- The index must be based on long-term statistical information and credible actuarial models. To this end, the public sector can develop information sources such as risk maps.

- Triggers must be verified independently (this will reduce vulnerability to political interference and manipulated farm losses).

- The payment schedule (what will and will not be covered and the extent of coverage) must be clear, quantifiable, and measured by an independent and credible third party.

- Education programs and technical assistance for stakeholders (both farmers and service providers) should be provided.
- Private sector involvement must be encouraged from the outset, and any government subsidies must be kept to a minimum with a clear directive for complete phasing out.

- Combining index-based programs with other types of insurance and financial services can improve the effectiveness of the trigger.

\section{PROJECT COUNTRY: INDIA}

\begin{tabular}{|c|c|}
\hline Project Name & $\begin{array}{l}\text { Index-based Weather Insurance } \\
\text { Pilot }\end{array}$ \\
\hline Contact Point & $\begin{array}{l}\text { Ulrich Hess } \\
\text { Telephone: (202) 458-8493 } \\
\text { E-mail: uhess@worldbank.org }\end{array}$ \\
\hline & $\begin{array}{l}\text { Commodity Risk Management } \\
\text { Group } \\
\text { The World Bank, I } 8 \text { I } 8 \text { H Street } \\
\text { NW,Washington, D.C. } 20433 \\
\text { Telephone: (202) 473- I } 7 \text { I } 8 \\
\text { Email: crmg@worldbank.org }\end{array}$ \\
\hline
\end{tabular}





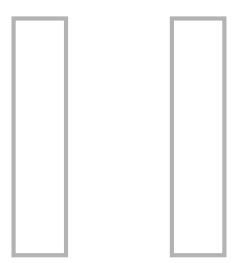

\section{SCALING UP AGRICULTURAL INVESTMENTS INTHE BANK'S CHANGING INTERNAL ENVIRONMENT}

$\mathrm{T}$

he World Bank, through its new rural development strategy, Reaching the Rural Poor, is committed to increased lending for agricultural and rural development, and to enhancing the impacts of that lending on poverty reduction. However, future investments must conform to new realities in the Bank's lending environment, new processes in country dialogue, such as Poverty Reduction Strategy Papers (PRSPs), and a renewed commitment to quality. This module explores some of the process options for investing in agriculture, in ways that are more sustainable than in the past and that have greater impact on poverty reduction.

\section{EXPANDING SUPPORT TO AGRICULTURE-SCALING UP SUCCESSES}

A key thrust in the implementation of the Bank's rural development strategy is identifying and "scaling up good practice investments and innovations in rural development" to broaden coverage and deepen developmental impact. Scaling up good practices, especially those shown to be effective in reducing poverty, must become an integral part of strategies to support agriculture. 
Box II.I India: success in scaling up watershed programs

The watershed development work by the Social Center and the Indo-German Watershed Development Programme (IGWDP) addressed the complex livelihoods and natural resource issues of water and watershed management. By 1994 , the IGWDP had shown a wide range of local economic (doubling of crop production, creation of employment opportunities, restoration of groundwater resources) and social gains (setting up a village watershed committee, involvement of marginal groups, and reduced out-migration). Through these successes the IGWDP has been extended to 146 watersheds involving over 200,000 villagers.

The state of practice evolved from early "innovative success stories" prior to the 1990s that focused on technical arrangements with little regard for social complexities, to a "good practice" stage in the 1990s, where watershed management was viewed as a social problem but approaches were not consistently replicable. The process of scaling up involved the generation of a set of "local-level ingredients" of success from pilot experiments. These provided specific mechanisms for building ownership, control, and motivation in communities, linking government communities and nongovernmental organizations (NGOs), defining exit strategies, and developing mechanisms for continued local funding. This process took approximately 4 years and built on 25 years of experience in the area. Successes included marshalling of political support, developing guidelines for government staff, coordinating government agencies, adopting a long-term "cluster" approach, and developing NGO capacity.

These experiences were further scaled up in other states, with the support of other donors. The World Bank became an active supporter of watershed management projects in India, building on the experience of the IGWDP.The first of these projects, the Northern Hills Watershed Project (1991-97) was highly rated in terms of the impact it achieved, and a second project is now in operation to extend the scaling up.

Source:World Bank 2003; World Bank Internal Documents.

The term "scaling up" is used with reference to the replication, spread, or adaptation of techniques, ideas, approaches, and concepts, to increase the scale of impact. An investment with potential to be scaled up typically moves through various stages: an innovation (minimal objective evidence); a good practice (clear evidence from several settings/evaluations); or a policy principle (proven in multiple settings; considered widely applicable "truism" essential for success) (World Bank, 2003). However, the lines between these categories are seldom clear, and depend on allocating sufficient resources for evaluation of promising innovations at each stage. Scaling up often requires a long process of phased stages (up to 10-15 years) for development and refinement of technologies and institutional processes, often with donor support (see box 11.1).

A particular problem with World Bank experience in scaling up has been the tendency to replicate successful models without sufficient attention to either the difficulties of using a specific intervention on a wider scale, its replicability or sustainability, or to the varying contexts in which that intervention is to be used. The training and visit extension system and integrated rural development programs are examples of models that were rapidly scaled up without sufficient attention to costs and sustainability, or to characteristics of local farmers and farming systems. Many interventions, such as community-driven development, have special issues of scaling up, which are related to local capacity building and to developing links between communities, local government, and higher levels of government. All interventions require adaptation to the local physical, socioeconomic, and institutional settings-replication across environments usually does not work well for agricultural investments. Much greater attention has to be given to developing institutional capacity to adapt and learn at the local level, based on established principles and processes, rather than replicating standard models.

There are no shortcuts to scaling up, and evaluation, learning, experimentation, and a long-term commitment (often over decades) are needed. Adaptable program lending (APL) introduced by the Bank in 1997 is especially appropriate for long-term sequencing of investments to allow learning and adaptation (see box 11.2).

Within countries, scaling up generally involves a number of steps (World Bank 2003): 
- Identify promising innovations or pilots.

- Assess country demand for scaling up.

- Review information on impacts, and factors that have enabled or hindered success.

- Assess current state of good practice.

- Review strategy options for scaling up in terms of processes, learning, and adaptation.

- Review institutional capacity and effective linkages and logistics among different types of participants-farmers, ministry, local government, NGOs, and the private sector-to permit and manage successful scaling up.

- Develop appropriate tool kits, manuals, and training programs to ensure effective implementation on a wider scale.

- Consult widely with key stakeholders about options and plans and their role (managerial, financial) in sustaining the changes.

Scaling across countries and regions requires strong programs of knowledge sharing through communities-of-practice that draw on the Bank's comparative advantage in accumulating experience from its activities throughout the world. Bank Thematic Groupsæformal or informal æand mechanisms such as this Sourcebook and the Bank Web site, promote this sharing of experience within the Bank and with partners (see box 11.3).

\section{GETTING AGRICULTURAL LENDING INTO THE PIPELINE}

Evaluation studies have consistently shown that success in lending is more likely when it is underpinned by thorough upstream analytical work. Economic and Sector Work (ESW) must support future investments in terms of both building and updating the stock of knowledge,

\section{Box II.2 Adaptable program lending}

Adaptable program lending (APL) is suited to development efforts that require longer-term phased planning and implementation common to agricultural sector activities, and that involve institutional development, technical change, and activities with long production lead times (tree crops, livestock). They have been extensively used in the agricultural portfolio, especially in Africa. A typical APL is phased in three stages - piloting and capacity building, scaling up, and institutionalization/consolidation. The key to successful APLs is to have a clear long-term vision for the sector/subsector, and to set well-defined "triggers" (indicators) for moving to the next phase. It is good practice to carry out an independent external evaluation before the end of each phase to evaluate progress and review strategy for the next phase. APLs also provide a transparent and flexible exit strategy for nonperforming loans.

Source: Authors.

\section{Box II.3 Improving knowledge management}

Future World Bank investments in agricultural development require substantial attention to the development, testing, and sharing of good practice in certain key areas. Thematic groups (TGs) have a crucial role in knowledge management, especially sharing experience across regional operations. However, the Bank and its TGs have generally not invested sufficiently in hard evaluation to identify and verify good practice, prior to wider scaling up. Special efforts are required to deepen the ongoing evaluation of programs and a proactive stance is being taken by the Bank in terms of addressing the key issues relating to knowledge management:

- Taking a strategic approach to prioritizing clients and their specific learning and information needs.

- Capitalizing on the comparative advantage of sector anchors in capturing and assessing cross-regional and multisector experience (including lessons learned from quality enhancement reviews), and disseminating the results to development practitioners.

- Ensuring the quality, timeliness, and accessibility of Webbased knowledge and information, and developing appropriate norms and standards for content management of Web sites.

- Systematically capturing knowledge and designing effective courses and learning activities to assist practitioners - the strategic focus of learning programs must accurately reflect both corporate priorities and the needs of operational staff.

- Ensuring that knowledge management activities are efficient, cost effective, and coordinated with minimal duplication of effort.

Source: Authors. 
and supporting investments and policy dialogue in client countries. By providing in-depth analysis and diagnosis of the agricultural sector's strengths and weaknesses, resource base, and prospects as a source of growth and poverty reduction, good ESW can help prioritize critical constraints and opportunities for agricultural and rural development. It provides the analytical basis for identifying what needs to be done to improve the sector's performance.

There is an increased push in lending programs for improved partnerships, a longer-term perspective, and an approach that is country-driven and results-oriented. ESW has to be done in a participatory manner, and requires building consensus and ownership of the vision of agricultural development by policymakers, their constituencies at all levels, and the development community. ESW should involve mobilization of institutions and development of partnerships across different sectors; broad local participation in the decentralized design and implementation of agricultural development programs, including coordinated timetables for the work, budgets, and responsibilities; and regular monitoring and evaluation (M\&E).

The treatment of agricultural issues in the Country Assistance Strategy (CAS) and related agriculture lending pipeline depends on the robustness of the stock of knowledge generated by ESW products. ESW also provides the stock of knowledge and relevant data that enrich the agricultural and rural content and diagnostics of PRSP preparation. For low-income countries, the PRSP process is now the major country strategic framework for shaping investment lending and aligning donor support around national strategies. To mainstream agricultural and rural development issues into the development dialogue and priorities of PRSPs requires a number of key actions by governments and donors:

- Support the preparation of national agricultural and rural development strategies and related economic sector work and analysis as necessary inputs into the PRSP process and its implementation.
- As part of preparation of strategies, emphasize the preparation of public expenditure reviews that feed into the development of medium-term expenditure frameworks for agriculture.

- Deepen rural poverty diagnosis and analysis, and support regular socioeconomic surveys of rural poverty, including reporting incidence of rural poverty by gender, farm size, ethnicity, agro-ecological zone, sources of income (commodities produced), rural nonfarm income, participation in markets, as well as access to services. Seek to understand the mechanisms for linking different groups of the poor to agricultural and rural growth, and different types of public interventions.

- Identify and evaluate new approaches to agricultural development to develop and support programs for rural-focused PRSPs. This will need to be based on solid evaluations that identify why various approaches or innovations have or have not worked or been adopted in the past, including an assessment of distributional impacts.

- Strengthen participatory processes and structures that build the voice of farmers (and those key public and private agencies that represent them) in the articulation of priority public actions. This might involve identifying new partners (that will often be farmers themselves), rather than the public agencies with which donors have traditionally worked.

\section{- Identify priority public actions for the} agricultural and rural sector from sound analysis of public policy and expenditures, with special reference to their impacts on the agricultural and rural poor.

\section{- Develop appropriate targets and indicators} to support the development of guidelines for a consistent set(s) of output, outcome, and impact indicators that address differentiated groups of farmers and the rural poor. 


\section{LENDING INSTRUMENTS: FROM PROJECTS TO PROGRAMS}

The Bank has a number of instruments that are well suited to institutional and program development, and to preparing for scaling up successful activities. The Bank along with other donors is shifting emphasis from discrete project lending to programmatic lending that provides direct budgetary support. Programmatic lending is a more efficient means of transferring resources, requiring relatively less Bank attention to detailed design and implementation supervision, and less borrower resources to comply with Bank fiduciary oversight requirements. By streamlining a program within core operations and activities, an implementing agency can ensure long-term commitment and sustainability of new initiatives. However, triggers for programmatic lending should be well defined, and monitorable performance indicators to assess intermediate and eventual outcomes (and the basis for continued support) should be agreed on and clearly defined. Where possible, the triggers should draw on existing government commitments for action, especially as identified in PRSPs.

Program lending. The agricultural sector program (ASP) is one form of a sector-wide approach being promoted by donors to provide support over the medium to long term. In principle it eliminates the fragmentation, duplication, and lack of country ownership that was common under the conventional project investment approach. ${ }^{1}$ Program approaches are most appropriate where there is a coherent policy framework for the sector, including an agricultural strategy, an adequate public expenditure review process in the sector, strong government commitment, and potential for donor collaboration. Poverty Reduction Support Credits (PRSCs) have extended this principle to multisectoral operations within the framework of the countrydriven PRSP.

\footnotetext{
I. See the AIN, "Agriculture Sector Program Lending"

2. See the IAP, "Turkey: Hybrid Adjustment/Investment Lending" (Module I)
}

Despite the attractiveness of programmatic lending, project lending remains important in the agricultural sector, especially for long-term institutional development. Projects allow for greater input of technical support to program design and implementation, thus enhancing the potential for innovation, reform, and shared learning. The higher profile (more-so within sectoral ministries and departments than in central agencies like Finance and Planning) associated with a discrete project activity attracts greater attention from sectoral policymakers, and enhances potential for institutional and policy reform in the sector. Project lending can also help to correct past misallocation of resources by directing investment to specific activities that are typically underfunded (for example, agricultural research with long-term payoffs). However, project lending should aim to improve existing programs and should avoid the creation of separate programs and administrative structures. This helps to increase government ownership and allows for the eventual inclusion of the activity into a broader sectoral or multisectoral program operation. Where appropriate, small projects may pilot new initiatives linked to improving ongoing programs, prior to wider scaling up. Some hybrid operations are also being implemented to combine objectives of short-term structural adjustment with longerterm institutional development. ${ }^{2}$

In line with the Operation and Evaluation Department (OED) findings (Battaile 2002), successful support to the agricultural sector will require a mix of instruments and effective sequencing of support to policy adjustment, capacity development, sectoral investments, and piloting of activities prior to scaling up. This mix will be strongly conditioned by the country-specific policy and institutional environment. In poor policy and institutional environments, simple project designs provide better results than complex and multifaceted undertakings. Although the current mix of 
lending to agriculture is still weighted toward investment projects (see figure 11.1), programmatic lending, especially Programmatic Structural Adjustment Lending (PSAL) and PRSCs, is growing. Within project lending, there has also been a dramatic switch toward multisectoral operations using a community-driven development approach.

Community-Driven Development Funds. Community driven development (CDD) is an approach to poverty reduction that seeks to empower communities and local governments with resources and decisionmaking powers, to enable decentralized implementation of programs in rural areas. Investments in agriculture implemented through the CDD approach should be targeted to provision of local public goods and to developing productive assets for the poor. This approach typically gives communities access to local investment funds (often, but not always, provided in the form of matching grants) to implement subprojects of their choice. Initially, CDD grants, responding to community priorities, were focused largely on social services and local infrastructure. In more recent operations, more CDD grants are focused on income-generating activities (IGAs), especially in the agricultural sector. In 2002, about 45 percent of lending to the agricultural sector was based on a CDD approach.
Although the approach has been rapidly scaled up, the impact and sustainability of the CDD approach for production activities are still uncertain, and development of criteria and guidance for scaling up are inadequate. A recent review suggests that economic assessment is generally inadequate in CDD projects (van der Meer and Noordam 2003). Where CDD projects move beyond purely public goods, particular care is needed to ensure that grants do not distort private markets for inputs and services, including financial markets. Another major requirement is to ensure that productive investments are pro-poor, and are not captured by local elites.

The development of manuals and tool kits to help capacity building at all levels is a key to scaling up CDD operations. Much sharing of good practice is required, particularly with regard to developing objectives, designing eligibility and selection criteria, and M\&E of grant programs. Proper procurement and capacity building for local institutions that ensure delivery of services is important to improve their efficiency and relevance. This includes:

- Good practice guidelines, tool kits, and standard manuals for grants that target IGAs, including technical backstopping through

FIGURE I I.I IBRD/IDA COMMITMENTS TO THE AGRICULTURE, FISHING AND FORESTRY SECTOR (INCLUDING AGRO-INDUSTRY, MARKETS AND TRADE): BY LENDING INSTRUMENT, FY0I-03

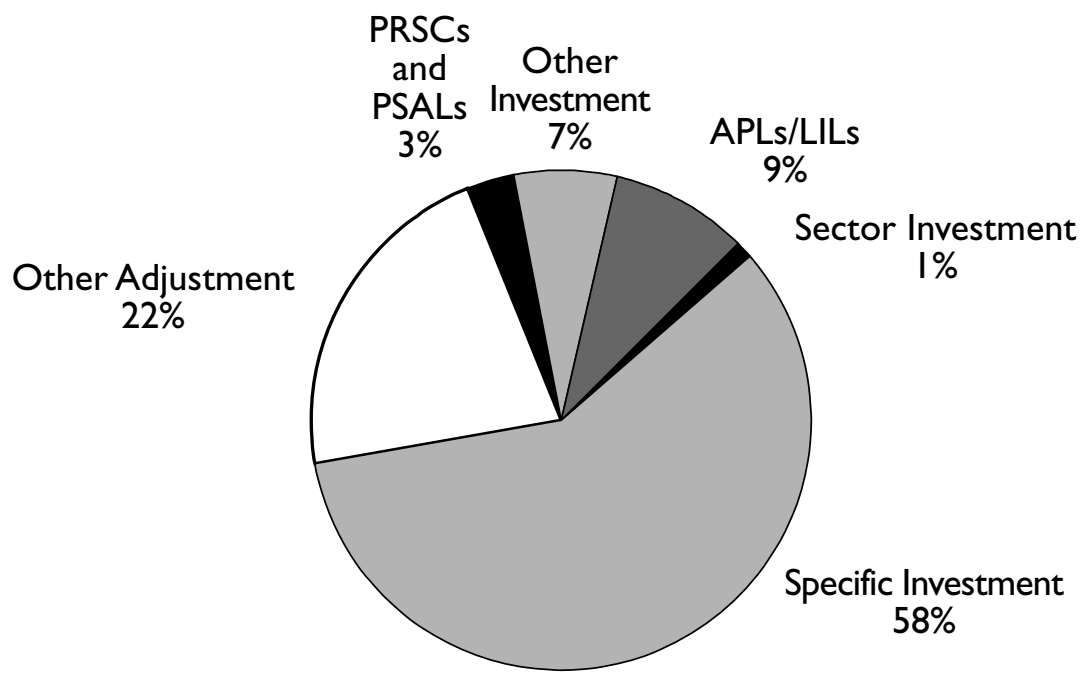

Source:World Bank Internal Documents. 
advisory services responsive to community needs, and good practice tools for undertaking economic analysis of grant schemes.

- Training to strengthen the capabilities of Bank staff and borrowers in identifying and assessing market failure, and in identifying cases in which grants and other interventions may or may not be a suitable instrument.

A companion note on CDD operations in agriculture provides additional information on current thinking regarding good practice.

Poverty Reduction Support Credits. The most rapidly expanding lending instrument is the PRSC, which was introduced as a specific form of structural adjustment credit (SAC) or sectoral adjustment credit (SECAC). Beginning in 2001, programmatic lending, mostly through PRSCs, accounted for 19 percent of fiscal year 2002 Bank commitments, although relatively little of this has been allocated to agriculture. A PRSC program is usually a multidonor operation that involves a series of sequential operations (individual PRSCs), and that together support the country's medium-term development and reform program to implement its poverty reduction strategy.

PRSCs differ from traditional Bank policy-based ("adjustment") lending, both in content and in the process of preparation and implementation. Development of PRSCs starts with a country's Own PRSPs and involves extensive consultation and donor coordination. It represents a move away from narrow adjustment operations that address economic stabilization and policy distortions through balance of payments support, to a more development-oriented agenda-poverty, institutional capacity, social and structural reforms, especially in public sector management-addressed through budgetary support. PRSCs are especially suited for cross-sectoral issues that transcend ministerial boundaries. Many of the first-generation PRSCs have focused on fiduciary and public sector administration issues, thereby laying the necessary groundwork for future, more sectorally focused, PRSCs. Basic auditing, procurement, disbursement, and public sector management systems need to be in place before PRSCs can provide sectoral support.

When backed by good PRSPs with strong rural content, PRSCs may provide an appropriate tool for addressing agricultural and rural development issues that increasingly cut across ministries. Although experience is still limited, where countries have in place a well-articulated agricultural and rural development strategy and a sector-based, medium-term expenditure framework, with wide ownership such as Uganda, the PRSC seems to have been effective in supporting investment in the agricultural sector. ${ }^{3}$ Experience to date suggests that for PRSCs to be effective:

- The country environment must be suitable for programmatic adjustment lending with appropriate institutional arrangements, a transparent budget process, and a stable macroeconomic framework.

- Investment programs should be backed by well-articulated and country-owned agricultural strategies, medium-term expenditure frameworks with sectoral outcome and output indicators, and related analytical work, such as public expenditure reviews.

- Sufficient institutional capacity should be in place within sectoral ministries to effectively implement the program.

However, the PRSC should not replace sector investment lending, especially for long-term institutional development where innovative practices are being piloted and tested prior to wider scaling up, and for lumpy infrastructure investments (for example roads and irrigation). And even when based on a good PRSP, there are doubts about the ability of weaker ministries (as agriculture often is) to effectively tap

3. See the IAP, "Uganda: Cross-Sectional Programmatic Adjustment Lending Focusing on Poverty Reduction" 
into PRSC support. Given the key role of agricultural and rural development, it will be important to put in place the preconditions, especially in agricultural ministries, to expand PRSC lending to agriculture.

MAKING DONOR COORDINATION WORK. DOnOr COOrdination is essential to improving the quality and impact of development activities. Much lip service is paid to donor coordination, but frequently the reality is that each donor wants to "coordinate the other donors around its own approaches and agenda." Effective coordination must, however, be based on a process of country-driven coordination in which donors contribute to definition of reform programs and investment initiatives, but do so in the context of country ownership of the process. This implies, ideally, an explicit agreement on donor commitment for support over a multiyear period, harmonization and streamlining of administrative and financial procedures, and a common M\&E framework and indicators. This is difficult to achieve, but less than total integration of program efforts still offers substantial benefits in improved efficiency of development assistance impacts.

The trend toward programmatic lending (including PRSCs) has stimulated cooperation and alignment among donors in client countries. Support for national donor platforms for agricultural and rural development is crucial for programmatic lending. The agricultural sector investment program in Mozambique is an example of successful multidonor collaboration within a country-driven agenda. ${ }^{4}$ The new "Rural Alliance Platform" has potential to provide a forum for better coordination of agriculture and rural development activities and approaches at a global level.

SCAling up at the REgional leVEl. A key challenge for agricultural lending is to find ways to support regional programs. Many development problems transcend national boundaries and solutions are best sought regionally. As an

4. See the IAP,"Mozambique: Harmonized Donor Funding Around Principles" example, it is extremely inefficient for all countries to invest in the same research activities, especially if the market within a country is small. Thus, there is a good case on efficiency grounds for regional or international funding and execution of such research. Natural and environmental resource conservation also presents a strong rationale for regional cooperation in the management of shared ecosystems.

For small countries, regional market development is essential to achieve economies of scale that make many private sector investments viable. Regional harmonization of grades, standards, and market regulations; phytosanitary and biosafety regulations, reciprocal recognition of business certifications and permits, including seed and varietal registration; and shared information systems are important to increasing competitiveness and marketing efficiency. Regional harmonization of seed trade regulations has been relatively successful in Central America, Eastern Africa, and Central Asia, but other initiatives of this sort are relatively few.

The case for regional programs is usually clear, but donors often provide support to sovereign countries, and tools and mechanisms are still evolving for implementing regional programs and coordinating or sharing knowledge across countries. Pilot mechanisms such as the Africa Region's Multicountry Agricultural Productivity Program (MAPP), have considerable potential, and warrant strong support and monitoring for potential adaptation to other situations.

\section{CHALLENGES FOR SCALING UP AGRICULTURAL DEVELOPMENT INITIATIVES}

IMPROVING PROJECT DESIGN FOR SUSTAINABLE PROJECT OUTCOMES. Investment in agriculture offers potential for high returns in terms of poverty reduction, economic growth, and environmental conservation. Consistent with economic realities, high returns sometimes implies high risk, a fact borne out by the perception of past 
low ratings for agricultural project performance and sustainability. Average OED and Quality Assurance Group (QAG) ratings for the Bank agricultural lending portfolio are generally somewhat lower than those for all Bank projects, in terms of quality at entry, performance, and impact (see table 11.1), although this gap has sharply narrowed in recent years. The biggest challenge is to raise OED ratings of sustainability and institutional impact to at least the Bank-wide average. Recent assessments by OED found that a sizable proportion of projects implemented in agriculture and rural development do not necessarily lead to satisfactory or sustainable outcomes.

Quality of project design in agricultural lending depends on many factors, but the following four stand out: ${ }^{5}$

- Set clearly defined and modest objectives with realistic assumptions of time requirements. Clearly link development objectives to the project components.
- Customize the design of the investment in line with a comprehensive poverty diagnosis.

- Link each component with a few carefully selected performance indicators that are quantifiable, and provide baseline information. Integrate $M \& E$ into project design from the start for ongoing learning and feedback.

-Explicitly analyze sustainability of project interventions over the long term, especially fiscal sustainability and institutional capacity.

Among these, the most urgent challenges for agricultural lending are to enhance poverty impacts and sustainability, and improve M\&E.

ENHANCING POVERTY IMPACTS. Poverty reduction must be the overarching objective of World Bank investments in the agricultural sector. There is now a better understanding of the determinants, complexity, and multidimensionality of poverty, which extends beyond low levels of income to include dimensions of:

Table II.I Agricultural project ratings compared to all Bank projects (\%)

Rating

Agriculture Portfolio
Total Bank Portfolio

QAG Performance Ratings

(Average 2002-03)

Problem Projects

10

At Risk Projects

OED Project Completion Reports

(Average 2000-02)

Satisfactory Outcomes

Likely Sustainability

Satisfactory Institutional Impact
II

74

63

46

Note: a. Using projects tagged as the responsibility of the Agriculture and Rural Sector Board as a proxy for the agriculture sector. Source:World Bank Internal Documents

5. See the AIN, "Nine Lessons for Improving Project Design for Better Investment Performance" 
- Lack of opportunity: This is generally associated with the level and distribution of human capital and social and physical assets, such as land and market opportunities.

- Low level of security: Exposure to risk and income shocks that may arise at the national, local, household, or individual levels.

- Lack of empowerment: The inability of poor people and other excluded groups to participate in, negotiate with, change, and hold institutions accountable.

The first step in targeting poverty within agriculture investment projects (aside from ensuring that national policy supports an agriculture growth strategy and avoids market distortions and environmental degradation) is to diagnose the nature of poverty (see box 11.4). A key issue is the relative emphasis on promoting

\section{Box II.4 Targeting investments in poverty reduction}

Agricultural investments can use various strategies for targeting investments on the poor, such as farm size, gender, farming system, region, ethnicity or caste. An essential first step in targeting poverty reduction is to ensure that national policy supports an agriculture-driven growth strategy. With this macropolicy environment in place, poverty-targeted investments must rely on:

- Sound diagnosis of the nature and causes of poverty that include: poverty profiles identifying the rural poor by income and nonincome indicators, and by geographic, social, gender, and temporal incidence of poverty; analyzing severity of poverty, and assessing the degree of asset and income inequality; and sources of vulnerability and their causes.

- Well-formulated poverty reduction strategies that provide a basis for comprehensive measures to reduce poverty, providing for growth within the agricultural sector.

- Investment project designs that address the lack of opportunity, security, and empowerment in the rural context, and that draw on better poverty analysis, participation by the poor in decisionmaking, and adopting a relevant focus (for example, land distribution, market access) to reach the poor through agriculture.

Source:World Bank Internal Documents. broad-based agricultural growth versus targeting specific poor groups, the balance depending on country-specific circumstances.

The initial conditions that define the nature of poverty (and thus the most appropriate investments for reducing poverty) vary widely, and a criticism of past Bank investments in agriculture has been the relatively homogeneous approach taken to highly diverse rural areas. Future investment designs must accommodate the differing initial conditions that shape poverty if benefits are to be effectively targeted to the poor. Implications and strategies for poverty targeting will vary according to the characteristics of farming systems (Dixon et al. 2001), especially the relative emphasis on intensification and diversification of agricultural activities, versus options for increasing off-farm work or eventual exit from agriculture. Even within farming systems, poverty reduction strategies must recognize different farm types (commercial, medium scale with market potential, and marginal). Concerns for economic growth and food security require public policy and programs to support growth in efficiency and competitiveness of commercial farms, while encouraging the shift of medium-scale farms with market potential to become fully competitive in domestic and international markets. Strategies for investing in marginal farms and marginal areas are more difficult, because many of these lack the resources and economies of scale necessary to become competitive. For many farmers in marginal areas and in middleincome countries, transition out of agriculture will be the best alternative. Women are especially important in agriculture and much more attention is required to mainstream gender concerns (see box 11.5).

More effective impact of agricultural operations on poverty requires actions on a number of fronts:

\section{- Deepen the understanding of agricultural} growth/poverty linkages seeking to increase poverty reduction for a given rate of growth, by understanding how poor people 
participate in and contribute to agricultural growth, and the mechanisms by which growth benefits poor people. In particular, more support is needed to strengthen qualitative and quantitative surveys to ensure information is collected and analyzed relevant to agricultural and rural households (for example, vulnerability, access to assets, livelihood options).

- Recognize the importance of agriculture to the national pro-poor growth agenda. For many low-income countries, agriculture is and will remain the mainstay of the rural and national economy, and its secure and equitable growth must be adequately addressed through the PRSP and other such processes.

- Build national and regional capacity for agricultural policy research, dialogue, and debate. Strengthening the underlying analytical framework for rural poverty reduction will allow public investment choices to be effectively debated and considered.

- Share good practice on approaches to agricultural and rural poverty reduction at country and global levels. Although there is growing global consensus on key approaches to rural poverty reduction, practical experience of what works and what does not work in different conditions could be better articulated, monitored, validated, and shared.

ENHANCING SUSTAINABILITY THROUGH EXPANDED PARTNERSHIPS. Enhancing long-term sustainability of lending operations, both institutional and financial, remains a critical challenge. This requires more attention to institutional analyses for investments, and a better understanding of the determinants of institutional sustainability. An important step in getting beyond purely public sector approaches to implement programs has been the development of partnerships among public and private sector and civil society. Much depends on building local constituencies of support for programs, enhancing the voice and influence of clients
Box I I.5 Gender enhancing and gender mainstreaming

Awareness of gender issues in rural projects has improved. However, very often investments remain as pilot activities lacking significant widespread impact. Gender analysis to guide project and program design is key. Analysis of gender dimension enhances the understanding and removal of barriers to inclusion of women and girls. Balanced analysis of women as economic actors and beneficiaries is essential. Recognizing women farmers and entrepreneurs as stakeholders can enhance the sustainability and effectiveness of projects, and lead to a stronger voice for women in their communities. The practice of including gender strategies and action plans arising from the gender analysis in project documentation is an effective approach to ensure gender integration throughout the project, from justification to activities, budget, and monitoring and evaluation.

Source: Authors.

(including farmer organizations, consumers, and other stakeholder groups). Impact studies and monitoring systems are useful in this regard, and a general orientation to results and accountability to clients helps in building a constituency.

Financial sustainability is enhanced by greater cost sharing and improved managerial, operational, and maintenance capacity of stakeholders other than government, and by more efficient implementation mechanisms. Objectives of many past projects have been far too ambitious for a short 5-year project period. Future donor involvement will often involve reduced public sector funding (and smaller loans), but longer-term projects to build institutions that benefit from stakeholder consultations, client participation, partnership and alliance building, and learning and adaptation.

\section{MONITORING AND EVALUATION}

$M \& E$ is a perennial "end of the list" entry in reviews and good practices for improving agricultural project and program performance. In fact, this should be at the top of the list, as there is little chance for a successful investment if government (and donors) do not define clearly what is to be accomplished, and how it 
is to be measured. Both the QAG and OED in the Bank have consistently flagged "chronic weakness" in M\&E systems that requires urgent attention in the portfolio in general, and in agriculture in particular.

M\&E serves as a practical tool for better resultsoriented management, and an input to planning and decisionmaking at many levels. When done well, it allows year-to-year tracking of outcome-level indicators. Moreover, as a necessary feedback loop for continuous assessment, good M\&E provides a knowledge system whereby lessons are learned for scaling up. The key issues for M\&E are to:

- Have an adequate MEE system in place before project/program approval for both implementation and impact monitoring from the beginning.

- Choose a few carefully selected indicators that can be readily tracked during implementation, including clear tracking and impact measurement indicators for gender impacts. Indicators of project outcomes should link to specific CAS outcomes.

- Establish a basis for comparison by defining a relevant reference point and basis for assessing impact at program outset. Where possible, ensure collection of baseline data and periodic updates, emphasizing only key variables related to indicators.

- Use beneficiary evaluation and other participatory evaluation tools to obtain feedback for use in guiding the management of a wide range of agricultural investment programs.

\section{SELECTED READINGS}

Asterisk (*) at the end of a reference indicates that it is available on the Web. See the Appendix for a full list of Web sites.

Battaile, W. 2002. "2001 Annual Review of Development Effectiveness: Making Choices." World Bank, Washington, D.C.*
World Bank. 2000. "World Bank Lending Instruments: Resources for Development Impact." Operations Policy and Strategy. World Bank, Washington, D.C.*

World Bank. Gender in Monitoring and Evaluation in Rural Development: A Tool Kit. http://lnweb18.worldbank.org/ESSD/ ardext.nsf/22ByDocName GenderinMonitoringandEvaluationinRural DevelopmentAToolKit.

World Bank. Poverty Reduction Strategies and PRSPs. http://www.worldbank.org/poverty/ strategies/.

\section{REFERENCES CITED}

Battaile, W. 2002. "2001 Annual Review of Development Effectiveness: Making Choices." World Bank, Washington, D.C.

Dixon, J. A., D. P. Gibbon, and A. Gulliver. 2001. Farming Systems and Poverty: Improving Farmers' Livelihoods in a Changing World. Rome: FAO; Washington, D.C.: World Bank.

van der Meer, K., and M. Noordam. 2002. "The Use of Grants in the Market Sector in Rural Development: A Review of World Bank Projects." World Bank, Washington, D.C.

World Bank. 2003. "Scaling-Up Issues and Options: Supporting the World Bank Rural Development Strategy on Implementation of Good Practice and Innovation." World Bank, Washington, D.C.

This Overview was prepared by Derek Byerlee, Sam Kane, Eija Pehu, and Gary Alex. Peer review comments were received from Ai Chin Wee and Louise Cord. 
AGRICULTURE INVESTMENT NOTE

\section{TARGETING AGRICULTURAL INVESTMENTSTO MAXIMIZE POVERTY IMPACTS}

There is considerable evidence that progress in the agricultural sector can have major impacts on poverty reduction. While broad-based agricultural growth strategies continue to be important in fighting poverty, investment programs must be increasingly targeted to ensure maximum impacts on the poor. Key mechanisms for targeting to directly improve the incomes of the poor include focusing investments on: commodities that are important to the poor or regions where poor people are concentrated, mechanisms to reduce household vulnerability and improve access to assets, and encouraging inclusive participation. Pro-poor investment design is built on effective poverty diagnosis, an appropriate project strategy, and inclusive implementation mechanisms.

The major theme running throughout the World Bank's current rural strategy, reaching the rural poor, is a focus on reaching the rural poor, by promoting a holistic approach to rural development. The first Millennium Development Goal (MDG) of halving by 2015 the proportion of people living on less than a dollar a day, and who suffer from hunger, is now the major driving force for Bank investments, including those in the agricultural sector.

The modules of this Sourcebook have outlined approaches to addressing poverty reduction for specific investment areas. This note outlines the more generic lessons involving design processes for agricultural investments. This is especially important, since a recent review of a sample of 177 rural projects approved from fiscal year 1999 to 2002 revealed that only about 20 percent were rated as satisfactory in terms of poverty analysis (see table 11.2). Ratings were also low for pro-poor project strategy and design. The challenge for future investment lending is to sharply increase these ratings to at least the average for other sectors.
Table II.2 Poverty reduction performance of

agriculture sector projects, FY99-02

\begin{tabular}{lcc}
\hline & \multicolumn{2}{c}{$\begin{array}{c}\text { Percent projects rated } \\
\text { "satisfactory" or better }\end{array}$} \\
\cline { 2 - 3 } Performance Area & $\begin{array}{c}\text { Agriculture } \\
\text { Sector }\end{array}$ & $\begin{array}{r}\text { Other } \\
\text { Sectors }\end{array}$ \\
\hline Poverty Diagnosis & 19 & 21 \\
Project Strategy & 36 & 47 \\
Project Design & 30 & 42 \\
\hline
\end{tabular}

Source: World Bank Project Documents.

\section{LINKAGES BETWEEN AGRICULTURAL GROWTH AND POVERTY REDUCTION}

In low-income countries, the agricultural sector is the primary engine of overall economic growth, providing around 60 percent of total employment, and 20 percent of GDP. Since most of the world's poor depend directly or indirectly on agriculture for their livelihoods, broad-based productivity increases in the sector is one of the most effective ways of reducing poverty (see box 11.6). Agricultural modernization and productivity growth increases income of small-scale farmers and creates jobs in related industries (processing, marketing, inputs) that are labor intensive. Increased productivity also indirectly benefits the poor through lower food prices (food forming a large share of expenditure of poor households). Overall, the estimated elasticities of poverty reduction with respect to agricultural productivity are high (for example, the elasticity of poverty reduction with respect to agricultural yields is about 0.72 percent in Africa (Thirtle et al. 2003), and in India it has been estimated to be 0.41 percent in the short run, and 1.9 percent in the long run (Ravallion and Datt 1998).

\section{CONDITIONS INFLUENCING POVERTY IMPACT OF AGRICULTURE INTERVENTIONS}

PoverTy Dimensions. The causes of poverty are multidimensional and typically interrelated. In general, poverty relates to inadequate assets 
In rural India, the percentage of the rural population living below the poverty line fluctuated between 50 and 65 percent before the mid-1960s, but then declined steadily to about one-third by 1993. Much of this decline has been attributed to broad-based growth in the agriculture sector and associated reductions in food prices. Yield-enhancing public investments in infrastructure, services, and institutions supporting agriculture have had a large, albeit mostly indirect, impact on poverty (see inset figure). The highest payoffs to public investments in terms of poverty reduction were achieved through rural roads, followed by agricultural research, education, rural and community development, and then soil and water conservation investment.

\section{INDIA: ELASTICITY OF POVERTY REDUCTION WITH RESPECT TO YIELD GROWTH}

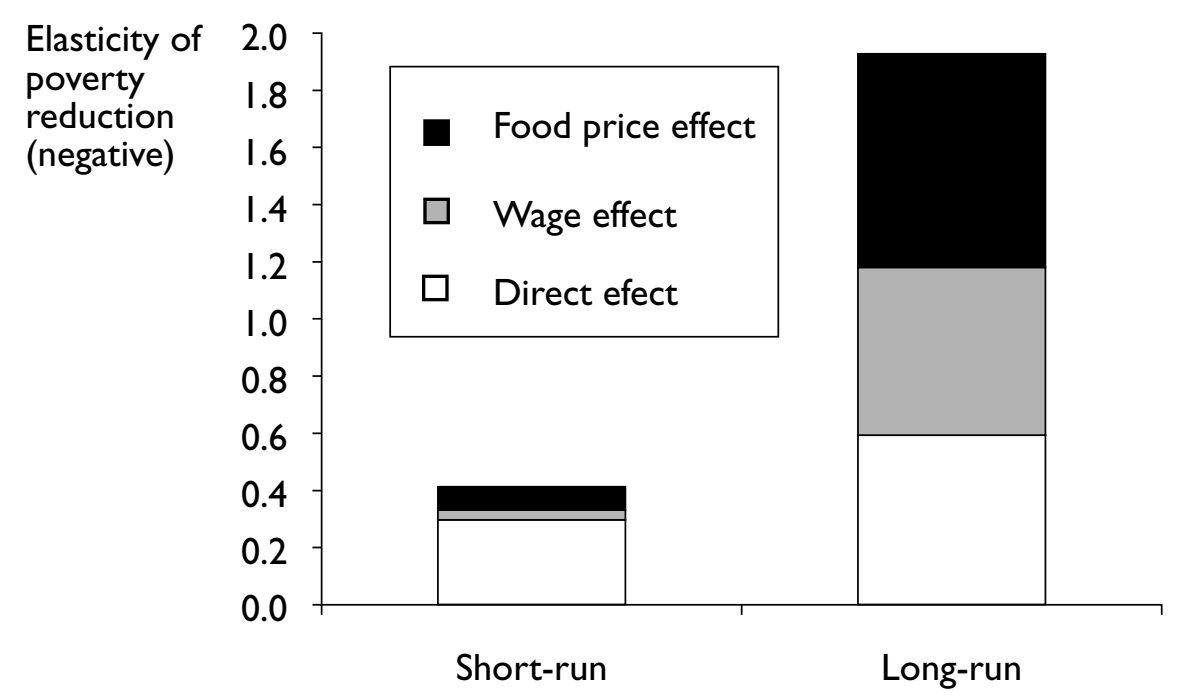

Source: Fan, Hazell, and Thorat 2000 ; Ravallion and Datt 1998.

(human, natural, physical, financial, and social), the returns to these assets, lack of political power, and vulnerability to shocks. The 200001 World Development Report outlined a threepronged framework for action to reduce poverty: (i) promoting opportunity by stimulating economic growth, making markets work better for poor people, and building their assets; (ii) facilitating the empowerment of poor people by making state and social institutions more responsive to them; and (iii) enhancing security, by lowering the risk from events such as bad weather and natural disasters, and reducing poor people's vulnerability to risks.

Broad-BASED Agricultural GROWTH. Broad-based agricultural growth can be expected to have the greatest impact on poverty where a large number of poor people depend on agriculture, the agro-ecological base allows significant potential for productivity growth, most land is controlled by small- and medium-scale farmers, farmers have (or potentially have) access to markets, and governance structures are sensitive to the needs of the poor. The strength of the link between agricultural growth and poverty is, however, conditioned by agroecological conditions, the structure of farm types and markets, level of technology use, access to assets, infrastructure, markets, and institutions, and other factors. Therefore, for any specific situation, an analysis of the potential for agricultural growth to contribute to poverty reduction must start with a review and assessment of the broader sectoral context for investment. Quite different agricultural investment priorities and strategies may emerge between and within countries depending on the local context (Byerlee and Alex 2002). Nonetheless, in many developing countries the 
FIGURE II.2 EMPLOYMENT AND EXPENDITURE;THE POOR AND NONPOOR IN MALAWI, 1998

Percent

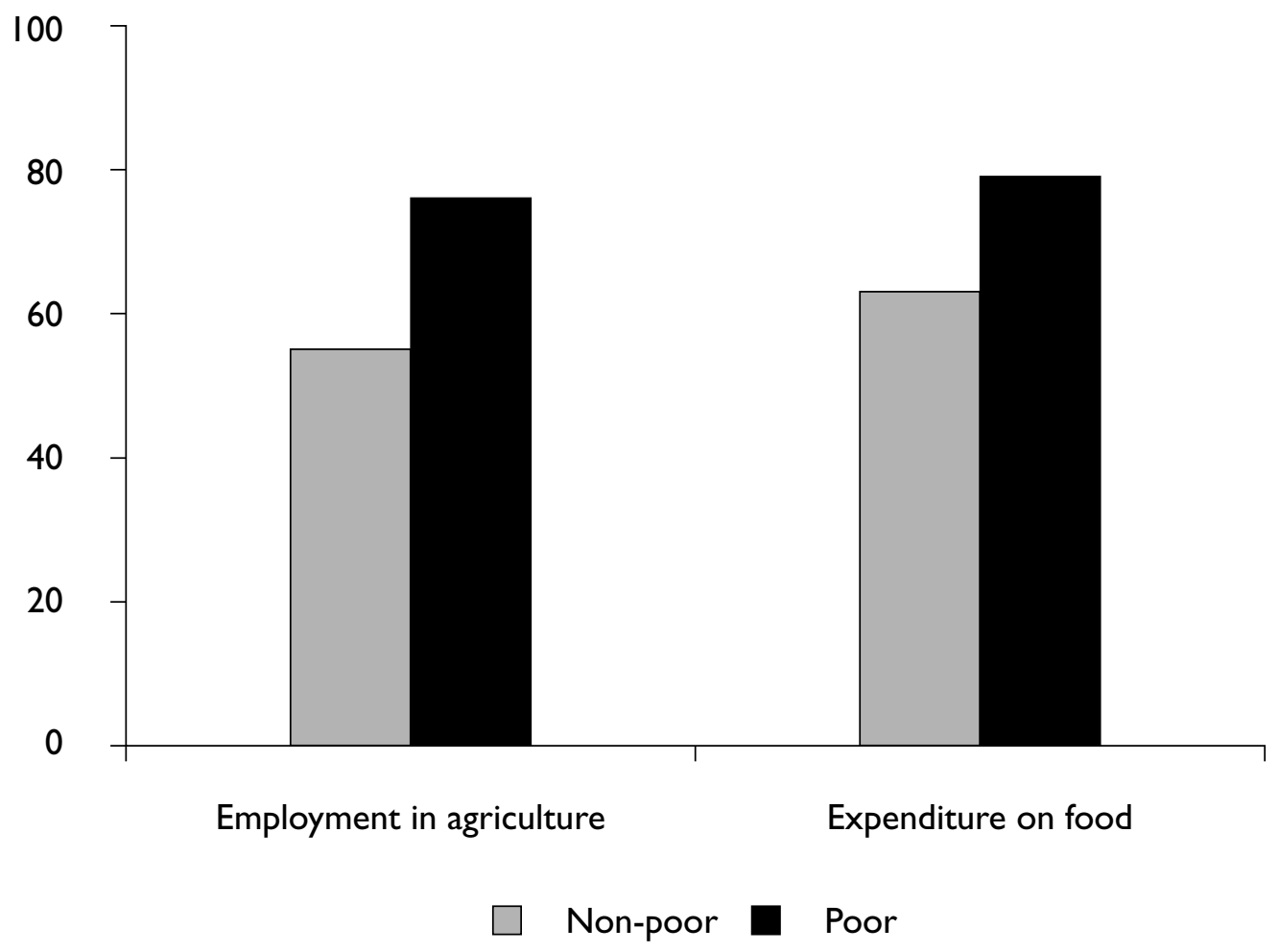

Source:World Bank Internal Documents.

high dependence by the poorest of the poor on agriculture necessitates that agricultural development be central to poverty reduction (see figure 11.2).

CHANGING CONTEXT FOR TARGETING POVERTY. Increasingly, interventions must be more effectively targeted as the opportunities for high poverty impacts from broad-based growth are becoming less common. This is particularly so in middle-income countries in which the poor represent a smaller proportion of the population and are more marginalized (broad-based growth may easily bypass the poor). Liberalization of trade has integrated markets, reducing effects of productivity growth on domestic prices of tradable food staples, and opening opportunities for high-value crops in some areas. Competitive pressures from liberalization may also squeeze farmers out of markets or further marginalize them, unless they develop new knowledge and skills. Livelihood shocks (natural disasters and market risks) may also be more common. In these situations, there are likely to be trade-offs between the poverty reduction impacts of investment in general productivity growth versus direct poverty targeting. Specific strategies will depend largely on poverty diagnosis relating to livelihood strategies of the poor, their resource constraints, and the market environment.

\section{STEPS FOR TARGETING POVERTY}

POVERTY Diagnosis. A criticism of past investments in agricultural development has been the relatively homogeneous approach taken to rural areas that are highly diverse in terms of resources, livelihoods, and people. Future investments must accommodate the differing initial conditions that shape the nature of poverty. A good poverty diagnosis should include: 
Box II.7 Web sources for diagnosis and design information

- The World Bank Poverty Monitoring Database http:// www.worldbank.org/poverty/data/povmon.htm

- LSMS Living Standards Measurement Study; Information Tables http://www.worldbank.org//sms/guide/select.html

- World Bank Africa Household Survey Databank http:// www4.worldbank.org/afr/poverty/databank/default.cfm

- World Bank Research http://econ.worldbank.org/

- World Bank Poverty Reduction Strategy Sourcebook http:/ /www.worldbank.org/poverty/strategies/sourcons.htm

Source: Authors.

Box II.8 Brazil rural poverty project; developing good strategy from effective diagnosis

Poverty diagnosis for the "Brazil, State of Piaui, Rural Poverty Reduction Project" summarized national and state-specific poverty data relating to the dimensions, characteristics, and causes of rural poverty. The diagnosis recognized that rural poverty is fostered by a relatively weak natural resource base, vulnerability to frequent droughts, low labor productivity, high levels of illiteracy and poor quality and coverage of education, relatively large family size, poor access to basic infrastructure and services, skewed land distribution, and poorly functioning rural financial markets. A multipronged set of strategies was developed to meet needs of diverse groups and thus better target poverty. The strategy developed from this diagnosis included a thorough review of strategic choices and was rated as highly satisfactory. It included:

- Intensification of the economically viable small-farm sector.

- Revitalizing commercial agriculture to absorb wage labor and foster downstream growth.

- Stimulating growth of the rural nonfarm sector, especially processing and services.

- Accepting a certain level of migration as inevitable and rational.

- Provision of adequate safety nets for the rural poor who will not benefit from intensification.

Source:World Bank Internal Documents

- A poverty profile that identifies the rural poor based on income and nonincome indicators, analyzes the severity of rural poverty, and assesses income and asset (particularly land) inequality.

- An analysis of the main correlates of rural poverty, for example, asset levels, market participation, sources of income, and geographic factors.
- An analysis of the relative merits of reducing poverty through: i) new livelihoods: both farm and nonfarm sources, including migration; ii) reduced vulnerability: treatment of critical long-run trends (for example, degrading natural resources); shocks (for example, natural, such as drought or flooding), and economic, such as prices), and seasonality (both production and prices); and iii) access to, use of, and satisfaction with services and institutions

There is now a rich database for carrying out this analysis in many countries (see box 11.7).

Strategy. Project interventions need to be derived from the poverty diagnosis and appropriate in the context of the country and other sector interventions (see box 11.8). Strategies can be focused, inclusive, or enabling. Focused or targeted actions center predominantly on actions that bring benefits to poor people and specifically improve their social, environmental, and/or economic conditions, and remove barriers to their participation. Inclusive actions are broad-based ones that improve opportunities and services generally, and also address issues of equity and barriers to participation of poor people. Enabling actions relate to policies that underpin pro-poor economic growth, and promote sound and economic management, governance, and social policies. Where available, investment strategies should be developed within a strategic framework for national poverty reduction, such as the PRSP.

Project Design. Project design should have appropriate organizational and institutional mechanisms to meet the particular needs of target groups identified in the diagnosis. These mechanisms may emphasize one or more of the following:

\section{- Broad-based productivity enbancement} through technology and markets is still the most efficient means of reducing poverty in many situations. This involves investments in research, extension, infrastructure, and human resources that drive equitable growth processes. 
- Geographic areas, particularly marginalized and resource-poor locations with limited access to social services and markets.

- Specific disadvantaged groups-particularly those that are excluded because of their gender, religion, caste, or ethnicity.

- Certain commodities (cassava or pulses) on which the poor in particular depend for income or consumption.

- Equitable land distribution to provide the poor with secure access to land.

- Improved quality of natural resource assets, through improved management of land, water and forest resources, and investments such as irrigation.

- Microfinancial services to promote savings and investment by poor households.

- Building social capital and social inclusion through decentralized development efforts (for example, CDD) that increase community participation (particularly women, indigenous groups, and remote/ marginal producers) in decisionmaking (see box 11.9).

- Managing risk and vulnerability - may involve farm diversification or better coping strategies, reducing market risks (for example by improving market access and information), and improving food security (reducing production risks, or safety nets). Effective programs include good targeting, high transfer efficiency, program transparency, and well-defined exit criteria.

- Reliable and affordable access to rural infrastructure services-transport, water and sanitation, and information and communication technology-dramatically increases rural people's access to markets and services.

- Access to health and education that improves productivity in farm and nonfarm jobs.
Box II.9 India: watershed project design for social inclusion

One of four key elements of the strategy developed for the Karnataka Watershed Development Project in India was to reach marginalized and vulnerable groups. The project selected watersheds with some of the poorest populations in Karnataka's rainfed areas, and included those who subsist on the most marginal of resources: tribals and other vulnerable groups (scheduled castes, other backward classes, landless, and populations below the poverty line). The project design involved the implementation of a Tribals and Vulnerable Groups Development Plan to cover all tribals and other vulnerable groups. Project implementation committees are composed of various stakeholder groups: at least 50 percent of the executive committee are women, and six are from scheduled tribes and other vulnerable groups. NGOs were intensively involved to build capacity of stakeholders in social aspects, beneficiary groups formation and nurturing, participatory planning and implementation, and $M \& E$ throughout the life of the project.

Source:World Bank Internal Documents.

Monitoring AND evaluation. Monitoring of project implementation and impact must be integrated into project design from the initial phases of the process, with a specific focus on poor and vulnerable groups. Performance indicators should not be limited to income, but may include indicators of access to assets, proportion of population below a minimum level of dietary consumption, and indicators of participation by the poor. These indicators can include both quantitative (factor productivity, income, health statistics, for example) and qualitative (satisfaction with the provision of services, for example) measures.

\section{SELECTED READINGS}

Asterisk (*) at the end of a reference indicates that it is available on the Web. See the Appendix for a full list of Web sites.

Byerlee, D., and G. Alex. 2002. "Designing Investments in Agricultural Research for Enhanced Poverty Impacts." SASKI Good Practice Note. World Bank, Washington, D.C.*

World Bank. 2001. World Development Report 2000/2001: Attacking Poverty. New York: Oxford University Press; Washington, D.C.: World Bank.* 
World Bank. Poverty Reduction Strategy

Sourcebook. http://www.worldbank.org/

poverty/strategies/

\section{REFERENCES CITED}

Byerlee, D., and G. Alex. 2002. "Designing

Investments in Agricultural Research for Enhanced Poverty Impacts." SASKI Good

Practice Note. World Bank, Washington, D.C.*

Datt, G., and M. Ravallion. 1998. "Farm Productivity and Rural Development in India." The Journal of Development Studies 34 (4): 62-85.

Fan, S., S. Thorat, and P. Hazell. 2000. "Impact of Public Expenditure on Poverty in Rural India." Economic and Political Weekly XXXV (40).

Thirtle, C., L. Lin, and J. Piesse. 2003. "The Impact Of Research Led Agriculture Productivity Growth On Poverty Reduction In Africa, Asia And Latin America." Contributed paper for the 25th conference of the International Association of Agricultural Economists, Durban.

This Note was prepared by Derek Byerlee and Sam Kane. 
AGRICULTURE INVESTMENT NOTE

\section{NINE LESSONS FOR IMPROVING PROJECT DESIGN FOR BETTER INVESTMENT PERFORMANCE}

Agriculture's importance to poverty reduction is now widely recognized, but the complexity and perceived difficulty of investing in the sector, along with somewhat poorer performance relative to other investment areas, has contributed to a decline in lending. The World Bank OED recently identified seven key lessons from previous experience that can help improve the quality of project design and implementation, and thus significantly increase project performance. ${ }^{6}$ Several key recommendations include: clearly identifying project rationale, analyzing poverty, phasing implementation, good M\&E, and structuring stakeholder incentives.

The environment in which the agriculture sector contributes to poverty reduction, and the means by which it can most effectively contribute, continues to change rapidly. Fully exploiting the poverty reduction potential of agriculture requires that projects be evaluated critically to build an information base from which knowledge can be leveraged to improve future investment initiatives. This note draws from a recent OED study to outline the key generic issues to be addressed by practitioners during project design (World Bank 2003). It recognizes that sound project design is a fundamental precondition to good project performance, and that the design process must: draw from relevant past lessons, be an ongoing process in which changes in direction and the rationale for these are well documented, and include effective M\&E systems such that lessons can be articulated and used to guide future investments toward more sustainable and effective outcomes and impacts.
In recent years, Bank lending to agriculture has had persistent problems of sustainability and institutional development-generally below 50 percent of projects are rated as "likely sustainable," and a little over 40 percent rated as contributing to "substantial institutional development." This poor performance can be attributable to a variety of factors relating largely to project design. Problems include weak specification of objectives, weak translation of objectives into outcome-focused design, and poor policy and institutional design. An analysis of project evaluation results has identified several key lessons outlined below for future investments (World Bank 2003).

\section{RECOMMENDATIONS FOR PRACTITIONERS}

Rationale identification. Clearly spell out the rationale for the project and the linkages from the rationale to the design. If the project rationale is not explicitly identified in an outcomefocused design, sound judgments made during preparation and appraisal may be compromised and M\&E may be hindered. Without documented recording of the evolution of project logic, staff changes may obliterate earlier logic and decisions. All significant design issues should be separately identified and addressed or disposed of rationally and explicitly in superseding documents (box 11.10).

Box II.10 Bangladesh: failure to document justification for reform changes

In the Bangladesh Agricultural Research Management Project, carefully analyzed and well-articulated institutional reforms were developed early in preparation for consultation with the borrower, but were dropped later without clearly articulated and recorded justification. Consequently, the project reverted to "more of the same" and performed poorly. Such situations tend to be associated with a lack of ownership and pressure to lend as negotiations approach.

Source: Authors.

6. This note draws from R. Nelson, "Sector Lessons Note: OED's Seven Leading Rural Lessons" (World Bank, Washington, D.C., Forthcoming). 
POVERTY ANALYsis. Critically analyze who is poor and why they are poor to improve the propoor focus of the project. Project design must include effective logical framework links between specific policy and investment actions and prior poverty diagnosis. Rigid target-based approaches are typically ineffective, and linkages are better made through incentive structures to encourage key agents (such as extension agents) to work with the poor. The challenge is generally to provide for increased participation of the poor through group approaches, and through access to marketing channels suitable for resource-poor farmers. A clear section in the project appraisal document (PAD) should indicate:

- Who are the poor, how many are there, and what are the reasons for their poverty?

- Who are the likely gainers and losers from the proposed project interventions?

- Is the project area selection pro-poor (for example, poor geographical zones)?

- To what extent is each main investment or policy reform selectively pro-poor?

- To what extent are participation processes expected to be pro-poor?

- Are there any grievance mechanisms accessible to the poor?

- What indicators will suggest the achievement of any pro-poor objective?

This analysis can be used to customize project design to address specific characteristics, location-specific constraints, and opportunities of the poor.

Monitoring and evaluation. From the outset, integrate M\&E into project design. M\&E should be an organic part of project design, not an afterthought. Effective M\&E must be in place to learn lessons for future, larger-scale operations (see box 11.11). As soon as project objectives are initially formulated, even tentatively, con- sideration should be given to realistic targets, and readily quantifiable indicators linked to the objectives, and initiation of M\&E design. Management and information systems need to be established at an early stage to enable effective and responsive management:

- Get the objectives stated appropriatelyneither too high and abstract nor too low and detailed. Aim for outcome-focused design.

- Start early, and reread Logical Framework Guidelines or attend training.

- Initiate plans for baseline surveys if needed during early preparation. If possible embed $M \& E$ in a permanent institution or link it to one.

- Build sustainable evaluation capacity not just one-off project-specific M\&E systems.

- Look at incentives for M\&E performance of different stakeholders and get commitment at the project management level with incentives to results-based management processes.

- Try to ensure that M\&E staff are recognized professionally within the institution and are not in a temporary position.

- Coordinate M\&E methods and reporting formats with other donors.

Design REALISM. Make sure that the elements of the project design are not only time-specific and measurable, but also are realistic and achievable-especially with regard to CDDtype activities and the incremental processes required for CDD implementation. Frequently, donors underestimate the time required to meet targets, and do so such that impacts will be sustained into the future. This is particularly so for capacity building investments where the building of trust and social capital is an incremental process that demands iterative learning. Creating incentives and stabilizing expectations takes time, and creating capacity at all levels 
(government, community, private sector) usually takes more time than anticipated. Project closure (along with inadequate followup work) just when organizations are established and most in need of external support, has occurred far too frequently in past projects- the result is lost trust in donor organizations due to the unfulfilled expectations that they initially created within the community. Project design must recognize that organizational development typically spans multiple project periods, and thus any one project must seek to build upon previous initiatives, and also provide the basis for future efforts to expand on its own outcomes.

Technical Backing. Ensure that project components are based on thorough technical analysis, either through internal resources or via outsourcing of the expertise required. The World Bank (along with numerous other donors) has lost much of its capacity (technically specialized human resources in particular) to identify technical opportunities that would greatly enhance agricultural projects. In the past, donors have made major contributions in many technology-intensive fields including; precision irrigation, conservation tillage, pastoral livestock systems, export horticulture, and integrated pest management. However, a reduction in skilled staff has reduced capacity to identify and exploit these types of opportunities - many of which still exist in agriculture (and are addressed throughout this Sourcebook). Building professional and institutional relationships among donors, universities, government agencies, and private sector providers can enable stakeholders to exploit their areas of specialization and comparative advantage, and facilitate outsourcing of technical expertise.

Implementation actions. Design not just the substance but the phased implementation actions involved in agricultural investment and reform initiatives. Detailing the process by which policy and institutional reforms are to be achieved, and appropriately sequencing implementation, are as important as detailing the substance of the reforms. Ensuring that action is
Box II.II Pakistan: consequences of ineffective monitoring and evaluation

Weaknesses in monitoring and evaluation (M\&E) of the Pakistan Punjab Forest Sector Development Project were due to the failure to design M\&E during preparation, inappropriate institutional location of the M\&E function, and lack of incentives to report. This inhibited management responsiveness. For example, lack of M\&E data and marketing studies left unaddressed serious questions about possible oversupply of wood and alternative marketing strategies.

Source: Authors.

not just rhetoric can be achieved by working simultaneously and cooperatively with diverse interest groups to build support for reform. Reforms typically involve changes in laws and regulations, new governance and administrative structures and procedures, financial arrangements, and capacity building. Those who manage reform processes on a day-to-day basis need political commitment and support from politicians and senior policymakers. Implementation delays in institutional development are usually not unpredictable, but some scheduling or flow charts can guide the sequence, timing, and realistic length of each implementation step.

Stakeholder InCEnTIVes. Through new policies and institutional arrangements, create incentives for various stakeholders to fulfill their respective roles and responsibilities. There should be thorough analysis of incentives created by any new "rules of the game" for individual and institutional stakeholders, and the time needed for these to have impact. Institutional arrangements typically involve four sets of actors with different incentives:

- At the central government level, key functions include new laws and regulations, nationwide coordination, building capacity, and financial decentralization.

- At the local government level, decentralizing public services involves establishing a national framework with an appropriate mixture of administrative, political, and fiscal decentralization, and establishing 
institutional arrangements for each service assigned to local governments.

- Incentives at the community level are needed to make service providers accountable to farmers and enable the poor to exert pressure on local governments.

- For the private sector, including individual farmers, successful liberalization and privatization of commercial activities may require capacity building and transitional arrangements as circumstances, capacity, and incentives evolve.

Participation of all legitimate stakeholder groups in reform processes helps to establish the credibility of the proposed reforms, assemble relevant information, and instill ownership in reforms. It is important to work closely with the potential losers who may undermine the reform process. A revival in the use of farm budget analysis would help to assess private financial incentives for investments.

DONOR COORDINATION. Ensure donor coordination by basing project design on a clear understanding of respective roles, responsibilities, and constraints of various partners. Without an understanding of the roles of various stakeholders, the leverage and broader development experience that may be obtained from effective donor coordination will never be realized (see box 11.12). The following are important ingredients for better donor coordination:

- Willingness to really listen to donors and cultivate close relationships-what donors formally say may not reflect what is felt in private. Country-level dialogue can be important, but major decisions generally come from donor headquarters.

- Sufficient time to build trust. Donors have often felt rushed to make commitments, even in cases where project preparation takes a long time. This can result in many donors pulling out very quickly when things start to go wrong.

- Clear definition of what elements are being coordinated (for example, overall strategy, procurement, disbursement, phasing, community processes, reporting, subsidies or incentive payments), and realism about the limits to donor's procedural (especially procurement) flexibility.

- For the Bank, a willingness to let other donors chair coordination efforts may reduce risk of perceived Bank heavy-handedness.

FINANCIAL PROJECTIONS. Improve the financial sustainability of the project by incorporating specific analytical financial projections into the project design. Low sustainability ratings indicate problems with planning for overall financial sustainability (see box 11.13). This is attributable to the uncertainties involved with agricultural production and the complexities of technical, political, and institutional dimensions of project settings. PADs should provide:

- A table projecting local funding needs for the project period and at least 5 years beyond and including other significant incremental donor projects in the sector.

- A table of the past 5 years of budgetary allocation to that sector or subsector.

Box II.I2 Nepal: an uncooperative and thus ineffective approach

Individual donors have supported different aspects of the community forestry program in Nepal, depending on their individual priorities, and have preferred to work in specific districts. Both aspects have put a great coordination burden on the government and stretched its limited institutional capacity. Diverse implementation strategies in different districts have created confusion, especially among field staff. This uncoordinated approach resulted in some important institutional issues receiving inadequate attention-for example, support for research has fallen between the cracks.

Source: Authors. 
Box II.I3 Poor financial sustainability: a Bangladesh research project as a typical example

Despite two earlier projects with serious financial sustainability issues, the Bangladesh Agricultural Research Management Project had no analysis of financial sustainability. The Staff Appraisal Report (SAR) refers briefly to the risk of inadequate counterpart funding, and notes that the government agreed at negotiations that adequate funds would be made available for the project-the largely boiler-plate statement found in many SARs/Project Appraisal Documents (PADs). The post-project scenario for funding was not discussed or analyzed in relation to past budgetary allocations.

Source: Authors.

- Analysis of any gap between these twothat is, between the demand for funds and a reasonable expectation of the supply of funds.

- Supporting evidence of changed government priorities for sectoral budgetary allocations if budget demand is shown to go significantly beyond past actuals.

- A substantive discussion on the implications of the data for financial sustainability, and an outline of how it has affected project design (for example, toward reduced scale, increased cost recovery, phasing, retrenchment).

Designing a project to be within the financial capacity of the borrower requires more than simplistic budget-cutting solutions, such as line agency staff reductions and needs to be assessed in the context of overall national budget management and civil service reform (staff reduction may not release funds if budgetary allocations are related to staff numbers).

\section{SELECTED READINGS}

Asterisk (*) at the end of a reference indicates that it is available on the Web. See the Appendix for a full list of Web sites.

Nelson, R. Forthcoming. "Sector Lessons Note: OED's Seven Leading Rural Lessons." World Bank, Washington, D.C.

UNDP. 1998. Capacity Assessment and Development: In a Systems and Strategic Management Context. Technical Advisory Paper 3. New York: United Nations Development Program.*
World Bank. 2002. "Toward Sharpening the Focus on Rural Poverty: A Review of World Bank Experience." Operations Evaluation Study 24072. World Bank, Washington, D.C.*

World Bank. 2002. The Next Ascent: An Evaluation of the Aga Khan Rural Support Program, Pakistan. OED Report. Washington, D.C.: World Bank.*

\section{REFERENCES CITED}

Nelson, R. Forthcoming. "Sector Lessons Note: OED's Seven Leading Rural Lessons." World Bank, Washington, D.C.

This Note was prepared by Ridley Nelson. 


\section{AGRICULTURE INVESTMENT NOTE}

\section{AGRICULTURE SECTOR PROGRAM LENDING}

The agriculture sector program (ASP), a sector approach to development, is a medium to long term national program specifically for agriculture. The formulation, scope, and sequencing of ASP depends on the depth of the country's private sector, the status of its policy framework, and its institutional capacity to plan and implement a development program. Donors support government priorities as contained in the program. This eliminates the fragmentation, duplication, and lack of country ownership common under the conventional project investment approach. Donor involvement should include technical assistance for capacity building (through training of preparation and management teams, workshops, and other activities), sector studies, and developing information and communication systems.

In many countries, the effectiveness of donor assistance provided to the agriculture sector has been less than satisfactory. An important reason is that when aid is delivered through a variety of projects, it results in a fragmented approach to agricultural development. Even if individual projects are well designed, the multiplicity of donors, objectives, management systems, and procedures make it difficult for sector managers to absorb and manage aid efficiently. Often donors have taken the lead in identifying, designing, and implementing projects. Although they do so with good intentions, this does little to help the country develop capacity or foster a sense of ownership of their development projects.

\section{AGRICULTURE SECTOR-WIDE PROGRAMS}

Agriculture sector-wide programs, like programs in other sectors, function as an umbrella to help ensure the coherence of donor-supported government activities. Sector program approaches support a single sector policy and expenditure program, under government leadership, adopting uniform procedures to disburse and account for all funds. A sector program is defined as one that covers all the activities in a given sector (often used to mean all the activities of a government ministry's budgetary programs). A sector-wide program: (a) is sector-wide in scope or coverage; (b) is based on a coherent sector policy framework; (c) is prepared and managed by local stakeholders; (d) includes program participation by all major donors, thus avoiding duplication and conflict with other donor projects; (e) adopts, to the extent possible, the same arrangements for accounting, budgeting, procurement, and progress reporting, for all donors; and (f) is in line with the country's institutional capacity.

\section{BENEFITS}

Evidence suggests that projects perform significantly worse in situations of macroeconomic instability. However, stand-alone projects are ill-equipped to initiate macroeconomic reform, and adjustment lending, although suited to addressing "stroke of the pen reforms" (such as export tariff elimination), is not very successful in dealing with complex issues requiring longer gestation periods (for example, privatization of parastatals). ASP combines reforms in key sectoral policies, expenditure patterns, and institutions with financing for a sectoral expenditure program with a longer-term horizon. The approach broadens sources of funding, makes coverage of the sector more comprehensive, brings ongoing projects into line with the sector policy, and develops common procedures. It provides policymakers and practitioners the opportunity for systematic and comprehensive review of the public expenditure program, ensuring that priority programs are supported effectively, and are appropriately sequenced. When successful, sector programs focus discussions between donors and government, link policy and implementation, balance investment and operating expenditure, and improve service coverage and quality (Foster, Brown, and Naschold 2001). 
ASPs will not be appropriate in all countries, especially where serious macroeconomic problems exist, where there is not a broad agreement on the aggregate pattern of priority public expenditure, and where institutional capacity to formulate, implement, and monitor programs is weak. ASPs cannot be thought of as substitutes for sound adjustment policies.

\section{DESIGN AND IMPLEMENTATION ISSUES}

MULTIPLE STAKEHOLDERS AND CROSS-SECTORAL ISSUES. The agriculture sector has many stakeholders, including private sector entities, multiple government agencies, and numerous donor organizations and NGOs (see box 11.14). Many government functions of greatest importance to agriculture (for example, regulation of transport and trade, trade policy) are located outside of the agricultural ministry itself. This makes it difficult to develop consensus among stakeholders, and to concentrate public sector initiatives. For improved coordination, governments and donors must seek consensus and a common agreement on the most suitable structure (and ministry) to lead public sector reforms and program initiation.

COUNTRY CAPACITY. A major obstacle to agriculture sector program success is lack of country capacity to plan and execute a comprehensive program-in particular, capacity for financial management and for M\&E. Initial ASPs should focus on reforming institutions and building capacity, keeping early programs relatively simple, focusing on a few core activities in one or two subsectors, and undertaking further tasks as capacity expands. A sector program may focus entirely on institutional development and capacity building, and may not involve capital investments at all. The determining factor as to whether a program qualifies as ASP or not, is the extent to which coherent policy and institutional frameworks exists and the degree of government commitment.

DONOR COORDINATION. Donor coordination and harmonization of donor support is generally difficult to achieve. Governments may lack the capacity or experience to handle this task, and
Box II.I4 Kenya: agriculture sector program stakeholders

In Kenya, a workshop on the findings of the agricultural sector review identified the following key stakeholders:

- Farmers and their organizations: Smallholders and commercial farmers, farmers' groups (male and female), cooperative societies, apex and national farmer organizations.

- Public sector: Ministry of agriculture, other line ministries, treasury, ministry of planning and national development, department of personnel management, parastatals, area development authorities, and local government including provincial and district administrations.

- Private sector:Traders, exporters, and agro-industries (including small-scale traders).

- Policy group: Academic institutions, other institutes and think-tanks, elected representatives at the national and local levels, financial institutions, and nongovernmental organizations.

Source: Okidegbe et al. 1998.

donors may be unwilling or unable to harmonize their support due to their own internal procedures. The Special Program of Assistance for the Africa region is one mechanism for improving donor coordination offering donors the opportunity to discuss ways to coordinate their assistance and providing a model for governments. Adoption of common implementation arrangements is likely to be a slow process. Project implementation manuals should highlight the proposed implementation arrangements. Donors are likely to agree to harmonize some activities but resist harmonizing others. While donors are likely to agree to common reporting and auditing functions, they are less likely to harmonize procurement and pooling of funds. ASP initial successes can build receptivity to further coordination.

\section{LESSONS LEARNED}

Experience from recent ASPs not only offer some important lessons for future ASPs, but also show that ASPs are not panaceas for development success. ASPs have worked well in some countries, and have experienced significant implementation difficulties in others. 
SuCCESS CRITERIA. Experiences have shown that ASPs work better in countries with:

- A coherent policy framework that addresses key macroeconomic and sectoral policy issues (there are no major policy distortions or at least measures are in place to redress existing distortions).

- An institutional framework that is based on a detailed assessment of key institutions in the sector, and supported by institutional reforms and rationalization.

- A sectoral public expenditure review process that identifies ways to improve the efficiency and impact of the public expenditure program.

- A government commitment to the program with concrete evidence of political, fiscal, and administrative commitment to program preparation and implementation.

ClaRifying SCOPE and BUILDing CONSENSUS. Experience shows that when initiating ASP preparation, it is useful for ASP advocates within government to clarify the scope of the ASP activities by first preparing a concept summary. This can be used to build consensus within government and among the key stakeholders on the need for an ASP. Once a consensus is reached to move forward, an ASP team, comprising representatives from key stakeholders, can prepare a program document to guide the preparation effort. Such a document should communicate to principal stakeholders; the ASP scope, evaluation criteria, design features, and preparation processes. Views of rural stakeholders throughout the country need to be incorporated in the preparation process.

\section{Agriculture sector program design. Past ASPs} have illustrated the importance of taking into account the country's implementation capacity and natural endowments. There is therefore no one standard design that is generally applicable. While flexibility is important, experience shows that ASP preparations must:
- Demonstrate the consistency of ASP activities with program objectives, the outputs required to achieve objectives, and the inputs needed to achieve outputs, emphasizing cause and effect linkages.

- Assess the affordability and sustainability of the program through a detailed public expenditure review.

- Address cross-cutting issues by evaluating the extent to which the program minimizes environmental degradation, reduces poverty, and improves gender equity, for example.

- Identify the technical capacity required to ensure that productivity gains in agriculture, especially among smallholders, can be achieved.

- Establish common donor implementation arrangements, possibly pooling funds to reduce preparation costs, delays, and confusion.

Client Participation AND SOUnd MANAGEMENT. ASP implementation is likely to be affected by the quality of public sector management, and the guidance provided to those implementing the program at all levels. It is important to involve stakeholders at early stages of program implementation, establishing mechanisms for generating feedback from different client groups and for assessing farmers' opinions on the quality, affordability, and relevance of services. For example, a Zambian ASP successfully involved a wide range of stakeholders in the preparation stages, but this was not followed up during implementation (see box 11.15). The end result was loss of ownership, poor implementation, and low impact. This illustrates the importance of making efforts to sustain client participation/ ownership throughout the entire ASP process. Options for generating such feedback include beneficiary assessment, participatory rural appraisal, systematic client consultation, participatory M\&E, and involving stakeholders in advisory roles. ASPs should institutionalize a learning culture and provide training for staff at 
all levels to familiarize them with ASP principles and implementation issues, particularly the need for client consultation and special attention to gender issues, management, personnel, and incentives. Planning must ensure smooth implementation, as any ongoing projects are systematically integrated into the ASP.

Monitoring and eValuation. Good M\&E systems are needed for effective implementation of ASPs, especially for early identification of inadequate performance (deviations from plans, client dissatisfaction, or weaker than expected linkages between inputs, outputs, and objectives) and timely remedial measures. The systems may also identify corrective actions to rectify deficiencies. Impact assessments require a suitable $M \& E$ framework for the overall performance of the sector, and can be viewed as a Sector Performance Analysis (SPA) (see box 11.16). Statistics from the years preceding the ASP usually provide the "benchmarks" for assessing performance and impact. Sector performance findings should be summarized in interim and final reports and, following discussions/consultations with major stakeholders and the ministry of agriculture, should be distributed to all stakeholders for action.

\section{RECOMMENDATIONS FOR PRACTITIONERS}

- Begin by identifying key stakeholders and important areas for investment, launching generic studies, appointing and training preparation and management teams, and preparing a concept document (see box 11.17). Gain consensus through startup workshops that enable dialogue and information sharing among stakeholders. Ensure that generic studies and the priorities, resources, and needs of stakeholders inform the final preparation report. Complete a comprehensive evaluation of the scope and technical feasibility of the ASP.

- Conduct a sectoral institutional analysis, including analysis of sources of power and influence, and a sector expenditure report, to inform the ASP (data generated by
Box II.I5 Zambia:Agriculture Sector Program and local stakeholder ownership

Prior to the agriculture sector program (ASP), there were some 180 known donor-funded projects in the agricultural sector in Zambia. The government had at best only partial knowledge of most of these. When the ASP was launched in October 1992, it was agreed with all major donors that the government would drive the preparation process. The government began an 18 month preparation process to design a new, affordable program to revive the country's agricultural sector. To do so, it created a national task force with 14 working subgroups. Representatives of nongovernmental organizations, private farmers, the universities, farmer groups, and public servants participated. They covered such issues as research, extension, privatization, rural finance, animal health, and land use and administration. Wherever possible, private sector members chaired the groups. The key to the eventual success of the program was to bring in the private sector in a major way to run these groups.

Source: Harrold et al. 1995.

\section{Box II.16 Requirements for sector performance analysis}

Monitoring systems for sector performance analysis (SPA) should track such things as changes in cultivated area, production of key crops as well as total production, employment, and incidence of poverty. A combination of quantitative and qualitative methods can help to capture the main sources of variation and explain the reasons for change. For example, SPA analyses may try to quantify the impact of variable weather conditions, increased adoption of new technologies (including the impact of extension services), investments, availability of credit, policy changes, and external shocks (changes in export crop prices, for instance), as well as obtain qualitatiave information through consultations with farmers and other stakeholders.

Source: Okidegbe et al. 1998
Box II.17 Potential investments

- Policy, regulatory, and institutional reform.

- Information services.

- Provision of extension services to smallholder farmers.

- Research priority setting.

- Development and protection of the natural resource base.

- Private sector support.

- Rural infrastructure.

Source: Okidegbe et al. 1998. 
poverty assessments can be useful here), and to develop realistic and time-specific objectives for the ASP.

- Develop effective common implementation arrangements among donors.

- Project design must reflect the constraints and capacities faced, illustrate consistency between activities and objectives, assess sustainability through public cexpenditure reviews, and provide for linkages with other sectors (trade, roads, water, forestry, health) and the accommodation of crosssectoral issues (environment, poverty, food security).

- Build a sound M\&E system.

- Restructure donor support to conform to the country's budget cycle, and phase out individual projects in return for recognition as a stakeholder in the sector.

\section{SELECTED READINGS}

Asterisk (*) at the end of a reference indicates that it is available on the Web. See the Appendix for a full list of Web sites.

Foster, M., A. Brown, and F. Naschold. 2001. "Sector Programme Approaches: Will They Work in Agriculture?" Development Policy Review 19 (3): 321-338.*

Harrold, P. 1995. The Broad Sector Approach to Investment Lending: Sector Investment Programs. Discussion Paper 302. Washington, D.C.: World Bank.*

Jones, S. P. 1997. Sector Investment Programs in Africa: Issues and Experience. Technical Paper 374. Washington, D.C.: World Bank.*

Okidegbe, N. 1997. Fostering Sustainable Development: The Sector Investment Program. Discussion Paper 363. Washington, D.C.: World Bank.*
Okidegbe, N. 1998. Agriculture Sector Programs: Sourcebook. Technical Paper 418. Washington, D.C.: World Bank.*

\section{REFERENCES CITED}

Foster, M., A. Brown, and F. Naschold. 2001. "Sector Programme Approaches: Will They Work in Agriculture?" Development Policy Review 19 (3): 321-338.

Harrold, P. 1995. The Broad Sector Approach to Investment Lending: Sector Investment Programs. Discussion Paper 302. Washington, D.C.: World Bank.

Okidegbe, N. 1998. Agriculture Sector Programs: Sourcebook. Technical Paper 418. Washington, D.C.: World Bank.

This Note was prepared by Nwanze Okidegbe with input from Sam Kane. 
AGRICULTURE INVESTMENT NOTE

\section{COMMUNITY-DRIVEN DEVELOPMENT FOR INCREASED AGRICULTURAL INCOME}

Community-driven development (CDD) investments use a variety of mechanisms to empower communities to define priorities and take charge of their own development investments. Typically, CDD programs provide resources, often through cash grants, to enable communities to undertake local development activities. Initial community projects frequently involve small-scale infrastructure, but increasingly productive projects become a priority to address poverty and income issues. Agricultural projects are potentially an important element of the subproject portfolio, though experience to date offers limited guidance on how to maximize sustainable impact on agricultural production systems with CDD investments. Supporting income-generating activities (IGAs) without introducing unsustainable subsidies and market distortions is a challenge to be addressed in future analyses of CDD investments.

CDD is an approach to poverty reduction that seeks to empower communities and local governments with resources and decisionmaking powers so that they can take charge of their own development. "Empowerment" refers to increasing the assets and capabilities of poor people to participate in, negotiate with, and hold accountable the institutions that affect their lives. Achieving empowerment means promoting a stronger voice, access to information, social inclusion, accountability, and organizational strength. CDD is an established corporate priority of the World Bank and a key design principle in an increasing number of projects in rural areas. At present, approximately 45 percent of the lending to the agriculture sector uses some variant of the CDD approach-a proportion that is likely to increase in future.
Typically, the CDD approach gives communities access to funds to implement subprojects of their choice. Local investment funds are often, but not always, provided in the form of matching grants, whereby participating communities are expected to make a contribution in cash or in kind. To the extent that rural communities consider food security and income from agricultural sources as their priority needs, projects using the CDD approach are expected to promote agricultural development.

\section{POLICY AND IMPLEMENTATION ISSUES}

Local investment that is explicitly guided by community priorities and, in most cases, implemented by communities themselves, is the hallmark of the CDD approach. In order to respect the diverse needs of the poor, eligibility criteria for selection of subprojects are typically kept fairly open, either using a negative list of things that may not be financed (for example, religious structures or investments with potential negative environmental impacts); or a broad positive list of eligible subprojects for project financing (for example, social and economic infrastructure, natural resource management). Most World Bank lending using the CDD approach over the past decade has focused on infrastructure and social services, but other options are increasingly being explored, such as IGAs and natural resource management (NRM). Community choices are conditioned by several factors:

MeEting the most BASIC NEEDS. When CDD projects target the poorest, beneficiaries usually lack basic needs, such as safe drinking water and access to health services. When presented with the opportunity to improve critical services, those priorities prevail. Once those needs are met, communities will address secondary needs.

Defining the community. Subproject choice often depends on the working definition of "community." If defined narrowly as a water-users organization, for example, it would not be surprising to find demands for irrigation pumps 
Box II.18 Typology of community organizations in World Bank

\section{operations}

- Common property resource groups. Water user or forestry management associations.

- Producer organizations. Groups that engage in crop and livestock production, forest and forest products, fish production, postharvest and processing activities.

- Multisector functional committees. Village or municipal development committees.

- Single-sector functional committees. Health or education committees (common in Social Fund projects).

- Microcredit institutions. Community savings and loan groups or revolving credit accounts.

Source: Parmesh Shah, personal communication. choices, face important trade-offs in selecting subprojects from a range of sectors (health, education, water supply, transport, and agriculture; see box 11.18).

Appraisal methods. Another determinant of subproject choice is the method of community mobilization and planning used. Tools that focus on community problems often come up with priorities such as health and education. Tools that focus on a community's resources and abilities may favor economic development priorities. Planning based on community strengths and opportunities may produce a priority list different from that established by local government (Goldman 2003).

\section{Box II.19 Brazil: Hives of income-generating activity}

Throughout the State of Piaur in Brazil, 17 beekeeping subprojects financed by the Rural Poverty Alleviation Project have generated an estimated total incremental income $R \$ 348,000$, or $\mathrm{R} \$ 660$ per beneficiary family. Total estimated production of honey is 189 tons ( 17 percent of state production). The subproject package for beekeeping financed honey-bees, fumigation equipment, centrifuge, honey filters/decanters, beehives and other materials and equipment. CEFAS, an nongovernmental organization, provided technical assistance. In one example 30 families formed the Association of Small Bee Keepers in the Floriano Region. Previously, only four of those families were producing honey with a total yearly output of 320 kilograms. The 30 families now produce 9,000 kilograms annually. Average family income from honey increased from $R \$ 18$ to $R \$ 510$ per year.The association obtained financing from Banco do Brasil for the construction of additional infrastructure to store the honey.

Source: Parker 1995.

or carts for produce. If the project works with parent-teacher organizations, then proposals would naturally focus on education. More typically, however, CDD projects work with villages or groups of villages defined by administrative boundaries, physical proximity, and/or social cohesion. Communities comprise numerous constituencies, which given hard budget
USING MATCHING GRANTS TO GENERATE INCOME. COMmunities often identify productive activities as priorities, and matching grants have been used successfully to stimulate substantial gains in productivity and income (see box 11.19). Using grants to support IGAs in farm and rural nonfarm activity is controversial, with a growing number of detractors and proponents on both sides. ${ }^{7}$

Detractors argue that grants increase dependency, undermine a culture of financial discipline, and crowd out development of sustainable microfinance institutions. Grants that benefit only a small minority of the population may not support financially viable activities, and are not sustainable because fiscal transfers are insufficient after a project to continue such support.

Proponents argue that, from a social assistance point of view, direct transfers may be justified for poverty reduction, particularly if they target the very poor. ${ }^{8}$ From a rural development perspective, direct support for productive assets may be justified to raise the income-earning potential of the community and "kick-start" the local economy. Others point to positive externalities generated from the associated private sector development. Several rules-of-thumb for use of grants in CDD are included in box 11.20.

\footnotetext{
7. This section is adapted from a concept note written by Jean Delion and William Steel, Africa Region.

8. Bank guidelines, specifically Operational Policy (OP) 8.30, state that "[s]ubsidies may be an appropriate use of public funds if they are fiscally sustainable and are economically justified or can be shown to be the least-cost way of achieving poverty reduction objectives."
} 
Using grants for IGAs for very poor people as social assistance is well accepted, although these interventions need to be carefully designed when working with the asset poor. In district poverty initiatives in India, project teams have had considerable success funding income generation for the poor who own a plot of land, however small. They have had less success with the absolute poor who have no assets (see box 11.21).

Grants can catalyze the formation of institutions for collective action. These, in turn, become the means for sustainably managing numerous goods and services. Many argue that establishment of viable institutions for collective action is the primary goal of CDD programs. Accordingly, the determining factor in whether or not to use grants may be the institutional outcome envisaged and not the individual goods and services produced, which may only be stepping stones to building institutions for collective action.

\section{LESSONS LEARNED AND RECOMMENDATIONS FOR PRACTITIONERS}

The CDD approach may encourage collective action for the purchase of inputs, technical support, and marketing. The logic of collective action is to bring new options to communities that are not open to individuals acting alone. Often collective action is in everyone's interest, but it may not be in any individual's interest to take on the cost of organizing the collective action. Certain investments are often needed to

\section{Box II.20 Suggested guidelines for providing grants for income}

\section{generating activities}

- Target grant assistance to very poor communities or groups that are beyond the current reach of microfinance institutions. One way is to make the grant amount large enough to be useful to the poorest, but too small to be worthwhile for better-off groups.

- Grants should be combined with training and support to establish local savings and credit associations to capture increased income flows and finance future income generating activities (IGAs).

- IGAs financed must be cost effective, as demonstrated by impact and cost effectiveness indicators.

- The investments should not compete directly with private investment (existing or likely).

- Beneficiaries should contribute to projects, with at least part of the contribution in cash (no less than 5 percent of total project cost). Over generous subsidies create false positive demand, and may jeopardize future maintenance of investments by beneficiaries. Subsidies can be structured so that the poor make lower contributions, but this may have a negative effect on their ability to assert and defend their rights to flow of benefits.

- If the economic returns to a subproject are higher than the financial returns, one can assume that some level of subsidy is justified, the social returns being greater than the private returns.

- If the profile of revenues is skewed so that returns do not accrue for some years after investment (for example, forestry, tree crops), a subsidy to encourage adoption can be justified.

- Subsidies used without tied commitments for repayment, user fees, or maintenance, may create perverse incentives for greater rent-seeking by beneficiaries.

Source: McKean and Ostrom 1995.

Box II.2I Income-generating activities for the absolute poor - innovative examples

The design of community driven development projects can address the difficult issue of income generation for beneficiaries with no assets:

- In a current project in India, a group of landless poor applied for a grant from a village fund for poultry. The proposal was not simply to purchase poultry, but to manage a poultry unit in a different way. One group member asked for training to market eggs; another specialized in transport; and another specialized in animal health. This approach proved potentially more profitable than simply asking for a grant to buy poultry.

- In another project, a village received a grant for irrigation. Although not everyone owned land, every member of the community contributed to the subproject and owned water rights. The landless were able to lease their water rights to landowners, thereby generating some income.

Source: Ethel Sennhauser and Philippe Dongier, personal communication. 
Box II.22 Demand-driven agricultural service funds

The demand-driven agriculture services fund is part of support to rural producer organization (PO) capacity in agricultural services projects in Senegal and Burkina Faso. Funds allow POs to access public or private services to improve farming practices or develop off-farm income-generating activities. Key implementation responsibilities are shared as follows.

- Local POs prepare capacity-building subproject proposals on the theme of their choice, requesting funding for training, advisory services, or small productive investments. POs submit proposals to a provincial forum composed solely of $\mathrm{PO}$ leaders.

- Facilitating NGOs help POs to form regional forums. The NGOs (i) disseminate information, (ii) help POs select representatives at the village and local level, (iii) assist them to elaborate operating rules, (iv) maintain a database of eligible service providers, (v) train PO leaders and farmers on subproject selection procedures, and (vi) monitor program progress.

- The Project maintains records on subprojects, prepares contracts with POs, transfers funds to their bank accounts, and organizes technical and financial audits of subprojects.

The Burkina Faso project over five years financed approximately I,250 capacity building subprojects, including 250 demanddriven agricultural extension subprojects. Financial audits have shown that funds were well managed, and demonstrated that POs have the ability to elaborate and implement subprojects. In Senegal, after the first 20 local farmers forums had been in place for less than a year, they had already financed 187 subprojects, 53 percent of which were for training and 38 percent for agricultural innovation testing.

Source: Pierre Rondot, personal communication.

complement the CDD approach. Targeted capacity-building efforts, for example, are needed for participatory appraisal at the grassroots and local government levels to ensure that local development plans are properly articulated (see box 11.22). These may require the use of NGOs or private companies experienced in local development. Public extension services may perform this role, although considerable efforts may be needed to sensitize personnel to participatory techniques and a demand-driven mentality. Technical support services may need to be strengthened to cope with new demand from the CDD program.
Some investments needed to overcome constraints to development may not figure in community proposals, because they are too expensive (large public goods); benefit only individuals (some private goods); or are too long term (natural resource management). Projects may need to consider complementary funding windows for larger infrastructure that needs to be planned and implemented above the community level (see box 11.23).

The CDD approach is not a panacea for agriculture or development in any other sector, but is becoming increasingly important as a way to

\section{Box II.23 Ethiopia: Funding windows to match needs}

The Pastoral Community Development Project in Ethiopia promotes sustainable livelihoods, improved services, and reduced vulnerability to drought by combining the CDD approach with:

- A community investment fund (up to US\$10,000 per community) with an open menu of possible microprojects to support nomadic lifestyles or diversification away from livestock.

- A drought preparedness fund (up to US\$80,000 per district) for local governments to implement larger infrastructure works that help pastoral communities cope with drought.

- A support services component aimed at increasing the capacity of public services (in water supply, animal health, education, and extension) to meet needs of pastoral communities.

Source:World Bank 2003. 
channel funds to the grassroots level. It increases the likelihood that such funds are used to meet the real demands of rural communities, and makes resulting investment more sustainable. Designers of projects that use the CDD approach to promote agricultural income generation will need to ensure that the financial instruments are compatible with the existing rural financial sector, and that complementary technical support services are present or provided by the project.

\section{SELECTED READINGS}

Asterisk (*) at the end of a reference indicates that it is available on the Web. See the Appendix for a full list of Web sites.

Castillo, C. P., and R. Lema. 1998. "Economic Analysis of Social Investment Fund Projects: Case Studies and Minimum Requirements Proposal." Report prepared for Latin America and the Caribbean Region Human Development. World Bank, Washington, D.C. Processed.*

de Silva, Samantha. 2002. "Communities Taking the Lead: A Handbook on Direct Financing of Community Subprojects." World Bank, Washington, D.C.*

van Zyl, J., T. Barbosa, A. N. Parker, and L. Sonn. 1995. "Decentralized Rural Development and Enhanced Community Participation: A Case Study from Northeast Brazil." Policy Research Working Paper 1498. World Bank, Washington, D.C.*

World Bank. Community Driven Development. http://www.worldbank.org/cdd.

\section{REFERENCES CITED}

Goldman, I. 2003. "Models of Working with Local Government: Mainstreaming Participation and Community Planning into Public Structures in Sub-Saharan Africa." Presentation to the World Bank, sponsored by Community Based Rural Development Community Driven Development Social
Funds, June 26. See related web resources at http://www.khanya-mrc.co.za/.

McKean, M., and E. Ostrom. 1995. "Common Property Regimes in the Forest: Just a Relic From the Past?" Unasylva 46 (180): 3-15.

Parker, A. N. 1995. "Decentralization: They Way Forward for Rural Development?" Policy Research Working Paper 1475. World Bank, Washington, D.C.

World Bank. 2003. "Ethiopia: Pastoral Community Development Project." Project Appraisal Document. World Bank, Washington, D.C.

This Note was prepared by Daniel Sellen, Talib Esmail, and Melissa Williams. 
AGRICULTURE INVESTMENT NOTE

MONITORING AND

EVALUATION: MEASURING

AND ASSESSING

AGRICULTURAL DEVELOPMENT PROGRAMS

Monitoring and evaluation (M\&E) are integral tools for assessing the efficiency and effectiveness of investment operations.? Designing M\&E systems must start early in project preparation and be put into effect from the beginning of implementation. Early definition of project objectives, identification of sound performance indicators and clear reporting requirements are important to effective $M \& E$ systems. Baseline studies and benchmark indicators can provide the basis for the M\&E process. Agricultural investment operations need to identify responsible institutional locations for M\&E responsibilities and ensure availability of adequate qualified staff with ownership of the M\&E system.

Invariably, PADs discuss M\&E at the end of the reporting requirements, and supervision missions-mostly occupied with institutional, procurement and financing issues-relegate $M \& E$ discussion to a minor element in progress reports. Both the World Bank QAG and the OED have consistently pointed out that attention is urgently needed to strengthen M\&E systems and to improve performance and impact measurement. An Agricultural Knowledge and Information Systems (AKIS) thematic group review of agricultural research and extension projects found that only about 25 percent of the projects reviewed had adequate M\&E plans (World Bank, 2003). M\&E issues as they relate to potential for scaling up are highlighted in the Overview of each module in this Agricultural Investment Sourcebook. This note summarizes key aspects of M\&E that should be considered in the design and implementation of agricultural operations.
MONITORING AND EVALUATION SYSTEMS

Monitoring is defined as "the continuous assessment of project implementation in relation to agreed schedules and the use of inputs infrastructure, and services by project beneficiaries" (Operational Directive (OD) 10.70). Evaluation is defined as "the periodic assessment of the relevance; performance, efficiency, and impact (both expected and unexpected) of the project in relation to stated objectives" (OD 10.70).

M\&E makes it possible to assess the links between lending assistance and development outcomes, and whether development objectives have been met. A well-designed M\&E system is characterized by clear objectives for investment outputs and outcomes, and for sector/social impacts. This typically requires:

- Clear and measurable performance indicators;

- A robust risk management system through well-identified assumptions about possible risks and ways to monitor, mitigate and manage them;

- Clear responsibility for data collection and management;

- A realistic agreement with the borrower, keeping in view the borrower's capacity to manage the proposed M\&E system, and opportunities for capacity building as a part of the operation;

- A good incentive environment with clear accountability; and

- Provision for annual review of the M\&E system to provide information on local constraints so that adjustments can be made in the project's implementation.

Monitoring focuses on project inputs, outputs, and outcomes, whereas periodic evaluation (such as the mid-term review, completion reports, beneficiary assessments, impact studies,

9. This note draws from the M\&E sections of the Agricultural Sourcebook modules and World Bank. 2003. "Monitoring and Evaluation Component in Agricultural Operations: A Toolkit." Agriculture and Rural Development Department Draft. World Bank, Washington, D.C. 
etc.) establishes causality and attribution. M\&E must be an integral part of the project design, not a peripheral item added as an afterthought. A well-designed M\&E system provides data on the progress of the project and whether it is meeting its objectives. This data may then require adjustments to the project to take into account different circumstances in the local environment. M\&E, with its focus on the project's objectives and its beneficiaries, contributes to the accountability of those implementing the project. The M\&E system also helps in clarifying objectives and improves accountability to stakeholders (see box 11.24).

\section{DESIGN OF SOUND MONITORING AND EVALUATION SYSTEMS}

Bank experience shows that use of the "logical framework approach" or its recently refined version "Results Framework" is an essential tool for development of a sound M\&E system.

Effectiveness is enhanced by:

- Participatory approaches to M\&E during both the design and implementation phase;

- Clear identification, at the project design stage, of data requirements and a workable plan (agreed to with the Borrower) for obtaining this data;

- Careful selection of a manageable number of good quality performance indicators;

- Preparation of a user-friendly project/ program-specific M\&E operations guide;

- Testing of the M\&E system in the first year of implementation to adapt it to local realities; and

- Annual reviews to make changes as appropriate.

The LOGICAL FRAMEWork AND M\&E. The logical framework (Log Frame) used since 1997 has been further refined as a "Results Framework" that essentially consists of a 16-box matrix to structure a project design (World Bank 2003).
Box II.24 World Bank monitoring and evaluation requirements

The Bank requires systematic monitoring and evaluation (M\&E) of both program and project lending (Operational Directive 10.70 and Operational Policy (OP)/Bank Procedure (BP) 13.05). Among other things, OD 10.70 sets out the concept of $M \& E$, and provides general guidance on the design and implementation of the information systems required for M\&E activities. OP I 3.05 explains the rationale for Bank's supervision of Bankfinanced projects, which includes monitoring, evaluative review and reporting. BP 13.05 explains the responsibilities of Task Teams (TT), and requires that the borrower and the TT agree on implementation arrangements, including M\&E arrangements, and use of appropriate performance indicators.

Source:World Bank Operational Manual.

The Logframe (see table 11.3) is used to: link with the country social goals; set project objectives; define performance indicators; distinguish between project impact and project

deliverables; define critical assumptions and risks on which the project is based; define the system for monitoring, evaluation and supervision; identify the basic component clusters for implementation planning; and define resources required for implementation.

Taken together, these core concepts provide an organizational framework for summarizing the fundamentals of the project. The Logframe does not replace or substitute for traditional analytical tools and methods. Instead, it provides a structure for using those tools productively and collaboratively.

Key PERformance indicators. Performance indicators are measures of project inputs, processes, outputs, outcomes and impacts that are monitored during project implementation to assess the project's achievements. Performance indicators should be ("SMARTS"): simple and easily defined; measurable; attributable; realistic; targeted; and specific. Indicators are classified by their level in a logframe: i) input indicators which measure physical and financial cost estimates needed to produce certain outputs; ii) output indicators which measure the results of using project inputs; iii) outcome indicators that measure progress in achieving project development 
Table I .3: Logical framework for project design and evaluation

\begin{tabular}{|c|c|c|c|}
\hline Narrative Summary & Performance Indicators & M\&E/ Supervision & Major assumptions \\
\hline $\begin{array}{l}\text { Impacts CAS Goal: } \\
\text { Higher objective to } \\
\text { which project will } \\
\text { contribute }\end{array}$ & $\begin{array}{l}\text { Indicators } \\
\text { (increasingly standardized) } \\
\text { to measure social change }\end{array}$ & $\begin{array}{l}\text { National databases; } \\
\text { program evaluation } \\
\text { system }\end{array}$ & $\begin{array}{l}\text { (Goal to Super Goal) } \\
\text { Risk regarding } \\
\text { strategic impact }\end{array}$ \\
\hline $\begin{array}{l}\text { Outcomes Development } \\
\text { Objective (DO) } \\
\text { Change in beneficiary } \\
\text { behavior, systems or } \\
\text { institutions }\end{array}$ & $\begin{array}{l}\text { Measures of } \\
\text { accomplishment of } \\
\text { the DO.The value, } \\
\text { benefit and return } \\
\text { on investment }\end{array}$ & $\begin{array}{l}\text { People, events, processes, } \\
\text { sources of data for } \\
\text { organizing the project } \\
\text { evaluation system }\end{array}$ & $\begin{array}{l}\text { (DO to CAS Goal) } \\
\text { Risk regarding } \\
\text { program level } \\
\text { impact }\end{array}$ \\
\hline $\begin{array}{l}\text { Outputs Products } \\
\text { of project activities. } \\
\text { What the project } \\
\text { can be held } \\
\text { accountable for }\end{array}$ & $\begin{array}{l}\text { Indicators that measure } \\
\text { the value added } \\
\text { of implementation } \\
\text { of the component }\end{array}$ & $\begin{array}{l}\text { People, events, } \\
\text { processes - program } \\
\text { management information } \\
\text { system }\end{array}$ & $\begin{array}{l}\text { (Output to DO) } \\
\text { Risk regarding } \\
\text { design effectiveness }\end{array}$ \\
\hline Components & Input/Resources & Program management & (Component \\
\hline $\begin{array}{l}\text { Resources used for } \\
\text { activity clusters } \\
\text { needed to accomplish } \\
\text { outputs }\end{array}$ & $\begin{array}{l}\text { Budget: financial, } \\
\text { physical, and human } \\
\text { resources required to } \\
\text { produce the outputs }\end{array}$ & information system & $\begin{array}{l}\text { to Output) } \\
\text { Risk regarding } \\
\text { implementation } \\
\text { and efficiency }\end{array}$ \\
\hline
\end{tabular}

objectives and particularly at completion; and iv) impact indicators which assess primarily project development impact usually after completion. The fewer the number indicators the better, with around six indicators in each category. In many projects the number of indicators grows beyond the capacity of staff resources. In these cases data collection predominates and reduces the time for reflection, evaluation and chartering new steps.

\section{MAJOR ISSUES IN MONITORING AND EVALUATION OF AGRICULTURAL PROJECTS}

LAG TIME FOR IMPACT. Many agricultural projects (for example, irrigation and research) have long gestation periods and impact on the sustainability of natural resources and poverty reduction can only be determined years after project completion. The project's impact is also affected by the variability of agricultural production and incomes due to weather and prices.

Project cycle And M\&E. M\&E systems must be part of initial design with its own chapter in the project implementation manual setting out its management information systems and plan for use of data. The mid-term review should undertake a detailed review of M\&E methodology and indicators. This Review assesses the likelihood of achieving the project's development objectives or whether changes are needed.

PARTICIPATORY M\&E. Involvement of stakeholders-particularly beneficiaries-in design and implementation of M\&E systems is important to ensure ownership of results. Approaches to the inclusion of stakeholders, with their valuable local knowledge, in evaluation, are improving. Such approaches are particularly 
critical for activities requiring extensive community participation (for example, CDDtype initiatives).

BASELINE STUDIES. Baseline surveys and studies provide benchmarks for measuring impact. However, frequently, baseline surveys are completed after project start-up and well into the implementation phase. This should be avoided. Appointing M\&E staff early in preparation is important if baseline studies are to be effective. Alternative means of assessing program results against baselines or controls are listed in box 11.25.

M\&E STAFFing AND BUdGeting. Funding for M\&E activities must be ensured, particularly for staff training and baseline studies. Retroactive financing of M\&E costs may be needed to cover baseline study costs. Selection of adequate numbers of qualified staff and funding for impact studies and beneficiary assessments, is essential to starting M\&E systems on a solid foundation. M\&E staff must avoid being seen as a police unit monitoring project management and financial conduct (this is the task of the auditors and project accountants). M\&E staff should function as an integral part of program management and institutional planning units to anticipate needed changes and provide advice when requested.

\section{RECOMMENDATIONS FOR PRACTITIONERS}

- M\&E costs should be distinct from other project management costs and should provide detailed budget items for staffing, training, technical assistance, studies, workshops, and equipment. During project identification and preparation early decisions on data collection should be undertaken, this being used for finalizing baseline surveys and studies needed for appraisal.

- The evaluation process particularly at midterm review and project completion should be transparent. Evaluation reports should be discussed in special workshops with representation from project stakeholders.

\section{Box I .25: Methods for Establishing Controls for Impact}

\section{Assessment}

- Randomized controls: Farmers or other beneficiaries are randomly placed into two groupsæthose affected by the program and those not. Program impact is assessed by comparing outcome variables.

- Constructed controls: Program participants are paired with an equivalent group not affected by program activities.

- Statistical controls: Program participants and nonparticipants are compared after correcting for other characteristics that differ statistically between the two groups.

- Reflexive controls: Data on program participants are compared before and after program assistance.

- Generic controls: Data on program participants are compared with established norms for changes occurring in the target population.

- Shadow controls: Actual changes in data for program participants are compared with estimates of what is normally expected based on judgement of experts, program administrators, or participants.

Source: Rossi and Freeman (1982) as summarized in Ezemenari and others (1999).

- Support to funding agencies (for example, competitive grants programs) must establish realistic and clearly understood performance measurement mechanisms.

- Measuring performance of agricultural projects must include indicators to assess output and impact not only on beneficiaries but also contribution to the national economy and relevant agricultural strategies. In CDD and extension projects, establishing effective systems to monitor decentralized programs must ensure that the data are available at the appropriate levels.

- Investments in intensification of sustainable agricultural production, environmental management and land resources require holistic monitoring systems capable of critically evaluating economic, social, and environmental changes throughout and following program implementation.

- Public investments in agricultural private sector and market development should be 
evaluated against the objectives of poverty reduction, efficiency and sustainability.

- Since poverty reduction is the primary objective of Bank investments, monitoring of impacts on the poor, women, and minority groups need special attention, even though many poverty reduction impacts for these are likely to be indirect.

\section{SELECTED READINGS}

Asterisk (*) at the end of a reference indicates that it is available on the Web. See the Appendix for a full list of Web sites.

AKIS. 2000. "Monitoring and Evaluation for AKIS Projects: Framework and Options." AKIS Good Practice Note. World Bank, Washington, D.C.*

World Bank. 2003. "Monitoring and Evaluation Component in Agricultural Operations: A Toolkit." Agriculture and Rural Development Department Draft. World Bank, Washington, D.C.

World Bank. The Logframe Handbook: A Logical Framework Approach to Project Cycle Management. http://wbln1023/OCS/ Quality.nsf/Main/MELFHandBook/\$File/ LFhandbook.pdf.

\section{REFERENCES CITED}

Ezemenari, K., A. Rudqvist, and K. Subbarao. 1999. "Impact Evaluation: A Note on Concepts and Methods." Poverty Reduction and Economic Management Network Draft. World Bank, Washington, D.C.

Rossi, P. H., H. E. Freeman, and S. Rosenbaum. 1982. Evaluation: A Systematic Approach. 2nd ed. Beverly Hills, Calif.: SAGE Publications.

World Bank. 2003. "Monitoring and Evaluation Component in Agricultural Operations: A Toolkit." Agriculture and Rural Develop- ment Department Draft. World Bank, Washington, D.C.

World Bank. Operational Manual. http:// wbln0018.worldbank.org/institutional/ manuals/opmanual.nsf/.

World Bank. The Logframe Handbook: A Logical Framework Approach to Project Cycle Management. http://wbln1023/OCS/ Quality.nsf/Main/MELFHandBook/\$File/ LFhandbook.pdf.

This Note was prepared by Hamdy Eisa. 
INNOVATIVE ACTIVITY PROFILE

\section{MOZAMBIQUE: HARMONIZED DONOR FUNDING AROUND PRINCIPLES}

Following the end of civil war and severe drought in Mozambique in 1992-93, the agricultural sector grew by an annual average of 14 percent, albeit from a very low base. Although this rapid growth partly reflected a recovery effect, it was also due to gradual liberalization of macro and sectoral policies that started in 1987. Unfortunately, severe flooding in 2000 slowed this progress. Although the flood and cyclone disaster constituted a large exogenous shock to Mozambique's economy, the potentially large fiscal and monetary effects of this shock were kept under control by the authorities' commitment to macroeconomic discipline, as well as the generous response of Mozambique's external partners. Although interest rates are still high, they are stable and market determined, as is the exchange rate. Agricultural markets have been liberalized and government has withdrawn from direct intervention in most economic activities.

\footnotetext{
What's innovative? Harmonization of donor funding through two key mechanisms: notionally earmarking of funds contributed to a pooled account and review of annual budgets against a matrix of basic principles rather than a list of specific tasks to be completed.
}

The Mozambique Agricultural Sector Public Expenditure Program is a 5-year APL project to support the Ministry of Agriculture and Rural Development (MADER) in implementing the first phase of a 15-year National Agricultural Development Program (PROAGRI). Through this program, some 20 development partners agreed to support PROAGRI, and 11 are already providing direct budget support to MADER. This support is not targeted at predetermined activities, but rather for those activities selected through a MADER-led participatory process, and reviewed by the donor group against a set of agreed principles and milestones.

\section{PROJECT OBJECTIVES AND DESCRIPTION}

The objectives of PROAGRI are to:

- Improve institutional arrangements for financing and delivery of core public agricultural services.

- Strengthen the government's capacity within MADER, at provincial and at local levels, to provide core public sector functions for the agricultural sector in a costeffective manner.

PROAGRI is a US $\$ 200$ million phase of a longterm program aimed at supporting sectoral development goals, by consolidating the sectoral public expenditure program, rationalizing the role of MADER, and improving the effectiveness of MADER in policy formulation, regulation, and public service provision. PROAGRI includes all agricultural public expenditure managed by MADER. PROAGRI has successfully replaced fragmented donordriven projects with a comprehensive program consistent with the role of MADER in a market-based economy. PROAGRI has three subprograms: institutional development, agricultural support services, and natural resource management.

\section{BENEFITS AND IMPACTS}

Although strengthening MADER's institutional capacity is the main focus of the institutional development subprogram, MADER's activities in the field have been maintained and in some cases strengthened. However, it is too early to see the expected true impact of PROAGRI on farmers. Institutional reforms implemented under PROAGRI have laid the groundwork to make MADER's activities much more effective, and make it possible for the agricultural support services to be more relevant and scaled up through the involvement of diversified providers and the beneficiaries. Sixty percent of the 
financial resources have already been channeled to provinces and districts, leading to an unprecedented level of decentralization and the establishment of an institutional environment favorable to the achievement of field-based results in coming years. An environment has developed within the government and MADER to assume true Mozambican ownership of their agricultural programs. PROAGRI is being studied by other ministries for use in the design of a new government-wide financial management system.

With MADER in the driving seat, MADER and donors have developed a true partnership and efficient coordination. The strict observation of essential provisions of the Memorandum of Understanding, namely the regular auditing of MADER accounts and the adoption of internationally accepted procurement procedures, made PROAGRI path-breaking (both nationally and globally) in successful pooling of donor support.

\section{LESSONS LEARNED AND ISSUES FOR WIDER APPLICABILITY}

The key lesson is that a host country and a significant number of donors can develop and adopt common procedures for program planning, procurement, disbursement, audit, and review. Although complicated to set up, it is highly effective in building host country skills, capacities, and ownership. This greatly enhances donor coordination, and host ministry's ownership and accountability, constructing agreement around basic principles for development activities rather than on a list of specific tasks or deliverables. PROAGRI is considered a leading model of donor coordination and apparently is one of the first examples of the complete pooling of donor funding in support of a program, in this case an agriculture sector program.

True partnership, understanding the institutional dynamics, and persistent collaboration with the institution's leadership are essential ingredients to ensure the success of a sectorwide program particularly when the host ministry begins from a relatively weak institutional development stage. Furthermore, there is little doubt that through an adequate focus on decentralization, the Government of Mozambique (at the various institutional and territorial levels) has significantly strengthened its capacity to carry out core public functions for the agriculture sector. MADER, at various levels, is being transformed into a modern public sector institution increasingly capable of promoting and managing diverse sets of agricultural interventions. The pooling of donor funds around a commonly agreed set of principles of development for host countries has potential for wide applicability throughout the developing world.

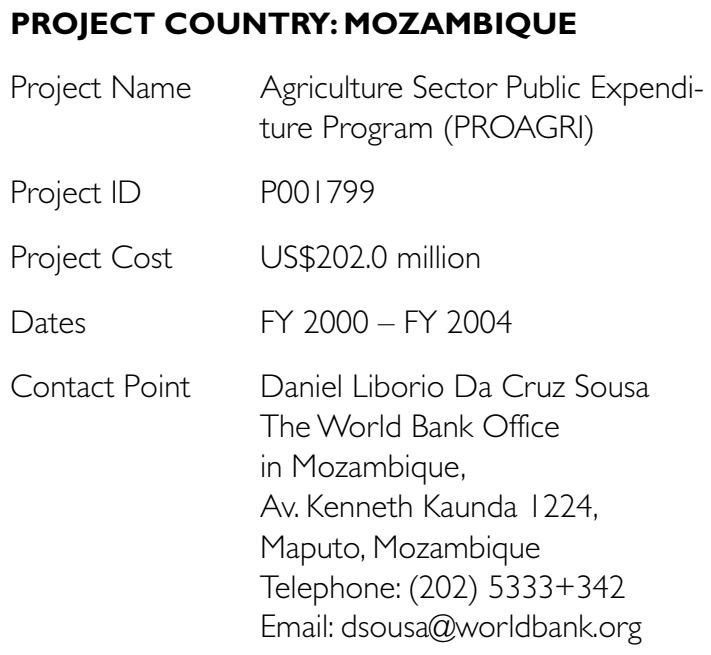


INNOVATIVE ACTIVITY PROFILE

\section{BRAZIL: EMPOWERING RURAL COMMUNITIES FOR POVERTY REDUCTION}

Northeast Brazil contains the single largest pocket of rural poverty in Latin America. The region comprises nine states and part of a tenth, with a population of 45 million (about 28 percent of Brazil's total population). About 16.8 million people in the Northeast live in rural areas, some 64 percent of whom live in extreme poverty. Development indicators paint a dismal picture of widespread misery, compared to the rest of Brazil. Poor rural families have limited access to land, water, markets, financial services, and other basic services. Adult illiteracy rates and the rates of chronic malnutrition of children are exceptionally high. The poor natural resource base and chronic drought exacerbate the problem of poverty. The overall result is a region widely characterized by poor social conditions and an agricultural system of low productivity, with modest input use and slow rates of technology adoption.

What's innovative? Sustainable rural poverty reduction through a decentralized approach to resource allocation, community participation, and creation of social capital.

\section{PROJECT OBJECTIVES AND DESCRIPTION}

The World Bank has been involved in supporting rural development and poverty reduction in Northeast Brazil since the mid 1970s. The emphasis shifted successfully from a set of rural and agricultural development objectives to poverty reduction objectives based on decentralization, matching grants, participation, and ownership. The era of CDD started with a small but successful pilot component of the Northeast Rural Development Program (NRDP) in 1985. In this component, resources were transferred directly to community associations. The activities were financed through a Fund for Community Support covering three "lines" of operation: (i) mobilization and organization of producers and communities; (ii) productive subprojects, including agricultural production, agro-processing and handicrafts; and (iii) investments for use by the larger community, mainly for infrastructure.

This component became the template for a radical program reformulation of NRDP (RNRDP), which was virtually paralyzed by fiscal crises and weakened administrative capacity. The NRDP projects were transformed in their entirety into a community-based development program, drawing on and scaling up the successful experience of the original component. R-NRDP covered not only those individuals with productive assets but all members of poor rural communities based on a matching grant mechanism linked to beneficiary contributions toward subproject costs. These matching grants were provided directly to community associations to finance small-scale subprojects identified by the association in a participatory manner. Two different delivery mechanisms for screening, approving, and implementing community subprojects were established. First, under the state community schemes (PAC), rural communities submitted subproject investment proposals directly to their State Technical Agency which screened, approved, and released funds directly to the communities. Second, under the pilot municipal community scheme (FUMAC), subprojects identified and prepared by rural communities were presented to Municipal Councils for approval. The Councils themselves screened and submitted subprojects to the agency for subsequent financing.

The NRDP projects were closed between 1995 and 1997, and progressively replaced by the ongoing Rural Poverty Alleviation Projects (RPAP) in eight Northeast states. These projects incorporate the lessons of the NRDP and other similar Bank CDD programs, expand successful aspects of the NRDP, and enhance decentralization. Community subprojects (broadly classified as infrastructure, productive, and social) and institutional development are the main components of RPAP. The FUMAC approach has become the central mechanism under the RPAP. In addition, another delivery mechanism, the 
Pilot Municipal Community Funds (FUMAC-P), was introduced. Moving from PAC to FUMAC to FUMAC-P represents increasing degrees of decentralization of decisionmaking and resource allocation responsibilities.

\section{BENEFITS AND IMPACTS}

The primary goal of the R-NRDP and RPAP - to alleviate poverty through the provision of basic economic and social infrastructure and income generation - is being achieved. The socioeconomic benefits are significant: more than 44,000 subprojects ( 77 percent infrastructure, 20 percent productive, and 3 percent social) were completed, benefiting about 7.5 million people in the long term and in a sustainable manner. These investments generated some 100,000 additional permanent jobs, and the cultivated area was increased by more than 80,000 hectares. Moreover, these investments generated additional, sustainable, annual income or savings of more than US\$200 million. Typical tractor and small-scale irrigation subprojects yield annual net income or savings exceeding US $\$ 20,000$. Another impressive aspect is the low overhead costs of 7 percent of total funds, with 93 percent going directly to the communities.

The social capital created by the programs, and the sustainability of these impacts, are essential in assessing the benefits. One of the primary achievements has been the support of a decentralized approach to resource allocation. The subproject development and approval process that was captured in the project design strengthened the capacity of both communities and municipal governments to prioritize investment decisions. Municipal governments are now more accustomed to participatory decisionmaking, with the community associations increasingly willing to voice their needs.

\section{LESSONS LEARNED AND ISSUES FOR WIDER APPLICABILITY}

R-NRDP and RPAP provide the following general lessons for rural development and specific lessons for project design and implementation:
- The decentralization of fiscal and investment decisionmaking from federal to state and local governments and to community organizations ensures efficient program administration and positive results.

- Enhanced participation in the financing of the subprojects generates a sense of ownership and a willingness to share responsibilities for project tasks, especially for the Operation and Maintenance of project investments.

- Poverty-targeting mechanisms should be simple and easily monitored. FUMAC and particularly FUMAC-P experiences demonstrated that communities themselves are the best positioned and informed to target effectively.

- Technical assistance should be provided to rural communities to enable them to identify and implement their own subprojects.

- Project sustainability improves when municipalities and communities contribute to project financing through cost-sharing arrangements, and when increased beneficiary participation is a substantial pillar of project design.

\section{PROJECT COUNTRY: BRAZIL}

$\begin{array}{ll}\text { Project Name } & \begin{array}{l}\text { Northeast Rural Development } \\ \text { Program (NRDP); } \\ \text { Reformulated Northeast Rural } \\ \text { Development Program (R-NRDP); } \\ \text { Rural Poverty Alleviation Program } \\ \text { (RPAP) }\end{array} \\ \text { Project Cost } & \text { R-NRDP and RPAP: } \\ & \text { US\$800 million } \\ \text { Dates } & \text { R-NRDP and RPAP: } \\ & \text { I993 - present } \\ \text { Contact Point } & \text { Luis O. Coirolo } \\ & \text { The World Bank, I8I8 H Street } \\ & \text { NW,Washington D.C. 20433 } \\ & \text { Email: Icoirolo@worldbank.org }\end{array}$


INNOVATIVE ACTIVITY PROFILE

\section{UGANDA: CROSS-SECTIONAL PROGRAMMATIC ADJUSTMENT LENDING FOCUSING ON POVERTY REDUCTION}

Eradication of poverty is the number one priority on Uganda's development agenda. Despite a significant progress in poverty reduction in the 1990s, 35 percent of the population still lives below the poverty line. Poverty is mainly a rural phenomenon: 85 percent of the Ugandans and 96 percent of the country's poor live in rural areas. Agriculture remains the backbone of Uganda's economy accounting for 43 percent of the GDP, and 80 percent of employment. Hence, increasing agricultural growth rates, diversifying agricultural production, and expanding non-farm employment are essential for effective poverty reduction.

What's innovative? Series of single-tranche programmatic structural adjustment credits that support the implementation of PRSP, and involve extensive consultations and donor coordination

In response to these challenges, the government developed a Poverty Eradication Action Plan (PEAP); a home-grown medium-term development plan to guide government policy and the development of sector and district plans. The overarching goal of PEAP is to reduce poverty to 10 percent or less by the year 2017. The specific goals include achieving universal access to primary education, primary health care and safe drinking water. As part of PEAP, through a broad-based consultative process, the government developed the Plan for Modernization of Agriculture, which promotes the transformation of subsistence agriculture to commercial agriculture. Because PEAP's objectives are fully consistent with the PRSP process, a summary of the PEAP was used as a basis for the Uganda PRSP.

\section{OBJECTIVES AND DESCRIPTION OF POVERTY REDUCTION SUPPORT CREDITS}

The Uganda Poverty Reduction Support Credit (PRSC) is a series of single-tranche programmatic structural adjustment credits to support the implementation of PEAP/PRSP. The first PRSC (PRSC1) established a rolling mediumterm policy framework that set out a three-year reform program with performance benchmarks, policy measures, and outcome targets. Subsequent PRSCs have refined and expanded the program, each adding a new year to the threeyear rolling program. The reform program selectively focuses on policy and institutional reforms in PEAP/PRSP with the highest poverty impact.

The objective of the reform program supported by PRSC is to improve public service delivery because weak public sector performance is one of the main constraints to economic development and poverty reduction. The reform program supports activities that improve access to and quality of education, health, water and sanitation, and rural services, aiming to raise quality of life and incomes of the poor. Since increasing access to and quality of these services requires more broad-based action than only addressing sector-specific constraints to their delivery, the program focuses heavily on activities enhancing efficient and equitable use of public resources and promoting good governance. The following key areas of reform support the implementation of the Plan for Modernization of Agriculture:

- Improve responsiveness and impact of publicly funded research;

- Increase access and effectiveness of agricultural advisory services;

- Develop the legal and regulatory framework governing microfinance, and improve operating capacity of microfinance institutions;

- Implement the 1998 Land Act in a prioritized manner and promote access to land by women and orphans; 
- Integrate environmental sustainability concerns in all government programs;

- Improve the network of district roads.

\section{BENEFITS AND IMPACTS}

Implementation of reforms in basic service sectors (education, health, water and sanitation) has proceeded broadly as planned. The net primary school enrollment has increased from 76 percent and 85 percent in 1999 to 83 percent and 90 percent in 2002 for the poorest and richest quintiles, respectively, with equal numbers of boys and girls. HIV/AIDs prevalence rates have declined and safe water coverage has increased from 46 percent in 1999 to 55 percent in 2002 .

The government has also made progress with structural reforms in the area of rural development. Preparations for a comprehensive reform of agricultural research delivery have been made, and a new strategy promoting more demand-driven agricultural research has been developed. The multi-donor supported $\mathrm{Na}$ tional Agricultural Advisory Services program promotes a comprehensive reform of agricultural extension services, and is a demanddriven program where public funds are channeled to farmer fora at the sub-county level to contract the services of farm advisors. Arrangements to implement land reforms have also been established.

\section{LESSONS LEARNED AND ISSUES FOR WIDER} APPLICABILITY

- The rolling nature of the policy framework enhances predictability of resource flows and improves the Bank's ability to carry out continuous policy dialogue with the Government on a key set of issues and monitor progress towards meeting agreed outcomes.

- PRSC has turned out to be a mechanism to bring donors together, and to harmonize donor practices. A large number of other donors have linked their budget support disbursements to the PRSC reform program, and PRSC missions have become joint donor missions.

- A series of PRSCs can be an effective mechanism to address comprehensively sector-level and system-wide reforms.

- The shift to PRSCs is also attractive in that it is consistent with the Comprehensive Development Framework approach and directly links the PEAP/PRSP and Bank Group's assistance program in Uganda.

\section{PROJECT COUNTRY: UGANDA}

$\begin{array}{ll}\text { Project Name } & \begin{array}{l}\text { Poverty Reduction Support Credit } \\ \text { I and II }\end{array} \\ \text { Project ID } & \text { PRSCI: P050438 } \\ & \text { PRSC 2: P07367I } \\ & \text { PRSC3: P07408I } \\ \text { Credit Amount } & \text { PRSCI: US\$ I50 million } \\ & \text { PRSC2: US\$ I50 million } \\ \text { Dates } & \text { PRSCI: Presented to the Board in } \\ & \text { May 200 I } \\ & \text { PRSC2: Presented to the Board in } \\ & \text { July 2002 } \\ & \text { PRSC3: Presented to the Board in } \\ & \text { September 2003 } \\ & \text { Satu Kahkonen } \\ & \text { The World Bank, I8I8 H Street } \\ & \text { NW,Washington D.C. 20433 } \\ \text { Contact Point } & \text { Telephone: (202) 473-2 I70 } \\ & \text { Email: skahkonen@worldbank.org }\end{array}$




\section{APPENDIX: KEY WEBSITES}

This list provides the websites where further material (including that listed within the "Selected Readings" sections within this Sourcebook) for readers seeking information about investing in agriculture for poverty reduction. It is not intended to be comprehensive but reflects the main sources for the selected readings. 
BASIS Collaborative Research Support Program

Blackwell publishing-Blackwell Synergy

CIMMYT International Maize and Wheat Improvement Center

Community Integrated Pest Management

CSIRO Land and Water

DFID (UK Department for International

Development)

eldis - Gateway to Development Information

European Centre for Development

Policy Management

European Forum on Rural Development

Cooperation

Food and Agriculture Organization

Game Management Africa

Gesellschaft fuer Technische Zusammenarbeit

(GTZ; German Aid Agency)

Institute of Development Studies.

Inter-American Development Bank -

Sustainable Development Department

International Food Policy Research Institute

International Land Coalition

International Service for National Agricultural

Research

Johannesburg Summit 2002

LEAD (Livestock, Environment and

Development Initiative) http://www.basis.wisc.edu/ and

http://www.basis.wisc.edu/pubs.html

http://www.blackwell-synergy.com/servlet

useragent?func $=$ show Home

http://www.cimmyt.org/

http://www.communityipm.org/

http://www.clw.csiro.au/ and

http://www.clw.csiro.au/publications/

http://www.dfid.gov.uk/

http://www.eldis.org/

http://www.ecdpm.org/

http://www.ruralforum.info/

http://www.fao.org/ and

http://www.fao.org/publishing/

http://www.gameranching.co.za/gameranching/

http://www.gtz.de/

http://www.ids.ac.uk/ids/

http://www.iadb.org/sds/ and http://www.iadb.org/

sds/publication_list_e.htm

http://www.ifpri.org/

http://www.landcoalition.org/

www.isnar.org and

http://www.isnar.cgiar.org/publications/

http://www.johannesburgsummit.org/html/

documents/documents.html

http://www.virtualcentre.org/selector.htm 
MicroSave Africa

National Bureau of Economic Research

OECD

Organic Consumers Association

Overseas Development Institute

Proceedings of the National Academy of

Sciences of the United States of America

Provention Consortium

ReliefWeb

Rural Development Institute

Stanford University: Institute for

Environmental Science and Policy

Sustainable Development International

Swiss Center for Agricultural Extension and

Rural Development

The Consultative Group to Assist the Poor

The International Center for Tropical Agriculture

The Microfinance Gateway

UNDP

United States Agency for International Development

University of Chicago Press

University of Florida - Geomatics

University ofWisconsin-Madison:

Land Tenure Center

World Bank Documents and Reports

World Bank Publications

World Bank Research

WTO
http://www.microsave-africa.com/home.asp?ID=I5

http://www.nber.org/

http://www.oecd.org/home/

http://www.organicconsumers.org/

http://www.odi.org.uk/ and

http://www.odi.org.uk/fpeg/publications/

http://www.pnas.org/

http://www.proventionconsortium.org/

http://www.reliefweb.int/w/rwb.nsf

http://www.rdiland.org/HOME/index2.html

http://iis-db.stanford.edu/featuredpublications.lhtml

http://www.sustdev.org/

http://www.lbl.ch/

http://www.cgap.org/ and

http://www.cgap.org/publications.html

http://www.ciat.cgiar.org/

http://www.microfinancegateway.org/

http://www.undp.org/

http://www.usaid.gov/

http://www.press.uchicago.edu

http://www.surv.ufl.edu/ and

http://www.surv.ufl.edu/publications/

http://www.wisc.edu/ltc/ and

http://www.wisc.edu/ltc/pubs.html

http://www-wds.worldbank.org/

http://publications.worldbank.org/ecommerce/

http://econ.worldbank.org/

http://www.wto.org/ 



\section{INDEX}

Accountability

client organization, 132

to clients, 112

research institution and researcher, 63

Ad valorem tariffs, 24

Adaptable program lending (APL), 221, 449

Adjustment lending

benefits of, 33

cross-sectional programmatic, 489-490

explanation of, 32-33

lessons learned from, 34-35

policy and implementation issues related to, 33-34

recommendations related to, 35-36

in transitional economies, 47-48 use of hybrid, 51-52

Africa, 290-293. See also specific countries

Agribusiness

export systems in Mali and, 301-302

farmer partnerships in Columbia and, 299300

future directions for lending to, 265-268

horticulture exports and, 275-279

issues in investment in, 261-265

market challenges in Africa and, 290-293

market-led export in Bangladesh and, 295296

past investment activity in, 261

private fertilizer distribution and, 285-288

private seed enterprises and, 280-283 
rationale for investment in, 259-261

scaling up investments in, 268

smallholder cattle development and, 297-298

supply chain development and, 270-273

Agribusiness development centers (ADCs), 266, 267

Agricultural biotechnology. See Biotechnology

Agricultural development initiatives

agriculture sector program lending as, 470474

community-driven, 452-453, 475-479

cross-sectional programmatic adjustment lending as, 489-490

donor coordination as, 454

empowerment and, 487-488

explanation of, 451

harmonized donor funding as, 485-486

to maximize poverty impacts, 459-463

monitoring and evaluation of, 457-458, 480-484

poverty reduction support credits as, 453454

program lending as, 451-452

project design for performance maximization in, 465-469

scaling up, 10, 447-449, 454-457

support for, 449-450

Agricultural development strategy

benefits of, 12-13

changing context of, $\mathrm{xx}$

emphasis in, $x x i$

explanation of, 12

importance of, 7

lessons learned from, 14

policy and implementation issues related to, 13-14

practitioner recommendations and, 14-15

Agricultural insurance

approaches to, 418

benefits of, $427-428$

explanation of, 417,427

lessons learned from, 429-431

policy and implementation issues related to, 428-429

Agricultural intensification. See Sustainable agricultural intensification

Agricultural investments

establishment of supportive environment for, 29

in extension services (See Extension services)

future directions in, 59-66 in intensification (See Sustainable agricultural intensification)

past activity in, 57-59

poverty reduction through targeted, 456, 459-463

priorities for, 66

rationale for, $55-57$

Agricultural knowledge and information systems (AKISs)

explanation of, 58, 60, 65

role of, 108

university research and, 78

Agricultural lending

background of, 57-59

challenges of, $\mathrm{xx}, \mathrm{xxi}$

future directions for, 59-66, 108-115

Agricultural markets

benefits of functional, 291

investment needs for functional, 290-291

lessons learned for functional, 292-293

policy and implementation issues related to functional, 291-292

recommendations for functional, 293

Agricultural policy. See also Policy reform

developing capacity for formulation of, 1720

farmer organizational capacity to influence, 42-45

future investments in, 7-10

issues in, 3-7

past investments in, 2-3

rationale for investment in, 1-2

reform of, $\mathrm{xx}, 22-26,32-36$

scaling up investments in, 10

Agricultural productivity

diversification in, xxii

effects of resource degradation on, 154

growth in, 55

irrigation and, 346-348

natural resource use and, 56, 213

participatory microcatchment strategy for, 248-249

sustainable intensification and, 153

Agricultural project design

poverty reduction and, 465

recommendations for, 465-469

Agricultural Reform Implementation Project (ARIP) (Turkey), 51-52

Agricultural research. See also Agricultural investments 
accountability of, 63

background of lending for, 57-59

biotechnology and, 88-92, 99-100

capacity building and, 97-98, 101-102

common problems in, 59

competitive research funds and, 68-72

decentralization and, 95-96

decentralizing and deconcentrating, 61, 62

demand-driven, 103-104

economic returns on, 57

foreign research and development laboratories and, 93-94

local agricultural research committees and, 83-87

management of, 63

market trends and, 64

poverty reduction and, 64

priorities for, 63-64

public research organizations and, 73-77

role of farmers in, 61

scientist salaries in, 75

strategies for, 65

university participation in, 78-82

uptake pathways for, 65-66

Agricultural sector adjustment loans (ASALs)

Bulgaria and, 47-48

explanation of, 32-34

Agricultural sector program (ASP)

benefits of, 470-471

design and implementation issues related to, 471

explanation of, 470

lessons learned from, 471-473

recommendations for, 473-474

Agricultural Services and Producer Organizations Project (Senegal), 43

Agriculture

international agreements related to, xxii, 8

organic, 158, 179-183

precision, 158-159, 201

rainfed, 228

sustainable, 153-154

urban and periurban, 184-188

Web sites related to, 491-493

Agroforestry systems

benefits in, 234

explanation of, 233

investments in, 233-234

lessons learned from, 235-236

policy and implementation issues related to,
234-235

recommendations for, 236-237

Animal health services

benefits of improved, 39

lessons learned and, 40

overview of, 37

policy and implementation issues related to, $39-40$

recommendations to improve, 40

reforms to improve, 37-38

Aquaculture

benefits of, 174-175

explanation of, 174

income generation through, 208-209

investments in, 174

lessons learned from, 176

policy implementation issues for, 175-176

recommendations for, 176-177

sustainable growth and, 159

Argentina, 225

Arid rangelands, 238-242

Armenia

land policy in, 407-408

natural resource management in, 224

Bangladesh

agricultural research in, 1876

aquaculture in, 177

capacity strengthening in, 18

extension services in, 119, 120

fertilizer subsidies in, 285

market-led export in, 295-296

project design issues in, 465

Basis risk, 428. See also Risk management

Bedouins, 252-253

Biodiversity, 217, 223

Biodrainage, 367

Biopesticide industry, 197

Biosafety systems, 90

Biotechnology

benefits of, 89

biosafety frameworks and, 89-90

explanation of, 88-89

in India, 99-100

lessons learned from investments in, 91

policy and implementation issues related to, 90-91

recommendations regarding, 91-92

in South Africa, 160

Bolivia 
financial services in, 315

local agricultural research committees in, 86

Botswana, 399

Brazil

agricultural research in, 93-94

agroforestry in, 235

beekeeping in, 476

competitive research grants program in, 69

financial services in, 321, 330

irrigation systems in, 361-362

land reform in, 409-410

participatory microcatchment strategy in, 248-249

poverty reduction in, 462, 487-488

watershed management in, 229

Bulgaria, adjustment lending in, 47-48

Burkina Faso, 478

Cancun World Trade Organization (WTO)

Ministerial Meeting (September 2003), 25

Capacity development

future priorities for, $7-10$

importance of, 10

issues in, 3-7

overview of, $\mathrm{xx}-\mathrm{xxi}$

past support for, 2-3

for policy formulation, 17-20

rationale for, $1-2$

recommendations for, 20

for rural finance, 310-311

sustainability and, 18

Cash transfer programs, 419

Chemical use, 24

Chile

contracted extension services in, 118

university research in, 80

China

agroforestry in, 235

aquaculture in, 176

benefits of biotechnology in, 89

commercial plantations in, 250-251

extension services in, 126

fruit promotion in, 204-205

irrigation and drainage systems in, 350, 371, 374-375

smallholder cattle development in, 297-298

watershed management in, 256-257

Client groups

as extension services intermediaries, 129-133 types of, 129-130

Climatic risk, 414. See also Risk management

Colombia

agribusiness/farmer partnerships in, 299-300

competitive technology generation in, 95-96

land reform in, 403

risk management in, 424

rural producer organizations in, 43, 44

silvopastoral approach in, 254, 255

Commercial plantations, 250-251

Commodity exchanges, 423

Commodity price risk management

benefits of, 422

explanation of, 422

lessons learned from, 424-425

policy and implementation issues related to, 423-424

recommendations for, $425-426$

Common property rights, 390-391

Communications technology. See Information and communications technology (ICT)

Community-based land reform

benefits of, 403

elements of, 388-389, 402

goals of, 402-403

lessons learned from, 404-405

models of, 394

participatory negotiations and, 409-410

policy and implementation issues related to, 403-404

recommendations for, 405

Community-based natural resources management (CBNRM)

benefits of, 223-224

explanation of, 223

lessons learned from, 225-226

policy and implementation issues related to, 224-225

recommendations for, 226

Community-driven development (CDD)

explanation of, 452-453, 475

lessons learned from, 477-479

policy and implementation issues related to, 475-477

Competition

parastatal, 286

promotion of, 264

supply chain and, 260, 272

Competitive research grants programs (CRGPs) 
benefits of, 68-69

in Ecuador, 97-98

explanation of, 68

goverance structure for, 70

lessons learned from, 70-71

policy and implementation issues related to, 69-70

recommendations for, $71-72$

Conservation farming, 158

Conservation tillage (CT)

benefits of, 189-190

criticisms of, 190

development of, 189

explanation of, 189

lessons learned from, 191

policy and implementation issues related to, 190-191

recommendations for, 191-192

Consultative Group on International Agricultural Research (CGIAR), 57, 65

Consumer demand, xxii

Contract farming, 271

Contracts

enforceability of, 292

futures, 423

options, 423

Cooperatives, 267-268

Correlated/systemic risk, 428. See also Risk management

Costa Rica

organic agriculture in, 183

silvopastoral approach in, 254, 255

Cote d'Ivoire, agricultural research in, 75

Covariate risk, 428. See also Risk management

Credit

explanation of, 306, 308, 321

from input suppliers, processors, and buyers, 324-327

inventory, 342-343

Credit lines, 308-309

Crop diversification, 360-363

Crop insurance. See Agricultural insurance; Risk management

Dairy production. See Smallholder dairy production

Decentralization

agricultural growth and, 3-4, 9

explanation of, 124 of extension services, 124-128, 142-143, 146-149

global trends toward, 124

of natural resource management, 219

research, 74-75

Demand-driven agriculture service fund, 478

Derivatives, 424

Disaster planning, 419

Diversification

agricultural productivity and, xxii

explanation of, 159, 163

irrigation for crop, 360-363

market-driven, 163-167

policy and implementation issues related to, 164-165

Drainage systems. See Irrigation and drainage systems

Drought management

community-based, 437-439

explanation of, 241, 437

Dumping, 170

Economic risk, 414. See also Risk management Ecuador

capacity building and research in, 97-98

competitive research grants program in, 68

consultative councils for policy formulation in, 49-50

Egypt

horticultural exports in, 276

irrigation and drainage systems in, 365, 366, 376-377

Matruh resource management project in, 252-253

El Salvador, 180

Empowerment

entrepreneurship and, 266-267

farmer, xxi-xxii, 61

poverty reduction and, 42, 487-488

of rural producer organizations, 43-44

of water user associations, 355-358

Entrepreneurial poor, 308

Environmental assessment, 161

Environmental issues. See also Natural resource management (NRM)

agricultural productivity and, 56

agroforestry and, 234

chemical and fertilizer use and, 24

conservation tillage and, 189-191 
extension services and, 106, 115

importance of, 18-19

organic agriculture and, 180

pastoralism and, 238-239

sustainable agricultural intensification and, 157

urban and periurban agriculture and, 186

Environmental risk, 414. See also Risk management

Equity issues. See Gender equity

Estonia, 140-141

Ethiopia

community development project in, 478

fertilizer sector in, 288

maize market in, 290

watershed management in, 230

European Union (EU), 278

Exports

horticultural, 275-279

in Mali, 301-302

market-let, 295-296

Extension services

agricultural technology transfer and, 142-143

client groups as intermediaries in, 129-133

demand for services and, 112-113

developing sustainable financing mechanisms and, 111-112

economic characteristics and delivery mechanisms for different, 110

explanation of, 105

fertilizer market and, 288

improving quality of, 114

issues for investment in, 107-108

mass media and communications technologies in, 115, 135-138, 144-145

Millennium Development Goals and, 114115

outsourcing, 119

past investment activity in, 106-107

private goods element of, 110-111

public and private sector roles and, 108-110

rationale for investment in, 105-106

reform of government, 113-114

returns to investments in, 106

scaling up investments in, 116

transition to private advisory, 140-141

Extension services contracting

benefits of, 119

decentralized, 148-149 explanation of, 111, 118-119

lessons learned from, 120-121

policy and implementation issues related to, 119-120

Extension services decentralization

benefits of, 124-125

explanation of, 124

in India, 142-143

lessons learned from, 126-127

policy and implementation issues related to, 125-126

recommendations for, $127-128$

trends toward, 124

in Uganda, 146-147

Farmer Field School (FFS) approach, 196

Farmers

benefits distribution to, 23-24

empowerment of, xxi-xxii, 61

poverty reduction and types of, 64

strengthening organizational capacity for, $42-45$

Farms, xxii-xxiii

Feed supply, 172

Females. See Gender equity

Fertilizer distribution systems

benefits of promoting, 285-286

explanation of, 285

lessons learned from promoting, 286-288

policy and implementation issues related to, 286

recommendations for, 288

Fertilizers, 24, 202

Financial services

AGENT program in Zimbabwe and, 336-337

input suppliers, processors, and buyers and, 324-327

institutions and individuals in rural, 306

inventory credit for small-scale farmers and, 342-343

membership-based, 329-333

microfinance institutions and, 314-318

microleasing and, 340-341

mobile banking and, 334-335

new directions for, 309-311

overview of, 303-304

past investment experiences for, 304-305

policy issues related to, 305-309

rationale for investments in, 304 
risk management and, 430-431

scaling-up investments in, 312

smart cards and, 338-339

through state banks, 319-323

Food and Agriculture Organization (FAO), 58, 60

Food prices, 27

Food safety, 264-265

Food security, 5, 56

Food system, 4

Forest conservation, commercial plantations for, 250-251

Forestry research, in India, 101-102

Former Soviet Union, 39. See also specific countries

Fourth WTO Ministerial Conference, 24, 28

Fruit promotion, in China, 204-205

Futures contracts, 423

Game ranching, 243, 245

Gender equity

agroforestry and, 234

extension programs and, 115

horticultural exports and, 277

land reform and, 393, 398-399, 403-404, 411-412

market and agribusiness development and, 265

seed production in, 282

sustainable agricultural intensification and, 156

Genetically modified organisms (GMOs)

explanation of, 88

risks associated with, 89-90

role of, 196

Ghana

extension services in, 127

inventory credit in, 342-343

seed production in, 283

university research in, 79

Global Environmental Facility (GEF) program, 217, 218

Grants

benefits of, 306, 308

for income generating activities, 477

for land purchases, 403

Guarantees, 308-309

Guatemala, 331

Guinea livestock sector partnership in, 53-54

potato production in, 267

Health issues, 186

HORTEX (Bangladesh), 295-296

Horticultural exports

benefits of, 276

expanding opportunities for, 275-276

explanation of, 275

lessons learned from, 278

policy and implementation issues related to, 276-278

recommendations for, 278-279

Idiosyncratic risk, 428. See also Risk management Import substitution, 297-298

Income transfer efficiency, 23

Index-based insurance, 430. See also Agricultural insurance; Risk management

India

agricultural diversification in, 167

aquaculture in, 177, 208-209

biotechnology in, 99-100

community organization for Sodic lands reclamation in, 206-207

conservation tillage in, 190

dairy production in, 169

extension services in, 126, 137, 142-143

forestry research in, 101-102

irrigation and drainage systems in, 361, 366, 370, 378-379

poverty reduction in, 460, 463

rainfall-indexed insurance in, 444-445

scaling up watershed program in, 448

seed production in, 281

smart cards in, 338-339

subsidy benefits in, 6

watershed management in, 229, 230

watershed project in, 463

Indian Council of Forest Research and Extension (ICFRE), 101-102

Indigenous and Afro-Ecuadorian Peoples

Development Project (Ecuador), 43

Indigenous cultures, 214

Indonesia, dairy production in, 171

Information and communications technology

(ICT)

extension services and, 115, 135-138

in Russia, 144-145 
Inorganic fertilizers, 202

Input subsidies, 23

Insecticides, overuse of, 24

Insurance. See Agricultural insurance; Risk management

Integrated crop-livestock production, 159

Integrated livestock and wildlife management (ILWM)

benefits of, 244

explanation of, 243-244

lessons learned from, 246

policy and implementation issues related to, 244-245

recommendations for, 246

Integrated nutrient management

benefits of, 200-201

explanation of, 199

lessons learned from, 202

policy and implementation issues related to, 201-202

recommendations for, 202-203

strategies for, 199-200

Integrated pest management (IPM)

benefits of, 195

explanation of, 194

investment in, 194-195

lessons learned from, 196

policy and implementation issues related to, 195-196

recommendations for, 197

requirements for, 158, 161

Intellectual property rights (IPRs), 65, 90

Intensification. See Sustainable agricultural intensification

International agreements

agricultural trade barriers and, 24

increased importance of, xxii

related to agriculture, $\mathrm{xxii}, 8$

International Center for Tropical Agriculture, 84

International Food Policy Research Institute (IFPRI), 56

Investment Climate Assessments (ICAs), 265

Investments. See Agricultural investments

Irrigation and drainage systems

agricultural productivity and, 376-377

in China, 374-375

crop diversification and, 360-363

farmer empowerment for management of, 355-359 farmer incentives for, 380-381

future priorities for investment in, 351-352

impact of, 346

issues for future investments in, 348-351

overview of, 345

past investments in, 346-348

public, private, and farmer roles in, 378-379

rationale for investment in, 345-346

scaling up investments in, 352-353

shallow tubwells and, 370-373

user needs and, 382-383

waterlogging and salinity control and, 365369

Irrigation management transfer (IMT), 356

Kenya

agricultural sector program stakeholders in, 471

benefits of biotechnology in, 89

community-based drought management in, 437-439

competitive grants for research outreach in, 121

dairy market in, 290

drought management in, 241

horticultural production in, 277

Kosovo, 287

LABEX progam (Brazil), 93-94

Land administration. See also Property rights

future directions in, 392-394

issues in, 387-389

key issues in, 389-391

rationale for investment in, 385-387

scaling up investments in, 394-395

social and economic aspects of, 391

titling and registration and, 393, 397-400, 407-408, 411-412

Land markets

development of, 391

improvements in, 404

rental, 391-392

sales, 392-393

Land reform

benefits of, 403

community-based, 388-389, 402-403

gender equity and, 393, 398-399, 403-404, 411-412

lessons learned from, 404-405 
market-assisted, 409-410

overview of, 388, 402

policy and implementation issues related to, 403-404

recommendations for, 405

support for, 393-394

Land sales markets, 392

Land tenure

creating security in, 397-400

perspectives on customary, 390

poverty reduction and, 385-386, 393

Land titling and registration programs

benefits of, 397-398

explanation of, 397

lessons learned from, 399-400

policy and implementation issues related to, 398-399

recommendation for, 400

Lao People's Democratic Republic, 398, 411412

Lending. See Adjustment lending; Agricultural lending

Lithuania, 400

Livestock insurance, 441

Livestock management. See also Animal health services

in China, 297-298

extension services and, 171

in Guinea, 53-54

integrated wildlife and, 243-246

Loans, adjustment. See Adjustment lending

Local agricultural research committees (CIALS)

benefits of, 84,85

explanation of, 83-84

lessons learned from, 85-86

policy and implementation issues related to, 84-85

recommendations for, $86-87$

Madagascar, 340-341

Malawi, 130

Mali

drainage and irrigation systems in, 355, 380381

export mango systems in, 301-302

financial services in, 331

market information system in, 291

rice market in, 290

Market-based price risk management instru- ments, 442-443. See also Risk manage-

ment

Markets. See Agricultural markets

Mass media, 115, 135-138

Matruh Resource Management Project (Egypt), 252-253

Membership-based financial organizations (MBFOs)

benefits of, 330

explanation of, 306, 329

lessons learned from, 332

policy and implementation issues related to, 331-332

recommendations for, 332-333

support to, 329-330

Mexico, 424

Microfinance institutions (MFIs)

benefits of, 316

effectiveness of, 308

explanation of, 306

involvement of, 314-316

lessons learned for supporting, 317

policy and implementation issues related to, 316-317

recommendations for involvement in, 317318

risk and, 316-317, 319

Microleasing, 340-341

Mid-Yangtze Agricultural Development Project (China), 204-205

Millennium Development Goals (MDG)

agricultural investment and, 55

explanation of, xvii-xviii

extension support and, 114

Mobile banking, in Vietnam, 334-335

Molecular biotechnology. See Biotechnology

Mongolia

financial services in, 320

high natural-disaster risk in, 440-441

Monitoring and evaluation (M\&E)

design of, 481-482

explanation of, 480-481

issues in, 482-483

recommendations for, 483-484

Morocco, veterinary services in, 39

Mozambique

financial services in, 325

harmonized donor funding around prin-

ciples in, 485-486 
Namibia, 245

National agricultural research organizations (NAROs)

benefits of, 74

creation of, 58

explanation of, 73

lessons learned about, 75-76

policy and implementation issues related to,

$$
\text { 74-75 }
$$

recommendations for, $76-77$

types of, 73-74

university participation in, 78-82

National Agricultural Services Program

(Guinea), 53-54

National Agricultural Technology Project (India), 99-100

Natural disaster risk, 440-441. See also Risk management

Natural resource management (NRM). See also Environmental issues

agroforestry, 233-237

on arid rangelands, 238-242

commercial plantation to conserve forests and, 250-251

community-based, 223-227

in dryland areas, 252-253

explanation of, 211-212

extension services and, 106

future directions in, 218-220

integrated livestock-wildlife, 243-246

irrigation and drainage and, 350-351

issues for investments in, 215-218

participatory microcatchment strategy, 248249

past investment activity in, 214

poverty reduction and, 213, 217, 220, 224, 234, 238, 245

productivity and, 56, 211

rationale for investment in, 212-214

research priorities and, 65

scaling-up investments in, 220-221

silvopastoral approaches to, 254-255

watershed, 228-232, 256-257

Nepal

project design issues in, 468

seed production in, 282

New Zealand, agricultural sector in, 7

Nicaraqua

silvopastoral approach in, 254, 255 titling efforts and, 399

Niger, 382-383

Nigeria, 371

Nongovernmental research corporations, 73

Norway, 130

NUTMON, 202

Options contracts, 423

Organic agriculture

benefits of, 158, 179-180

lessons learned from, 181-182

policy and implementation issues related to, 180-181

production systems for, 179

statistics regarding, 179

Organization for Economic Cooperation and

Development (OECD) countries, 22, 23

Outsourcing, 119

Pakistan

agricultural productivity in, 154

integrated pest management in, 195

irrigation and drainage systems in, 367

project design issues in, 467

Participatory irrigation management (PIM), 356

Participatory microcatchment strategy, 248-249

Participatory systems, 9-10

Pastoralism

benefits of, 238-239

explanation of, 238

lessons learned from, 240-241

policy and implementation issues related to, 239-240

recommendations for, 241-242

sustainable, 238

Periurban agriculture. See Urban and periurban agriculture (UPUA)

Peru, 326

Pilot projects, 272

Plantations, commercial, 250-251

Policy formulation

benefits of, 17-18

commodity chain consultative councils for, 49-50

issues related to, 18-19

lessons learned from, 19-20

overview of, $17-18$

planning and, 17

recommendations related to, 20 
Policy reform. See also Agricultural policy

benefits of, 22-23

issues for, 23-24

lessons learned from, 24-25

overview of, 22

Political risk, 414. See also Risk management

Politics, 215, 224

Portfolio diversification, 316-317

Poverty and social impact analysis (PSIA), 32, 33

Poverty reduction agricultural growth and, 459

agricultural investments and, 56, 57, 455-457

cross-sectional programmatic adjustment

lending focusing on, 489-490

empowerment and, 42, 487-488

extension investments and, 114-115

financial services and, 306

intensification and, 154, 156

land tenure and, 385-386, 393

natural resource management and, 213, 217, 220, 224, 234, 238, 245

research and, 63-64

strategies for, 152

targeting investments in, 456, 459-463

Poverty Reduction Strategy Papers (PRSPs)

explanation of, 447

government and donor actions and, 450, 451

Poverty reduction support credits (PRSCs), 116, 453-454

Poverty safety nets, 419

Precision agriculture, 158-159, 201

Price bands, 29

Price floors, 29

Price risk management instruments, 442-443.

See also Risk management

Private research corporations, 73

Private sector

communicating with, 263

extension services and, 108-111

partnerships between public and, 4-5

roles of public vs., xxi, 3-4

Privatization

agribusiness development and, 261, 266

agricultural growth and, 3-4

of animal health services, 39, 40

of parastatals, 286

of state banks, 321-322

of state lands, 390-391
Producer associations, 324-325

Productivity. See Agricultural productivity

Property rights. See also Land administration;

Land tenure

common, 390-391

elements of secure, 386, 389

enforcement of, 389-390

to natural resources, 218-219

pastoralism and, 239

water rights and, 349

Protected area management, 217. See also

Natural resource management

Protectionism, 24

Public expenditures, 6-7

Public goods agricultural investment and, 56-57, 266 investment in, 415

natural resources as, 215

Public/private partnerships, 37-40

Public research institutes. See National agricultural research organizations (NAROs)

Public sector

changing role of, $\mathrm{xxi}, 3-4$

extension services and, 108-110

goals for, 5

partnerships between private and, 4-5

reform of, 8-9

technical and human capital in, 6

Publicly-owned corporations, 73

Rainfall-indexed insurance, 444-445. See also Risk management

Reaching the Rural Poor, vii, 56, 346, 386, 447

Rental markets, 391-392

Research \& development (R\&D). See Agricultural investments; Agricultural research

Risk management

agricultural insurance and, 427-431

commodity price, 422-426

community-based drought, 437-439

future directions for investment in, 418-420

in high disaster-risk areas, 440-441

issues for investment in, 414-418

market-based, 10, 290-291, 418-419, 442443

microfinance institutions and, 316-317

past investment activity in, 414

rainfall-indexed, 444-445

rationale for investment in, 413-414 
scaling up investments in, 420

seed distribution and, 432-436

Rural Development Strategy

agricultural development strategy and, 13-14

elements of, 1-2

overview of, xviii, $\mathrm{xx}$

Rural producer organizations (RPOs)

benefits of, 42-43

explanation of, 42

lessons learned regarding, 44-45

policy and implementation issues related to, 43-44

recommendations regarding, 45

Russia, 144-145

Rwanda, 434

Salinity

benefits of control of, 367-368

explanation of, 365-366

investment needs for, 366-367

lessons learned from control of, 368

policy and implementation issues related to, 368

recommendations regarding, 368-369

Scaling up

in agribusiness, 268

in agricultural development initiatives, 447458

challenges to, 454-457

in extension services, 116

in irrigation and drainage systems, 352-353

in land administration, 394-395

in risk management, 420

in sustainable agricultural intensification, 161

Sector performance analysis (SPA), 471

Sectoral adjustment loans (SECALs), 32

Seed distribution

benefits of, 432

explanation of, 432

lessons learned from, 433-435

policy and implementation issues related to, 433

recommendations for, 435-436

Seed enterprise development

benefits of, 281

explanation of, 280-281

lessons learned from, 282-283

policy and implementation issues related to, 281-282 recommendations for, 283-284

Seed fairs, 434-435

Seed vouchers, 434-435

Seepage control, 366

Semi-arid rangelands, pastoralism on, 238-242

Semiautonomous organizations, agricultural research and, 73

Senegal

agricultural service projects in, 478

demand-driven research in, 103-104

rural producer organizations in, 43

Shallow tubewells

benefits of, 371

explanation of, 370

investments in, 370-371

lessons learned from, 372

policy and implementation issues regarding, 371-372

recommendations regarding, 372-373

Silvopastoral systems, 254-255

Smallholder dairy production

benefits of, 170

explanation of, 169

forms of, 169

lessons learned from, 170-172

policy and implementation issues related to, 170

recommendations for, 172

Smallholders

cattle development in China by, 297-298

inclusion of, 271-272

irrigation and drainage systems for, 352

market participation of, 292

Smart cards, 338-339

Social risk, 414. See also Risk management

Soil nutrient recapitalization, 200

South Africa

biotechnology products in, 160

game ranch management in, 243

land reform in, 404

State banks, financial services through, 319-323

Strategic Alliance Grants (SAGs) (Ecuador), 9798

Structural adjustment loans (SALs), 32

Subsidies

for crop insurance, 429

environmental issues and, 24

explanation of, 308-309

input, 23 
policy reform and, 5-6, 22-25

Supply chain systems

benefits of, 281

explanation of, 270

investment in, 270

lessons learned from, 272

policy and implementation issues and, 271-272

recommendations for, $272-273$

Supply chains

competitiveness and, 260

fertilizer, 286

for market integration, 268

Supply side constraints, 29-30

Support policies, 23, 25

Sustainability

capacity development and, 18

of past agricultural programs, 2

of R\&D investments, 62-63

Sustainable agricultural intensification

future directions for investment in, 158-161

investment issues for, 155-158

overview of, 151

past investment activity in, 154

policy issues affecting, 160

rationale for investment in, 152-154

scaling up investments in, 161

T \& V system, in India, 142

Tanzania

agricultural reform in, 9

financial services in, 320, 325

market-based price risk management instruments in, 442-443

seed distribution in, 435

wildlife policy in, 244

Tariffs, 24, 25

Taxes, 23, 391

Technological advances

in agroforestry, 233-234

in financial services operations, 315

for natural resource management, 219, 226

public and private sector, 272

Telecenters, 137

Thailand

financial services in, 322

fresh food supply chain in, 273

irrigation systems in, 361

land titling and registration systems in, 397

Trade associations, 287
Trade liberalization

benefits of, 27-28

explanation of, 27

lessons learned from, 29-30

policy and implementation issues related to, 28-29

recommendations regarding, 30-31

Tranching, 33

Transitional support programs, 419

Tree crops, 159

Trophy hunting, 244

Tubewells. See Shallow tubewells

Turkey

adjustment/investment lending in, 51-52

agricultural diversification in, 165

Turkmenistan, 195

Uganda

cross-sectional programmatic adjustment

lending in, 489-490

extension services in, 126, 146-147

modernization of agriculture in, 13

seed distribution in, 435

seed production in, 283

university research in, 81

Ukraine, 19

UNESCO, 137

University research, 78-82. See also Agricultural research

Urban and periurban agriculture (UPUA)

benefits of, 184

explanation of, 184

lessons learned from, 186-187

policy and implementation issues related to, 184-186

recommendations regarding, 187-188

Uruguay

agricultural research center in, 74

university research in, 79

Uruguay Round Agreement on Agriculture

(URAA), 24, 28

Venezuela, 148-149

Veterinary services. See Animal health services

Vietnam

agricultural diversification in, 167

capacity building in, 20

mobile banking in, 334-335

urban and periurban agriculture in, 187 
Water. See also Irrigation and drainage systems delivery of, 360, 362

multiple interests in, 349

pricing of, 349

use of, 349-350

Water user associations

empowerment of, 355-358

explanation of, 352

Waterlogging

benefits of control of, 367-368

explanation of, 365

investment needs for, 366-367

lessons learned from control of, 368

policy and implementation issues related to, 368

recommendations regarding, 368-369

Watershed management

in China, 256-257

explanation of, 228

investments in, 228-229

lessons learned from, 231

policy and implementation issues related to, 229-230

recommendations for, 231-232

Weather-based index insurance, 430. See also

Agricultural insurance; Risk management

Web site lists, 491-493

West Africa, extension services in, 131

Wild animal trappers, 244

Wildlife management. See Integrated livestock and wildlife management (ILWM)

Wildlife tourism, 244

Women. See Gender equity

World Bank. See also Rural Development

Strategy

agricultural lending by, 57-60, 449

conservation tillage investments and, 190

disaster management and, 420

extension systems expenditures of, 106-107

financial services and, 305, 308, 312, 326

financing for agricultural development by, xviii

irrigation and drainage investments and, 346, 348, 437

land policy and administration and, 385-390, 394, 395

monitoring and evaluation requirements of, 481

natural resource investments by, 214
Operations Evaluation Department, 107

scaling up and, 448

World Trade Organization (WTO)

agricultural support and, 25

global market access and, 260

trade liberalization and, 29, 30

Zambia, 473

Zimbabwe

AGENT program in, 336-337

financial services in, 325

natural resource management in, 224 

Investment in agricultural growth is central to the World Bank's efforts to reach the rural poor.

The Agriculture Investment Sourcebook contributes to the goal of rural poverty reduction by providing information on key issues in the following areas:

- Agricultural policy and institutional capacity building

- Science and technology

- Extension and information services

- Sustainable agricultural intensification

- Sustainable natural resource management

- Agribusiness and market development

- Rural finance for agriculture

- Irrigation and drainage

- Land administration, policy, and markets

- Risk management

In addition, the sourcebook describes options for program design and discusses the issues involved in scaling up investments for maximum impact.

The Agriculture Investment Sourcebook is an invaluable resource for anyone engaged in promoting agricultural growth to benefit the poor. 